DOUGLAS FABICHAK JUNIOR

ANÁLISE EXPERIMENTAL DA INFLUÊNCIA DO SISTEMA DE VENTILAÇÃO E DISTRIBUIÇÃO DE AR NO CONFORTO TÉRMICO E NA DISPERSÃO E REMOÇÃO DE PARTÍCULAS EXPIRATÓRIAS EM CABINE DE AERONAVE 
DOUGLAS FABICHAK JUNIOR

\section{ANÁLISE EXPERIMENTAL DA INFLUÊNCIA DO SISTEMA DE VENTILAÇÃO E DISTRIBUIÇÃO DE AR NO CONFORTO TÉRMICO E NA DISPERSÃO E REMOÇÃO DE PARTÍCULAS EXPIRATÓRIAS EM CABINE DE AERONAVE}

Tese de Doutorado apresentada à Escola Politécnica da Universidade de São Paulo para obtenção do título de Doutor em Ciências

Área de concentração:

Engenharia Mecânica

Orientador:

Prof. Dr. Arlindo Tribess

São Paulo

2018 
Autorizo a reprodução e divulgação total ou parcial deste trabalho, por qualquer meio convencional ou eletrônico, para fins de estudo e pesquisa, desde que citada a fonte.

Este exemplar foi revisado e corrigido em relação à versão original, sob responsabilidade única do autor e com a anuência de seu orientador.

São Paulo, de de

Assinatura do autor:

Assinatura do orientador:

Catalogação-na-publicação

Fabichak Junior, Douglas

Análise experimental da influência do sistema de ventilação e distribuição de ar no conforto térmico e na dispersão e remoção de partículas expiratórias em cabine de aeronave / D. Fabichak Junior -- versão corr. -- São Paulo, 2018. $182 \mathrm{p}$.

Tese (Doutorado) - Escola Politécnica da Universidade de São Paulo. Departamento de Engenharia Mecânica.

1.Conforto térmico 2.Qualidade do ar 3.Dispersão de partículas 4.Sistemas de Ventilação 5.Cabine de aeronave I.Universidade de São Paulo. Escola Politécnica. Departamento de Engenharia Mecânica II.t. 
À memória de meu pai. 


\section{AGRADECIMENTOS}

Ao meu orientador, Prof. Dr. Arlindo Tribess, que me ajudou em todos os caminhos que percorri, fundamental para o desenvolvimento deste trabalho.

Aos amigos do laboratório de Conforto Térmico e Qualidade do $\mathrm{Ar}$ do Departamento de Engenharia Mecânica da Escola Politécnica da USP, que me apoiaram fortemente na realização deste trabalho, dentre eles, agradeço ao Físico José Carlos Orsi Morel, ao Técnico Sidney Castilho Alves, ao Técnico Vilson Ribeiro dos Santos, à Arquiteta Adriana Camargo de Brito, ao Eng. Sandro Tavares Conceição e ao Eng. Rogério Vilain.

Aos amigos Eng. Evandro Souza da Silva, Eng. Victor Barbosa Félix e Eng. Paulo Celline pelo grande apoio na realização dos ensaios deste trabalho.

Aos membros da Banca do Exame de Qualificação, Prof. Dr. Maurício Silva Ferreira, e Prof. Dr. Cyro Albuquerque Neto, que muito contribuíram com comentários e sugestões de melhorias.

Aos funcionários Benedito Fragoso e ao saudoso Wilson da Costa Neves (in memoriam), pelos conhecimentos a mim transmitidos em marcenaria e técnicas mecânicas.

Agradecimento especial a Coordenação de Aperfeiçoamento de Pessoal de Nível Superior (CAPES), pela bolsa de Doutorado concedida. 


\section{RESUMO}

O conforto térmico e a dispersão e remoção de partículas em cabine de aeronave são função, fundamentalmente, do seu sistema de ventilação e distribuição de ar. Juntamente com a análise da influência do sistema de ventilação por mistura (MV), atualmente utilizado em aviões comerciais, no presente trabalho são propostos e analisados dois novos sistemas, o sistema de distribuição de ar pelo piso (UFAD) e o sistema de ventilação por deslocamento (DV). A análise experimental de condições de desconforto térmico local e de dispersão e remoção de partículas expiratórias foi realizada em um mock-up de uma aeronave comercial com 12 assentos, com 4 assentos por fileira. Os resultados mostram forte influência da temperatura do ar insuflado na cabine, de $18{ }^{\circ} \mathrm{C}$ e $22^{\circ} \mathrm{C}$, do ponto de geração de partículas na cabine, em assento junto à fuselagem e junto ao corredor, e da faixa de tamanhos de partículas, principalmente nas faixas de 2,0 a 3,0 $\mu \mathrm{m}$ e de 3,0 a $5,0 \mu \mathrm{m}$, de maior interesse no presente trabalho. Por fim, os resultados mostram que o sistema UFAD apresentou o melhor desempenho, tanto quanto ao desconforto térmico devido a correntes de ar, com valores abaixo de $20 \%$ preconizado pelas normas ISO 7730 (2005) e ASHRAE 55 (2013), quanto à menor dispersão de partículas e maior eficiência na remoção de partículas na região de respiração, com eficiência na remoção de partículas maior em até 18,8 \% em relação ao sistema DV e em até 41,6 \% em relação ao sistema MV. O sistema DV apresentou resultados intermediários com relação ao desconforto térmico local, com pior resultado na região dos pés com média do desconforto térmico local de 22,7 \% e muito boa eficiência na remoção de partículas em relação ao sistema convencional MV maior em até 32,0 \%. O sistema MV apresentou as piores condições com relação ao desconforto térmico para a região da cabeça e dos pés, com média de pessoas insatisfeitas de até 25,7\%. O sistema MV também apresentou as piores condições com relação à eficiência de remoção de partículas com a maior quantidade total de partículas na região de respiração ao longo da aeronave. 


\begin{abstract}
Thermal comfort and particles dispersion and removal in an aircraft cabin depend, essentially, on its ventilation and air distribution system. Together with the analysis of the influence of the mixing ventilation system (MV), used in commercial aircrafts, in the present work two new systems are proposed and analyzed, the underfloor air distribution system (UFAD) and the displacement ventilation system (DV). Experimental analysis of local thermal discomfort conditions and dispersion and removal of expiratory particles was performed in a mock-up of a commercial 12 seat aircraft with 4 seats per row. The results show a strong influence of the temperature ot the air inflated into the cabin, of $18^{\circ} \mathrm{C}$ and $22^{\circ} \mathrm{C}$, of the point of generation of particles in the cabin, at the seat next to the fuselage and near the corridor, and of the particle size range, mainly in the bands of 2.0 to $3.0 \mu \mathrm{m}$ and 3.0 to $5.0 \mu \mathrm{m}$, of greater interest in the present study. Finally, the results show that the UFAD system presented the best performance, as well as the thermal discomfort due to drafts, with values below 20\% recommended by ISO 7730 (2005) and ASHRAE 55 (2013), as well as the lower dispersion of particles and greater efficiency in the removal of particles in the respiratory region, with particle removal efficiency greater by up to $18.8 \%$ in relation to the DV system and by up to $41.6 \%$ in relation to the MV system. The DV system presented intermediate results in relation to the local thermal discomfort, with worse results in the feet region with a mean of the local thermal discomfort of $22.7 \%$ and very good particle removal efficiency in relation to the conventional MV system of up to $32,0 \%$. The MV system presented the worst conditions in relation to the thermal discomfort for the head and feet region, with an unsatisfied average of up to $25.7 \%$. The MV system also presented the worst conditions with respect to the removal efficiency of particles with the highest total amount of particles in the breathing region along the aircraft.
\end{abstract}




\section{LISTA DE ILUSTRAÇÕES}

Figura 1.1.Sistemas de ventilação em mock-up de aeronave A320: a) MV (Mixing ventilation); b) DV (Displacement Ventilation); c) interação entre os sistemas MV e DV (Bosbach et al., 2013 apud Schmid et al., 2008 e Müller et al., 2011)

Figura 2.1. Esquema básico do sistema de climatização em cabines de aeronaves (Figura adaptada de Walkinshaw, 2008)

.

Figura 2.2. Sistema de distribuição com mistura de ar na cabine, MV

Figura 2.3. Esquema do sistema DV (Displacement Ventilation) em cabine de aeronave (Figura adaptada de Gao et al., 2007; Zhang et al., 2007).

Figura 2.4. Esquema do sistema UFAD (UnderFloor Air Distribution) em cabine de aeronave (Figura adaptada de Gao et al., 2007; Zhang et al., 2007)...

Figura 3.1. Percentual de pessoas insatisfeitas (PPD) como função do voto médio estimado (PMV) (ASHRAE 55, 2013)

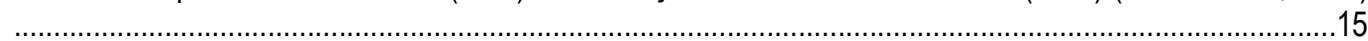

Figura 3.2. Correntes de ar para $15 \%$ de insatisfeitos em atividade sedentária (ASHRAE, 2013)

Figura 3.3. Percentual de pessoas insatisfeitas com a diferença vertical de temperatura do ar entre os pés e a cabeça (ASHRAE, 2013).

Figura 3.4. Percentual de pessoas insatisfeitas devido à assimetria da radiação (ASHRAE, 2013) ...............................20

Figura 3.5. Percentual de pessoas insatisfeitas com a temperatura do piso (ASHRAE, 2013). .......21

Figura 3.6. Efeito da temperatura e da velocidade do ar no índice de conforto térmico para isolamento de roupas de 0,6 clo (adaptado de GAN, 1994)

Figura 3.7. Efeito da temperatura e da velocidade do ar no índice de conforto térmico para isolamento de roupas de 1,0 clo (adaptado de GAN, 1994)

Figura 4.1. a) Velocidades sobre os manequins para as quatro distâncias entre ambos; b) Fluxo descendente sobre os manequins para distância de $0,50 \mathrm{~m}$ (Olmedo et al., 2013).

Figura 4.2. Localização das fontes de emissão e planos de medição (Li et al., 2014).

Figura 4.3. Gotículas expiratórias, baseado nas medições de Duguid, (1946). a) Quantidade absoluta de partículas b) Distribuição do tamanho de partículas normalizada pelo intervalo de medição c) Distribuição acumulada (adaptado por Conceição, 2012).

Figura 4.4. Pontos de injeção e de medição de gotículas para diferentes vazões de ar de cabine (Wan; Chao; Fang, 2005)

Figura 4.5. Mock-up de cabine de aeronave e planos de medição (Zhang et al., 2007) .................................................35

Figura 4.6. Estudo da dispersão de contaminantes em mock-up do Boeing 767-300 (Yan et al., 2009).................36

Figura 4.7. Mock-up de 20 lugares utilizado no desenvolvimento do trabalho de Conceição, 2012 ................................36

Figura 4.8. Mock-up de 12 lugares utilizado no desenvolvimento do trabalho de Fabichak Jr, 2013 .............................37

Figura 4.9. Linhas de corrente (a) sistema MV, (b) sistema UFAD e (c) sistema UFAD e ventilação personalizada (Zhang;

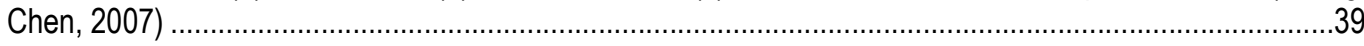

Figura 5.1. Laboratório (esquema simplificado dos sistemas de distribuição do ar ...................................................41

Figura 5.2. Laboratório (esquema simplificado dos sistemas de distribuição do ar (sistema de ventilação de cabine) .....42

Figura 5.3. Sistema Plenum (esquema simplificado dos sistemas de distribuição do ar pelo piso .................................43

Figura 5.4. CLP (imagem onde são configurados os ajustes no CLP (Fonte: Própria) ...................................................4

Figura 5.5. a) Esquema interno do mock-up, b) Acesso e vista externa do mock-up ...................................................45

Figura 5.6. Vista interna do mock-up com os manequins aquecidos ....................................................................

Figura 5.7. Sistema 1: Sistema de ventilação por mistura (MV) .......................................................................... 46 
Figura 5.8. Sistema 2: Sistema de distribuição de ar pelo piso (UFAD) ......................................................................47

Figura 5.9. Sistema 3: Sistema de ventilação por deslocamento (DV) ......................................................................47

Figura 5.10. Gerador de aerossol TSI modelo 3475 (TSI, 2010) - imagem de catálogo ..................................................48

Figura 5.11. Concentração de partículas em função do tamanho da gotícula gerada (gráfico do catálogo do gerador TSI modelo 3475)

Figura 5.12. Contadores de partículas da MetOne, modelo HHPC6 (MetOne HHPC-6, 2010), utilizados nos experimentos (Conceição, 2012).

Figura 5.13. Planos e alturas de medição de velocidade e temperatura do ar................................................................55

Figura 5.14. Sensor de anemômetro omnidirecional (elemento sensor livre) ................................................................55

Figura 5.15. Posicionamento das sondas para medição de temperatura e velocidade do ar na altura de 0,60 m e de 1,10 m a partir do piso (Silva, 2013) .

Figura 5.16. Posicionamento da sonda para medição de temperatura e velocidade do ar na altura de 0,10 $\mathrm{m}$ a partir do piso (Silva, 2013)

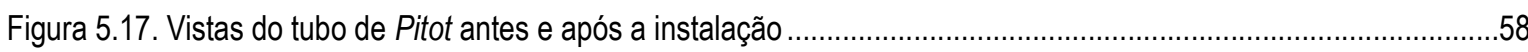

Figura 5.18. Manômetro diferencial para determinação e monitoramento da vazão de ar ..............................................58

Figura 5.19. Os manequins aquecidos e suas respectivas dimensões ...................................................................59

Figura 5.20. a) Gerador de aerossol TSI modelo 3475 e monitor PAM 3475 posicionados externamente ao mock-up, b) Detalhe dos tubos e mangueiras de conexão

Figura 5.21. Pontos de injeção e medição de partículas no mock-up a) injeção de partículas na poltrona 3D b) injeção de partículas na poltrona $3 \mathrm{E}$...

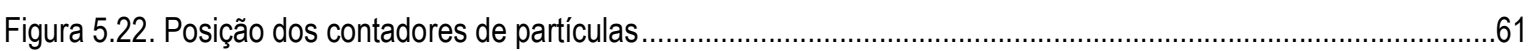

Figura 6.1. Perfis de velocidade do ar para temperatura de insuflamento de $18{ }^{\circ} \mathrm{C}$......................................................66

Figura 6.2. Perfis de velocidade do ar para temperatura de insuflamento de $22{ }^{\circ} \mathrm{C}$....................................................67

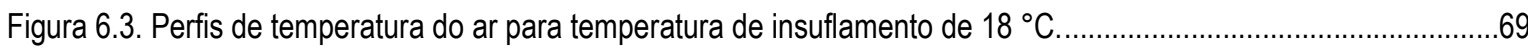

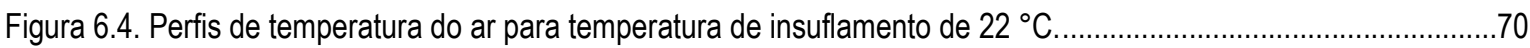

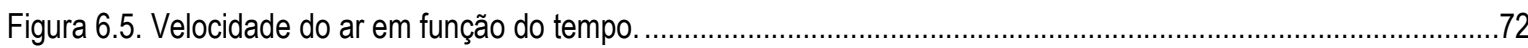

Figura 6.6. Percentual de insatisfeitos devido a correntes de ar para o sistema MV, com temperatura de insuflamento do ar de $18^{\circ} \mathrm{C}$

Figura 6.7. Percentual de insatisfeitos devido a correntes de ar para o sistema UFAD, com temperatura de insuflamento do ar de $18^{\circ} \mathrm{C}$

Figura 6.8. Percentual de insatisfeitos devido a correntes de ar para o sistema DV, com temperatura de insuflamento do ar de $18{ }^{\circ} \mathrm{C}$

Figura 6.9. Percentual de insatisfeitos devido a correntes de ar para o sistema MV, com temperatura de insuflamento do ar de $22^{\circ} \mathrm{C}$.

Figura 6.10. Percentual de insatisfeitos devido a correntes de ar para o sistema UFAD, com temperatura de insuflamento do ar de $22{ }^{\circ} \mathrm{C}$.

Figura 6.11. Percentual de insatisfeitos devido a correntes de ar para o sistema DV, com temperatura de insuflamento do ar de $22^{\circ} \mathrm{C}$

Figura 6.12. PD (\%) - Sistema UFAD: a) temperatura de insuflamento do ar de insuflamento a $18^{\circ} \mathrm{C}$; b) temperatura do ar de insuflamento a $22^{\circ} \mathrm{C}$

Figura 6.13. PD (\%) - Sistema DV: a) temperatura de insuflamento do ar de insuflamento a $18{ }^{\circ} \mathrm{C}$; b) temperatura do ar de insuflamento a $22^{\circ} \mathrm{C}$

Figura 6.14. PD (\%) - Sistema MV: a) temperatura de insuflamento do ar de insuflamento a $18{ }^{\circ} \mathrm{C}$; b) temperatura do ar de insuflamento a $22^{\circ} \mathrm{C}$.

Figura 6.15. Concentração de partículas para insuflamento $18^{\circ} \mathrm{C}$, injeção de partículas pelo assento $3 \mathrm{~A}$. .....................80

Figura 6.16 Concentração de partículas para insuflamento $18^{\circ} \mathrm{C}$, injeção de partículas pelo assento $3 \mathrm{~B}$.......................81

Figura 6.17 Concentração de partículas para insuflamento $22^{\circ} \mathrm{C}$, injeção de partículas pelo assento $3 \mathrm{~A}$......................82 
Figura 6.18 Concentração de partículas para insuflamento $22^{\circ} \mathrm{C}$, injeção de partículas pelo assento $3 \mathrm{~B}$.

Figura 6.19 Concentração de partículas entre 2,0 e 3,0 um ao longo da cabine, com injeção de partículas pelo assento $3 \mathrm{~A}$; .

Figura 6.20 Comparação da concentração de partículas entre 3,0 e 5,0 $\mu \mathrm{m}$ ao longo da cabine, com injeção de partículas pelo assento $3 \mathrm{~A}$;

a) temperatura de insuflamento: $18^{\circ} \mathrm{C}$;

b) temperatura de insuflamento: $22^{\circ} \mathrm{C}$

Figura 6.21 Concentração de partículas entre 2,0 e 3,0 um ao longo da cabine, com injeção de partículas pelo assento 3B.

Figura 6.22 Comparação da concentração de partículas entre 3,0 e 5,0 $\mu \mathrm{m}$ ao longo da cabine, com injeção de partículas pelo assento 3B

Figura 6.23 Concentração total de partículas na cabine com injeção, respectivamente, nos assentos 3A e 3B para temperatura de insuflamento de $18^{\circ} \mathrm{C}$

Figura 6.24. Concentração total de partículas na cabine com injeção, respectivamente, nos assentos 3Ae 3B para temperatura de insuflamento de $22^{\circ} \mathrm{C}$ 


\section{LISTA DE TABELAS}

Tabela 3.1. Metabolismos para diferentes atividades (ASHRAE 55, 2013)

Tabela 3.2. Determinação do voto médio estimado - PMV (ISO 7730, 2005)

Tabela 4.1. Infecções relatadas transmitidas em voos de companhias aéreas comerciais (adaptado de MANGILI; GEANDREAU, 2005)

Tabela 4.2. Características de contaminantes liberados em atividades expiratórias (CONCEIÇÃO, 2012) .33

Tabela 6.1. Média da concentração de partículas na cabine, desvio padrão coeficiente de variação de partículas de 2,0 3,0 $\mu \mathrm{m}-\operatorname{lnj} .3 \mathrm{~A}$

Tabela 6.2. Média da concentração de partículas na cabine, desvio padrão e coeficiente de variação de partículas de 3,0 $-5,0 \mu \mathrm{m}-\operatorname{lnj} .3 \mathrm{~A}$

Tabela 6.3. Média da concentração de partículas na região de respiração, desvio padrão e coeficiente de variação de partículas de 2,0 - 3,0 $\mu \mathrm{m}-\operatorname{lnj}$. 3B.

Tabela 6.4. Média da concentração de partículas na região de respiração, desvio padrão e coeficiente de variação de partículas de 3,0 - 5,0 $\mu \mathrm{m}-\operatorname{lnj}$. 3B

Tabela 6.5. Concentração total de partículas na cabine com injeção, respectivamente, nos assentos $3 \mathrm{~A}$ e $3 \mathrm{~B}$ para temperatura de insuflamento de $18^{\circ} \mathrm{C}$

Tabela 6.6. Concentração total de partículas na cabine com injeção, respectivamente, nos assentos $3 \mathrm{~A}$ e $3 \mathrm{~B}$ para temperatura de insuflamento de $22^{\circ} \mathrm{C}$

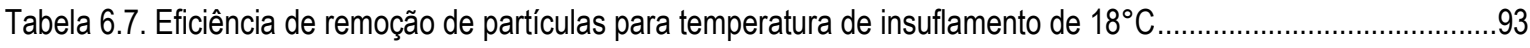

Tabela 6.8. Eficiência de remoção de partículas para temperatura de insuflamento de $22^{\circ} \mathrm{C}$.

Tabela 7.1. Condições de desconforto térmico local e de remoção de partículas da região de respiração com temperatura de insuflamento de $18{ }^{\circ} \mathrm{C}$

Tabela 7.2. Condições de desconforto térmico local e de remoção de partículas da região de respiração com temperatura de insuflamento de $22^{\circ} \mathrm{C}$

-Toc521854262 


\section{LISTA DE SÍMBOLOS}

$h_{\text {cal }}$ Coeficiente de transferência de calor calibrado

$h \quad$ Coeficiente de transferência de calor combinado

$\left[\mathrm{W} / \mathrm{m}^{2 \circ} \mathrm{C}\right]$

$h_{c} \quad$ Coeficiente de transferência de calor por convecção

$\left[\mathrm{W} / \mathrm{m}^{2 \circ} \mathrm{C}\right]$

$h_{r} \quad$ Coeficiente de transferência de calor por radiação

$\left[\mathrm{W} / \mathrm{m}^{2 \circ} \mathrm{C}\right]$

$f_{r} \quad$ Fator de área da vestimenta

$v_{a r}^{\prime} \quad$ Flutuação da velocidade

$\left[\mathrm{W} / \mathrm{m}^{2 \circ} \mathrm{C}\right]$

[adimensional]

$[\mathrm{m} / \mathrm{s}]$

$\left[\mathrm{W} / \mathrm{m}^{2}\right]$

Índice de atividade térmica

$I_{r} \quad$ Índice de isolamento térmico da roupa

[clo]

$T_{u} \quad$ Intensidade de turbulência

[\%]

$P D_{d} \quad$ Percentagem de pessoas insatisfeitas devido à resposta dinâmica [\%]

$P D_{e} \quad$ Percentagem de pessoas insatisfeitas devido à resposta estática [\%]

$D R \quad$ Percentual de insatisfeito devido ao risco de correntes de ar [\%]

$p_{v_{a r}} \quad$ Pressão parcial do vapor d'água no ambiente

$\dot{Q} \quad$ Soma da troca de calor por convecção e radiação

$C_{R} \quad$ Taxa de calor convectivo perdido pela respiração

$\left[\mathrm{W} / \mathrm{m}^{2}\right]$

$E_{R} \quad$ Taxa de calor evaporativo perdido pela respiração

$\left[\mathrm{W} / \mathrm{m}^{2}\right]$

$C \quad$ Taxa de calor perdido pela pele por convecção

$\left[\mathrm{W} / \mathrm{m}^{2}\right]$

$E_{\text {dif }} \quad$ Taxa de calor perdido pela pele por difusão de vapor d'água

$\left[\mathrm{W} / \mathrm{m}^{2}\right]$

$\left[\mathrm{W} / \mathrm{m}^{2}\right]$

$E_{e s} \quad$ Taxa de calor perdido pela pele por evaporação do suor

$\left[\mathrm{W} / \mathrm{m}^{2}\right]$

$R \quad$ Taxa de calor perdido pela pele por radiação

$\left[\mathrm{W} / \mathrm{m}^{2}\right]$

$W \quad$ Taxa de energia gasta pelo trabalho dos músculos

$\left[\mathrm{W} / \mathrm{m}^{2}\right]$

$M \quad$ Taxa de produção de energia, metabolismo

$\left[\mathrm{W} / \mathrm{m}^{2}\right]$

$\dot{U} \quad$ Taxa de variação de energia interna

$T_{p} \quad$ Temperatura da pele

$\left[\mathrm{W} / \mathrm{m}^{2}\right]$

$\left[{ }^{\circ} \mathrm{C}\right]$

$T_{\text {roupa }}$ Temperatura da roupa

$\left[{ }^{\circ} \mathrm{C}\right]$

$T_{s} \quad$ Temperatura da superfície

$\left[{ }^{\circ} \mathrm{C}\right]$

$T_{a r} \quad$ Temperatura do ar

$\left[{ }^{\circ} \mathrm{C}\right]$

$T_{e q} \quad$ Temperatura equivalente

$\left[{ }^{\circ} \mathrm{C}\right]$

$T_{o} \quad$ Temperatura operativa

$\left[{ }^{\circ} \mathrm{C}\right]$

$\overline{T_{r}} \quad$ Temperatura radiante média

$\left[{ }^{\circ} \mathrm{C}\right]$

var Velocidade instantânea [m/s]

$\overline{v_{a r}} \quad$ Velocidade média

$[\mathrm{m} / \mathrm{s}]$

\section{Símbolos Gregos}

$\sigma_{v_{a r}} \quad$ Desvio padrão da velocidade do ar

$\Psi \quad$ Função de análise simultânea

$[\mathrm{m} / \mathrm{s}]$

$\omega \quad$ Umidade absoluta do ar

[\%]

$\phi \quad$ Umidade relativa do ar 


\section{LISTA DE SIGLAS}

\begin{tabular}{|c|c|}
\hline ASHRAE & $\begin{array}{l}\text { American Society of Heating, Refrigerating and Air-Conditioning } \\
\text { Engineers }\end{array}$ \\
\hline CDF & Computational Fluid Dynamics \\
\hline $\mathrm{cfm}$ & Cubic feet per minute $\left(\mathrm{ft}^{3} / \mathrm{min}\right)$ - pés cúbicos por minuto ( $\left.\mathrm{pe}^{3} / \mathrm{min}\right)$ \\
\hline CLP & Controlador Lógico Programável \\
\hline $\mathrm{CO}_{2}$ & Gás carbônico \\
\hline DEHS & Di-Etil-Hexil-Sebacato \\
\hline DR & Draught Rate \\
\hline DV & Displacement Ventilation \\
\hline Exp & Experimental \\
\hline f.m.e & Força Eletromotriz \\
\hline H1N1 & Subtipo do vírus influenza A \\
\hline HEPA & High Efficiency Particulate Air \\
\hline ICEE & International Centre for Indoor Environment and Energy \\
\hline IMI & Interferometric Mie Imaging \\
\hline MV & Mixing Ventilation \\
\hline Num & Numérico \\
\hline N/A & Não Aplicável \\
\hline OMS & Organização Mundial da Saúde \\
\hline $\mathrm{P}$ & Partículas \\
\hline PD & Percentage of Dissatisfied \\
\hline PM & Particulate matter \\
\hline PPM & Partículas per minute \\
\hline PSL & Polystirene Latex Spheres \\
\hline SARS & Severe Acute Respiratory Syndrome \\
\hline $\mathrm{SF}_{6}$ & Gás Hexafluoreto de enxofre \\
\hline UFAD & UnderFloor Air Distribution \\
\hline UR & Umidade Relativa \\
\hline
\end{tabular}




\section{SUMÁRIO}

\section{RESUMO}

LISTA DE ILUSTRAÇÕES

LISTA DE TABELAS

\section{LISTA DE SÍMBOLOS}

LISTA DE SIGLAS

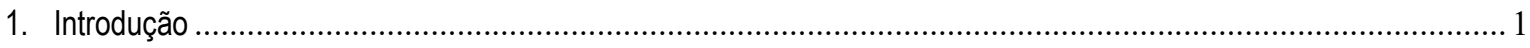

1.1 Motivação .

1.2 Objetivo .

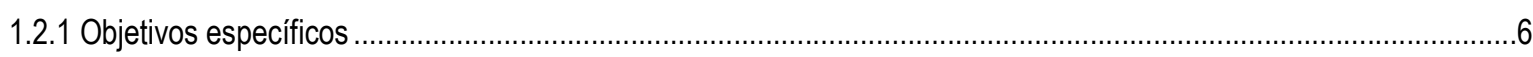

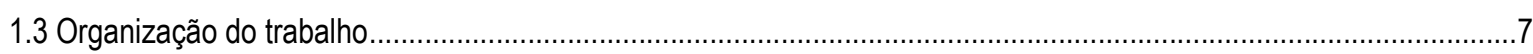

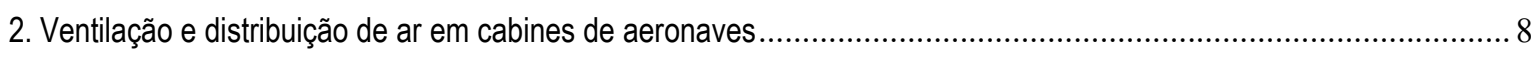

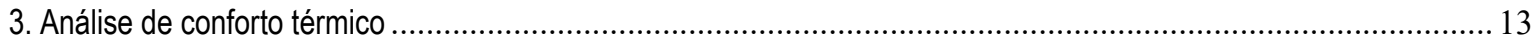

3.1 Condições de conforto de Fanger...................................................................................................13

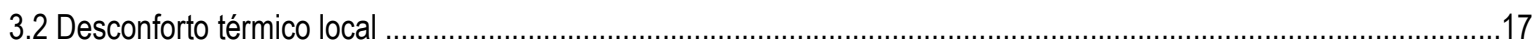

3.2.1 Correntes de ar (PD- Percentage of Dissatisfied; DR - Draught Rate) …........................................................17

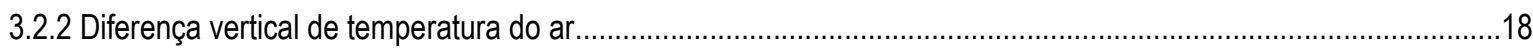

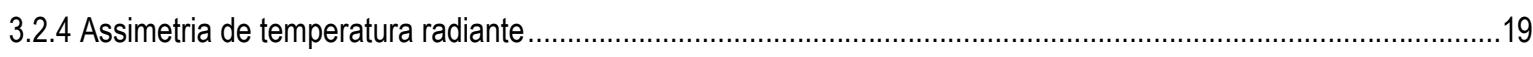

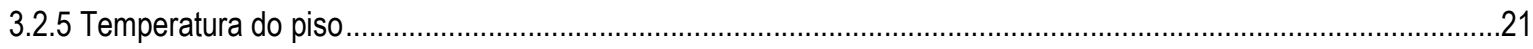

3.3 Análise simultânea de conforto térmico (PPD) e desconforto térmico local (PD) ..................................................21

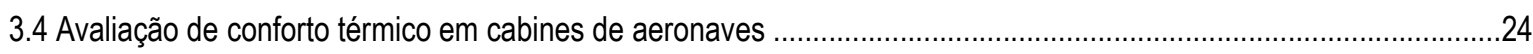

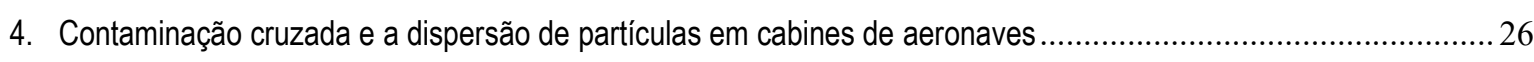

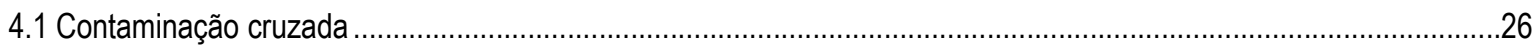

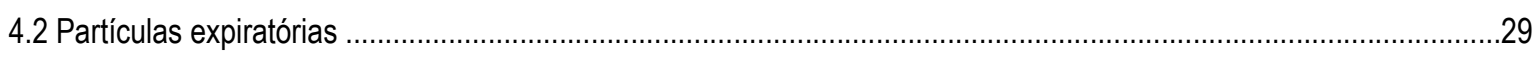

4.3 Estudos de dispersão de partículas em cabines de aeronaves........................................................................

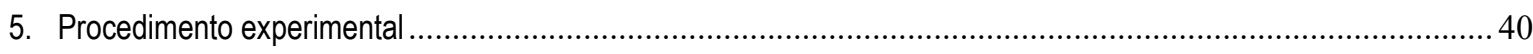

5.1 Introdução

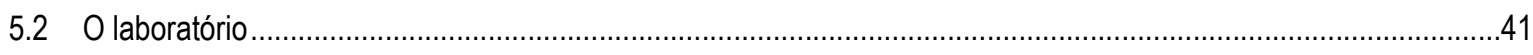

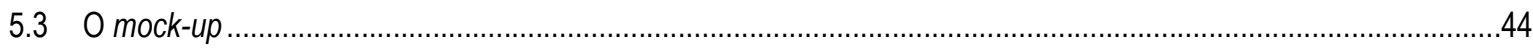

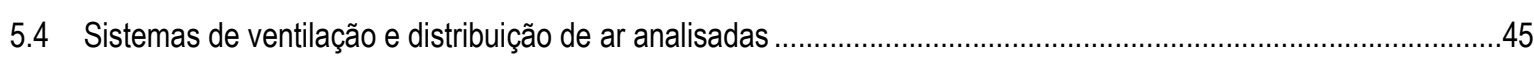

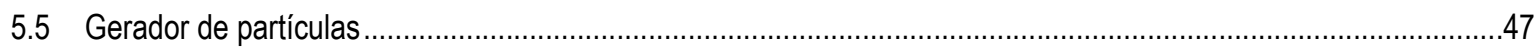

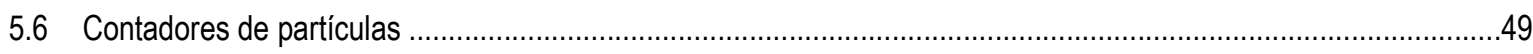

5.6 .1 Incerteza de medição na contagem de partículas ......................................................................................

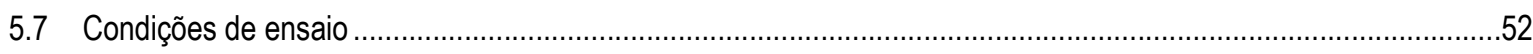

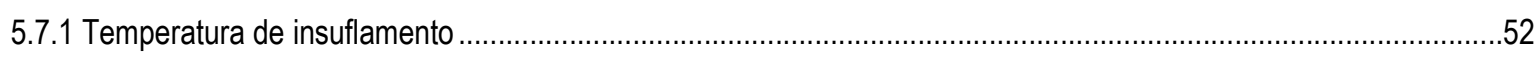

5.7.2 Temperaturas superficiais das paredes ....................................................................................................52

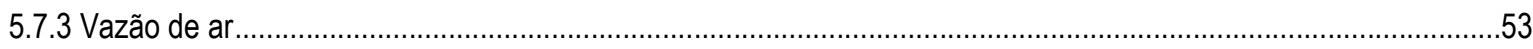

5.7.4 Vazão de ar de renovação e filtragem do ar ..............................................................................................5

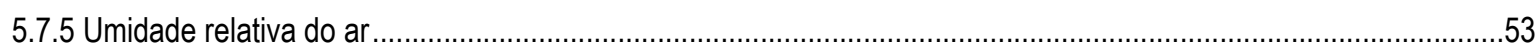




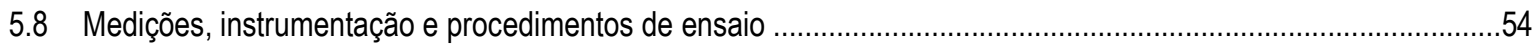

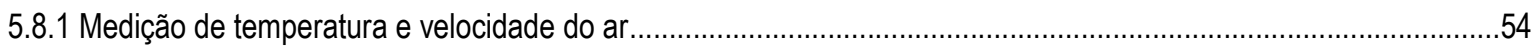

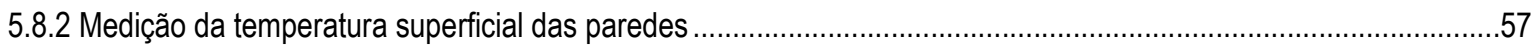

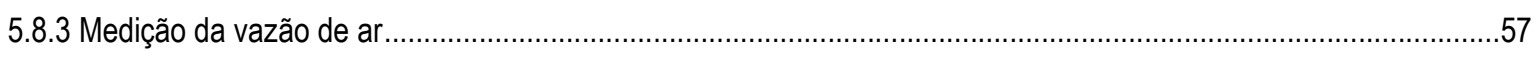

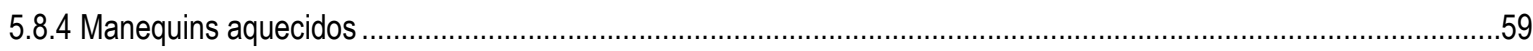

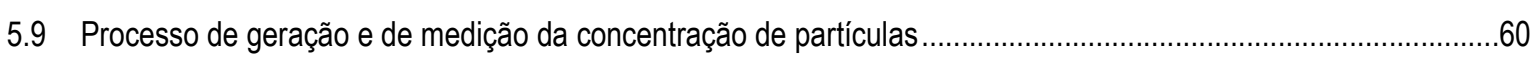

5.9 .1 Intervalo entre medições e tempo de medição das partículas.............................................................................62

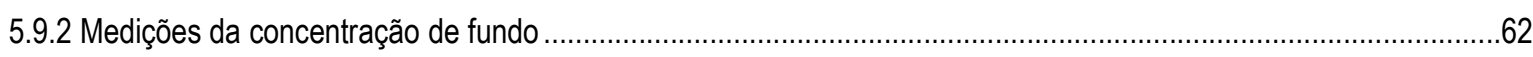

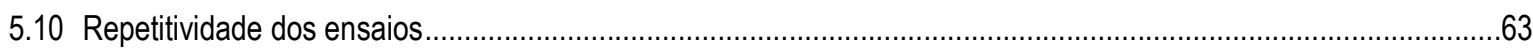

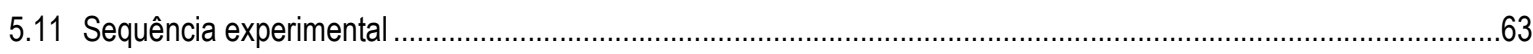

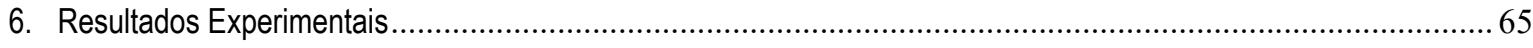

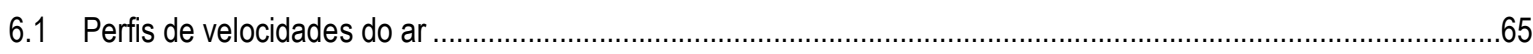

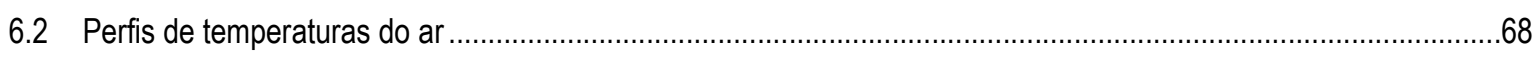

6.3 Percentagem de pessoas insatisfeitas devido a correntes de ar .......................................................................

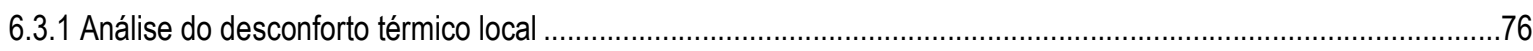

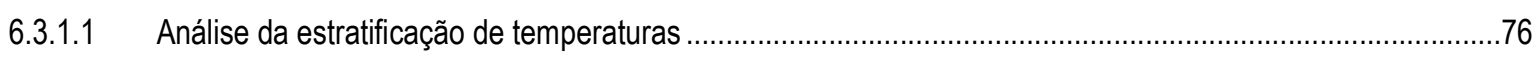

6.4 Concentração, Dispersão e Remoção de Partículas na Região de Respiração ........................................................79

6.4.1 Análise da concentração e dispersão de partículas com relação à temperatura do ar insuflado ..............................83

6.4.2 Análise da concentração e dispersão de partículas com relação ao ponto de injeção/geração de partículas...........88

6.4.3 Análise da remoção de partículas na região de respiração com relação ao sistema de ventilação.........................91

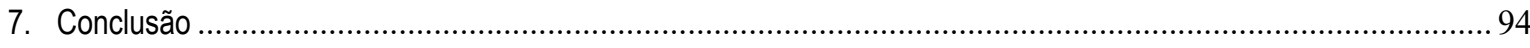

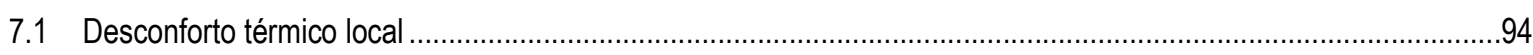

7.2 Concentração, dispersão e remoção de partículas na região de respiração ………………………………….....95

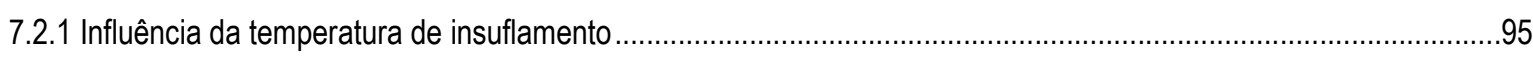

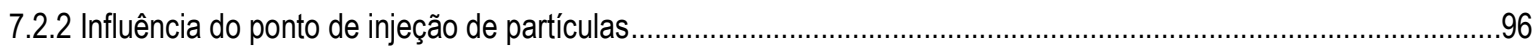

7.2.3 Influência do sistema de ventilação ..........................................................................................................96

7.3 Influência conjunta do sistema de ventilação no desconforto térmico local e na remoção de partículas na região de respiração

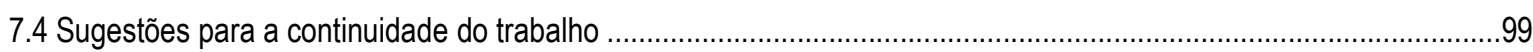

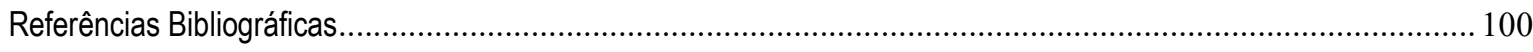

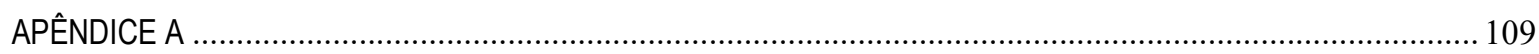

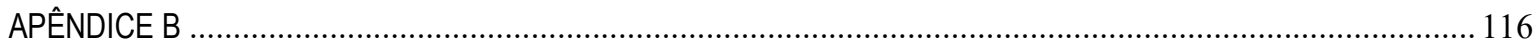

ANEXO A

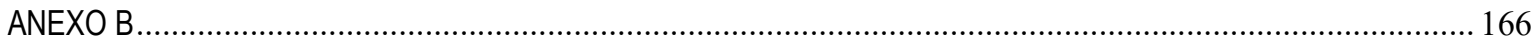




\section{Introdução}

Ao estudar conforto térmico e qualidade do ar em cabines de aeronaves verifica-se que são muitas as dificuldades encontradas para propiciar um ambiente confortável e saudável.

Em cabines de aeronaves comerciais, a elevada densidade de ocupação e os pequenos espaços de circulação de ar resultam em taxas de ventilação por pessoa relativamente baixas. Esse tipo de ambiente singular pode também gerar zonas de estagnação e redução na taxa de diluição de contaminantes potencialmente patogênicos exalados pelas pessoas. Além disso, o espaço interno limitado com elevado número de ocupantes faz com que os passageiros fiquem muito próximos uns aos outros (FISER; MIROSLAV, 2013, VOLAVÝ; FISER; NÖSKE, 2013; LI et al., 2014; YOU et al., 2016).

A temperatura externa da fuselagem pode ir de $80^{\circ} \mathrm{C}$ em solo a $-40^{\circ} \mathrm{C}$ em menos de uma hora. Em voo, temperaturas baixas das paredes internas da fuselagem podem criar assimetrias térmicas para os passageiros. A convecção natural e forçada, as plumas térmicas geradas ao redor dos passageiros e a radiação térmica desempenham um papel importante na troca de calor nesse tipo de ambiente. Espaços relativamente pequenos e diferentes temperaturas das superfícies interagem com a superfície do corpo humano gerando desconforto (STANCATO, 2009, VOLAVÝ; FISER; NÖSKE, 2013, WINZEN et al., 2013; GIACONA et al., 2015).

A adaptação dos passageiros a este ambiente complexo, com acesso limitado à mudança de vestimenta e de controle das variáveis ambientais na cabine, causa uma dificuldade maior para se atingir o conforto.

Outro importante fator é o longo tempo de permanência em um ambiente fechado. Esta condição, juntamente com a baixa taxa de ventilação por pessoa e a proximidade entre passageiros, podem prover um ambiente favorável para a transmissão de doenças infecciosas por contato e por partículas aéreas (WAN et al., 2009; CONCEIÇÃO, 2012; ZHENG et al., 2016).

A doença viral SARS (Severe Acute Respiratory Syndrome), que teve sua eclosão mundial em 2003, demonstrou que a disseminação de contaminantes 
aéreos é um evento não controlável, uma vez que foi rapidamente difundido, principalmente porque pessoas infectadas viajaram de avião para cidades distantes (OLSEN; CHANG; CHEUNG, 2003).

Estudos de contaminação em cabines de aeronaves têm sido focados na contaminação aérea resultante da dispersão de poluentes expiratórios gerados pelas pessoas na cabine (WAN; CHAO; FANG, 2005; ZHANG et al., 2009; WAN et al., 2009, SZE TO et al., 2009, YAN et al., 2009; GUPTA; LIN; CHEN, 2011; CONCEIÇÃO, 2012; CHEN et al., 2012; PANG et al., 2013; Ll et al., 2014; CAO, et al., 2016; Ll et al., 2016), objeto de estudo também no presente trabalho.

Embora o entendimento sobre a contaminação aérea em aeronaves e em outros tipos de ambientes tenha evoluído bastante, pouco ainda se conhece sobre a dinâmica das partículas e a influência do sistema de ventilação e distribuição de ar na dispersão de partículas para controlar e prevenir a sua disseminação (MORAWSKA, 2005; LI et al., 2007; YANG, 2007; NIELSEN, 2007; NIELSEN, 2008, MÜLLER; SCHMIDT; MÜLLER, 2011, BOSBACH et al., 2012; LIU; CHEN, 2013; BOSBACH et al., 2013; LIU et al., 2013; DUAN et al., 2015; GUO; KE; ZHANG, 2015; LI et al., 2016, BERLANGA; OLMEDO; ADANA, 2018).

Adicionalmente, existem muito poucos estudos que avaliam conjuntamente 0 conforto térmico e a dispersão de partículas em cabines de aeronaves. Trata-se de um ramo de atividade em que os avanços verificados normalmente não são divulgados na literatura aberta. Cada empresa aeronáutica acaba desenvolvendo as suas próprias avaliações.

A maior parte dos estudos experimentais são realizados em mock-ups que reproduzem o interior de cabines de aeronaves. Nesses mock-ups são simuladas as condições de troca de calor e do escoamento do ar na cabine com a aeronave em solo ou em voo. O uso de mock-ups justifica-se pelo alto custo de estudos experimentais em condições reais de voo. Na condição real de voo existem variações do escoamento do ar em função da dificuldade de se conduzir o experimento com uma resolução espacial razoável, influenciando significativamente a obtenção de resultados confiáveis. (ZHANG; CHEN, 2007).

A realização de estudos em mock-ups é bastante recente e, via de regra, os estudos são desenvolvidos em centros de pesquisa diretamente ligados ou subvencionados pela indústria aeronáutica. 
Em um desses estudos, no German Aerospace Center - o DLR (Deutscher Luftund Raumfahrt), da Alemanha, foram realizados, inicialmente, estudos do escoamento do ar na cabine de aeronave Airbus A380 utilizando simulação numérica (CFD - Computational Fluid Mechanics) e medidas de velocidade com técnica PIV (Particle Image Velocimetry) em condições reais de voo (PENNECOT et al., 2004).

Mais recentemente, também no $D L R$, estão sendo desenvolvidos estudos numéricos e validações experimentais em um mock-up simulando a cabine de uma aeronave modelo A320. O objetivo é a análise de conforto térmico resultante do uso do sistema convencional de ventilação e distribuição de ar por mistura MV (Mixing Ventilation), de sistema de ventilação e distribuição de ar por deslocamento - DV (Displacement Ventilation) e da interação entre esses dois sistemas de ventilação e distribuição de ar, conforme apresentado na Figura 1.1 (BOSBACH et al. 2012; BOSBACH et al., 2013; WINZEN et al, 2013, DEHNE et al., 2018).
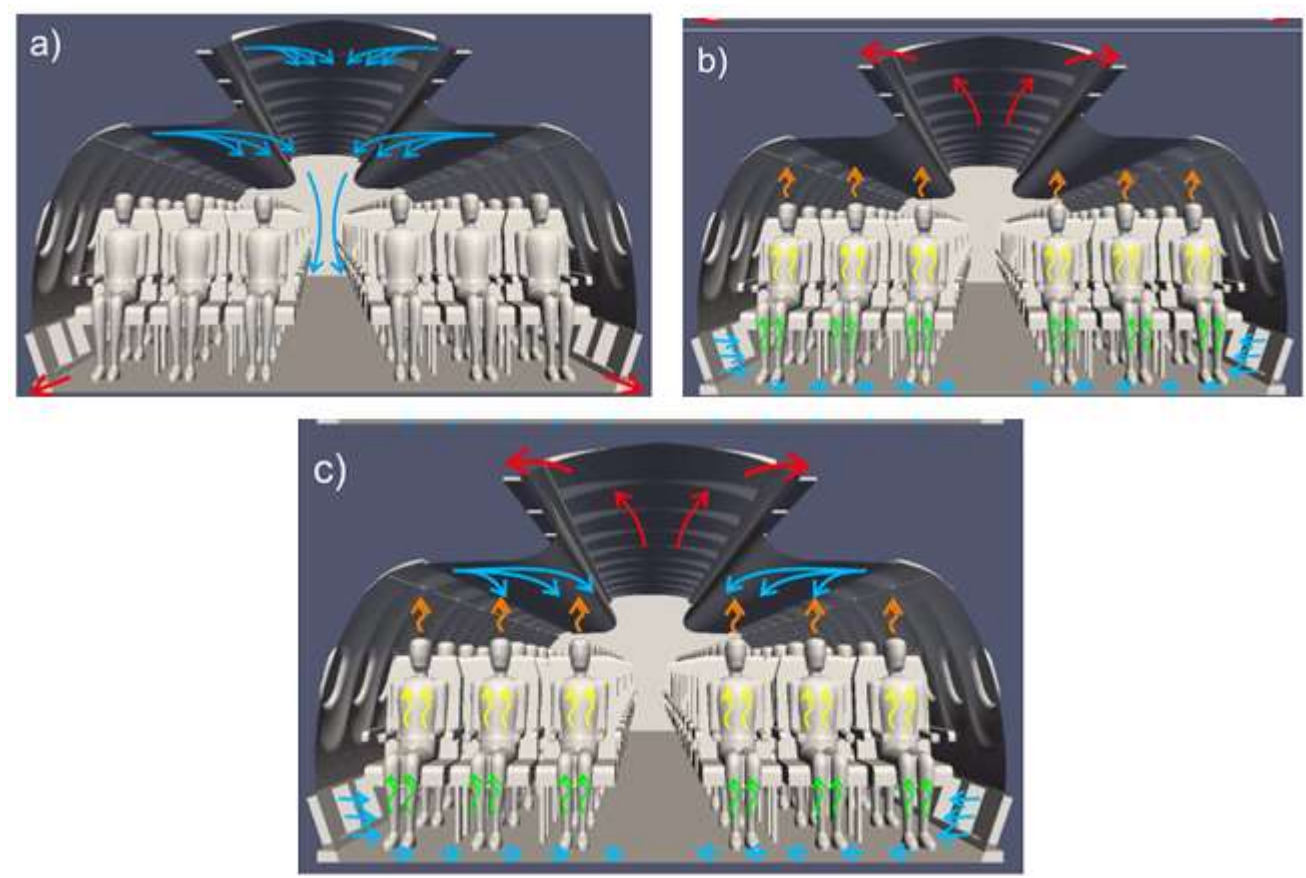

Figura 1.1.Sistemas de ventilação em mock-up de aeronave A320: a) MV (Mixing ventilation); b) DV (Displacement Ventilation); c) interação entre os sistemas MV e DV (BOSBACH et al., 2013 apud SCHMID et al., 2008 e MÜLLER; SCHMIDT; MÜLLER, 2011)

Ainda no DLR foi realizado estudo experimental com pessoas com o objetivo de avaliar a viabilidade do sistema de ventilação e distribuição de ar DV em propiciar conforto térmico em cabine de aeronave Donier 728 (WINZEN et al., 
2013). Estes estudos também contemplaram a avaliação sobre a interação entre sistemas diferentes de ventilação, como o sistema DV aliado ao sistema MV, de forma similar ao realizado nos estudos numéricos desenvolvidos por Bosbach et al., (2012).

No International Center for Indoor Environment and Energy, na Dinamarca estão sendo realizados estudos em um mock-up com 21 assentos - três fileiras de sete assentos, instalado em uma câmara climática com temperatura controlada de forma a obter superfícies das paredes internas com temperaturas "realisticamente" baixas, simulando condições reais de voo, com a utilização de cilindros aquecidos simulando pessoas. Neste mock-up foram realizados estudos de conforto térmico utilizando manequins térmicos (IRGENS; MELIKOV, 2004; STROM-TEJSEN et al., 2005; STROM-TEJSEN et al., 2007) e de dispersão de partículas expiratórias, utilizando gerador de partículas para a simulação de pessoa tossindo (WAN; CHAO; FANG, 2005)

$\mathrm{Na}$ Universidade de Illinois foram realizados estudos de dispersão de contaminantes, empregando gás traçador $\left(\mathrm{CO}_{2}\right)$ na simulação de atividades expiratórias em mock-up de Boeing 767-300, dotado de sistema convencional de ventilação, sistema MV (YAN et al., 2009). Os ensaios foram realizados simulando um passageiro infectado e o controle foi realizado mediante a utilização de sensores de $\mathrm{CO}_{2}$ por infravermelho não dispersivo.

$\mathrm{Na}$ Escola de Engenharia Mecânica da Universidade de Purdue, EUA, em parceria com a Escola de Ciências Ambientais e Engenharia da Universidade Tianjin, China, estão sendo desenvolvidos estudos experimentais e numéricos relacionados à distribuição de ar em cabines de aeronaves, avaliação de conforto térmico, deposição de partículas e dispersão de contaminantes. (ZHANG et al.,2007; ZHANG; CHEN, 2007; YAN et al., 2009; LIU; CHEN, 2013; LIU et al., 2013; LI et al., 2014; CUI; OUYANG; ZHU,2014; GUO; KE; ZHANG, 2015; LIU et al., 2015; DUAN et al., 2015; CAO et al., 2016; WEl; ZHANG; WANG, 2016; YOU et al., 2016; ZHENG et al., 2016; LI et al., 2016, ZHANG et al., 2017, YOU et al., 2018a, YOU et al., 2018b). Os estudos estão sendo realizados em mock-ups de aeronave modelo MD-82, Boeing 767 e analisados os sistemas de ventilação e distribuição de ar convencional - MV e sistemas de ventilação e distribuição de ar personalizada.

Paralelamente, no Centro de Engenharia de Conforto da Escola Politécnica da USP estão sendo desenvolvidos estudos em mock-ups de aeronaves comerciais 
de quatro assentos por fileira na análise do conforto térmico, vibro-acústico, lumínico e de qualidade do ar. Com relação ao conforto térmico e à qualidade do ar, estão sendo realizados estudos do escoamento do ar na cabine, de conforto térmico e de dispersão de partículas expiratórias (MOURA, 2009; STANCATO, 2009; CONCEIÇÃO, 2012; SILVA, 2013; FABICHAK JR, 2013), em mock-up de 20 lugares com sistema de ventilação MV (MOURA, 2009; STANCATO, 2009; CONCEIÇÃO, 2012) e em mock-up de 12 lugares com sistema de ventilação MV e sistema de distribuição de ar pelo piso, UnderFloor Air Distribution - UFAD (SILVA, 2013; FABICHAK JR, 2013) e de sistema MV com sistema de ventilação personalizada (CELLINE; FABICHAK; TRIBESS, 2017; CELLINE, 2017; FELIX et al., 2018).

\subsection{Motivação}

Com o incremento da autonomia de voo de novas aeronaves e com o crescimento do número de passageiros em viagens aéreas, surge também a preocupação com a permanência por períodos maiores nesse tipo de ambiente. Estudos relacionados ao conforto térmico e à qualidade do ar são desenvolvidos de modo a ser um diferencial na competitividade que existe entre as indústrias aeronáuticas, que são poucas.

Uma grande preocupação com relação à saúde dos ocupantes de aeronaves está diretamente relacionada à contaminação cruzada entre os passageiros, sobretudo depois dos surtos da doença viral SARS, gripe suína (H1N1), gripe aviária, etc. (MANGILI; GEANDREAU, 2005; WALKINSHAW, 2010), que tem motivado governos, empresas e instituições de pesquisa a investirem fortemente em pesquisa e desenvolvimento (NRC, 1986, NRC, 2002, COT, 2006; ACER, 2010, POSSOU et al., 2010, GUPTA; LIN; CHEN, 2011).

Adicionalmente, novos sistemas de ventilação e de distribuição de ar em aeronaves estão começando a ser estudados numericamente (ZHANG; CHEN, 2007; SCHMID et al., 2008; MÜLLER; SCHMIDT; MÜLLER, 2011; BOSBACH et al., 2012; BOSBACH et al., 2013; WINZEN et al., 2013) e testados experimentalmente (DLR, 2011; BOSBACH et al, 2012; WINZEN et al, 2013), baseados em sistema de ventilação por deslocamento, Displacement Ventilation - DV (CHEN; GLICKSMAN, 2003; BOSBACH et al., 2012; BOSBACH et al., 2013; WINZEN et al., 2013, ZHANG 
et al., 2017) e em sistema UFAD (BAUMAN; DAILY, 2003; SILVA, 2013; FABICHAK JR., 2013), já aplicados em edificações.

E é justamente neste contexto que se insere o presente trabalho. O de testar, simultaneamente, o conforto térmico e a qualidade do ar em cabines de aeronaves. O que, na visão deste grupo de pesquisa, é fundamental, pois ambas são dependentes no projeto de um novo sistema de ventilação e distribuição de ar. Os sistemas de ventilação propostos neste trabalho não tratam de opções aprimoradas de projeto, mas de sistemas testados e utilizados em edifícios. O que torna a aplicação desses sistemas em cabines de aeronaves ainda mais relevante. Um dos fatores de notoriedade dessa pesquisa se dá pela escolha de uma cabine que atende uma classe de aeronaves com menor capacidade, que difere de trabalhos correlatos por atender a demanda de aeronaves menores da classe executiva, por exemplo.

\subsection{Objetivo}

O objetivo deste trabalho consiste na análise experimental da influência do sistema de ventilação e distribuição de ar no conforto térmico e na dispersão e remoção de partículas expiratórias em cabine de aeronave.

\subsubsection{Objetivos específicos}

Para atingir o objetivo do trabalho têm-se os seguintes objetivos específicos:

- Analisar a influência do sistema de ventilação e distribuição de ar no padrão de escoamento do ar e relacionar os padrões do escoamento com o conforto térmico e a dispersão de partículas na região da respiração.

- Analisar condições de desconforto térmico local devido à estratificação de temperaturas e correntes de ar.

- Avaliar a influência da pluma térmica gerada pelos passageiros no conforto térmico e na remoção de partículas.

- Analisar a eficiência dos sistemas de ventilação na remoção de partículas da cabine na região da respiração. 


\subsection{Organização do trabalho}

No Capítulo 1 foi feita a introdução do assunto e um breve relato dos principais estudos experimentais de conforto térmico e de dispersão de partículas realizados em mock-ups de cabines de aeronaves.

No Capítulo 2 os sistemas de ventilação e distribuição de ar a serem testados no presente trabalho são apresentados e discutidos.

No Capítulo 3 são apresentados as condições para o conforto térmico e os métodos de avaliação em cabines de aeronaves, com ênfase no desconforto térmico local devido a correntes de ar. Estudos relativos ao conforto térmico em mock-ups são enfatizados.

No Capítulo 4 são apresentados aspectos gerais sobre contaminação cruzada em cabines de aeronaves, as características relevantes sobre as partículas liberadas em atividades expiratórias, bem como a apresentação de estudos de dispersão de partículas em cabines de aeronaves.

No capítulo 5 é apresentado o método experimental, com a descrição do laboratório, em especial o mock-up e os instrumentos utilizados para a realização do trabalho, os sistemas de ventilação e de distribuição de ar analisadas, bem como o procedimento experimental e as condições de ensaio.

O capítulo 6 apresenta uma análise do conforto térmico e da dispersão de partículas no interior do mock-up para os sistemas de ventilação e distribuição de ar propostas.

No capítulo 7 apresentam-se a conclusão da Tese e sugestões para trabalhos futuros. Por fim, no capítulo 8 são apresentadas as referências bibliográficas. 


\section{Ventilação e distribuição de ar em cabines de aeronaves}

Em aeronaves o controle do ar-condicionado parte dos comandos ordenados pelo piloto, a partir do painel de comando da cabine do piloto. Esse sistema é o responsável por controlar as válvulas e, por meio delas, regular as condições desejadas. Ele é composto por sensores, cabos elétricos e acionadores das válvulas que fazem parte do sistema de controle ambiental. $\mathrm{O}$ ambiente de cabine de aeronaves é regulado por este sistema que controla a pressurização, a temperatura, a ventilação e a filtração do ar da aeronave.

A norma ASHRAE 161 (2007) preconiza que a vazão total de ar (recirculação + ar externo de renovação) deve ser de $20 \mathrm{cfm}$ por pessoa $\left(0,00944 \mathrm{~m}^{3} / \mathrm{s}\right.$ por pessoa). Na maioria das aeronaves comerciais $50 \%$ do ar insuflado na cabine é recirculado como forma de melhorar o controle da umidade do ar e da eficiência no consumo de combustível, como mostrado na Figura 2.1.

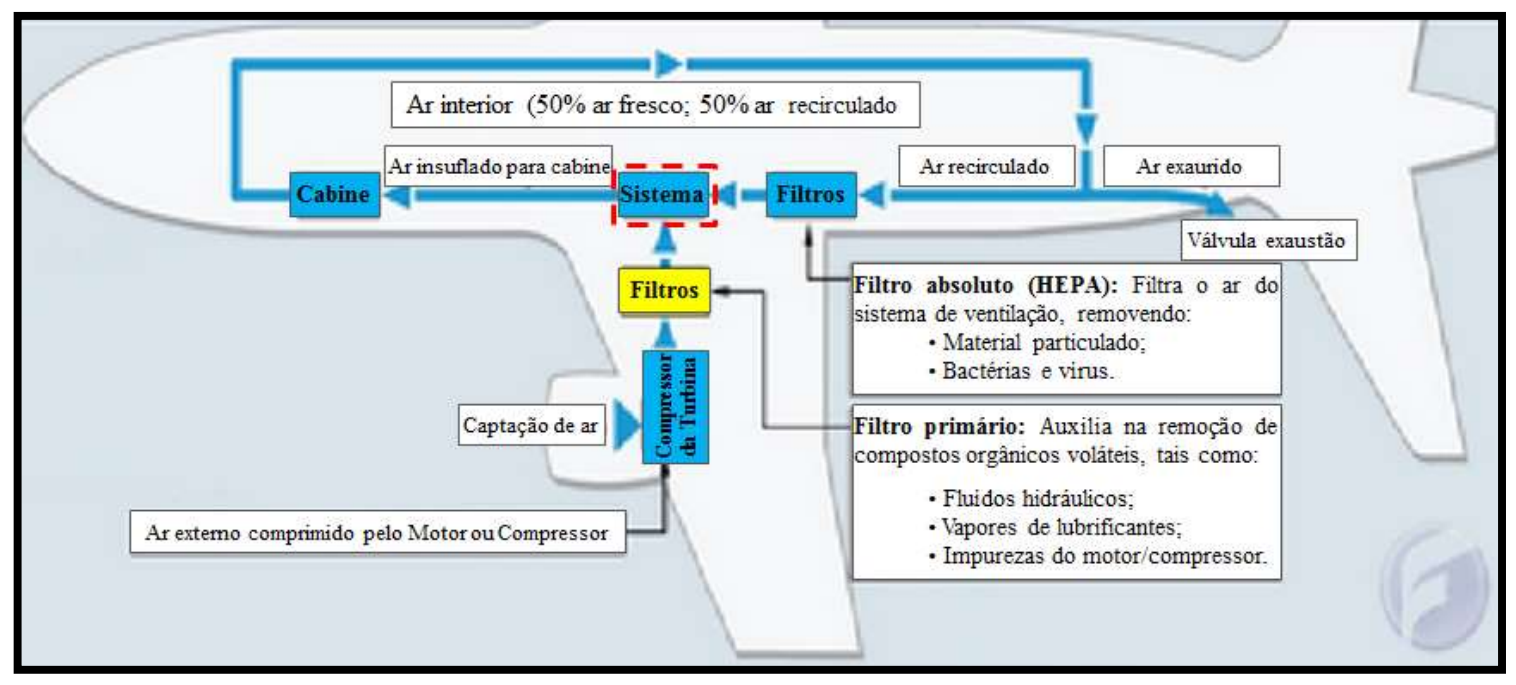

Figura 2.1. Esquema básico do sistema de climatização em cabines de aeronaves (Figura adaptada de WALKINSHAW, 2008)

Embora os filtros HEPA (High Efficiency Particulate Air) utilizados em aeronaves sejam eficazes na remoção de vírus e bactérias, os contaminantes gerados por um passageiro podem ser inalados por outros passageiros antes de 
serem coletados por estes filtros, que se encontram instalados nos dutos de ar de recirculação (CONCEIÇÃO; PEREIRA; TRIBESS, 2011).

O sistema de ventilação e distribuição de ar comumente utilizado em cabines de aeronaves consiste no insuflamento de ar na parte superior e retorno na parte inferior com mistura do ar na cabine, Mixing Ventilation - MV, Figura 2.2. O resultado é uma temperatura quase uniforme na cabine e a dispersão de contaminantes. Normalmente, o sistema MV apresenta velocidade de insuflamento do ar relativamente maior quando comparado a outros sistemas de ventilação.

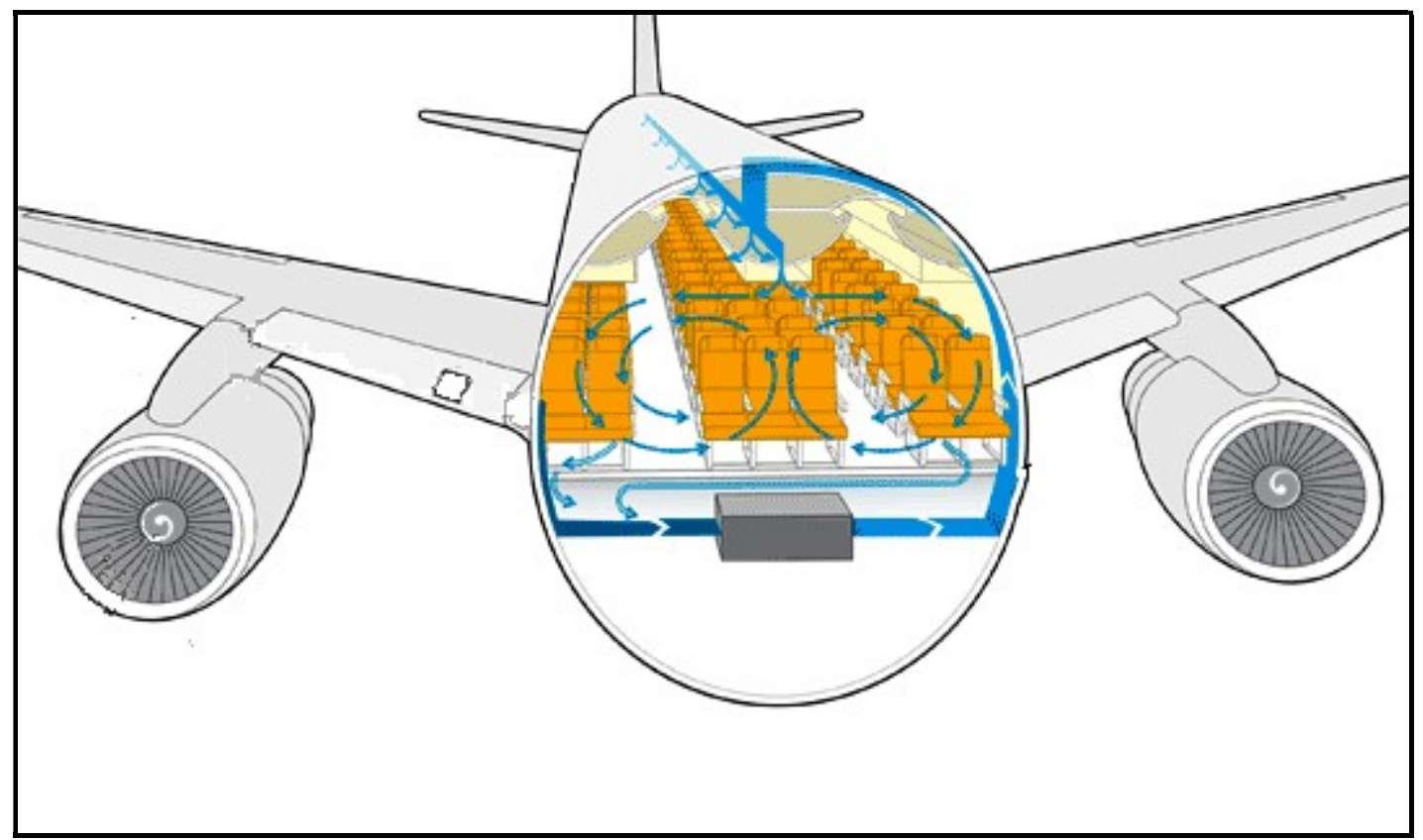

Figura 2.2. Sistema de distribuição com mistura de ar na cabine, MV

Embora, o sistema MV, normalmente, proporcione um ambiente com baixa estratificação de temperatura, problemas de conforto térmico têm sido verificados. Além disso, devido à sua característica de mistura, podem dispersar mais facilmente contaminantes pelo ar na cabine (GAO et al., 2007, ZHANG et al. 2007, LI et al., 2014; CAO et al., 2016; LI et al., 2016).

Para tentar resolver os problemas de conforto térmico e de qualidade do ar novos sistemas de ventilação e de distribuição de ar em aeronaves estão começando a ser estudados numericamente (ZHANG; CHEN, 2007) e testados experimentalmente (DLR, 2011; WINZEN et al, 2013, BOSBACH et al. 2012; BOSBACH et al. 2013; SILVA, 2013 E FABICHAK JR., 2013, ZHANG et al., 2017). 
No sistema de ventilação e distribuição de ar DV, o ar é introduzido no ambiente com baixa velocidade por difusores de ar montados na parede próxima ao piso e o retorno de ar é feito normalmente pelo teto, de maneira que o escoamento de ar acompanhe o sentido natural da pluma térmica dos ocupantes e leve consigo os contaminantes por eles gerados (Fig. 2.3).

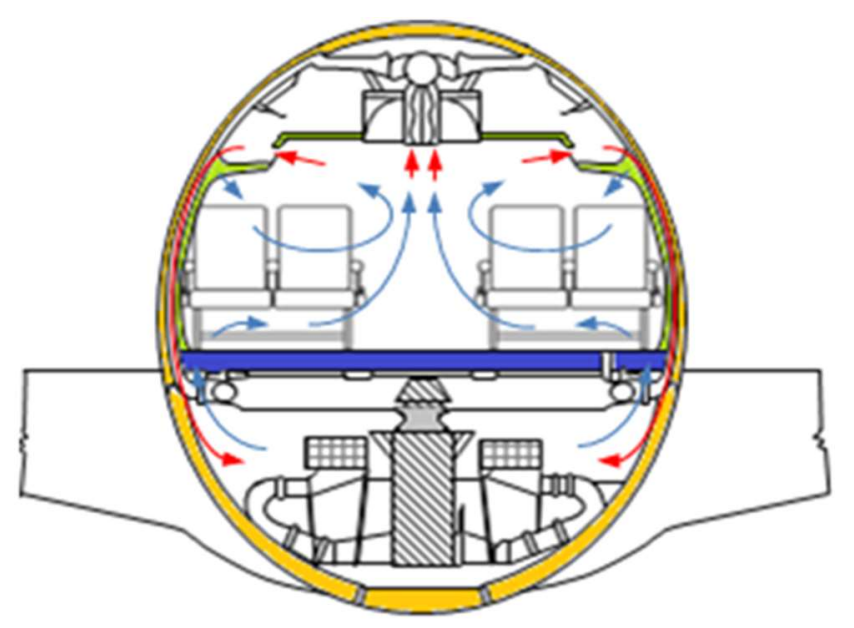

Figura 2.3. Esquema do sistema DV (Displacement Ventilation) em cabine de aeronave (Figura adaptada de GAO et al., 2007; ZHANG et al., 2007)

No sistema de ventilação e distribuição de ar UFAD, o ar é insuflado no ambiente a partir do piso (Fig. 2.4) e, de maneira semelhante ao sistema DV, o escoamento se soma à pluma térmica dos ocupantes levando os contaminantes até a exaustão pelo teto (BAUMAN; DAILY, 2003, LEITE; TRIBESS, 2006, PEREIRA et al., 2009).

Como resultado, o sistema de ventilação por deslocamento (DV) e o sistema de ventilação pelo piso (UFAD) podem apresentar algumas vantagens e limitações.

Como uma das vantagens tem-se a flexibilidade na distribuição de ar, sabendo que o ar tem movimento gerado pelas correntes de convecção natural causadas pelas trocas de calor no ambiente. Esses sistemas poderão então, compensar quaisquer eventuais alterações na distribuição de pessoas no interior do ambiente. Essa característica é bastante interessante para uma cabine de aeronave, já que este tipo de ambiente nem sempre opera com capacidade máxima de passageiros, principalmente em voos com conexões. (LEITE; TRIBESS, 2006; YUSOF et al., 2006; KOSONEN; TAN, 2004; LEITE, 2003; BAUMAN; ARENS, 1996; BAUMAN; DAILY, 2003; SHIRAI; BAUMAN; ZAGREUS, 2003) 


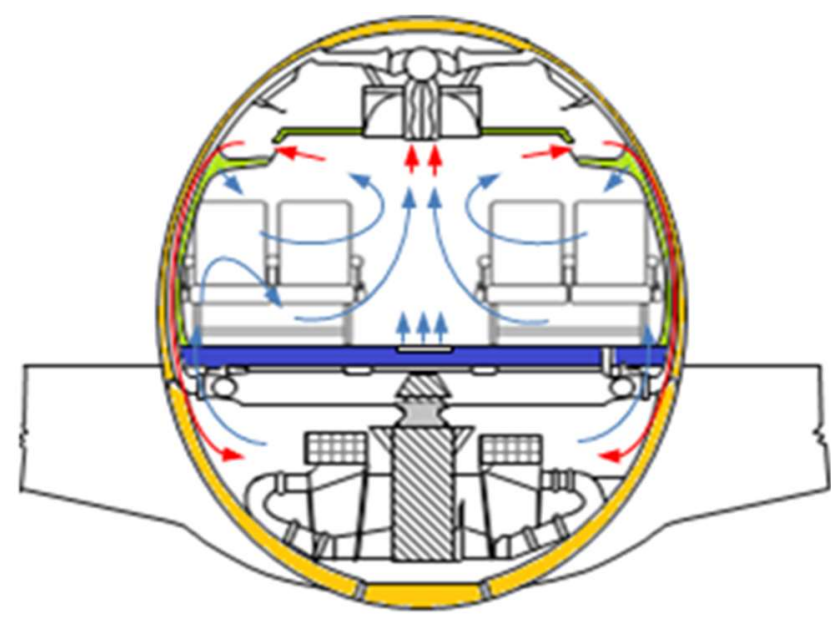

Figura 2.4. Esquema do sistema UFAD (UnderFloor Air Distribution) em cabine de aeronave (Figura adaptada de GAO et al., 2007; ZHANG et al., 2007)

A qualidade do ar é outra condição que pode ser melhorada por meio da utilização desses sistemas de ventilação. Os sistemas DV e UFAD possibilitam, com o auxílio das plumas térmicas geradas, que possíveis contaminantes sejam extraídos na zona de respiração e sejam carregados para o sistema de exaustão instalado na parte superior.

Sistemas de ventilação que operam com baixas velocidades como o DV e o UFAD, podem ainda apresentar potencial para a economia de energia. Com a seleção de menores equipamentos de ventilação e com temperaturas maiores de insuflamento, quando comparados a outros sistemas. E devido à eficiência causada pela direção ascendente do ar no ambiente na remoção de contaminantes, esses sistemas poderão reduzir a taxa de ventilação por pessoa no ambiente, reduzindo o custo de operação, principalmente para climas com umidade elevada, onde o custo para a desumidificação é significativo.

Como desvantagens, a localização das grandes áreas de saída dos difusores no ambiente pode se tornar um problema para áreas onde há espaço limitado de parede no sistema de ventilação DV.

Em ambientes de edificações os sistemas de ventilação DV e UFAD tem sua capacidade de resfriamento limitada, principalmente pelos limites de estratificação estabelecidos pelas normas ASHRAE (2013) e ISO (2005). Em função do ar ser insuflado na altura dos pés dos ocupantes, aumenta-se o risco de desconforto por correntes de ar (FANGER et al., 1988; ZUKOWSKI, 2007). Embora possam promover melhor qualidade do ar que o sistema MV (ZHANG; CHEN, 2006), estes 
sistemas podem causar estratificação de temperatura não desejável (BAUMAN; DAILY, 2003; LEITE; TRIBESS, 2006), que pode ser potencializada em cabines de aeronaves, onde o volume ocupado por passageiro e a altura da cabine são bastante menores do que em edificações (WAN et al., 2009). 


\section{Análise de conforto térmico}

Conforto térmico é definido pela norma ASHRAE 55 (2013) como sendo "um estado de espírito que reflete a satisfação com o ambiente térmico que envolve a pessoa". Assim, se as condições necessárias para o indivíduo se sentir termicamente confortável existirem, a sensação de bem-estar poderá ser atingida.

O corpo humano precisa trocar energia em quantidade suficiente para que sua temperatura corporal se mantenha em uma temperatura média em torno de $37^{\circ} \mathrm{C}$, em atividade sedentária. Todas as exigências humanas de conforto térmico estão relacionadas com o funcionamento do organismo, que pode ser comparado ao funcionamento de uma máquina térmica.

As condições ambientais e pessoais requeridas para o conforto térmico não são as mesmas para todos. O organismo provoca reações desencadeadas pelo sistema termorregulador, que irá agir para manter a temperatura interna do corpo constante frente a variações térmicas externas, causando o desconforto (FANGER, 1972).

A necessidade de estudar e controlar as variáveis que envolvem o conforto térmico surge com a necessidade do ser humano de se sentir termicamente confortável para o seu bem-estar e para realizar melhor as suas tarefas, aumentando a sua produtividade.

Segundo Van Hoof (2008), o método mais utilizado mundialmente na análise de conforto térmico em ambientes interiores, principalmente em ambientes climatizados, é o método PMV/PPD (Predicted Mean Vote/Predicted Percentage of Dissatisfied), desenvolvido por Fanger (1972).

\subsection{Condições de conforto de Fanger}

A partir do balanço térmico do corpo humano, Fanger (1972) mostra que o conforto térmico depende das seguintes variáveis: 
a) parâmetros pessoais: a taxa de metabolismo, função do nível de atividade da pessoa, $(\mathrm{MET})^{1}$, e o tipo de vestimenta $(\mathrm{CLO})^{2}$. Na Tabela 3.1 são apresentados valores de metabolismo para diferentes atividades.

b) parâmetros ambientais: a temperatura do ar, $T_{a}$, a temperatura radiante média, $\overline{T_{r}}$, a velocidade do ar, $V_{a}$, e a umidade relativa do ar, $\phi$.

Por meio de medições das variáveis de conforto térmico e de ensaios realizados com pessoas, Fanger (1972) concebeu um modelo de conforto térmico baseado no voto médio estimado - PMV, que varia de frio (-2) a quente (+2). Além disso, Fanger (1972) estabeleceu uma relação entre o PMV e o percentual de pessoas insatisfeitas PPD, apresentada na Figura 3.1.

Tabela 3.1. Metabolismos / por área superficial para diferentes atividades

\begin{tabular}{|l|c|c|}
\hline \multicolumn{1}{|c|}{ Atividade } & \multicolumn{2}{c|}{ Taxa metabólica } \\
\hline Sentado reclinado & $46 \mathrm{~W} / \mathrm{m}^{2}$ & 0,8 met \\
\hline Sentado relaxado & $58 \mathrm{~W} / \mathrm{m}^{2}$ & 1,0 met \\
\hline Em pé relaxado & $70 \mathrm{~W} / \mathrm{m}^{2}$ & $1,2 \mathrm{met}$ \\
\hline Dirigindo automóvel & $80 \mathrm{~W} / \mathrm{m}^{2}$ & $1,4 \mathrm{met}$ \\
\hline Em pé, atividade leve & $93 \mathrm{~W} / \mathrm{m}^{2}$ & 1,6 met \\
\hline Em pé, atividades moderadas (trabalho doméstico) & $116 \mathrm{~W} / \mathrm{m}^{2}$ & 2,0 met \\
\hline Caminhando horizontalmente, 5 km/h & $200 \mathrm{~W} / \mathrm{m}^{2}$ & 3,4 met \\
\hline Trabalhadores da construção civil & $275 \mathrm{~W} / \mathrm{m}^{2}$ & 4,7 met \\
\hline Esportes - correndo a 15 km/h & $550 \mathrm{~W} / \mathrm{m}^{2}$ & $9,5 \mathrm{met}$ \\
\hline
\end{tabular}

Fonte: ASHRAE 55, 2013

As normas ISO 7730 (2005) e ASHRAE 55 (2013) apresentam uma rotina para utilização em microcomputador e tabelas, como aquela apresentada na Tabela. 3.2, que permitem determinar o PMV para diferentes atividades, tipos de vestimenta e condições ambientais.

${ }^{1} \mathrm{MET}$ - medida que representa a estimativa do equivalente metabólico.

${ }^{2} \mathrm{CLO}$ - 1,0 CLO equivale a $0,15^{\circ} \mathrm{C} \mathrm{W} / \mathrm{m}^{2}$, a escala CLO é projetada de modo que uma pessoa despida tenha valor de 0,0 CLO e vestindo um terno típico um valor de 1,0 CLO. 


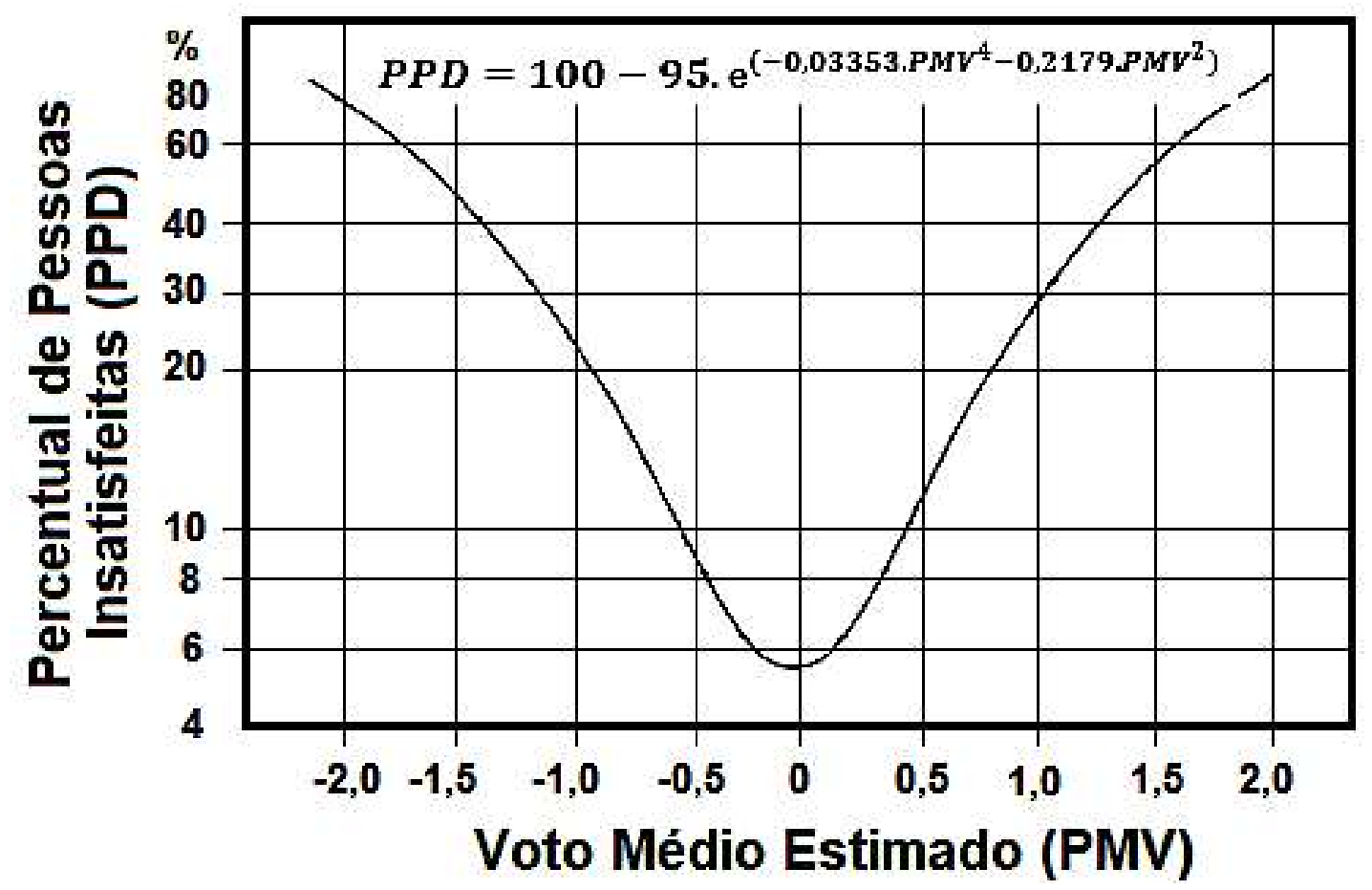

Figura 3.1. Percentual de pessoas insatisfeitas (PPD) como função do voto médio estimado (PMV)

Fonte: ASHRAE 55, 2013

Verifica-se na Tabela 3.2 que os resultados são apresentados em função da temperatura operativa, $T_{o}^{3}$, que é uma função da temperatura radiante média, $\bar{T}_{r}$, e da temperatura do ar, $T_{a}$, dada pela equação:

$$
T_{o}=a \cdot T_{a}+(1-a) \cdot \bar{T}_{r}
$$

Em que a constante a varia de acordo com a velocidade do ar $\left(V_{a}\right)$ :

$$
\begin{array}{cccc}
V_{a}(\mathrm{~m} / \mathrm{s}) & 0-0,2 & 0,2-0,6 & 0,6-1,0 \\
\mathbf{a} & 0,5 & 0,6 & 0,7
\end{array}
$$

A norma ISO 7726 (1998) apresenta procedimentos de medição e métodos para a obtenção das variáveis ambientais: velocidade média do ar, $V_{a}$, temperatura radiante média, $\bar{T}_{r}$, da temperatura do ar, $T_{a}$, e umidade do ar: umidade absoluta, $\omega$, e umidade relativa, $\phi$.

\footnotetext{
${ }^{3} \mathrm{~T}_{\mathrm{o}}=$ temperatura operativa $\left({ }^{\circ} \mathrm{C}\right):$ a temperatura de um meio imaginário (envolvendo ar e superfícies) com o qual a pessoa troca a mesma quantidade de calor por convecção e radiação que aquela trocada com o meio real.
} 
Tabela 3.2. Determinação do voto médio estimado - PMV

\begin{tabular}{|c|c|c|c|c|c|c|c|c|c|c|}
\hline \multicolumn{2}{|c|}{ Vestimenta } & \multirow{2}{*}{$\begin{array}{c}\text { Temperatura } \\
\text { Operativa } \\
{ }^{\circ} \mathrm{C} \\
\end{array}$} & \multicolumn{8}{|c|}{ Velocidade Relativa do ar $-\mathrm{m} / \mathrm{s}$} \\
\hline CLO & $\frac{\mathrm{m}^{20} \mathrm{C}}{\mathrm{W}}$ & & $<0.10$ & 0.10 & 0.15 & 0.20 & 0.30 & 0.40 & 0.50 & 1.00 \\
\hline 0 & 0 & $\begin{array}{l}26 \\
27 \\
28 \\
29 \\
30 \\
31 \\
32 \\
33\end{array}$ & $\begin{array}{r}-1.62 \\
-1.00 \\
-0.39 \\
0.21 \\
0.80 \\
1.39 \\
1.96 \\
2.50\end{array}$ & $\begin{array}{r}-1.62 \\
-1.00 \\
-0.42 \\
0.13 \\
0.68 \\
1.25 \\
1.83 \\
2.41\end{array}$ & $\begin{array}{r}-1.96 \\
-1.36 \\
-0.76 \\
-0.15 \\
0.45 \\
1.08 \\
1.71 \\
2.34\end{array}$ & $\begin{array}{r}-2.34 \\
-1.69 \\
-1.05 \\
-0.39 \\
0.26 \\
0.94 \\
1.61 \\
2.29\end{array}$ & & & & \\
\hline 0.25 & 0.039 & $\begin{array}{l}24 \\
25 \\
26 \\
27 \\
28 \\
29 \\
30 \\
31\end{array}$ & $\begin{array}{r}-1.52 \\
-1.05 \\
-0.58 \\
-0.12 \\
0.34 \\
0.80 \\
1.25 \\
1.71\end{array}$ & $\begin{array}{r}-1.52 \\
-1.05 \\
-0.61 \\
-0.17 \\
0.27 \\
0.71 \\
1.15 \\
1.61\end{array}$ & $\begin{array}{r}-1.80 \\
-1.33 \\
-0.87 \\
-0.40 \\
0.07 \\
0.54 \\
1.02 \\
1.51\end{array}$ & $\begin{array}{r}-2.06 \\
-1.57 \\
-1.08 \\
-0.58 \\
-0.09 \\
0.41 \\
0.91 \\
1.43\end{array}$ & $\begin{array}{r}-2.47 \\
-1.94 \\
-1.41 \\
-0.87 \\
-0.34 \\
0.20 \\
0.74 \\
1.30\end{array}$ & $\begin{array}{r}-2.24 \\
-1.67 \\
-1.10 \\
-0.53 \\
0.04 \\
0.61 \\
1.20\end{array}$ & $\begin{array}{r}-2.48 \\
-1.89 \\
-1.29 \\
-0.70 \\
-0.10 \\
0.50 \\
1.12\end{array}$ & $\begin{array}{r}-2.66 \\
-1.97 \\
-1.28 \\
-0.58 \\
0.11 \\
0.83\end{array}$ \\
\hline 0.50 & 0.078 & $\begin{array}{l}23 \\
24 \\
25 \\
26 \\
27 \\
28 \\
29 \\
30\end{array}$ & $\begin{array}{r}-1.10 \\
-0.72 \\
-0.34 \\
0.04 \\
0.42 \\
0.80 \\
1.17 \\
1.54\end{array}$ & $\begin{array}{r}-1.10 \\
-0.74 \\
-0.38 \\
-0.01 \\
0.35 \\
0.72 \\
1.08 \\
1.45\end{array}$ & $\begin{array}{r}-1.33 \\
-0.95 \\
-0.56 \\
-0.18 \\
0.20 \\
0.59 \\
0.98 \\
1.37\end{array}$ & $\begin{array}{r}-1.51 \\
-1.11 \\
-0.71 \\
-0.31 \\
0.09 \\
0.49 \\
0.90 \\
1.30\end{array}$ & $\begin{array}{r}-1.78 \\
-1.36 \\
-0.94 \\
-0.51 \\
-0.08 \\
0.34 \\
0.77 \\
1.20\end{array}$ & $\begin{array}{r}-1.99 \\
-1.55 \\
-1.11 \\
-0.66 \\
-0.22 \\
0.23 \\
0.68 \\
1.13\end{array}$ & $\begin{array}{r}-2.16 \\
-1.70 \\
-1.25 \\
-0.79 \\
-0.33 \\
0.14 \\
0.60 \\
1.06\end{array}$ & $\begin{array}{r}-2.22 \\
-1.71 \\
-1.19 \\
-0.68 \\
-0.17 \\
0.34 \\
0.86\end{array}$ \\
\hline 0.75 & 0.118 & $\begin{array}{l}21 \\
22 \\
23 \\
24 \\
25 \\
26 \\
27 \\
28\end{array}$ & $\begin{array}{r}-1.11 \\
-0.79 \\
-0.47 \\
-0.15 \\
0.17 \\
0.49 \\
0.81 \\
1.12\end{array}$ & $\begin{array}{r}-1.11 \\
-0.81 \\
-0.50 \\
-0.19 \\
0.12 \\
0.43 \\
0.74 \\
1.05\end{array}$ & $\begin{array}{r}-1.30 \\
-0.96 \\
-0.66 \\
-0.33 \\
-0.01 \\
0.31 \\
0.64 \\
0.96\end{array}$ & $\begin{array}{r}-1.44 \\
-1.11 \\
-0.78 \\
-0.44 \\
-0.11 \\
0.23 \\
0.56 \\
0.90\end{array}$ & $\begin{array}{r}-1.66 \\
-1.31 \\
-0.96 \\
-0.61 \\
-0.28 \\
0.09 \\
0.45 \\
0.80\end{array}$ & $\begin{array}{r}-1.82 \\
-1.46 \\
-1.09 \\
-0.73 \\
-0.37 \\
0.00 \\
0.36 \\
0.73\end{array}$ & $\begin{array}{r}-1.95 \\
-1.58 \\
-1.20 \\
-0.83 \\
-0.46 \\
-0.08 \\
0.29 \\
0.67\end{array}$ & $\begin{array}{r}-2.36 \\
-1.95 \\
-1.55 \\
-1.14 \\
-0.74 \\
-0.33 \\
0.08 \\
0.48\end{array}$ \\
\hline 1.00 & 0.155 & $\begin{array}{l}20 \\
21 \\
22 \\
23 \\
24 \\
25 \\
26 \\
27\end{array}$ & $\begin{array}{r}-0.85 \\
-0.57 \\
-0.30 \\
-0.02 \\
0.26 \\
0.53 \\
0.81 \\
1.08\end{array}$ & $\begin{array}{r}-0.87 \\
-0.60 \\
-0.33 \\
-0.07 \\
0.20 \\
0.48 \\
0.75 \\
1.02\end{array}$ & $\begin{array}{r}-1.02 \\
-0.74 \\
-0.46 \\
-0.18 \\
0.10 \\
0.38 \\
0.66 \\
0.95\end{array}$ & $\begin{array}{r}-1.13 \\
-0.84 \\
-0.55 \\
-0.27 \\
0.02 \\
0.31 \\
0.60 \\
0.89\end{array}$ & $\begin{array}{r}-1.29 \\
-0.99 \\
-0.69 \\
-0.39 \\
-0.09 \\
0.21 \\
0.51 \\
0.81\end{array}$ & $\begin{array}{r}-1.41 \\
-1.11 \\
-0.80 \\
-0.49 \\
-0.18 \\
0.13 \\
0.44 \\
0.75\end{array}$ & $\begin{array}{r}-1.51 \\
-1.19 \\
-0.88 \\
-0.56 \\
-0.25 \\
0.07 \\
0.39 \\
0.71\end{array}$ & $\begin{array}{r}-1.81 \\
-1.47 \\
-1.13 \\
-0.79 \\
-0.46 \\
-0.12 \\
0.22 \\
0.56\end{array}$ \\
\hline 1.50 & 0.233 & $\begin{array}{l}14 \\
16 \\
18 \\
20 \\
22 \\
24 \\
26 \\
28\end{array}$ & $\begin{array}{r}-1.36 \\
-0.94 \\
-0.52 \\
-0.09 \\
0.35 \\
0.79 \\
1.23 \\
1.67\end{array}$ & $\begin{array}{r}-1.36 \\
-0.95 \\
-0.54 \\
-0.13 \\
0.30 \\
0.74 \\
1.18 \\
1.62\end{array}$ & $\begin{array}{r}-1.48 \\
-1.07 \\
-0.64 \\
-0.22 \\
0.23 \\
0.68 \\
1.13 \\
1.56\end{array}$ & $\begin{array}{r}-1.58 \\
-1.15 \\
-0.72 \\
-0.28 \\
0.18 \\
0.63 \\
1.09 \\
1.56\end{array}$ & $\begin{array}{r}-1.72 \\
-1.27 \\
-0.82 \\
-0.37 \\
0.10 \\
0.57 \\
1.04 \\
1.52\end{array}$ & $\begin{array}{r}-1.82 \\
-1.36 \\
-0.90 \\
-0.44 \\
0.04 \\
0.52 \\
1.01 \\
1.48\end{array}$ & $\begin{array}{r}-1.89 \\
-1.43 \\
-0.96 \\
-0.49 \\
0.00 \\
0.49 \\
0.98 \\
1.47\end{array}$ & $\begin{array}{r}-2.12 \\
-1.63 \\
-1.14 \\
-0.65 \\
-0.14 \\
0.37 \\
0.89 \\
1.40\end{array}$ \\
\hline 2.00 & 0.310 & $\begin{array}{l}10 \\
12 \\
14 \\
16 \\
18 \\
20 \\
22 \\
24\end{array}$ & $\begin{array}{r}-1.38 \\
-1.03 \\
-0.68 \\
-0.32 \\
0.03 \\
0.40 \\
0.76 \\
1.13\end{array}$ & $\begin{array}{r}-1.39 \\
-1.05 \\
-0.70 \\
-0.35 \\
-0.00 \\
0.36 \\
0.72 \\
1.09\end{array}$ & $\begin{array}{r}-1.49 \\
-1.14 \\
-0.79 \\
-0.43 \\
-0.07 \\
0.30 \\
0.67 \\
1.05\end{array}$ & $\begin{array}{r}-1.56 \\
-1.21 \\
-0.85 \\
-0.48 \\
-0.11 \\
0.26 \\
0.54 \\
1.02\end{array}$ & $\begin{array}{r}-1.67 \\
-1.30 \\
-0.93 \\
-0.56 \\
-0.18 \\
0.20 \\
0.59 \\
0.98\end{array}$ & $\begin{array}{r}-1.74 \\
-1.37 \\
-0.99 \\
-0.61 \\
-0.23 \\
0.16 \\
0.55 \\
0.95\end{array}$ & $\begin{array}{r}-1.80 \\
-1.42 \\
-1.04 \\
-0.65 \\
-0.26 \\
0.13 \\
0.53 \\
0.93\end{array}$ & $\begin{array}{r}-1.96 \\
-1.57 \\
-1.17 \\
-0.77 \\
-0.37 \\
0.04 \\
0.45 \\
0.87\end{array}$ \\
\hline
\end{tabular}

OBS: 1) Valores de PMV em torno de zero indicam condições de conforto térmico.

2) Valores de CLO igual a 0,5 representam uma vestimenta leve de verão (calça comprida com camisa de mangas curtas), enquanto valores de CLO igual a 1,0 representam uma vestimenta pesada de inverno.

Fonte: ISO 7730, 2005 


\subsection{Desconforto térmico local}

Mesmo que sejam satisfeitas as condições de conforto, ou de desconforto térmico dentro dos limites aceitáveis, insatisfações térmicas locais podem ocorrer ocasionando sensação de "frio" ou de "calor" em uma parte particular do corpo, ou seja, um desconforto térmico local.

Neste caso, a norma ISO 7730 (2005) e a norma ASHRAE 55 (2013) recomendam limites adicionais para a aceitação do ambiente, baseados em um critério de $5 \%$ a $15 \%$ de insatisfação. Mas, esses percentuais não são aditivos, pois pessoas que sentem conforto ou desconforto, podem sentir ou não desconforto localizado e de modos diferentes.

O desconforto local ocorre devido a alguns fatores que alteram a uniformidade no ambiente. Tais fatores podem ser devido a correntes de ar, janelas ou superfícies frias ou quentes, ou variações dessas. As principais causas são as descritas a seguir.

\subsubsection{Correntes de ar (PD- Percentage of Dissatisfied; DR - Draught Rate)}

Segundo a norma ASHRAE 55 (2013), "correntes de ar (draft ou draught) é um resfriamento local indesejado do corpo causado pelo movimento do ar". A sensação de correntes de ar depende da velocidade do ar, temperatura do ar, da intensidade de turbulência, da atividade (metabolismo) e da vestimenta. A sensibilidade em relação às correntes de ar tende a ser maior onde a pele não é coberta. Especialmente a região da cabeça (a região da cabeça compreende cabeça, pescoço e ombros) e região das pernas (a região das pernas compreende pernas, tornozelos e pés).

Portanto, a ocorrência de correntes de ar deve ser analisada principalmente na altura da cabeça e tronco das pessoas $(1,10 \mathrm{~m}$ do piso para pessoas sentadas e 1,70 $\mathrm{m}$ para pessoas em pé). E para pernas descobertas, deve ser feita a verificação também na altura a $0,10 \mathrm{~m}$ do piso.

Segundo Fanger et al. (1988), para atividade sedentária ou leve, o percentual de insatisfação com correntes de ar, $\mathrm{PD}^{4}$ - Percentage of Dissatisfied ou DR Draught Rate é dada pela Equação (3.2), 


$$
P D=D R=\left[\left(34-T_{a}\right)\left(V_{a}-0,05\right)^{0,62}\right]\left(0,37 \cdot V_{a} \cdot T_{u}+3,14\right)
$$

$$
\text { Em que: } \quad \begin{aligned}
T_{a} & =\text { temperatura do ar local }\left({ }^{\circ} \mathrm{C}\right) ; \\
V_{a} & =\text { velocidade média do ar local }(\mathrm{m} / \mathrm{s}) ; \\
T_{u} & =\text { intensidade de turbulência }(\%) ;
\end{aligned}
$$

A intensidade de turbulência $\left(T_{u}\right)$ é a relação entre o desvio padrão $(D P V)$ e a média da velocidade do ar $\left(V_{a}\right)$, expresso em porcentagem. Esta relação pode ser calculada pela equação 3.3, com base nos valores de velocidade do ar, medidos com intervalos de 0,2 segundos, durante, pelo menos, três minutos e o desvio padrão $\left(D P_{v}\right)$, referente à respectiva coleção de dados.

$$
T_{u}=\frac{D P_{V}}{V_{a}} \cdot 100
$$

A norma ISO 7730 (2005) propõe, como limite para desconforto, 15\% de insatisfeitos. Na Figura 3.2 ilustra-se algumas condições limites de temperatura e velocidade do ar, dependentes da intensidade de turbulência para ambientes, nos quais, o percentual de pessoas insatisfeitas seja o máximo tolerável ( $D R=15 \%)$.

\subsubsection{Diferença vertical de temperatura do ar}

Geralmente, em ambientes fechados, a temperatura do ar aumenta do piso para o teto. Se este aumento é muito grande, pode ocorrer desconforto local expresso por calor na cabeça e frio nos pés, embora o corpo como um todo possa estar em situação de conforto. Para que este fato não ocorra, a diferença de temperatura não deve ser maior que $3^{\circ} \mathrm{C}$, para pessoas em atividade leve, vestindo roupa com isolamento de 0,5 clo a 0,7 clo.

4PD se refere exatamente ao mesmo termo DR. O termo PD (Percentage of Dissatisfied) foi utilizado por Fanger (1972), e norma ASHRAE 161 (2007), utilizou o termo DR (Draught Rate), que representa o mesmo desconforto representado por Fanger, com relação ao desconforto térmico local por correntes de ar. 
A curva ilustrada na Figura 3.3 pode ser usada para determinar a máxima diferença de temperatura no ambiente, de acordo com o limite do percentual de insatisfação para o caso.

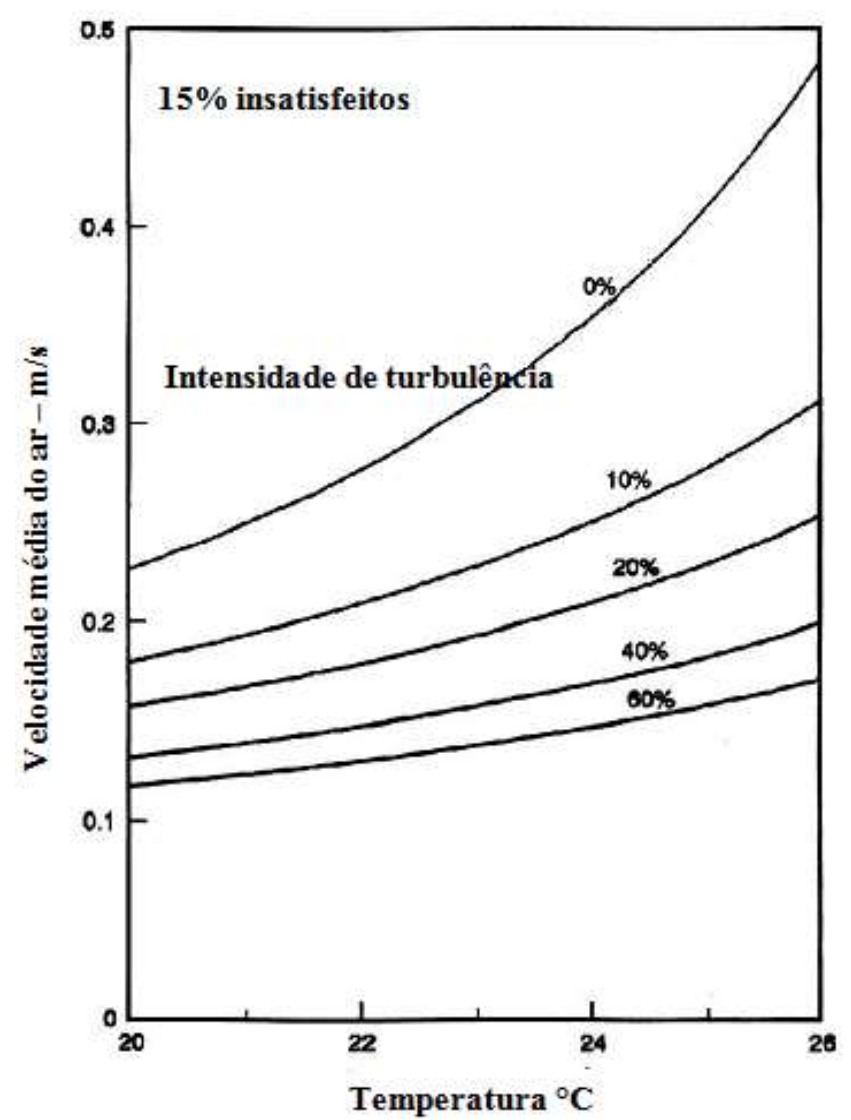

Figura 3.2. Correntes de ar para $15 \%$ de insatisfeitos em atividade sedentária Fonte: ASHRAE, 2013

\subsubsection{Assimetria de temperatura radiante}

A radiação térmica em torno do ocupante pode não ser uniforme, devido tanto a superfícies frias ou quentes quanto à radiação solar direta. Esta assimetria pode causar desconforto local e reduzir a aceitabilidade térmica do ambiente. Em geral, as pessoas são mais sensíveis à radiação assimétrica causada por teto quente do que àquelas por superfícies verticais frias ou quentes.

A medida da assimetria da temperatura radiante plana é dada pela diferença entre as temperaturas radiantes planas de dois lados opostos de um elemento plano pequeno. Deve ser medida na altura $0,60 \mathrm{~m}$ para pessoas sentadas e a $1,10 \mathrm{~m}$ do piso, para pessoas em pé. De acordo os com critérios determinados pela norma ASHRAE 55 (2013), para indivíduos nas condições de atividade e vestimenta 
especificadas anteriormente, os limites para a assimetria da temperatura radiante, apresentados no gráfico apresentado na Figura 3.4, são os seguintes:

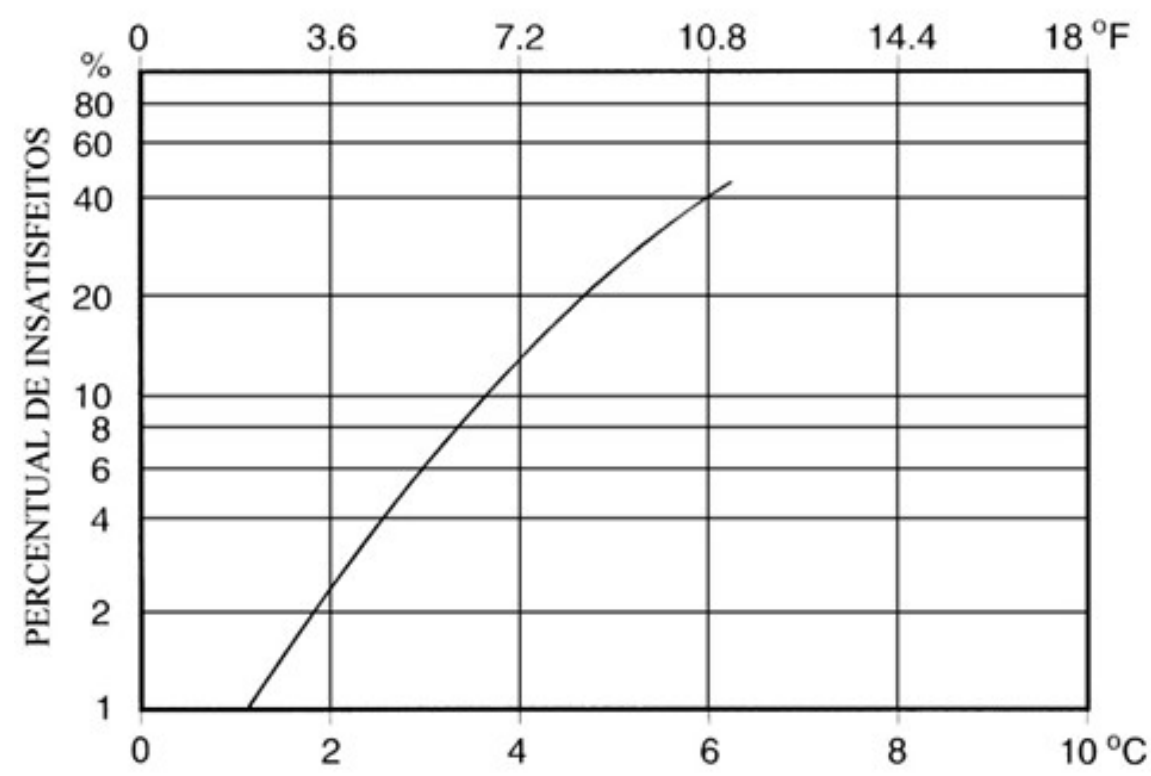

DIFERENÇA DA TEMPERATURA DO AR ENTRE A CABEÇA E OS PÉS

Figura 3.3. Percentual de pessoas insatisfeitas com a diferença vertical de temperatura do ar entre os pés e a cabeça

Fonte: ASHRAE, 2013

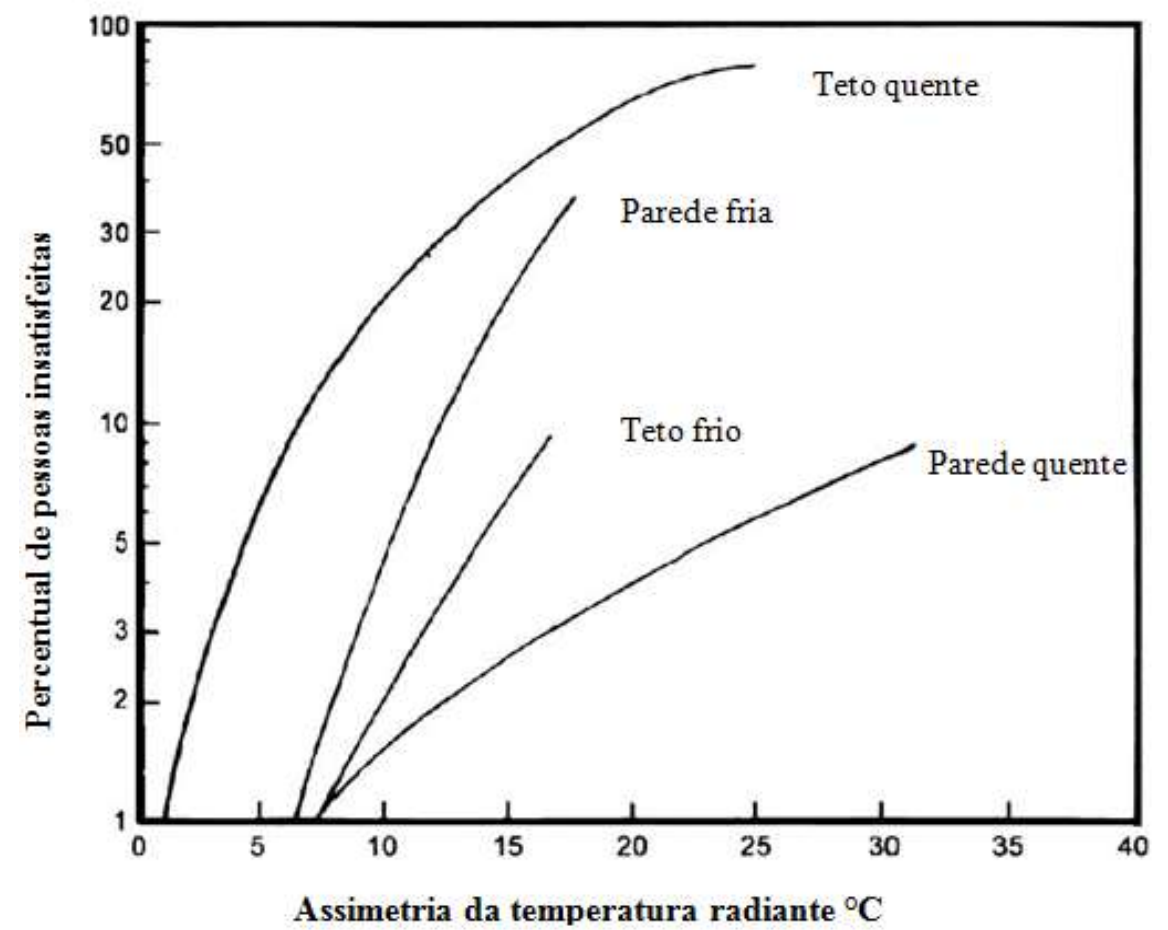

Figura 3.4. Percentual de pessoas insatisfeitas devido à assimetria da radiação Fonte: ASHRAE, 2013 
- Para teto quente, assimetria $<5^{\circ} \mathrm{C}$;

- Para teto frio, assimetria $<14{ }^{\circ} \mathrm{C}$;

- Para parede quente, assimetria $<23^{\circ} \mathrm{C}$;

- Para parede fria, assimetria $<10^{\circ} \mathrm{C}$;

\subsubsection{Temperatura do piso}

Ocupantes de ambientes fechados, nas condições de atividade e vestimenta já mencionadas, podem sentir desconforto nos pés, mesmo calçados, devido ao contato direto com o piso, se este estiver frio ou quente. Os limites de temperatura do piso indicados pela norma ASHRAE 55 (2013) são de $19^{\circ} \mathrm{C}$ a $29^{\circ} \mathrm{C}$, cujos limites correspondem a um percentual de $15 \%$ de insatisfeitas (Figura 3.5).

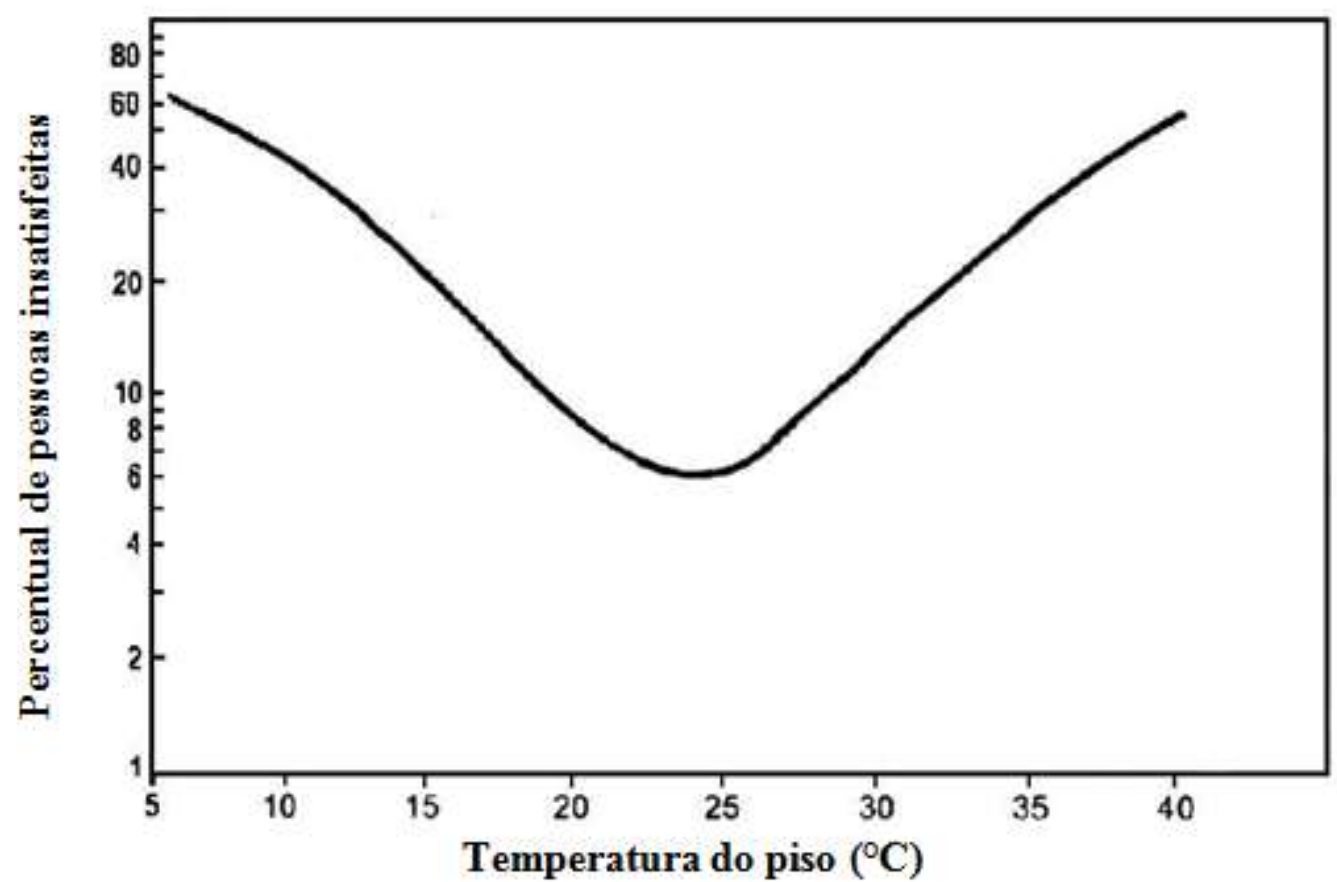

Figura 3.5. Percentual de pessoas insatisfeitas com a temperatura do piso Fonte: ASHRAE, 2013

\subsection{Análise simultânea de conforto térmico (PPD) e desconforto térmico local (PD)}

Gan (1994) propôs um índice para a análise simultânea do desconforto para o corpo como um todo (PPD) e do desconforto devido a correntes de ar (PD) correlacionando os índices PPD e PD, na função $\Psi$, dado pela Equação (3.4). 


$$
\Psi=\operatorname{máx}[\mathrm{PPD}, \mathrm{PD}]
$$

em que $\Psi$ é o maior valor entre PPD e PD

Gan (1994) desenvolveu um programa para a determinação numérica das variáveis ambientais $\left(\overline{V_{a r}}, \overline{T_{a r}}, \phi \mathrm{e} \overline{T_{r}}\right)$ e aplicou esse índice na avaliação de conforto térmico considerando pessoa desenvolvendo atividade sedentária em uma sala. Nas Figuras 3.6 e 3.7 mostra-se os resultados para quatro níveis de intensidade de turbulência $10 \%, 30 \%, 50 \%$ e $70 \%$ e dois níveis de isolamento de roupas 0,6 clo (condição de verão) e 1,0 clo (condição de inverno).

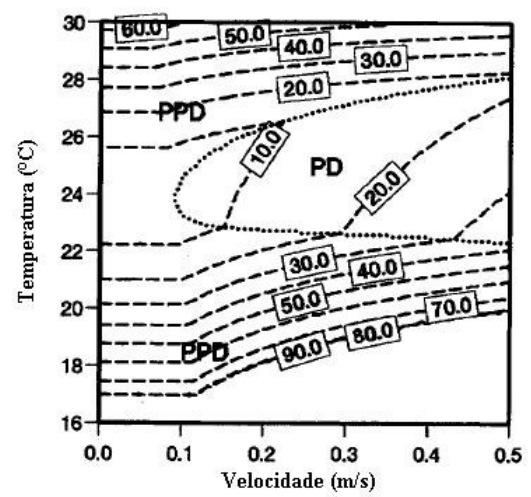

(a) $\mathrm{Tu}=10 \%$

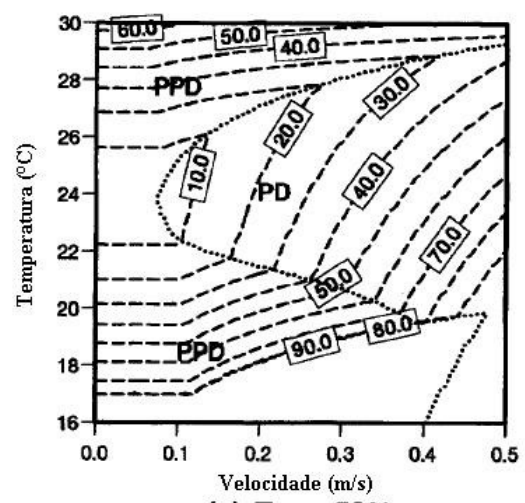

(c) $\mathrm{Tu}=50 \%$

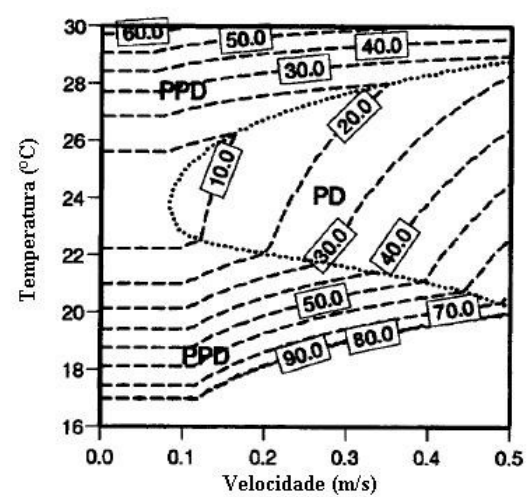

(b) $\mathrm{Tu}=30 \%$

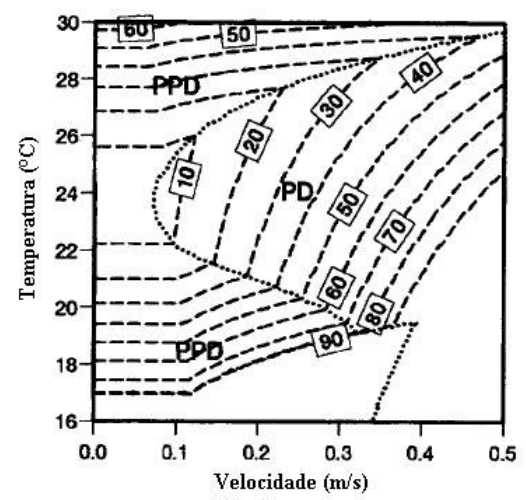

(d) $\mathrm{Tu}=70 \%$

Figura 3.6. Efeito da temperatura e da velocidade do ar no índice de conforto térmico para isolamento de roupas de 0,6 clo

Fonte: adaptado de GAN, 1994 


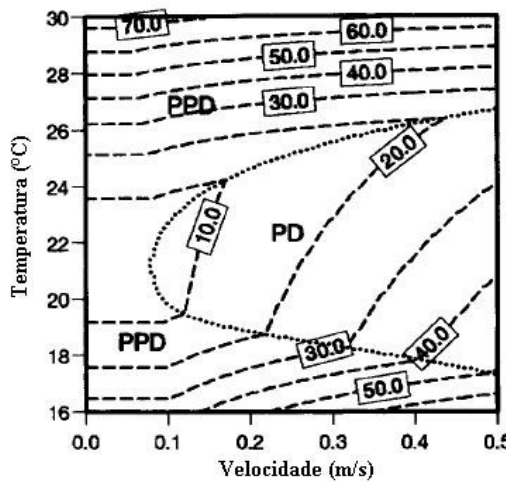

(a) $\mathrm{Tu}=10 \%$

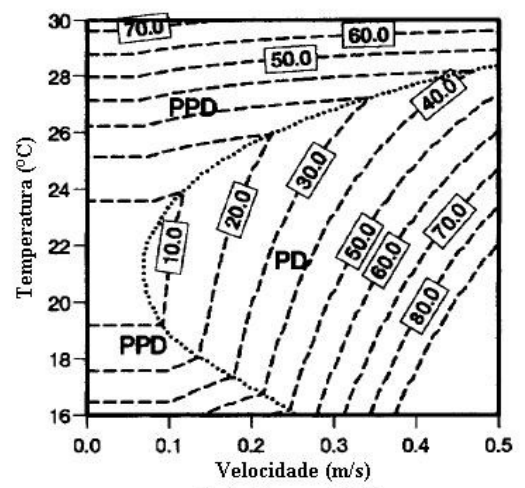

(c) $\mathrm{Tu}=\mathbf{5 0} \%$

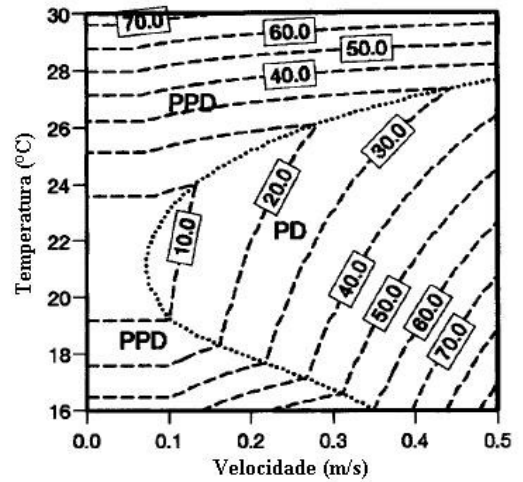

(b) $\mathrm{Tu}=\mathbf{3 0} \%$

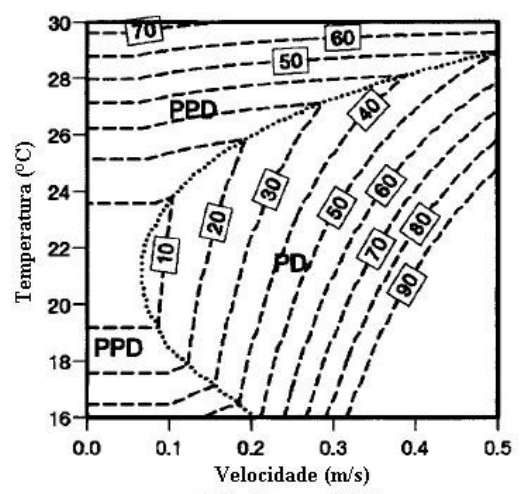

(d) $\mathrm{Tu}=70 \%$

Figura 3.7. Efeito da temperatura e da velocidade do ar no índice de conforto térmico para isolamento de roupas de 1,0 clo

Fonte: adaptado de GAN, 1994

A linha pontilhada na qual os índices PPD e PD se intersectam é dada pela relação $\mathrm{PPD}=\mathrm{PD}$. Quando a velocidade do ar é baixa, $\overline{V_{a r}}<0,08 \mathrm{~m} / \mathrm{s}$, a percentagem de pessoas insatisfeitas, PPD, é em geral mais crítica do que o risco de correntes de ar, PD, e, portanto $\Psi=$ PPD. Isto quer dizer que se a exigência para PPD é a mesma para $\mathrm{PD}$, as correntes de ar não causarão desconforto significativo, desde que o nível de conforto seja aceitável e não haja outras fontes de desconforto como assimetria de radiação ou diferenças verticais de temperatura (estratificação de temperatura), por exemplo. Portanto, o uso do PPD é suficiente para avaliar conforto térmico.

Quando a velocidade do ar aumenta, o risco de correntes de ar é maior do que a percentagem de pessoas insatisfeitas, PPD, especialmente se o nível de turbulência é alto. Portanto, $\Psi$ = PD.

As curvas apresentadas nas Figuras 3.6 e 3.7 são aproximadamente simétricas ao redor das temperaturas do ar de 24 e $22,5{ }^{\circ} \mathrm{C}$ (temperatura neutra para velocidade do ar, $\overline{V_{a r}}<0,1 \mathrm{~m} / \mathrm{s}$ ), para isolamentos térmicos da roupa de 0,6 e 1,0 clo, respectivamente. Acima dessas temperaturas, a sensação de desconforto é 
causada pela sensação de calor e abaixo pela sensação de frio para o corpo como um todo (PPD).

É importante destacar que em condições de temperaturas do ar menores, caracterizadas com nível de isolamento térmico maior da roupa (Fig. 3.7), aumenta significativamente o risco de correntes de ar, razão pela qual as pessoas são mais suscetíveis ao desconforto devido a correntes de ar no inverno.

\subsection{Avaliação de conforto térmico em cabines de aeronaves}

Os métodos utilizados para a avaliação de conforto térmico em cabines de veículos automotivos, de uma forma geral, têm sido a avaliação com pessoas, a análise de campos de velocidade e de temperatura do ar, o método PMV/PPD e a determinação de temperaturas equivalentes utilizando manequins térmicos.

Em cabines de aeronaves os estudos de conforto térmico têm sido focados, principalmente, na análise do escoamento do ar e a sua influência no conforto térmico, quer seja a partir da medição de temperaturas e de velocidades do ar em mock-ups ou mesmo em voo, ou pela sua determinação utilizando CFD (IRGENS; MELIKOV, 2004; JACOBS; GIDS, 2005; STROM-TEJSEN et al., 2005; STROMTEJSEN et al., 2007; ZHANG; CHEN, 2007; ZHANG et al., 2007; GAO et al., 2007; WANG et al., 2008; MOURA, 2009; STANCATO, 2009; YAN et al., 2009; BOSBACH et al., 2012; BOSBACH, 2013; SILVA, 2013; VOLAVÝ; FISER; NÖSKE, 2013; CUI; OUYANG; ZHU, 2014; GIACONIA; ORIOLI; GANGI, 2015; LIU et al., 2015; WEI; ZHANG; WANG, 2016; LI et al., 2016, ZHANG et al., 2017).

Zhang et al. (2017) realizam avaliações relacionadas ao conforto térmico em sistemas de ventilação e distribuição do ar. A pesquisa foi realizada em um mockup com manequins aquecidos (Fig. 3.8), simulando um Boeing 737-200. Os resultados mostram que em uma comparação abrangente do sistema de ventilação por mistura ventilação de mistura (MV) e do sistema ventilação por deslocamento (DV), a ventilação por deslocamento (DV) possui alta eficiência de ventilação na remoção de calor dentro da cabine. 


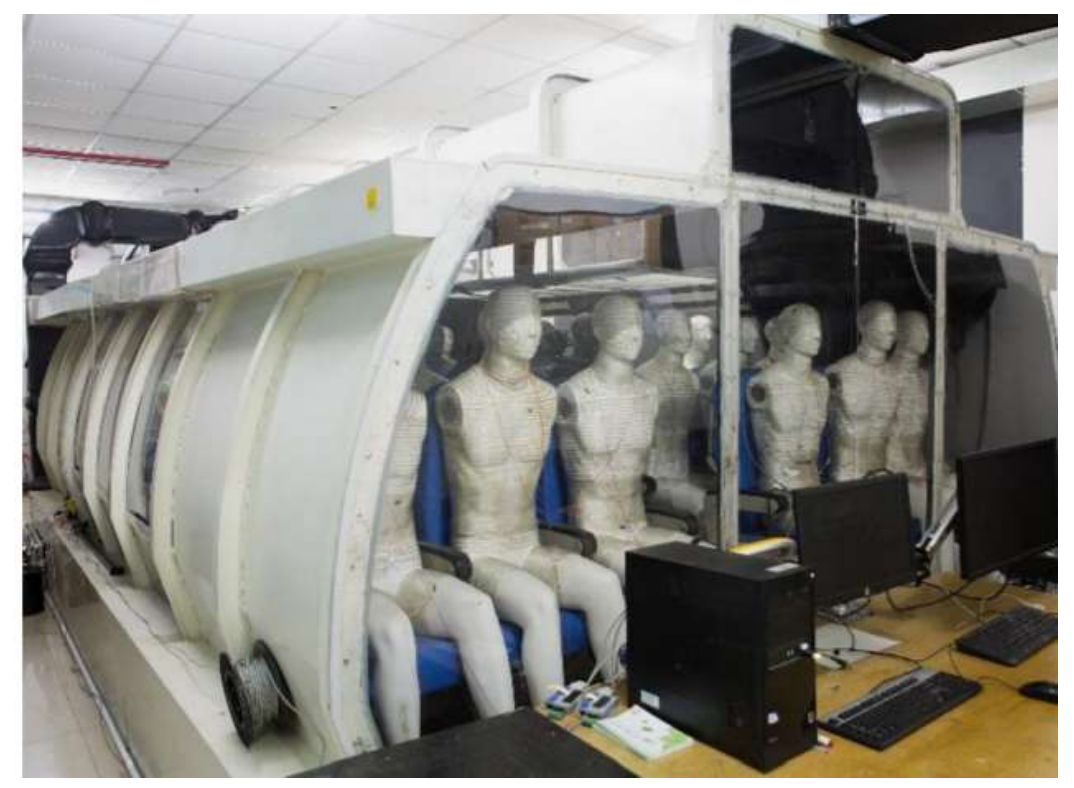

Figura 3.8. Mock-up (Boeing 737-200) utilizado no desenvolvimento do trabalho de Fonte: Zhang et al. 2017

A análise do conforto térmico em aeronaves a partir de resultados de medição de temperaturas e velocidades do ar mostra-se adequada, uma vez que neste tipo de cabine o desconforto térmico local é o grande responsável pelo desconforto térmico dos passageiros.

Diferentemente de ambientes de edificações, no qual as pessoas, normalmente, desenvolvem algum tipo de atividade, em cabines de aeronaves as pessoas permanecem sentadas em atividade sedentária, relaxadas, por muito tempo. Em função disso, as pessoas estarão sujeitas a sentirem intensamente alterações locais de temperatura e velocidade do ar, que se manifestam no desconforto devido a correntes de ar (GAN, 1994) e devido à estratificação de temperatura.

Portanto, no presente trabalho também são realizadas medições de temperaturas e velocidade do ar para a determinação do risco de correntes de ar e a avaliação da ocorrência de estratificação de temperatura, na análise do conforto térmico considerando os diferentes sistemas de ventilação testados. 


\section{Contaminação cruzada e a dispersão de partículas em cabines de aeronaves}

Neste Capítulo são apresentados aspectos gerais sobre contaminação cruzada em cabines de aeronaves e algumas características relevantes sobre os contaminantes liberados em atividades expiratórias, protagonistas nos eventos de contaminação cruzada em cabines de aeronaves.

Estudos de contaminação em cabines de aeronaves têm sido focados na contaminação aérea resultante da dispersão de poluentes expiratórios gerados por pessoas infectadas contaminando outras pessoas - a contaminação cruzada (WAN et al., 2005; ZHANG et al., 2009; WAN et al., 2009, SZE TO et al., 2009, YAN et al., 2009; GUPTA; LIN; CHEN, 2011; CONCEIÇÃO, 2012, BOSBACH et al., 2012, CHEN et al., 2012, PANG et al., 2013, LI et al.,2016).

\subsection{Contaminação cruzada}

Há um crescimento ascendente no número de pessoas que utilizam o transporte aéreo no mundo. De acordo com a International Air Transport Association (IATA) 3,6 bilhões de passageiros realizaram viagens de avião pelo mundo em 2016. O que representa um aumento de 800 milhões de passageiros em 5 anos, levando em consideração os 2,8 bilhões de passageiros que voaram em aviões em 2011. Os cinco maiores mercados para passageiros de voos domésticos em 2016 foram os Estados Unidos (710,2 milhões), China (415 milhões), Brasil (118,9 milhões), Índia (107,2 milhões) e Japão (93,2 milhões).

O deslocamento massivo de pessoas em aeronaves aumenta a preocupação com o fato da transmissão de doenças em voos serem bem maior do que aquela efetivamente registrada, já que algumas enfermidades possuem um tempo de incubação maior do que aquele do voo, com os sintomas aparecendo somente alguns dias ou semanas depois (CONNOR, 2009). Na Tabela 4.1 apresenta-se relação de infecções relatadas transmitidas em voos de companhias aéreas comerciais. Segundo Wagner; Coburn; Blower (2009), a capacidade de um passageiro infectado com $\mathrm{H} 1 \mathrm{~N} 1$ transmitir a doença em voo de 17 horas na classe 
econômica quando esta está lotada, com 309 passageiros, pode chegar ao número de 17 pessoas infectadas, e de 2 a 5 pessoas em voo de 5 horas.

Tabela 4.1. Infecções relatadas transmitidas em voos de companhias aéreas comerciais

\begin{tabular}{|c|c|c|}
\hline \multicolumn{3}{|c|}{ Infecções relatadas transmitidas em voos de companhias aéreas comerciais } \\
\hline & $\begin{array}{l}\text { Número de } \\
\text { relatos }\end{array}$ & Comentários \\
\hline \multicolumn{3}{|l|}{ Transportadas pelo ar } \\
\hline Tuberculose & 2 & $\begin{array}{l}\text { Teste de pele positivo para a tuberculose, } \\
\text { porém tuberculose não ativa }\end{array}$ \\
\hline SARS & 4 & Nenhum caso desde orientações da OMS \\
\hline Resfriado comum & 0 & Difícil de investigar \\
\hline Influenza & 2 & Nenhum desde regulamentos de ventilação \\
\hline Doença meningocócica & 0 & $\begin{array}{l}21 \text { relatos de passageiros doentes, nenhum } \\
\text { caso secundário }\end{array}$ \\
\hline Sarampo & 3 & Casos internacionais \\
\hline \multicolumn{3}{|l|}{ De origem alimentar } \\
\hline Salmonelose & 15 & Não surtos recentes \\
\hline Estafilococos & 8 & Não surtos recentes \\
\hline \multicolumn{3}{|l|}{ Envenenamento } \\
\hline Shigelose & 3 & Não surtos recentes \\
\hline Cólera & 3 & Durante epidemia de cólera \\
\hline Enterite viral & 1 & Comum em outros tipos de transporte \\
\hline \multicolumn{3}{|l|}{ Vetor-borne } \\
\hline Malária & 7 & Provavelmente subestimado \\
\hline Dengue & 1 & Provavelmente aeroporto, não aviões \\
\hline Febre amarela & 0 & $\begin{array}{l}\text { Quaisquer focos, desde desinfecção de } \\
\text { aeronaves }\end{array}$ \\
\hline \multicolumn{3}{|l|}{ Agentes do bioterrorismo } \\
\hline Varíola & 1 & Antes da erradicação \\
\hline
\end{tabular}

Fonte: adaptado de MANGILI; GEANDREAU, 2005

Em cabines de aeronaves o risco de contaminação cruzada é potencializado tendo em vista os longos períodos de voo em espaços confinados, a alta densidade 
de passageiros, bem como as características de mistura do sistema de ventilação empregado em aeronaves comerciais.

Outro fator importante no risco de contaminação cruzada está associado à direção do fluxo de ar na cabine resultante do sistema de ventilação empregado. Olmedo et al. (2013) avaliaram o risco de contaminação cruzada com relação à sistema de ventilação com fluxo descendente, similar ao do sistema MV, para diferentes distâncias entre manequins (Fig. 4.1), com um dos manequins aquecidos simulando respiração com liberação de contaminantes expiratórios. Os resultados mostraram que o sistema de ventilação descendente não é eficaz na remoção de partículas. Principalmente quando a distância entre os manequins é pequena.

(a)

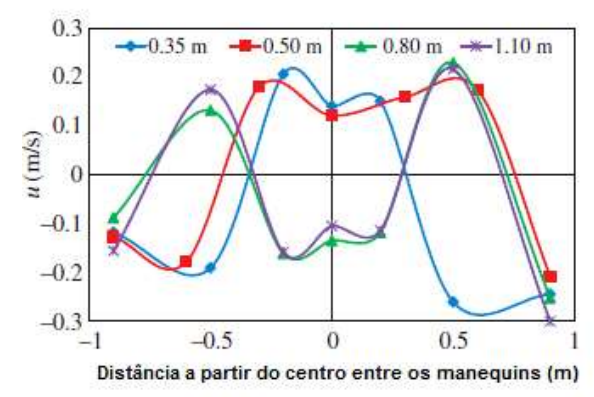

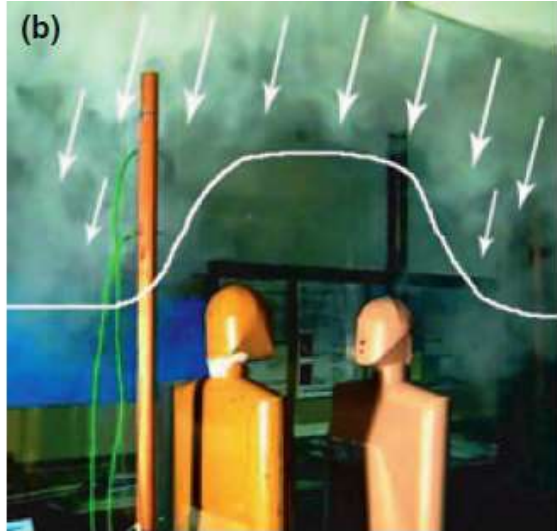

Figura 4.1. a) Velocidades sobre os manequins para as quatro distâncias entre ambos; b) Fluxo descendente sobre os manequins para distância de $0,50 \mathrm{~m}$ Fonte: OLMEDO et al., 2013

O transporte de contaminantes tem um forte efeito sobre a propagação de doenças no ambiente de cabine de aeronave. Além da preocupação relacionada entre as distâncias dos passageiros, existe a preocupação com relação ao ponto de emissão dos contaminantes. Li et al. (2014), apresentaram estudo numérico e experimental em uma aeronave funcional modelo MD-82, buscando analisar os campos de velocidade do ar e a importância da localização da fonte de emissão de contaminantes em uma cabine. Para isso foi utilizado gás traçador, hexafluoreto de enxofre (SF6) e Di-etil-hexil-Sebacat (DEHS) simulando partículas contaminadas. Toda a medição foi realizada em uma parte da cabine de primeira classe com 12 manequins aquecidos simulando pessoas e a classe econômica desocupada sem a utilização de manequins (Figura 4.2). Os resultados obtidos mostram que uma 
pequena diferença na localização de liberação do contaminante pode levar a uma diferença significativa na dispersão de contaminantes ao longo da cabine.

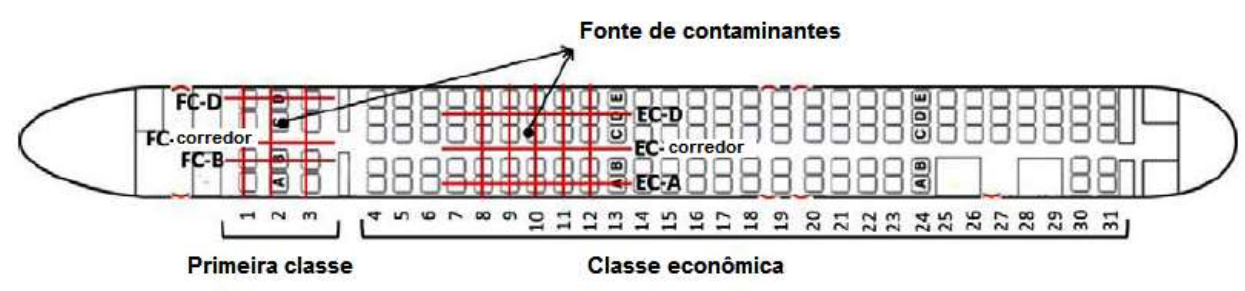

Figura 4.2. Localização das fontes de emissão e planos de medição Fonte: LI et al., 2014

\subsection{Partículas expiratórias}

A preocupação com a qualidade do ar em ambientes externos está sempre relacionada em identificar quais são as potenciais fontes de emissão. Ambientes externos, processos industriais, queima de combustíveis, ressuspensão de poeira são algumas das fontes de emissão em que existe atenção sobre monitoramento e controle. No caso de um ambiente interior como de uma cabine de aeronave, com realização de filtragem e taxa de renovação de ar, o monitoramento e controle se dão pela fonte de possíveis contaminantes que são gerados pelos próprios passageiros.

Durante as atividades expiratórias, tais como respiração, fala, tosse e espirro, os seres humanos produzem gotículas líquidas geradas pela passagem de meios gasosos, com uma dada velocidade, sobre a superfície de uma substância líquida (MORAWSKA, 2005). Quando essas gotículas são produzidas por uma pessoa infectada, contaminantes patogênicos presentes no seu trato respiratório podem ser carreados e expelidos. Esses contaminantes dispersos podem ser transmitidos diretamente para outras pessoas via inalação, ou indiretamente pelo contato sobre superfícies contaminadas (MANGILI; GEANDREAU, 2005).

Pesquisas realizadas em cabines de aeronaves mostraram que, de uma forma geral, o nível médio de bioaerossóis na cabine é baixo. Contudo, elevados picos de concentração foram observados devido a espirros, tosse ou outras ações respiratórias dos passageiros. Este fato sugere que o maior risco de infecção é a transmissão de pessoa para a pessoa via dispersão de gotículas exaladas dentro da cabine (DECHOW; SOHN; STEINHANSES, 1997). 
Essas gotículas, uma vez dispersas no ar, sofrem processos químicos e físicos que modificam a sua composição química, características físicas e a concentração, influenciando na dinâmica desse tipo de partícula. De acordo com Morawska, (2005), os processos mais relevantes que ocorrem com partículas suspensas no ar são a coagulação, onde partículas de tamanhos semelhantes colidem umas com as outras formando partículas maiores; a deposição de partículas menores na superfície de partículas maiores; mudanças no tamanho das partículas devido a mudanças no seu conteúdo de umidade (crescimento higroscópico ou redução por evaporação); a sedimentação; e a deposição em superfícies.

Devido à força peso, as gotículas maiores do que $5 \mu \mathrm{m}$, em geral, depositamse em superfícies mais rapidamente (CONNOR, 2009). Já as gotículas menores são carreadas mais facilmente pelo escoamento, pois possuem coeficiente de transporte por difusão similar ao coeficiente de difusão dos gases (BÉMER et al., 2000). Por este motivo, podem permanecer em suspensão por longos períodos de tempo e transportar os biocontaminantes por distâncias maiores (TANG et al., 2006) e evaporar formando os resíduos de gotículas ou núcleos de gotículas (droplet nuclei).

Embora as partículas líquidas ou sólidas menores sigam o escoamento como se fossem partículas gasosas, são normalmente depositados nas superfícies quando encontram obstáculos, diferentemente das partículas gasosas, que depois do choque são normalmente refletidas (BÉMER et al., 2000).

Para determinar o tamanho e a quantidade de partículas geradas durante a fala, tosse e espirro, Duguid (1946), fez a coleta das gotículas em placas oleosas posicionadas nas proximidades da boca das pessoas e as contou e mediu com o auxílio de microscópio e micrômetro. Segundo Duguid (1946), as atividades expiratórias podem gerar milhares de partículas polidispersas, sendo que 95\% delas possuem tamanho médio entre 2 e $100 \mu \mathrm{m}$, e a maior quantidade está entre 4 e $8 \mu \mathrm{m}$ (Fig. 4.3).

Contagens mais recentes do tamanho e da quantidade de partículas geradas durante atividades expiratórias foram realizadas, com técnicas mais apuradas (Tab. 4.2). Papineni; Rosenthal (1997), aplicaram contadores de partículas ópticos, reportando que a maior parte das gotículas geradas em atividades expiratórias seria menor do que $1 \mu \mathrm{m}$. Nicas; Nazaroff; Hubbard (2005), revisaram esse estudo, dentre 
outros, e concluíram que os estudos originais de Duguid (1946), são mais consistentes. Na mesma direção, ainda mais recentemente, Chao et al. (2009), utilizaram o método óptico IMI - Interferometric Mie Imaging - para medir gotículas expiratórias liberadas na tosse e fala, e obtiveram certa concordância com os resultados obtidos por Duguid (1946).

Finalmente, com base na literatura consultada, observa-se que os dados de Duguid (1946), continuam sendo referenciados em estudos recentes da dispersão de biocontaminantes em ambientes interiores (CHAO; WAN, 2006, WAN; CHAO; FANG, 2005, SZE TO et al., 2009, WAN et al., 2009, CONCEIÇÃO, 2012), e foram considerados também como referência no desenvolvimento do presente estudo, assim como foram consideradas em trabalho anterior do presente autor (FABICHAK JR., 2013).

\subsection{Estudos de dispersão de partículas em cabines de aeronaves}

Os estudos de dispersão de partículas em aeronaves praticamente tiveram o seu início neste século, com o desenvolvimento de um número ainda pequeno de trabalhos. E, na sua maioria, são trabalhos que utilizam CFD. Em número ainda bem mais reduzido são os trabalhos experimentais, realizados em mock-ups.

O primeiro trabalho experimental importante é o de Wan; Chao; Fang (2005), que realizaram estudo experimental de dispersão de gotículas expiratórias em mock-up com 21 assentos (três fileiras de sete assentos). O mock-up, instalado no International Center for Indoor Environment and Energy, da Dinamarca, é dotado de sistema de ventilação convencional, sistema MV, com a utilização de manequins aquecidos simulando a presença de pessoas. 


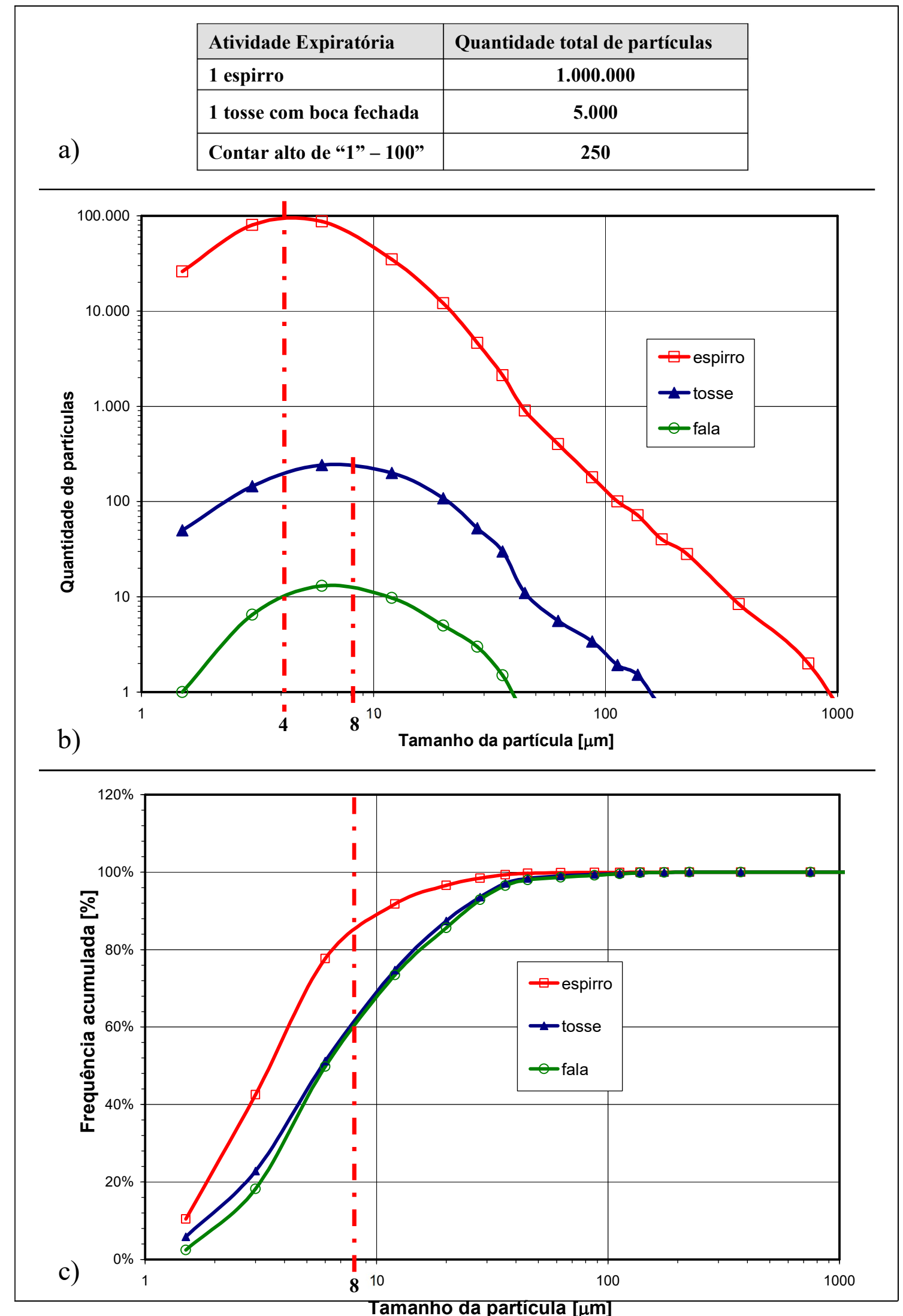

Figura 4.3. Gotículas expiratórias, baseado nas medições de Duguid (1946).

a) Quantidade absoluta de partículas b) Distribuição do tamanho de partículas normalizada pelo intervalo de medição c) Distribuição acumulada adaptado

Fonte: Adaptado por Conceição (2012) 
Tabela 4.2. Características de contaminantes liberados em atividades expiratórias

\begin{tabular}{|c|c|c|c|c|c|c|c|}
\hline Referência & $\begin{array}{l}\text { Tipo de } \\
\text { estudo }\end{array}$ & $\begin{array}{l}\text { Atividade } \\
\text { expiratória }\end{array}$ & Gás / aerossol & $\begin{array}{c}\text { Quantidade } \\
\text { de } \\
\text { partículas/gás }\end{array}$ & Concentração & $\begin{array}{c}\text { Tamanho } \\
{\left[10^{-6} \mathrm{~m}\right]}\end{array}$ & $\begin{array}{c}\text { Velocidade } \\
{[\mathrm{m} / \mathrm{s}]}\end{array}$ \\
\hline $\begin{array}{l}\text { Yan et al. } \\
\text { (2009) }\end{array}$ & $\begin{array}{l}\text { Num e } \\
\text { Exp }\end{array}$ & $\begin{array}{c}\text { Não } \\
\text { específico }\end{array}$ & $\mathrm{CO}_{2}$ & $7,5 \cdot 10^{-5} \mathrm{~m}^{3} / \mathrm{s}$ & $100 \%$ & $\mathrm{~N} / \mathrm{A}$ & $?$ \\
\hline $\begin{array}{c}\text { Zhang; } \\
\text { Chen } \\
(2007) \\
\end{array}$ & Num & Respiração & $\mathrm{CO}_{2}$ & $5,0.10^{-6} \mathrm{~m}^{3} / \mathrm{s}$ & $100 \%$ & $\mathrm{~N} / \mathrm{A}$ & $?$ \\
\hline $\begin{array}{l}\text { Gao et al. } \\
(2007)\end{array}$ & Num & Espirro & $\begin{array}{c}\text { água, } \\
\text { monodisperso }\end{array}$ & 9600 / espirro & $\mathrm{N} / \mathrm{A}$ & 1 & 20 \\
\hline \multirow{3}{*}{$\begin{array}{l}\text { Duguid } \\
\text { (1946) }\end{array}$} & \multirow{3}{*}{ Medição } & $\begin{array}{c}\text { Fala } \\
\text { (contar de } \\
1-100)\end{array}$ & \multirow{3}{*}{$\begin{array}{c}\text { Saliva, } \\
\text { polidisperso }\end{array}$} & 250 & \multirow{3}{*}{$\mathrm{N} / \mathrm{A}$} & \multirow{3}{*}{$\begin{array}{c}\text { 4-8 } \\
\text { (mais } \\
\text { comum) }\end{array}$} & \multirow{3}{*}{$\mathrm{N} / \mathrm{A}$} \\
\hline & & Tosse & & $5.000 /$ tosse & & & \\
\hline & & Espirro & & $\begin{array}{c}1.000 .000 / \\
\text { espirro }\end{array}$ & & & \\
\hline $\begin{array}{l}\text { Wan et al. } \\
(2009)\end{array}$ & $\begin{array}{c}\text { Num e } \\
\text { Exp }\end{array}$ & Tosse & $\begin{array}{c}\text { água, } \\
\text { polidisperso }\end{array}$ & $\mathrm{N} / \mathrm{A}$ & $2,5 \cdot 10^{9} / \mathrm{m}^{3}$ & $\begin{array}{c}6,75 \\
\text { (média) }\end{array}$ & 10 \\
\hline \multirow{2}{*}{$\begin{array}{l}\text { Zhang et } \\
\text { al. (2009) }\end{array}$} & \multirow{2}{*}{$\begin{array}{l}\text { Num } \\
\text { and Exp }\end{array}$} & \multirow{2}{*}{$\begin{array}{c}\text { Não } \\
\text { específico }\end{array}$} & $\begin{array}{c}\text { DEHS, } \\
\text { monodisperso }\end{array}$ & $7,5.10^{-5} \mathrm{~m}^{3} / \mathrm{s}$ & $10^{12} / \mathrm{m}^{3}$ & 0,7 & $?$ \\
\hline & & & $\mathrm{SF}_{6}$ & $5 \times 10^{-8} \mathrm{~m}^{3} / \mathrm{s}$ & $100 \%$ & $\mathrm{~N} / \mathrm{A}$ & $?$ \\
\hline $\begin{array}{c}\text { Shimada, } \\
\text { et al. } \\
(1996) \\
\end{array}$ & $\begin{array}{l}\text { Num e } \\
\text { Exp }\end{array}$ & $\begin{array}{c}\text { Não } \\
\text { específico }\end{array}$ & $\begin{array}{c}\text { Poliestireno } \\
\text { de Latex, } \\
\text { polidisperso }\end{array}$ & $1,67 \cdot 10^{-5} \mathrm{~m}^{3} / \mathrm{s}$ & $3,0.10^{10}$ & 0,14 & $?$ \\
\hline \multirow{3}{*}{$\begin{array}{l}\text { Gupta; } \\
\text { Lin; Chen } \\
(2011)\end{array}$} & \multirow{3}{*}{$\begin{array}{l}\text { Num e } \\
\text { Exp }\end{array}$} & Tosse & \multirow{3}{*}{$\begin{array}{c}\text { água, } \\
\text { monodisperso }\end{array}$} & $10^{6} /$ tosse & \multirow{3}{*}{$\mathrm{N} / \mathrm{A}$} & 8,5 & 9 (max) \\
\hline & & Respiração & & $\begin{array}{c}525 / \\
\text { respiração }\end{array}$ & & 0,4 & $4(\max )$ \\
\hline & & Fala 15s & & 2250 / fala & & 30 & $?$ \\
\hline \multirow{2}{*}{$\begin{array}{l}\text { Chao et } \\
\text { al. (2009) }\end{array}$} & \multirow[b]{2}{*}{ Medição } & Tosse & \multirow{2}{*}{$\begin{array}{c}\text { Saliva, } \\
\text { polidisperso }\end{array}$} & $\begin{array}{c}2085(\max ) / \\
\text { tosse }\end{array}$ & $\begin{array}{c}5,2.10^{6} / \mathrm{m}^{3} \\
(\max )\end{array}$ & $4-8$ & 11,7 \\
\hline & & $\begin{array}{c}\text { Fala } \\
\text { (contar de } \\
1-100)\end{array}$ & & $\begin{array}{l}6.720 / \text { tosse } \\
(\max )\end{array}$ & $\begin{array}{c}0,223 \cdot 10^{6} / \mathrm{m}^{3} \\
(\max )\end{array}$ & \begin{tabular}{|c|}
$4-8$ \\
(mais \\
comum) \\
\end{tabular} & 3,1 \\
\hline $\begin{array}{l}\text { Yang, et } \\
\text { al. (2007) }\end{array}$ & Medição & Tosse & $\begin{array}{c}\text { Saliva, } \\
\text { polidisperso }\end{array}$ & $\begin{array}{c}\text { 9.10-4 } \mathrm{m}^{3} / \mathrm{s} \\
(\max )\end{array}$ & $\begin{array}{c}0,2355 \cdot 10^{10} / \mathrm{m}^{3} \\
(\max )\end{array}$ & \begin{tabular}{|c|} 
Picos em \\
1,4 e 8 \\
\end{tabular} & $?$ \\
\hline $\begin{array}{l}\text { Fabian et } \\
\text { al. (2008) }\end{array}$ & Medição & Respiração & $\begin{array}{c}\text { Saliva, } \\
\text { polidisperso }\end{array}$ & $\mathrm{N} / \mathrm{A}$ & $\begin{array}{c}8,5.10^{6} / \mathrm{m}^{3} \\
(\mathrm{max})\end{array}$ & $0,3-0,5$ & $N / A$ \\
\hline \multirow{2}{*}{$\begin{array}{c}\text { Fairchild; } \\
\text { Stampfer } \\
(1987)\end{array}$} & \multirow[b]{2}{*}{ Medição } & Respiração & \multirow{2}{*}{$\begin{array}{c}\text { Saliva, } \\
\text { polidisperso }\end{array}$} & \multirow[b]{2}{*}{$\mathrm{N} / \mathrm{A}$} & $10^{6} / \mathrm{m}^{3}$ & \multirow{2}{*}{$\mathrm{N} / \mathrm{A}$} & \multirow[b]{2}{*}{$N / A$} \\
\hline & & Fala & & & $10^{6} / \mathrm{m}^{3}$ & & \\
\hline
\end{tabular}

Nota: Num=numérico; Exp=experimental; Max=máximo; N/A=Não aplicável ?=não informado.

Fonte: CONCEIÇÃO, 2012

No trabalho de Wan; Chao; Fang (2005), os contaminantes expiratórios foram simulados com gás traçador $\mathrm{SF}_{6}$ e partículas polidispersas, por meio de um gerador próprio que foi alimentado com ar comprimido e líquido semelhante à saliva. Esse gerador de aerossol é capaz de imitar a produção de gotículas geradas pela tosse humana e tem sido utilizado em estudos para simular a dispersão aérea de gotículas provenientes de atividades expiratórias. Tanto as partículas gasosas como as líquidas foram geradas e injetadas mediante tubos metálicos e 
monitoradas em 48 pontos distintos, distribuídos em dois planos de medição, conforme apresentado na Figura 4.4.
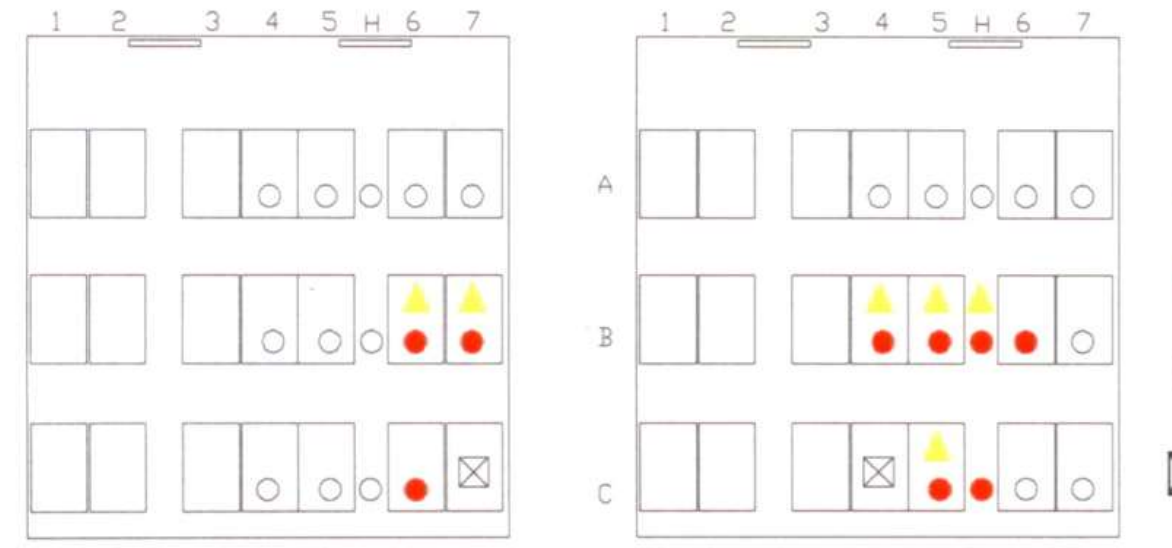

$\triangle$ Medição para $200 \mathrm{~L} / \mathrm{s}$

Medição para $100 \mathrm{~L} / \mathrm{s}$

Pontos de Medição

Pontos de Injeção

Figura 4.4. Pontos de injeção e de medição de gotículas para diferentes vazões de ar de cabine

Fonte: WAN; CHAO; FANG, 2005

Os resultados obtidos por Wan; Chao; Fang (2005) mostraram que um menor número de partículas foi disperso para outros assentos quando a injeção das partículas foi feita simulando passageiro junto à fuselagem em comparação com passageiro sentado em um assento no centro do mock-up. Segundo os autores, isso sugere que o fluxo de ar descendente junto à fuselagem tenha suprimido a dispersão de partículas, enquanto o fluxo ascendente no centro do mock-up tenha aumentado a dispersão.

Zhang et al. (2007) também estudaram a dispersão de partículas em mock-up de avião, com manequins aquecidos do tipo caixa (Fig. 4.5) e sistema de ventilação convencional - sistema MV, focando nos campos de velocidade, temperatura e concentração de contaminantes. O objetivo do trabalho foi à validação e avaliação de modelos numéricos.

Na mesma linha de trabalho proposto por Wan; Chao; Fang (2005), e utilizando as mesmas instalações e equipamentos, Sze To et al. (2009) tinham por objetivo caracterizar a dispersão e deposição de gotículas provenientes de atividades expiratórias em cabine de aeronaves, bem como identificar os efeitos do sistema de ventilação, sistema MV, na diluição e remoção dessas partículas.

Os resultados obtidos por Sze To et al. (2009) mostraram que o aumento da vazão de ar de renovação (maior vazão) provoca redução na concentração de partículas nas proximidades do ponto de injeção, devido ao efeito de diluição. 
Porém, a dispersão de partículas aumentou, o que provocou uma elevação da concentração de contaminantes nos assentos mais distantes do ponto de geração. Foi observado também que a dispersão das partículas depende do seu tamanho médio, tendo sido obtidas taxas de deposição de partículas da ordem de 60 a 70\% do total de partículas. Neste estudo não foi investigada a influência de diferentes formas de ventilação na dispersão dos contaminantes na cabine.

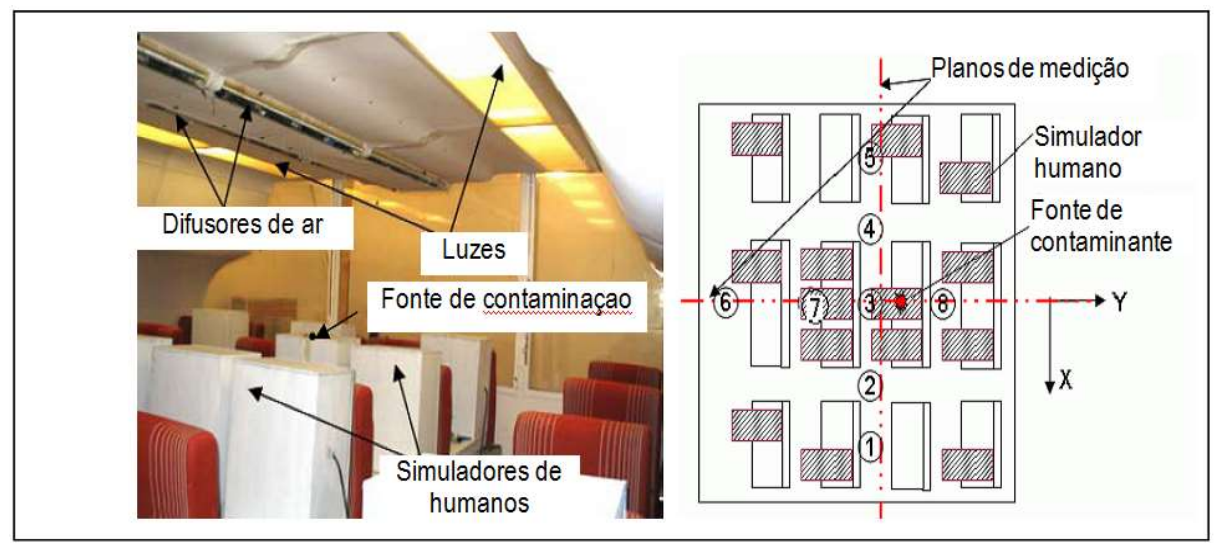

Figura 4.5. Mock-up de cabine de aeronave e planos de medição Fonte: ZHANG et al., 2007

Yan et al. (2009), estudaram a transmissão de contaminantes simulando atividades expiratórias em mock-up de Boeing 737-300 (Fig. 4.6), também dotado de sistema convencional de ventilação, sistema MV, empregando gás traçador $\left(\mathrm{CO}_{2}\right)$, focando também partículas menores. Os pesquisadores injetaram $4,5 \mathrm{~L} / \mathrm{min}$ do gás traçador durante 5 minutos nas proximidades da zona de respiração, simulando um passageiro infectado, e a partir deste momento, monitoraram a concentração de $\mathrm{CO}_{2}$ na zona de respiração dos outros passageiros, mediante a utilização de 14 sensores de $\mathrm{CO}_{2}$ por infravermelho não dispersivo. 


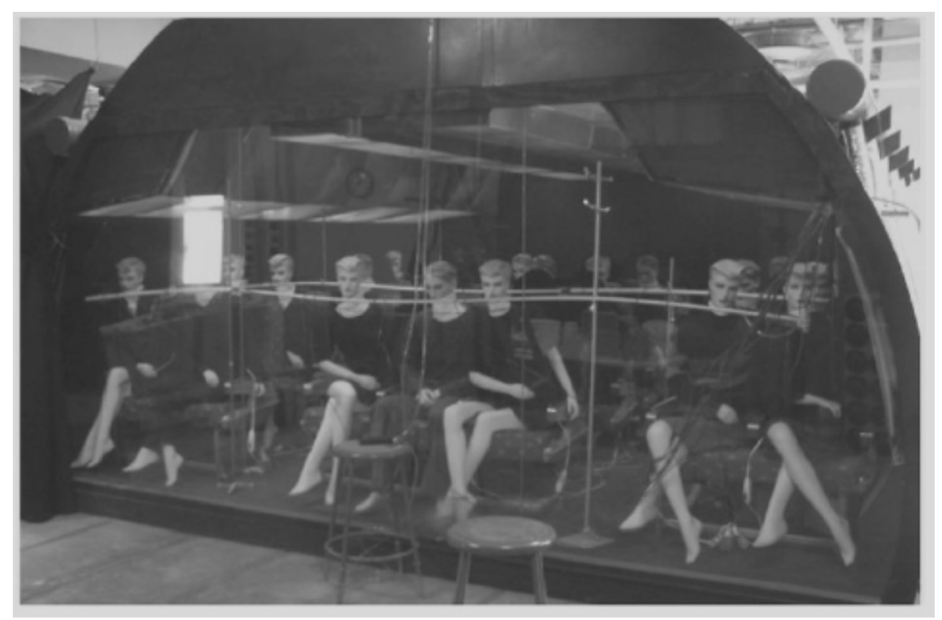

Figura 4.6. Estudo da dispersão de contaminantes em mock-up do Boeing 767-300 Fonte: YAN et al., 2009

Conceição (2012), desenvolveu trabalho de análise experimental e numérica (CFD) de contaminação cruzada em mock-up de aeronave de 20 lugares (Fig. 4.7), utilizando sistema convencional MV. Nesse trabalho foi desenvolvido um processo de avaliação de dispersão de partículas em cabines climatizadas, que foi utilizado na análise da influência de sistema de ventilação e distribuição de ar personalizada (válvula gasper) como uma possível barreira contra a contaminação cruzada. 0 processo desenvolvido por Conceição (2012) foi utilizado em trabalho anterior por Fabichak Jr. (2013), e foi também utilizado no presente trabalho, conforme apresentado no Capítulo 5.

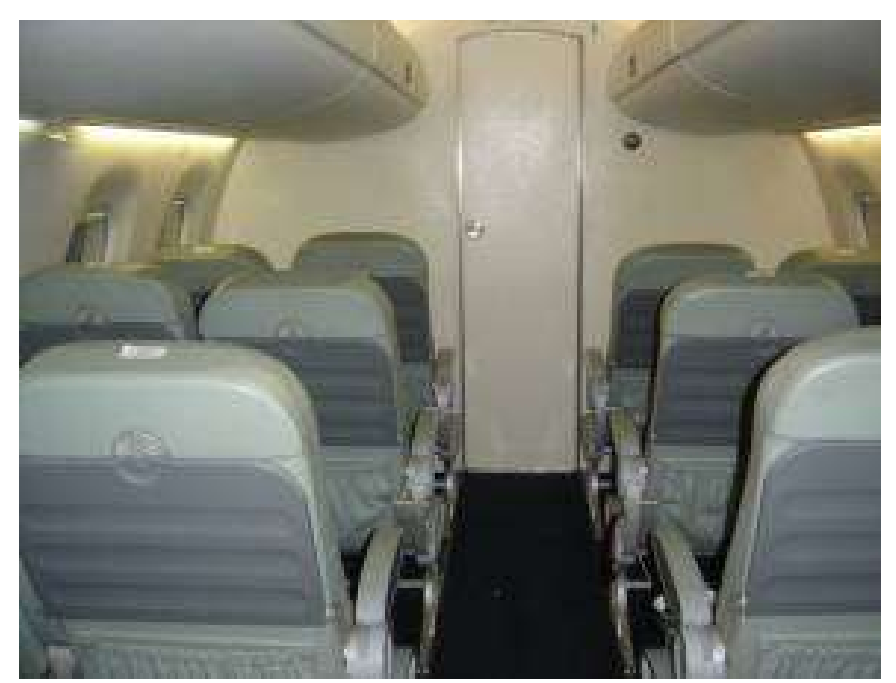

Figura 4.7. Mock-up de 20 lugares utilizado no desenvolvimento do trabalho de Conceição (2012). 
No trabalho anterior realizado pelo presente autor, concluído em 2013, foi realizada a análise experimental da dispersão de partículas em mock-up de 12 lugares (Fig. 4.8). Nesse trabalho foram analisados os sistemas de ventilação $e$ distribuição de ar MV e UFAD e uma combinação entre o sistema MV e o sistema UFAD. Verificou-se nesse estudo uma eficiência de remoção de partículas de até $63,4 \%$ maior do sistema UFAD com relação ao sistema MV.

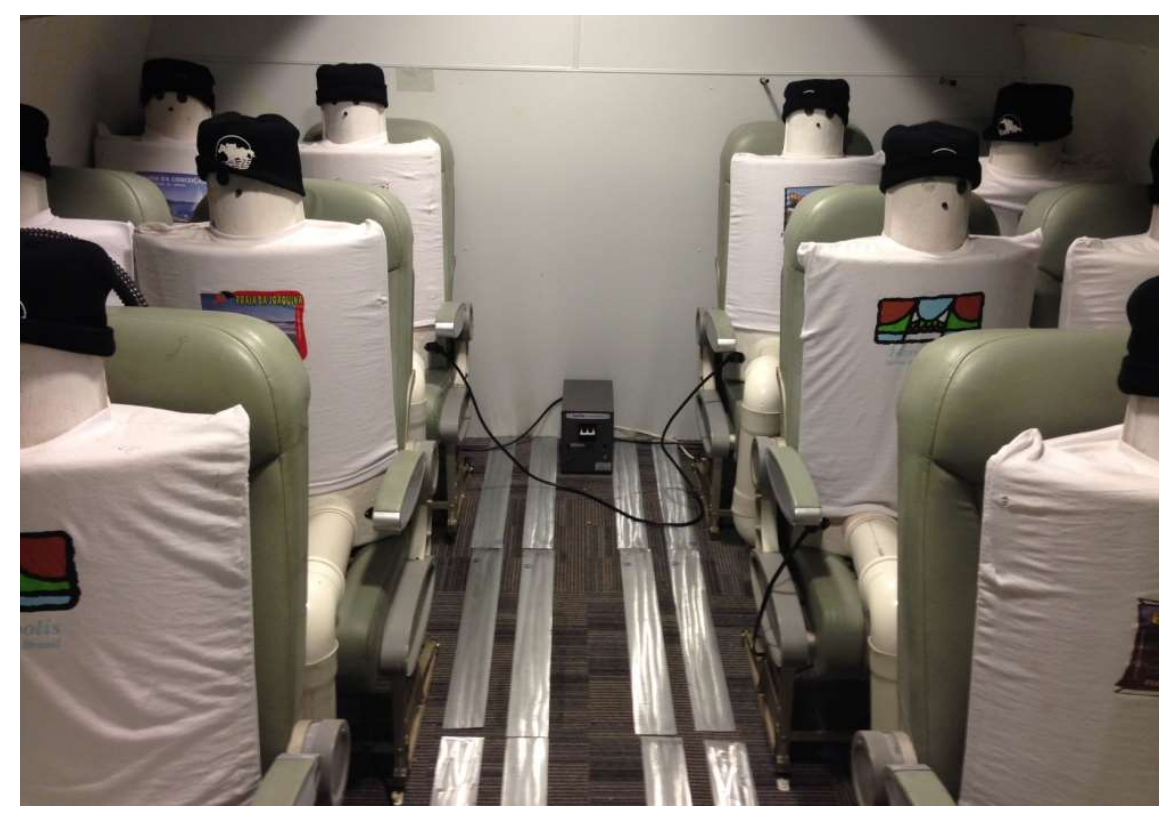

Figura 4.8. Mock-up de 12 lugares utilizado no desenvolvimento do trabalho de Fabichak $\operatorname{Jr}(2013)$

Mais recentemente, Li et al. (2016), realizaram estudo experimental para estudar o impacto do fluxo de ar sobre a qualidade do ar em uma cabine de aeronave, avaliando os campos de velocidade e temperatura do ar e a concentração de contaminantes gasosos em um avião comercial MD-82.

No mesmo centro de conforto utilizado na pesquisa de Fabichak Jr (2013), os pesquisadores Celline, Fabichak e Tribess, (2017) realizaram de forma similar a influência do sistema personalizado na redução de material particulado dentro da cabine. O sistema de ventilação e distribuição de ar personalizado foi capaz de reduzir até $65 \%$ da quantidade de partículas expiratórias na zona de respiração com esse sistema. Ainda na mesma linha de pesquisa, Felix et al. (2018), testaram novos dispositivos de ventilação personalizada e comprovaram índices parecidos com o Celline, Fabichak e Tribess, 2017. 
Observa-se nos estudos experimentais de dispersão de partículas em cabines de aeronaves encontrados na literatura, que estes tratam da análise em sistema de ventilação por mistura, sistema MV, que é o sistema utilizado nas aeronaves comerciais. Não foram encontrados na literatura aberta estudos experimentais de dispersão de partículas com outros sistemas de ventilação e distribuição de ar em cabines de aeronaves, exceto aquele desenvolvido por este autor (FABICHAK JR., 2013), com o sistema MV e UFAD.

Paralelamente, estão sendo desenvolvidos trabalhos utilizando CFD. E um dos trabalhos está diretamente relacionado ao estudo da influência de diferentes sistemas de ventilação na dispersão de partículas em cabines de aeronaves. Tratase do trabalho de Zhang; Chen (2007), que realizaram estudos da dispersão de $\mathrm{CO}_{2}$ simulado pela respiração de passageiros em cabine de B767-300, com três formas de insuflamento de ar: ventilação por mistura - MV, ventilação pelo piso UFAD, e ventilação pelo piso com ventilação personalizada.

A partir dos resultados obtidos com a simulação numérica (Fig. 4.9), os autores verificaram que o sistema convencional, sistema MV, Figura 4.9a, proporciona temperatura mais homogênea do ar. Porém, esse sistema oferece um risco maior de dispersar a contaminação gerada de um local para os demais. No sistema com insuflamento pelo piso, sistema UFAD, Figura 4.9b, o risco de contaminação diminui, pois as velocidades são baixas e o ar segue um fluxo ascendente, mais regular. O que também foi verificado no trabalho desenvolvido por Fabichak Jr. (2013). 


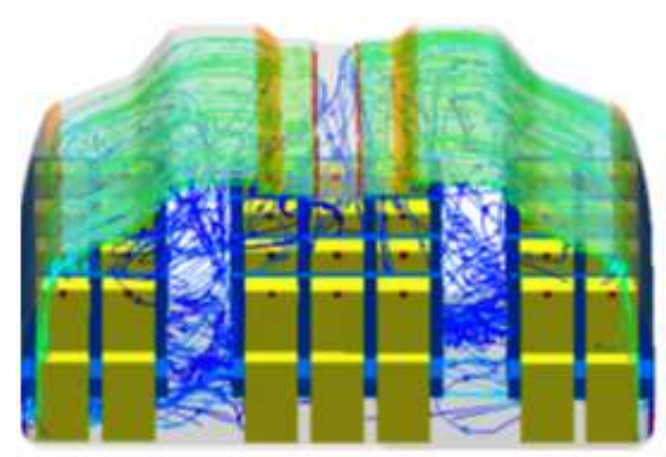

(a)

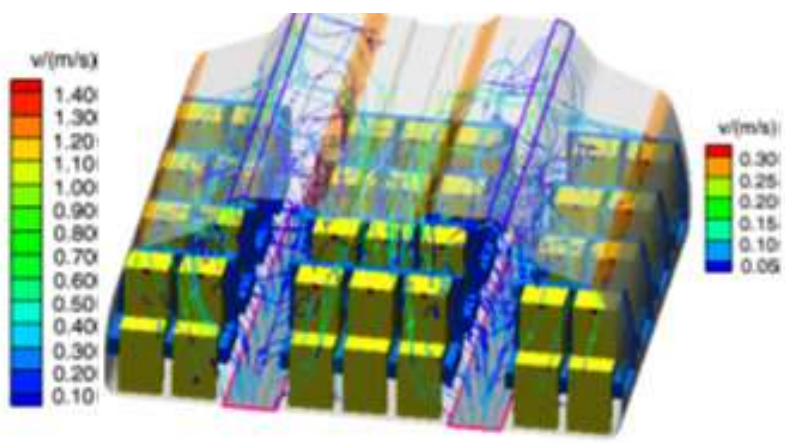

(b)

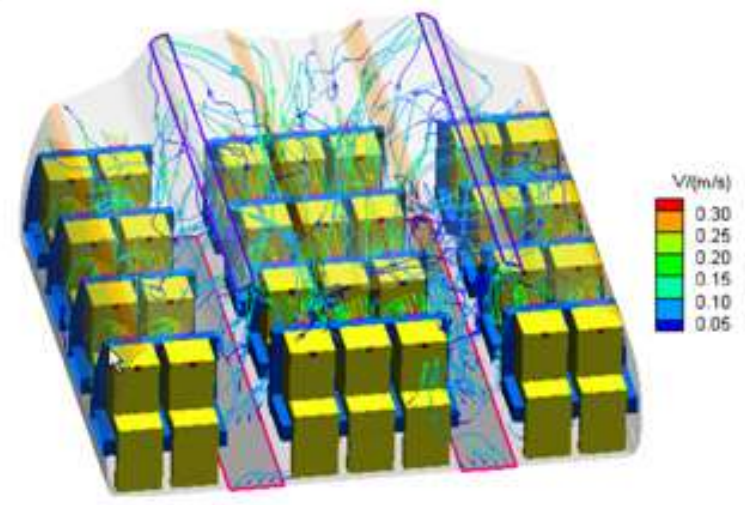

(c)

Figura 4.9. Linhas de corrente (a) sistema MV, (b) sistema UFAD e (c) sistema UFAD e ventilação personalizada

Fonte: ZHANG; CHEN, 2007

Além do trabalho de Zhang; Chen (2007), outros trabalhos utilizando CFD foram desenvolvidos na análise da dispersão de partículas em aeronaves (ZHANG et al., 2009; WAN et al., 2009, SZE TO et al., 2009, YAN et al., 2009; GUPTA; LIN; CHEN, 2011; CONCEIÇÃO, 2012; LIU et al., 2013; MAZUNDAR et al., 2014, DUAN et al., 2015, YOU et al., 2016) 


\section{Procedimento experimental}

Neste capítulo é apresentado o método para a análise experimental de conforto térmico e de dispersão de partículas, considerando diferentes sistemas de ventilação e distribuição de ar, em mock-up de 12 lugares, utilizando manequins aquecidos simulando pessoas, instrumentação para controle e medição de temperatura, velocidade e umidade do ar e gerador/contadores de partículas.

\subsection{Introdução}

Conforme ressaltado no Capítulo 1, o sistema de ventilação e distribuição de ar em cabines de aeronaves tem um papel fundamental para criar um ambiente seguro, saudável e confortável no interior dessas cabines. Normalmente, o sistema de ventilação e distribuição de ar utilizado é o sistema de ventilação por mistura (MV), ou seja, insuflamento de ar pela parte superior e lateral inferior dos bagageiros (bins) e retorno pela parte inferior lateral da cabine. A distribuição de temperaturas nesse sistema é mais uniforme. Entretanto, pode ocorrer grande circulação de ar com velocidade muito alta próximo aos difusores, não provendo boas condições de conforto térmico e possibilitando uma maior dispersão de partículas, aumentando assim o risco de propagação de doenças infecciosas.

Este grupo de pesquisa vem trabalhando no desenvolvimento de estudos buscando investigar possíveis inovações nesses sistemas de ventilação e distribuição de ar para solucionar problemas relacionados ao conforto térmico dos passageiros e qualidade do ar dentro da cabine. Estes estudos tiveram início com Moura (2009) que buscou definir as condições de escoamento do ar e de conforto térmico dentro da cabine de aeronave, para o sistema convencional MV. De forma concomitante o pesquisador Stancato (2009) analisou o conforto térmico para aeronaves. Posteriormente o pesquisador Conceição (2012) avaliou a influência da válvula gasper como uma barreira contra a contaminação cruzada ainda utilizando um sistema convencional de ventilação e distribuição do ar (MV). Em 2013, Silva (2013) e Fabichak Jr. (2013) avaliaram a implementação de novos sistemas de ventilação e distribuição de ar (MV e UFAD), com relação ao conforto térmico e qualidade do ar separadamente. Celline (2017) investigou a influência de sistemas 
de ventilação de ar personalizados contra a contaminação cruzada dentro da cabine para o sistema de ventilação (MV) e de forma concomitante o Felix et al. (2018) avaliam a influência de sistemas personalizados contra a contaminação cruzada em novos sistemas de ventilação e distribuição do ar (MV e DV).

No presente trabalho foi realizada análise experimental de conforto térmico e de dispersão de partículas expiratórias considerando diferentes sistemas de ventilação e distribuição de ar (MV, UFAD e DV) em um mock-up que reproduz o interior de cabine de aeronave comercial.

\subsection{O laboratório}

Para a realização dos ensaios foi realizada a montagem de um laboratório que permite a análise de diferentes sistemas de ventilação e distribuição de ar (sistema de ventilação de cabine), bem como de diferentes sistemas de ventilação personalizada (sistema personalizado) em um mock-up de cabine de aeronave instrumentado, como ilustrado na Figura 5.1. O sistema de controle central permite a definição e controle das condições de temperatura, umidade e vazão do ar na cabine do mock-up.

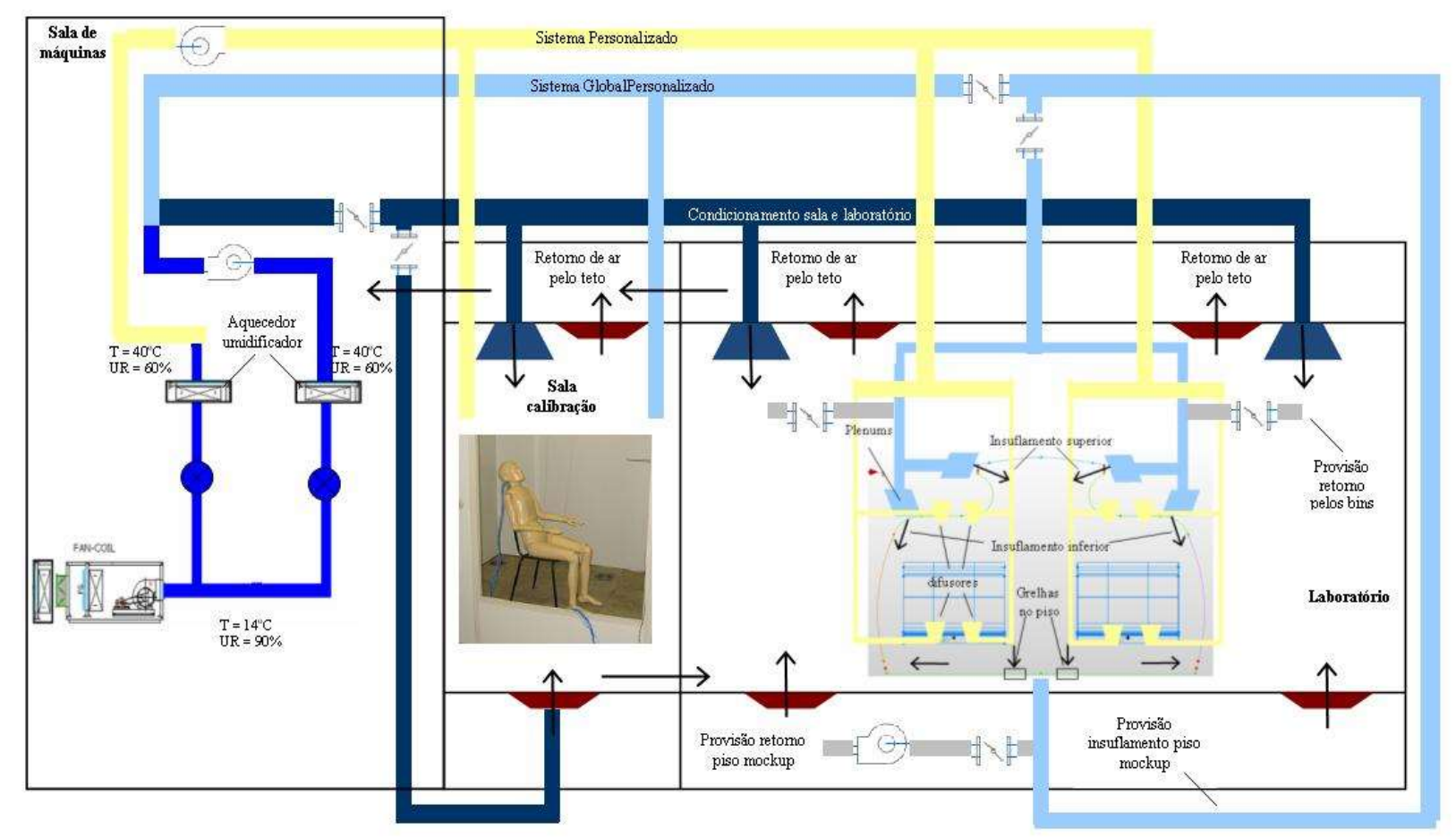

Figura 5.1. Laboratório (esquema simplificado dos sistemas de distribuição do ar) 
O sistema de ventilação de cabine e o sistema personalizado são constituídos de equipamentos com ventilador, sistema com resistências elétricas para aquecimento de ar e um tubo difusor de vapor para umidificação do ar, instalados no duto de sucção do equipamento, duto este proveniente do fan-coil responsável pelo resfriamento e desumidificação de ar. A rede de dutos atende o mock-up, a sala do mock-up, o laboratório e a sala de calibração, como mostrado na Figura 5.2 .

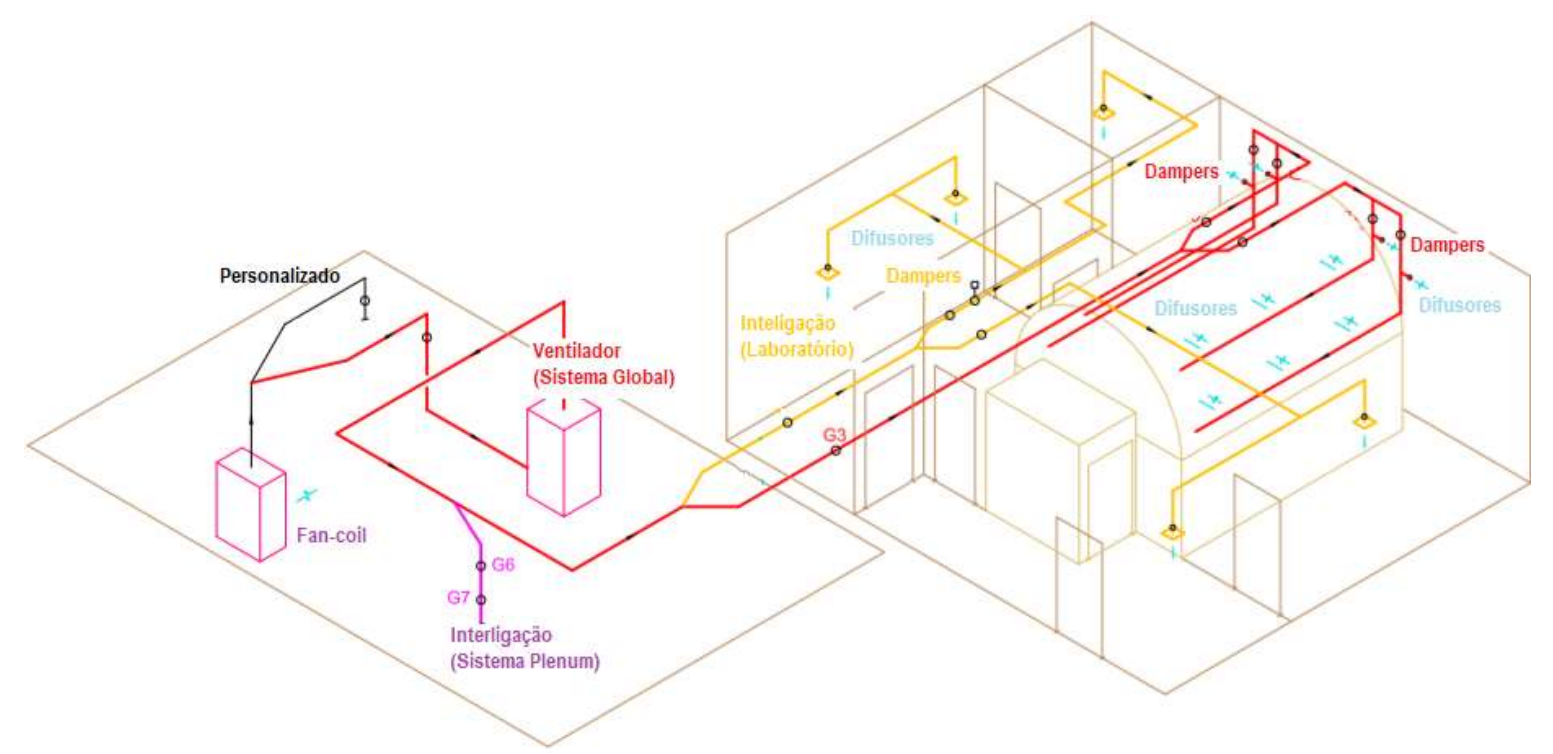

Figura 5.2. Laboratório - Esquema simplificado dos sistemas de distribuição do ar (sistema de ventilação de cabine)

O sistema de distribuição plenum é constituído de um equipamento com ventilador, com duto de sucção interligado ao duto de insuflação do sistema de ventilação de cabine (para condicionamento de ar) ou ao piso do mock-up, como mostrado na Figura 5.3. A rede de dutos atende o piso do mock-up. O sistema pode insuflar o ar condicionado ou exaurir ar do mock-up para o ambiente externo. 


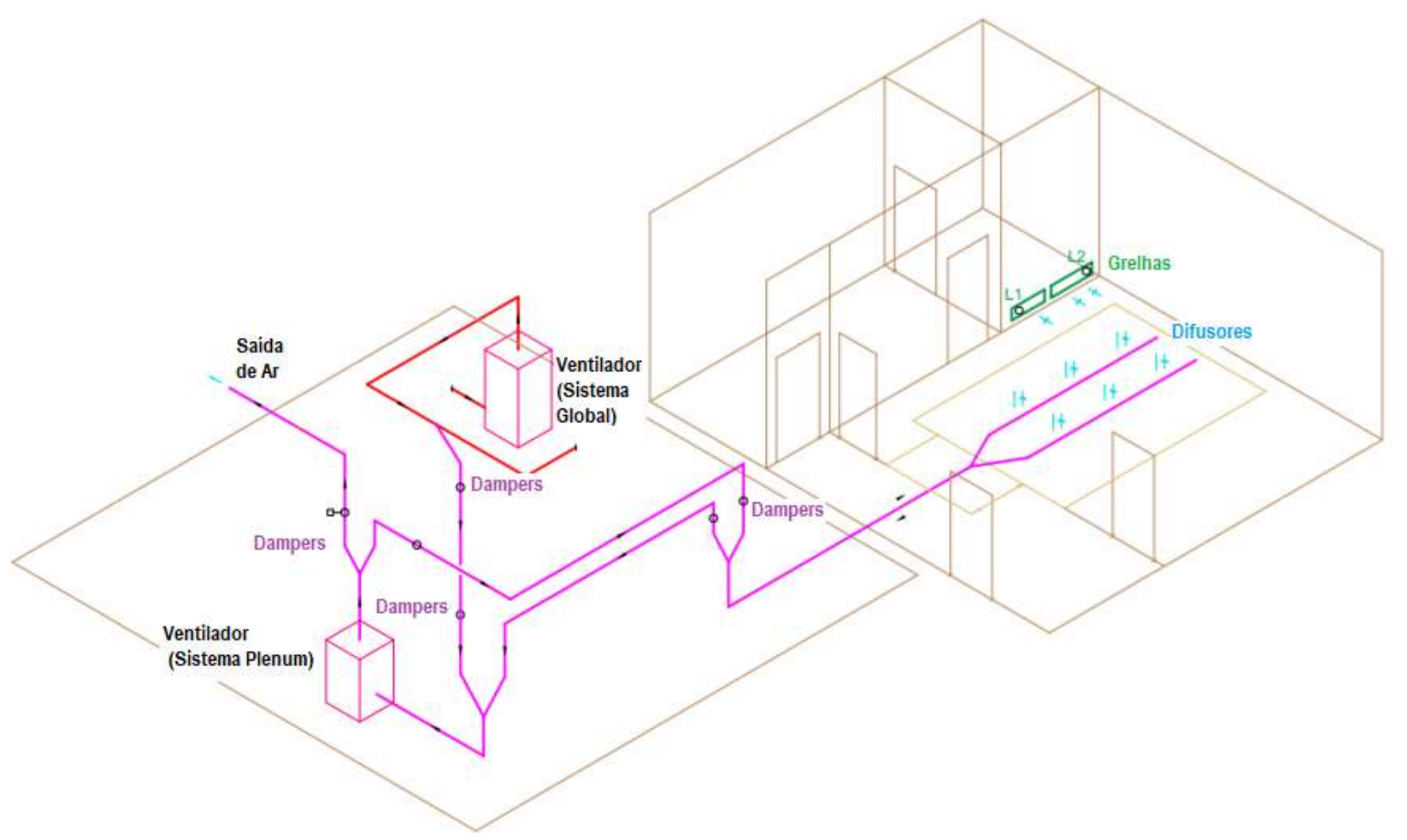

Figura 5.3. Sistema Plenum (esquema simplificado dos sistemas de distribuição do ar pelo piso)

O sistema de exaustão é constituído de um equipamento com ventilador, com duto de sucção interligado ao duto de captação de ar de retorno, proveniente do plenum, acima do forro das salas atendidas. O ar captado é exaurido para o ambiente externo.

O laboratório é dotado de um sistema de climatização do tipo expansão indireta, composto por chiller e fan-coil, com controlador lógico programável, CLP, que fornece ar tratado ao mock-up instrumentado. A captação do ar do fan-coil é efetuada na casa de máquinas através de um duto com damper, ligado ao ambiente externo. Um exaustor, instalado na linha de retorno do ar, permite a exaustão e renovação de $100 \%$ do ar, importante para a realização do presente trabalho. Para a tomada de ar externo foi instalado um registro (damper) com filtro classe G4, para captação de ar externo, instalados na casa de máquinas.

O controle e o ajuste da temperatura e da umidade do ar configurados pelo CLP (Figura 5.4) são obtidos por meio de transmissores de temperatura e umidade relativa do ar da Vaisala, modelo HMT-333, com faixas de operação de 0 a $100 \%$ UR $\pm(1,0+0,008$ x leitura $) \%$ UR e -40 a $80{ }^{\circ} \mathrm{C}\left( \pm 0,2{ }^{\circ} \mathrm{C} @+20^{\circ} \mathrm{C}\right)$, que foram instalados nos dutos de insuflamento de ar do mock-up. 


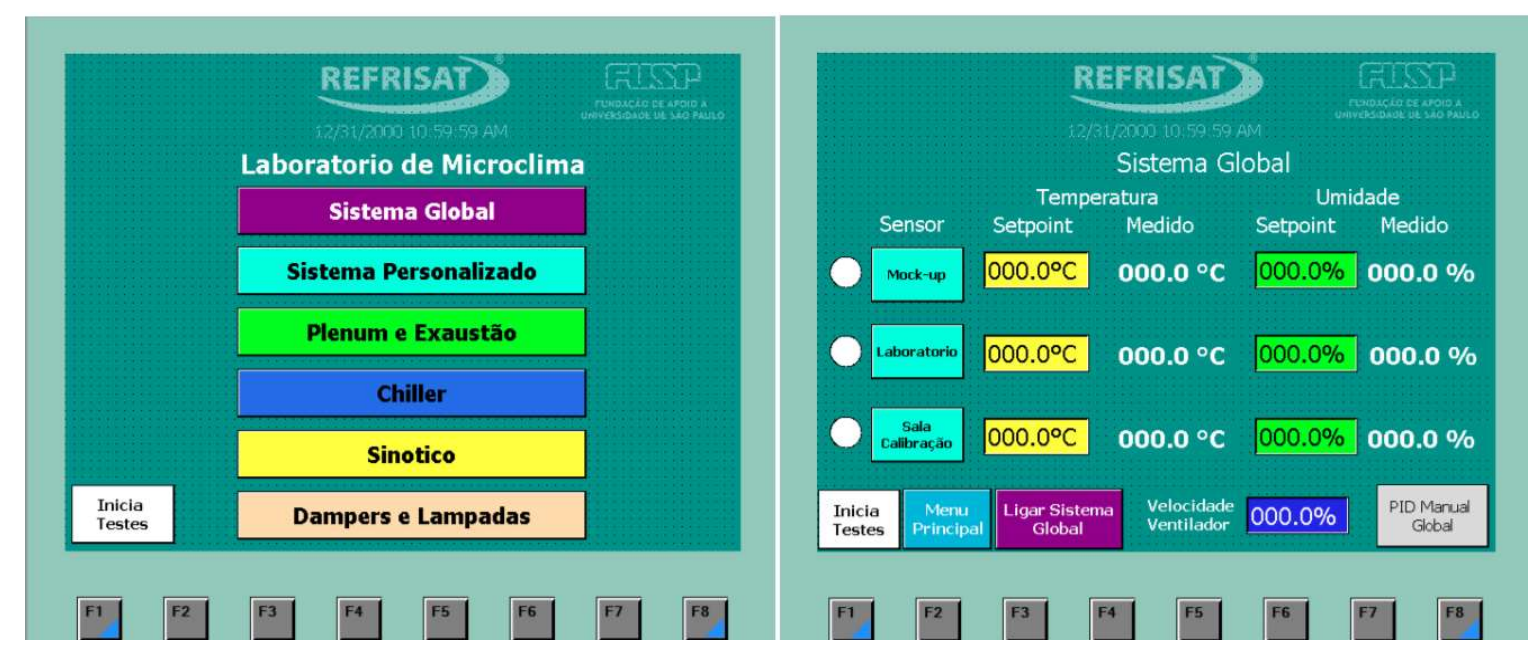

Figura 5.4. CLP (imagem onde são configurados os ajustes no CLP)

\subsection{O mock-up}

O interior do mock-up foi construído de modo a representar adequadamente o interior de uma cabine de aeronave comercial. Para isso, as curvas internas dos bagageiros (bins) e as paredes foram construídas em tubo estrutural e chapa metálica, com acabamento interno em revestimento melamínico e tecido automotivo com acabamento similar ao utilizado em aeronaves. O piso elevado foi confeccionado em madeira e revestido com carpete. A Figura 5.5 mostra-se o esquema interno do mock-up e um esquema de sua vista externa. Note-se que os detalhes na figura representam a posição das entradas e saídas de ar do mock-up.

Os assentos utilizados são assentos de aeronave comercial e suas dimensões e espaçamentos entre assentos representam o interior deste tipo de cabine de aeronave. A Figura 5.6 mostra o interior do mock-up, juntamente com os manequins aquecidos, simulando a presença de passageiros, detalhados no item 5.8.4. 


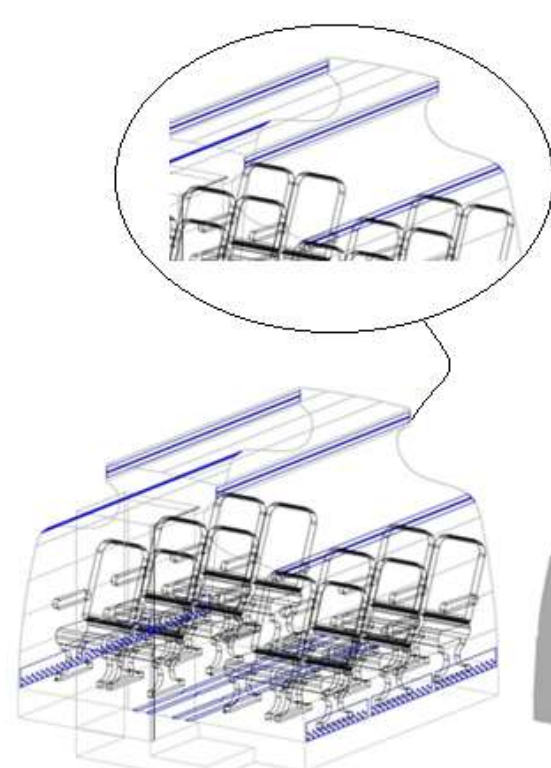

a)

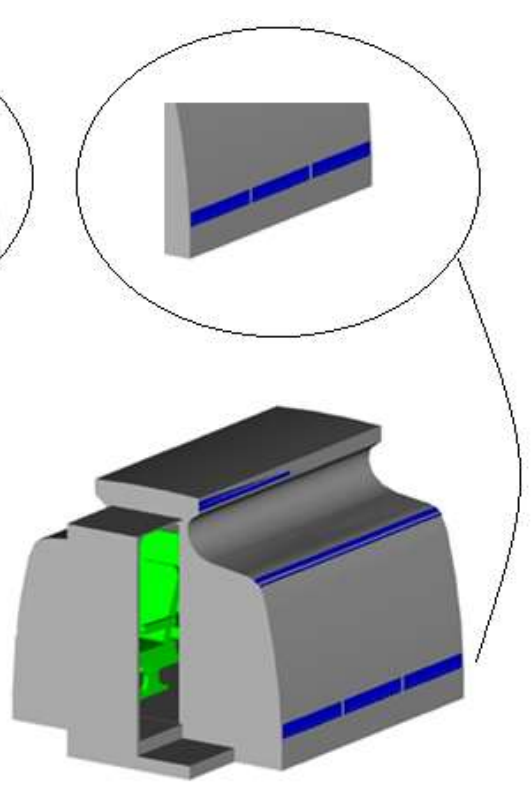

b)

Figura 5.5. a) Esquema interno do mock-up, b) Acesso e vista externa do mock-up

\subsection{Sistemas de ventilação e distribuição de ar analisadas}

Nas Figuras 5.7 a 5.9 ilustra-se os sistemas de ventilação e distribuição de ar que foram analisadas no presente trabalho, respectivamente: sistema de ventilação e distribuição de ar por mistura (MV), sistema de ventilação e distribuição de ar por deslocamento (DV) e sistema de ventilação e distribuição de ar pelo piso (UFAD), conforme detalhado a seguir.

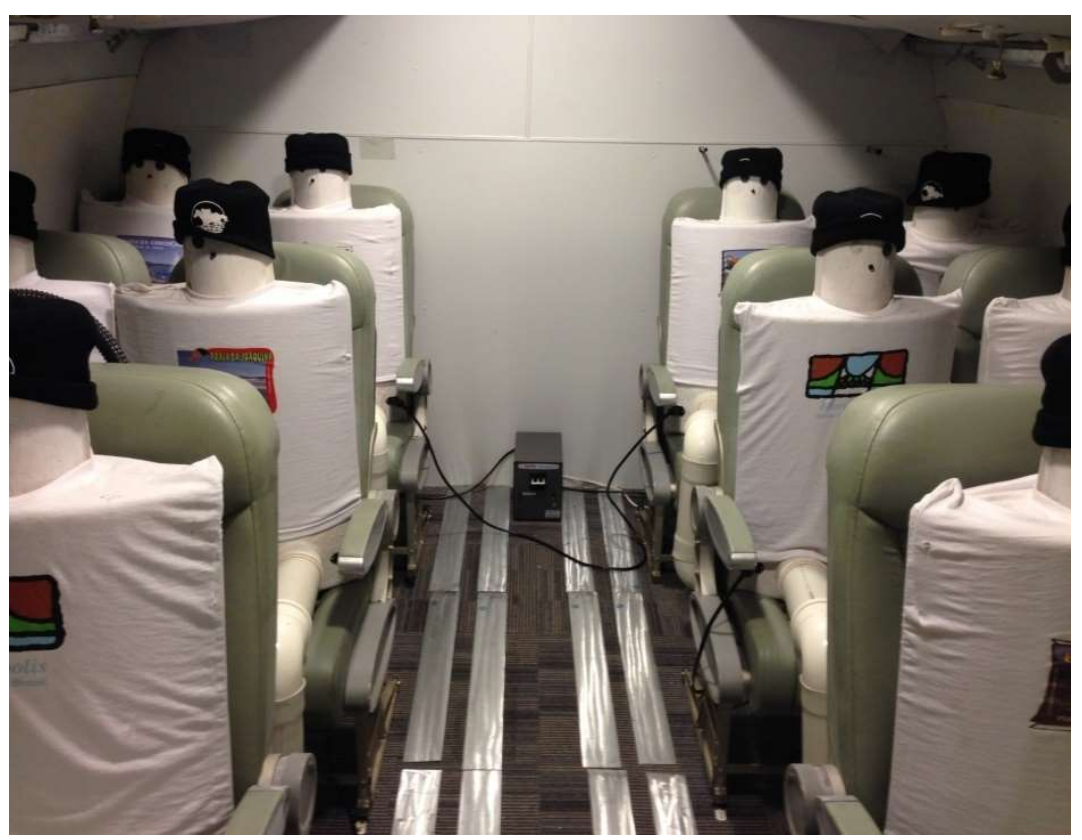

Figura 5.6. Vista interna do mock-up com os manequins aquecidos 
- Sistema 1 - Sistema de ventilação por mistura (MV), com 40\% de vazão de ar insuflada por difusores instalados na parte superior dos bins e $60 \%$ da ${ }^{5}$ vazão de ar insuflada pelos difusores na parte lateral inferior dos bins e com exaustão de $100 \%$ da vazão de ar por grelhas instaladas na parte inferior lateral da cabine, sistema convencional de ventilação e distribuição de ar, Figura 5.7.

- $\quad$ Sistema 2 - Sistema de ventilação e distribuição de ar pelo piso (UFAD), com $100 \%$ da vazão de ar insuflada por difusores instalados na região central da cabine e com exaustão de $40 \%$ da vazão de ar por grelhas localizadas na parte superior dos bins e com exaustão de $60 \%$ da vazão de ar pelas grelhas localizadas na parte lateral inferior dos bins, Figura 5.8.

- Sistema 3 - Sistema de ventilação e distribuição de ar por deslocamento (DV), com $100 \%$ de vazão de ar insuflada por difusores instalados na região lateral inferior da cabine, e com exaustão de $40 \%$ da vazão de ar por grelhas localizadas na parte superior dos bins e com exaustão de $60 \%$ da vazão de ar pelas grelhas localizadas na parte lateral inferior dos bins, Figura 5.9.

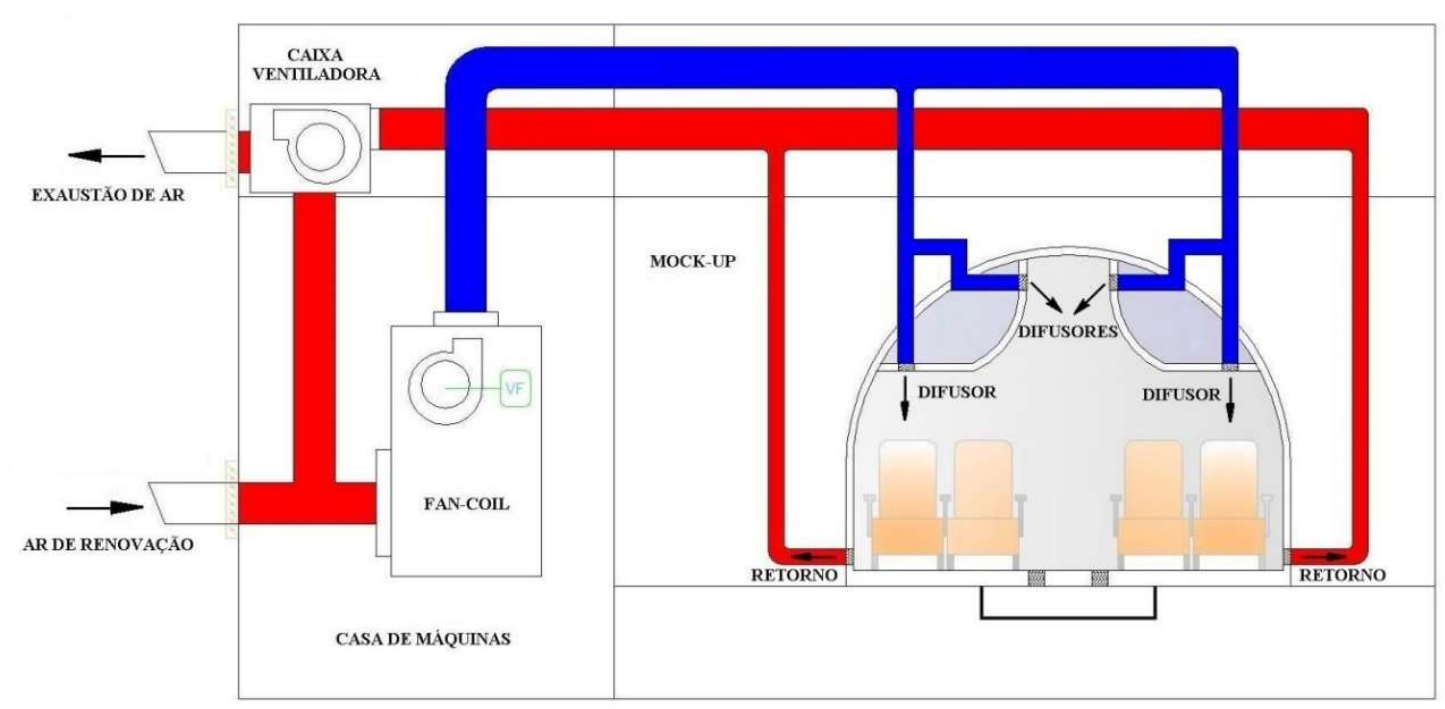

Figura 5.7. Sistema 1: Sistema de ventilação por mistura (MV)

${ }^{5}$ A utilização da proporção da vazão de ar de $40 \%$ na parte superior dos bins e de $60 \%$ na parte lateral inferior dos bins é usual no setor aeronáutico (fonte: comunicação pessoal). 


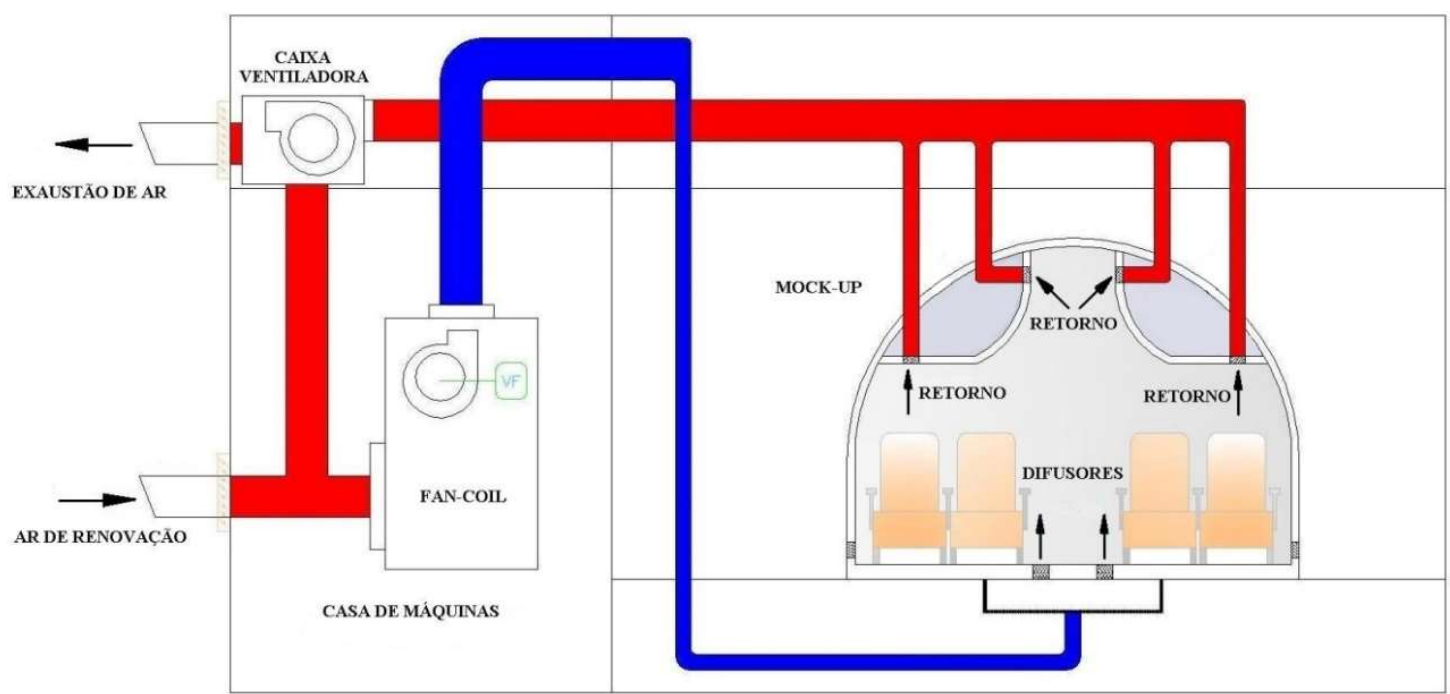

Figura 5.8. Sistema 2: Sistema de distribuição de ar pelo piso (UFAD)

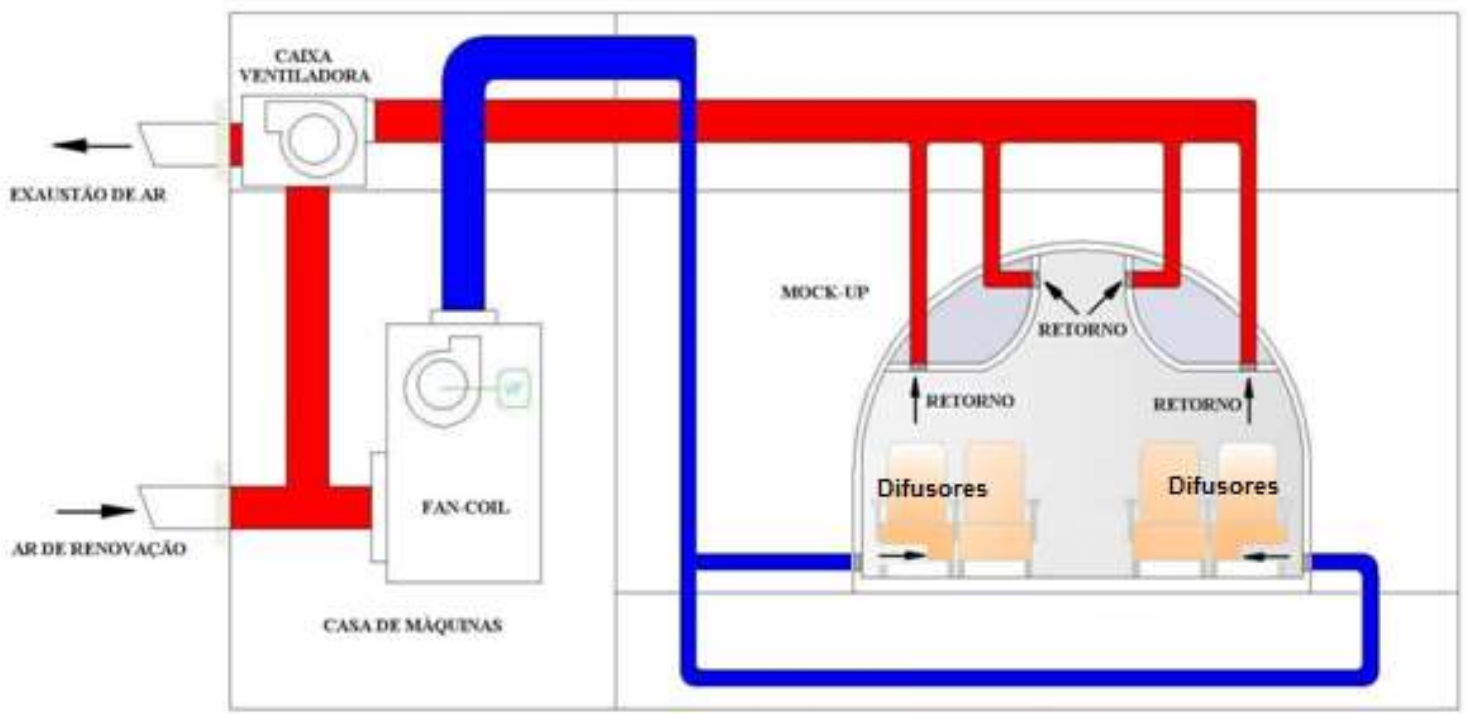

Figura 5.9. Sistema 3: Sistema de ventilação por deslocamento (DV)

\subsection{Gerador de partículas}

Com base nos requisitos estabelecidos por Conceição (2012), apresentados no Capítulo 3, foi escolhido o gerador de aerossol da TSI Modelo 3475 (Fig. 5.10), que permite variar o tamanho médio e a concentração das partículas geradas. Este equipamento necessita de uma fonte de nitrogênio para seu funcionamento, pressurizando a linha durante a operação em aproximadamente 6 bar. 


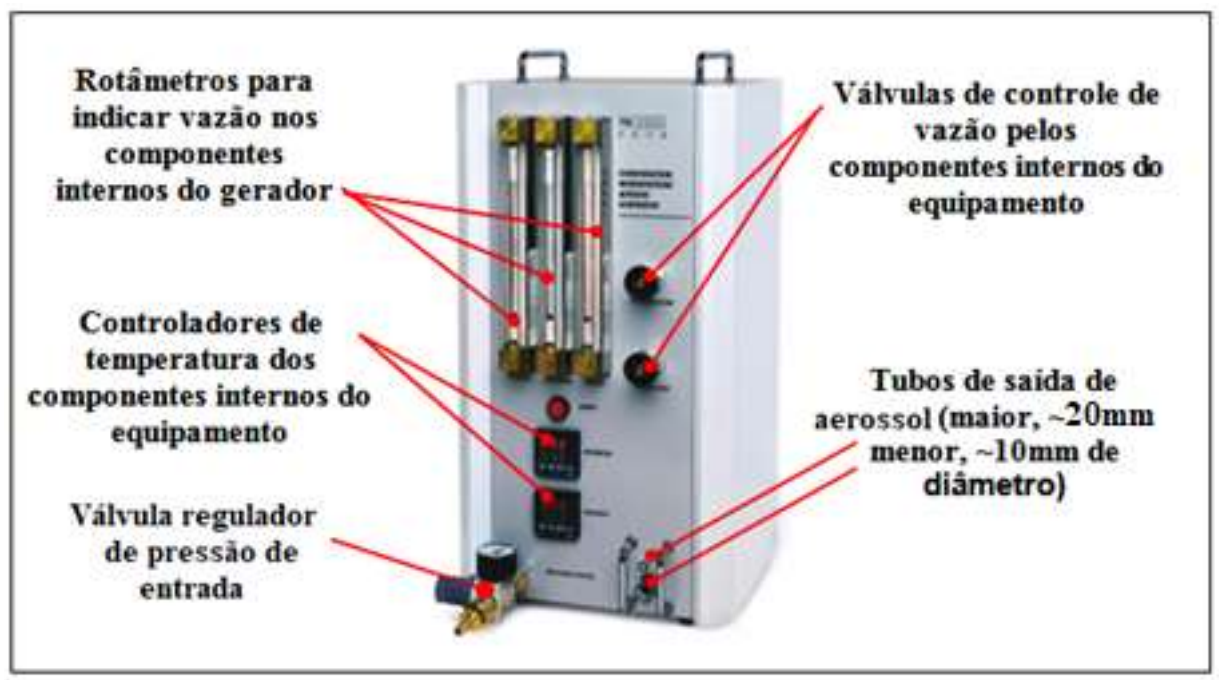

Figura 5.10. Gerador de aerossol TSI modelo 3475 (TSI, 2010) - imagem de catálogo

O gerador TSI 3475 produz partículas com diâmetro médio entre 0,1 a $8 \mu \mathrm{m}$, faixa esta que engloba a maior quantidade de partículas geradas em atividades expiratórias (ver Figura 4.3) e pode produzir aerossol com concentração de $10^{11} / \mathrm{m}^{3}$ (TSI, 2004), que é da mesma ordem de grandeza da concentração de gotículas geradas em um espirro, conforme discutido no item 4.2. O aerossol é gerado com DEHS (Di-etil-hexil-sebacato), que é um líquido com baixa taxa de evaporação e massa específica próxima à da água $\left(915 \mathrm{~kg} / \mathrm{m}^{3}\right)$ (HINDS, 1999). Acompanha o equipamento um monitor de partículas PAM 3475 , instalado em série, que monitora o diâmetro médio das partículas geradas, bem como a sua concentração (TSI, 2004).

Nos ensaios do presente trabalho o gerador operou com vazão de aerossol da ordem de $4 \mathrm{~L} / \mathrm{min}\left(6,67.10^{-5} \mathrm{~m}^{3} / \mathrm{s}\right)$, semelhante à vazão média de ar de inalação/exalação das pessoas (YAN et al., 2009). Considerando que o diâmetro do tubo de saída de aerossol é da ordem de $10 \mathrm{~mm}$, a velocidade em sua saída será de aproximadamente $1 \mathrm{~m} / \mathrm{s}$. É importante destacar que o gerador selecionado foi utilizado por outros pesquisadores em estudos correlatos, dentre eles Zhang et al. (2009), Jones; Nicas; Nazaroff; Hubbard (2009) e Conceição (2012), e também por Fabichak Jr. (2013).

O gerador de aerossol foi configurado para gerar partículas com tamanho

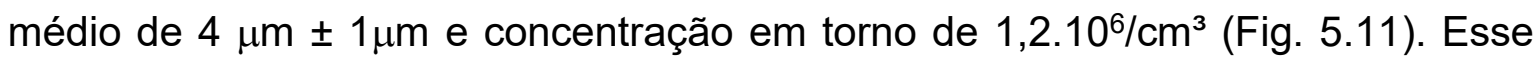
tamanho médio de $4 \mu \mathrm{m}$ foi escolhido devido aos resultados do gráfico apresentado na Figura 4.3, que mostram que para a atividade expiratória de um espirro tem-se uma quantidade maior de partículas nesse diâmetro escolhido. Esta concentração 
de partículas é da mesma ordem de grandeza da concentração de gotículas geradas em um espirro (ver item 4.2).

Embora este gerador produza, em sua grande maioria, partículas com o tamanho e a concentração desejados, ele também produz partículas, em menor quantidade, nas outras faixas de tamanho de 0,1 até $8 \mu \mathrm{m}$. O fato da geração não ser totalmente monodispersa, poderá ser interessante, pois permite a análise da dispersão de partículas também em faixas de tamanhos maiores de partículas, além daquela de 3,0 a $5,0 \mu \mathrm{m}(4 \mu \mathrm{m} \pm 1 \mu \mathrm{m})$.

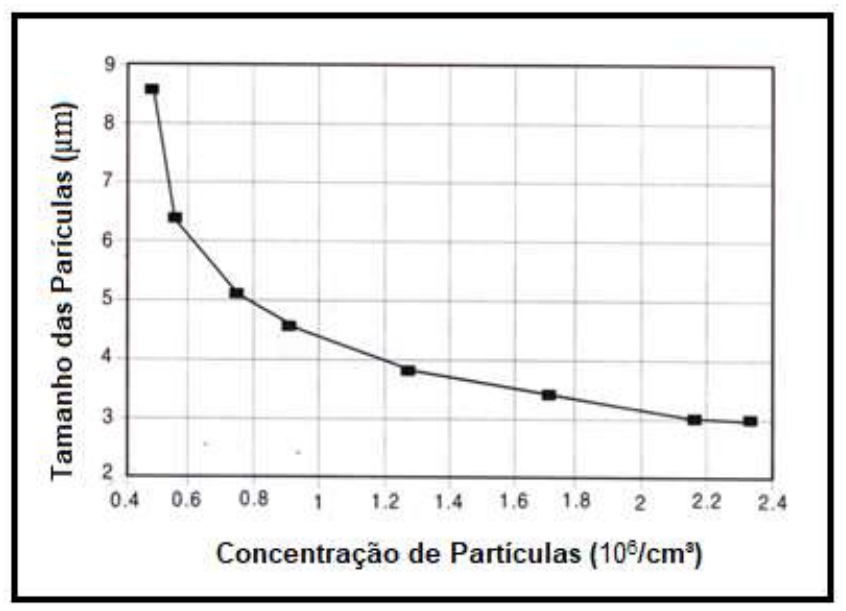

Figura 5.11. Concentração de partículas em função do tamanho da gotícula gerada (gráfico do catálogo do gerador TSI modelo 3475)

\subsection{Contadores de partículas}

A medição das partículas foi realizada com contador óptico da marca Met One (Fig. 5.12). O emprego dos contadores portáteis neste trabalho mostra-se bastante adequado para os objetivos propostos, pois embora não apresentem precisão tão boa quanto os espectrômetros, possuem características que motivam seu emprego, dentre elas: a sua portabilidade e volume reduzido, o que facilita o manuseio ao longo dos experimentos. A robustez deste equipamento permite várias horas de medição contínua, e pode ser operado de maneira remota, via cabos de comunicação RS232, tanto para comandar as medições como para transferir os dados medidos.

O contador possui 6 canais para contagem de partículas na faixa de 1,0 a 10,0 $\mu \mathrm{m}(1,0$ a 2,0 $\mu \mathrm{m}$, de 2,0 a $3,0 \mu \mathrm{m}$, de 3 a $5 \mu \mathrm{m}$, de 5 a $7 \mu \mathrm{m}$, de 7 a $10 \mu \mathrm{m}$, e maior do que $10 \mu \mathrm{m})$. Adequados, portanto, para a realização do presente trabalho, tendo 
em vista a faixa de partículas geradas pelo gerador TSI modelo 3475 , conforme descrito no item 5.5 .

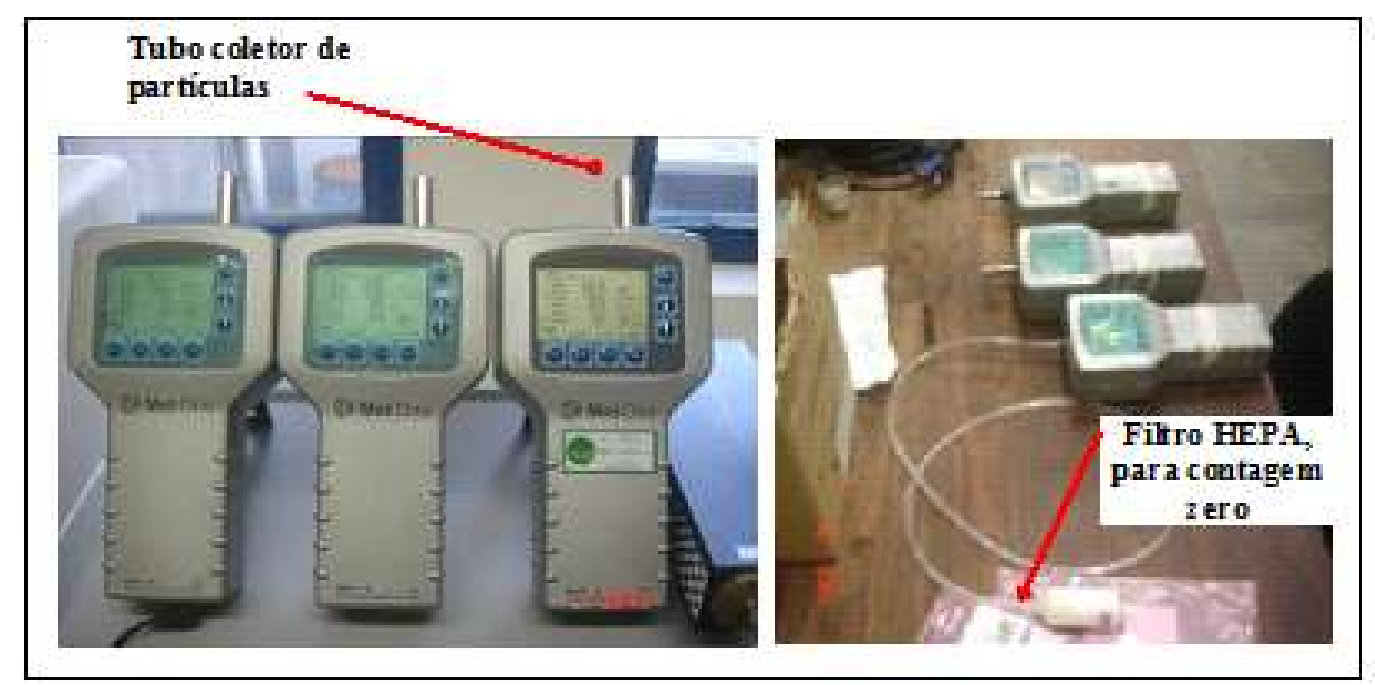

Figura 5.12. Contadores de partículas da MetOne, modelo HHPC6 (MetOne HHPC-6, 2010), utilizados nos experimentos

Fonte: CONCEIÇÃO, 2012

Este equipamento captura o ar do seu entorno por sucção promovida por uma bomba interna com vazão volumétrica de $0,1 \mathrm{cfm}\left(2,83 \cdot 10^{-3} \mathrm{~m}^{3} / \mathrm{s}\right)$. A duração de cada amostragem pode ser definida entre 6 s e $10 \mathrm{~min}$, o que determina o volume total de ar amostrado em cada medição. Já o intervalo entre as amostragens pode ser definido entre $1 \mathrm{~s}$ e $1 \mathrm{~h}$. $\mathrm{O}$ tempo de duração mais adequado pode variar em função da aplicação específica e deve ser definido empiricamente. No presente estudo foi adotado tempo de 10 minutos de amostragem por assento, com um tempo de 10 minutos antes da medição de partículas.

O contador opera pelo princípio de dispersão de um feixe luminoso (laser de diodo) ocasionada pela passagem das partículas aspiradas pela bomba. Um tubo coletor de partículas com diâmetro interno de $10 \mathrm{~mm}$ acompanha o contador de partículas, como mostrado na Figura 5.12.

$\mathrm{Na}$ Figura 5.12 mostra-se também os contadores de partículas quando da limpeza com contagem zero, realizada com o auxílio de um filtro absoluto (HEPA), conectado ao tubo coletor de partículas por intermédio de uma mangueira flexível de silicone. Essa tarefa deve ser realizada idealmente sempre antes de começar as medições, para garantir que o aparelho não tenha impurezas aprisionadas nas proximidades do seu sensor ótico. 


\subsubsection{Incerteza de medição na contagem de partículas}

Segundo o manual deste equipamento, o erro de coincidência é da ordem $5 \%$ para concentrações de $2.10^{6} /$ pés $^{3}\left(7,0.10^{7} / \mathrm{m}^{3}\right)$ e a eficiência de contagem é de $50 \%$ para partículas de $0,3 \mu \mathrm{m}$ e de $100 \%$ para partículas maiores do que $\quad 0,45 \mu \mathrm{m}$.

Conforme artigo técnico publicado pelo fabricante do equipamento (LATIMER; TANG, 2007), a incerteza de medição na classificação de tamanhos das partículas coletadas é da ordem $7 \%$. Porém, como não se sabe o tamanho exato das partículas contadas em cada faixa de medição, esta informação parece não ajudar na definição das incertezas de medição.

Segundo Hinds (1999) o erro sistemático de um contador de partículas óptico é função, principalmente, do diâmetro da partícula e de seu índice de refração. Como, de fato, os contadores utilizados são calibrados com partículas de PSL (polystirene latex spheres) que possuem índice de refração de 1,59 (MetOne HHPC-6, 2010), e o aerossol de DEHS contado nos experimentos possui índice de refração de 1,45 (TOPAS, 2012), este desvio precisaria ser investigado. Porém, com base nos estudos desenvolvidos por Yoo; Chae; Liu (1996), com contadores ópticos semelhantes ao empregado no presente trabalho, tem-se que uma diferença de aproximadamente 0,15 no índice de refração não deve impactar significativamente nos resultados das medições.

Não obstante, considerando-se que a incerteza na contagem de partículas segue a estatística de Poisson (KULKARNI; BARON; WILLEKE, 2011), a incerteza poderia ser estimada pela raiz quadrada do número de partículas contadas em cada medição.

Cabe ainda ressaltar que foram realizadas algumas avaliações do erro quadrático de Gauss com resultados preliminares da contagem de partículas na cabine, e percebeu-se que este se manteve sempre abaixo de $5 \%$.

Função do acima exposto utiliza-se como valor de incerteza na contagem das partículas $(\Delta N)$, o maior valor numérico obtido por qualquer um dos dois critérios listados a seguir:

- $\Delta N= \pm \sqrt{N}$, (estatística de Poisson)

- $\Delta N=+5 \% N$ (perdas por coincidência) 
- $\Delta N= \pm \sqrt{\frac{\sum\left(N_{i}-\bar{N}\right)^{2}}{n(n-1)}}$ (erro quadrático de Gauss)

(Em que: " $N_{i}$ " é o valor contado em uma dada medição; " $\bar{N}$ " é a média dos valores medidos; e " $n$ " é o número de amostras)

\subsection{Condições de ensaio}

\subsubsection{Temperatura de insuflamento}

As temperaturas do ar de insuflamento para as três arquiteturas que foram avaliadas foram estabelecidas em:

- Temperatura de insuflamento de $18^{\circ} \mathrm{C} \pm 0,5^{\circ} \mathrm{C}$;

- Temperatura de insuflamento de $22^{\circ} \mathrm{C} \pm 0,5^{\circ} \mathrm{C}$;

Essas temperaturas foram estabelecidas com base em requerimentos de operação da ASHRAE 161 (2007), que estabelece temperaturas do ar de cabine de $18,3^{\circ} \mathrm{C}$ a $23,9^{\circ} \mathrm{C}$ com tolerância do set point de $\pm 1,1^{\circ} \mathrm{C}$.

\subsubsection{Temperaturas superficiais das paredes}

A cabine foi isolada termicamente do ambiente externo, com isolamento térmico colocado na parte externa da cabine, de tal forma que a temperatura radiante média, $\bar{T}_{r}$, no interior da cabine fosse praticamente igual à temperatura média do ar na cabine. Este procedimento foi utilizado para que não ocorresse a interferência de assimetria de radiação na análise dos resultados de desconforto térmico local e também na dispersão das partículas no ar, relacionadas com as condições de escoamento do ar no mock-up.

As temperaturas superficiais das paredes do mock-up foram monitoradas para a verificação do estabelecimento de condições de regime permanente. A monitoração destas temperaturas também é necessária para a verificação da condição de temperatura radiante média, $\bar{T}_{r}$, no interior da cabine ser praticamente igual à temperatura média do ar na cabine. Além da colocação de material de isolamento na parte externa do mock-up, foi realizado o controle da temperatura do ar no ambiente externo ao mock-up. 


\subsubsection{Vazão de ar}

Para os três sistemas de ventilação e distribuição de ar propostas, Figuras 5.7 a 5.9, a vazão de referência considerada é de $9,5 \mathrm{~L} / \mathrm{s}$ por pessoa, que corresponde a $34 \mathrm{~m} / \mathrm{h}(20 \mathrm{cfm})$ por pessoa, valor recomendado pela norma ASHRAE 161 (2007). Considerando que a cabine comporta 12 passageiros, a vazão de ar de insuflamento do mock-up foi controlada em aproximadamente $408 \mathrm{~m}^{3} / \mathrm{h}(240 \mathrm{cfm})$.

\subsubsection{Vazão de ar de renovação e filtragem do ar}

Conforme ressaltado no item 1.1, na maioria das aeronaves comerciais $50 \%$ do ar fornecido ao passageiro é recirculado como forma de melhorar o controle da circulação do ar na cabine, a umidade e a eficiência no consumo de combustível. Filtros HEPA são instalados nos dutos de recirculação para reter os contaminantes gerados na cabine. Estes $50 \%$ do ar recirculado, acrescidos dos $50 \%$ de ar de renovação, constituem a vazão de ar que é insuflado na cabine da aeronave.

No presente trabalho, conforme descrito no item 4.2, o sistema de climatização do mock-up conta com um exaustor, instalado na linha de retorno do ar, que permite a exaustão e renovação de $100 \%$ do ar do mock-up, não sendo necessária a instalação de filtro HEPA para retenção das partículas geradas na cabine, que serão eliminadas na exaustão.

Também não houve necessidade de instalação de filtro adicional no sistema de climatização, uma vez que medições de partículas no ar de renovação insuflado no mock-up realizados no trabalho anterior, Fabichak Jr. (2013), mostraram valores bastante baixos para partículas maiores que $4,0 \mu \mathrm{m}$ (ver item 5.9.2). Objeto também de interesse no presente trabalho.

\subsubsection{Umidade relativa do ar}

Durante o voo a umidade do ar no interior da cabine tende a ser baixa, devido à aridez do ar externo, da altitude e da umidade mínima que é gerada pelos ocupantes e equipamentos. Segundo Hunt; Space (1994), a umidade relativa do ar em aeronaves fica entre 5 e $35 \%$, com média entre 15 e $20 \%$. Gao et al. (2007) afirmam que a umidade relativa do ar é muito baixa em voos intercontinentais, tipicamente de 3 a $8 \%$. Park et al. (2011) mencionam que a umidade relativa é 
baixa, inferior a 15\%. A norma ASHRAE 161 (2007) não estabelece valores para a umidade do ar.

Em avaliações de conforto térmico, em que não se utilizam pessoas, como é o caso deste estudo, os ensaios podem ser feitos em condições normais de ambientes climatizados (ASHRAE 55, 2013), com umidade relativa do ar em torno de $50 \%$, que será o procedimento adotado no presente trabalho.

Conforme procedimento adotado por Zhang et al. (2009), Conceição (2012), Fabichak Jr (2013), Fabichak et al. (2013), Celline, Fabichak e Tribess, (2017), Celline (2017), Felix et al. (2018), este procedimento é suficiente, uma vez que a umidade relativa do ar da cabine também não influencia significativamente na concentração das partículas medidas ao longo do experimento. Esta afirmação está baseada no fato de que o gerador de partículas TSI Modelo 3475 utiliza o DEHS, para geração do aerossol, que é um líquido com baixa taxa de evaporação conforme especificação do fabricante (TOPAS, 2012). Assim, a umidade relativa do ar da cabine não deve influenciar significativamente na concentração de partículas medidas ao longo do experimento, o que também foi considerado por Zhang et al. (2007). Portanto, a umidade foi apenas monitorada ao longo dos experimentos na região central da cabine.

\subsection{Medições, instrumentação e procedimentos de ensaio}

Nessa etapa são detalhadas as medições que foram realizadas para análise das condições de desconforto térmico local e de dispersão de partículas nas três arquiteturas de ventilação e distribuição de ar, bem como a instrumentação e os procedimentos de ensaio que foram realizados em conformidade com a norma ISO 7726 (1998), com base nos requisitos estabelecidos por Conceição (2012) e utilizados por Silva (2013), Fabichak Jr. (2013) e Celline (2017).

\subsubsection{Medição de temperatura e velocidade do ar}

A medição de velocidades e temperaturas do ar na cabine, bem como o levantamento da intensidade de turbulência para os sistemas de ventilação e distribuição de ar propostos, seguem as recomendações da norma ASHRAE 55 (2013) com medição nas alturas $0,10,0,60$, e $1,10 \mathrm{~m}$ a partir do piso, correspondendo à região dos pés e tornozelos, das mãos e braços e do pescoço e 
cabeça, respectivamente, de uma pessoa sentada. Para a situação de pessoas em pé (corredor) foi adotada altura de 1,60 m. As medições foram realizadas entre cada fileira de assentos (Figura 5.13), perfazendo três fileiras no total.

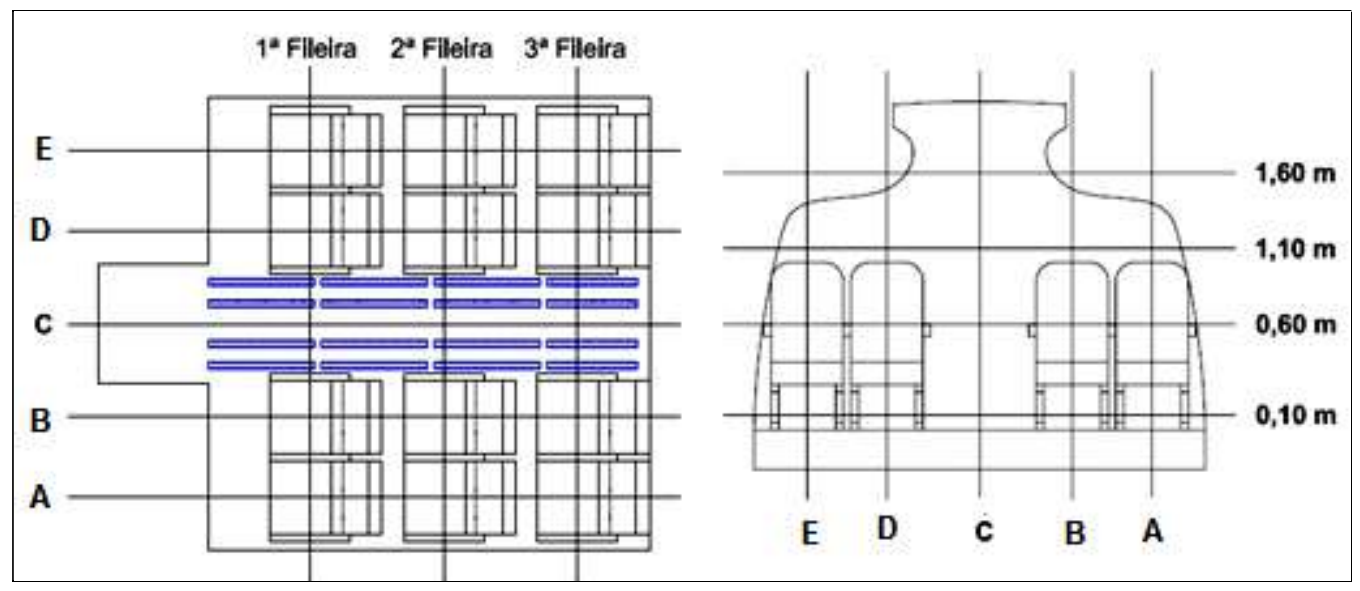

Figura 5.13. Planos e alturas de medição de velocidade e temperatura do ar

Para as medições de velocidade e de temperatura do ar foi utilizado o sistema Comfort Sense da Dantec Dynamics (Fig. 5.14), que consiste de três mini estruturas modulares, 54N95, com entrada para um canal e dois drivers DAQmx da National Instruments para a conexão com o computador.

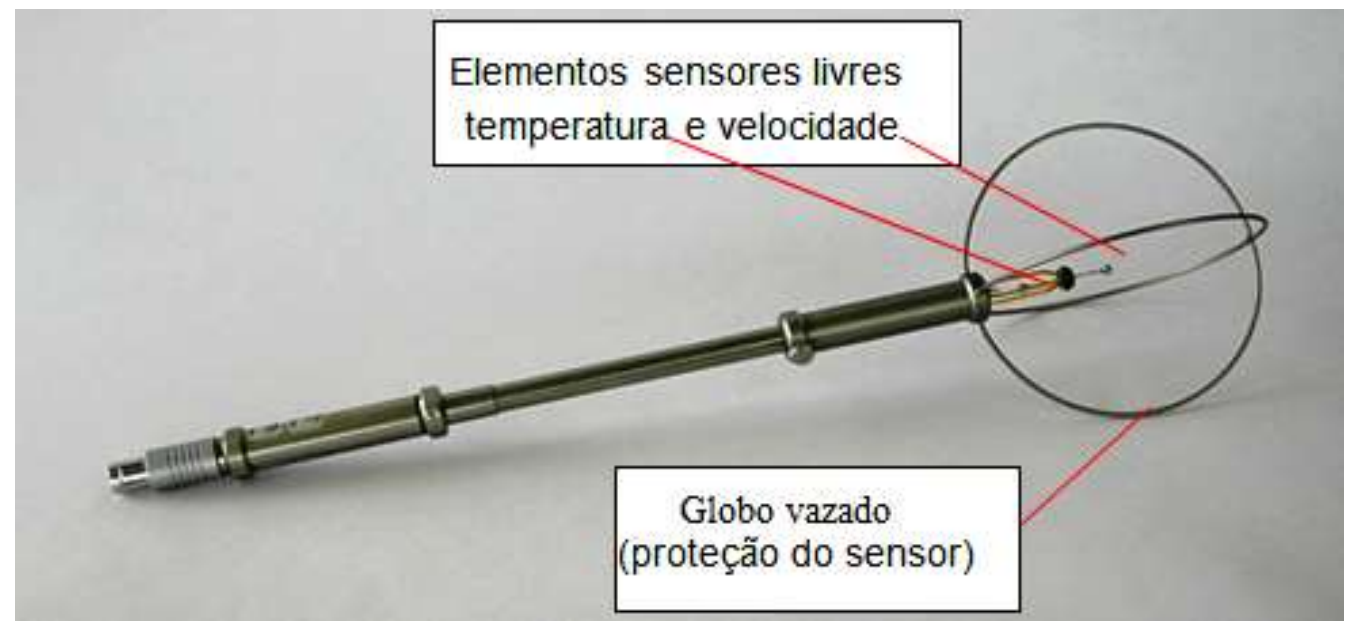

Figura 5.14. Sensor de anemômetro omnidirecional (elemento sensor livre)

Foram utilizados três transdutores 54T33, que são sondas omnidirecionais de medição de velocidade do ar com frequência de resposta superior a $2 \mathrm{~Hz}$, com faixa de operação de 0 a $5 \mathrm{~m} / \mathrm{s}$ e incerteza de medição de $\pm 0,02 \mathrm{~m} / \mathrm{s}$ para faixa de 
medição de 0 a $1 \mathrm{~m} / \mathrm{s}$, com sensores de temperatura integrados, de resposta rápida, com faixa de operação de $-20{ }^{\circ} \mathrm{C}$ até $80{ }^{\circ} \mathrm{C}$, e incerteza de medição de $\pm 0,2^{\circ} \mathrm{C}$ para a faixa de medição de 0 a $45^{\circ} \mathrm{C}$.

Um programa de computador faz a interface amigável com o usuário. Nesse programa é possível configurar a posição de cada sonda no ambiente em estudo e um gráfico em tempo real mostra o comportamento da temperatura do ar, da velocidade do ar, da intensidade de turbulência e Draught Rate para cada sonda. Para a aquisição dos dados, o usuário configura o tempo desejado para a gravação. Após esse período, é possível exportar os resultados para uma planilha, exportar os gráficos ou ainda emitir um relatório em formato pdf com um resumo das informações de uma dada aquisição. A título de ilustração, nas Figuras 5.15 e 5.16 mostra-se a instalação das três sondas na cabine.

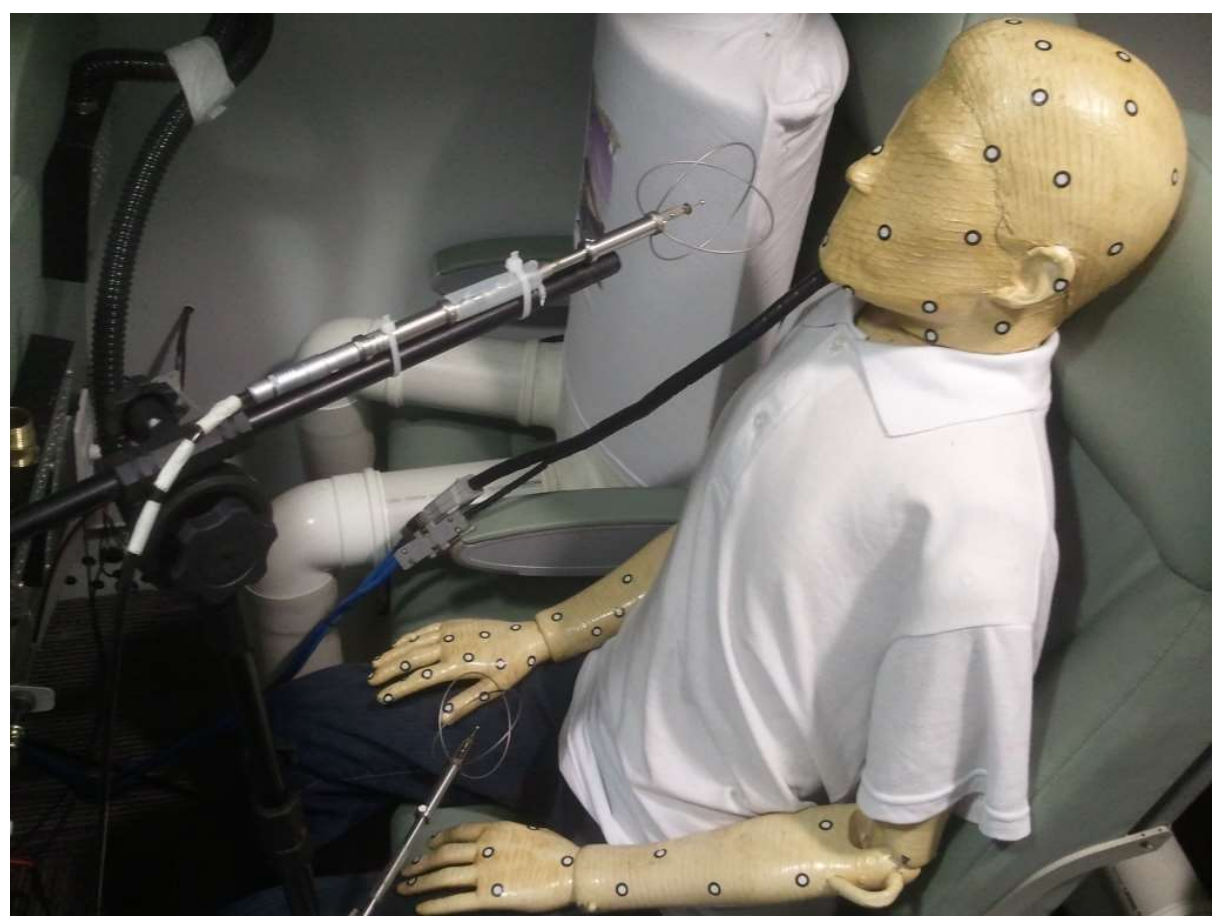

Figura 5.15. Posicionamento das sondas para medição de temperatura e velocidade do ar na altura de $0,60 \mathrm{~m}$ e de $1,10 \mathrm{~m}$ a partir do piso

Fonte: SILVA, 2013 


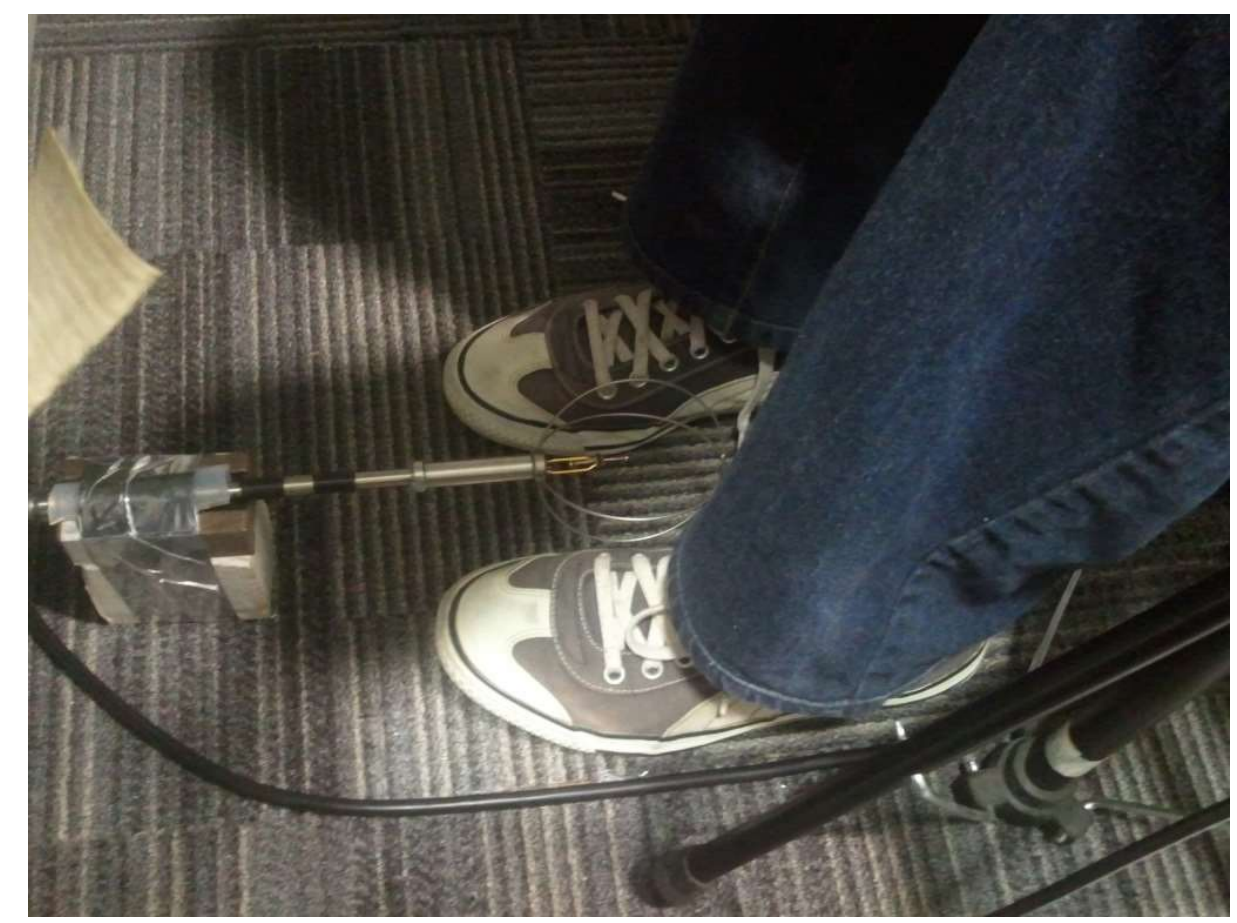

Figura 5.16. Posicionamento da sonda para medição de temperatura e velocidade do ar na altura de $0,10 \mathrm{~m}$ a partir do piso

Fonte: SILVA, 2013

\subsubsection{Medição da temperatura superficial das paredes}

As temperaturas superficiais das paredes do mock-up e da sala de calibração foram monitoradas por meio de termopares tipo T (cobre/constantan), com faixa de operação $-270{ }^{\circ} \mathrm{C}$ a $370{ }^{\circ} \mathrm{C}$ e f.e.m. (força eletromotriz) de $-6,258 \mathrm{mV}$ a 20,872 $\mathrm{mV}$. Os termopares estão conectados a um data logger Agilent, modelo 34970A.

\subsubsection{Medição da vazão de ar}

A vazão de ar foi determinada e monitorada a partir da medição da velocidade do ar nos dutos de exaustão do ar da cabine utilizando tubos de Pitot (Fig. 5.17). Foi projetado um sistema composto por um conjunto de manômetros diferenciais e tubos de Pitot instalados em tubos de PVC de $100 \mathrm{~mm}$ de diâmetro nas linhas de exaustão. 

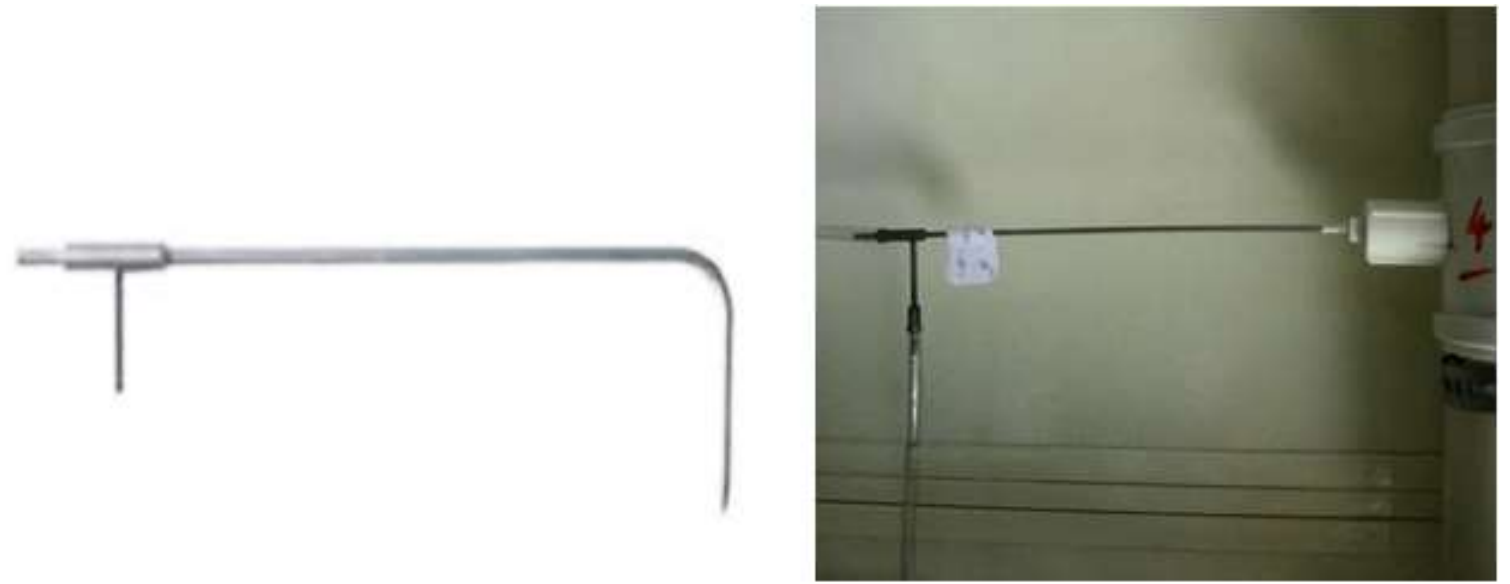

Figura 5.17. Vistas do tubo de Pitot antes e após a instalação

O tubo de Pitot que foi utilizado é da série 160 de aço inoxidável. Os manômetros diferenciais são do fabricante Dwyer (Fig. 5.18). A conexão dos tubos de Pitot com os manômetros foi realizada com mangueiras transparentes de silicone de 5/16". Foi realizado um memorial de ${ }^{6}$ cálculo para converter o valor da diferença de pressão do manômetro em vazão.

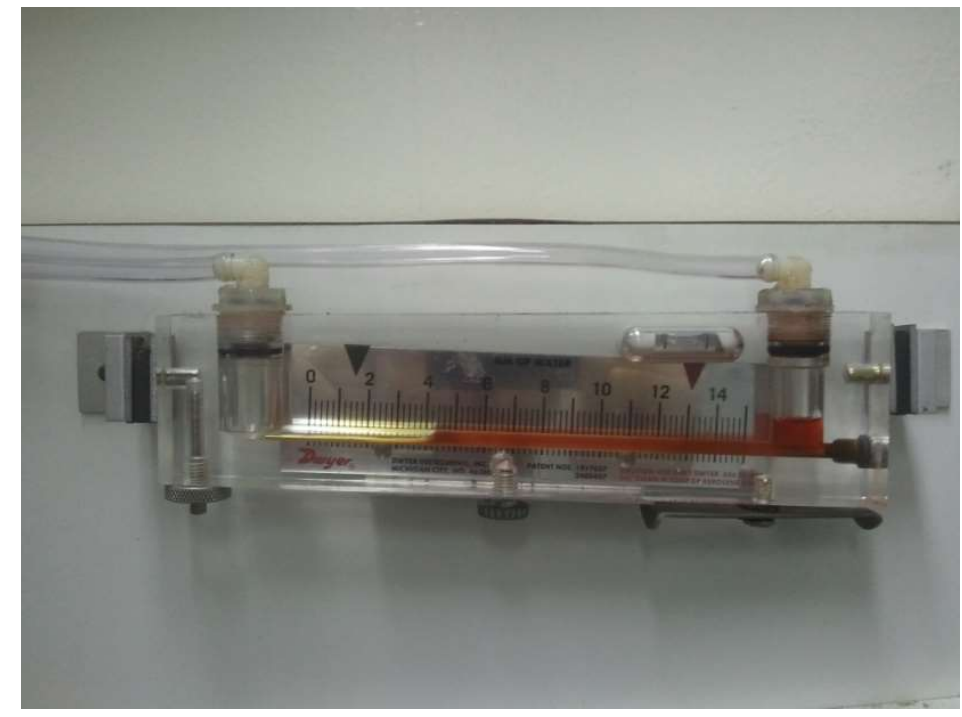

Figura 5.18. Manômetro diferencial para determinação e monitoramento da vazão de ar

$\mathrm{Na}$ entrada das linhas de exaustão (saídas do mock-up) foram instaladas telas metálicas retificadoras de fluxo e a $1000 \mathrm{~mm}$ (correspondente a 10 diâmetros dos dutos de PVC) das telas retificadoras foram instalados os tubos de Pitot, para garantir condições de perfil completamente desenvolvido no local de medição de

\footnotetext{
${ }^{6} \mathrm{O}$ memorial de cálculo encontra-se no Anexo B.
} 
velocidades máximas do ar no centro dos dutos (FOX; MC DONALD; PRITCHARD, 2006).

Para o controle da vazão de ar nos diferentes sistemas propostos e analisadas, em cada linha de exaustão foram instalados dampers.

Uma vez que cada linha de exaustão do ar é independente uma da outra, a vazão total é calculada como a soma das vazões em cada linha. Este fato é importante, pois permite ajustar, de forma independente, a vazão de ar conforme a necessidade de cada ensaio.

\subsubsection{Manequins aquecidos}

Os manequins aquecidos para simular a presença de passageiros foram construídos em fibra de vidro e tubos e conexões de PVC, com forma semelhante a um corpo humano sentado (Figura 5.19). Internamente, em cada manequim existe uma resistência elétrica que dissipa calor e um ventilador que propicia uma distribuição uniforme da temperatura do ar ao longo de toda a superfície do manequim. Os manequins são acoplados a uma unidade de potência por meio de cabos tripolares. A potência de dissipação de calor é ajustável por meio de software. A faixa de operação dos manequins aquecidos é de 30 a $120 \mathrm{~W} / \mathrm{m}^{2}$.
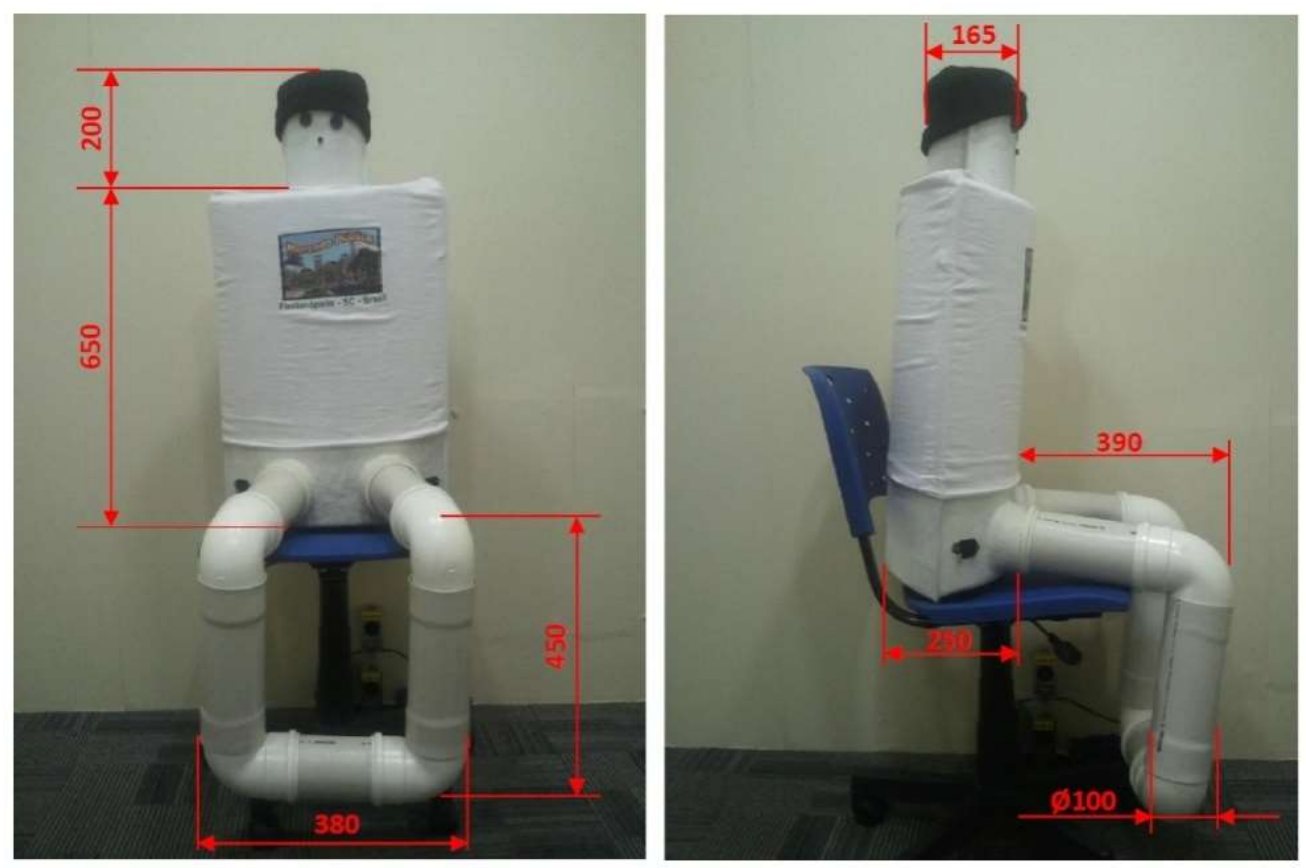

Figura 5.19. Os manequins aquecidos e suas respectivas dimensões 


\subsection{Processo de geração e de medição da concentração de partículas}

Para minimizar influências no escoamento do ar no interior da cabine, o gerador de aerossol está posicionado externamente ao mock-up, como mostrado na Figura 5.20a e o aerossol gerado injetado no ambiente interno da cabine mediante tubos metálicos e mangueiras de silicone de $10 \mathrm{~mm}$ de diâmetro interno, como ilustrado no detalhe na Figura 5.20b.

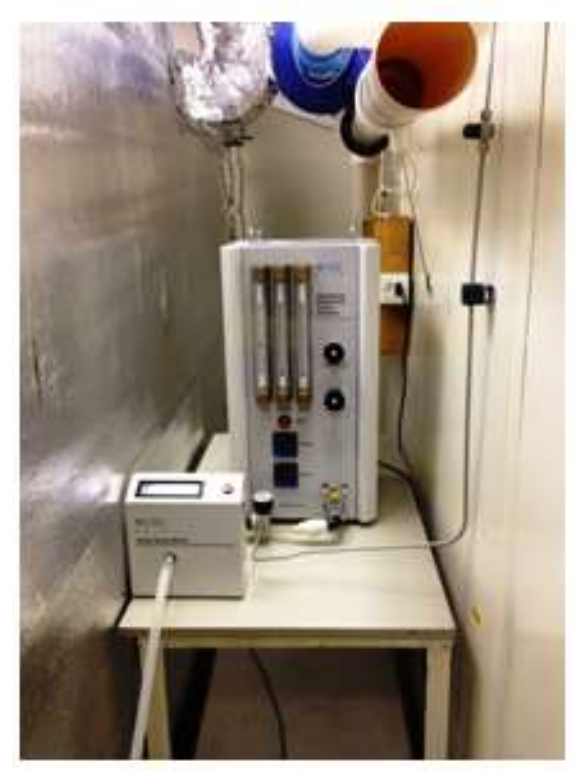

a)

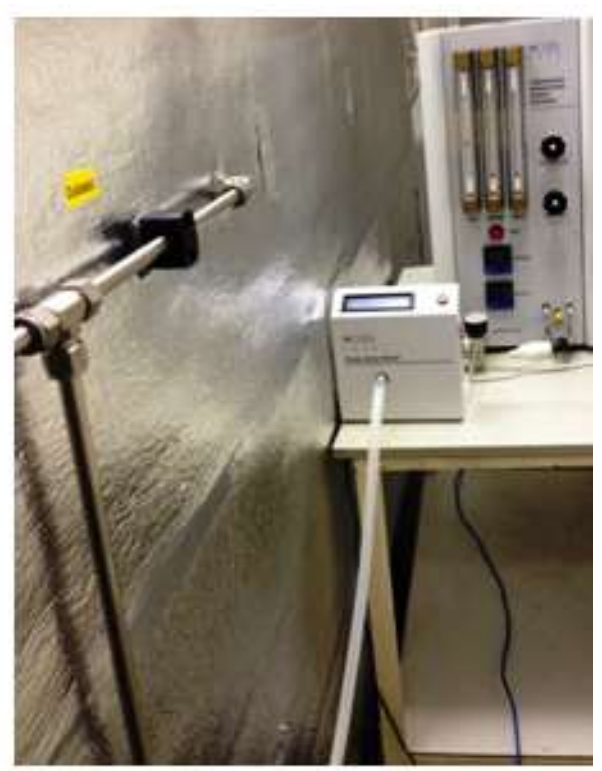

b)

Figura 5.20. a) Gerador de aerossol TSI modelo 3475 e monitor PAM 3475 posicionados externamente ao mock-up, b) Detalhe dos tubos e mangueiras de conexão

O tamanho e a concentração das partículas geradas são constantemente monitorados com o uso do monitor PAM 3475. Este procedimento é de importância fundamental, porque assim pode-se garantir que todos os testes sejam realizados com a mesma quantidade e concentração de partículas geradas e injetadas no ambiente.

Adotando procedimento similar ao realizado por Wan; Chao; Fang (2005), a injeção das partículas, simulando pessoa liberando partículas expiratórias ao tossir, foi feita, inicialmente, na poltrona junto à fuselagem e, posteriormente, na poltrona do passageiro sentado junto ao corredor. As partículas foram injetadas a $1,10 \mathrm{~m}$ a partir do piso, que corresponde à zona de respiração das pessoas, nas posições 3A e 3B, respectivamente (Fig. 5.21). 
Na medição da concentração de partículas em cada poltrona do mock-up os contadores de partículas também foram posicionados na zona de respiração dos manequins, a 1,10 m do piso, como mostrado na Figura 5.22 .

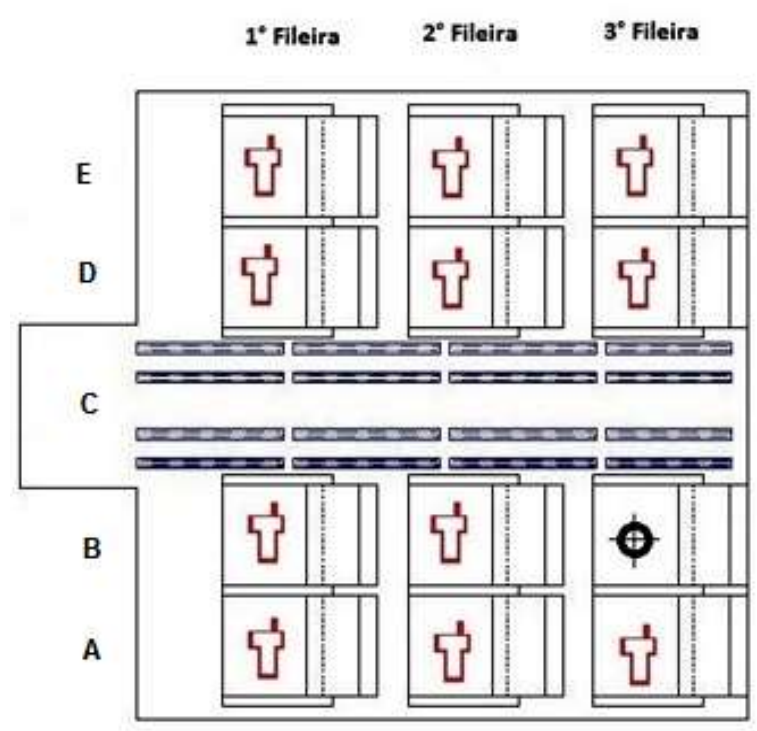

(a)

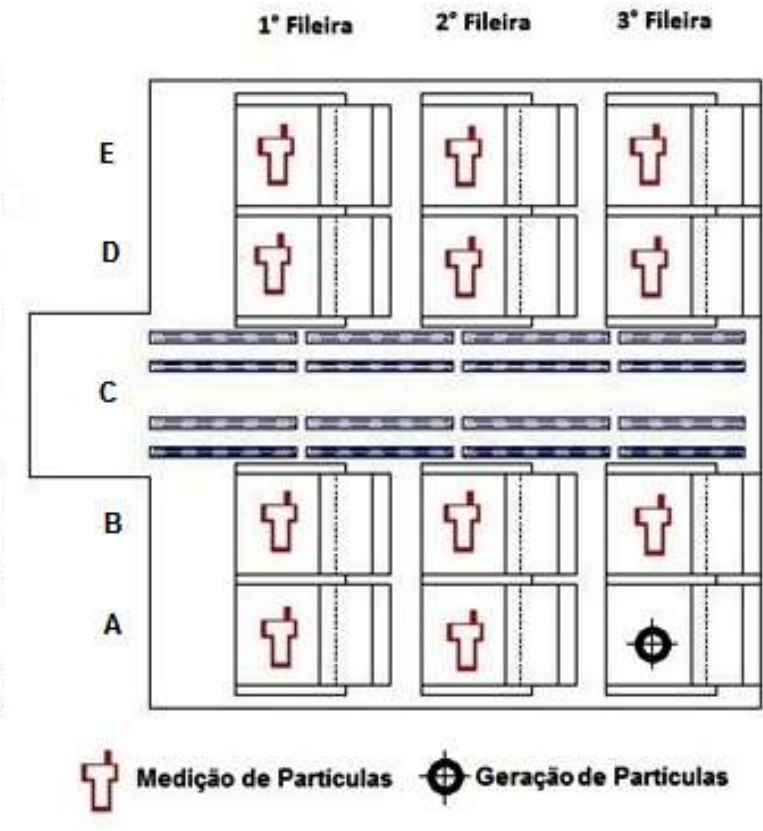

(b)

Figura 5.21. Pontos de injeção e medição de partículas no mock-up a) injeção de partículas na poltrona 3D b) injeção de partículas na poltrona 3E

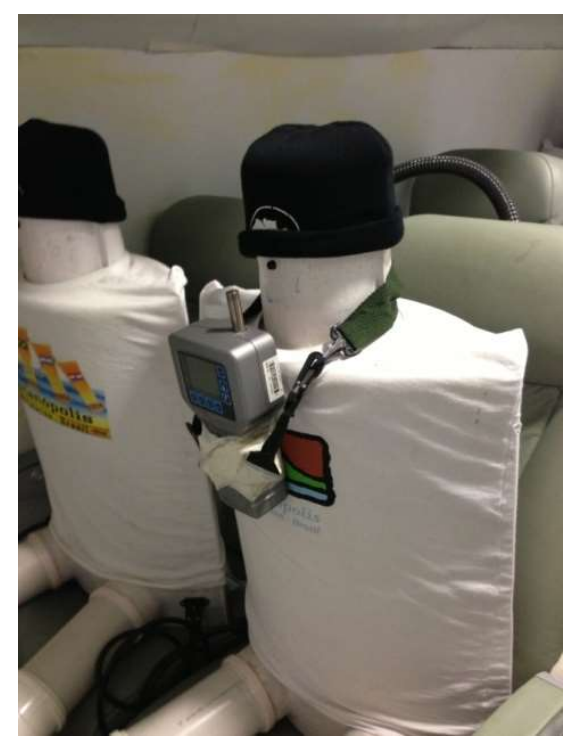

Figura 5.22. Posição dos contadores de partículas 


\subsubsection{Intervalo entre medições e tempo de medição das partículas}

O intervalo entre medições é função do tamanho das partículas analisadas. Quanto menor o tamanho das partículas, maior o tempo para a sua deposição após a ressuspensão causada pela movimentação no interior da cabine na troca da posição do contador de partículas.

No trabalho anterior, Fabichak Jr. (2013), cuja análise foi focada em partículas maiores que $3 \mu \mathrm{m}$, verificou-se a necessidade de 10 minutos para que ocorresse a estabilização. Assim, o tempo de medição também será de 10 minutos, que é o mesmo tempo adotado na medição da velocidade e da temperatura do ar e de partículas por Zhang et al. (2007).

\subsubsection{Medições da concentração de fundo}

Entende-se por concentração de fundo a concentração de partículas medidas dentro do mock-up com o sistema de climatização em operação, insuflando ar na cabine, antes da injeção das partículas com a utilização do gerador.

Em medições realizadas por Fabichak Jr. (2013), verificou-se que para partículas acima de $3 \mu \mathrm{m}$, a concentração de fundo pode ser desprezada. Medidas de partículas de fundo para partículas entre 3 e $5 \mu \mathrm{m}$ " $C_{3-5 \mu \mathrm{m}}$ " no assento 2D, por exemplo, mostraram valor máximo de aprox. $6,67.10^{3} \mathrm{P} / \mathrm{m}^{3}$. Considerando que o volume de ar aspirado pelos contadores " $v$ " é $0,0003 \mathrm{~m}^{3}$, pode-se calcular o número absoluto de partículas que efetivamente passaram pelo contador, com:

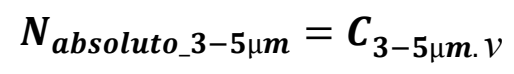

Aplicando-se a equação 5.1, chega-se à quantidade de partículas de fundo na faixa de 3 a $5 \mu \mathrm{m}$, medidas no assento 2D, de 2 partículas na média das medições. Nesta mesma situação, ao fazer a medição para a faixa de 5 a $7 \mu \mathrm{m}$ chegou-se ao valor de 0 partículas.

Nas mesmas faixas e na mesma posição (2D), o número médio de partículas depois da injeção de aerossol foi de 14.419 partículas para a faixa de 3 a $5 \mu \mathrm{m}$ e de 2.946 partículas para a faixa de 5 a $7 \mu \mathrm{m}$. 


\subsection{Repetitividade dos ensaios}

Para aumentar a confiabilidade das medições e dos resultados, para cada uma das arquiteturas propostas e para cada temperatura de insuflamento do ar na cabine, os ensaios foram repetidos em três dias diferentes.

\subsection{Sequência experimental}

A seguir é apresentada a sequência experimental para efetuar as medições, apresentada na forma de rotina, conforme Fabichak Jr. (2013):

- Inicialmente, são ajustadas as válvulas dos dutos de insuflamento e exaustão do ar para a arquitetura em estudo;

- Em seguida, é ligado o sistema de automação e controle e demais equipamentos e configurados todos os parâmetros para o ensaio;

- Depois, são ligados os manequins aquecidos para iniciar o processo de estabilização;

- Feito isso, são ligados os ventiladores instalados nos dutos de exaustão do mock-up;

- Em seguida, são realizadas medições da diferença de pressão nos manômetros diferenciais e realizados cálculos de vazão de ar, para o ajuste das vazões utilizando os dampers instalados em cada linha de exaustão;

- Depois, é iniciado o registro de dados do sistema de automação e controle e no data logger para determinar o período de estabilização das condições ambientais na cabine;

- Nesse momento, o gerador de partículas é ligado para que sua resistência seja aquecida, configurando-o para a geração do diâmetro e da concentração de partículas desejados;

- Feito isso, as sondas omnidirecionais são posicionadas na posição a ser medida, simultaneamente com o contador de partículas, colocados próximos à zona de respiração (a 1,10 m do piso); 
- Após a estabilização das condições ambientais na cabine, são efetuadas as medições para cada uma das posições do plano de medição do mock-up;

- Finalizadas as medições, são efetuados os registros e armazenamento dos dados;

- Finalmente, é verificada novamente a diferença de pressão nos manômetros para assegurar que não houve variação durante os ensaios e;

- Após as etapas anteriores, os equipamentos são desligados e o processo de medição é concluído. 


\section{Resultados Experimentais}

Neste capítulo são apresentados os resultados de medição e a sua análise. Inicialmente, são apresentados os resultados das medições de velocidades e temperaturas do ar, e respectiva análise do padrão de escoamento e das diferenças de temperatura do ar na cabine, em cada um dos sistemas de ventilação e distribuição de ar testados (MV, UFAD e DV). Em seguida, são apresentados os resultados de desconforto térmico devido à estratificação de temperatura e a correntes de ar. Depois, são apresentados os resultados de concentração de partículas e a análise da dispersão e remoção de partículas na região de respiração.

Objetivando a realização de análise comparativa dos resultados para cada sistema de ventilação e distribuição de ar testados, os resultados de velocidade e de temperatura do ar são apresentados na forma de perfis e os de concentração de partículas, na forma de barras.

\subsection{Perfis de velocidades do ar}

Nas Figuras 6.1 e 6.2 são apresentados os perfis de velocidade do ar para os três sistemas de ventilação e distribuição de ar testados (MV, UFAD e DV) nas temperaturas de insuflamento do ar na cabine de 18 e $22{ }^{\circ} \mathrm{C}$, respectivamente. É importante lembrar que as posições $1 \mathrm{C}, 2 \mathrm{C}$ e $3 \mathrm{C}$, correspondem à região do corredor, enquanto a alocação das asas e da cauda indicam a direção de voo e a localização dos assentos.

Os valores das medições de velocidade do ar, juntamente com as incertezas de medição, em cada situação analisada, são apresentados nas Tabelas A.1 a A.6 do Apêndice A. 


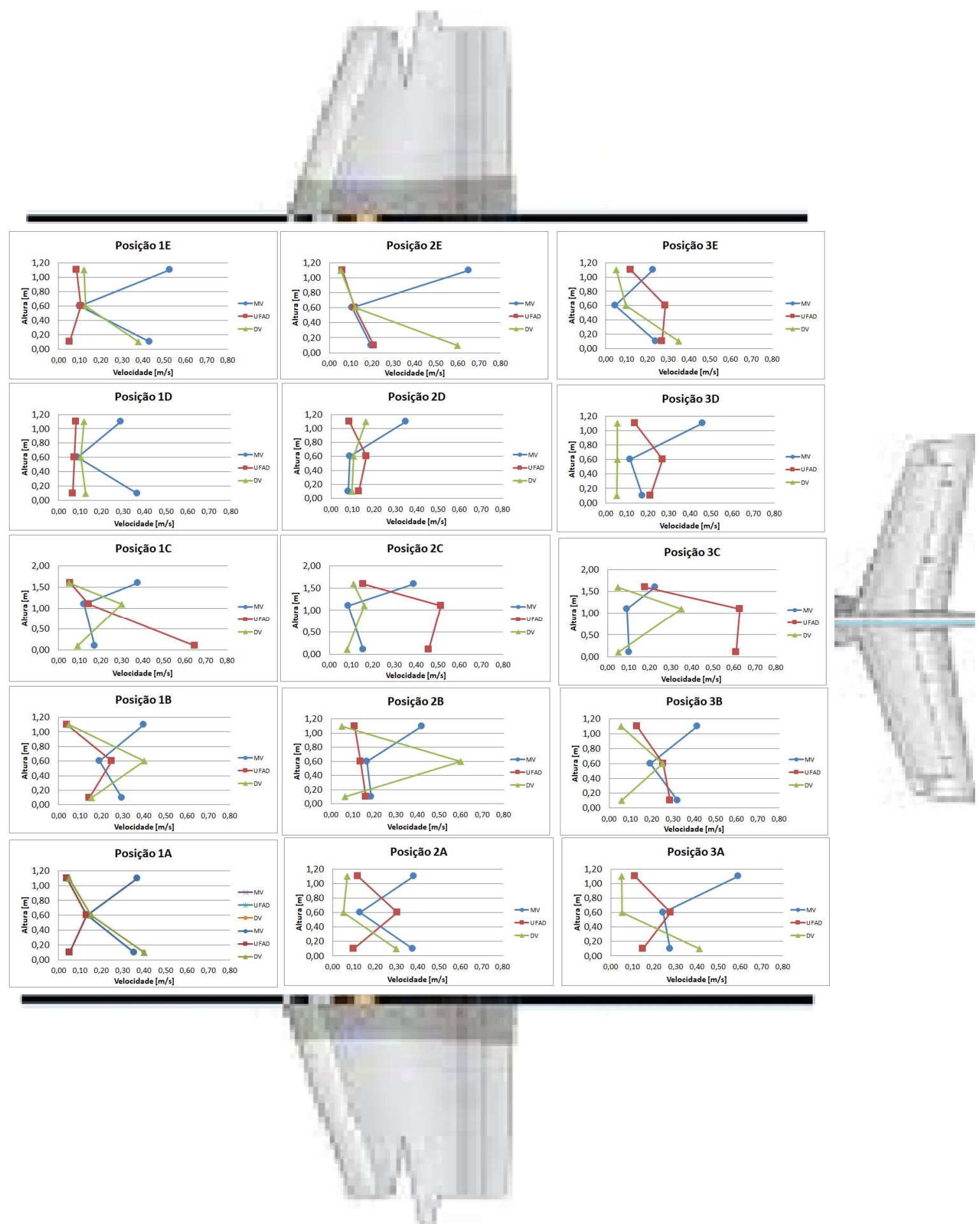

Figura 6.1. Perfis de velocidade do ar para temperatura de insuflamento de $18^{\circ} \mathrm{C}$. 


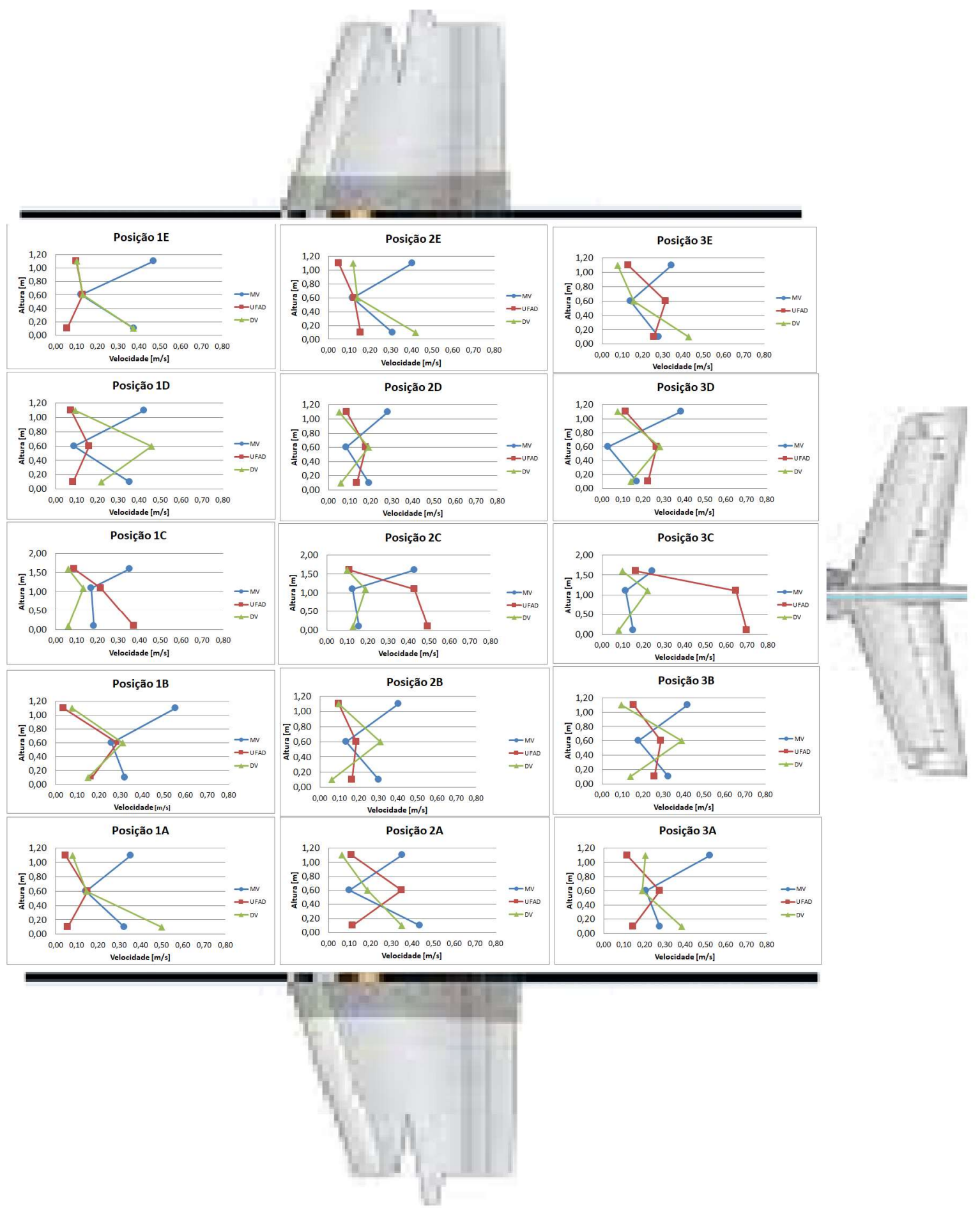

Figura 6.2. Perfis de velocidade do ar para temperatura de insuflamento de $22^{\circ} \mathrm{C}$. 
$\mathrm{Na}$ análise das Figuras 6.1 e 6.2 verifica-se, na região dos assentos, que:

a) os perfis de velocidade do ar para o sistema MV apresentam velocidades maiores na região da cabeça, próxima à área de insuflamento, com redução na região das coxas, mãos e antebraços, aumentando novamente na região dos pés.

b) O sistema UFAD, apresenta perfis bem definidos de baixa velocidade do ar na região dos pés, aumento da velocidade na região das coxas, mãos e antebraços, com redução na região da cabeça.

c) O sistema DV apresenta velocidades maiores na região dos pés para assentos ao lado da fuselagem e um aumento da velocidade do ar na região das coxas, mãos e antebraços para assentos ao lado do corredor.

É importante destacar que comportamento similar da velocidade do ar (Figs. 6.1 e 6.2), para o sistema MV e UFAD, também foi verificado no trabalho de simulação numérica de Zhang; Chen (2007), discutido no item 4.3, Figura 4.9. E também no sistema DV, no trabalho experimental desenvolvido por Zhang et al. (2017), discutido no item 3.3.

Adicionalmente, verifica-se da análise das Figuras 6.1 e 6.2, que a temperatura do ar insuflado na cabine, de $18{ }^{\circ} \mathrm{C}$ para $22^{\circ} \mathrm{C}$, tem influência nos perfis de velocidade do ar. Isto ocorre devido ao menor efeito da pluma térmica em temperaturas mais elevadas do ar na cabine (menor diferença entre a temperatura superficial dos passageiros e a temperatura do ar na cabine). Este fato tem consequência na quantidade de partículas na região de respiração, conforme será discutido no item 6.4 .

\subsection{Perfis de temperaturas do ar}

Nas Figuras 6.3 e 6.4 são apresentados os perfis de temperatura do ar para os três sistemas de ventilação e distribuição do ar testados (MV, UFAD e DV) nas temperaturas de insuflamento do ar na cabine de 18 e $22^{\circ} \mathrm{C}$, respectivamente.

Os valores das medições de temperaturas do ar, juntamente com as incertezas de medição, em cada situação analisada, são apresentados nas Tabelas A.1 a A.6 do Apêndice $A$. 


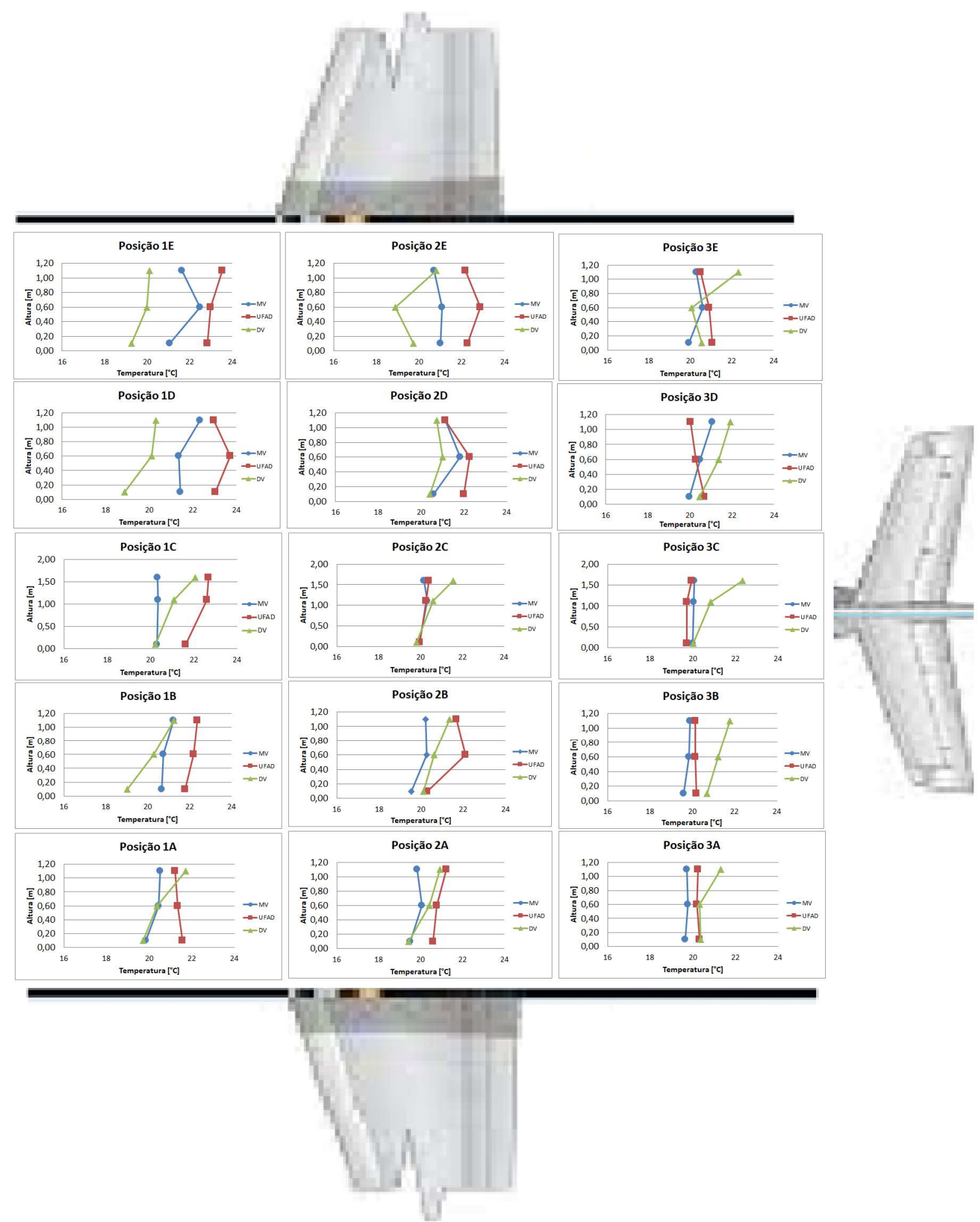

Figura 6.3. Perfis de temperatura do ar para temperatura de insuflamento de $18^{\circ} \mathrm{C}$. 


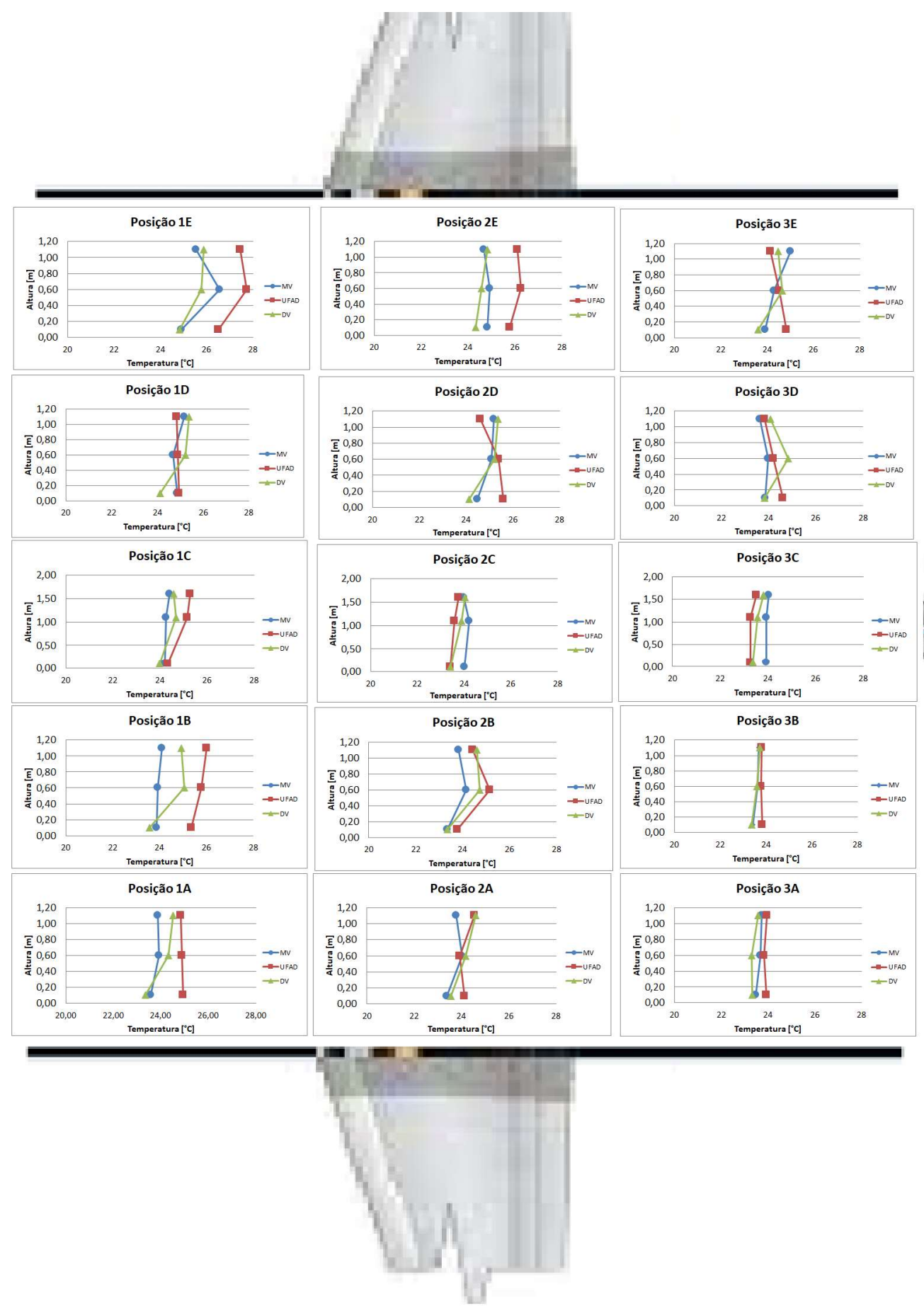

Figura 6.4. Perfis de temperatura do ar para temperatura de insuflamento de $22^{\circ} \mathrm{C}$.

$\mathrm{Na}$ análise das Figuras 6.3 e 6.4 verifica-se a ocorrência de diferenças pequenas de temperatura do ar com a altura na cabine para os três sistemas de ventilação e distribuição de ar testados, nas duas condições de temperatura do ar insuflado.

Para a temperatura de insuflamento de $18^{\circ} \mathrm{C}$ foram encontrados valores máximos de diferença de temperatura entre os pés e a cabeça de $1,4^{\circ} \mathrm{C}$ para o 
sistema de mistura $\mathrm{MV}$, de $1,8^{\circ} \mathrm{C}$ para o sistema de ventilação pelo piso UFAD e de $1,6{ }^{\circ} \mathrm{C}$ para o sistema de ventilação por deslocamento DV. Para a temperatura de insuflamento de $22^{\circ} \mathrm{C}$ foram encontrados valores máximos de $1,7{ }^{\circ} \mathrm{C}$ para $\mathrm{O}$ sistema de mistura $\mathrm{MV}$, de $1,4{ }^{\circ} \mathrm{C}$ para o sistema de ventilação pelo piso UFAD e de $1,5{ }^{\circ} \mathrm{C}$ para o sistema de ventilação por deslocamento DV.

\subsection{Percentagem de pessoas insatisfeitas devido a correntes de ar}

Com os dados de velocidade e de temperatura do ar determinou-se a percentagem de pessoas insatisfeitas, PD, devido a correntes de ar, o Draught Rate - DR. Para pessoas sentadas, as alturas correspondentes foram 0,10 m, 0,60 m e $1,10 \mathrm{~m}$. Para pessoas em pé, as alturas foram $0,10 \mathrm{~m}, 1,10 \mathrm{~m} \mathrm{e1,60} \mathrm{m.}$

Para calcular o risco de correntes de ar, foram utilizados os dados coletados dos perfis de velocidade e temperatura do ar para cada posição. A partir dos dados de velocidade do ar foi possível determinar a intensidade de turbulência para cada situação.

Para exemplificar a determinação da intensidade de turbulência, $T_{u}$, na Figura 6.5 apresenta-se o gráfico da velocidade do ar em função do tempo, para a posição 2B do sistema de ventilação e distribuição de ar UFAD, na altura de 0,60 m. Esse mesmo tipo de gráfico foi gerado para todas as posições e são apresentados em tabela. Nas Tabelas A.1 a A.6 do Apêndice A apresenta-se os valores calculados.

No gráfico da Figura 6.5 apresenta-se uma média da velocidade do ar igual a $0,13 \mathrm{~m} / \mathrm{s}$ e desvio padrão igual a $0,05 \mathrm{~m} / \mathrm{s}$. A partir desses dados foi possível determinar a intensidade de turbulência por meio da Equação 3.3, resultando em $38 \%$ de intensidade de turbulência.

$$
T_{u}=\frac{\sigma_{V a r}}{V_{a r}} \cdot 100
$$




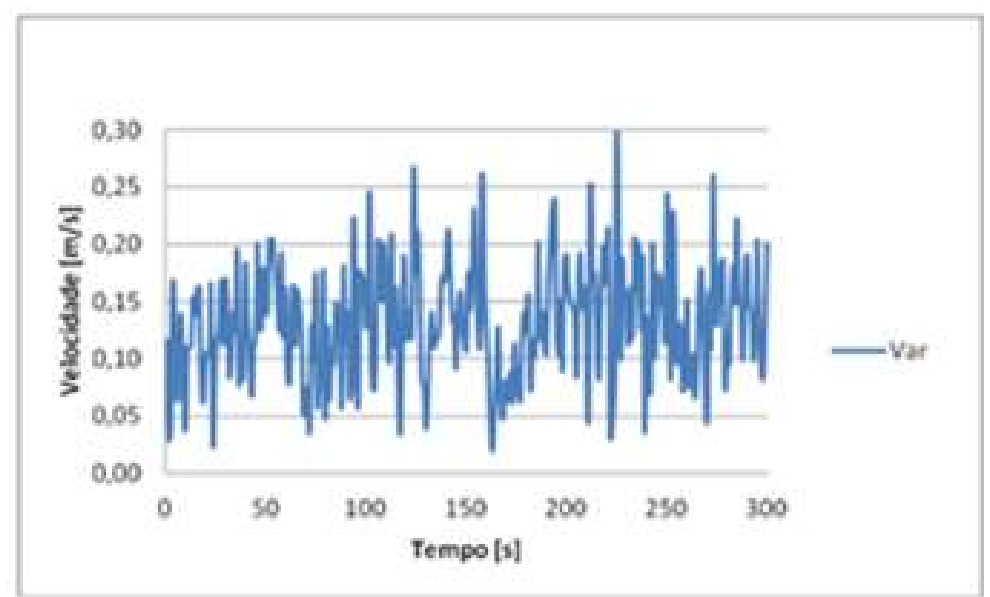

Figura 6.5. Velocidade do ar em função do tempo.

Com os valores de intensidade de turbulência para cada posição e altura, foi possível calcular o percentual de pessoas insatisfeitas devido a correntes de ar, utilizando a Equação 3.2.

$$
\mathrm{PD}=\mathrm{DR}=\left[\left(34-T_{a}\right)\left(V_{a}-0,05\right)^{0,62}\right] \cdot\left(0,37 \cdot V_{a} \cdot T_{u}+3,14\right)
$$

Os resultados para cada sistema de ventilação e distribuição de ar são apresentados nas Figuras 6.6 a 6.8 para temperatura de insuflamento igual a $18{ }^{\circ} \mathrm{C}$ e nas Figuras 6.9 a 6.11 para temperatura de insuflamento igual a $22{ }^{\circ} \mathrm{C}$.

Nas Tabelas A.1 a A.6 do Apêndice A apresenta-se os valores calculados do percentual de pessoas insatisfeitas devido a correntes de ar, PD.

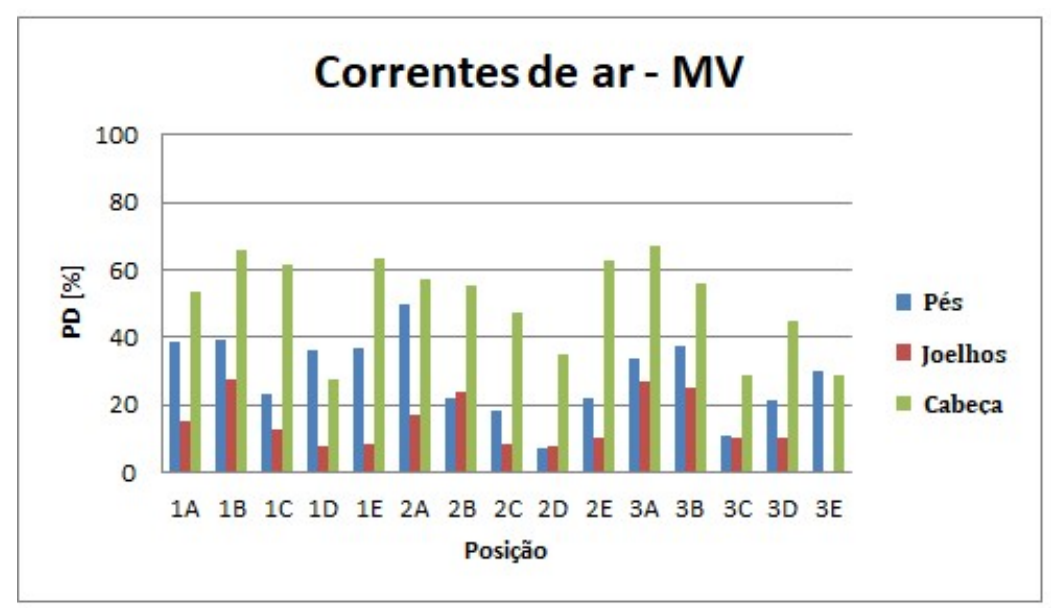

Figura 6.6. Percentual de insatisfeitos devido a correntes de ar para o sistema MV, com temperatura de insuflamento do ar de $18^{\circ} \mathrm{C}$. 


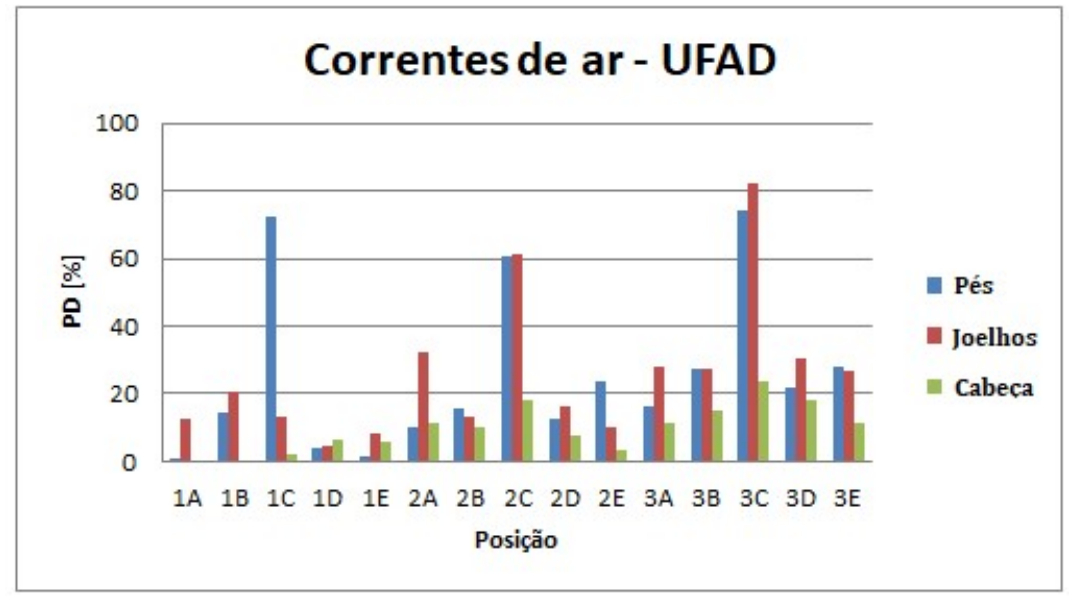

Figura 6.7. Percentual de insatisfeitos devido a correntes de ar para o sistema UFAD, com temperatura de insuflamento do ar de $18^{\circ} \mathrm{C}$.

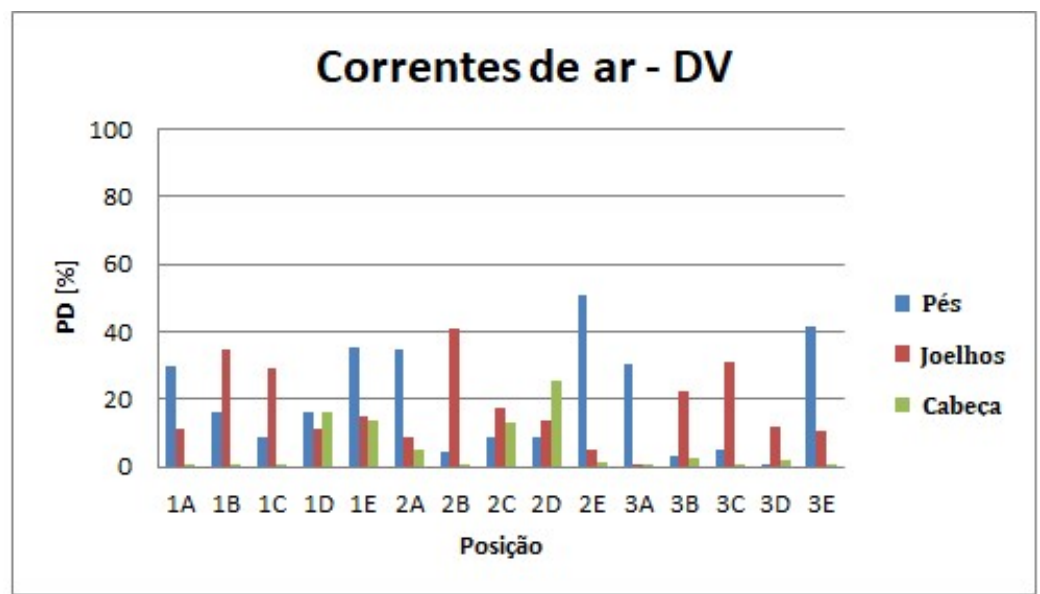

Figura 6.8. Percentual de insatisfeitos devido a correntes de ar para o sistema DV, com temperatura de insuflamento do ar de $18{ }^{\circ} \mathrm{C}$

De acordo com os resultados das Figuras 6.6 a 6.8 podem ser feitas as seguintes considerações sobre o risco de correntes de ar, PD:

- A região mais crítica para o sistema MV é a região superior, região da cabeça, pescoço e ombros, pois o percentual de pessoas insatisfeitas devido a correntes de ar, PD, foi superior a 27,82 \% atingindo valores de até $63,02 \%$. Para a região inferior, região dos pés, o percentual também ficou acima dos $20 \%$, atingindo valores de até 49,87\%. Na região central, altura de $0,60 \mathrm{~m}$ (joelhos), o percentual é aceitável, pois na maioria das posições o valor ficou abaixo dos $20 \%$, devido aos menores valores de velocidade do ar nesta região.

- O percentual de pessoas insatisfeitas devido a correntes de ar para o sistema UFAD, ficaram bem abaixo dos valores para o sistema MV; 
além disso, na região dos assentos, os valores de PD são inferiores a 20 \%; atendendo ao preconizado pelas normas ASHRAE 55 (2017) e ISO 7730 (2005) para ambientes climatizados. A exceção fica por conta dos valores de PD no corredor, região de passagem e de insuflamento do ar, com valores de PD de até $80 \%$

- De forma geral o sistema DV apresentou um percentual de pessoas insatisfeitas satisfatório, não se verificando índices maiores que 45\%. A situação crítica para o sistema DV ocorre para assentos ao lado da fuselagem, onde justamente estão posicionados os difusores de ar. Observa-se que os assentos 1A, 1E, 2A, 2E, 3A e 3E, assentos ao lado da fuselagem, são os responsáveis pelos maiores percentuais de pessoas insatisfeitas nesse sistema. Verificou-se que 10 assentos apresentam valores abaixo dos $20 \%$ preconizado pelas normas ASHRAE 55 (2017) e ISO 7730 (2005), com exceção da região dos pés.

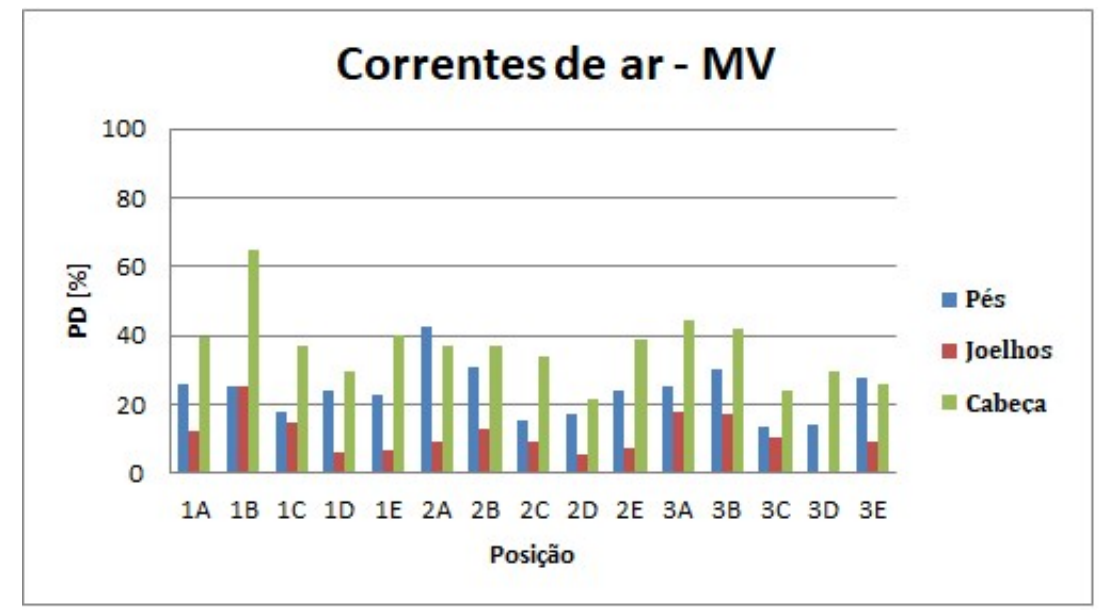

Figura 6.9. Percentual de insatisfeitos devido a correntes de ar para o sistema MV, com temperatura de insuflamento do ar de $22{ }^{\circ} \mathrm{C}$. 


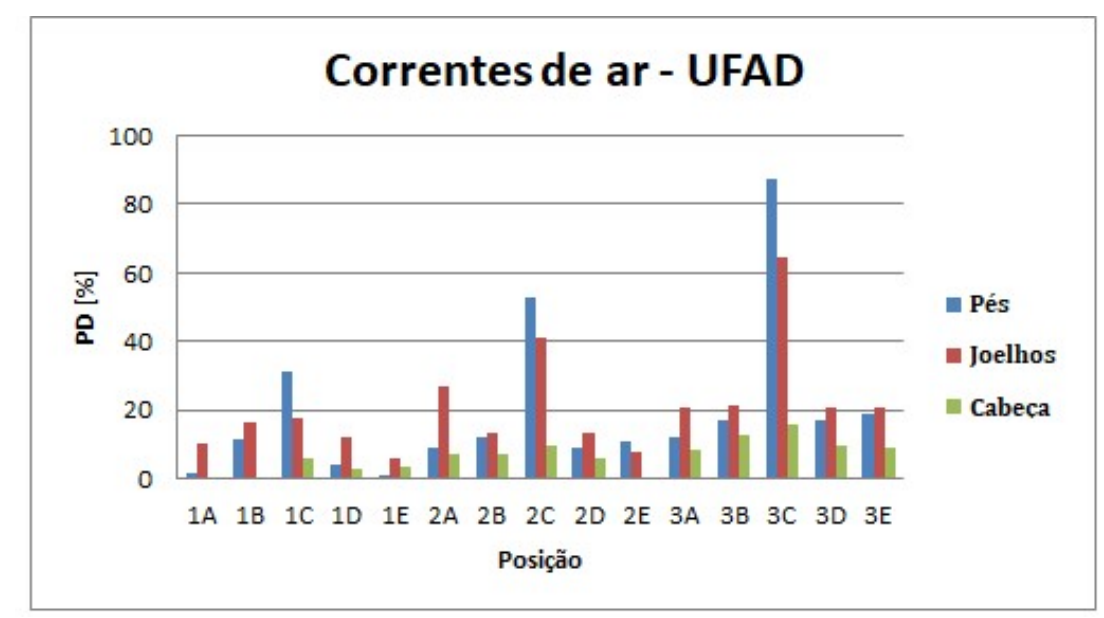

Figura 6.10. Percentual de insatisfeitos devido a correntes de ar para o sistema UFAD, com temperatura de insuflamento do ar de $22^{\circ} \mathrm{C}$.

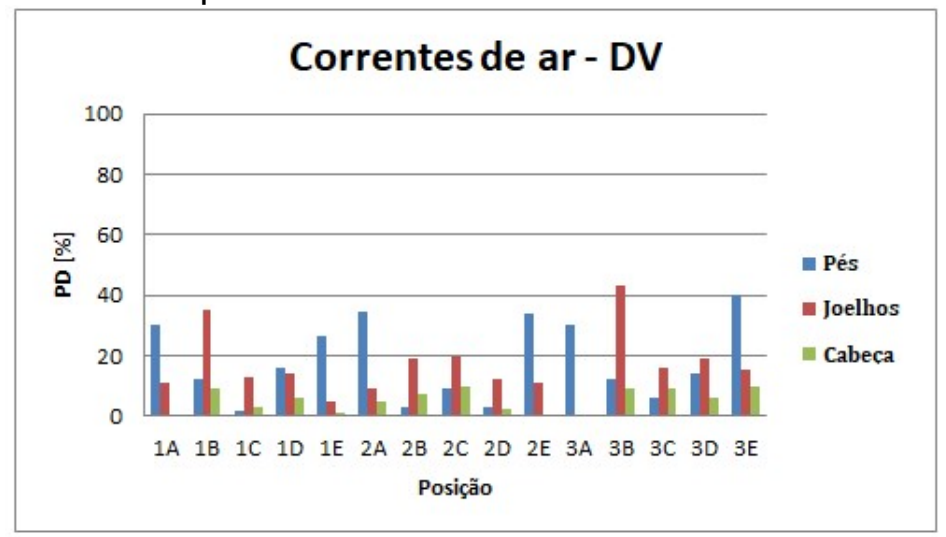

Figura 6.11. Percentual de insatisfeitos devido a correntes de ar para o sistema DV, com temperatura de insuflamento do ar de $22^{\circ} \mathrm{C}$.

De modo análogo, da análise das Figuras 6.9 a 6.11 verifica-se que:

- No sistema MV o percentual de pessoas insatisfeitas, PD, na região da cabeça, em sua maioria, ficou em torno de $40 \%$. Novamente, por ser a região mais próxima do insuflamento de ar esta é a região mais crítica para o sistema MV. A região dos pés também apresentou valores acima dos $20 \%$, para a maioria das posições, atingindo valores um pouco acima de $40 \%$ Nesse sistema, a região dos joelhos apresentou um percentual aceitável, inferior aos $20 \%$.

- No sistema UFAD os valores de PD na região dos assentos também são inferiores a $20 \%$; atendendo ao preconizado pelas normas ASHRAE 55 (2017) e ISO 7730 (2005) para ambientes climatizados. De modo similar ao verificado na temperatura de insuflamento de 18 ${ }^{\circ} \mathrm{C}$, a exceção fica por conta dos valores de PD no corredor, região de 
insuflamento do ar, contudo, os valores de PD baixaram para valores máximos abaixo de $40 \%$ na região dos pés, parte mais crítica.

- O sistema DV apresentou um percentual de insatisfeitos superior a $20 \%$ somente na região dos pés para os assentos ao lado da fuselagem. Na região dos joelhos o percentual de pessoas insatisfeitas ficou abaixo dos $20 \%$, com exceção de quatro assentos (1B, 1D, 3B e 3D). Na região da cabeça todos os valores de PD ficaram bem abaixo de $20 \%$.

\subsubsection{Análise do desconforto térmico local}

\subsubsection{Análise da estratificação de temperaturas}

Embora a estratificação da temperatura seja um fenômeno associado ao insuflamento pelo piso e ao sistema de ventilação por deslocamento, a sua influência não foi significativa nos três sistemas testados (MV, UFAD e DV). As diferenças de temperatura entre os pés e a cabeça ficaram entre 1,4 e $1,8{ }^{\circ} \mathrm{C}$, considerando, os três sistemas de ventilação e distribuição de ar analisados e as temperaturas de insuflamento de 18 e $22^{\circ} \mathrm{C}$.

Atendem, portanto, ao preconizado nas normas ASHRAE 55 (2017) e ISO 7730 (2005), com valores máximos inferiores a $3{ }^{\circ} \mathrm{C}$ entre a região dos pés e a região da cabeça nos três sistemas analisados, com diferenças máximas entre $1,4^{\circ} \mathrm{C}$ e $1,8^{\circ} \mathrm{C}$.

\subsubsection{Análise do desconforto devido a correntes de ar}

Ao se comparar os resultados das Figuras 6.6 a 6.11 , considerando as duas temperaturas de insuflamento de ar, de $18{ }^{\circ} \mathrm{C}$ e $22^{\circ} \mathrm{C}$, observa-se que a temperatura de insuflamento de ar a $22{ }^{\circ} \mathrm{C}$ causa menor desconforto com relação a correntes de ar; o que é esperado, devido à menor diferença de temperatura entre a pele em condição de conforto térmico para atividade sedentária ou leve $\left(34^{\circ} \mathrm{C}\right)$ e o ar (Equação 3.2).

Verifica-se também que o sistema de distribuição de ar UFAD apresentou os melhores resultados, com menores percentuais de pessoas insatisfeitas devido a correntes de ar nas posições dos assentos. As posições críticas medidas para esse 
sistema foram as posições do corredor. Região onde ficam posicionados os difusores para insuflamento do ar.

A mudança de temperatura de insuflamento de $18^{\circ} \mathrm{C}$ para $22^{\circ} \mathrm{C}$ faz com que o percentual de desconforto pelas correntes de ar diminuísse; o que aconteceu nos três sistemas testados.

Nas Figuras 6.12a e 6.12b, visualiza-se o que acontece no sistema UFAD, com relação ao percentual de pessoas insatisfeitas devido a correntes de ar na região mais crítica, os pés, para as duas temperaturas de insuflamento do ar, para passageiros sentados ao lado da fuselagem e para passageiros sentados ao lado do corredor.

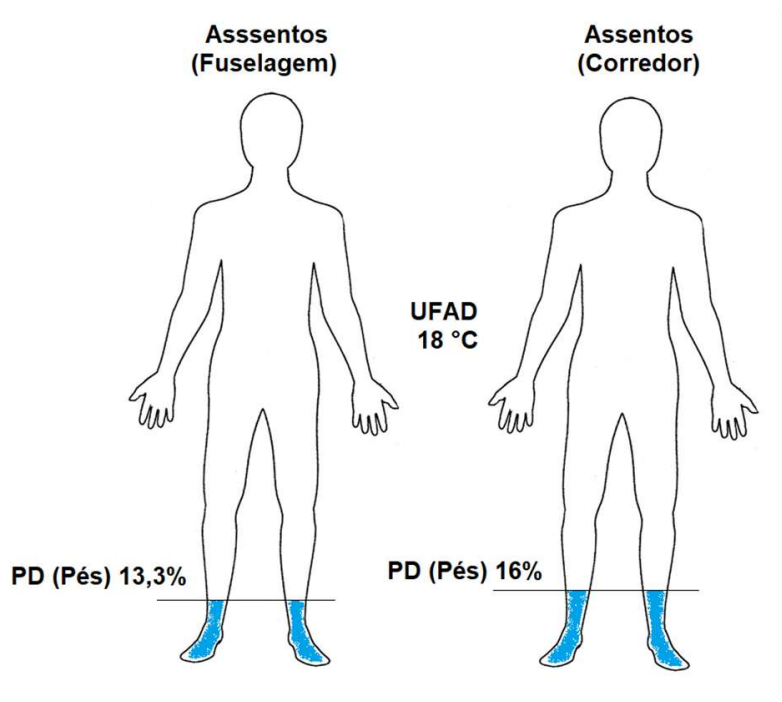

a)

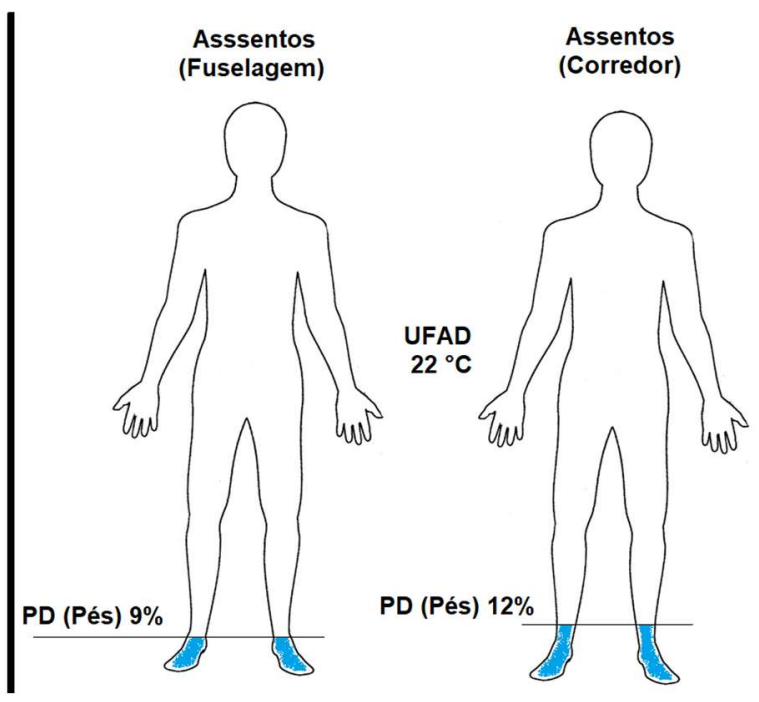

b)

Figura 6.12. PD (\%) - Sistema UFAD: a) temperatura de insuflamento do ar de insuflamento a $18{ }^{\circ} \mathrm{C}$; b) temperatura do ar de insuflamento a $22^{\circ} \mathrm{C}$

Na Figura 6.12 verifica-se a redução do percentual de insatisfeitos à medida que a temperatura de insuflamento aumenta, de 13,3\% para $9 \%$, para passageiros ao lado da fuselagem e a redução de $16 \%$ para $12 \%$, para passageiros ao lado do corredor.

Ainda é possível verificar que passageiros sentados ao lado da fuselagem possuem percentual de desconforto menor quando comparados a passageiros que estão sentados ao lado do corredor, para temperatura de $18^{\circ} \mathrm{C}$, onde se observam valores de $13,3 \%$ e $16 \%$, respectivamente, para passageiros sentados ao lado da fuselagem e para passageiros sentados ao lado do corredor. 
Embora com resultados não tão bons quanto o sistema UFAD, o sistema DV apresentou resultados promissores com relação ao percentual de insatisfeitos, como mostrado nas Figuras 6.13a e 6.13b.

Isso ocorre porque o sistema DV, diferentemente do sistema UFAD, apresenta regiões de maior velocidade do ar para passageiros ao lado da fuselagem, com valores iguais a $37,2 \%$ e $32,0 \%$ para a região dos pés. Para passageiros sentados ao lado do corredor os índices foram muito bons variando de 7,2\% a 10,0\%. Verifica-se que para este sistema também o aumento de temperatura influenciou na diminuição significativa do percentual de pessoas insatisfeitos devido a correntes de ar.

O sistema de ventilação MV apresentou valores mais elevados no percentual de pessoas insatisfeitas a correntes de ar, como mostrado nas Figuras 6.14a e 6.14b. Diferentemente de outros sistemas, o sistema MV, apresenta a região dos pés e também a região da cabeça, como regiões críticas. Isso devido à posição das grelhas de exaustão e de seus difusores de insuflamento do ar na cabine.

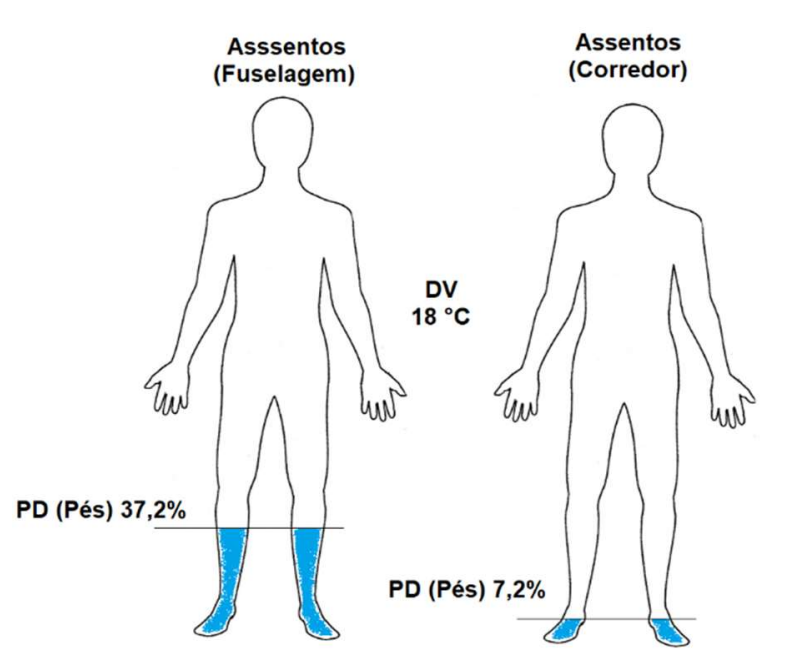

a)

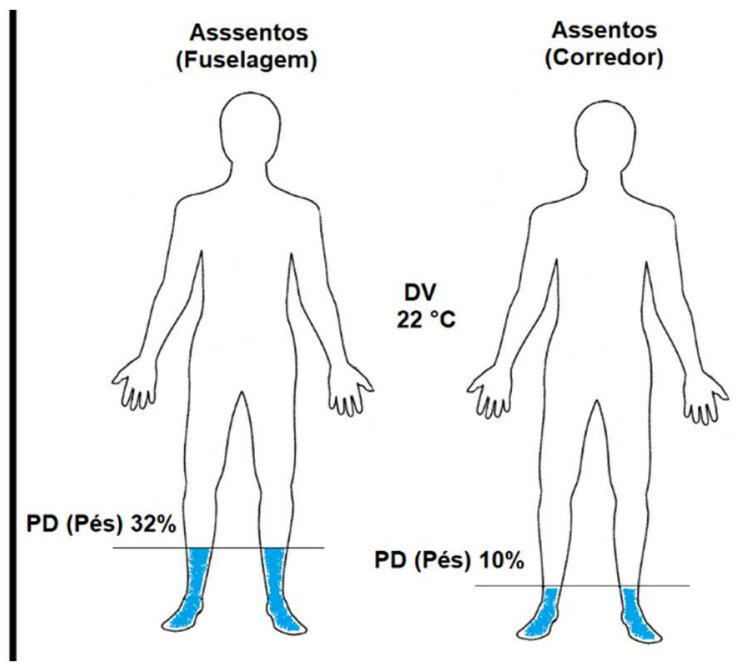

b)

Figura 6.13. PD (\%) - Sistema DV: a) temperatura de insuflamento do ar de insuflamento a $18{ }^{\circ} \mathrm{C}$; b) temperatura do ar de insuflamento a $22^{\circ} \mathrm{C}$

Na Figura 6.14 mostra-se que para temperatura do ar de $18^{\circ} \mathrm{C}$ os percentuais de insatisfação para passageiros sentados ao lado da fuselagem e para passageiros sentados ao lado do corredor foram, respectivamente, de $58,6 \%$ na região da cabeça e $35,1 \%$ na região dos pés, e $47,3 \%$ da região da cabeça e $27,1 \%$ na região dos pés. Para temperatura do ar de $22{ }^{\circ} \mathrm{C}$ os percentuais de insatisfação para passageiros sentados ao lado da fuselagem e para passageiros sentados ao 
lado do corredor foram, respectivamente, de 37,5\% na região da cabeça e 27,8\% na região dos pés, e $36 \%$ da região da cabeça e $23,5 \%$ na região dos pés. Ou seja, passageiros sentados ao lado da fuselagem também apresentam percentual de insatisfação maior quando comparado a passageiros sentados ao lado do corredor.

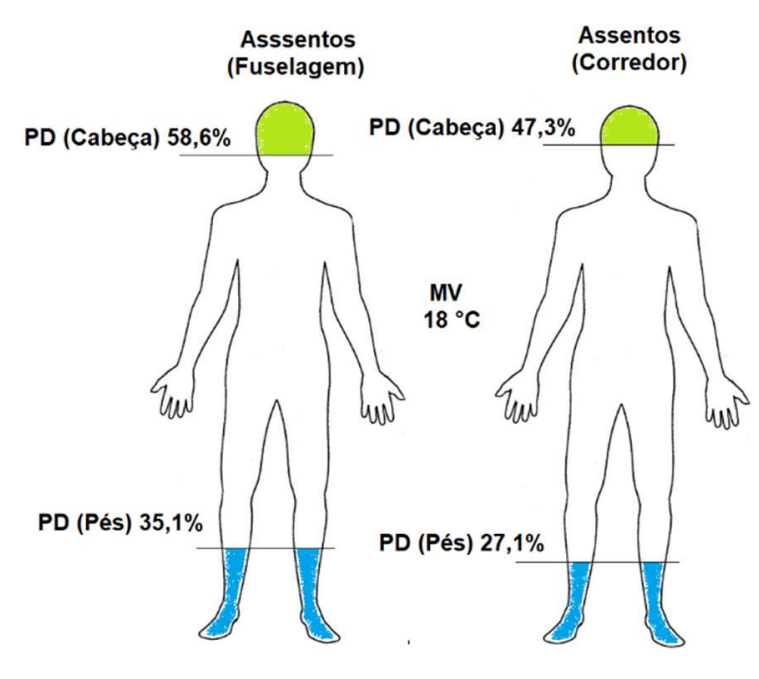

a)

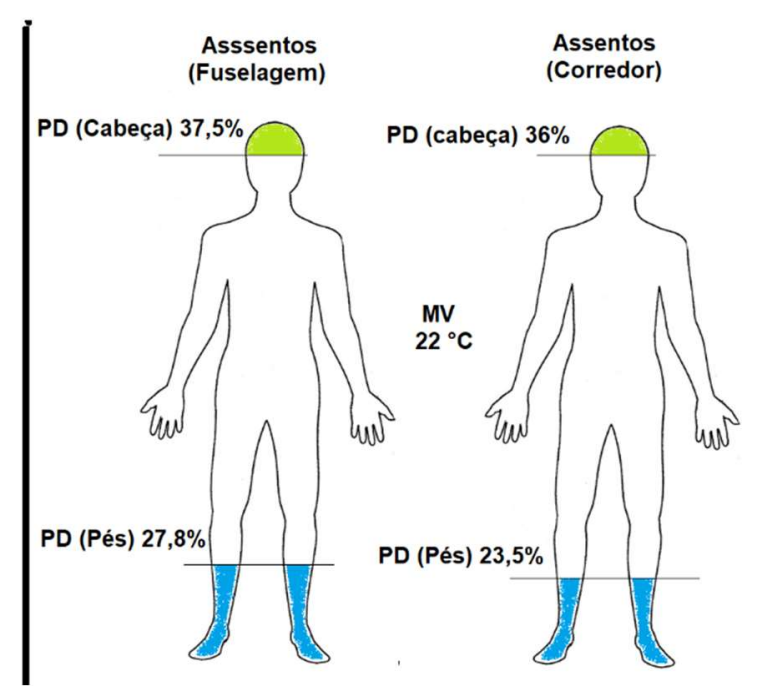

b)

Figura 6.14. PD (\%) - Sistema MV: a) temperatura de insuflamento do ar de insuflamento a $18{ }^{\circ} \mathrm{C}$; b) temperatura do ar de insuflamento a $22^{\circ} \mathrm{C}$

Conforme destacado no início deste subitem, o incremento da temperatura do ar de insuflamento faz com que diminua os percentuais de pessoas insatisfeitas a corrente de ar em todos os sistemas de ventilação, devido à menor diferença de temperatura entre a pele do passageiro e o ar, Eq.3.2.

\subsection{Concentração, Dispersão e Remoção de Partículas na Região de Respiração}

Nas Figuras 6.15 a 6.18 são apresentados os resultados de concentração de partículas para os três sistemas de ventilação testados (MV, UFAD e DV). Nas Figuras 6.15 e 6.16 são apresentados os resultados para temperatura de 
insuflamento do ar de $18{ }^{\circ} \mathrm{C}$, considerando injeção/geração de partículas nos assentos $3 \mathrm{~A}$ e $3 \mathrm{~B}$, respectivamente.

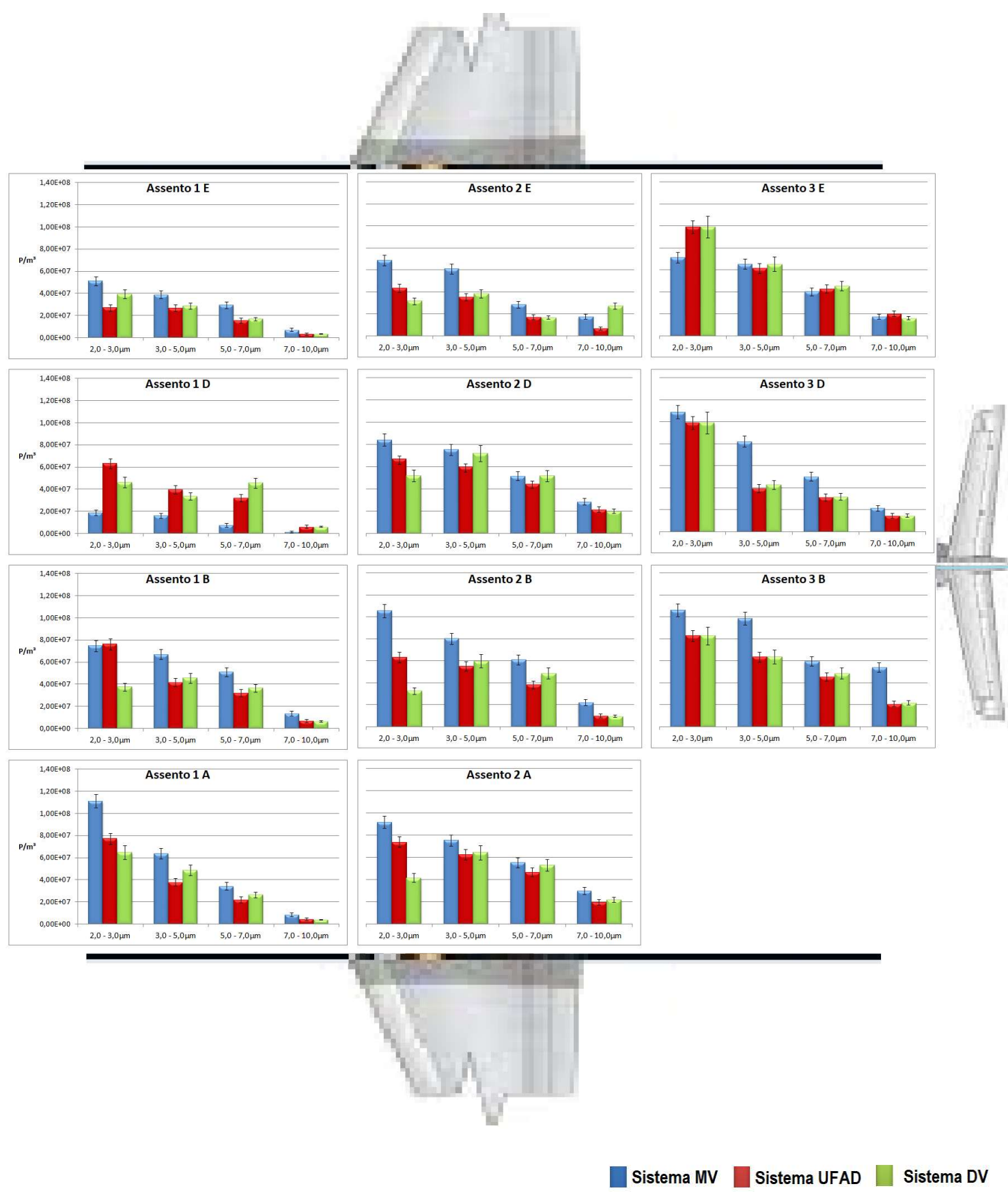

Figura 6.15. Concentração de partículas para insuflamento $18^{\circ} \mathrm{C}$, injeção de partículas pelo assento $3 \mathrm{~A}$. 


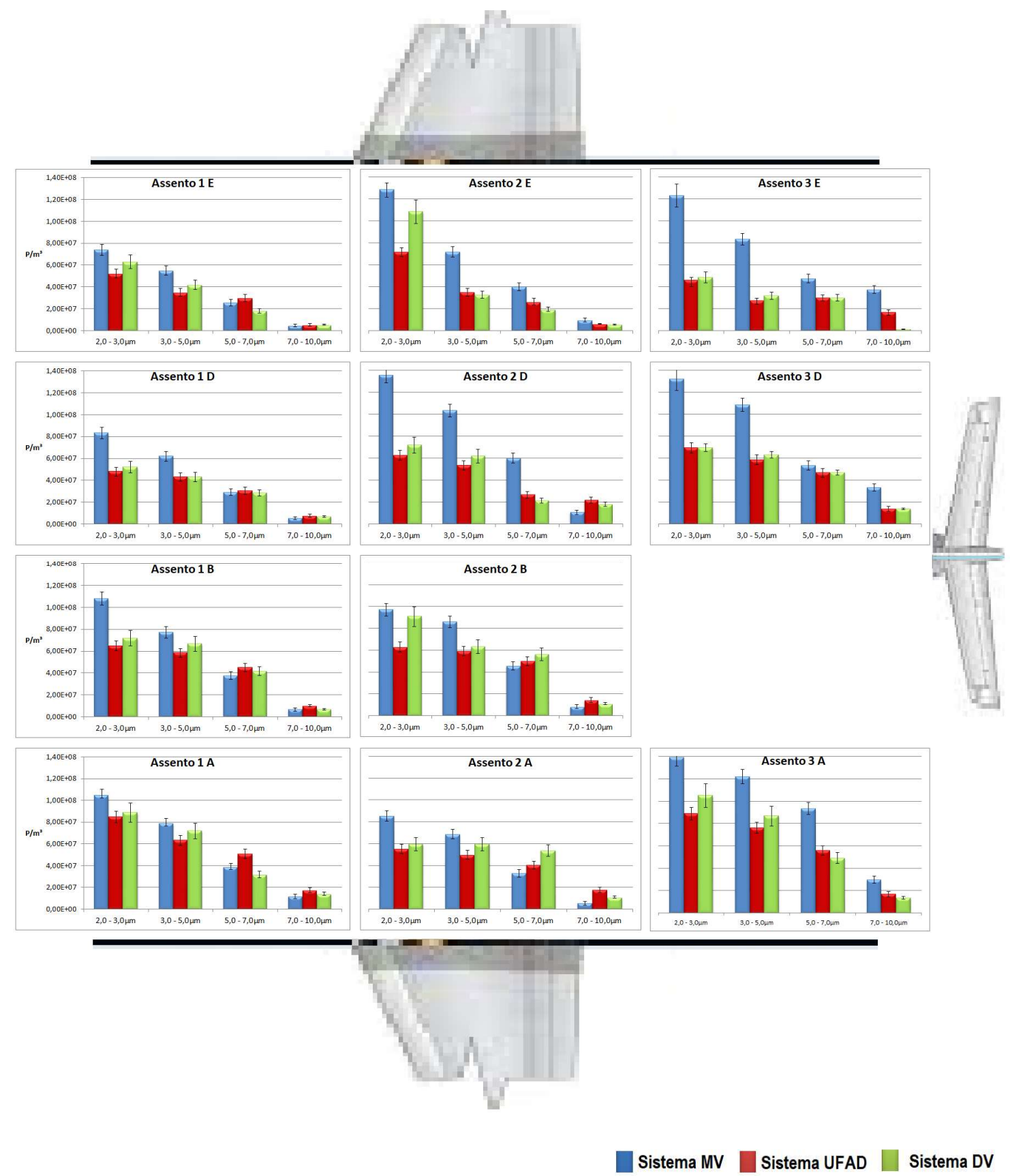

Figura 6.16 Concentração de partículas para insuflamento $18^{\circ} \mathrm{C}$, injeção de partículas pelo assento 3B.

Nas Figuras 6.17 e 6.18 são apresentados os resultados para temperatura de insuflamento do ar de $22^{\circ} \mathrm{C}$, também considerando injeção/geração de partículas nos assentos $3 \mathrm{~A}$ e $3 \mathrm{~B}$, respectivamente. 


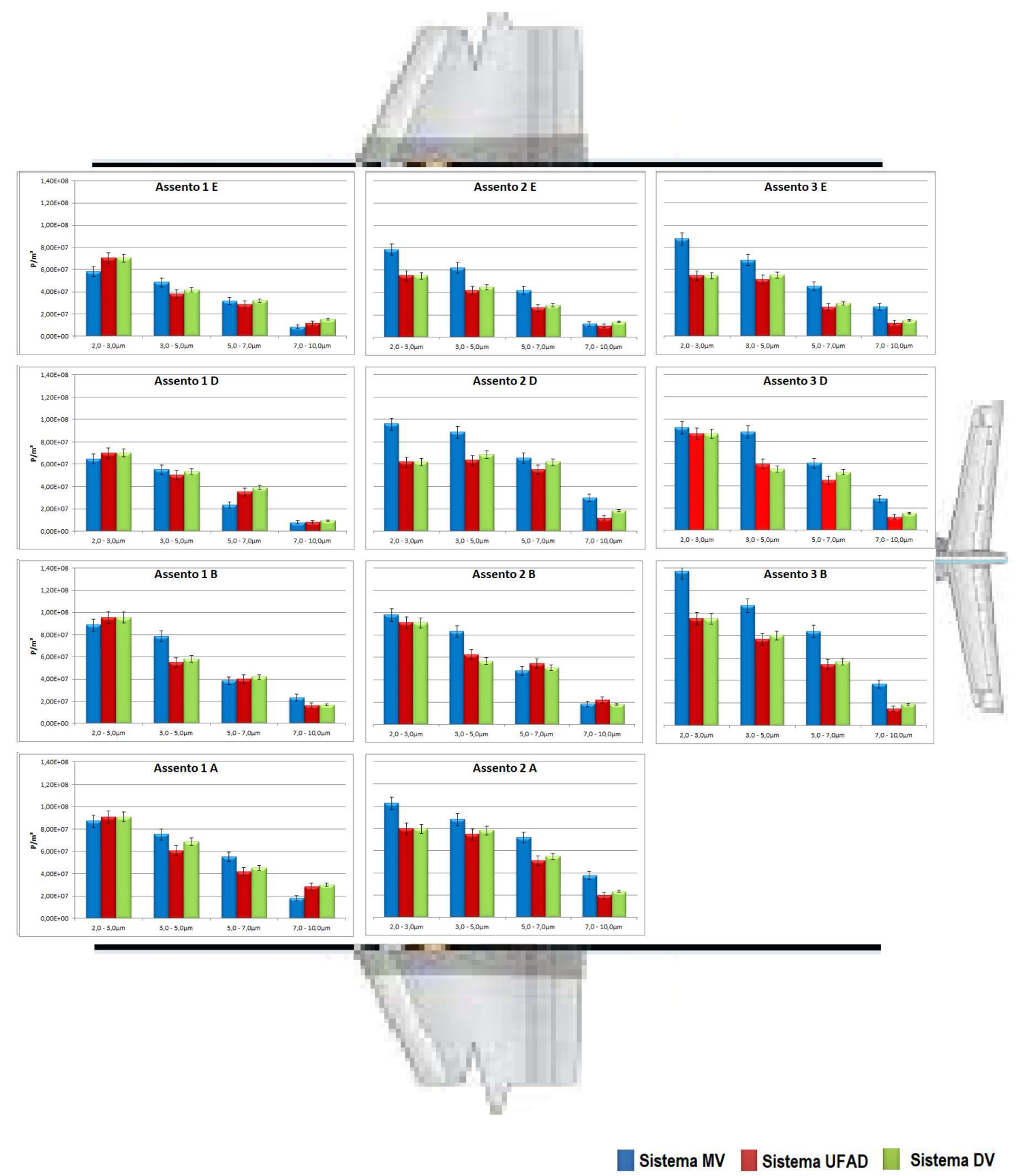

Figura 6.17 Concentração de partículas para insuflamento $22^{\circ} \mathrm{C}$, injeção de partículas pelo assento $3 \mathrm{~A}$.

Os valores das medições de concentração de partículas, juntamente com as incertezas de medição, em cada situação analisada, são apresentados nas Tabelas B.1 a B.12 do Apêndice B. 


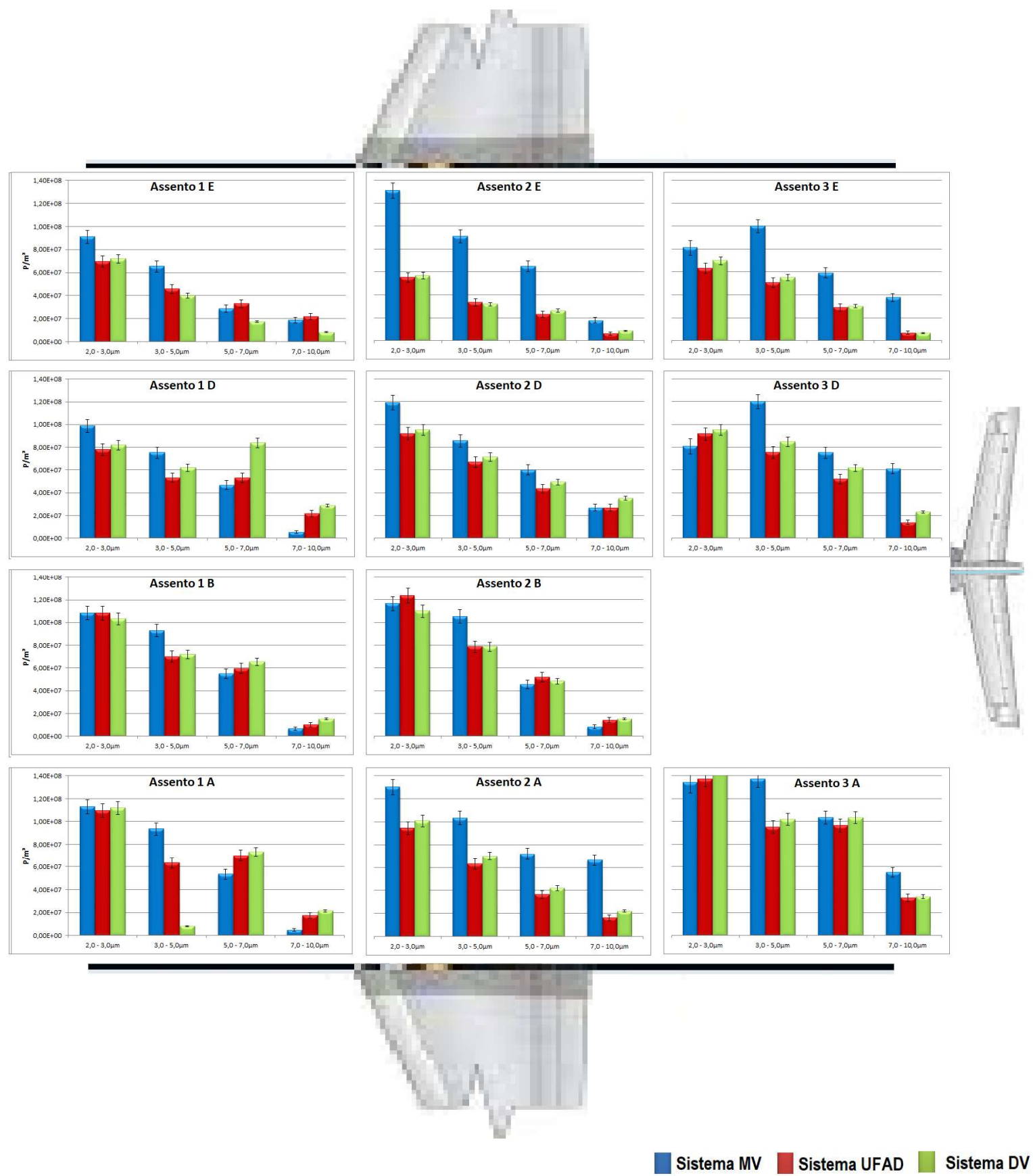

Figura 6.18 Concentração de partículas para insuflamento $22^{\circ} \mathrm{C}$, injeção de partículas pelo assento 3B.

\subsubsection{Análise da concentração e dispersão de partículas com relação à temperatura do ar insuflado}

Da análise das Figuras 6.15 a 6.18 verifica-se que, de uma maneira geral, há um aumento na concentração de partículas na zona de respiração com o aumento da temperatura de insuflamento do ar de $18{ }^{\circ} \mathrm{C}$ para $22{ }^{\circ} \mathrm{C}$, principalmente nos 
sistemas de insuflamento pelo piso e de deslocamento, UFAD e DV, respectivamente.

Para auxiliar na visualização dos resultados das Figuras 6.15 a 6.18, nas Figuras 6.19 e 6.20 são detalhados os resultados de concentração das partículas ao longo da cabine para as faixas de concentração de maior interesse no presente trabalho, de 2,0 a 3,0 $\mu \mathrm{m}$ e de 3,0 a $5,0 \mu \mathrm{m}^{7}$, respectivamente, com injeção de partículas realizada pelo assento $3 \mathrm{~A}$.

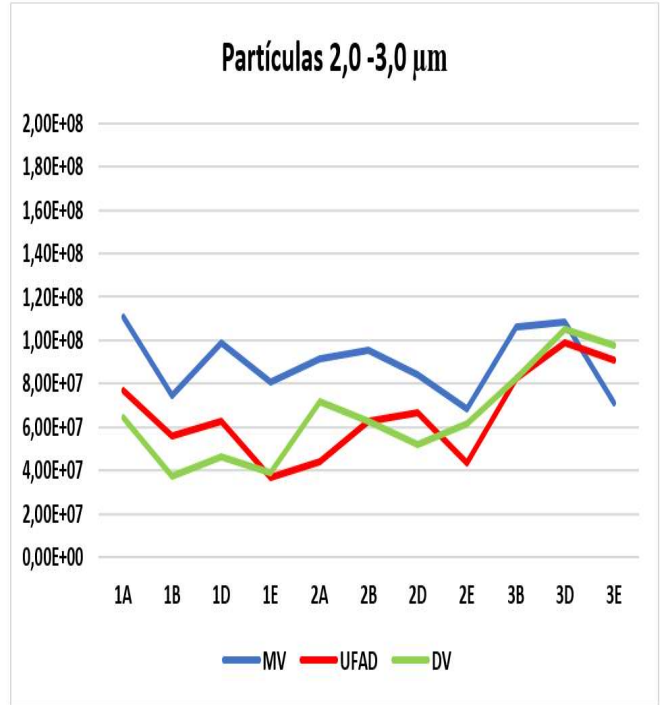

a)

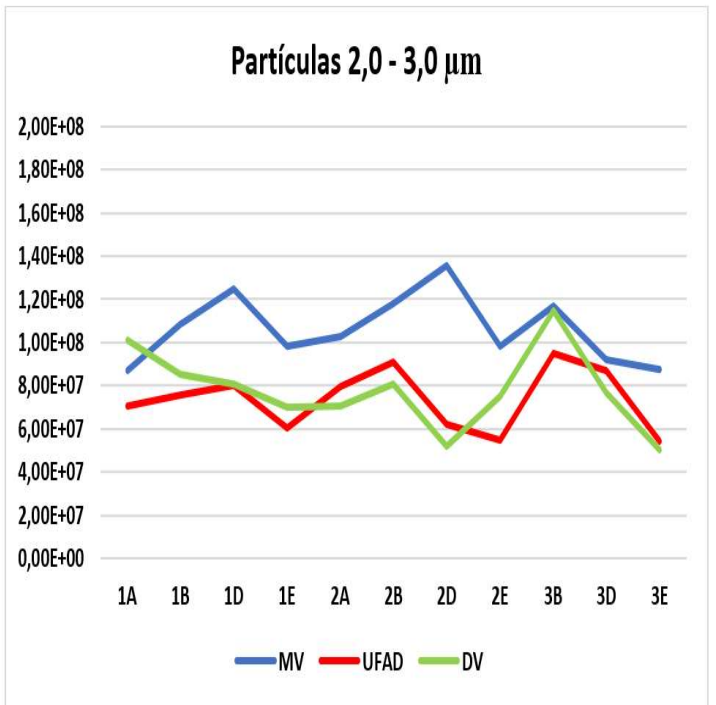

b)

Figura 6.19 Concentração de partículas entre 2,0 e 3,0 $\mu \mathrm{m}$ ao longo da cabine, com injeção de partículas pelo assento $3 \mathrm{~A}$;

a) temperatura de insuflamento: $18^{\circ} \mathrm{C}$; b) temperatura de insuflamento: $22^{\circ} \mathrm{C}$.

Em complemento às Figuras 6.19 e 6.20 são apresentadas as Tabelas $6.1 \mathrm{e}$ 6.2 , onde constam a média da concentração de partículas na cabine na região de respiração, o desvio padrão e o coeficiente de variação. ${ }^{8}$

\footnotetext{
${ }^{7}$ As faixas de tamanhos de partículas entre 2 a $3 \mu \mathrm{m}$ e 3 a $5 \mu \mathrm{m}$ representam as maiores concentrações de partículas nas atividades expiratórias, Fig. 4.3 (DUGUID, 1946). Adicionalmente, partículas de 2 a $3 \mu \mathrm{m}$, por serem mais finas e poderem rapidamente se alojar no pulmão, são de especial interesse (CHAO; WAN; SZE, 2008; WAN et al., 2009)

${ }^{8}$ O coeficiente de variação é uma medida padronizada de dispersão de uma distribuição de probabilidade ou de uma distribuição de frequências. É expresso como uma porcentagem, sendo definido como a razão do desvio padrão pela média.
} 


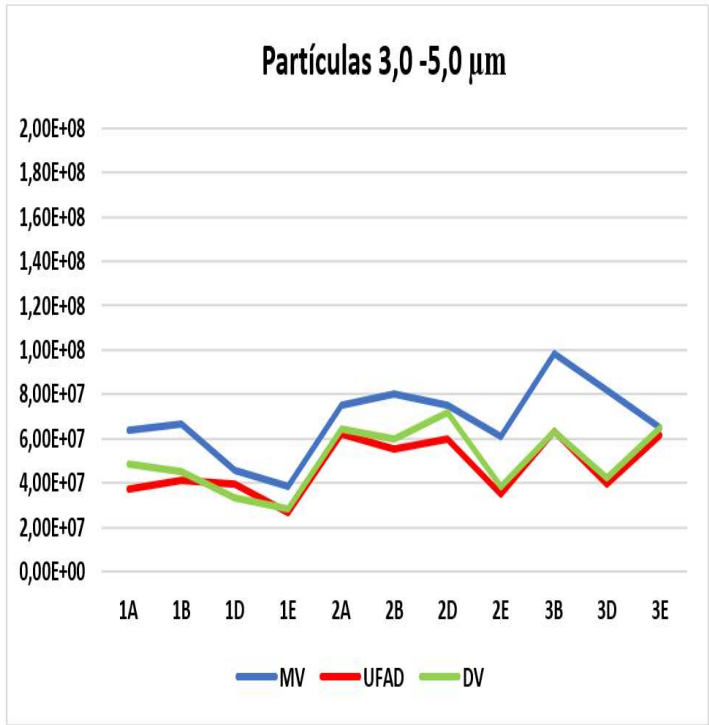

a)

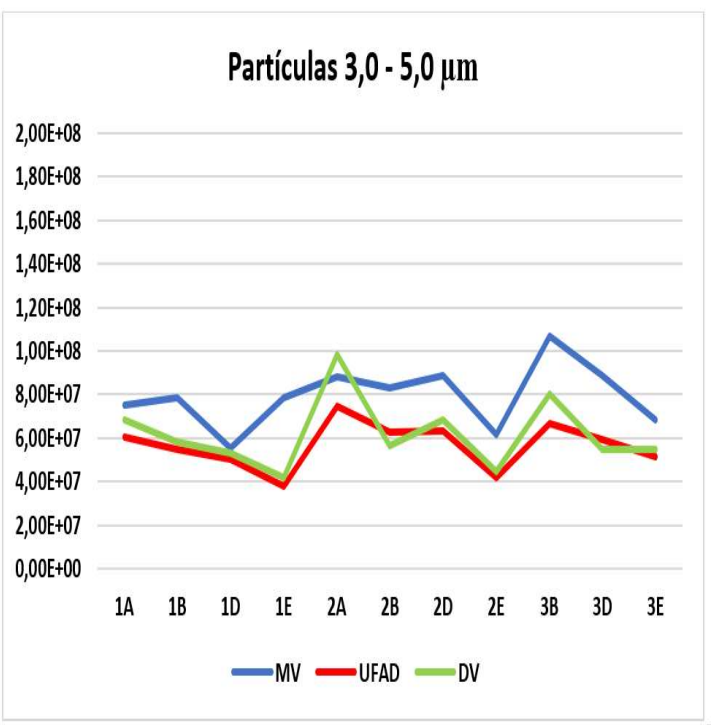

b)

Figura 6.20 Comparação da concentração de partículas entre 3,0 e 5,0 $\mu \mathrm{m}$ ao longo da cabine, com injeção de partículas pelo assento $3 \mathrm{~A}$;

a) temperatura de insuflamento: $18^{\circ} \mathrm{C}$; b) temperatura de insuflamento: $22^{\circ} \mathrm{C}$.

Tabela 6.1. Média da concentração de partículas na cabine, desvio padrão coeficiente de variação de partículas de 2,0 - 3,0 $\mu \mathrm{m}-\operatorname{lnj}$. 3 A

\begin{tabular}{|c|c|c|c|c|}
\hline $\begin{array}{c}\text { Temperatura } \\
\text { de } \\
\text { insuflamento }\end{array}$ & Sistema & $\begin{array}{c}\text { Média da } \\
\text { concentração } \\
\text { de partículas } \\
\left(\mathrm{P} / \mathrm{m}^{3}\right)\end{array}$ & $\begin{array}{l}\text { Desvio } \\
\text { Padrão } \\
\left(\mathrm{P} / \mathrm{m}^{3}\right)\end{array}$ & $\begin{array}{c}\text { Coeficiente } \\
\text { de variação } \\
(\%)\end{array}$ \\
\hline \multirow{3}{*}{$18^{\circ} \mathrm{C}$} & MV & $9,00 \mathrm{E}+07$ & $1,52 \mathrm{E}+07$ & 16,9 \\
\hline & UFAD & $6,56 \mathrm{E}+07$ & $2,02 \mathrm{E}+07$ & 30,8 \\
\hline & DV & $6,54 \mathrm{E}+07$ & $2,23 E+07$ & 34,2 \\
\hline \multirow{3}{*}{$22^{\circ} \mathrm{C}$} & MV & $1,06 \mathrm{E}+08$ & $1,59 \mathrm{E}+07$ & 15,0 \\
\hline & UFAD & $7,36 \mathrm{E}+07$ & $1,43 \mathrm{E}+07$ & 19,4 \\
\hline & DV & $7,79 \mathrm{E}+07$ & $1,88 \mathrm{E}+07$ & 24,1 \\
\hline
\end{tabular}

Tabela 6.2. Média da concentração de partículas na cabine, desvio padrão e coeficiente de variação de partículas de 3,0-5,0 $\mu \mathrm{m}-$ Inj. $3 \mathrm{~A}$

\begin{tabular}{ccccc}
$\begin{array}{c}\text { Temperatura } \\
\text { de } \\
\text { insuflamento }\end{array}$ & Sistema & $\begin{array}{c}\text { Média da } \\
\text { concentração de } \\
\text { partículas } \\
\left(\mathbf{P} / \mathbf{m}^{\mathbf{3}} \mathbf{)}\right.\end{array}$ & $\begin{array}{c}\text { Desvio } \\
\text { Padrão } \\
\left(\mathbf{P} / \mathbf{m}^{\mathbf{3}} \mathbf{)}\right.\end{array}$ & $\begin{array}{c}\text { Coeficiente } \\
\text { de variação } \\
(\%)\end{array}$ \\
\hline \hline \multirow{3}{*}{$\mathbf{1 8}{ }^{\circ} \mathrm{C}$} & $\mathbf{M V}$ & $6,83 \mathrm{E}+07$ & $1,38 \mathrm{E}+07$ & 20,2 \\
\cline { 2 - 5 } & UFAD & $4,73 \mathrm{E}+07$ & $1,32 \mathrm{E}+07$ & 27,8 \\
\cline { 2 - 5 } & $\mathbf{D V}$ & $5,10 \mathrm{E}+07$ & $1,45 \mathrm{E}+07$ & 28,5 \\
\hline \multirow{2}{*}{$\mathbf{2 2}{ }^{\circ} \mathrm{C}$} & $\mathbf{M V}$ & $7,93 \mathrm{E}+07$ & $1,42 \mathrm{E}+07$ & 17,9 \\
\cline { 2 - 5 } & UFAD & $5,67 \mathrm{E}+07$ & $1,08 \mathrm{E}+07$ & 19,1 \\
\cline { 2 - 5 } & $\mathbf{D V}$ & $6,18 \mathrm{E}+07$ & $1,13 \mathrm{E}+07$ & 18,2 \\
\cline { 2 - 5 } & & & &
\end{tabular}


Analisando as curvas apresentadas nas Figuras 6.19 e 6.20 e os dados mostrados nas Tabelas 6.1 e 6.2, verifica-se que quando há uma mudança de temperatura de insuflamento de $18{ }^{\circ} \mathrm{C}$ para $22{ }^{\circ} \mathrm{C}$, a média da concentração de partículas aumenta nos três sistemas de ventilação testados, tanto para as partículas de 2,0 a 3,0 $\mu \mathrm{m}$, quanto para as partículas de 3,0 a 5,0 $\mu \mathrm{m}$.

O aumento da concentração de partículas na região de respiração guarda relação direta com a formação de plumas térmicas menores em condições de temperatura do ar de insuflamento a $22^{\circ} \mathrm{C}$, em função de uma menor diferença de temperatura entre os manequins aquecidos e a temperatura do ar na cabine. Plumas térmicas menores implicam em uma menor velocidade do ar localmente e o arrasto de uma quantidade menor de partículas para a exaustão pelo teto nos sistemas UFAD e DV.

Verifica-se também que os valores da média da concentração são maiores no sistema MV e menores nos sistemas UFAD e DV, com valores similares nestes dois últimos sistemas, caracterizando uma maior remoção de partículas nos sistemas UFAD e DV, conforme será pormenorizado nos itens 6.4.2 e 6.4.3

Verifica-se ainda uma diminuição maior na variação da concentração de partículas ao longo da cabine nos sistemas UFAD e DV com relação ao sistema MV com o aumento da temperatura de insuflamento do ar na cabine. Ou seja, embora a concentração de partículas na cabine seja menor nos sistemas UFAD e DV, ocorre uma maior variação na concentração de partículas ao longo da cabine das partículas na região de respiração, função do movimento ascendente do fluxo de ar característico destes sistemas de ventilação somado ao fluxo ascendente causado pelas plumas térmicas, que torna o escoamento do ar e a dispersão de partículas mais instável.

Nas Figuras 6.21 e 6.22 são detalhados os resultados de concentração de partículas ao longo da cabine também para as faixas de concentração de 2,0 a 3,0 $\mu \mathrm{m}$ e de 3,0 a 5,0 $\mu \mathrm{m}$, respectivamente, agora com injeção de partículas realizada pelo assento 3B (ao lado do corredor). 


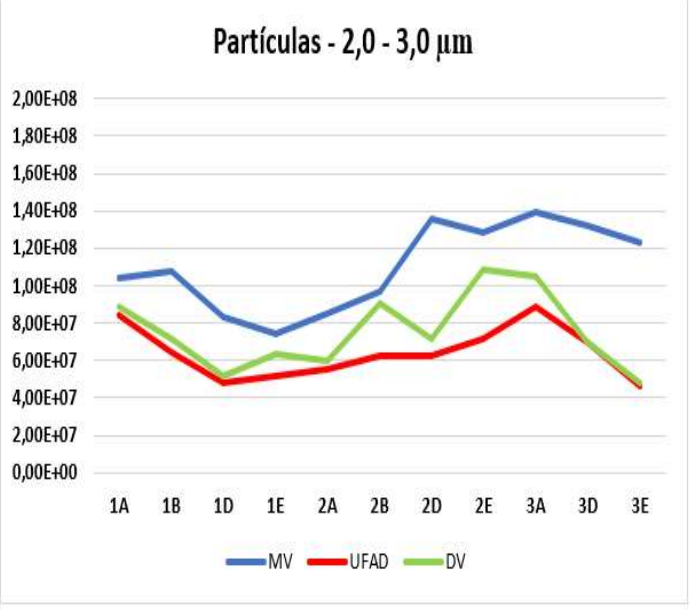

a)

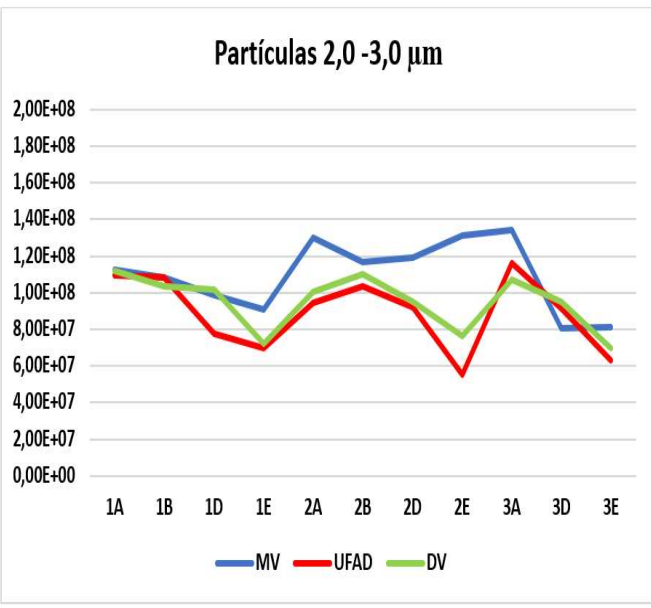

b)

Figura 6.21 Concentração de partículas entre 2,0 e 3,0 $\mu \mathrm{m}$ ao longo da cabine, com injeção de partículas pelo assento 3B.

a) temperatura de insuflamento: $18^{\circ} \mathrm{C}$; b) temperatura de insuflamento: $22^{\circ} \mathrm{C}$.

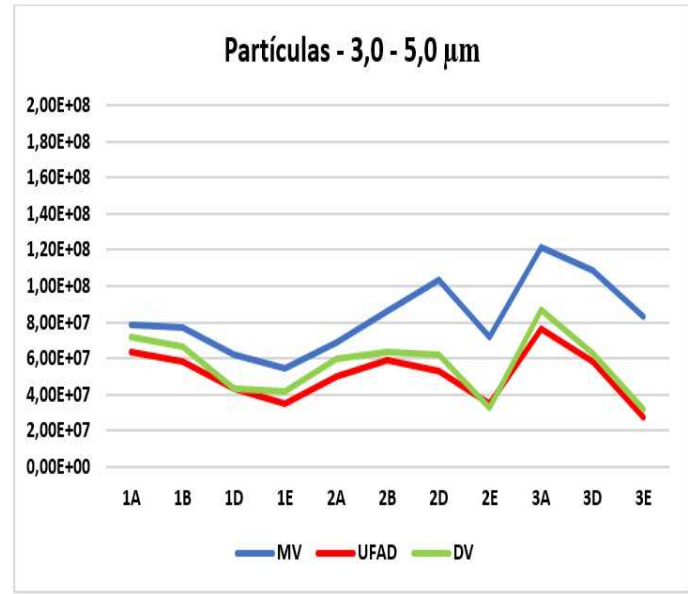

a)

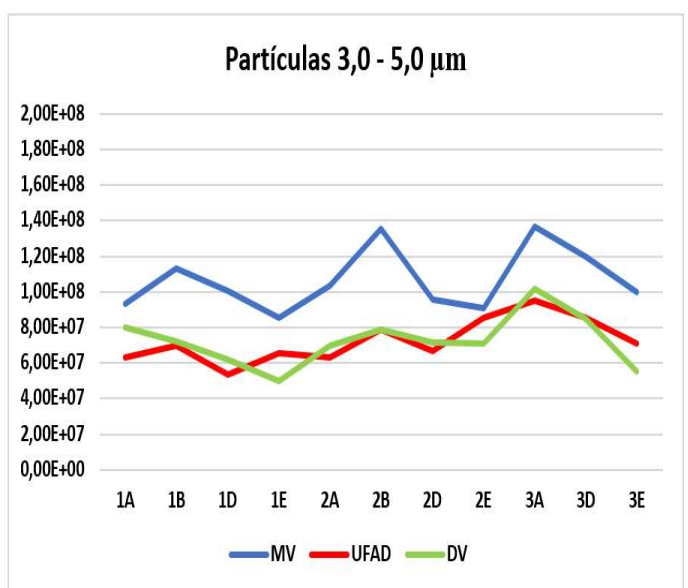

b)

Figura 6.22 Comparação da concentração de partículas entre 3,0 e 5,0 $\mu \mathrm{m}$ ao longo da cabine, com injeção de partículas pelo assento 3B

a) temperatura do ar a $18^{\circ} \mathrm{C}$; b) temperatura do ar a $22^{\circ} \mathrm{C}$.

Em complemento nas Figuras 6.21 e 6.22 são apresentadas as Tabelas 6.3 e 6.4, onde constam a média da concentração de partículas na região de respiração, o desvio padrão e o coeficiente de variação 
Tabela 6.3. Média da concentração de partículas na região de respiração, desvio padrão e coeficiente de variação de partículas de 2,0 - 3,0 $\mu \mathrm{m}$ - Inj. 3B

\begin{tabular}{ccccc}
$\begin{array}{c}\text { Temperatura } \\
\text { de } \\
\text { insuflamento }\end{array}$ & Sistema & $\begin{array}{c}\text { Média da } \\
\text { concentração de } \\
\text { partículas }\left(\mathbf{P} / \mathbf{m}^{\mathbf{3}} \mathbf{)}\right.\end{array}$ & $\begin{array}{c}\text { Desvio } \\
\text { Padrão } \\
\left(\mathbf{P} / \mathbf{m}^{\mathbf{3}} \mathbf{)}\right.\end{array}$ & $\begin{array}{c}\text { Coeficiente } \\
\text { de variação } \\
(\%)\end{array}$ \\
\hline \hline \multirow{3}{*}{$\mathbf{1 8}{ }^{\circ} \mathrm{C}$} & $\mathbf{M V}$ & $1,10 \mathrm{E}+08$ & $2,01 \mathrm{E}+07$ & 18,3 \\
\cline { 2 - 5 } & UFAD & $6,41 \mathrm{E}+07$ & $1,69 \mathrm{E}+07$ & 26,4 \\
\cline { 2 - 5 } & $\mathbf{D V}$ & $7,53 \mathrm{E}+07$ & $2,03 \mathrm{E}+07$ & 26,9 \\
\hline \multirow{2}{*}{$\mathbf{2 2}^{\circ} \mathrm{C}$} & $\mathbf{M V}$ & $1,09 \mathrm{E}+08$ & $1,93 \mathrm{E}+07$ & 17,6 \\
\cline { 2 - 5 } & UFAD & $8,91 \mathrm{E}+07$ & $2,02 \mathrm{E}+07$ & 22,7 \\
\cline { 2 - 5 } & DV & $9,49 \mathrm{E}+07$ & $1,52 \mathrm{E}+07$ & 16,0 \\
\cline { 2 - 5 } & & & &
\end{tabular}

Tabela 6.4. Média da concentração de partículas na região de respiração, desvio padrão e coeficiente de variação de partículas de 3,0 - 5,0 $\mu \mathrm{m}-$ Inj. 3B

\begin{tabular}{|c|c|c|c|c|}
\hline $\begin{array}{c}\text { Temperatura } \\
\text { de } \\
\text { insuflamento }\end{array}$ & Sistema & $\begin{array}{c}\text { Média da } \\
\text { concentração de } \\
\text { partículas }\left(\mathrm{P} / \mathrm{m}^{3}\right)\end{array}$ & $\begin{array}{l}\text { Desvio } \\
\text { Padrão } \\
\left(\mathrm{P} / \mathrm{m}^{3}\right)\end{array}$ & $\begin{array}{c}\text { Coeficiente } \\
\text { de variação } \\
(\%)\end{array}$ \\
\hline \multirow{3}{*}{$18^{\circ} \mathrm{C}$} & MV & $8,32 \mathrm{E}+07$ & $1,45 \mathrm{E}+07$ & 17,4 \\
\hline & UFAD & $5,08 \mathrm{E}+07$ & $1,45 \mathrm{E}+07$ & 28,6 \\
\hline & DV & $5,66 \mathrm{E}+07$ & $1,71 \mathrm{E}+07$ & 30,2 \\
\hline \multirow{3}{*}{$22^{\circ} \mathrm{C}$} & MV & $1,07 E+08$ & $1,74 \mathrm{E}+07$ & 16,3 \\
\hline & UFAD & $7,25 \mathrm{E}+07$ & $1,23 E+07$ & 17,0 \\
\hline & DV & $7,24 \mathrm{E}+07$ & $1,43 E+07$ & 19,7 \\
\hline
\end{tabular}

Da análise das curvas apresentadas nas Figuras 6.21 e 6.22 e dos dados mostrados nas Tabelas 6.3 e 6.4, com injeção de partículas no assento 3B (junto ao corredor) verifica-se comportamento similar ao verificado com injeção de partículas no assento $3 \mathrm{~A}$ (junto à fuselagem) quanto ao aumento da temperatura de insuflamento do ar na cabine, tanto na média de concentração, quanto na variação da concentração de partículas.

\subsubsection{Análise da concentração e dispersão de partículas com relação ao ponto de injeção/geração de partículas}

Para a análise da concentração e dispersão de partículas na região de respiração com relação ao ponto de injeção de partículas nos assentos 3A e 3B foi realizada a soma de todas as partículas na cabine medidas no nível da respiração $(1,10 \mathrm{~m}$ do piso), representadas nas concentrações apresentadas nas Tabelas 6.1 a 6.4, cujos resultados são apresentados na Figura 6.23 e na Tabela 6.5 , para temperatura de insuflamento do ar de $18^{\circ} \mathrm{C}$, e na Figura 6.24 e na Tabela 6.6, para temperatura de insuflamento do ar de $22^{\circ} \mathrm{C}$. 


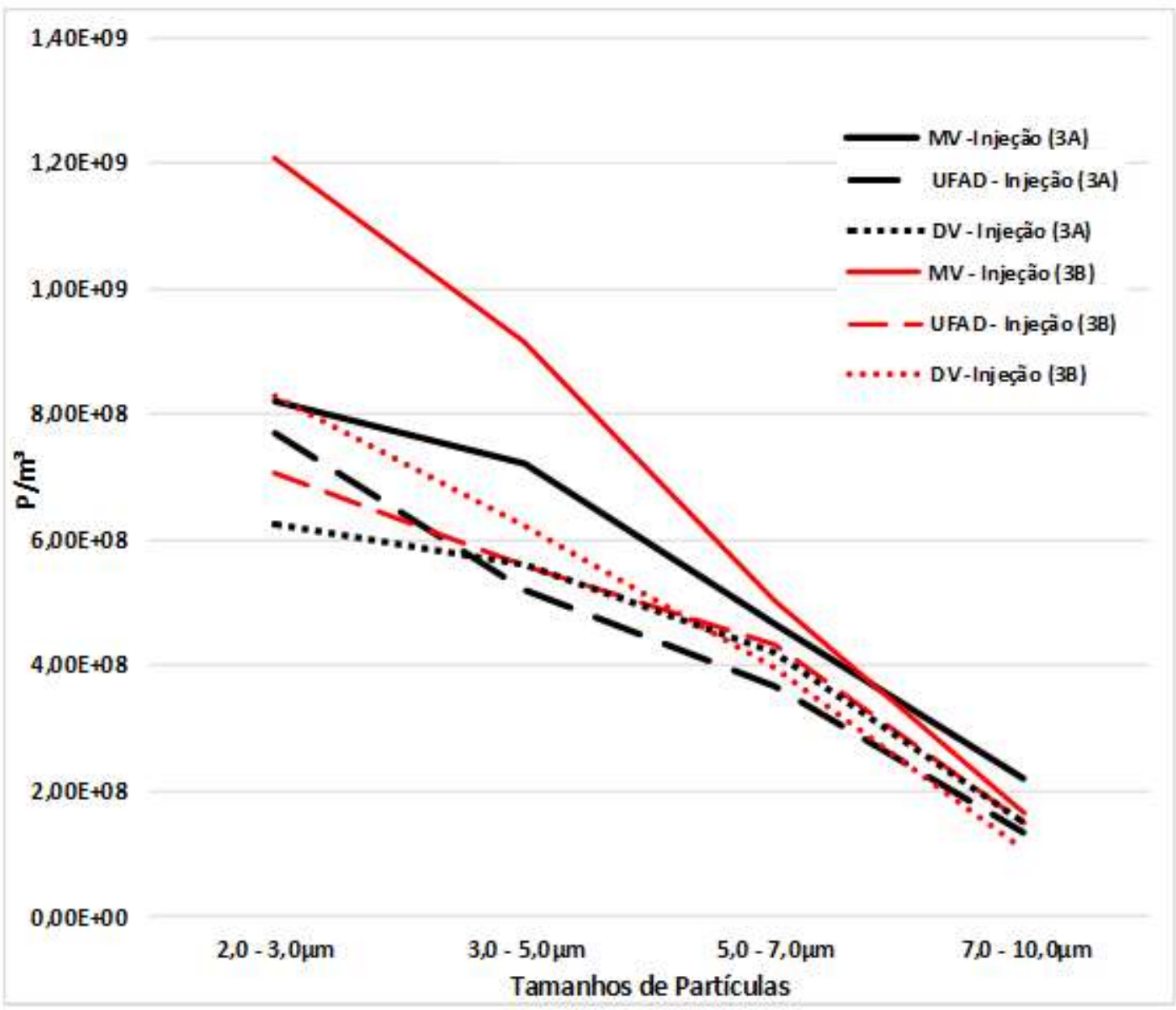

Figura 6.23 Concentração total de partículas na cabine com injeção, respectivamente, nos assentos $3 \mathrm{~A}$ e $3 \mathrm{~B}$ para temperatura de insuflamento de $18^{\circ} \mathrm{C}$

Tabela 6.5. Concentração total de partículas na cabine com injeção, respectivamente, nos assentos $3 \mathrm{~A}$ e $3 \mathrm{~B}$ para temperatura de insuflamento de $18^{\circ} \mathrm{C}$

\begin{tabular}{|c|c|c|c|c|}
\hline \multicolumn{5}{|c|}{ Sistema MV } \\
\hline Tamanhos de Partículas & $2,0-3,0 \mu \mathrm{m}$ & $3,0-5,0 \mu \mathrm{m}$ & $5,0-7,0 \mu \mathrm{m}$ & $7,0-10,0 \mu \mathrm{m}$ \\
\hline Injeção pelo assento (3A) $\left[\mathrm{P} / \mathrm{m}^{3}\right]$ & $8,21 \mathrm{E}+08$ & $7,21 \mathrm{E}+08$ & $4,67 \mathrm{E}+08$ & $2,20 \mathrm{E}+08$ \\
\hline Injeção pelo assento (3B) $\left[\mathrm{P} / \mathrm{m}^{3}\right]$ & $1,21 \mathrm{E}+09$ & $9,16 \mathrm{E}+08$ & $5,03 \mathrm{E}+08$ & $1,63 \mathrm{E}+08$ \\
\hline \multicolumn{5}{|c|}{ Sistema UFAD } \\
\hline Injeção pelo assento (3A) $\left[\mathrm{P} / \mathrm{m}^{3}\right]$ & $7,70 \mathrm{E}+08$ & $5,21 \mathrm{E}+08$ & $3,66 \mathrm{E}+08$ & $1,33 \mathrm{E}+08$ \\
\hline Injeção pelo assento (3B) $\left[\mathrm{P} / \mathrm{m}^{3}\right]$ & $7,06 \mathrm{E}+08$ & $5,59 \mathrm{E}+08$ & $4,32 \mathrm{E}+08$ & $1,47 \mathrm{E}+08$ \\
\hline \multicolumn{5}{|c|}{ Sistema DV } \\
\hline Injeção pelo assento (3A) $\left[\mathrm{P} / \mathrm{m}^{3}\right]$ & $6,25 \mathrm{E}+08$ & $5,61 \mathrm{E}+08$ & $4,19 \mathrm{E}+08$ & $1,51 \mathrm{E}+08$ \\
\hline Injeção pelo assento (3B) $\left[\mathrm{P} / \mathrm{m}^{3}\right]$ & $8,29 \mathrm{E}+08$ & $6,22 \mathrm{E}+08$ & $3,96 \mathrm{E}+08$ & $1,07 \mathrm{E}+08$ \\
\hline
\end{tabular}




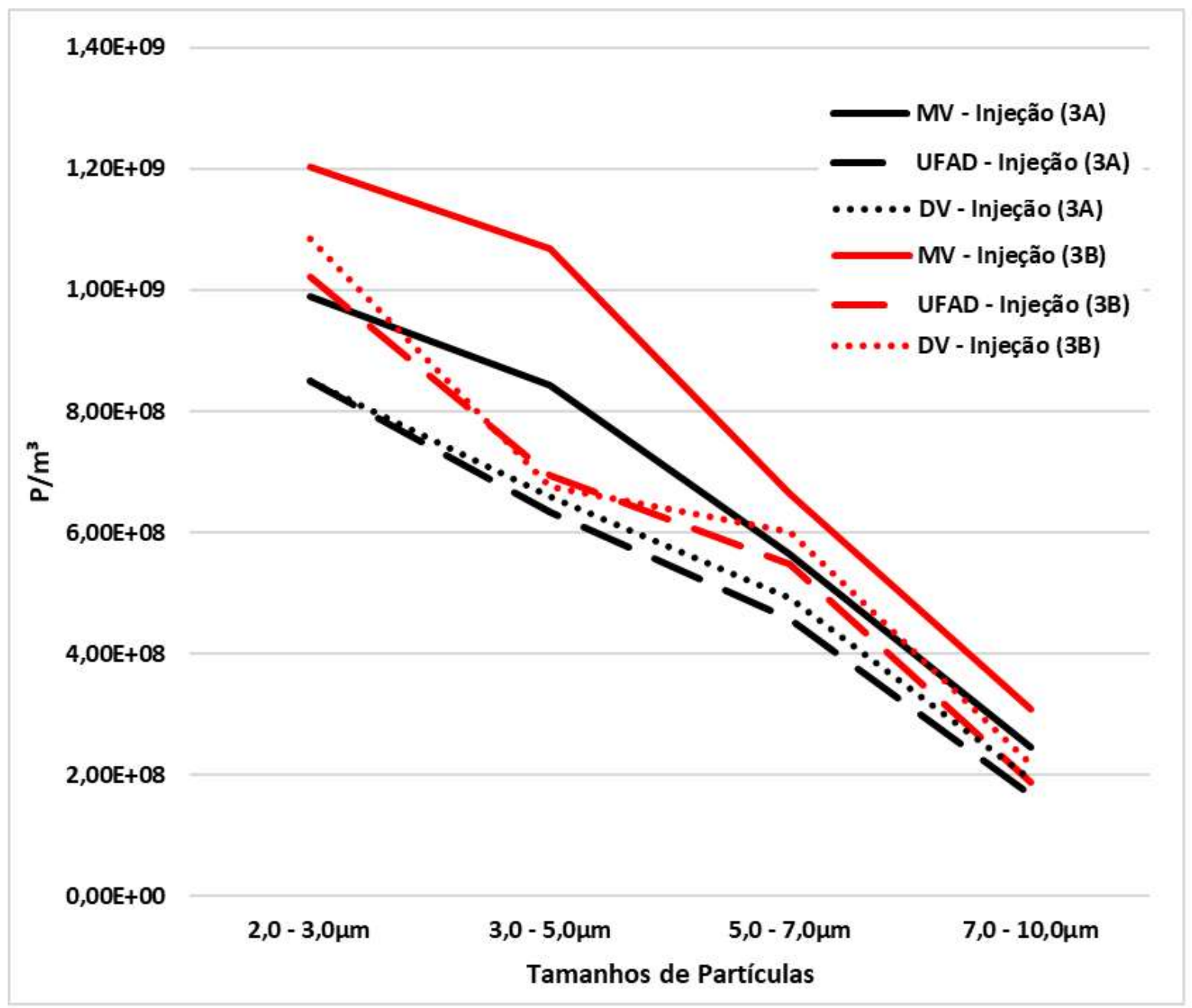

Figura 6.24. Concentração total de partículas na cabine com injeção, respectivamente, nos assentos $3 \mathrm{Ae} 3 \mathrm{~B}$ para temperatura de insuflamento de $22^{\circ} \mathrm{C}$

Tabela 6.6. Concentração total de partículas na cabine com injeção, respectivamente, nos assentos $3 \mathrm{~A}$ e $3 \mathrm{~B}$ para temperatura de insuflamento de $22^{\circ} \mathrm{C}$

\begin{tabular}{|c|c|c|c|c|}
\hline \multicolumn{5}{|c|}{ Sistema MV } \\
\hline Tamanhos de Partículas & $\mathbf{2 , 0}-\mathbf{3 , 0} \boldsymbol{\mu m}$ & $\mathbf{3 , 0}-\mathbf{5 , 0} \boldsymbol{\mu m}$ & $\mathbf{5 , 0}-\mathbf{7 , 0} \boldsymbol{\mu m}$ & $\mathbf{7 , 0}-\mathbf{1 0 , 0} \boldsymbol{\mu m}$ \\
\hline Injeção pelo assento (3A) $\left[\mathbf{P} / \mathbf{m}^{\mathbf{3}}\right]$ & $9,89 \mathrm{E}+08$ & $8,42 \mathrm{E}+08$ & $5,65 \mathrm{E}+08$ & $2,47 \mathrm{E}+08$ \\
\hline Injeção pelo assento (3B) $\left[\mathbf{P} / \mathbf{m}^{\mathbf{3}}\right]$ & $1,20 \mathrm{E}+09$ & $1,07 \mathrm{E}+09$ & $6,64 \mathrm{E}+08$ & $3,08 \mathrm{E}+08$ \\
\hline \multicolumn{5}{|c|}{ Sistema UFAD } \\
\hline Injeção pelo assento (3A) $\left[\mathbf{P} / \mathbf{m}^{\mathbf{3}}\right]$ & $8,49 \mathrm{E}+08$ & $6,33 \mathrm{E}+08$ & $4,58 \mathrm{E}+08$ & $1,67 \mathrm{E}+08$ \\
\hline Injeção pelo assento (3B) $\left[\mathbf{P} / \mathbf{m}^{\mathbf{3}}\right]$ & $1,02 \mathrm{E}+09$ & $6,95 \mathrm{E}+08$ & $5,47 \mathrm{E}+08$ & $1,88 \mathrm{E}+08$ \\
\hline \multicolumn{5}{|c|}{ Sistema DV } \\
\hline Injeção pelo assento (3A) $\left[\mathbf{P} / \mathbf{m}^{\mathbf{3}}\right]$ & $8,51 \mathrm{E}+08$ & $6,60 \mathrm{E}+08$ & $4,92 \mathrm{E}+08$ & $1,92 \mathrm{E}+08$ \\
\hline Injeção pelo assento (3B) $\left[\mathbf{P} / \mathbf{m}^{\mathbf{3}}\right]$ & $1,08 \mathrm{E}+09$ & $6,75 \mathrm{E}+08$ & $6,01 \mathrm{E}+08$ & $2,17 \mathrm{E}+08$ \\
\hline
\end{tabular}


Os resultados apresentados nas Figuras 6.23 e 6.24 e nas Tabelas 6.5 e 6.6 mostram dispersão maior de partículas, com aumento na concentração de partículas na região de respiração (a 1,10 m do piso - zona de respiração), quando a injeção de partículas é realizada no assento 3B em comparação à injeção no assento $3 \mathrm{~A}$.

Conforme apresentado no item 4.3, este fato também foi observado por Wan; Chao; Fang. (2005), em ensaios com sistema MV em mock-up de 21 assentos (três fileiras de sete assentos). Segundo esses autores, o resultado teria sido função do fluxo do ar descendente junto à fuselagem, com exaustão próxima ao piso, ter suprimido a dispersão de partículas, enquanto o fluxo ascendente no centro do mock-up ter aumentado a dispersão de partículas. No caso dos sistemas UFAD e DV, do presente trabalho, o resultado é similar, embora os fenômenos envolvidos sejam diferentes. Nos sistemas UFAD e DV ocorre fluxo ascendente de ar, com maior remoção de partículas junto à parede em função da maior exaustão de ar nesta região do mock-up (60\%).

$\mathrm{Da}$ análise destes resultados verifica-se ainda que 0 ponto de injeção/geração de partículas na cabine tem influência significativa na dispersão de partículas em toda a cabine do mock-up. Verifica-se que o sistema de ventilação pelo teto, MV, promove uma maior dispersão de partículas ao longo da cabine, com uma quantidade maior de partículas nos assentos na região de respiração, função da característica de mistura desse tipo de sistema de ventilação.

\subsubsection{Análise da remoção de partículas na região de respiração com relação ao sistema de ventilação}

Da análise das curvas apresentadas nas Figuras 6.23 e 6.24 e dos dados mostrados nas Tabelas 6.5 e 6.6, verifica-se que o sistema de ventilação $\mathrm{MV}$, amplamente utilizado em aeronaves comerciais, apresentou a maior quantidade de partículas na região de respiração em todas as situações analisadas. Ou seja, o sistema MV apresenta menor remoção de partículas, tanto grandes quanto pequenas. A menor remoção de partículas da região de respiração no sistema MV em relação aos sistemas UFAD e DV deve-se ao escoamento descendente do ar no sistema MV, que dificulta o arraste das partículas para a exaustão da cabine, principalmente as menores, mais leves, suspensas no ar. 
Para avaliar o potencial dos sistemas UFAD e DV na remoção de partículas na região de respiração foram calculados percentuais de remoção de partículas dos sistemas UFAD e DV com relação ao sistema MV por meio das Equações 6.1 e 6.2, UFAD/MV e DV/MV, apresentados nas Tabelas 6.7 e 6.8, dados por:

$$
\begin{aligned}
& \mathrm{UFAD} / \mathrm{MV}=\frac{(\mathrm{MV}-\mathrm{UF})}{\mathrm{MV}} \\
& \mathrm{DV} / \mathrm{MV}=\frac{(\mathrm{MV}-\mathrm{DV})}{\mathrm{MV}}
\end{aligned}
$$

Onde:

$\mathrm{MV}=$ concentração de partículas no sistema $\mathrm{MV}\left(\mathrm{P} / \mathrm{m}^{3}\right)$

UFAD = concentração de partículas no sistema UFAD $\left(\mathrm{P} / \mathrm{m}^{3}\right)$

$\mathrm{DV}=$ concentração de partículas no sistema $\mathrm{DV}\left(\mathrm{P} / \mathrm{m}^{3}\right)$

Da análise dos dados mostrados nas Tabelas 6.7 e 6.8 verifica-se que os sistemas UFAD e DV apresentam as maiores eficiências na remoção de partículas com temperatura de insuflamento de $18^{\circ} \mathrm{C}$, exceto para diâmetros de partículas de 2,0 a 3,0 $\mu \mathrm{m}$, injeção assento 3A. Conforme já salientado anteriormente, a menor quantidade de partículas na região de respiração com a temperatura de insuflamento de $18^{\circ} \mathrm{C}$ é função de um maior efeito das plumas térmicas, com movimento ascendente mais pronunciado do ar do que aquele que se verifica com temperatura de insuflamento de $22^{\circ} \mathrm{C}$, notadamente nas partículas menores mais facilmente arrastadas pelo movimento ascendente do ar.

Para temperatura de insuflamento do ar de $18^{\circ} \mathrm{C}$ a remoção de partículas é um pouco maior para o sistema UFAD, exceto para diâmetros de partículas de 2,0 a 3,0 $\mu \mathrm{m}$, injeção no assento $3 \mathrm{~A}$, onde o sistema DV apresenta resultado melhor. 
Tabela 6.7. Eficiência de remoção de partículas para temperatura de insuflamento de $18^{\circ} \mathrm{C}$

\begin{tabular}{|c|c|c|c|c|}
\hline \multicolumn{5}{|c|}{ Eficiência da remoção de partículas (\%) } \\
\hline \multirow{3}{*}{$\begin{array}{c}\text { Temperatura } \\
18{ }^{\circ} \mathbf{C}\end{array}$} & Tamanho de Partículas & $\mathbf{2 , 0}-\mathbf{3 , 0} \boldsymbol{\mu m}$ & $\mathbf{3 , 0}-\mathbf{5 , 0} \mathbf{~ m}$ \\
\cline { 2 - 5 } & \multirow{2}{*}{ UFAD/MV } & Injeção 3A & 6,3 & 27,8 \\
\cline { 2 - 5 } & & Injeção 3B & 41,6 & 39,0 \\
\cline { 2 - 5 } & \multirow{2}{*}{ DV/MV } & Injeção 3A & 23,9 & 22,3 \\
\cline { 3 - 5 } & & Injeção 3B & 31,4 & 32,0 \\
\hline
\end{tabular}

Tabela 6.8. Eficiência de remoção de partículas para temperatura de insuflamento de $22^{\circ} \mathrm{C}$

\begin{tabular}{|c|c|c|c|c|}
\hline \multicolumn{5}{|c|}{ Eficiência da remoção de partículas (\%) } \\
\hline \multirow{4}{*}{$\begin{array}{c}\text { Temperatura } \\
22^{\circ} \mathbf{C}\end{array}$} & Tamanho de Partículas & $\mathbf{2 , 0}-\mathbf{3 , 0} \boldsymbol{\mu m}$ & $\mathbf{3 , 0}-\mathbf{5 , 0} \boldsymbol{\mu m}$ \\
\cline { 2 - 5 } & \multirow{2}{*}{ UFAD/MV } & Injeção 3A & 14,2 & 24,8 \\
\cline { 3 - 5 } & & Injeção 3B & 15,1 & 34,9 \\
\cline { 2 - 5 } & \multirow{2}{*}{ DV/MV } & Injeção 3A & 13,9 & 21,7 \\
\cline { 3 - 5 } & Injeção 3B & 9,9 & 36,8 \\
\hline
\end{tabular}

Para temperatura de insuflamento do ar de $22{ }^{\circ} \mathrm{C}$ os sistemas UFAD e DV, apresentam eficiências de remoção de partículas similares para todos os tamanhos de partículas e ponto de injeção de partículas. 


\section{Conclusão}

Neste capítulo são apresentadas as principais conclusões e sugestões de continuidade do presente trabalho. Inicialmente, o foco é o desconforto térmico local. Em seguida, a ênfase é na dispersão e remoção de partículas na região de respiração. Finalizando com as conclusões relativas à influência conjunta dos sistemas de ventilação no desconforto térmico local e na remoção de partículas da região de respiração.

\subsection{Desconforto térmico local}

Houve uma influência significativa da temperatura de insuflamento do ar nas condições de desconforto térmico local para todos os sistemas de ventilação e distribuição de ar testados (MV, UFAD e DV).

O sistema UFAD apresentou os menores percentuais de desconforto térmico devido a correntes de ar, com quase todos os valores menores que o valor referência, preconizado pelas normas ISO 7730 (2005) e ASHRAE 55 (2013), de $20 \%$, na zona ocupada por pessoas sentadas, mesmo para temperatura de insuflamento de $18^{\circ} \mathrm{C}$,

O sistema DV, por sua vez, apresentou resultados promissores, mesmo para temperatura de insuflamento de $18{ }^{\circ} \mathrm{C}$, com percentuais menores de $20 \%$ na maioria dos assentos. Ajustes na distribuição de ar com a colocação de defletores para que o ar não seja insuflado diretamente para a região dos pés podem apresentar resultados melhores.

O sistema de ventilação por mistura, MV, apresentou as piores condições de desconforto térmico local, com valores bem acima de $20 \%$ não só para a região da cabeça, em função do ar ser insuflado a velocidades relativamente elevadas na região superior da cabine, quanto nos pés, onde ocorre a exaustão do ar, neste sistema de ventilação.

As condições térmicas promovidas pelo sistema UFAD e pelo sistema DV, mostraram bons resultados em comparação com o sistema MV e podem ser bem aceitas pelos usuários do transporte aéreo. Embora os sistemas de ventilação pelo piso e por deslocamento possam promover significativa estratificação da 
temperatura do ar, no presente trabalho isto não foi verificado. As diferenças máximas de temperatura entre os pés e a cabeça foram inferiores a $2{ }^{\circ} \mathrm{C}$, valor menor que aquele de referência, preconizado pelas normas ISO 7730 (2005) e ASHRAE 55 (2013), que é de $3^{\circ} \mathrm{C}$.

\subsection{Concentração, dispersão e remoção de partículas na região de respiração}

A temperatura de insuflamento, o ponto de injeção/geração de partículas e o sistema de ventilação tem grande influência na concentração, dispersão e remoção de partículas na região de respiração ao longo da cabine nos três sistemas de ventilação e de distribuição de ar testados (MV, UFAD, DV).

\subsubsection{Influência da temperatura de insuflamento}

Uma menor temperatura do ar insuflado na cabine favorece a formação de plumas térmicas maiores junto aos passageiros, aumentando a eficiência na remoção de partículas na região de respiração. Em função do escoamento do ar também ser ascendente nos sistemas UFAD e DV, nestes sistemas a remoção de partículas é bem mais pronunciada com temperatura de insuflamento de $18^{\circ} \mathrm{C}$ com relação à temperatura de insuflamento de $22^{\circ} \mathrm{C}$.

Os melhores resultados quanto à eficiência na remoção de partículas expiratórias da região de respiração, na temperatura de insuflamento de $18^{\circ} \mathrm{C}$ com relação à $22^{\circ} \mathrm{C}$, foram obtidos com o sistema UFAD para partículas de 2,0 a 3,0 $\mu \mathrm{m}$ e 3,0 a 5,0 $\mu \mathrm{m}$, com diferença percentual na concentração total de partículas, de $30,9 \%$ e $19,6 \%$, respectivamente.

O sistema DV para as mesmas condições apresentou uma diferença percentual na concentração total de 26,6 \% para partículas de 2,0 a 3,0 $\mu$ m e de 15 $\%$ para partículas de 3,0 a 5,0 $\mu \mathrm{m}$.

O sistema MV apresentou as maiores concentrações de partículas comparado aos outros sistemas e foi o sistema que menos sofreu influência com a mudança de temperatura de $18{ }^{\circ} \mathrm{C}$ para $22^{\circ} \mathrm{C}$. Para partículas de 2,0 a $3,0 \mu \mathrm{m}$ a diferença percentual na concentração total foi de $17,0 \%$ e para partículas de 3,0 a 5,0 $\mu \mathrm{m}$ verificou-se uma diferença de $14,3 \%$. 


\subsubsection{Influência do ponto de injeção de partículas}

A injeção/geração de partículas na zona de respiração do assento simulando passageiro ao lado da fuselagem (assento $3 \mathrm{~A}$ ), em comparação com passageiro sentado em assento ao lado do corredor (assento $3 \mathrm{~B}$ ) do mock-up, resultou em uma menor dispersão de partículas na zona de respiração ao longo da cabine. Ou seja, as partículas expiratórias geradas por um passageiro sentado junto ao corredor têm um potencial maior de serem inaladas por outros passageiros da cabine do que aquelas geradas por um passageiro sentado junto à fuselagem nos sistemas de ventilação e distribuição de ar analisados (MV, UFAD, DV).

O sistema MV foi o sistema com maior variação na dispersão de partículas expiratórias na cabine, comparando-o com os outros sistemas de ventilação que também foram avaliados, quando há mudança do ponto de injeção do assento $3 \mathrm{~A}$ para o assento 3B. Assim como os demais sistemas, a alteração do ponto de injeção foi mais significativa para partículas menores na faixa de 2,0 a 3,0 $\mu \mathrm{m}$, para o sistema MV essa diferença percentual na concentração de partículas foi de até $32,0 \%$.

O sistema UFAD e o sistema DV apresentaram um comportamento similar ao apresentado pelo sistema MV. A diferença apresentada por sistemas com sistemas com fluxo ascendente do ar, como UFAD e DV, é que a diferença no percentual de dispersão quando há mudança do ponto de injeção na cabine, fica mais acentuado para partículas com tamanho menores entre 2,0 a 3,0 $\mu \mathrm{m}$, com variação de até 24,6 $\%$.

\subsubsection{Influência do sistema de ventilação}

O sistema de ventilação MV apresentou a maior quantidade de partículas na região de respiração em todas as situações analisadas. A menor remoção de partículas da região de respiração no sistema MV em relação aos sistemas UFAD e DV deve-se ao escoamento descendente do ar no sistema MV, que dificulta o arraste das partículas para a exaustão da cabine, principalmente as menores, mais leves, suspensas no ar.

Os sistemas UFAD e DV apresentaram eficiências máximas de remoção de partículas similares, em relação ao sistema MV, para todos os tamanhos de partículas e ponto de injeção de partículas para temperaturas de insuflamento de 
$22^{\circ} \mathrm{C}$. O sistema UFAD apresentou eficiências de remoção máximas de partículas de $15,1 \%$ e $34,9 \%$ e o sistema DV de $13,9 \%$ e $36,8 \%$ para partículas de 2,0 a 3,0 $\mu \mathrm{m}$ e de 3,0 a $5,0 \mu \mathrm{m}$, respectivamente.

Em função de um maior efeito das plumas térmicas, com movimento ascendente mais pronunciado do ar para temperatura de insuflamento de $18^{\circ} \mathrm{C}$ do que aquele verificado com temperatura de insuflamento de $22^{\circ} \mathrm{C}$, as eficiências máximas de remoção de partículas dos sistemas UFAD e DV, com relação ao sistema MV, são maiores para temperatura de insuflamento de $18^{\circ} \mathrm{C}$. O sistema UFAD apresentou eficiências de remoção máximas de partículas de 41,6 \% e $39,0 \%$ e o sistema DV de $31,4 \%$ e $32,0 \%$ para partículas de 2,0 a 3,0 $\mu$ m e de 3,0 a $5,0 \mu \mathrm{m}$, respectivamente.

\subsection{Influência conjunta do sistema de ventilação no desconforto térmico local e na remoção de partículas na região de respiração}

Dos quadros resumo apresentados nas Tabelas 7.1 e 7.2, com as condições de desconforto térmico local e de remoção de partículas na região de respiração tem-se que o sistema UFAD foi o sistema que apresentou os melhores resultados de desconforto térmico local e de concentração total de partículas na região de respiração.

Os resultados de desconforto térmico para o sistema UFAD para regiões críticas como pés e cabeça ficaram abaixo dos $20 \%$, preconizado pelas normas ISO 7730 (2005) e ASHRAE 55 (2013). Quanto à eficiência na remoção de partículas, o sistema UFAD apresentou eficiência maior, com valores de até 18,8 \% em relação ao sistema DV e de até 41,6 \% em relação ao sistema MV.

Embora o sistema UFAD tenha apresentado excelentes resultados na região dos assentos, existem problemas de desconforto térmico local na região do corredor, local de instalação dos difusores para insuflamento de ar na cabine. Ademais, a instalação e manutenção de difusores, que consistem de pequenos furos no piso, é bem mais complexa daquela do sistema de ventilação DV, com instalação de difusores, na forma de grelhas, instaladas na parte inferior lateral da fuselagem. 
Tabela 7.1. Condições de desconforto térmico local e de remoção de partículas da região de respiração com temperatura de insuflamento de $18{ }^{\circ} \mathrm{C}$

\begin{tabular}{|c|c|c|c|c|c|c|}
\hline \multicolumn{4}{|c|}{ Desconforto térmico local } & \multicolumn{3}{|c|}{ Concentração total de partículas } \\
\hline \multicolumn{7}{|c|}{ Sistema MV } \\
\hline \multirow{2}{*}{ Região do corpo } & \multicolumn{3}{|c|}{ PD } & \multirow{2}{*}{ Posição de injeção } & \multicolumn{2}{|c|}{ Tamanhos de Partículas } \\
\hline & Mínimo & Médio & Máximo & & $2,0-3,0 \mu \mathrm{m}$ & $3,0-5,0 \mu \mathrm{m}$ \\
\hline Pés (\%) & 6,9 & 31,1 & 49,9 & Injeção (3A) [P/m $\left.\mathrm{m}^{3}\right]$ & $8,21 \mathrm{E}+08$ & $7,21 E+08$ \\
\hline Cabeça (\%) & 27,8 & 51,4 & 63,0 & Injeção (3B) [P/m $\left.\mathrm{m}^{3}\right]$ & $1,21 \mathrm{E}+09$ & $9,16 \mathrm{E}+08$ \\
\hline \multicolumn{7}{|c|}{ Sistema UFAD } \\
\hline Pés (\%) & 4,0 & 14,7 & 27,9 & Injeção (3A) [P/m³] & $7,70 E+08$ & $5,21 E+08$ \\
\hline Cabeça (\%) & 3,3 & 8,4 & 17,9 & Injeção (3B) $\left[\mathrm{P} / \mathrm{m}^{3}\right]$ & $7,06 \mathrm{E}+08$ & $5,59 \mathrm{E}+08$ \\
\hline \multicolumn{7}{|c|}{ Sistema DV } \\
\hline Pés (\%) & 3,0 & 22,8 & 51,0 & Injeção (3A) [P/m³] & $6,25 \mathrm{E}+08$ & $5,61 \mathrm{E}+08$ \\
\hline Cabeça (\%) & 0,1 & 5,7 & 25,4 & Injeção (3B) $\left[P / m^{3}\right]$ & $8,29 E+08$ & $6,22 \mathrm{E}+08$ \\
\hline
\end{tabular}

Tabela 7.2. Condições de desconforto térmico local e de remoção de partículas da região de respiração com temperatura de insuflamento de $22^{\circ} \mathrm{C}$

\begin{tabular}{|c|c|c|c|c|c|c|}
\hline \multicolumn{4}{|c|}{ Desconforto térmico local } & \multicolumn{3}{|c|}{ Concentração total de partículas } \\
\hline \multicolumn{7}{|c|}{ Sistema MV } \\
\hline \multirow{2}{*}{$\begin{array}{l}\text { Região do } \\
\text { corpo }\end{array}$} & \multicolumn{3}{|c|}{ PD } & \multirow{2}{*}{\begin{tabular}{|c|}
$\begin{array}{c}\text { Posição de } \\
\text { injeção }\end{array}$ \\
\end{tabular}} & \multicolumn{2}{|c|}{ Tamanhos de Partículas } \\
\hline & Mínimo & Médio & Máximo & & $2,0-3,0 \mu \mathrm{m}$ & $3,0-5,0 \mu \mathrm{m}$ \\
\hline Pés (\%) & 14,3 & 25,7 & 42,0 & Injeção (3A) [P/m $\left.\mathrm{m}^{3}\right]$ & $9,89 \mathrm{E}+08$ & $8,42 \mathrm{E}+08$ \\
\hline Cabeça (\%) & 21,0 & 37,5 & 65,0 & Injeção (3B) $\left[\mathrm{P} / \mathrm{m}^{3}\right]$ & $1,20 \mathrm{E}+09$ & $1,07 \mathrm{E}+09$ \\
\hline \multicolumn{7}{|c|}{ Sistema UFAD } \\
\hline Pés (\%) & 1,2 & 10,5 & 19,3 & Injeção (3A) $\left[\mathrm{P} / \mathrm{m}^{3}\right]$ & $8,49 \mathrm{E}+08$ & $6,33 E+08$ \\
\hline Cabeça (\%) & 0,0 & 5,7 & 13,4 & Injeção (3B) $\left[\mathrm{P} / \mathrm{m}^{3}\right]$ & $1,02 \mathrm{E}+09$ & $6,95 \mathrm{E}+08$ \\
\hline \multicolumn{7}{|c|}{ Sistema DV } \\
\hline Pés (\%) & 2,1 & 21,2 & 40,3 & Injeção (3A) $\left[\mathrm{P} / \mathrm{m}^{3}\right]$ & $8,51 \mathrm{E}+08$ & $6,60 \mathrm{E}+08$ \\
\hline Cabeça (\%) & 0,0 & 4,7 & 10,2 & Injeção (3B) $\left[\mathrm{P} / \mathrm{m}^{3}\right]$ & $1,08 \mathrm{E}+09$ & $6,75 E+08$ \\
\hline
\end{tabular}

Acrescente-se que o sistema DV apresentou resultados bastante satisfatórios com relação ao desconforto térmico local, com exceção da região dos pés do lado da fuselagem, e muito bons com relação à eficiência na remoção de partículas em relação ao sistema $\mathrm{MV}$, com aumento na eficiência de até 32,0 \%. Com relação ao desconforto térmico local, o aperfeiçoamento dos difusores no insuflamento do ar na cabine, com a instalação de defletores nas grelhas para melhor distribuição do ar, poderia fazer com que as condições de conforto térmico também melhorem neste sistema.

O sistema MV, por sua vez, apresentou os maiores percentuais de desconforto térmico local, com valores de até $65 \%$, e de concentração total de partículas na zona de respiração com valor máximo de $1,21.10^{9} \mathrm{P} / \mathrm{m}^{3}$. Valores bem piores que 
nos outros sistemas quanto ao conforto térmico e à dispersão e remoção de partículas na região de respiração, evidenciam não se tratar de um bom sistema de ventilação e distribuição de ar, embora seja amplamente utilizado em aeronaves comerciais.

Para finalizar, é importante destacar que os sistemas de ventilação propostos neste trabalho são sistemas testados e utilizados em edifícios. O que tornou a pesquisa sobre a aplicação desses sistemas em cabines de aeronaves, analisando o conforto térmico local e qualidade do ar, ainda mais relevante.

A escolha por um mock-up com disposição de 4 assentos por fileira difere de trabalhos correlatos, atendendo uma classe de aeronaves com menor capacidade, com aplicação por uma demanda de aeronaves da classe executiva.

\subsection{Sugestões para a continuidade do trabalho}

Como desenvolvimento de trabalhos futuros, propõem-se os seguintes estudos:

a) Avaliar a influência de diferentes difusores e defletores na ventilação e distribuição do ar nos três sistemas testados (MV, UFAD, DV) para melhorar o conforto térmico e a qualidade do ar em cabines de aeronaves;

b) Avaliar a influência de sistemas de ventilação personalizada, juntamente com diferentes sistemas de ventilação, na dispersão e remoção de partículas na cabine;

c) Desenvolvimento de estudos de simulação numérica na avaliação de condições de conforto térmico e de qualidade do ar com diferentes sistemas de ventilação em cabines de aeronaves;

d) Realização de testes subjetivos com usuários de transporte aéreo para testar diferentes sistemas de ventilação e distribuição de ar; 


\section{Referências Bibliográficas}

ACER. Airliner Cabin Environmental Research. Atlantic City, 2010. Disponível emhttps://www.fire.tc.faa.gov/2010Conference/files/Cabin_Safety_V/HaneyOverfel tSensors/HaneyOverfeltSensorsPres.pdf. Acessado em 05.08.2018.

ASHRAE 55. Thermal environmental conditions for human occupancy, American Society of Heating, Refrigerating and Air Conditioning Engineers Inc., Atlanta, 2013.

ANSI/ASHRAE Standard 161. Air Quality Within Commercial Aircraft. American Society of Heating, Refrigerating and Air-Conditioning Engineers, Inc., Atlanta, 2007.

BAUMAN F.; DAILY A. Underfloor air distribution (UFAD) design guide. American Society of Heating, Refrigerating and Air-Conditioning Engineers, Inc., Atlanta, 2003.

BAUMAN, F. S.; ARENS, E. A. Task/Ambient Conditioning Systems: engineering and application guidelines. California: Center for Environmental Design Research, University of California. Berkeley, 1996. 70 p.

BÉMER, D.; CALLÉ, S.; GODINOT, S.; RÉGNIER, R.; DESSAGNE, J.M. Measurement of the Emission Rate of an Aerosol Source-Comparison of Aerosol and Gas Transport Coefficients, Journal of Appl. Occup. Environ. Hyg. 2000, 15:904-910.

BERLANGA, F.A.; OLMEDO, I.; ADANA, M.R. Experimental measurements of the exposure to exhaled contaminants from different breathing modes. Roomvent and ventilation. 2018, 685-690.

BOSBACH, J.; HEIDER, A.; DEHNE, T.; MARKWART, M.; GORES, I.; BENDFELDT, $P$. Evaluation of cabin displacement ventilation under fight conditions. ICAS 2012, Brisbane

BOSBACH, J.; LANGE, S.; DEHNE, T.; LAVENROTH, G.; , HESSELBACH, T.; ALLZEIT, M. Alternative ventilation concepts for aircraft cabins. CEAS Aeronaut J., 2013, 4: 301-313

CAO, Q.; LIU, Y.; LIU, W.; LIN, C-H.; WEI, D.; BAUGHCUM, S.; NORRIS, S.; SHEN, X.; LONG, Z.; AND CHEN, Q. Experimental study of particle deposition in the environmental control systems of commercial airlines. Building and Environment, 2016, 96:62-71

CELLINE, P. R.; FABICHAK JR, D.; TRIBESS, A. Influence of personalized ventilation system installed in the armchair in dispersion of expiratory particles in aircraft cabin: final results. In: XXV Simpósio Internacional de Engenharia Automotiva - SIMEA 2017, 2017, São Paulo. PAP 24

CELLINE, P. R. Estudo experimental da influência de sistema de ventilação personalizada instalado na poltrona da dispersão de partículas expiratorias em cabine de aeronave. Dissertação de Mestrado - Escola Politécnica da Universidade de São Paulo, 2017, 123 p. 
CHAO, C.Y.H; WAN, M.P. A study of the dispersion of expiratory aerosols in unidirectional downward and ceiling-return type airflows using a multiphase approach. Journal of Indoor Air, 2006, 16:296-312

CHAO, C.Y.H.; WAN, M.P.; SZE, G.N. Transport and removal of expiratory droplets in hospital ward enviroment. Aerosol science and technology. Issue 5, 2008, 42:377-394

CHAO, C.Y.H.; WAN, M.P.; MORAWSKA, L.; JOHNSON, G.R.; RISTOVSKI, Z.D.; HARGREAVES, M.; MENGERSEN, K.; CORBETTE, S.; LI, Y., XIE; X., KATOSHEVSKI, D. Characterization of expiration air jets and droplet size distributions immediately at the mouth opening, Journal of Aerosol Science, 2009, 40:122-133

CHEN, Q.; GLICKSMAN, L. System performance evaluation and design guidelines for displacement ventilation. Altanta, 2003, GA: ASHRAE

CHEN, Q.; MCDEVITT, J.J.; GUPTA, J.K.; JONES, B.W.; MAZUMDAR, S.; POUSSOU, S.B. Infectious disease transmission in airliner cabins. Report No. RITE-ACER-CoE-2012-1.:National Air Transportation Center of Excellence RITE/ACER, Auburn, 2012 USA

COLEMAN, H. W.; STEELE, W. G. Experimentation and uncertainty analysis for engineers. John Wiley \& Son. New York, 1989.

CONCEIÇÃO, S.T.; PEREIRA, M.L.; TRIBESS, A. A review of methods applied to study airborne biocontaminants inside aircraft cabins, Hindawi Publishing Corporation, International Journal of Aerospace Engineering, 2011, artigo 824591, $15 \mathrm{p}$.

CONCEIÇÃO, S. T. Contaminação aérea em cabines climatizadas: Processo de avaliação e análise da influência de sistema de ventilação personalizado. Tese de Doutorado. Departamento de Engenharia Mecânica, Escola Politécnica da USP, São Paulo, 2012, 218p.

CONNOR, M. Transmission of diseases and long-haul flights, ICE International Aviation Conference, NHS Dumfires \& Galloway, UK Scotland, 2009.

COT. Committee on Toxicity of Chemicals in Food Consumer Product and the Environment, UK, 2006, disponível em http://cot.food.gov.uk/, acessado em julho, 2018.

CUI, W.; OUYANG, Q.; ZHU, Y. Field study of thermal environment spatial distribuition and passanger local thermal comfort in aircraft cabin. Building and Environment, 2014, 80: 213-220

DECHOW, M.; SOHN, J.; STEINHANSES, J. Concentrations of cabin air of airbus arcraft, chemosphere, 1997, 35, 21-31

DEHNE, T.; BOSBACH, J.; LECHNER, T.; HESSELBACH, F., Multi-zonal temperature control of transient thermal loads in aircraft cabin airflow. Roomvent and ventilation, 2018: 785-790

DLR. DLR and Airbus flight-test new aircraft ventilation system. Alemanha, 2011, http://www.dlr.de/dlr/en/desktopdefault.aspx/tabid-10256/366_read-1664. acessado em 05.08.2018. 
DUAN, R.; LIU, W.; XU, L.; HUANG, Y.; SHEN, X.; LIN, C.-H; LIU, J.; CHEN, Q.; SASANAPURI, B. Mesh type and number for CFD simulations of air distribution in an aircraft cabin. Numerical heat transfer, part B: fundamentals, 2015, 67(6), 489-506

DUGUID, J. P. The Size and the Duration of Air-Carriage of Respiratory Droplets and Droplet-Nuclei. J. Hyg., 1946, 44:471-479.

FABIAN, P.; MCDEVITT, J.J.; DEHAAN, W.H.; FUNG, R.O.P.; COWLING, B.J.; CHAN, K.H.; LEUNG, G.M.; MILTON, D.K. Influenza virus in human exhaled breath: an observational study, PLoS ONE, 2008, 3(7),e2691.

FABICHAK Jr, D; SILVA, E.S; MOREL, J.C.O.; TRIBESS, A. Análise experimental da distribuição de partículas aéreas em cabine de aeronave com insuflamento de ar pelo piso. ENCAC, XII Encontro Nacional de Conforto no Ambiente Construído, Brasília, 2013a,10p.

FABICHAK Jr, D; SILVA, E.S; MOREL, J.C.O; TRIBESS, A. Dispersão de partículas em cabine de aeronave com insuflamento convencional pelo teto e pelo piso. XXI Simpósio Internacional de Engenharia Automotiva, São Paulo. SIMEA 2013b, 16p.

FABICHAK Jr., D. Arquiteturas de distribuição de ar em cabines de aeronaves: Análise experimental da dispersão de partículas expiratórias. Dissertação de Mestrado. Departamento de Engenharia Mecânica, Escola Politécnica da USP, São Paulo, Brasil, 2013c. 126p.

FAIRCHILD, C.I.; STAMPFER, J.K. Particle concentration in exhaled breath. Journal of Am. Ind. Hyg. Assoc., 1987, 48 (11), 948-949.

FANGER, P.O. Thermal comfort. Analysis and applications in environmental engineering. McGraw-Hill Book Company, New York, 1972, 244p.

FANGER, P. O.; MELIKOV, A. K.; HAMNZAWA, H.; RING, J., 1988. Air turbulence and sensation of draught. Energy and Buildings, 1988, 12: 21-39.

FISER, J.; MIROSLAV, J. Impact of air distribution system on quality of ventilation in small aircraft cabin. Building and Environment Technická, Czech Republic, 2013, 2896/2, 61669 Brno

FELIX, V. B.; FABICHAK, D.; CELLINE, P. R.; TRIBESS, A. Experimental analysis of the influence of a personalized ventilation system on the back of the front seat on the dispersion of expiratory droplets in an aircraft cabin. Proceding Roomvent \& Ventilation. 2018, p. 779-784

FOX, R. W.; MCDONALD, A. T.; PRITCHARD, P. J. Introdução à Mecânica dos Fluidos. LTC, 6ª . Ed., Rio de Janeiro, 2006.

GAN, G. Numerical Method for a Full Assessment of Indoor Thermal Comfort. Indoor Air .1994, 4:154-168.

GAO, N.P.; NIU, J.L.; PERINO, M.; HEISELBERG,P. The airborne transmission of infection between flats in high-rise residential buildings: Tracer gas simulation. Building and Environment, 2007, 43: 1805-1817.

GIACONIA, C.; ORIOLI, A.; GANGI, A. A correlation linking the predicted mean vote and the mean thermal vote based on an investigation on the thermal comfort in short-haul domestic flights. Applied ergonomics, 2015, 48: 202-213 
GUO, W.; KE, P.; ZHANG, S. Effects of environment control system operation on ozone retention inside airplane cabin. Procedia Engineering, 2015, 121: 396403

GUPTA, J.K.; Lin, C.H.; Chen, Q. Transport of expiratory droplets in an aircraft cabin, Indoor Air, 2011; 21: 3-11

HINDS, W. C. Aerosol Technology. New York, 1999, John Wiley Sons, Inc.

HUNT, E.H.; SPACE, D.R. The Airplane Cabin Environment - Issues Pertaining to Flight Attendant Comfort, The Boeing Company, International In-flight Service Management Organization Conference, Montreal, Canada, 1994.

INMETRO, 1998. Guia para expressão da incerteza de medição, segunda edição brasileira publicada pelo INMETRO e pela ABNT, Agosto, 1998.

IRGENS, S.; MELIKOV, A. Assessment of the thermal environment in an aircraft cabin. Proceedings of the $9^{\text {th }}$ International Conference on Air Distribution in Rooms. Coimbra, 2004.

ISO 7726. Thermal Environments - Instruments and Methods for Measuring Physical Quantities. International Organization for Standardization, Geneva, 1998.

ISO 7730. Ergonomics of the Thermal Environment - Analytical Determination and Interpretation of Thermal Comfort using Calculation of the PMV and PPD Indices and Local Thermal Comfort Criteria. European Committee for Standardization, 2005.

JACOBS, P.; GIDS, W. F.; The aircraft seat as indoor air quality and temperature control system. Proceedings of Indoor Air, Beijing, 2005, p.1-10.

JONES, R.; NICAS, M. Experimental Determination of Supermicrometer Particle Fate Subsequent to a Point Release within a Room under Natural and Forced Mixing. Aerosol Science and Technology, 2009, 43:9, 921-938.

KOSONEN, R.; TAN, F. The effect of perceived indoor air quality on productivity loss. Energy and Buildings, 2004, 36:981-986

KULKARNI, P.; BARON, P.A.; WILLEKE, K. Aerosol Measurement: Principles, Techniques, and Applications, John Wiley \& Sons, 2011

ZUKOWSKI, M. A new formula for determining a minimum recommended value of inlet air velocity from UFAD system to prevent occupants from draught risk. Building and Environment, 2007, 42:171-179

LATIMER, B.; TANG, P. ISO 21501-4: Calibration of Air Particle Counters from a Metrology Perspective. HACH white paper, 2012.

LEITE, B. C. C. Sistema de ar condicionado com insuflamento pelo piso em ambientes de escritórios: Avaliação do conforto térmico e condições de operação. Tese de doutorado - Escola Politécnica da Universidade de São Paulo, 2003, 62 p.

LEITE, B. C. C.; TRIBESS, A. Analysis of thermal comfort in an office environment with underfloor air supply in a tropical climate. HVAC\&R Research, 2006, 12(2): 215-229.

LI, Y.; LEUNG, G.M.; Tang, J.W.; YANG, X.; CHAO, C.Y.H.; LI, J.Z.; LU, J.W.; NIELSEN, P.V.; NIU, J.; QIAN, H.; SLEIGH, A.C.; SU, J.; SUNDELL, J.; WONG, 
T.W.; YUEN, P.L. Role of ventilation in airborne transmission of infectious agents in the built environment - a multidisciplinary systematic review. Indoor Air, 2007, 17, pp. 2-18.

LI, F.; LIU, J.; PEI, J.; LIN, C.-H.; CHEN, Q. Experimental study of gaseous and particulate contaminants distribution in an aircraft cabin. Atmospheric Environment, 2014, vol 85, 223-233

LI, F.; LIU, J.; REN, J.; CAO, X.; ZHU, Y. Numerical investigation of airborne contaminant transport under different vortex structures in the aircraft cabin. International Journal of heat and mass transfer, 2016, 96 -287-295.

LI, B.; LI, J.; HUANG, Y.; YIN, H.; LIN, C.-H; WEI, D.; SHEN, X.; LIU, J. D.; CHEN, Q. Experimental studies of thermal enviroment and contaminat tranport in a commercial aircraft cabin with gaspers on. Indoor air, 2016

LIU, W.; CHEN, Q.Current studies on air distributions in commercial airliner cabins. Theoretical \& applied mechanics letters, 2013, Volume 3 , issue.6

LIU, W.; WEN, J.; LIN, C.-H.; LIU, J.; LONG, Z.; CHEN, Q. Evalution of various categories of turbulence models for predicting air distribuition in an airliner cabin. Building and Environment, 2013, 65:118-131

LIU, W.; DUAN, R.; CHEN, C.; LIN, C.,-H.; CHEN, Q. Inverse design of the thermal environment in airliner cabin by use of the CFD- based adjoint method, Energy and buildings, 2015.

MANGILI, A.; GENDREAU, M.A. Transmission of infectious diseases during commercial air travel. Lancet, 2005; 365: 989-96

MAZUMDAR, S.; LONG, Z.; CHEN, Q. A coupled CDF and analytical model to simulate airborne contaminant transmission in cabins. Indoor and Built environment, 2014, 23: 946-954

MET ONE HHPC-6 Handheld Airborne Particle Counter, Data sheet, 2010.

MORAWSKA, L. Droplet fate in indoor environments, or can we prevent the spread of infection?, Proceedings of Indoor Air , Beijing, China, 2005.

MOURA, D. Condições do escoamento e de conforto térmico em cabine de aeronave. Dissertação de Mestrado. Departamento de Engenharia Mecânica da Escola Politécnica da USP, São Paulo, 2009, 74 p.

MÜLLER, D.; SCHMIDT, M.; MÜLLER, B. Application of a displacement ventilation system for air distribution in aircraft cabins. AST 2011, Hamburg, Germany, 2011

NICAS, M.; NAZAROFF, W.W.; HUBBARD, A. Toward Understanding the Risk of Secondary Airborne Infection: Emission of Respirable Pathogens. J. Occup. Environ. Hyg., 2005, 2:143-154.

NIELSEN, P.V; BARTHOLOMAEUSSEN, N.M.; JAKUBOWSKA, E.; JIANG, H.; JONSSON, O.T.; KRAWIECKA, K.; MIERZEJEWSKI, A.; THOMAS, S.J.; TRAMPCZYNSKA, K.; POLAK, M.; SOENNICHSEN, M. Chair with integrated personalized ventilation for minimizing cross infection. Procedings of Roomvent, 2007.

NIELSEN, P.V.; BARSZCZ, E.; CZARNOTA, T.; DYMALSKI, D.P.; JASIENSKI, M.A.; NOWOTKA, A.; MOZER, A.; WIANKOWSKA, S.M.; JENSEN, R.L. The 
influence of draught on a seat with integrated personalized ventilation. Proceedings of Indoor Air 2008, Copenhagen, Denmark, 2008, Paper ID: 247

NRC (National Research Council). 1986. The Airliner Cabin Environment: Air Quality and Safety. National Academy Press, Washington, DC, 1986

NRC. The airliner cabin environment and the health of passengers and crew. National Research Council, National Academy Press ,Washington, DC, 2002.

OLMEDO, I.; NIELSEN, P.V.; RUIZ DE ADANA, M.; JENSEN, R.L. The risk of airborne cross-infection in a room with vertical low-velocity ventilation. Indoor Air, 2013; 23:62-73

OLSEN S.J.; CHANG H.L.; CHEUNG T.Y. Transmission of the severe acute respiratory syndrome on aircraft. New England Journal of Medicine, 2003, 349: pp. 2416-2422.

PARK, S.; KIM, W.; TIAN, G.; GYGI, S.P.; FINLEY, D. Structural defects in the regulatory particle-core particle interface of the proteasome inouce a novel proteasome strees response. J biol chem, 2011, 286(42):36652-66.

PANG, L.; XU, J.; FANG, L.; GONG, M.; ZHANG, H.; ZHANG, Y. Evaluation of an improved air distribution system for aircraft cabin. Building and Environment, 2013, 59:145e52

PAPINENI, R. S.; ROSENTHAL, F. S. The Size Distribution of Droplets in the Exhaled Breath of Healthy Human Subjects. J. Aerosol Med., 1997, 10:105-161.

PENNECOT. J.; BOSBACH, J.; WAGNER, C.; RAFAEL, M.; LERCHE, T.; REPP, $S$. Mixed convection in Idealized Airplane-Cabins: A Comparison Between Numerical Simulations and Particle Image Velocimetry Measurements. Proceedings of the 9th International Conference on Air Distribution in Rooms, Roomvent 2004. Coimbra, 2004.

PEREIRA, M. L.; GRAUDENZ, G.; TRIBESS, A.; MORAWSKA, L. Determination of particle concentration in the breathing zone for four different types of office ventilation systems. Building and Environment, 2009, 44: 904-911.

POUSSOU, S.B.; MAZUMDAR, S.; PLESNIAK, M.W.; SOJKA, P.W.; CHEN, Q. Flow and contaminant transport in an airliner cabin induced by a moving body: Model experiments and CFD predictions, Journal of Atmospheric Environment, 2010, 44:2830-2839.

SILVA, E. S. Arquiteturas de distribuição de ar em cabines de aeronaves: Análise experimental do desconforto térmico local, Dissertação de Mestrado, Departamento de Eng. Mecânica, Escola Politécnica da USP, São Paulo, Brasil, 2013. 131p.

STANCATO, F. Análise do ambiente térmico de cabine de aeronave, Tese de Doutorado, Departamento de Eng. Mecânica, Escola Politécnica da USP, São Paulo, Brasil, 2009. 154p.

SCHMID, M.; MÜLLER, D.; GORES, I.; MARKWART, M. Numerical Study of Different Air Distribution Systems for Aircraft Cabins. 11th International Conference on Indoor Air Quality and Climate, Copenhagen, Denmark, 2008

SHIRAI, R.; BAUMAN, F.; ZAGREUS, L. First Post-Occupancy Evaluation (POE) of Block 225: capitol area east end complex. 2003. Disponível em: 
http://www.cbe.berkeley.edu/research/briefs-eastend.htm Acesso em: 05 agos. 2018.

STROM-TEJSEN, P.S.; WYON, D.P.; ZUKOWSJA, D.; JAMA, A.; FANG, L. Occupant evaluation of 7-hours exposures in a simulated aircraft cabin. Part 2: thermaleffects. Proceedings Indoor Air 2005. Beijing, China, 2005.

STROM-TEJSEN, P.; ZUKOWSKA, D.; JAMA, A.; WYON, D. P. Assesment of the thermal environment in a simulated aircraft cabin using thermal manikin exposure. Proceedings of the $10^{\text {th }}$ International Conference on Air Distribution in Rooms - Roomvent 2007. Helsinki, 2007.

SZE TO, G.N.; WAN, M. P.; CHAO, C. Y. H.; Fang, L.; Melikov, A. Experimental Study of Dispersion and Deposition of Expiratory Aerosols in Aircraft Cabins and Impact on Infectious Disease Transmission, Aerosol Science and Technology, 2009, 43: 5, $466-485$.

TANG, J.W.; LI, Y.; EAMES, I.; CHAN, P.K.S.; RIDGWAY, G.L. Factors involved in the aerosol transmission of infection and control of ventilation in healthcare premises, Journal of Hospital Infection, 2006, 64, 100-114.

TOPAS. Descrição técnica do aerossol DEHS (Di-Etil-Hexil-Sebacato), 2012. Disponível em: www.topas-gmbh.de, acessado em agosto de 2018.

TSI, Particle Generator Model 3079. Manufacturer manual. Monodisperse Aerosol Generator Instruction Manual, 2004. Revision. Disponível em: www.atitest.com. Acessado em agosto de 2018.

VAN HOOF, J. Forty years of Fanger's model of thermal comfort: Comfort for all?. Journal Indoor Air, 2008, 18:182-201.

VOLAVÝ, J.; FISER, J.; NÖSKE, I., Prediction of air temperature in the aircraft cabin under different operational conditions. EPJ Web of Conferences, 2013, 4501096

VUOLO, J. H. Fundamentos da teoria de erros, $2^{\circ}$ ed., Edgard Blücher Ltda, 1996. WAGNER, B.G.; COBURN, C.; BLOWER. Calculating the potential for withinflight transmission of influenza A (H1N1). BMC, Medicine, 2009, 7:81 doi:10.1186/1741-7015-7-81

WALKINSHAW, D.S. Passengers aircraft indoor air quality challenges and solutions. Part II - Presentation to the ASHRAE Ottawa Valley Chapter Meeting, 2008

WALKINSHAW, D.S. Germs flying and the Truth. ASHRAE Journal, 2010, Vol. 52.

WAN, M.P.; CHAO, C.Y.H.; FANG, L. Transmission characteristics of passenger-exhaled droplets in a simulated air-cabin environment. Proceedings of Indoor Air, 2005.

WAN, M. P.; SZE TO, G.N.; CHAO, C. Y. H.; FANG, L.; MELIKOV, A. Modeling the Fate of Expiratory Aerosols and the Associated Infection Risk in an Aircraft Cabin Environment. Aerosol Science and Technology, 2009, 43: 4, 322-343.

WANG, A.; ZHANG, Y.; SUN, Y.; WANG, X. Experimental study of ventilation effectiveness and air velocity distribution in an aircraft cabin mockup. Building and Environment, 2008, 43: 337-343 
WEI, Y.; ZHANG, T.; WANG, S. Prompt design of te air-supply opening size for a commercial airplane based on the proper orthogonal decompositon of flows. Building and Environment, 2016, 96: 131-141.

WINZEN, J.; MARGGRAF-MICHEEL, M. Climate preferences and expectations and theirinfluence on comfort evaluations in an aircraft cabin.2013, 146-151.

YAN, W.; ZHANG, Y.; SUN, Y.; LI, D. Experimental and CFD study of unsteady airborne pollutant transport within an aircraft cabin mock-up. Building and Environment, 2009, 44: 34-43.

YANG, C.; YANG, X.; XU, Y.; SREBRIC, J. Contaminant dispersion in personal displacement ventilation, Proceedings of Building Simulation, 2007.

YOO, S.H.; CHAE, S.K.; LIU, B.Y.H. Influence of Particle Refractive Index on the Lower Detection Limit of Light Scattering Aerosol Counters, Aerosol Science and Technology, 1996, 25:1, 1-10, First.

YOU,R.; CHEN, J.; SHI, Z.; LIU, W.; LIN, C.-H.; WEI, D.; CHEN, Q. Experimental and numerical study of airflow distribution in an aircraft cabin mockup with a gasper on. Building performance simulation, 2016

YOU, R.; LIN, C-H.; WEI, D.; CHEN, Q. Assement of a new ventilation system for commercial aircraft cabins. Roomvent e Ventilation, 2018a, 767-772

YOU, R.; LIN, C-H; WEI, D.; CHEN, Q. An innovative personalized displacement for airliner cabins. Building and enviroment, 2018b 137: 41-50

YUSOF, M. Z. M. et al. The Effectiveness of Underfloor Air Distribution (UFAD) System in Controlling Thermal Comfort and Indoor Air Quality. In: Healthy Buildings: Creating a healthy indoor environment for people, Lisboa: IDMEC/FEUP, 2006. v. 2, p. 135-140.

ZHANG, T.; CHEN, X.; MAZUNDAR, S.; ZHANG, T.; CHEN, Q. Experimental and numerical investigation of airflow and contaminant transport in an airliner cabin mock-up. Proceedings of the $10^{\text {th }}$ International Conference on Air Distribution in Rooms - Roomvent, 2007. Helsinki.

ZHANG, T.; CHEN, Q. Novel air distribution systems for commercial aircraft cabins. Building and Environment, 2007, (42):1675-1684.

ZHANG, Z.; CHEN, X.; MAZUNDAR, S.; ZHANG, T.; CHEN, Q. Experimental and numerical investigation of airflow and contaminant transport in an airliner cabin mock-up. Building and Environment, 2009, 44(1) 85-94.

ZHANG, Z.; CHEN, Q. Experimental measurements and numerical simulations of particle transport and distribution in ventilated rooms. Atmospheric Environment, 2006, 40(18), 3396-3408.

ZHANG, Z.; CHEN, Q. Comparison of the eulerian and lagrangian methods for predicting particle transport in enclosed spaces. Atmospheric Environment, 2007, 41: 5236-5248.

Zhang, Y.; Liu, J.; Pei, J.; Li, J.; Wang, C. Performance evaluation of different air distribuition systems in an aircraft cabin. Aerospace Science and technology. 2017, 70:359-366 
ZHENG, L.; CHEN, Q.; XU, J.; WU, F. Evaluation of intervention measures for repiratory disease transmission on cruise ships. Indoor and built environment, 2016 


\section{APÊNDICE A}

Resultados das medições e respectivas incertezas das velocidades e das temperaturas do ar

Os resultados das velocidades e das temperaturas do ar, juntamente com as incertezas de medição, são apresentados nas Tabelas A.1 a A.6.

Os valores das velocidades e das temperaturas do ar são a média dos valores dos resultados dos três ensaios (ensaios em triplicata) em cada posição e em cada condição estudada.

As incertezas são o resultado da combinação das incertezas dos equipamentos de medição e dos desvios padrão em cada posição e em cada condição de ensaio (COLEMAN e STEELE, 1989; VUOLO, 1996; INMETRO, 1998).

A média das variáveis foi calculada utilizando a seguinte equação:

$$
\bar{x}=\frac{1}{n} \sum_{i=1}^{n} x_{i}
$$

onde: $x$ representa o valor da variável e $n$ o número de amostras.

O desvio padrão das variáveis foi calculado utilizando a seguinte equação:

$$
\sigma_{x}=\sqrt[2]{\frac{\sum(x-\bar{x})^{2}}{n-1}}
$$

O desvio padrão para o valor médio foi calculado utilizando a equação:

$$
\sigma_{m}=\frac{\sigma_{x}}{\sqrt{n}}
$$

E por fim, a incerteza padrão $\varepsilon$ que é a combinação da incerteza sistemática residual (incerteza do instrumento) e o desvio padrão para o valor médio, foi calculada utilizando a equação:

$$
\varepsilon=\sqrt[2]{\sigma_{m}^{2}+\sigma_{r}^{2}}
$$

onde: $\sigma_{r}$ é a incerteza sistemática residual (incerteza do instrumento). 
Tabela A-1. Resultados das velocidades e temperaturas do ar para temperatura de insuflamento de $18{ }^{\circ} \mathrm{C}$, região inferior. $(0,10 \mathrm{~m})$

\begin{tabular}{|c|c|c|c|c|c|c|c|c|c|c|c|c|c|c|c|c|c|c|}
\hline \multicolumn{19}{|c|}{ MV } \\
\hline & \multicolumn{2}{|c|}{ Dia 1} & \multicolumn{2}{|c|}{ Dia 2} & \multicolumn{2}{|c|}{ Dia 3} & & & \multicolumn{2}{|c|}{ Dia 1} & \multicolumn{2}{|c|}{ Dia 2} & \multicolumn{2}{|c|}{ Dia 3} & \multirow[b]{2}{*}{$\overline{T_{a r}}$} & \multirow[b]{2}{*}{$\varepsilon_{T_{a r}}$} & \multirow[b]{2}{*}{$T_{u}$} & \multirow[b]{2}{*}{$D R$} \\
\hline Posição & $\overline{v_{a r}}$ & $\sigma_{v_{a r}}$ & $\overline{v_{a r}}$ & $\sigma_{v_{a r}}$ & $\overline{v_{a r}}$ & $\sigma_{v_{a r}}$ & $\overline{v_{a r}}$ & $\varepsilon_{v_{a r}}$ & $\overline{\overline{T_{a r}}}$ & $\sigma_{T_{a r}}$ & $\overline{T_{a r}}$ & $\sigma_{T_{a r}}$ & $\overline{\overline{T_{a r}}}$ & $\sigma_{T_{a r}}$ & & & & \\
\hline $1 \mathrm{~A}$ & 0,35 & 0,07 & 0,36 & 0,08 & 0,35 & 0,08 & 0,35 & 0,04 & 19,8 & 0,2 & 19,8 & 0,2 & 19,9 & 0,2 & 19,8 & 0,1 & 21 & 39 \\
\hline $1 \mathrm{~B}$ & 0,30 & 0,08 & 0,29 & 0,16 & 0,29 & 0,08 & 0,30 & 0,05 & 20,6 & 0,2 & 20,7 & 0,2 & 20,7 & 0,2 & 20,7 & 0,1 & 36 & 40 \\
\hline $1 \mathrm{C}$ & 0,17 & 0,09 & 0,16 & 0,09 & 0,18 & 0,09 & 0,17 & 0,05 & 20,3 & 0,2 & 20,3 & 0,2 & 20,3 & 0,2 & 20,3 & 0,1 & 52 & 24 \\
\hline $1 \mathrm{D}$ & 0,37 & 0,08 & 0,36 & 0,07 & 0,38 & 0,08 & 0,37 & 0,04 & 21,3 & 0,2 & 21,4 & 0,2 & 21,5 & 0,2 & 21,4 & 0,1 & 21 & 36 \\
\hline $1 \mathrm{E}$ & 0,43 & 0,06 & 0,43 & 0,06 & 0,43 & 0,06 & 0,43 & 0,03 & 21,2 & 0,2 & 21,1 & 0,2 & 21,0 & 0,2 & 21,1 & 0,1 & 14 & 38 \\
\hline $2 \mathrm{~A}$ & 0,37 & 0,11 & 0,36 & 0,10 & 0,40 & 0,10 & 0,37 & 0,06 & 19,5 & 0,2 & 19,5 & 0,2 & 19,4 & 0,2 & 19,5 & 0,1 & 28 & 50 \\
\hline $2 B$ & 0,18 & 06 &, 19 & 0,06 & 0,19 & 0,06 & 0,18 & 0,03 & 19,5 & 0,2 & 19,5 & 0,2 & 19,5 & 0,2 & 19,5 & 1 & 33 & 22 \\
\hline $2 C$ & 0,14 & 0,06 & 0,16 & 0,06 & 0,16 & 0,06 & 0,16 & 0,03 & 20,0 & 0,2 & 19,9 & 0,2 & 19,9 & 0,2 & 19,9 & 0,1 & 38 & 19 \\
\hline $2 D$ & 0,08 & 0,04 & 0,08 & 0,04 & 0,08 & 0,04 & 0,08 & 0,02 & 20,5 & 0,2 & 20,6 & 0,2 & 20,6 & 0,2 & 20,6 &, 1 & 54 & 7 \\
\hline $2 \mathrm{E}$ & 20 & 06 & 20 & 0,07 & 0,19 & 0,06 & 0,20 & 0,0 & 21,0 & & 21,0 & 0,2 & 21,0 & 0,2 & 21,0 & 1 & 34 & 22 \\
\hline $3 A$ & 0,27 & 0,08 & 0,28 & 0,08 & 0,27 & 0,08 & 0,27 & 0,04 & 19,7 & 0,2 & 19,6 & 0,2 & 19,6 & 0,2 & 19,6 & 1 & 28 & 34 \\
\hline $3 B$ & ,31 & 0,08 & 0,33 & 0,08 & 0,32 & 0,07 & 0,32 & & 19,6 & 2 & 19,6 & 2 & 19,6 & 2 & 9,6 & 1 & 24 & 38 \\
\hline $3 C$ & 10 & 0,05 & 10 & 0,05 & 0,10 & 0,05 & 0,10 & & 20,0 & & 20,0 &, 2 & 20,0 & 2 & 20,0 & 1 & 52 & 11 \\
\hline $3 D$ & 0,17 & 0,07 & 0,17 & 0,07 & 0,18 & 0,07 & 0,17 & 0,04 & 20,0 & 0 & 20,0 & 0,2 & 20,0 & 0,2 & 20,0 & 1 & 40 & 22 \\
\hline $3 \mathrm{E}$ & 0,24 & 0,08 & 0,24 & 0,08 & 0,24 & 0,08 & \begin{tabular}{|l|l|}
0,24 \\
\end{tabular} & 0,05 & 20,0 & 0 , & 19,9 & 0,2 & 19,9 & 0,2 & 19,9 & & 33 & 30 \\
\hline \multicolumn{19}{|c|}{ UFAD } \\
\hline & \multicolumn{2}{|c|}{ Dia 1} & & a 2 & & a 3 & & & & a 1 & Dia & & $\mathrm{Di}$ & & & & & \\
\hline Posição & $\overline{v_{a r}}$ & $\sigma_{v_{a r}}$ & $\overline{v_{a r}}$ & $\sigma_{v_{a r}}$ & & & $\overline{v_{a r}}$ & & $\overline{T_{a r}}$ & $\sigma_{T_{a r}}$ & $\overline{T_{a r}}$ & & $\overline{T_{a r}}$ & $\sigma_{T_{a r}}$ & $\overline{T_{a r}}$ & $\varepsilon_{T_{a r}}$ & $\boldsymbol{T}_{\boldsymbol{u}}$ & $D R$ \\
\hline $1 \mathrm{~A}$ & 0,45 & 0,06 & 0,45 & 0,05 & 0,45 & 0,05 & 0,45 & 0,03 & 17,5 & 0,2 & 17,5 & 0,2 & 17,5 & 0,2 & 17,5 & 0,1 & 12 & 47 \\
\hline $1 \mathrm{~B}$ & 0,37 & 0,08 & 0,38 & 0,08 & 0,37 & 0,08 & 0,37 & 0,05 & 18,0 & $\mathrm{C}$ & 17,9 & 2 & 17,9 & 2 & 7,9 & 1 & 22 & 50 \\
\hline $1 \mathrm{C}$ & 0,40 & 0,12 & 0,41 & 0,13 & 0,41 & 0,1 & 0,41 & 0,0 & 18,1 & 0 & 18,4 & 0,2 & 18,4 & 0,2 & 18,3 & 1 & 31 & 65 \\
\hline $1 \mathrm{D}$ & 0,39 & 0 & 0,40 & 0,06 & 0,3 & 0,0 & 0,40 & & 19,2 & & 19,2 & & 19,2 & & 9,2 & 1 & 15 & 40 \\
\hline $1 \mathrm{E}$ & 0,40 & 0,05 & 0,39 & 0,06 & 0,40 & 0,06 & 0,40 & 0,03 & 18,9 & 0 & 18,9 & 0,2 & 18,9 & 2 & 18,9 & 1 & 14 & 41 \\
\hline $2 \mathrm{~A}$ & 0,35 & 0,08 & 0,34 & 0,07 & 0,36 & 0,08 & 0,35 & & 17,7 & & 17,7 & 0,2 & 17,7 & 0,2 & 17,7 & 1 & 22 & 47 \\
\hline $2 B$ & 0 & 05 & 0,29 & 0,05 & 0,2 & & 0,29 & & 17,6 & & 17,6 & & 17,6 & & 7,6 & & 19 & 35 \\
\hline $2 C$ & 0,34 & 0,08 & 0,34 & 0,08 & 0,36 & 0,09 & 0,34 & 0,05 & 17,8 & 0 & 17,7 & 0,2 & 17,7 & 0,2 & 17,7 & 0,1 & 25 & 48 \\
\hline $2 \mathrm{D}$ & 0,35 & 0,11 & 0,35 & 0,10 & 0,3 & 0, & 0,35 & & 18,4 & & 18,5 & 0,2 & 18,4 & 0,2 & 18,4 & 1 & 32 & 54 \\
\hline $2 \mathrm{E}$ & 0 & 0 & 49 & 0, & 0,5 & & 0,50 & & 18,4 & & 18,3 & & 18,4 & & 8,4 & & 21 & 56 \\
\hline $3 A$ & 0,39 & 0,08 & 0,38 & 0,08 & 0,38 & 0,08 & 0,39 & 0,04 & 17,3 & 0,2 & 17,3 & 0,2 & 17,3 & 0,2 & 17,3 & 0,1 & 20 & 51 \\
\hline $3 B$ & 0,3 & 0,08 & 0,30 & 0,08 & 0,3 & 0,0 & 0,31 & & 17,6 & & 17,5 & & 17,6 & &, 5 & 1 & 27 & 44 \\
\hline $3 C$ & & 0 & 78 & & 0,7 & & 0,77 & & 17,7 & & 17,8 & & 17,7 & & 7,7 & & 12 & 85 \\
\hline $3 D$ & 0,27 & 0,09 & 0,29 & 0,10 & 0,28 & 0,10 & 0,28 & 0,06 & 18,1 & 0,2 & 18,0 & 0,2 & 18,0 & 0,2 & 18,0 & 0,1 & 34 & 43 \\
\hline $3 \mathrm{E}$ & 0,37 & 0,12 & 0,36 & 0,12 & 0,36 & 0,11 & 0,36 & \begin{tabular}{|l|}
0,07 \\
\end{tabular} & 17,7 & 0,2 & 17,7 & 0,2 & 17,7 & 0,2 & 17,7 & 0,1 & 32 & 59 \\
\hline & & & & & & & & & & & & & & & & & & \\
\hline & & a 1 & & a 2 & & a 3 & & & & a 1 & Dia & & Di & & & & & \\
\hline Posição & $\overline{v_{a r}}$ & $\sigma_{v_{a r}}$ & $\overline{v_{a r}}$ & & & $\sigma_{v_{a r}}$ & $\overline{v_{a r}}$ & & $\overline{T_{a r}}$ & $\sigma_{T_{a r}}$ & $\overline{T_{a r}}$ & $\sigma_{T_{a r}}$ & $\overline{T_{a r}}$ & $\sigma_{T_{a r}}$ & $\overline{T_{a r}}$ & $\varepsilon_{T_{a r}}$ & $T_{u}$ & $D R$ \\
\hline $1 \mathrm{~A}$ & 0,05 & 0,04 & 0,05 & 0,04 & 0,05 & 0,04 & 0,05 & 0,02 & 21,6 & 0,2 & 21,5 & 0,2 & 21,5 & 0,2 & 21,6 & 0,1 & 75 & 1 \\
\hline $1 \mathrm{~B}$ & & 0,06 & 0,14 & 0,05 & & & 0,14 & & 21,7 & & 21,8 & & 21,9 & & 21,8 & 0,1 & 39 & 15 \\
\hline $1 \mathrm{C}$ & 0,66 & 0,13 & 0,64 & 0,14 & 0,64 & 0,13 & 0,65 & 0,08 & 21,6 & 0,2 & 21,6 & 0,2 & 21,6 & 0,2 & 21,6 & 0,1 & 21 & 73 \\
\hline $1 \mathrm{D}$ & 0,06 & 0,04 & 0,07 & 0,05 & 0,07 & 0,04 & 0,07 & 0,0 & 23,0 & & 23,0 & & 23,1 & 0,2 & 23,0 & 0,1 & 69 & 4 \\
\hline $1 \mathrm{E}$ & 0,05 & 0,03 & 0,05 & 0,03 & 0,05 & 0,03 & 0,05 & 0,02 & 22,8 & & 22,8 & 0,2 & 22,9 & & 22,8 & 0,1 & 57 & 1 \\
\hline $2 \mathrm{~A}$ & 0,10 & 0,05 & 0,09 & 0,05 & 0,11 & 0,05 & 0,10 & 0,03 & 20,6 & 0,2 & 20,6 & 0,2 & 20,5 & 0,2 & 20,6 & 0,1 & 50 & 10 \\
\hline $2 B$ & 0,16 & 0,04 & 0,16 & 0,04 & 0,16 & 0,04 & 0,16 & 0,02 & 20,3 & 0, & 20,3 & 0,2 & 20,2 & 0,2 & 20,3 & 0,1 & 26 & 16 \\
\hline $2 C$ & 0,46 & 0,11 & 0,45 & 0,13 & 0,46 & 0,12 & 0,46 & 0,07 & 20,0 & 0,2 & 20,0 & 0,2 & 19,9 & 0,2 & 20,0 & 0,1 & 26 & 61 \\
\hline $2 D$ & 0,13 & 0,06 & 0,13 & 0,06 & 0,13 & 0,06 & 0,13 & 0,03 & 22,0 & 0,2 & 22,0 & 0,2 & 22,1 & 0,2 & 22,0 & 0,1 & 44 & 13 \\
\hline $2 \mathrm{E}$ & 0,21 & 0,09 & 0,22 & 0,09 & 0,20 & 0,09 & 0,21 & 0,05 & 22,3 & 0,2 & 22,3 & 0,2 & 22,3 & 0,2 & 22,3 & 0,1 & 42 & 24 \\
\hline $3 \mathrm{~A}$ & 0,15 & 0,05 & 0,15 & 0,06 & 0,14 & 0,06 & 0,15 & 0,03 & 20,4 & 0,2 & 20,3 & 0,2 & 20,2 & 0,2 & 20,3 & 0,1 & 38 & 17 \\
\hline $3 B$ & 0,27 & 0,05 & 0,28 & 0,05 & 0,30 & 0,05 & 0,29 & 0,03 & 20,2 & 0,2 & 20,2 & 0,2 & 20,2 & 0,2 & 20,2 & 0,1 & 18 & 29 \\
\hline $3 C$ & 0,62 & 0,13 & 0,61 & 0,11 & 0,60 & 0,11 & 0,61 & 0,07 & 19,7 & 0,2 & 19,7 & 0,2 & 19,7 & 0,2 & 19,7 & 0,1 & 19 & 75 \\
\hline $3 D$ & 0,21 & 0,06 & 0,22 & 0,06 & 0,21 & 0,06 & 0,21 & 0,03 & 20,7 & 0,2 & 20,7 & 0,2 & 20,6 & 0,2 & 20,7 & 0,1 & 27 & 23 \\
\hline $3 \mathrm{E}$ & 0,27 & 0,07 & 0,28 & 0,06 & 0,27 & 0,07 & 0,27 & 0,04 & 21,1 & 0,3 & 21,1 & 0,3 & 21,0 & 0,3 & 21,1 & 0,1 & 25 & 29 \\
\hline
\end{tabular}


Tabela A-2. Resultados das velocidades e temperaturas do ar para temperatura de insuflamento de $18{ }^{\circ} \mathrm{C}$, região inferior. $(0,60 \mathrm{~m})$

\begin{tabular}{|c|c|c|c|c|c|c|c|c|c|c|c|c|c|c|c|c|c|c|}
\hline \multicolumn{19}{|c|}{ MV } \\
\hline & \multicolumn{2}{|c|}{ Dia 1} & \multicolumn{2}{|c|}{ Dia 2} & \multicolumn{2}{|c|}{ Dia 3} & & & \multicolumn{2}{|c|}{ Dia 1} & \multicolumn{2}{|c|}{ Dia 2} & \multicolumn{2}{|c|}{ Dia 3} & \multirow[b]{2}{*}{$\overline{T_{a r}}$} & \multirow[b]{2}{*}{$\varepsilon_{T_{a r}}$} & \multirow[b]{2}{*}{$T_{u}$} & \multirow[b]{2}{*}{$D R$} \\
\hline Posição & $\overline{v_{a r}}$ & $\sigma_{v_{a r}}$ & $\overline{v_{a r}}$ & $\sigma_{v_{a r}}$ & $\overline{v_{a r}}$ & $\sigma_{v_{a r}}$ & $\overline{v_{a r}}$ & $\varepsilon_{v_{a r}}$ & $\overline{\overline{T_{a r}}}$ & $\sigma_{T_{a r}}$ & $\overline{T_{a r}}$ & $\sigma_{T_{a r}}$ & $\overline{\overline{T_{a r}}}$ & $\sigma_{T_{a r}}$ & & & & \\
\hline $1 \mathrm{~A}$ & 0,13 & 0,06 & 0,13 & 0,07 & 0,13 & 0,06 & 0,13 & 0,04 & 20,4 & 0,2 & 20,4 & 0,2 & 20,5 & 0,2 & 20,4 & 0,1 & 47 & 16 \\
\hline $1 \mathrm{~B}$ & 0,19 & 0,10 & 0,22 & 0,14 & 0,17 & 0,09 & 0,18 & 0,06 & 20,7 & 0,2 & 20,8 & 0,3 & 20,8 & 0,2 & 20,8 & 0,1 & 57 & 27 \\
\hline $1 \mathrm{C}$ & 0,13 & 0,05 & 0,12 & 0,05 & 0,11 & 0,05 & 0,12 & 0,03 & 20,3 & 0,2 & 20,3 & 0,2 & 20,3 & 0,2 & 20,3 & 0,1 & 42 & 13 \\
\hline $1 \mathrm{D}$ & 0,08 & 0,05 & 0,09 & 0,05 & 0,10 & 0,05 & 0,09 & 0,03 & 21,3 & 0,2 & 21,4 & 0,2 & 21,4 & 0,2 & 21,4 & 0,1 & 53 & 8 \\
\hline $1 \mathrm{E}$ & 0,10 & 0,04 & 0,10 & 0,04 & 0,10 & 0,05 & 0,10 & 0,03 & 22,5 & 0,3 & 22,5 & 0,3 & 22,4 & 0,3 & 22,5 & 0,2 & 45 & 8 \\
\hline $2 \mathrm{~A}$ & 0,13 & 0,08 & 0,14 & 0,08 & 0,11 & 0,08 & 0,13 & 0,05 & 20,1 & 0,2 & 20,0 & 0,2 & 20,1 & 0,2 & 20,1 & 0,1 & 63 & 17 \\
\hline $2 B$ & 0,17 & 0,10 & 16 & 0,09 & 0,17 & 0,10 & 0,17 & 0,05 & 20,3 & 0,2 & 20,3 & 0,2 & 20,3 & 0,2 & 20,3 &, 1 & 57 & 24 \\
\hline $2 C$ & 0,09 & 0,05 & 0,08 & 0,05 & 0,09 & 0,05 & 0,09 & 0,03 & 20,3 & 0,2 & 20,3 & 0,2 & 20,3 & 0,2 & 20,3 &, 1 & 54 & 8 \\
\hline $2 D$ & 0,09 & 0,05 & 0,09 & 0,05 & 0,09 & 0,05 & 0,09 & 0,03 & 21,8 & 0,3 & 21,9 & 0,3 & 21,9 & 0,3 & 21,8 &, 2 & 60 & 8 \\
\hline $2 \mathrm{E}$ & 11 & 0,04 & 10 & 0,05 & 0,10 & 0,05 & 0,11 & 0,03 & 21,1 & & 21,1 & & 21,1 & 0,2 & 21,1 & 1 & 43 & 10 \\
\hline $3 A$ & 0,24 & 0,06 & 0,25 & 0,06 & 0,24 & 0,06 & 0,24 & 0,04 & 19,8 & 0,2 & 19,7 & 0,2 & 19,7 & 0,2 & 19,8 & 1 & 5 & 28 \\
\hline $3 B$ & 19 & 0,07 & 0,19 & 0,08 & 0,19 & 0,08 & 0,19 & & 19,8 & 0 & 19,8 & 0,2 & 19,8 & 0,2 & 19,8 & 1 & 0 & 25 \\
\hline $3 C$ & 08 & 0,06 & 09 & 0,06 & 0,10 & 0,06 & 0,09 & & 20,1 & 0 & 20,1 &, 2 & 20,0 & 2 & 20,0 & 1 & 9 & 11 \\
\hline $3 D$ & 0,12 & 0,03 & 0,12 & 0,03 & 0,11 & 0,04 & 0,12 & 0,02 & 20,5 & 0 & 20,5 & 0,2 & 20,5 & 0,2 & 20,5 & 1 & 29 & 11 \\
\hline $3 \mathrm{E}$ & 0,04 & 0,03 & 0,05 & 0,03 & 0,05 & 0,03 & 0,05 & 0,02 & 20,6 & 0 , & 20,6 & 0,2 & 20,6 & 0,2 & 20,6 & & 71 & 0 \\
\hline \multicolumn{19}{|c|}{ UFAD } \\
\hline & \multicolumn{2}{|c|}{ Dia 1} & & a 2 & & a 3 & & & & a 1 & & & $\mathrm{Di}$ & & & & & \\
\hline Posição & $\overline{v_{a r}}$ & $\sigma_{v_{a r}}$ & $\overline{v_{a r}}$ & $\sigma_{v_{a r}}$ & & & & & $\overline{T_{a r}}$ & $\sigma_{T_{a r}}$ & $\overline{T_{a r}}$ & & $\overline{T_{a r}}$ & $\sigma_{T_{a r}}$ & $\overline{T_{a r}}$ & $\varepsilon_{T_{a r}}$ & $T_{u}$ & $D R$ \\
\hline $1 \mathrm{~A}$ & 0,14 & 0,07 & 0,15 & 0,07 & 0,15 & 0,06 & 0,15 & 0,04 & 18,5 & 0,2 & 17,5 & 0,2 & 18,6 & 0,2 & 18,2 & 0,1 & 46 & 22 \\
\hline 1B & 0,19 & 0,07 & 0,20 & 0,07 & 0,18 & 0,07 & 0,19 & 0,04 & 19,2 & $\mathrm{C}$ & 17,9 & 2 & 19,3 & 2 & 18,7 & 1 & 6 & 25 \\
\hline $1 \mathrm{C}$ & 0,14 & 0,06 & 0,13 & 0,06 & 0,12 & 0,06 & 0,13 & 0,0 & 19,0 & 0 & 19,2 & 0,2 & 19,2 & 0,2 & 19,1 &, 1 & 46 & 16 \\
\hline 1D & 0,23 & 06 & 23 & 0,06 & 0,19 & 0,0 & 0,22 & & 20,1 & & 20 & & 20,2 & & 20,1 & 1 & 28 & 25 \\
\hline $1 \mathrm{E}$ & 0,39 & 0,07 & 0,39 & 0,08 & 0,39 & 0,07 & 0,39 & 0,04 & 20,1 & 0 & 20,1 & 0,2 & 20,1 & 2 & 20,1 & 1 & 9 & 42 \\
\hline $2 \mathrm{~A}$ & 0,20 & 0,08 & 0,21 & 0,08 & 0,19 & 0,08 & 0,20 & & 18,2 & 0 & 18,3 & 0,2 & 18,3 & 0,2 & 18,3 & 1 & 40 & 30 \\
\hline $2 B$ & 0,0 & 0,05 & 0,09 & 0,05 & 0,09 & & 0,09 & & 18,5 & & 18 & & 18,6 & & 18,6 & & 4 & 10 \\
\hline $2 C$ & 0,47 & 0,11 & 0,47 & 0,11 & 0,46 & 0,12 & 0,47 & 0,06 & 18,3 & 0,2 & 18,3 & 0,2 & 18,3 & 2 & 18,3 & 0,1 & 24 & 67 \\
\hline $2 \mathrm{D}$ & 0,41 & 0,08 & 0,41 & 0,08 & 0,40 & 0,0 & 0,41 & & 19,5 & & 19,7 & 0,3 & 19,6 & 0,2 & 19,6 & 1 & 18 & 45 \\
\hline $2 \mathrm{E}$ & & 0 & & 0,10 & 0,39 & & 0,3 & & 18,7 & & 18,6 & & 18,6 & & 8,6 & & 7 & 53 \\
\hline $3 A$ & 0,60 & 0,12 & 0,59 & 0,12 & 0,60 & 0,12 & 0,60 & 0,07 & 17,3 & 0,2 & 17,4 & 0,2 & 17,3 & 0,2 & 17,3 & 0,1 & 20 & 85 \\
\hline $3 B$ & & 0,06 & 0,23 & 0,07 & 0,2 & 0,0 & 0,23 & & 17,7 & & 17,7 & & 17,7 & & 17,7 & 1 & 7 & 31 \\
\hline $3 C$ & & 0 & & & 0,4 & & 0,41 & & 18,0 & & 18 & & 17,9 & & 18,0 & & 9 & 65 \\
\hline $3 D$ & 0,13 & 0,06 & 0,12 & 0,06 & 0,12 & 0,06 & 0,13 & 0,03 & 18,8 & 0,3 & 18,8 & 0,2 & 18,9 & 0,2 & 18,9 & 0,1 & 47 & 16 \\
\hline $3 \mathrm{E}$ & 0,19 & 0,06 & 0,19 & 0,06 & 0,18 & 0,06 & 0,19 & 0,03 & 18,4 & 0,2 & 18,4 & 0,2 & 18,4 & 0,2 & 18,4 & 0,1 & 32 & 24 \\
\hline & & & & & & & & & & & & & & & & & & \\
\hline & & a 1 & & a 2 & & a 3 & & & & a 1 & & & Di & & & & & \\
\hline Posição & $\overline{v_{a r}}$ & $\sigma_{v_{a r}}$ & $\overline{v_{a r}}$ & & & $\sigma_{v_{a r}}$ & $\overline{v_{a r}}$ & & $\overline{T_{a r}}$ & $\sigma_{T_{a r}}$ & $\overline{T_{a r}}$ & $\sigma_{T_{a r}}$ & $\overline{T_{a r}}$ & $\sigma_{T_{a r}}$ & $\overline{T_{a r}}$ & $\varepsilon_{T_{a r}}$ & $T_{u}$ & $D R$ \\
\hline $1 \mathrm{~A}$ & 0,13 & 0,05 & 0,13 & 0,05 & 0,13 & 0,05 & 0,13 & 0,03 & 21,3 & 0,2 & 21,3 & 0,2 & 21,4 & 0,2 & 21,3 & 0,1 & 35 & 13 \\
\hline $1 \mathrm{~B}$ & 0,25 & 0,05 & 0,25 & 0,05 & 0,25 & & 0,25 & & 22,1 & & 22 & & 22,3 & & 22,2 & 0,2 & 19 & 21 \\
\hline $1 \mathrm{C}$ & 0,15 & 0,06 & 0,14 & 0,06 & 0,14 & 0,05 & 0,14 & 0,03 & 22,7 & 0,2 & 22,6 & 0,2 & 22,5 & 0,2 & 22,6 & 0,1 & 41 & 14 \\
\hline $1 \mathrm{D}$ & 0,07 & 0,04 & 0,08 & 0,04 & 0,07 & 0,04 & 0,07 & 0,0 & 23,6 & & 23,7 & & 23,8 & 0,2 & 23,7 & 0,1 & 49 & 5 \\
\hline $1 \mathrm{E}$ & 0,11 & 0,04 & 0,10 & 0,04 & 0,10 & 0,04 & 0,11 & 0,02 & 22,9 & & 23,0 & 0,2 & 23,1 & & 23,0 & 0,1 & 40 & 9 \\
\hline $2 A$ & 0,30 & 0,07 & 0,30 & 0,08 & 0,30 & 0,07 & 0,30 & 0,04 & 20,8 & 0,2 & 20,8 & 0,2 & 20,7 & 0,2 & 20,8 & 0,1 & 24 & 33 \\
\hline $2 B$ & 0,14 & 0,06 & 0,13 & 0,05 & 0,13 & 0,05 & 0,14 & 0,03 & 22,0 & 0,3 & 22,2 & 0,3 & 22,2 & 0,3 & 22,1 & 0,2 & 40 & 13 \\
\hline $2 C$ & 0,52 & 0,11 & 0,51 & 0,11 & 0,51 & 0,11 & 0,51 & 0,06 & 20,3 & 0,2 & 20,3 & 0,2 & 20,2 & 0,2 & 20,3 & 0,1 & 22 & 62 \\
\hline $2 D$ & 0,16 & 0,07 & 0,17 & 0,06 & 0,16 & 0,06 & 0,16 & 0,04 & 22,1 & 0,4 & 22,2 & 0,4 & 22,5 & 0,5 & 22,2 & 0,2 & 37 & 17 \\
\hline $2 \mathrm{E}$ & 0,12 & 0,05 & 0,11 & 0,05 & 0,13 & 0,05 & 0,12 & 0,03 & 22,9 & 0,2 & 22,9 & 0,2 & 22,8 & 0,2 & 22,9 & 0,1 & 44 & 11 \\
\hline $3 \mathrm{~A}$ & 0,28 & 0,05 & 0,28 & 0,06 & 0,27 & 0,05 & 0,28 & 0,03 & 20,3 & 0,2 & 20,2 & 0,2 & 20,1 & 0,2 & 20,2 & 0,1 & 20 & 29 \\
\hline $3 B$ & 0,25 & 0,06 & 0,26 & 0,07 & 0,26 & 0,06 & 0,25 & 0,04 & 20,1 & 0,2 & 20,1 & 0,2 & 20,2 & 0,2 & 20,2 & 0,1 & 25 & 28 \\
\hline $3 C$ & 0,63 & 0,13 & 0,62 & 0,15 & 0,63 & 0,13 & 0,63 & 0,08 & 19,7 & 0,2 & 19,7 & 0,2 & 19,7 & 0,2 & 19,7 & 0,1 & 22 & 83 \\
\hline $3 D$ & 0,28 & 0,07 & 0,27 & 0,07 & 0,27 & 0,07 & 0,27 & 0,04 & 20,3 & 0,2 & 20,3 & 0,2 & 20,2 & 0,2 & 20,3 & 0,1 & 27 & 31 \\
\hline $3 \mathrm{E}$ & 0,28 & 0,05 & 0,29 & 0,05 & 0,28 & 0,06 & 0,29 & 0,03 & 20,9 & 0,2 & 20,9 & 0,2 & 20,9 & 0,2 & 20,9 & 0,1 & 19 & 28 \\
\hline
\end{tabular}


Tabela A-3. Resultados das velocidades e temperaturas do ar para temperatura de insuflamento de $18{ }^{\circ} \mathrm{C}$, região inferior. $(1,10 \mathrm{~m})$

\begin{tabular}{|c|c|c|c|c|c|c|c|c|c|c|c|c|c|c|c|c|c|c|}
\hline \multicolumn{19}{|c|}{ MV } \\
\hline & \multicolumn{2}{|c|}{ Dia 1} & \multicolumn{2}{|c|}{ Dia 2} & \multicolumn{2}{|c|}{ Dia 3} & & & \multicolumn{2}{|c|}{ Dia 1} & \multicolumn{2}{|c|}{ Dia 2} & \multicolumn{2}{|c|}{ Dia 3} & \multirow[b]{2}{*}{$\overline{T_{a r}}$} & \multirow[b]{2}{*}{$\varepsilon_{T_{a r}}$} & \multirow[b]{2}{*}{$T_{u}$} & \multirow[b]{2}{*}{$D R$} \\
\hline Posição & $\overline{v_{a r}}$ & $\sigma_{v_{a r}}$ & $\overline{v_{a r}}$ & $\sigma_{v_{a r}}$ & $\overline{v_{a r}}$ & $\sigma_{v_{a r}}$ & $\overline{v_{a r}}$ & $\varepsilon_{v_{a r}}$ & $\overline{\overline{T_{a r}}}$ & $\sigma_{T_{a r}}$ & $\overline{T_{a r}}$ & $\sigma_{T_{a r}}$ & $\overline{T_{a r}}$ & $\sigma_{T_{a r}}$ & & & & \\
\hline $1 \mathrm{~A}$ & 0,36 & 0,13 & 0,36 & 0,14 & 0,39 & 0,14 & 0,37 & 0,08 & 20,4 & 0,2 & 20,5 & 0,2 & 20,6 & 0,2 & 20,5 & 0,1 & 37 & 54 \\
\hline $1 \mathrm{~B}$ & 0,51 & 0,14 & 0,20 & 0,17 & 0,48 & 0,14 & 0,42 & 0,08 & 21,2 & 0,3 & 21,2 & 0,3 & 21,2 & 0,3 & 21,2 & 0,1 & 46 & 71 \\
\hline $1 \mathrm{C}$ & 0,37 & 0,15 & 0,39 & 0,16 & 0,37 & 0,17 & 0,38 & 0,09 & 20,3 & 0,2 & 20,3 & 0,2 & 20,3 & 0,2 & 20,3 & 0,1 & 42 & 62 \\
\hline $1 \mathrm{D}$ & 0,28 & 0,07 & 0,29 & 0,07 & 0,30 & 0,08 & 0,29 & 0,04 & 22,3 & 0,2 & 22,4 & 0,2 & 22,4 & 0,2 & 22,3 & 0,1 & 26 & 28 \\
\hline $1 \mathrm{E}$ & 0,53 & 0,15 & 0,52 & 0,13 & 0,52 & 0,14 & 0,53 & 0,08 & 21,7 & 0,2 & 21,6 & 0,2 & 21,6 & 0,2 & 21,6 & 0,1 & 26 & 64 \\
\hline $2 \mathrm{~A}$ & 0,37 & 0,13 & 0,38 & 0,13 & 0,39 & 0,14 & 0,38 & 0,08 & 19,9 & 0,2 & 19,8 & 0,2 & 19,8 & 0,2 & 19,8 & 0,1 & 35 & 58 \\
\hline $2 B$ & 0,42 & 12 &, 43 & 0,12 & 0,41 & 11 & 0,42 & 0,07 & 20,2 & 0,3 & 20,2 & 0,3 & 20,3 & 0,3 & 20,2 &, 2 & 28 & 56 \\
\hline $2 C$ & 0,39 & 0,11 & 0,39 & 0,09 & 0,38 & 0,10 & 0,39 & 0,06 & 20,2 & 0,2 & 20,2 & 0,2 & 20,2 & 0,2 & 20,2 & 0,1 & 25 & 48 \\
\hline $2 D$ & 0,34 & 0,07 & 0,36 & 0,07 & 0,35 & 0,07 & 0,35 & 0,04 & 21,1 & 0,2 & 21,1 & 0,2 & 21,1 & 0,2 & 21,1 & 0,1 & 21 & 35 \\
\hline $2 \mathrm{E}$ & 65 & 0,15 & 0,65 & 0,14 & 0,65 & 0,14 & 0,65 & 0,08 & 20,7 & & 20,7 & 0,2 & 20,7 & 0,2 & 20,7 & 1 & 22 & 82 \\
\hline $3 A$ & 0,59 & 0,10 & 0,60 & 0,10 & 0,59 & 0,11 & 0,59 & 0,06 & 19,8 & 0,2 & 19,7 & 0,2 & 19,7 & 0,2 & 19,7 & 1 & 17 & 68 \\
\hline $3 B$ & 0,41 & 0,12 & 0,41 & 0,12 & 0,42 & 0,1 & 0,42 & 0,0 & 19,9 & 2 & 19,9 & 0,2 & 19,9 & 0,2 & 19,9 & 1 & 8 & 56 \\
\hline $3 C$ & 22 & 08 & 23 & 0,08 & 0,23 & 0,09 & 0,22 & & 20,1 & & 0,1 & & 20,0 & 2 & 20,1 & 1 & 6 & 29 \\
\hline $3 D$ & 0,46 & 0,08 & 0,46 & 0,08 & 0,46 & 0,08 & 0,46 & 0,05 & 21,0 & 0 & 21,1 & 0,2 & 21,1 & 0,2 & 21,1 &, 1 & 17 & 45 \\
\hline $3 \mathrm{E}$ & 0,23 & 0,08 & 0,23 & 0,08 & 0,23 & 0,08 & 0,23 & 0,05 & 20,4 & 0,2 & 20,3 & 0,2 & 20,2 & 0,2 & 20,3 & & 37 & 29 \\
\hline \multicolumn{19}{|c|}{ UFAD } \\
\hline & \multicolumn{2}{|c|}{ Dia 1} & & a 2 & & a 3 & & & & a 1 & & & $\mathrm{Di}$ & & & & & \\
\hline Posição & $\overline{v_{a r}}$ & $\sigma_{v_{a r}}$ & $\overline{v_{a r}}$ & $\sigma_{v_{a r}}$ & & & $\overline{v_{a r}}$ & & $\overline{T_{a r}}$ & $\sigma_{T_{a r}}$ & $\overline{T_{a r}}$ & & $\overline{T_{a r}}$ & $\sigma_{T_{a r}}$ & $\overline{T_{a r}}$ & $\varepsilon_{T_{a r}}$ & $T_{u}$ & $D R$ \\
\hline $1 \mathrm{~A}$ & 0,10 & 0,03 & 0,09 & 0,03 & 0,09 & 0,03 & 0,09 & 0,02 & \begin{tabular}{|l|}
18,7 \\
\end{tabular} & 0,2 & 17,5 & 0,2 & 18,7 & 0,2 & 18,3 & 0,1 & 35 & 10 \\
\hline $1 \mathrm{~B}$ & 0,08 & 0,05 & 0,08 & 0,05 & 0,08 & 0,04 & 0,08 & 0,03 & 19,2 & 2 & 17,9 & & 19,2 & 2 & 18,8 & 1 & 8 & 8 \\
\hline $1 \mathrm{C}$ & 0,05 & 0,04 & 0,06 & 0,04 & 0,05 & 0,04 & 0,05 & 0,02 & 18,9 & 0 & 19,1 & 0,2 & 19,1 & 0,2 & 19,0 & 1 & 74 & 2 \\
\hline $1 \mathrm{D}$ & 0,10 & 0,04 & 0,09 & 0,04 & 0,1 & 0,0 & 0,10 & & 19,4 & & 19,4 & & 19,5 & & 19,4 & & 2 & 11 \\
\hline $1 \mathrm{E}$ & 0,12 & 0,04 & 0,12 & 0,04 & 0,13 & 0,04 & 0,12 & 0,02 & 20,5 & 0 & 20,5 & 0,3 & 20,6 & 3 & 20,5 & 2 & 3 & 12 \\
\hline $2 \mathrm{~A}$ & 0,07 & 0,04 & 0,07 & 0,04 & 0,07 & 0,04 & 0,07 & 0, & 18,7 & 0 & 18,8 & 0,2 & 18,8 & 0,2 & 18,8 & 1 & 63 & 6 \\
\hline $2 B$ & 0,09 & 04 & 0,10 & 0,04 & 0,09 & & 0,09 & & 18,8 & & 18 & & 18,8 & & 18,7 & & 2 & 10 \\
\hline $2 C$ & 0,09 & 0,05 & 0,09 & 0,05 & 0,09 & 0,05 & 0,09 & 0,03 & 18,4 & 0 & 18,4 & 0,2 & 18,4 & 2 & 18,4 & 1 & 59 & 10 \\
\hline $2 \mathrm{D}$ & 0,07 & 0,05 & 0,06 & 0,05 & 0,07 & 0,0 & 0,07 & & 19,4 & & 19,4 & 0,3 & 19,4 & 0,3 & 19,4 &, 2 & 73 & 6 \\
\hline $2 \mathrm{E}$ & & 0 & 10 & 0,0 & 0,0 & & 0,10 & & 19,0 & & 18,9 & & 9,0 & & 9,0 & & 2 & 11 \\
\hline $3 A$ & 0,27 & 0,11 & 0,28 & 0,11 & 0,27 & 0,11 & 0,27 & 0,06 & 17,4 & 0,2 & 17,5 & 0,2 & 17,5 & 0,2 & 17,5 & 0,1 & 41 & 47 \\
\hline $3 B$ & 0,06 & 0,0 & 0,06 & 0,0 & 0,0 & 0,0 & 0,06 & & 17,9 & & 17,8 & & 17,9 & & 9 & 1 & 7 & 4 \\
\hline $3 C$ & & 0,0 & 10 & & 0,1 & & 0,10 & & 18,3 & & 18,2 & & 18,2 & & 18,2 & & 2 & 12 \\
\hline $3 D$ & 0,05 & 0,04 & 0,06 & 0,04 & 0,06 & 0,04 & 0,06 & 0,03 & 18,5 & 0,2 & 18,5 & 0,2 & 18,5 & 0,2 & 18,5 & 0,1 & 77 & 3 \\
\hline $3 \mathrm{E}$ & 0,08 & 0,05 & 0,08 & 0,05 & 0,07 & 0,05 & 0,08 & 0,03 & 18,3 & 0,2 & 18,3 & 0,2 & 18,3 & 0,2 & 18,3 & 0,1 & 62 & 8 \\
\hline & & & & & & & & & & & & & & & & & & \\
\hline & & a 1 & & a 2 & & a 3 & & & & a 1 & & & $\mathrm{Di}$ & & & & & \\
\hline Posição & $\overline{v_{a r}}$ & $\sigma_{v_{a r}}$ & $\overline{v_{a r}}$ & & & $\sigma_{v_{a r}}$ & $\overline{v_{a r}}$ & & $\overline{T_{a r}}$ & $\sigma_{T_{a r}}$ & $\overline{T_{a r}}$ & $\sigma_{T_{a r}}$ & $\overline{T_{a r}}$ & $\sigma_{T_{a r}}$ & $\overline{T_{a r}}$ & $\varepsilon_{T_{a r}}$ & $T_{u}$ & $D R$ \\
\hline $1 \mathrm{~A}$ & 0,04 & 0,04 & 0,04 & 0,04 & 0,04 & 0,04 & 0,04 & 0,02 & 21,2 & 0,2 & 21,2 & 0,2 & 21,2 & 0,3 & 21,2 & 0,1 & 93 & 0 \\
\hline $1 \mathrm{~B}$ & 0,04 & 0,04 & 0,04 & 0,03 & 0,04 & 0,03 & 0,04 & & 22,2 & & 22,4 & 0,2 & 22,5 & & 22,4 & 0,1 & 85 & 0 \\
\hline $1 \mathrm{C}$ & 0,06 & 0,04 & 0,06 & 0,04 & 0,05 & 0,04 & 0,06 & 0,02 & 22,8 & 0,3 & 22,7 & 0,3 & 22,6 & 0,3 & 22,7 & 0,2 & 69 & 2 \\
\hline $1 \mathrm{D}$ & 0,08 & 0,05 & 0,08 & 0,05 & 0,08 & 0,05 & 0,08 & 0,0 & 22,8 & 0 , & 23,0 & 0,2 & 23,1 & 0,2 & 23,0 & 0,1 & 59 & 6 \\
\hline $1 \mathrm{E}$ & 0,08 & 0,04 & 0,09 & 0,04 & 0,09 & 0,04 & 0,09 & 0,02 & 23,4 & & 23,6 & 0,3 & 23,6 & & 23,6 & 0,1 & 44 & 6 \\
\hline $2 \mathrm{~A}$ & 0,12 & 0,04 & 0,11 & 0,04 & 0,12 & 0,05 & 0,12 & 0,03 & 21,3 & 0,3 & 21,2 & 0,3 & 21,1 & 0,2 & 21,2 & 0,1 & 39 & 12 \\
\hline $2 B$ & 0,11 & 0,05 & 0,11 & 0,05 & 0,10 & 0,05 & 0,11 & 0,03 & 21,7 & 0,4 & 21,6 & 0,4 & 21,7 & 0,5 & 21,7 & 0,3 & 46 & 11 \\
\hline $2 C$ & 0,16 & 0,06 & 0,15 & 0,06 & 0,15 & 0,07 & 0,15 & 0,04 & 20,5 & 0,2 & 20,4 & 0,2 & 20,3 & 0,2 & 20,4 & 0,1 & 42 & 19 \\
\hline $2 D$ & 0,08 & 0,05 & 0,08 & 0,05 & 0,09 & 0,06 & 0,08 & 0,03 & 21,1 & 0,3 & 21,1 & 0,3 & 21,2 & 0,2 & 21,1 & 0,1 & 59 & 8 \\
\hline $2 \mathrm{E}$ & 0,06 & 0,04 & 0,06 & 0,04 & 0,07 & 0,04 & 0,06 & 0,02 & 22,2 & 0,3 & 22,2 & 0,3 & 22,1 & 0,4 & 22,2 & 0,2 & 62 & 3 \\
\hline $3 \mathrm{~A}$ & 0,11 & 0,04 & 0,11 & 0,05 & 0,11 & 0,04 & 0,11 & 0,03 & 20,4 & 0,2 & 20,2 & 0,2 & 20,2 & 0,2 & 20,3 & 0,1 & 40 & 12 \\
\hline $3 B$ & 0,13 & 0,06 & 0,14 & 0,06 & 0,13 & 0,06 & 0,13 & 0,03 & 20,1 & 0,2 & 20,1 & 0,2 & 20,2 & 0,2 & 20,1 & 0,1 & 45 & 16 \\
\hline $3 C$ & 0,17 & 0,07 & 0,19 & 0,09 & 0,18 & 0,09 & 0,18 & 0,05 & 20,0 & 0,2 & 19,9 & 0,2 & 19,9 & 0,2 & 20,0 & 0,1 & 46 & 24 \\
\hline $3 D$ & 0,14 & 0,07 & 0,13 & 0,07 & 0,15 & 0,08 & 0,14 & 0,04 & 20,0 & 0,2 & 20,0 & 0,2 & 20,0 & 0,2 & 20,0 & 0,1 & 53 & 18 \\
\hline $3 \mathrm{E}$ & 0,11 & 0,04 & 0,12 & 0,04 & 0,12 & 0,04 & 0,12 & 0,02 & 20,5 & 0,2 & 20,5 & 0,2 & 20,4 & 0,2 & 20,5 & 0,1 & 35 & 12 \\
\hline
\end{tabular}


Tabela A-4. Resultados das velocidades e temperaturas do ar para temperatura de insuflamento de $22{ }^{\circ} \mathrm{C}$, região inferior. $(0,10 \mathrm{~m})$

\begin{tabular}{|c|c|c|c|c|c|c|c|c|c|c|c|c|c|c|c|c|c|c|}
\hline \multicolumn{19}{|c|}{ MV } \\
\hline & \multicolumn{2}{|c|}{ Dia 1} & \multicolumn{2}{|c|}{ Dia 2} & \multicolumn{2}{|c|}{ Dia 3} & & & \multicolumn{2}{|c|}{ Dia 1} & \multicolumn{2}{|c|}{ Dia 2} & \multicolumn{2}{|c|}{ Dia 3} & \multirow[b]{2}{*}{$\overline{T_{a r}}$} & \multirow[b]{2}{*}{$\varepsilon_{T_{a r}}$} & \multirow[b]{2}{*}{$T_{u}$} & \multirow[b]{2}{*}{$D R$} \\
\hline Posição & $\overline{v_{a r}}$ & $\sigma_{v_{a r}}$ & $\overline{v_{a r}}$ & $\sigma_{v_{a r}}$ & $\overline{v_{a r}}$ & $\sigma_{v_{a r}}$ & $\overline{v_{a r}}$ & $\varepsilon_{v_{a r}}$ & $\overline{\overline{T_{a r}}}$ & $\sigma_{T_{a r}}$ & $\overline{T_{a r}}$ & $\sigma_{T_{a r}}$ & $\overline{\overline{T_{a r}}}$ & $\sigma_{T_{a r}}$ & & & & \\
\hline $1 \mathrm{~A}$ & 0,32 & 0,06 & 0,33 & 0,07 & 0,32 & 0,07 & 0,32 & 0,04 & 23,6 & 0,2 & 23,6 & 0,2 & 23,6 & 0,2 & 23,6 & 0,1 & 21 & 26 \\
\hline $1 \mathrm{~B}$ & 0,32 & 0,07 & 0,32 & 0,07 & 0,32 & 0,06 & 0,32 & 0,04 & 23,9 & 0,2 & 23,9 & 0,2 & 23,9 & 0,2 & 23,9 & 0,1 & 21 & 26 \\
\hline $1 \mathrm{C}$ & 0,18 & 0,09 & 0,18 & 0,09 & 0,19 & 0,09 & 0,18 & 0,05 & 24,2 & 0,2 & 24,2 & 0,2 & 24,2 & 0,2 & 24,2 & 0,1 & 49 & 18 \\
\hline $1 \mathrm{D}$ & 0,36 & 0,07 & 0,35 & 0,06 & 0,36 & 0,07 & 0,35 & 0,04 & 24,9 & 0,2 & 24,9 & 0,2 & 24,9 & 0,2 & 24,9 & 0,1 & 19 & 25 \\
\hline $1 \mathrm{E}$ & 0,38 & 0,05 & 0,37 & 0,05 & 0,38 & 0,05 & 0,38 & 0,03 & 24,9 & 0,2 & 24,9 & 0,2 & 24,9 & 0,2 & 24,9 & 0,1 & 14 & 23 \\
\hline $2 \mathrm{~A}$ & 0,45 & 0,11 & 0,43 & 0,11 & 0,43 & 0,11 & 0,43 & 0,06 & 23,4 & 0,2 & 23,4 & 0,2 & 23,4 & 0,2 & 23,4 & 0,1 & 26 & 43 \\
\hline $2 B$ & 0,31 & 10 & 0,29 & 0,10 & 0,31 & 10 & 0,30 & 0,06 & 23,4 & 0,2 & 23,3 & 0,2 & 23,3 & 0,2 & 23,3 &, 1 & 33 & 31 \\
\hline $2 C$ & 0,15 & 0,08 & 0,15 & 0,09 & 0,17 & 0,08 & 0,16 & 0,05 & 24,0 & 0,2 & 24,0 & 0,2 & 24,0 & 0,2 & 24,0 & 0,1 & 54 & 16 \\
\hline $2 D$ & 0,39 & 0,06 & 0,09 & 0,06 & 0,09 & 0,05 & 0,17 & 0,03 & 25,0 & 0,2 & 24,2 & 0,2 & 24,3 & 0,2 & 24,5 & 0,1 & 44 & 15 \\
\hline $2 \mathrm{E}$ & 31 & 0,08 & 31 & 0,08 & 0,30 & 0,08 & 0,31 & 0,05 & 24,8 & & 24,8 & 0,2 & 24,8 & 0,2 & 24,8 & 1 & 26 & 24 \\
\hline $3 A$ & 0,28 & 0,08 & 0,27 & 0,08 & 0,28 & 0,08 & 0,27 & 0,05 & 23,6 & 0,2 & 23,5 & 0,2 & 23,4 & 0,2 & 23,5 & 1 & 9 & 26 \\
\hline $3 B$ & 0,32 & 0,09 & 0,32 & 0,09 & 0,33 & 0,09 & 0,32 & & 23,5 & 0 & 23,4 & 2 & 23,4 & 0,2 & 23,4 & 1 & 7 & 30 \\
\hline $3 C$ & 15 & 0,07 & 15 & 0,07 & 0,15 & 0,07 & 0,15 & & 23,9 & & 23,9 & & 24,0 & 2 & 23,9 & 1 & 5 & 14 \\
\hline $3 \mathrm{D}$ & 0,17 & 0,06 & 0,17 & 0,06 & 0,17 & 0,06 & 0,17 & 0,03 & 23,8 & 0 & 23,8 & 0,2 & 23,9 & 0,2 & 23,8 & 1 & 5 & 14 \\
\hline $3 \mathrm{E}$ & 0,28 & 0,10 & 0,28 & 0,10 & 0,28 & 0,10 & 0,28 & 0,06 & 23,9 & 0,2 & 23,9 & 0,2 & 24,0 & 0,2 & 23,9 & & 36 & 28 \\
\hline \multicolumn{19}{|c|}{ UFAD } \\
\hline & \multicolumn{2}{|c|}{ Dia 1} & & a 2 & & a 3 & & & & a 1 & & & $\mathrm{Di}$ & & & & & \\
\hline Posição & $\overline{v_{a r}}$ & $\sigma_{v_{a r}}$ & $\overline{v_{a r}}$ & & & & $\overline{v_{a r}}$ & & $\overline{T_{a r}}$ & $\sigma_{T_{a r}}$ & $\overline{T_{a r}}$ & & $\overline{T_{a r}}$ & $\sigma_{T_{a r}}$ & $\overline{T_{a r}}$ & $\varepsilon_{T_{a r}}$ & $T_{u}$ & $D R$ \\
\hline $1 \mathrm{~A}$ & 0,50 & 0,06 & 0,50 & 0,06 & 0,50 & 0,06 & 0,50 & 0,03 & 21,4 & 0,2 & 21,4 & 0,2 & 21,4 & 0,2 & 21,4 & 0,1 & 11 & 40 \\
\hline 1B & 0,56 & 0,07 & 0,56 & 0,07 & 0,56 & 0,07 & 0,56 & 0,04 & 21,6 & $\mathrm{C}$ & 21,6 & 2 & 21,6 & 2 & 21,6 & 1 & 2 & 47 \\
\hline $1 \mathrm{C}$ & 0,46 & 0,13 & 0,46 & 0,13 & 0,47 & 0,13 & 0,46 & \begin{tabular}{|l|l}
0,07 \\
\end{tabular} & 22,1 & 0 & 22,0 & 0,2 & 21,9 & 0,2 & 22,0 &, 1 & 28 & 55 \\
\hline 1D & 0,46 & 0,0 & 0,45 & 0,06 & 0,46 & 0,0 & 0,46 & & 22,8 & & 22,8 & & 22,8 & & 22,8 & 1 & 4 & 35 \\
\hline $1 \mathrm{E}$ & 0,37 & 0,05 & 0,38 & 0,05 & 0,37 & 0,05 & 0,37 & 0,03 & 22,8 & 0 & 22,8 & 0,2 & 22,8 & 2 & 22,8 & 1 & 3 & 27 \\
\hline $2 \mathrm{~A}$ & 0,35 & 0,07 & 0,35 & 0,08 & 0,35 & 0,08 & 0,35 & & 21,6 & 0 & 21,6 & 0,2 & 21,5 & 0,2 & 21,6 & 1 & 1 & 35 \\
\hline $2 B$ & 0,3 & 0,05 & 0,31 & & 0,3 & & 0,31 & & 21,4 & & & & 21,4 & & 21,4 & & 7 & 27 \\
\hline $2 C$ & 0,52 & 0,11 & 0,51 & 0,12 & 0,52 & 0,11 & 0,52 & 0,07 & 21,4 & 0,2 & 21,4 & 0,2 & 21,5 & 0,2 & 21,4 & 0,1 & 22 & 58 \\
\hline $2 \mathrm{D}$ & 0,31 & 0,10 & 0,31 & 0,1 & 0,3 & 0,1 & 0,31 & & 22,1 & & 22,1 & 0,2 & 22,1 & 0,2 & 22,1 &, 1 & 33 & 36 \\
\hline $2 \mathrm{E}$ & 41 & 0,0 & & 0, & 0,4 & 0,1 & 0,42 & & 22,3 & & 22 & & 22,3 & & 22,3 & & 3 & 42 \\
\hline $3 A$ & 0,39 & 0,08 & 0,38 & 0,08 & 0,38 & 0,08 & 0,38 & 0,05 & 21,4 & 0,2 & 21,3 & 0,2 & 21,3 & 0,2 & 21,3 & 0,1 & 21 & 39 \\
\hline $3 B$ & & 0,1 & 0,39 & 0,09 & 0,38 & 0, & 0,39 & & 21,4 & & 21 & & 21,4 & & 21,4 & 1 & 5 & 43 \\
\hline $3 C$ & 0 & 0 & & & 0,67 & & 0,65 & & & & & & 1,4 & & 21,4 & & 0 & 73 \\
\hline $3 D$ & 0,28 & 0,09 & 0,29 & 0,10 & 0,28 & 0,10 & 0,28 & 0,06 & 21,9 & 0,2 & 21,8 & 0,2 & 21,8 & 0,2 & 21,8 & 0,1 & 34 & 33 \\
\hline $3 \mathrm{E}$ & 0,42 & 0,13 & 0,43 & 0,13 & 0,43 & 0,12 & 0,43 & \begin{tabular}{|l|l|}
0,07 \\
\end{tabular} & 21,6 & 0,2 & 21,6 & 0,2 & 21,6 & 0,2 & 21,6 & 0,1 & 29 & 53 \\
\hline & & & & & & & & & & & & & & & & & & \\
\hline & & a 1 & & a 2 & & a 3 & & & & a 1 & & & Di & & & & & \\
\hline Posição & $\overline{v_{a r}}$ & $\sigma_{v_{a r}}$ & $\overline{v_{a r}}$ & & & $\sigma_{v_{a r}}$ & $\overline{v_{a r}}$ & & $\overline{T_{a r}}$ & $\sigma_{T_{a r}}$ & $\overline{T_{a r}}$ & $\sigma_{T_{a r}}$ & $\overline{T_{a r}}$ & $\sigma_{T_{a r}}$ & $\overline{T_{a r}}$ & $\varepsilon_{T_{a r}}$ & $T_{u}$ & $D R$ \\
\hline $1 \mathrm{~A}$ & 0,06 & 0,04 & 0,06 & 0,04 & 0,06 & 0,04 & 0,06 & 0,02 & 24,9 & 0,2 & 24,9 & 0,2 & 25,0 & 0,2 & 25,0 & 0,1 & 69 & 2 \\
\hline $1 \mathrm{~B}$ & 0,17 & 0,06 & & 0,06 & 0,17 & 0,05 & 0,17 & & 25,3 & & 25 & & 25,4 & & 25,3 & 0,1 & 33 & 12 \\
\hline $1 \mathrm{C}$ & 0,37 & 0,09 & 0,37 & 0,10 & 0,38 & 0,10 & 0,37 & 0,05 & 24,2 & 0,2 & 24,3 & 0,2 & 24,4 & 0,2 & 24,3 & 0,1 & 25 & 32 \\
\hline $1 \mathrm{D}$ & 0,09 & 0,05 & 0,08 & 0,05 & 0,08 & 0,05 & 0,08 & 0,0 & 26,4 & & 26,5 & 0,2 & 26,3 & 0,2 & 26,4 & 0,1 & 56 & 5 \\
\hline $1 \mathrm{E}$ & 0,06 & 0,03 & 0,06 & 0,03 & 0,05 & 0,03 & 0,06 & 0,02 & 26,5 & & 26,5 & 0,2 & 26,5 & & 26,5 & 0,1 & 60 & 1 \\
\hline $2 \mathrm{~A}$ & 0,12 & 0,05 & 0,12 & 0,06 & 0,11 & 0,05 & 0,12 & 0,03 & 24,3 & 0,2 & 24,1 & 0,2 & 24,0 & 0,2 & 24,1 & 0,1 & 47 & 9 \\
\hline $2 B$ & 0,17 & 0,04 & 0,16 & 0,04 & 0,17 & 0,04 & 0,16 & 0,03 & 23,8 & 0,2 & 23,8 & 0,2 & 23,7 & 0,2 & 23,8 & 0,1 & 27 & 13 \\
\hline $2 C$ & 0,52 & 0,15 & 0,48 & 0,13 & 0,48 & 0,14 & 0,49 & 0,08 & 23,4 & 0,2 & 23,4 & 0,2 & 23,4 & 0,2 & 23,4 & 0,1 & 28 & 53 \\
\hline $2 D$ & 0,13 & 0,06 & 0,14 & 0,06 & 0,13 & 0,05 & 0,13 & 0,03 & 25,6 & 0,2 & 25,6 & 0,2 & 25,6 & 0,2 & 25,6 & 0,1 & 42 & 9 \\
\hline $2 \mathrm{E}$ & 0,15 & 0,06 & 0,16 & 0,06 & 0,16 & 0,06 & 0,16 & 0,04 & 25,8 & 0,2 & 25,8 & 0,2 & 25,8 & 0,2 & 25,8 & 0,1 & 41 & 11 \\
\hline $3 \mathrm{~A}$ & 0,15 & 0,05 & 0,14 & 0,06 & 0,14 & 0,06 & 0,14 & 0,03 & 24,1 & 0,2 & 23,9 & 0,2 & 23,9 & 0,2 & 23,9 & 0,1 & 41 & 12 \\
\hline $3 B$ & 0,26 & 0,04 & 0,25 & 0,04 & 0,26 & 0,04 & 0,26 & 0,02 & 23,9 & 0,2 & 23,8 & 0,2 & 23,8 & 0,2 & 23,8 & 0,1 & 17 & 18 \\
\hline $3 C$ & 0,74 & 0,21 & 0,68 & 0,21 & 0,68 & 0,20 & 0,70 & 0,12 & 23,3 & 0,2 & 23,3 & 0,2 & 23,3 & 0,2 & 23,3 & 0,1 & 29 & 88 \\
\hline $3 D$ & 0,22 & 0,06 & 0,22 & 0,07 & 0,23 & 0,06 & 0,22 & 0,04 & 24,6 & 0,2 & 24,6 & 0,2 & 24,6 & 0,2 & 24,6 & 0,1 & 28 & 17 \\
\hline $3 \mathrm{E}$ & 0,26 & 0,07 & 0,26 & 0,07 & 0,26 & 0,06 & 0,26 & 0,04 & 24,8 & 0,2 & 24,9 & 0,2 & 24,9 & 0,2 & 24,8 & 0,1 & 26 & 19 \\
\hline
\end{tabular}


Tabela A-5. Resultados das velocidades e temperaturas do ar para temperatura de insuflamento de $22{ }^{\circ} \mathrm{C}$, região inferior. $(0,60 \mathrm{~m})$

\begin{tabular}{|c|c|c|c|c|c|c|c|c|c|c|c|c|c|c|c|c|c|c|}
\hline \multicolumn{19}{|c|}{ MV } \\
\hline & \multicolumn{2}{|c|}{ Dia 1} & \multicolumn{2}{|c|}{ Dia 2} & \multicolumn{2}{|c|}{ Dia 3} & & & \multicolumn{2}{|c|}{ Dia 1} & \multicolumn{2}{|c|}{ Dia 2} & \multicolumn{2}{|c|}{ Dia 3} & \multirow[b]{2}{*}{$\overline{T_{a r}}$} & \multirow[b]{2}{*}{$\varepsilon_{T_{a r}}$} & \multirow[b]{2}{*}{$T_{u}$} & \multirow[b]{2}{*}{$D R$} \\
\hline Posição & $\overline{v_{a r}}$ & $\sigma_{v_{a r}}$ & $\overline{v_{a r}}$ & $\sigma_{v_{a r}}$ & $\overline{v_{a r}}$ & $\sigma_{v_{a r}}$ & $\overline{v_{a r}}$ & $\varepsilon_{v_{a r}}$ & $\overline{T_{a r}}$ & $\sigma_{T_{a r}}$ & $\overline{T_{a r}}$ & $\sigma_{T_{a r}}$ & $\overline{T_{a r}}$ & $\sigma_{T_{a r}}$ & & & & \\
\hline $1 \mathrm{~A}$ & 0,14 & 0,07 & 0,14 & 0,06 & 0,15 & 0,07 & 0,14 & 0,04 & 24,0 & 0,2 & 23,9 & 0,2 & 23,9 & 0,2 & 23,9 & 0,1 & 47 & 13 \\
\hline $1 B$ & 0,27 & 0,10 & 0,25 & 0,10 & 0,26 & 0,10 & 0,26 & 0,06 & 23,9 & 0,2 & 23,9 & 0,2 & 23,9 & 0,2 & 23,9 & 0,1 & 38 & 26 \\
\hline $1 C$ & 0,17 & 0,07 & 0,17 & 0,07 & 0,18 & 0,07 & 0,17 & 0,04 & 24,3 & 0,2 & 24,3 & 0,2 & 24,2 & 0,2 & 24,3 & 0,1 & 41 & 15 \\
\hline $1 \mathrm{D}$ & 0,08 & 0,05 & 0,09 & 0,05 & 0,09 & 0,05 & 0,09 & 0,03 & 24,7 & 0,2 & 24,7 & 0,2 & 24,7 & 0,2 & 24,7 & & 53 & 6 \\
\hline $1 \mathrm{E}$ & 0,13 & 0,04 & 0,12 & 0,04 & 0,12 & 0,04 & 0,12 & 0,03 & 26,5 & 0,3 & 26,6 & 0,3 & 26,6 & 0,3 & 26,6 & 0,2 & 36 & 7 \\
\hline $2 \mathrm{~A}$ & 0,08 & 0,07 & 0,11 & 0,07 & 0,11 & 0,08 & 0,10 & 0,04 & 24,1 & 0,2 & 24,0 & 0,2 & 24,0 & 0,2 & 24,0 & 0,1 & 76 & 9 \\
\hline $2 B$ &, 12 & 0,07 & 0,15 & 0,09 & 0,13 & 0,08 & 0,13 & 0,05 & 24,2 & 0,2 & 24,1 & 0,2 & 24,1 & 0,2 & 24,1 & & 60 & 13 \\
\hline $2 C$ & 0,13 & 0,05 & 0,13 & 0,05 & 0,12 & 0,04 & 0,13 & 0,03 & 24,2 & 0,2 & 24,2 & 0,2 & 24,2 & 0,2 & 24,2 & 1 & 38 & 10 \\
\hline $2 \mathrm{D}$ & 0,09 & 0,05 & 0,08 & 0,05 & 0,08 & 0,05 & 0,08 & 0,03 & 24,1 & 0,2 & 25,6 & 0,3 & 25,6 & 0,3 & 24,9 & & 61 & 6 \\
\hline $2 \mathrm{E}$ &, 12 & 0,04 & 0,11 & 0,04 & 0,12 & 0,04 & 0,12 & 0,02 & 25,0 & 0,2 & 24,9 & 0,2 & 24,9 & 0,2 & 24,9 & & 33 & 8 \\
\hline $3 \mathrm{~A}$ & 0,21 & 0,07 & 0,20 & 0,06 & 0,21 & 0,06 & 0,21 & 0,04 & 23,8 & 0 & 23,6 & 2 & 23,6 & 2 & 23,7 & & 31 & 18 \\
\hline $3 B$ & 0,18 & 0,08 & 0,19 & 08 & 0,17 & 0,08 & 0,18 & 0,05 & 23,7 & 0 , & 23,6 & & 23,6 & & 23,6 & & 4 & 17 \\
\hline $3 C$ & 11 & 0,07 & 12 & 07 & 0,11 & 0,0 & 11 & & 24,0 & & 3,9 & & 23,9 & & 23,9 & & 63 & 11 \\
\hline $3 D$ & 0,03 & 0,03 & 0,03 & 0,03 & 0,03 & 0,03 & 0,03 & 0,0 & 24,0 & 0 & 24,0 & 2 & 24,0 & 2 & 24,0 & 1 & 104 & 0 \\
\hline $3 \mathrm{E}$ & 0,14 & 0,04 & \begin{tabular}{|l|l|}
0,14 \\
\end{tabular} & 0,03 & 0,14 & 0,03 & 0,14 & \begin{tabular}{|l|l|}
0,02 \\
\end{tabular} & 24,3 & 0,2 & 24,3 & 0,2 & 24,4 & & 24,3 & & 25 & 10 \\
\hline \multicolumn{19}{|c|}{ UFAD } \\
\hline & \multicolumn{2}{|c|}{ Dia 1} & $\mathrm{Di}$ & a 2 & & a 3 & & & $\mathrm{Dia}$ & a 1 & $\mathrm{Di}^{2}$ & a 2 & $\mathrm{Di}$ & a 3 & & & & \\
\hline Posição & $\overline{v_{a r}}$ & $\sigma_{v_{a r}}$ & $\overline{v_{a r}}$ & & $\overline{v_{a r}}$ & & & & $\overline{T_{a r}}$ & $\sigma_{T_{a r}}$ & $\overline{T_{a r}}$ & $\sigma_{T_{a r}}$ & $\overline{T_{a r}}$ & $\sigma_{T_{a r}}$ & $\overline{T_{a r}}$ & $\varepsilon_{T_{a r}}$ & $T_{u}$ & $D R$ \\
\hline $1 \mathrm{~A}$ & 0,13 & 0,05 & 0,15 & 0,06 & 0,16 & 0,05 & 0,15 & 0,03 & 22,3 & 0,2 & 22,3 & 0,2 & 22,3 & 0,2 & 22,3 & 0,1 & 37 & 14 \\
\hline $1 \mathrm{~B}$ & 0,20 & 0,06 & 0,19 & 0,06 & 0,20 & 0,06 & 0,20 & 0,04 & 23,1 & & 23,0 & & 23,0 & & 23,0 & & 32 & 18 \\
\hline $1 \mathrm{C}$ & 0,13 & 0,07 & 0,13 & 0,06 & 0,14 & 0, & 0,13 & 0, & 22,7 & 0 & 22,7 & 2 & 22,6 & 2 & 22,7 & & 50 & 13 \\
\hline $1 \mathrm{D}$ & 0,22 & 0,06 & 22 & 05 & 0,21 & 0, & 0,2 & & 24,1 & & 24,2 & & 24,3 & & 24,2 & & 6 & 7 \\
\hline $1 \mathrm{E}$ & 0,35 & 0,09 & 0,29 & 0,09 & 0,30 & 0,09 & 0,31 & 0,05 & 23,7 & & 23,8 & 2 & 23,8 & 2 & 23,8 & & 9 & 29 \\
\hline $2 \mathrm{~A}$ & 0,18 & 0,07 & 0,19 & 0,07 & 0,19 & 0, & 0,19 & 0, & 22,3 & 0 & 22,2 & & 22,1 & & 22,2 & & 40 & 20 \\
\hline $2 B$ & 0,06 & 0,04 & 07 & 3 & 0,07 & & & & 22,7 & & 22,8 & & 22,8 & & 22,7 & & 5 & 4 \\
\hline $2 C$ & 0,57 & 0,12 & 0,55 & 0,13 & 0,56 & 0,11 & 0,56 & 0,07 & 21,9 & & 21,9 & 2 & 21,9 & 2 & 21,9 & 1 & 21 & 60 \\
\hline $2 \mathrm{D}$ & 0,49 & 0,0 & 0,50 & 0,07 & 0,49 & 0, & 0,4 & & 23,2 & & 23,2 & & 23,2 & & 23,2 & & 14 & 38 \\
\hline $2 \mathrm{E}$ & 37 & 0,1 & 38 & 1 & 0,36 & & & & 22,6 & & 6 & & 22,6 & & 22,6 & & 1 & 13 \\
\hline $3 A$ & 0,62 & 0,11 & 0,63 & 0,11 & 0,63 & 0,10 & 0,63 & 0,06 & 21,3 & 0,2 & 21,3 & 2 & 21,3 &, 2 & 21,3 &, 1 & 17 & 64 \\
\hline $3 B$ & 0,23 & 0,0 & 3 & 0,06 & 0,23 & & & & 21,6 & & & & 6 & & 6 & & 27 & 23 \\
\hline $3 C$ & 53 & 0,1 & 3 & 2 & 0,53 & & & & 21,6 & & 21,6 & & 21,6 & & 21 & & 3 & 60 \\
\hline $3 D$ & 0,13 & 0,06 & 0,14 & 0,06 & 0,14 & 0,07 & 0,14 & 0,04 & 22,9 & 0,3 & 22,8 & 0,3 & 22,8 & 0,3 & 22,8 & 0,2 & 47 & 14 \\
\hline $3 \mathrm{E}$ & 0,16 & 0,07 & 0,16 & 0,06 & 0,15 & 0,06 & 0,16 & 0,04 & 22,7 & 0,2 & 22,6 & 0,2 & 22,7 & 0,2 & 22,7 & & 39 & 15 \\
\hline & & & & & & & & & & & & & & & & & & \\
\hline & & a 1 & D & a 2 & & a 3 & & & $\mathrm{Dic}$ & a 1 & Dis & & $\mathrm{Dis}$ & & & & & \\
\hline Posição & $\overline{v_{a r}}$ & $\sigma_{v_{a r}}$ & & & & & $\overline{v_{a r}}$ & & $\overline{T_{a r}}$ & $\sigma_{T_{a r}}$ & $\overline{T_{a r}}$ & $\sigma_{T_{a r}}$ & $\overline{T_{a r}}$ & $\sigma_{T_{a r}}$ & $\overline{T_{a r}}$ & $\varepsilon_{T_{a r}}$ & $\boldsymbol{T}_{\boldsymbol{u}}$ & $D R$ \\
\hline $1 \mathrm{~A}$ & 0,15 & 0,05 & 0,16 & 0,04 & 0,15 & 0,05 & 0,15 & 0,03 & 24,8 & 0,2 & 24,9 & 0,2 & 24,9 & & 24,9 & & 30 & 11 \\
\hline $1 \mathrm{~B}$ & 0,28 & 0,06 & 0,29 & 0,05 & 0,29 & & 0,29 & & 25,8 & & 25,8 & & 25,8 & & 25,8 & & 19 & 17 \\
\hline $1 \mathrm{C}$ & 0,21 & 0,08 & 0,22 & 0,09 & 0,22 & 0,08 & 0,21 & 0,05 & 25,0 & 0,2 & 25,2 & 0,2 & 25,3 & 0,2 & 25,2 & 0,1 & 39 & 18 \\
\hline $1 \mathrm{D}$ & 0,08 & 0,04 & 0,08 & 0,03 & 0,08 & 0,0 & 0,08 & 0,02 & 27,5 & & 27,5 & & 27,3 & & 27,5 & & 45 & 3 \\
\hline $1 \mathrm{E}$ & 0,13 & 0,05 & 0,13 & 0,05 & 0,13 & 0,04 & 0,13 & 0,03 & 27,7 & 0,2 & 27,7 & & 27,7 & & 27,7 & & 36 & 6 \\
\hline $2 \mathrm{~A}$ & 0,35 & 0,07 & 0,35 & 0,08 & 0,35 & 0,07 & 0,35 & 0,04 & 24,0 & 0,2 & 23,9 & 0,2 & 23,9 & 0,2 & 23,9 & 0,1 & 21 & 28 \\
\hline $2 B$ & 0,18 & 0,06 & 0,19 & 0,06 & 0,18 & 0,06 & 0,19 & 0,03 & 25,2 & 0,2 & 25,2 & 0,3 & 25,1 & 2 & 25,2 & 1 & 31 & 14 \\
\hline $2 C$ & 0,44 & 0,11 & 0,43 & 0,11 & 0,42 & 0,12 & 0,43 & 0,06 & 23,6 & 0,2 & 23,6 & 0,2 & 23,5 & 0,2 & 23,6 & 0,1 & 26 & 42 \\
\hline $2 \mathrm{D}$ & 0,17 & 0,06 & 0,18 & 0,07 & 0,18 & 0,07 & 0,18 & 0,04 & 25,4 & 0,3 & 25,4 & 0,3 & 25,3 & 0,3 & 25,4 & 0,2 & 37 & 13 \\
\hline $2 \mathrm{E}$ & 0,12 & 0,05 & 0,12 & 0,06 & 0,13 & 0,06 & 0,12 & 0,03 & 26,2 & 0,3 & 26,3 & 0,2 & 26,3 & 0,3 & 26,3 & 0,1 & 44 & 8 \\
\hline $3 \mathrm{~A}$ & 0,28 & 0,06 & 0,28 & 0,06 & 0,27 & 0,06 & 0,28 & 0,03 & 23,9 & 0,2 & 23,8 & 0,2 & 23,8 & 0,2 & 23,8 & 0,1 & 21 & 21 \\
\hline $3 B$ & 0,28 & 0,06 & 0,29 & 0,06 & 0,29 & 0,06 & 0,29 & 0,03 & 23,8 & 0,2 & 23,8 & 0,2 & 23,8 & 0,2 & 23,8 & 0,1 & 20 & 22 \\
\hline $3 C$ & 0,64 & 0,14 & 0,66 & 0,13 & 0,64 & 0,14 & 0,65 & 0,08 & 23,3 & 0,2 & 23,3 & 0,2 & 23,2 & 0,2 & 23,3 & 0,1 & 21 & 65 \\
\hline $3 D$ & 0,26 & 0,06 & 0,27 & 0,06 & 0,27 & 0,07 & 0,26 & 0,04 & 24,2 & 0,2 & 24,2 & 0,2 & 24,2 & 0,2 & 24,2 & 0,1 & 25 & 21 \\
\hline $3 \mathrm{E}$ & 0,31 & 0,05 & 0,31 & 0,06 & 0,31 & 0,05 & 0,31 & 0,03 & 24,5 & 0,2 & 24,5 & 0,2 & 24,5 & 0,2 & 24,5 & 0,1 & 17 & 21 \\
\hline
\end{tabular}


Tabela A-6. Resultados das velocidades e temperaturas do ar para temperatura de insuflamento de $22{ }^{\circ} \mathrm{C}$, região inferior. $(1,10 \mathrm{~m})$

\begin{tabular}{|c|c|c|c|c|c|c|c|c|c|c|c|c|c|c|c|c|c|c|}
\hline \multicolumn{19}{|c|}{ MV } \\
\hline & \multicolumn{2}{|c|}{ Dia 1} & \multicolumn{2}{|c|}{ Dia 2} & \multicolumn{2}{|c|}{ Dia 3} & & & \multicolumn{2}{|c|}{ Dia 1} & \multicolumn{2}{|c|}{ Dia 2} & \multicolumn{2}{|c|}{ Dia 3} & \multirow[b]{2}{*}{$\overline{T_{a r}}$} & \multirow[b]{2}{*}{$\varepsilon_{T_{a r}}$} & \multirow[b]{2}{*}{$T_{u}$} & \multirow[b]{2}{*}{$D R$} \\
\hline Posição & $\overline{v_{a r}}$ & $\sigma_{v_{a r}}$ & $\overline{v_{a r}}$ & $\sigma_{v_{a r}}$ & $\overline{v_{a r}}$ & $\sigma_{v_{a r}}$ & $\overline{v_{a r}}$ & $\varepsilon_{v_{a r}}$ & $\overline{T_{a r}}$ & $\sigma_{T_{a r}}$ & $\overline{T_{a r}}$ & $\sigma_{T_{a r}}$ & $\overline{T_{a r}}$ & $\sigma_{T_{a r}}$ & & & & \\
\hline $1 \mathrm{~A}$ & 0,36 & 0,13 & 0,36 & 0,14 & 0,35 & 0,13 & 0,35 & 0,08 & 23,9 & 0,2 & 23,9 & 0,2 & 23,9 & 0,2 & 23,9 & 0,1 & 38 & 40 \\
\hline $1 \mathrm{~B}$ & 0,55 & 0,18 & 0,57 & 0,20 & 0,54 & 0,18 & 0,55 & 0,11 & 24,1 & 0,2 & 24,1 & 0,2 & 24,1 & 0,2 & 24,1 & 0,1 & 34 & 65 \\
\hline $1 \mathrm{C}$ & 0,36 & 0,14 & 0,36 & 0,14 & 0,34 & 0,13 & 0,35 & 0,08 & 24,5 & 0,2 & 24,4 & 0,2 & 24,4 & 0,2 & 24,4 & 0,1 & 38 & 37 \\
\hline $1 \mathrm{D}$ & 0,42 & 08 & 0,43 & 0,08 & 0,42 & 0,08 & 0,42 & 0,05 & 25,2 & 0,2 & 25,1 & 0,2 & 25,2 & 0,2 & 25,2 & 0,1 & 19 & 30 \\
\hline $1 \mathrm{E}$ & 0,48 & 0,14 & 0,46 & 0,14 & 0,47 & 0,13 & 0,47 & 0,08 & 25,6 & 0,2 & 25,5 & 0,2 & 25,5 & 0,2 & 25,5 & 0,1 & 29 & 40 \\
\hline $2 \mathrm{~A}$ & 0,36 & 0,12 & 0,36 & 0,12 & 0,33 & 0,12 & 0,35 & \begin{tabular}{|l|l|}
0,07 \\
\end{tabular} & 23,8 & 0,2 & 23,7 & 0,2 & 23,7 & 0,2 & 23,8 & 1 & 34 & 37 \\
\hline $2 B$ & 40 & 0,10 & 0,41 & 0,11 & 0,41 & 0,10 & 0,40 & 0,06 & 23,8 & 0,2 & 23,9 & 0,2 & 23,8 & 0,2 & 23,8 &, 1 & 25 & 37 \\
\hline $2 C$ & 0,43 & 0,09 & 0,43 & 0,08 & 0,43 & 0,08 & 0,43 & 0,05 & 24,0 & 0,2 & 24,0 & 0,2 & 24,0 & 0,2 & 24,0 & 0,1 & 19 & 34 \\
\hline $2 D$ & 08 & ,04 & 0,39 & $\mid 0,07$ & 0,38 & 0,07 & \begin{tabular}{|l|l|}
0,22 \\
\end{tabular} & 0,03 & 25,7 & 0,3 & 25,0 & 0,2 & 24,9 & 0,2 & 25,1 & 1 & 31 & 17 \\
\hline $2 \mathrm{E}$ & 41 & 13 & 0,40 & 0,13 & 0,41 & 13 & 0,41 & 0,08 & 24,7 & 0,2 & 24,7 & 0,2 & 24,7 & 0,2 & 24,7 & 1 & 32 & 39 \\
\hline $3 A$ & 0,52 & 0,10 & 0,52 & 0,11 & 0,52 & 0,10 & 0,52 & 0,06 & 24,0 & 0,2 & 23,7 & 0,2 & 23,5 & 0,2 & 23,7 &, 1 & 20 & 45 \\
\hline $3 B$ & 41 & 12 & 0,43 & 0,12 & 0,41 & 0,12 & \begin{tabular}{|l|}
0,42 \\
\end{tabular} & \begin{tabular}{|l|}
0,07 \\
\end{tabular} & 23,7 & 0,2 & 23,7 & 0,2 & 23,7 & 0,2 & 23,7 &, 1 & 29 & 42 \\
\hline $3 C$ & 25 & 10 & 0,24 & 0,09 & 0,24 & & \begin{tabular}{|l|}
0,24 \\
\end{tabular} & 0,06 & 24,0 & 0,2 & 24,0 & & 24,0 & 0,2 & 24,0 & 1 & 41 & 24 \\
\hline $3 \mathrm{D}$ & 0,38 & 0,07 & 0,38 & 0,07 & 0,39 & 0,07 & 0,38 & 0,04 & 23,7 & 0,2 & 23,6 & 0,2 & 23,6 & 0,2 & 23,6 & 0,1 & 19 & 30 \\
\hline $3 \mathrm{E}$ & 0,36 & 0,08 & 0,33 & 0,08 & 0,34 & 0,08 & 0,34 & 0,05 & 25,0 & 0,2 & 25,0 & 0,2 & 25,0 & 0,2 & 25,0 & & 24 & 26 \\
\hline \multicolumn{19}{|c|}{ UFAD } \\
\hline & \multicolumn{2}{|c|}{ Dia 1} & $\mathrm{Di}$ & a 2 & $\mathrm{Di}$ & a 3 & & & $\mathrm{Di}$ & & Dia & & $\mathrm{Di}$ & & & & & \\
\hline Posição & $\overline{v_{a r}}$ & $\sigma_{v_{a r}}$ & $\overline{v_{a r}}$ & $\sigma_{v_{a r}}$ & $\overline{v_{a r}}$ & $\sigma_{v_{a r}}$ & $\overline{v_{a r}}$ & $\varepsilon_{v_{a r}}$ & $\overline{T_{a r}}$ & $\sigma_{T_{a r}}$ & $\overline{T_{a r}}$ & $\sigma_{T_{a r}}$ & $\overline{T_{a r}}$ & $\sigma_{T_{a r}}$ & $\overline{T_{a r}}$ & $\varepsilon_{T_{a r}}$ & $T_{u}$ & $D R$ \\
\hline $1 \mathrm{~A}$ & 0,08 & 0,04 & 0,08 & 0,04 & 0,08 & 0,03 & 0,08 & 0,02 & 22,5 & 0,2 & 22,5 & 0,2 & 22,5 & 0,2 & 22,5 & 0,1 & 44 & 6 \\
\hline $1 \mathrm{~B}$ & 0,07 & 0,04 & 0,08 & 0,05 & 0,08 & 0,04 & 0,08 & 0,03 & 22,9 & 0,2 & 22,9 &, 2 & 22,9 & 2 & 22,9 & 1 & 60 & 5 \\
\hline $1 \mathrm{C}$ & 0,06 & 0,04 & 0,06 & 0,04 & 0,06 & 0,04 & 0,06 & 0,02 & 22,6 & 0,2 & 22,6 & 0,2 & 22,5 & 0,2 & 22,6 & 0,1 & 68 & 3 \\
\hline $1 \mathrm{D}$ & 09 & 0 & 0,09 & 0,04 & 0,09 & & 0,09 & 0,02 & 23,5 & 0,2 & 23,4 & 2 & 23,5 & 2 & 23,5 & 1 & 37 & 7 \\
\hline $1 \mathrm{E}$ & 0,11 & 0,04 & 0,10 & 0,03 & 0,10 & 0,03 & 0,10 & 0,02 & 24,0 & 0,3 & 23,8 &, 3 & 23,8 &, 3 & 23,9 &, 2 & 4 & 7 \\
\hline $2 \mathrm{~A}$ & 0,06 & 0,04 & 0,07 & 0,04 & 0,07 & 0,0 & 0,06 & 0,03 & 22,7 & 0,2 & 22,6 & 0,2 & 22,5 & 0,2 & 22,6 & 1 & 68 & 4 \\
\hline $2 B$ & 09 & & 0,09 & 0,0 & 0, & & 0,10 & 02 & 22,6 & 0,2 & 22,6 & & 22,6 & 2 & 22,6 & 1 & 39 & 8 \\
\hline $2 C$ & 0,10 & 0,06 & 0,10 & 0,06 & 0,10 & 0,06 & 0,10 & 0,03 & 22,0 & 0,2 & 22,0 & 0,2 & 22,1 & 0,2 & 22,0 & 0,1 & 60 & 10 \\
\hline $2 \mathrm{D}$ & 05 & 0,04 & 0,05 & 0,0 & 0,07 & 0, & 0,06 & 0,02 & 23,4 & 0,3 & 23,4 & 0,3 & 23,3 & 0,3 & 23,4 &, 2 & 72 & 2 \\
\hline $2 \mathrm{E}$ & 12 & & 0,11 & 0,04 & 0,1 & & 0,12 & 0 , & 22,9 & 0,2 & 22,8 & & 22,8 & 2 & 22,8 & 1 & 35 & 10 \\
\hline $3 A$ & 0,21 & 0,09 & 0,20 & 0,08 & 0,20 & 0,08 & 0,20 & 0,05 & 21,6 & 0,2 & 21,6 & 0,2 & 21,5 & 0,2 & 21,6 & 0,1 & 41 & 24 \\
\hline $3 B$ & 09 & & 0,10 & 0,0 & 0,0 & & 0,10 & 0,03 & 21,8 & 0,2 & 21,7 & 0,2 & 1,7 & 0,2 & 21,7 & 1 & 56 & 9 \\
\hline $3 C$ & & & 0,10 & 0,0 & 0,1 & & 0,10 & & 21,8 & & 21,8 & & 21,8 & 0 & 21,8 & 1 & 56 & 10 \\
\hline $3 \mathrm{D}$ & 0,07 & 0,05 & 0,08 & 0,04 & 0,08 & 0,05 & 0,08 & 0,03 & 22,1 & 0,2 & 22,1 & 0,2 & 22,0 & 0,2 & 22,1 & 0,1 & 62 & 6 \\
\hline $3 \mathrm{E}$ & 0,08 & 0,04 & 0,07 & 0,04 & 0,08 & 0,04 & 0,08 & 0,02 & 22,5 & 0,3 & 22,5 & 0,3 & 22,5 & 0,3 & 22,5 & 0,2 & 54 & 6 \\
\hline & & & & & & & & & & & & & & & & & & \\
\hline & & a 1 & $\mathrm{Di}$ & a 2 & $\mathrm{Di}$ & a 3 & & & $\mathrm{Di}$ & & Dia & & Di & & & & & \\
\hline Posição & $\overline{v_{a r}}$ & & & & & & & & $\overline{T_{a r}}$ & $\sigma_{T_{a r}}$ & $\overline{T_{a r}}$ & $\sigma_{T_{a r}}$ & $\overline{T_{a r}}$ & $\sigma_{T_{a r}}$ & $\overline{T_{a r}}$ & $\varepsilon_{T_{a r}}$ & $T_{u}$ & $D R$ \\
\hline $1 \mathrm{~A}$ & 0,05 & 0,04 & 0,04 & 0,04 & 0,05 & 0,04 & 0,05 & 0,02 & 24,8 & 0,3 & 24,9 & 0,3 & 24,9 & 0,3 & 24,8 & 0,2 & 83 & 0 \\
\hline $1 \mathrm{~B}$ & 0,04 & & 0,04 & 0,03 & 0,04 & & 0,04 & 0,02 & 26,0 & 0,2 & 26,1 & 0,2 & 26,0 & 0,2 & 26,0 & 0,1 & 95 & 0 \\
\hline $1 \mathrm{C}$ & 0,09 & 0,06 & 0,09 & 0,06 & 0,09 & 0,06 & 0,09 & 0,04 & 25,2 & 0,2 & 25,3 & 0,2 & 25,4 & 0,2 & 25,3 & 0,1 & 68 & 6 \\
\hline $1 \mathrm{D}$ & 0,07 & 0,04 & 0,07 & 0,04 & 0,07 & 0,0 & 0,07 & \begin{tabular}{|l|}
0,02 \\
\end{tabular} & 27,0 & 0,2 & 27,0 & 0,2 & 26,9 & 0,2 & 27,0 & 0,1 & 57 & 3 \\
\hline $1 \mathrm{E}$ & 0,10 & 0,04 & 0,10 & 0,04 & 0,10 & 0,04 & 0,10 & 0,02 & 27,4 & 0,2 & 27,5 & 0,3 & 27,4 & 0,3 & 27,4 & 0,1 & 37 & 5 \\
\hline $2 \mathrm{~A}$ & 0,12 & 0,04 & 0,10 & 0,04 & 0,12 & 0,04 & 0,11 & 0,02 & 24,7 & 0,2 & 24,5 & 0,2 & 24,5 & 0,2 & 24,5 & 0,1 & 38 & 8 \\
\hline $2 B$ & 0,09 & 0,06 & 0,10 & 0,05 & 0,10 & 0,06 & 0,10 & 0,03 & 24,5 & 0,2 & 24,4 & 0,2 & 24,4 & 0,2 & 24,4 & 0,1 & 57 & 7 \\
\hline $2 C$ & 0,12 & 0,06 & 0,11 & 0,06 & 0,11 & 0,06 & 0,11 & 0,03 & 23,8 & 0,2 & 23,8 & 0,2 & 23,7 & 0,2 & 23,8 & 0,1 & 52 & 10 \\
\hline $2 \mathrm{D}$ & 0,08 & 0,05 & 0,09 & 0,05 & 0,09 & 0,05 & 0,09 & 0,03 & 24,7 & 0,2 & 24,6 & 0,3 & 24,6 & 0,3 & 24,6 & 0,1 & 57 & 6 \\
\hline $2 \mathrm{E}$ & 0,05 & 0,04 & 0,05 & 0,04 & 0,05 & 0,04 & 0,05 & 0,02 & 26,0 & 0,3 & 26,2 & 0,3 & 26,1 & 0,3 & 26,1 & 0,2 & 80 & 0 \\
\hline $3 \mathrm{~A}$ & 0,11 & 0,05 & 0,12 & 0,05 & 0,11 & 0,05 & 0,11 & 0,03 & 24,1 & 0,2 & 23,9 & 0,2 & 23,9 & 0,2 & 23,9 & 0,1 & 42 & 9 \\
\hline $3 B$ & 0,15 & 0,06 & 0,16 & 0,06 & 0,16 & 0,06 & 0,16 & 0,03 & 23,9 & 0,2 & 23,8 & 0,2 & 23,8 & 0,2 & 23,8 & 0,1 & 36 & 13 \\
\hline $3 C$ & 0,16 & 0,08 & 0,16 & 0,07 & 0,17 & 0,07 & 0,16 & 0,04 & 23,6 & 0,2 & 23,5 & 0,2 & 23,5 & 0,2 & 23,5 & 0,1 & 46 & 16 \\
\hline $3 \mathrm{D}$ & 0,12 & 0,06 & 0,12 & 0,06 & 0,11 & 0,06 & 0,11 & 0,03 & 23,8 & 0,2 & 23,8 & 0,2 & 23,9 & 0,2 & 23,8 & 0,1 & 51 & 10 \\
\hline $3 \mathrm{E}$ & 0,13 & 0,04 & 0,13 & 0,04 & 0,13 & 0,04 & 0,13 & 0,03 & 24,1 & 0,2 & 24,2 & 0,2 & 24,2 & 0,2 & 24,2 & 0,1 & 34 & 10 \\
\hline
\end{tabular}




\section{APÊNDICE B}

\section{Resultados das medições e respectivas incertezas da concentração de partículas}

Os resultados da concentração de partículas, juntamente com as incertezas de medição, são apresentados nas Tabelas B.1 a B.12.

Os valores das concentrações de partículas são a média dos valores dos resultados dos três ensaios (ensaios em triplicata) em cada posição e em cada condição estudada.

A exemplo do Apêndice $C$, as incertezas das medições são o resultado da combinação das incertezas do equipamento de medição (contador de partículas) e dos desvios padrão em cada posição e em cada condição de ensaio dos ensaios em triplicata (COLEMAN e STEELE, 1989; VUOLO, 1996; INMETRO, 1998).

A incerteza do equipamento de medição (contador de partículas) na contagem de partículas segue a estatística de Poisson (KULKARNI; BARON; WILLEKE, 2011), com esta incerteza sendo estimada pela raiz quadrada do número de partículas contadas em cada medição. 
Tabela B-1. Resultados das medições de partículas no assento (Sistema MV à $18^{\circ} \mathrm{C}$ - injeção pelo assento $3 \mathrm{~B}$ )

\begin{tabular}{|c|c|c|c|c|c|c|c|c|}
\hline & & Unidade & $1,0-2,0 \mu \mathrm{m}$ & $2,0-3,0 \mu \mathrm{m}$ & $3,0-5,0 \mu \mathrm{m}$ & $5,0-7,0 \mu \mathrm{m}$ & $7,0-10,0 \mu \mathrm{m}$ & $>10,0 \mu \mathrm{m}$ \\
\hline \multirow{8}{*}{ Assento $3 \mathrm{E}$} & $\begin{array}{c}\text { Concentração média de } \\
\text { fundo }\end{array}$ & $\mathrm{p} / \mathrm{m}^{3}$ & $8,00 E+04$ & $3,67 E+04$ & $6,67 E+03$ & $0,00 E+00$ & $0,00 E+00$ & $0,00 E+00$ \\
\hline & $\begin{array}{c}\text { Número de particulas de } \\
\text { fundo }\end{array}$ & $\mathbf{P}$ & 24 & 11 & 2 & 0 & 0 & 0 \\
\hline & $\begin{array}{c}\text { Concentração média } \\
\text { liquida }\end{array}$ & $\mathrm{P} / \mathrm{m}^{3}$ & $2,65 E+08$ & $1,86 \mathrm{E}+08$ & $1,22 E+08$ & $9,33 E+07$ & $2,98 E+07$ & $1,20 E+06$ \\
\hline & $\begin{array}{c}\text { Número de Particulas } \\
\text { média liquida }\end{array}$ & $\mathbf{p}$ & 79511 & 55685 & 36542 & 28000 & 8942 & 361 \\
\hline & Desvio - Poisson & $\#$ & 281,98 & 235,98 & 191,16 & 167,33 & 94,56 & 19,00 \\
\hline & $\begin{array}{c}\text { Desvio - Poisson - } \\
\text { Relativo } \\
\end{array}$ & $\%$ & 0,4 & 0,4 & 0,5 & 0,6 & 1,1 & 5,3 \\
\hline & $\begin{array}{l}\text { Desvio padrão } \\
\text { Concentração }\end{array}$ & $\mathrm{P} / \mathrm{m}^{3}$ & $2,51 E+04$ & $1,68 E+04$ & $1,25 \mathrm{E}+04$ & $1,03 E+04$ & $3,89 \mathrm{E}+02$ & $1,53 \mathrm{E}+02$ \\
\hline & DP/Concentração média & $\%$ & 0,0095 & 0,0091 & 0,0103 & 0,0111 & 0,0013 & 0,0127 \\
\hline \multicolumn{2}{|c|}{ Erro total medições(ઘ) } & $\mathrm{P} / \mathrm{m}^{3}$ & $9,40 E+05$ & $7,87 E+05$ & $6,37 E+05$ & $5,58 E+05$ & $3,15 E+05$ & $6,33 E+04$ \\
\hline & & Unidade & $1,0-2,0 \mu \mathrm{m}$ & $2,0-3,0 \mu \mathrm{m}$ & $3,0-5,0 \mu \mathrm{m}$ & $5,0-7,0 \mu \mathrm{m}$ & $7,0-10,0 \mu \mathrm{m}$ & $>10,0 \mu \mathrm{m}$ \\
\hline \multirow{8}{*}{ Assento 2D } & $\begin{array}{c}\text { Concentração média de } \\
\text { fundo }\end{array}$ & $\mathrm{P} / \mathrm{m}^{3}$ & $1,63 E+05$ & $4,33 E+04$ & $3,33 \mathrm{E}+03$ & $1,67 \mathrm{E}+03$ & $0,00 E+00$ & $0,00 E+00$ \\
\hline & $\begin{array}{c}\text { Número de particulas de } \\
\text { fundo }\end{array}$ & $\mathbf{P}$ & 49 & 13 & 1 & 0,5 & 0 & 0 \\
\hline & \begin{tabular}{|c|}
$\begin{array}{c}\text { Concentração média } \\
\text { liquida }\end{array}$ \\
\end{tabular} & $\mathrm{P} / \mathrm{m}^{3}$ & $1,23 E+08$ & $9,70 \mathrm{E}+07$ & $8,61 \mathrm{E}+07$ & $4,55 E+07$ & $8,17 E+06$ & $5,13 E+05$ \\
\hline & $\begin{array}{l}\text { Número de Particulas } \\
\text { média liquida }\end{array}$ & $\mathbf{P}$ & 36984 & 29100 & 25818 & 13650 & 2452 & 154 \\
\hline & Desvio - Poisson & \# & 192,31 & 170,59 & 160,68 & 116,83 & 49,51 & 12,41 \\
\hline & $\begin{array}{c}\text { Desvio - Poisson - } \\
\text { Relativo } \\
\end{array}$ & $\%$ & 0,5 & 0,6 & 0,6 & 0,9 & 2,0 & 8,1 \\
\hline & $\begin{array}{l}\text { Desvio padrão } \\
\text { Concentração }\end{array}$ & $\mathrm{P} / \mathrm{m}^{3}$ & $1,75 E+03$ & $3,67 E+03$ & $4,73 E+03$ & $2,00 E+03$ & $4,90 E+02$ & $1,10 \mathrm{E}+02$ \\
\hline & DP/Concentração média & $\%$ & 0,0014 & 0,0038 & 0,0055 & 0,0044 & 0,0060 & 0,0215 \\
\hline \multirow{2}{*}{\multicolumn{2}{|c|}{ Erro total medições( $(\varepsilon)$}} & $\mathrm{p} / \mathrm{m}^{3}$ & $6,41 E+05$ & $5,69 \mathrm{E}+05$ & $5,36 \mathrm{E}+05$ & $3,89 \mathrm{E}+05$ & $1,65 E+05$ & $4,14 \mathrm{E}+04$ \\
\hline & & Unidade & $1,0-2,0 \mu \mathrm{m}$ & $2,0-3,0 \mu \mathrm{m}$ & $3,0-5,0 \mu \mathrm{m}$ & $5,0-7,0 \mu \mathrm{m}$ & $7,0-10,0 \mu \mathrm{m}$ & $>10,0 \mu \mathrm{m}$ \\
\hline \multirow{8}{*}{ Assento $2 \mathrm{E}$} & $\begin{array}{c}\text { Concentração média de } \\
\text { fundo }\end{array}$ & $\mathrm{P} / \mathrm{m}^{3}$ & $1,03 E+05$ & $3,00 E+04$ & $6,67 E+03$ & $0,00 E+00$ & $0,00 E+00$ & $0,00 E+00$ \\
\hline & $\begin{array}{c}\text { Número de particulas de } \\
\text { fundo } \\
\end{array}$ & $\mathbf{P}$ & 31 & 9 & 2 & 0 & 0 & 0 \\
\hline & $\begin{array}{c}\text { Concentração média } \\
\text { liquida }\end{array}$ & $\mathrm{P} / \mathrm{m}^{3}$ & $9,72 E+07$ & $8,50 E+07$ & $6,85 E+07$ & $3,28 E+07$ & $5,77 E+06$ & 3,43E+05 \\
\hline & $\begin{array}{c}\text { Número de Particulas } \\
\text { média liquida }\end{array}$ & $\mathbf{P}$ & 29147 & 25515 & 20539 & 9848 & 1732 & 103 \\
\hline & Desvio - Poisson & \# & 170,72 & 159,73 & 143,31 & 99,23 & 41,61 & 10,15 \\
\hline & $\begin{array}{c}\text { Desvio - Poisson - } \\
\text { Relativo } \\
\end{array}$ & $\%$ & 0,6 & 0,6 & 0,7 & 1,0 & 2,4 & 9,9 \\
\hline & $\begin{array}{l}\text { Desvio padrão } \\
\text { Concentração }\end{array}$ & $\mathrm{p} / \mathrm{m}^{3}$ & $1,86 \mathrm{E}+03$ & $2,79 E+03$ & $1,19 E+03$ & $6,20 E+02$ & $1,20 \mathrm{E}+02$ & $1,87 \mathrm{E}+01$ \\
\hline & DP/Concentração média & $\%$ & 0,0019 & 0,0033 & 0,0017 & 0,0019 & 0,0021 & 0,0054 \\
\hline \multicolumn{2}{|c|}{ Erro total medições(ઘ) } & $\mathrm{P} / \mathrm{m}^{3}$ & $5,69 \mathrm{E}+05$ & $5,32 \mathrm{E}+05$ & $4,78 E+05$ & $3,31 E+05$ & $1,39 \mathrm{E}+05$ & $3,38 \mathrm{E}+04$ \\
\hline
\end{tabular}


Unidade $1,0-2,0 \mu \mathrm{m}|2,0-3,0 \mu \mathrm{m}| 3,0-5,0 \mu \mathrm{m}|5,0-7,0 \mu \mathrm{m}| 7,0-10,0 \mu \mathrm{m} \mid>10,0 \mu \mathrm{m}$

\begin{tabular}{|c|c|c|c|c|c|c|c|c|}
\hline \multirow{8}{*}{ Assento 1D } & $\begin{array}{c}\text { Concentração média de } \\
\text { fundo }\end{array}$ & $\mathrm{P} / \mathrm{m}^{3}$ & $1,87 E+05$ & $8,33 \mathrm{E}+04$ & $1,33 \mathrm{E}+04$ & $3,33 \mathrm{E}+03$ & $0,00 \mathrm{E}+00$ & $0,00 \mathrm{E}+00$ \\
\hline & $\begin{array}{c}\text { Número de particulas de } \\
\text { fundo }\end{array}$ & $\mathbf{P}$ & 56 & 25 & 4 & 1 & 0 & 0 \\
\hline & $\begin{array}{l}\text { Concentração média } \\
\text { liquida }\end{array}$ & $\mathrm{P} / \mathrm{m}^{3}$ & $1,10 \mathrm{E}+08$ & $1,08 \mathrm{E}+08$ & $7,71 \mathrm{E}+07$ & $3,77 \mathrm{E}+07$ & $6,69 \mathrm{E}+06$ & $4,18 \mathrm{E}+05$ \\
\hline & $\begin{array}{c}\text { Número de Particulas } \\
\text { média liquida }\end{array}$ & $\mathbf{P}$ & 33036 & 32349 & 23125 & 11300 & 2006 & 126 \\
\hline & Desvio - Poisson & $\#$ & 181,76 & 179,86 & 152,07 & 106,30 & 44,79 & 11,20 \\
\hline & $\begin{array}{c}\text { Desvio - Poisson - } \\
\text { Relativo }\end{array}$ & $\%$ & 0,6 & 0,6 & 0,7 & 0,9 & 2,2 & 8,9 \\
\hline & $\begin{array}{l}\text { Desvio padrão } \\
\text { Concentração }\end{array}$ & $\mathrm{P} / \mathrm{m}^{3}$ & $3,55 E+03$ & $3,44 E+03$ & $2,18 \mathrm{E}+03$ & $1,13 \mathrm{E}+03$ & $1,88 \mathrm{E}+02$ & $1,66 \mathrm{E}+01$ \\
\hline & DP/Concentração média & $\%$ & 0,0032 & 0,0032 & 0,0028 & 0,0030 & 0,0028 & 0,0040 \\
\hline \multirow{2}{*}{\multicolumn{2}{|c|}{ Erro total medições(६) }} & $\mathrm{P} / \mathrm{m}^{3}$ & $6,06 \mathrm{E}+05$ & $6,00 \mathrm{E}+05$ & $5,07 E+05$ & $3,54 \mathrm{E}+05$ & $1,49 E+05$ & $3,73 \mathrm{E}+04$ \\
\hline & & Unidade & $1,0-2,0 \mu \mathrm{m}$ & $2,0-3,0 \mu \mathrm{m}$ & $3,0-5,0 \mu \mathrm{m}$ & $5,0-7,0 \mu \mathrm{m}$ & $7,0-10,0 \mu \mathrm{m}$ & $>10,0 \mu \mathrm{m}$ \\
\hline \multirow{8}{*}{ Assento 1E } & $\begin{array}{c}\begin{array}{c}\text { Concentração média de } \\
\text { fundo }\end{array} \\
\end{array}$ & $\mathrm{P} / \mathrm{m}^{3}$ & $1,43 \mathrm{E}+05$ & $7,67 \mathrm{E}+04$ & $6,67 \mathrm{E}+03$ & $0,00 \mathrm{E}+00$ & $0,00 \mathrm{E}+00$ & $0,00 \mathrm{E}+00$ \\
\hline & $\begin{array}{c}\begin{array}{c}\text { Número de particulas de } \\
\text { fundo }\end{array} \\
\end{array}$ & $\mathbf{p}$ & 43 & 23 & 2 & 0 & 0 & 0 \\
\hline & $\begin{array}{l}\text { Concentração média } \\
\text { liquida } \\
\end{array}$ & $\mathrm{P} / \mathrm{m}^{3}$ & $1,16 \mathrm{E}+08$ & $1,04 \mathrm{E}+08$ & $7,85 \mathrm{E}+07$ & $3,85 \mathrm{E}+07$ & $1,17 \mathrm{E}+07$ & $3,10 E+05$ \\
\hline & $\begin{array}{c}\text { Número de Particulas } \\
\text { média liquida }\end{array}$ & $\mathbf{P}$ & 34653 & 31276 & 23560 & 11540 & 3500 & 93 \\
\hline & Desvio - Poisson & \# & 186,15 & 176,85 & 153,49 & 107,42 & 59,16 & 9,64 \\
\hline & $\begin{array}{c}\text { Desvio - Poisson - } \\
\text { Relativo } \\
\end{array}$ & $\%$ & 0,5 & 0,6 & 0,7 & 0,9 & 1,7 & 10,4 \\
\hline & $\begin{array}{l}\text { Desvio padrão } \\
\text { Concentração } \\
\end{array}$ & $\mathrm{P} / \mathrm{m}^{3}$ & $5,49 E+03$ & $4,70 E+03$ & $3,14 \mathrm{E}+03$ & $2,40 E+03$ & $1,18 \mathrm{E}+03$ & $9,84 E+00$ \\
\hline & DP/Concentração média & $\%$ & 0,0048 & 0,0045 & 0,0040 & 0,0063 & 0,0101 & 0,0032 \\
\hline \multirow{2}{*}{\multicolumn{2}{|c|}{ Erro total medições(દ) }} & $\mathrm{P} / \mathrm{m}^{3}$ & $6,21 E+05$ & $5,90 E+05$ & $5,12 \mathrm{E}+05$ & $3,58 \mathrm{E}+05$ & $1,97 E+05$ & $3,21 \mathrm{E}+04$ \\
\hline & & Unidade & $1,0-2,0 \mu \mathrm{m}$ & $2,0-3,0 \mu \mathrm{m}$ & $3,0-5,0 \mu \mathrm{m}$ & $5,0-7,0 \mu \mathrm{m}$ & $7,0-10,0 \mu \mathrm{m}$ & $>10,0 \mu \mathrm{m}$ \\
\hline \multirow{8}{*}{ Assento 1B } & $\begin{array}{c}\text { Concentração média de } \\
\text { fundo } \\
\end{array}$ & $\mathrm{P} / \mathrm{m}^{3}$ & $1,93 \mathrm{E}+05$ & $1,13 \mathrm{E}+05$ & $1,33 \mathrm{E}+04$ & $0,00 E+00$ & $0,00 \mathrm{E}+00$ & $0,00 E+00$ \\
\hline & $\begin{array}{c}\text { Número de particulas de } \\
\text { fundo }\end{array}$ & $\mathbf{P}$ & 58 & 34 & 4 & 0 & 0 & 0 \\
\hline & $\begin{array}{l}\text { Concentração média } \\
\text { liquida } \\
\end{array}$ & $\mathrm{P} / \mathrm{m}^{3}$ & $8,46 \mathrm{E}+07$ & $8,31 E+07$ & $6,19 \mathrm{E}+07$ & $2,91 \mathrm{E}+07$ & $5,36 \mathrm{E}+06$ & $3,73 E+05$ \\
\hline & $\begin{array}{c}\text { Número de Particulas } \\
\text { média liquida }\end{array}$ & $\mathbf{P}$ & 25391 & 24939 & 18578 & 8737 & 1608 & 112 \\
\hline & Desvio - Poisson & $\#$ & 159,35 & 157,92 & 136,30 & 93,47 & 40,10 & 10,58 \\
\hline & $\begin{array}{c}\text { Desvio - Poisson - } \\
\text { Relativo } \\
\end{array}$ & $\%$ & 0,6 & 0,6 & 0,7 & 1,1 & 2,5 & 9,4 \\
\hline & $\begin{array}{l}\text { Desvio padrão } \\
\text { Concentração }\end{array}$ & $\mathrm{P} / \mathrm{m}^{3}$ & $4,92 E+03$ & $4,76 E+03$ & $3,00 E+03$ & $1,35 \mathrm{E}+03$ & $1,84 \mathrm{E}+02$ & $2,88 \mathrm{E}+01$ \\
\hline & DP/Concentração média & $\%$ & 0,0058 & 0,0057 & 0,0048 & 0,0046 & 0,0034 & 0,0077 \\
\hline \multicolumn{2}{|c|}{ Erro total medições( $(\varepsilon)$} & $\mathrm{P} / \mathrm{m}^{3}$ & $5,31 E+05$ & $5,26 \mathrm{E}+05$ & $4,54 E+05$ & $3,12 \mathrm{E}+05$ & $1,34 \mathrm{E}+05$ & $3,53 \mathrm{E}+04$ \\
\hline
\end{tabular}


Unidade $1,0-2,0 \mu \mathrm{m}|2,0-3,0 \mu \mathrm{m}| 3,0-5,0 \mu \mathrm{m}|5,0-7,0 \mu \mathrm{m}| 7,0-10,0 \mu \mathrm{m} \mid>10,0 \mu \mathrm{m}$

\begin{tabular}{|c|c|c|c|c|c|c|c|c|}
\hline \multirow{8}{*}{ Assento $1 \mathrm{~A}$} & $\begin{array}{c}\text { Concentração média de } \\
\text { fundo } \\
\end{array}$ & $\mathrm{P} / \mathrm{m}^{3}$ & $3,00 E+05$ & $1,13 E+05$ & $1,00 \mathrm{E}+04$ & $0,00 E+00$ & $0,00 \mathrm{E}+00$ & $0,00 \mathrm{E}+00$ \\
\hline & $\begin{array}{c}\text { Número de particulas de } \\
\text { fundo }\end{array}$ & $\mathbf{P}$ & 90 & 34 & 3 & 0 & 0 & 0 \\
\hline & $\begin{array}{c}\text { Concentração média } \\
\text { liquida } \\
\end{array}$ & $\mathrm{P} / \mathrm{m}^{3}$ & $7,52 E+07$ & $7,39 \mathrm{E}+07$ & $5,48 \mathrm{E}+07$ & $2,56 \mathrm{E}+07$ & $4,79 \mathrm{E}+06$ & $3,37 E+05$ \\
\hline & $\begin{array}{c}\text { Número de Particulas } \\
\text { média liquida }\end{array}$ & $\mathbf{P}$ & 22554 & 22169 & 16433 & 7668 & 1436 & 101 \\
\hline & Desvio - Poisson & $\#$ & 150,18 & 148,89 & 128,19 & 87,57 & 37,89 & 10,05 \\
\hline & $\begin{array}{c}\text { Desvio - Poisson - } \\
\text { Relativo }\end{array}$ & $\%$ & 0,7 & 0,7 & 0,8 & 1,1 & 2,6 & 10,0 \\
\hline & $\begin{array}{l}\text { Desvio padrão } \\
\text { Concentração } \\
\end{array}$ & $\mathrm{P} / \mathrm{m}^{3}$ & $1,81 E+04$ & $1,74 \mathrm{E}+04$ & $1,12 \mathrm{E}+04$ & $6,25 E+03$ & $1,09 \mathrm{E}+03$ & $5,17 \mathrm{E}+0$ \\
\hline & DP/Concentração média & $\%$ & 0,0241 & 0,0236 & 0,0205 & 0,0245 & 0,0227 & 0,015 \\
\hline \multirow{2}{*}{\multicolumn{2}{|c|}{ Erro total medições(દ) }} & $\mathrm{P} / \mathrm{m}^{3}$ & $5,01 E+05$ & $4,97 E+05$ & $4,27 E+05$ & $2,92 E+05$ & $1,26 \mathrm{E}+05$ & $3,35 \mathrm{E}+0$ \\
\hline & & Unidade & $1,0-2,0 \mu \mathrm{m}$ & $2,0-3,0 \mu \mathrm{m}$ & $3,0-5,0 \mu \mathrm{m}$ & $5,0-7,0 \mu \mathrm{m}$ & $7,0-10,0 \mu \mathrm{m}$ & $>10,0 \mu \mathrm{m}$ \\
\hline \multirow{8}{*}{ Assento 2B } & $\begin{array}{c}\begin{array}{c}\text { Concentração média de } \\
\text { fundo }\end{array} \\
\end{array}$ & $\mathrm{P} / \mathrm{m}^{3}$ & $3,37 E+05$ & $1,83 E+05$ & $1,33 E+04$ & $3,33 E+03$ & $0,00 E+00$ & $0,00 E+00$ \\
\hline & $\begin{array}{c}\begin{array}{c}\text { Número de particulas de } \\
\text { fundo }\end{array} \\
\end{array}$ & $\mathbf{P}$ & 101 & 55 & 4 & 1 & 0 & 0 \\
\hline & $\begin{array}{c}\text { Concentração média } \\
\text { liquida }\end{array}$ & $\mathrm{P} / \mathrm{m}^{3}$ & $1,49 E+08$ & $1,46 E+08$ & $1,03 E+08$ & $6,00 E+07$ & $1,06 \mathrm{E}+07$ & $6,00 E+05$ \\
\hline & $\begin{array}{c}\text { Número de Particulas } \\
\text { média liquida }\end{array}$ & $\mathbf{P}$ & 44681 & 43661 & 31013 & 17988 & 3177 & 180 \\
\hline & Desvio - Poisson & $\#$ & 211,38 & 208,95 & 176,11 & 134,12 & 56,36 & 13,42 \\
\hline & $\begin{array}{c}\text { Desvio - Poisson - } \\
\text { Relativo }\end{array}$ & $\%$ & 0,5 & 0,5 & 0,6 & 0,7 & 1,8 & 7,5 \\
\hline & $\begin{array}{l}\text { Desvio padrão } \\
\text { Concentração } \\
\end{array}$ & $\mathrm{P} / \mathrm{m}^{3}$ & $9,46 \mathrm{E}+03$ & $9,04 \mathrm{E}+03$ & $5,49 E+03$ & $2,96 \mathrm{E}+03$ & $7,22 \mathrm{E}+02$ & $4,41 \mathrm{E}+0$ \\
\hline & DP/Concentração média & $\%$ & 0,0063 & 0,0062 & 0,0053 & 0,0049 & 0,0068 & 0,007 \\
\hline \multirow{2}{*}{\multicolumn{2}{|c|}{ Erro total medições $(\varepsilon)$}} & $\mathrm{P} / \mathrm{m}^{3}$ & $7,05 E+05$ & $6,97 \mathrm{E}+05$ & $5,87 \mathrm{E}+05$ & 4,47E+05 & $1,88 \mathrm{E}+05$ & $4,47 \mathrm{E}+0$ \\
\hline & & Unidade & $1,0-2,0 \mu \mathrm{m}$ & $2,0-3,0 \mu \mathrm{m}$ & $3,0-5,0 \mu \mathrm{m}$ & $5,0-7,0 \mu \mathrm{m}$ & $7,0-10,0 \mu \mathrm{m}$ & $>10,0 \mu \mathrm{m}$ \\
\hline \multirow{8}{*}{ Assento 2A } & $\begin{array}{c}\text { Concentração média de } \\
\text { fundo } \\
\end{array}$ & $\mathrm{P} / \mathrm{m}^{3}$ & $2,60 \mathrm{E}+05$ & $1,47 E+05$ & $2,00 E+04$ & $0,00 E+00$ & $0,00 \mathrm{E}+00$ & $0,00 E+00$ \\
\hline & $\begin{array}{c}\text { Número de particulas de } \\
\text { fundo } \\
\end{array}$ & $\mathbf{P}$ & 78 & 44 & 6 & 0 & 0 & 0 \\
\hline & $\begin{array}{l}\text { Concentração média } \\
\text { liquida }\end{array}$ & $\mathrm{P} / \mathrm{m}^{3}$ & $1,31 E+08$ & $1,28 \mathrm{E}+08$ & $7,18 \mathrm{E}+07$ & $4,00 E+07$ & $9,71 E+06$ & $5,77 E+05$ \\
\hline & $\begin{array}{c}\text { Número de Particulas } \\
\text { média liquida }\end{array}$ & $\mathbf{P}$ & 39445 & 38490 & 21550 & 12000 & 2912 & 173 \\
\hline & Desvio - Poisson & $\#$ & 198,61 & 196,19 & 146,80 & 109,54 & 53,96 & 13,15 \\
\hline & $\begin{array}{c}\text { Desvio - Poisson - } \\
\text { Relativo } \\
\end{array}$ & $\%$ & 0,5 & 0,5 & 0,7 & 0,9 & 1,9 & 7,6 \\
\hline & $\begin{array}{l}\text { Desvio padrão } \\
\text { Concentração }\end{array}$ & $\mathrm{P} / \mathrm{m}^{3}$ & $5,02 E+04$ & $4,68 \mathrm{E}+04$ & $3,45 E+03$ & $1,18 \mathrm{E}+03$ & $6,20 E+03$ & $2,03 E+0$ \\
\hline & DP/Concentração média & $\%$ & 0,0382 & 0,0365 & 0,0048 & 0,0029 & 0,0639 & 0,035 \\
\hline \multicolumn{2}{|c|}{ Erro total medições(દ) } & $\mathrm{P} / \mathrm{m}^{3}$ & $6,64 E+05$ & $6,56 E+05$ & $4,89 E+05$ & $3,65 E+05$ & $1,80 E+05$ & $4,38 \mathrm{E}+0$ \\
\hline
\end{tabular}




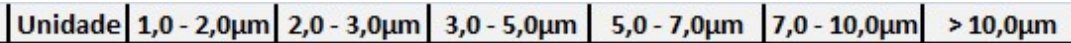

\begin{tabular}{|c|c|c|c|c|c|c|c|c|}
\hline \multirow{8}{*}{ Assento 3B } & $\begin{array}{c}\text { Concentração média de } \\
\text { fundo }\end{array}$ & $\mathrm{P} / \mathrm{m}^{3}$ & $1,13 E+05$ & $9,33 E+04$ & $1,00 E+04$ & $0,00 E+00$ & $0,00 E+00$ & $0,00 E+00$ \\
\hline & \begin{tabular}{|c|} 
Número de particulas de \\
fundo
\end{tabular} & $\mathbf{P}$ & 34 & 28 & 3 & 0 & 0 & 0 \\
\hline & $\begin{array}{c}\begin{array}{c}\text { Concentração média } \\
\text { liquida }\end{array} \\
\end{array}$ & $\mathrm{P} / \mathrm{m}^{3}$ & $3,17 E+08$ & $3,02 E+08$ & $1,08 \mathrm{E}+08$ & $5,33 E+07$ & $3,33 E+07$ & 4,07E+06 \\
\hline & $\begin{array}{c}\text { Número de Particulas } \\
\text { média liquida }\end{array}$ & $\mathbf{P}$ & 95195 & 90505 & 32520 & 16000 & 10000 & 1222 \\
\hline & Desvio - Poisson & $\#$ & 308,54 & 300,84 & 180,33 & 126,49 & 100,00 & 34,96 \\
\hline & $\begin{array}{c}\text { Desvio - Poisson - } \\
\text { Relativo } \\
\end{array}$ & $\%$ & 0,3 & 0,3 & 0,6 & 0,8 & 1,0 & 2,9 \\
\hline & $\begin{array}{l}\text { Desvio padrão } \\
\text { Concentração }\end{array}$ & $\mathrm{P} / \mathrm{m}^{3}$ & $4,08 \mathrm{E}+04$ & $3,83 \mathrm{E}+04$ & $1,97 E+03$ & $2,19 E+03$ & $3,10 E+03$ & $6,17 E+02$ \\
\hline & DP/Concentração média & $\%$ & 0,0129 & 0,0127 & 0,0018 & 0,0041 & 0,0093 & 0,0151 \\
\hline \multirow{2}{*}{\multicolumn{2}{|c|}{ Erro total medições(દ) }} & $\mathrm{P} / \mathrm{m}^{3}$ & $1,03 E+06$ & $1,00 E+06$ & $6,01 E+05$ & $4,22 E+05$ & $3,33 \mathrm{E}+05$ & $1,17 E+05$ \\
\hline & & Unidade & $1,0-2,0 \mu \mathrm{m}$ & $2,0-3,0 \mu \mathrm{m}$ & $3,0-5,0 \mu \mathrm{m}$ & $5,0-7,0 \mu \mathrm{m}$ & $7,0-10,0 \mu \mathrm{m}$ & $>10,0 \mu \mathrm{m}$ \\
\hline \multirow{8}{*}{ Assento 3A } & \begin{tabular}{|c|}
$\begin{array}{c}\text { Concentração média de } \\
\text { fundo }\end{array}$ \\
\end{tabular} & $\mathrm{P} / \mathrm{m}^{3}$ & $1,63 E+05$ & $8,33 E+04$ & $1,00 E+04$ & $0,00 E+00$ & $0,00 E+00$ & $0,00 E+00$ \\
\hline & $\begin{array}{c}\text { Número de particulas de } \\
\text { fundo }\end{array}$ & $\mathbf{P}$ & 49 & 25 & 3 & 0 & 0 & 0 \\
\hline & \begin{tabular}{|c|}
$\begin{array}{c}\text { Concentração média } \\
\text { liquida }\end{array}$ \\
\end{tabular} & $\mathrm{P} / \mathrm{m}^{3}$ & $3,47 E+08$ & $3,33 E+08$ & $8,33 E+07$ & $4,75 E+07$ & $3,75 E+07$ & $1,41 E+06$ \\
\hline & $\begin{array}{c}\text { Número de Particulas } \\
\text { média liquida }\end{array}$ & $\mathbf{P}$ & 104057 & 99882 & 25000 & 14250 & 11264 & 423 \\
\hline & Desvio - Poisson & $\#$ & 322,58 & 316,04 & 158,11 & 119,37 & 106,13 & 20,57 \\
\hline & $\begin{array}{c}\text { Desvio - Poisson - } \\
\text { Relativo } \\
\end{array}$ & $\%$ & 0,3 & 0,3 & 0,6 & 0,8 & 0,9 & 4,9 \\
\hline & \begin{tabular}{|l}
$\begin{array}{l}\text { Desvio padrão } \\
\text { Concentração }\end{array}$ \\
\end{tabular} & $\mathrm{P} / \mathrm{m}^{3}$ & $2,93 E+04$ & $2,76 \mathrm{E}+04$ & $4,94 \mathrm{E}+03$ & $1,37 \mathrm{E}+04$ & $2,08 \mathrm{E}+03$ & $2,80 E+02$ \\
\hline & DP/Concentração média & $\%$ & 0,0084 & 0,0083 & 0,0059 & 0,0288 & 0,0055 & 0,0199 \\
\hline \multicolumn{2}{|c|}{ Erro total medições(દ) } & $\mathrm{P} / \mathrm{m}^{3}$ & $1,08 \mathrm{E}+06$ & $1,05 \mathrm{E}+06$ & $5,27 E+05$ & $3,98 \mathrm{E}+05$ & $3,54 \mathrm{E}+05$ & $6,86 \mathrm{E}+04$ \\
\hline
\end{tabular}


Tabela B-2. Resultados das medições de partículas no assento (Sistema UFAD à $18^{\circ} \mathrm{C}$ - injeção pelo assento $3 \mathrm{~B}$ )

\begin{tabular}{|c|c|c|c|c|c|c|c|c|}
\hline & & Unidade & $1,0-2,0 \mu \mathrm{m}$ & $2,0-3,0 \mu \mathrm{m}$ & $3,0-5,0 \mu \mathrm{m}$ & $5,0-7,0 \mu \mathrm{m}$ & $7,0-10,0 \mu \mathrm{m}$ & $>10,0 \mu \mathrm{m}$ \\
\hline \multirow{8}{*}{ Assento 3E } & $\begin{array}{c}\text { Concentração média de } \\
\text { fundo }\end{array}$ & $\mathrm{P} / \mathrm{m}^{3}$ & $8,00 E+04$ & $4,00 E+04$ & $3,33 E+03$ & $0,00 E+00$ & $0,00 E+00$ & $0,00 E+00$ \\
\hline & $\begin{array}{l}\text { Número de particulas de } \\
\text { fundo }\end{array}$ & $\mathbf{P}$ & 24 & 12 & 1 & 0 & 0 & 0 \\
\hline & $\begin{array}{l}\text { Concentração média } \\
\text { liquida }\end{array}$ & $\mathrm{P} / \mathrm{m}^{3}$ & $1,04 E+08$ & $8,87 E+07$ & $7,61 \mathrm{E}+07$ & $5,57 E+07$ & $1,68 \mathrm{E}+07$ & $2,02 E+06$ \\
\hline & $\begin{array}{l}\text { Número de Particulas } \\
\text { média liquida }\end{array}$ & $\mathbf{P}$ & 31257 & 26619 & 22833 & 16719 & 5033 & 607 \\
\hline & Desvio - Poisson & $\#$ & 176,80 & 163,15 & 151,11 & 129,30 & 70,94 & 24,64 \\
\hline & $\begin{array}{l}\text { Desvio - Poisson - } \\
\text { Relativo }\end{array}$ & $\%$ & 0,6 & 0,6 & 0,7 & 0,8 & 1,4 & 4,1 \\
\hline & $\begin{array}{l}\text { Desvio padrão } \\
\text { Concentração }\end{array}$ & $\mathrm{P} / \mathrm{m}^{3}$ & $8,56 E+03$ & $6,47 E+03$ & $3,98 \mathrm{E}+03$ & $4,06 E+02$ & $6,18 \mathrm{E}+01$ & $9,72 E+01$ \\
\hline & DP/Concentração média & $\%$ & 0,0082 & 0,0073 & 0,0052 & 0,0007 & 0,0004 & 0,0048 \\
\hline \multirow{2}{*}{\multicolumn{2}{|c|}{ Erro total medições(E) }} & $\mathrm{P} / \mathrm{m}^{3}$ & $5,89 \mathrm{E}+05$ & $5,44 \mathrm{E}+05$ & $5,04 \mathrm{E}+05$ & $4,31 E+05$ & $2,36 \mathrm{E}+05$ & $8,21 \mathrm{E}+04$ \\
\hline & & Unidade & $1,0-2,0 \mu \mathrm{m}$ & $2,0-3,0 \mu \mathrm{m}$ & $3,0-5,0 \mu \mathrm{m}$ & $5,0-7,0 \mu \mathrm{m}$ & $7,0-10,0 \mu \mathrm{m}$ & $>10,0 \mu \mathrm{m}$ \\
\hline \multirow{8}{*}{ Assento 2D } & $\begin{array}{c}\text { Concentração média de } \\
\text { fundo }\end{array}$ & $\mathrm{P} / \mathrm{m}^{3}$ & $1,80 \mathrm{E}+05$ & $7,33 E+04$ & $1,00 \mathrm{E}+04$ & $3,33 E+03$ & $0,00 E+00$ & $0,00 E+00$ \\
\hline & $\begin{array}{c}\text { Número de particulas de } \\
\text { fundo }\end{array}$ & $\mathbf{P}$ & 54 & 22 & 3 & 1 & 0 & 0 \\
\hline & $\begin{array}{c}\text { Concentração média } \\
\text { liquida }\end{array}$ & $\mathrm{P} / \mathrm{m}^{3}$ & $6,36 \mathrm{E}+07$ & $6,29 \mathrm{E}+07$ & $5,92 \mathrm{E}+07$ & $4,99 \mathrm{E}+07$ & $1,44 E+07$ & $1,71 \mathrm{E}+06$ \\
\hline & $\begin{array}{c}\text { Número de Particulas } \\
\text { média liquida }\end{array}$ & $\mathbf{P}$ & 19070 & 18864 & 17769 & 14970 & 4309 & 514 \\
\hline & Desvio - Poisson & $\#$ & 138,09 & 137,35 & 133,30 & 122,35 & 65,64 & 22,67 \\
\hline & $\begin{array}{c}\text { Desvio - Poisson - } \\
\text { Relativo } \\
\end{array}$ & $\%$ & 0,7 & 0,7 & 0,8 & 0,8 & 1,5 & 4,4 \\
\hline & $\begin{array}{l}\text { Desvio padrão } \\
\text { Concentração }\end{array}$ & $\mathrm{P} / \mathrm{m}^{3}$ & $4,13 E+03$ & $4,05 E+03$ & $2,30 E+03$ & $2,25 \mathrm{E}+03$ & $9,52 E+02$ & $1,29 \mathrm{E}+02$ \\
\hline & DP/Concentração média & $\%$ & 0,0065 & 0,0064 & 0,0039 & 0,0045 & 0,0066 & 0,0075 \\
\hline \multirow{2}{*}{\multicolumn{2}{|c|}{ Erro total medições(દ) }} & $\mathrm{P} / \mathrm{m}^{3}$ & $4,60 E+05$ & $4,58 \mathrm{E}+05$ & $4,44 \mathrm{E}+05$ & $4,08 \mathrm{E}+05$ & $2,19 \mathrm{E}+05$ & $7,56 \mathrm{E}+04$ \\
\hline & & Unidade & $1,0-2,0 \mu \mathrm{m}$ & $2,0-3,0 \mu \mathrm{m}$ & $3,0-5,0 \mu \mathrm{m}$ & $5,0-7,0 \mu \mathrm{m}$ & $7,0-10,0 \mu \mathrm{m}$ & $>10,0 \mu \mathrm{m}$ \\
\hline \multirow{8}{*}{ Assento $2 \mathrm{E}$} & $\begin{array}{l}\text { Concentração média de } \\
\text { fundo }\end{array}$ & $\mathrm{P} / \mathrm{m}^{3}$ & $1,37 E+05$ & $5,67 E+04$ & $6,67 E+03$ & $0,00 E+00$ & $0,00 E+00$ & $0,00 E+00$ \\
\hline & $\begin{array}{c}\begin{array}{c}\text { Número de particulas de } \\
\text { fundo }\end{array} \\
\end{array}$ & $\mathbf{P}$ & 41 & 17 & 2 & 0 & 0 & 0 \\
\hline & $\begin{array}{c}\text { Concentração média } \\
\text { liquida }\end{array}$ & $\mathrm{P} / \mathrm{m}^{3}$ & $5,578 E+07$ & $5,518 \mathrm{E}+07$ & $4,968 \mathrm{E}+07$ & $4,039 E+07$ & $1,770 E+07$ & $2,76 \mathrm{E}+06$ \\
\hline & $\begin{array}{c}\text { Número de Particulas } \\
\text { média liquida }\end{array}$ & $\mathbf{P}$ & 16734 & 16555 & 14905 & 12118 & 5310 & 827 \\
\hline & Desvio - Poisson & $\#$ & 129,36 & 128,66 & 122,08 & 110,08 & 72,87 & 28,75 \\
\hline & $\begin{array}{c}\text { Desvio - Poisson - } \\
\text { Relativo } \\
\end{array}$ & $\%$ & 0,8 & 0,8 & 0,8 & 0,9 & 1,4 & 3,5 \\
\hline & $\begin{array}{l}\text { Desvio padrão } \\
\text { Concentração }\end{array}$ & $\mathrm{P} / \mathrm{m}^{3}$ & $2,67 E+03$ & $2,63 E+03$ & $2,23 E+03$ & $1,80 E+03$ & $9,22 E+02$ & $1,86 \mathrm{E}+02$ \\
\hline & DP/Concentração média & $\%$ & 0,0048 & 0,0048 & 0,0045 & 0,0045 & 0,0052 & 0,0067 \\
\hline \multicolumn{2}{|c|}{ Erro total medições( $\varepsilon)$} & $\mathrm{P} / \mathrm{m}^{3}$ & $4,31 \mathrm{E}+05$ & $4,29 \mathrm{E}+05$ & $4,07 E+05$ & $3,67 E+05$ & $2,43 E+05$ & $9,58 \mathrm{E}+04$ \\
\hline
\end{tabular}




\begin{tabular}{|c|c|c|c|c|c|c|c|c|}
\hline & & Unidade & $1,0-2,0 \mu \mathrm{m}$ & $2,0-3,0 \mu \mathrm{m}$ & $3,0-5,0 \mu \mathrm{m}$ & $5,0-7,0 \mu \mathrm{m}$ & $7,0-10,0 \mu \mathrm{m}$ & $>10,0 \mu \mathrm{m}$ \\
\hline \multirow{8}{*}{ Assento 1D } & $\begin{array}{l}\text { Concentração média de } \\
\text { fundo }\end{array}$ & $\mathrm{P} / \mathrm{m}^{3}$ & $2,20 \mathrm{E}+05$ & $9,67 E+04$ & $1,50 \mathrm{E}+04$ & $1,67 E+03$ & $0,00 E+00$ & $0,00 E+00$ \\
\hline & $\begin{array}{l}\text { Número de particulas de } \\
\text { fundo }\end{array}$ & $\mathbf{P}$ & 66 & 29 & 5 & 1 & 0 & 0 \\
\hline & $\begin{array}{l}\text { Concentração média } \\
\text { liquida }\end{array}$ & $\mathrm{P} / \mathrm{m}^{3}$ & $6,89 \mathrm{E}+07$ & $6,47 E+07$ & $5,85 E+07$ & $4,51 E+07$ & $1,00 E+07$ & $1,46 \mathrm{E}+06$ \\
\hline & $\begin{array}{c}\text { Número de Particulas } \\
\text { média liquida }\end{array}$ & $\mathbf{p}$ & 20657 & 19414 & 17540 & 13520 & 3012 & 437 \\
\hline & Desvio - Poisson & $\#$ & 143,73 & 139,33 & 132,44 & 116,28 & 54,88 & 20,89 \\
\hline & $\begin{array}{l}\text { Desvio - Poisson - } \\
\text { Relativo } \\
\end{array}$ & $\%$ & 0,7 & 0,7 & 0,8 & 0,9 & 1,8 & 4,8 \\
\hline & $\begin{array}{l}\text { Desvio padrão } \\
\text { Concentração } \\
\end{array}$ & $\mathrm{P} / \mathrm{m}^{3}$ & $6,79 E+03$ & $6,67 E+03$ & $5,97 E+03$ & $4,76 \mathrm{E}+03$ & $1,49 \mathrm{E}+03$ & $2,71 E+02$ \\
\hline & DP/Concentração média & $\%$ & 0,0099 & 0,0103 & 0,0102 & 0,0106 & 0,0148 & 0,0186 \\
\hline \multirow{2}{*}{\multicolumn{2}{|c|}{ Erro total medições( $(\varepsilon)$}} & $\mathrm{P} / \mathrm{m}^{3}$ & $4,79 \mathrm{E}+05$ & $4,64 E+05$ & $4,42 E+05$ & $3,88 \mathrm{E}+05$ & $1,83 E+05$ & $6,96 \mathrm{E}+04$ \\
\hline & & Unidade & $1,0-2,0 \mu \mathrm{m}$ & $2,0-3,0 \mu \mathrm{m}$ & $3,0-5,0 \mu \mathrm{m}$ & $5,0-7,0 \mu \mathrm{m}$ & $7,0-10,0 \mu \mathrm{m}$ & $>10,0 \mu \mathrm{m}$ \\
\hline \multirow{8}{*}{ Assento $1 \mathrm{E}$} & $\begin{array}{c}\text { Concentração média de } \\
\text { fundo }\end{array}$ & $\mathrm{P} / \mathrm{m}^{3}$ & $1,50 \mathrm{E}+05$ & $1,13 E+05$ & $1,33 \mathrm{E}+04$ & $0,00 E+00$ & $0,00 E+00$ & $0,00 E+00$ \\
\hline & $\begin{array}{c}\text { Número de particulas de } \\
\text { fundo }\end{array}$ & $\mathbf{p}$ & 45 & 34 & 4 & 0 & 0 & 0 \\
\hline & $\begin{array}{l}\text { Concentração média } \\
\text { liquida }\end{array}$ & $\mathrm{P} / \mathrm{m}^{3}$ & $9,36 E+07$ & $8,46 \mathrm{E}+07$ & $6,33 \mathrm{E}+07$ & $5,08 \mathrm{E}+07$ & $1,75 E+07$ & $1,51 E+06$ \\
\hline & $\begin{array}{c}\text { Número de Particulas } \\
\text { média liquida }\end{array}$ & $\mathbf{p}$ & 28089 & 25381 & 19004 & 15237 & 5247 & 453 \\
\hline & Desvio - Poisson & $\#$ & 167,60 & 159,31 & 137,85 & 123,44 & 72,44 & 21,28 \\
\hline & $\begin{array}{c}\text { Desvio - Poisson - } \\
\text { Relativo } \\
\end{array}$ & $\%$ & 0,6 & 0,6 & 0,7 & 0,8 & 1,4 & 4,7 \\
\hline & $\begin{array}{l}\text { Desvio padrão } \\
\text { Concentração }\end{array}$ & $\mathrm{P} / \mathrm{m}^{3}$ & $5,19 \mathrm{E}+03$ & $6,80 E+03$ & $5,64 E+03$ & $4,04 E+03$ & $1,08 \mathrm{E}+03$ & $1,51 \mathrm{E}+02$ \\
\hline & DP/Concentração média & $\%$ & 0,0055 & 0,0080 & 0,0089 & 0,0079 & 0,0062 & 0,0100 \\
\hline \multirow{2}{*}{\multicolumn{2}{|c|}{ Erro total medições(દ) }} & $\mathrm{P} / \mathrm{m}^{3}$ & $5,59 E+05$ & $5,31 E+05$ & $4,60 E+05$ & $4,11 E+05$ & $2,41 E+05$ & $7,09 \mathrm{E}+04$ \\
\hline & & Unidade & $1,0-2,0 \mu \mathrm{m}$ & $2,0-3,0 \mu \mathrm{m}$ & $3,0-5,0 \mu \mathrm{m}$ & $5,0-7,0 \mu \mathrm{m}$ & $7,0-10,0 \mu \mathrm{m}$ & $>10,0 \mu \mathrm{m}$ \\
\hline \multirow{8}{*}{ Assento $1 \mathrm{~B}$} & $\begin{array}{c}\text { Concentração média de } \\
\text { fundo }\end{array}$ & $\mathrm{P} / \mathrm{m}^{3}$ & $2,50 \mathrm{E}+05$ & $1,20 \mathrm{E}+05$ & $1,00 \mathrm{E}+04$ & $0,00 E+00$ & $0,00 E+00$ & $0,00 \mathrm{E}+00$ \\
\hline & $\begin{array}{c}\text { Número de particulas de } \\
\text { fundo }\end{array}$ & $\mathbf{P}$ & 75 & 36 & 3 & 0 & 0 & 0 \\
\hline & $\begin{array}{c}\text { Concentração média } \\
\text { liquida } \\
\end{array}$ & $\mathrm{P} / \mathrm{m}^{3}$ & $5,49 \mathrm{E}+07$ & $4,78 \mathrm{E}+07$ & $4,31 E+07$ & $3,05 E+07$ & $7,49 \mathrm{E}+06$ & $1,27 E+06$ \\
\hline & $\begin{array}{c}\text { Número de Particulas } \\
\text { média liquida }\end{array}$ & $\mathbf{p}$ & 16471 & 14341 & 12925 & 9140 & 2248 & 380 \\
\hline & Desvio - Poisson & $\#$ & 128,34 & 119,75 & 113,69 & 95,60 & 47,41 & 19,49 \\
\hline & $\begin{array}{c}\text { Desvio - Poisson - } \\
\text { Relativo } \\
\end{array}$ & $\%$ & 0,8 & 0,8 & 0,9 & 1,0 & 2,1 & 5,1 \\
\hline & $\begin{array}{c}\text { Desvio padrão } \\
\text { Concentração } \\
\end{array}$ & $\mathrm{P} / \mathrm{m}^{3}$ & $8,24 E+02$ & $2,03 E+03$ & $1,69 \mathrm{E}+03$ & $1,16 \mathrm{E}+03$ & $3,89 E+02$ & $8,57 E+01$ \\
\hline & DP/Concentração média & $\%$ & 0,0015 & 0,0042 & 0,0039 & 0,0038 & 0,0052 & 0,0068 \\
\hline \multicolumn{2}{|c|}{ Erro total medições(દ) } & $\mathrm{P} / \mathrm{m}^{3}$ & $4,28 E+05$ & $3,99 E+05$ & $3,79 E+05$ & $3,19 E+05$ & $1,58 \mathrm{E}+05$ & $6,50 E+04$ \\
\hline
\end{tabular}




\begin{tabular}{|c|c|c|c|c|c|c|c|c|}
\hline & & Unidade & $1,0-2,0 \mu \mathrm{m}$ & $2,0-3,0 \mu \mathrm{m}$ & $3,0-5,0 \mu \mathrm{m}$ & $5,0-7,0 \mu \mathrm{m}$ & $7,0-10,0 \mu \mathrm{m}$ & $>10,0 \mu \mathrm{m}$ \\
\hline \multirow{8}{*}{ Assento 1A } & $\begin{array}{c}\text { Concentração média de } \\
\text { fundo }\end{array}$ & $\mathrm{P} / \mathrm{m}^{3}$ & $3,10 \mathrm{E}+05$ & $1,40 \mathrm{E}+05$ & $3,33 \mathrm{E}+03$ & $0,00 \mathrm{E}+00$ & $0,00 E+00$ & $0,00 E+00$ \\
\hline & $\begin{array}{c}\text { Número de particulas de } \\
\text { fundo }\end{array}$ & $\mathbf{p}$ & 93 & 42 & 1 & 0 & 0 & 0 \\
\hline & $\begin{array}{l}\text { Concentração média } \\
\text { liquida }\end{array}$ & $\mathrm{P} / \mathrm{m}^{3}$ & $4,63 \mathrm{E}+07$ & $4,58 \mathrm{E}+07$ & $3,51 \mathrm{E}+07$ & $2,99 \mathrm{E}+07$ & $5,09 E+06$ & $4,00 E+05$ \\
\hline & $\begin{array}{l}\text { Número de Particulas } \\
\text { média liquida }\end{array}$ & $\mathbf{p}$ & 13881 & 13742 & 10520 & 8961 & 1526 & 120 \\
\hline & Desvio - Poisson & $\#$ & 117,82 & 117,23 & 102,57 & 94,66 & 39,06 & 10,95 \\
\hline & $\begin{array}{l}\text { Desvio - Poisson - } \\
\text { Relativo }\end{array}$ & $\%$ & 0,8 & 0,9 & 1,0 & 1,1 & 2,6 & 9,1 \\
\hline & $\begin{array}{l}\text { Desvio padrão } \\
\text { Concentração } \\
\end{array}$ & $\mathrm{P} / \mathrm{m}^{3}$ & $2,00 E+03$ & $1,98 \mathrm{E}+03$ & $1,45 \mathrm{E}+03$ & $1,01 E+03$ & $6,06 E+02$ & $2,71 E+02$ \\
\hline & DP/Concentração média & $\%$ & 0,0043 & 0,0043 & 0,0041 & 0,0034 & 0,0119 & 0,0678 \\
\hline \multirow{2}{*}{\multicolumn{2}{|c|}{ Erro total medições(દ) }} & $\mathrm{P} / \mathrm{m}^{3}$ & $3,93 \mathrm{E}+05$ & $3,91 E+05$ & $3,42 E+05$ & $3,16 \mathrm{E}+05$ & $1,30 E+05$ & $3,65 \mathrm{E}+04$ \\
\hline & & Unidade & $1,0-2,0 \mu \mathrm{m}$ & $2,0-3,0 \mu \mathrm{m}$ & $3,0-5,0 \mu \mathrm{m}$ & $5,0-7,0 \mu \mathrm{m}$ & $7,0-10,0 \mu \mathrm{m}$ & $>10,0 \mu \mathrm{m}$ \\
\hline \multirow{8}{*}{ Assento 2B } & $\begin{array}{c}\text { Concentração média de } \\
\text { fundo }\end{array}$ & $\mathrm{P} / \mathrm{m}^{3}$ & $3,37 E+05$ & $1,83 \mathrm{E}+05$ & $1,67 E+04$ & $0,00 \mathrm{E}+00$ & $0,00 E+00$ & $0,00 \mathrm{E}+00$ \\
\hline & $\begin{array}{c}\text { Número de particulas de } \\
\text { fundo }\end{array}$ & $\mathbf{P}$ & 101 & 55 & 5 & 0 & 0 & 0 \\
\hline & $\begin{array}{c}\text { Concentração média } \\
\text { liquida }\end{array}$ & $\mathrm{P} / \mathrm{m}^{3}$ & $6,78 \mathrm{E}+07$ & $6,25 \mathrm{E}+07$ & $5,33 \mathrm{E}+07$ & $2,67 E+07$ & $2,17 E+07$ & $1,17 E+06$ \\
\hline & $\begin{array}{c}\text { Número de Particulas } \\
\text { média liquida }\end{array}$ & $\mathbf{p}$ & 20328 & 18742 & 16000 & 8000 & 6520 & 352 \\
\hline & Desvio - Poisson & $\#$ & 142,58 & 136,90 & 126,49 & 89,44 & 80,75 & 18,76 \\
\hline & $\begin{array}{c}\text { Desvio - Poisson - } \\
\text { Relativo } \\
\end{array}$ & $\%$ & 0,7 & 0,7 & 0,8 & 1,1 & 1,2 & 5,3 \\
\hline & $\begin{array}{l}\text { Desvio padrão } \\
\text { Concentração }\end{array}$ & $\mathrm{P} / \mathrm{m}^{3}$ & $5,24 E+03$ & $1,57 \mathrm{E}+03$ & $3,21 E+03$ & $1,07 E+03$ & $2,18 \mathrm{E}+03$ & $1,34 E+02$ \\
\hline & DP/Concentração média & $\%$ & 0,0077 & 0,0025 & 0,0060 & 0,0040 & 0,0100 & 0,0114 \\
\hline \multirow{2}{*}{\multicolumn{2}{|c|}{ Erro total medições $(\varepsilon)$}} & $\mathrm{P} / \mathrm{m}^{3}$ & $4,75 E+05$ & $4,56 \mathrm{E}+05$ & $4,22 E+05$ & $2,98 \mathrm{E}+05$ & $2,69 \mathrm{E}+05$ & $6,25 \mathrm{E}+04$ \\
\hline & & Unidade & $1,0-2,0 \mu \mathrm{m}$ & $2,0-3,0 \mu \mathrm{m}$ & $3,0-5,0 \mu \mathrm{m}$ & $5,0-7,0 \mu \mathrm{m}$ & $7,0-10,0 \mu \mathrm{m}$ & $>10,0 \mu \mathrm{m}$ \\
\hline \multirow{8}{*}{ Assento 2A } & $\begin{array}{c}\text { Concentração média de } \\
\text { fundo }\end{array}$ & $\mathrm{P} / \mathrm{m}^{3}$ & $3,23 \mathrm{E}+05$ & $1,53 \mathrm{E}+05$ & $2,00 E+04$ & $0,00 \mathrm{E}+00$ & $0,00 \mathrm{E}+00$ & $0,00 E+00$ \\
\hline & $\begin{array}{c}\text { Número de particulas de } \\
\text { fundo }\end{array}$ & $\mathbf{P}$ & 97 & 46 & 6 & 0 & 0 & 0 \\
\hline & $\begin{array}{c}\text { Concentração média } \\
\text { liquida }\end{array}$ & $\mathrm{P} / \mathrm{m}^{3}$ & $5,78 \mathrm{E}+07$ & $4,58 \mathrm{E}+07$ & $3,50 \mathrm{E}+07$ & $2,63 E+07$ & $6,15 E+06$ & $1,08 \mathrm{E}+06$ \\
\hline & $\begin{array}{l}\text { Número de Particulas } \\
\text { média liquida }\end{array}$ & $\mathbf{P}$ & 17328 & 13742 & 10500 & 7890 & 1845 & 324 \\
\hline & Desvio - Poisson & $\#$ & 131,64 & 117,23 & 102,47 & 88,83 & 42,95 & 18,00 \\
\hline & $\begin{array}{c}\text { Desvio - Poisson - } \\
\text { Relativo } \\
\end{array}$ & $\%$ & 0,8 & 0,9 & 1,0 & 1,1 & 2,3 & 5,6 \\
\hline & $\begin{array}{l}\text { Desvio padrão } \\
\text { Concentração }\end{array}$ & $\mathrm{P} / \mathrm{m}^{3}$ & $4,44 E+03$ & $1,98 \mathrm{E}+03$ & $2,04 E+03$ & $1,63 E+03$ & $5,17 E+02$ & $1,45 E+02$ \\
\hline & DP/Concentração média & $\%$ & 0,0077 & 0,0043 & 0,0058 & 0,0062 & 0,0084 & 0,0134 \\
\hline \multicolumn{2}{|c|}{ Erro total medições $(\varepsilon)$} & $\mathrm{P} / \mathrm{m}^{3}$ & $4,39 E+05$ & $3,91 E+05$ & $3,42 E+05$ & $2,96 \mathrm{E}+05$ & $1,43 E+05$ & $6,00 \mathrm{E}+04$ \\
\hline
\end{tabular}




\begin{tabular}{|c|c|c|c|c|c|c|c|c|}
\hline & & Unidade & $1,0-2,0 \mu \mathrm{m}$ & $2,0-3,0 \mu \mathrm{m}$ & $3,0-5,0 \mu \mathrm{m}$ & $5,0-7,0 \mu \mathrm{m}$ & $7,0-10,0 \mu \mathrm{m}$ & $>10,0 \mu \mathrm{m}$ \\
\hline \multirow{8}{*}{ Assento 3B } & $\begin{array}{l}\text { Concentração média de } \\
\text { fundo }\end{array}$ & $\mathrm{P} / \mathrm{m}^{3}$ & $1,87 \mathrm{E}+05$ & $9,33 E+04$ & $1,00 E+04$ & $0,00 E+00$ & $0,00 E+00$ & $0,00 E+00$ \\
\hline & $\begin{array}{l}\text { Número de particulas de } \\
\text { fundo }\end{array}$ & $\mathbf{P}$ & 56 & 28 & 3 & 0 & 0 & 0 \\
\hline & $\begin{array}{c}\text { Concentração média } \\
\text { liquida }\end{array}$ & $\mathrm{P} / \mathrm{m}^{3}$ & $8,48 \mathrm{E}+07$ & $6,94 \mathrm{E}+07$ & $5,84 \mathrm{E}+07$ & $4,67 E+07$ & $1,39 \mathrm{E}+07$ & $2,53 \mathrm{E}+06$ \\
\hline & $\begin{array}{l}\text { Número de Particulas } \\
\text { média liquida }\end{array}$ & $\mathbf{P}$ & 25440 & 20831 & 17520 & 14000 & 4163 & 760 \\
\hline & Desvio - Poisson & $\#$ & 159,50 & 144,33 & 132,36 & 118,32 & 64,52 & 27,57 \\
\hline & $\begin{array}{l}\text { Desvio - Poisson - } \\
\text { Relativo } \\
\end{array}$ & $\%$ & 0,6 & 0,7 & 0,8 & 0,8 & 1,5 & 3,6 \\
\hline & $\begin{array}{c}\text { Desvio padrão } \\
\text { Concentração }\end{array}$ & $\mathrm{P} / \mathrm{m}^{3}$ & $4,56 \mathrm{E}+03$ & $4,14 \mathrm{E}+03$ & $3,04 \mathrm{E}+03$ & $3,18 \mathrm{E}+03$ & $3,17 E+02$ & $8,98 \mathrm{E}+01$ \\
\hline & DP/Concentração média & $\%$ & 0,0054 & 0,0060 & 0,0052 & 0,0068 & 0,0023 & 0,0035 \\
\hline \multirow{2}{*}{\multicolumn{2}{|c|}{ Erro total medições(દ) }} & $\mathrm{P} / \mathrm{m}^{3}$ & $5,32 \mathrm{E}+05$ & $4,81 \mathrm{E}+05$ & $4,41 E+05$ & $3,94 \mathrm{E}+05$ & $2,15 E+05$ & $9,19 \mathrm{E}+04$ \\
\hline & & Unidade & $1,0-2,0 \mu \mathrm{m}$ & $2,0-3,0 \mu \mathrm{m}$ & $3,0-5,0 \mu \mathrm{m}$ & $5,0-7,0 \mu \mathrm{m}$ & $7,0-10,0 \mu \mathrm{m}$ & $>10,0 \mu \mathrm{m}$ \\
\hline \multirow{8}{*}{ Assento $3 \mathrm{~A}$} & $\begin{array}{c}\text { Concentração média de } \\
\text { fundo }\end{array}$ & $\mathrm{P} / \mathrm{m}^{3}$ & $1,83 E+05$ & $8,33 E+04$ & $1,00 \mathrm{E}+04$ & $0,00 E+00$ & $0,00 \mathrm{E}+00$ & $0,00 \mathrm{E}+00$ \\
\hline & $\begin{array}{c}\text { Número de particulas de } \\
\text { fundo } \\
\end{array}$ & $\mathbf{P}$ & 55 & 25 & 3 & 0 & 0 & 0 \\
\hline & $\begin{array}{c}\text { Concentração média } \\
\text { liquida }\end{array}$ & $\mathrm{P} / \mathrm{m}^{3}$ & $5,11 E+07$ & $4,60 \mathrm{E}+07$ & $2,71 E+07$ & $3,00 \mathrm{E}+07$ & $1,66 \mathrm{E}+07$ & $1,74 \mathrm{E}+06$ \\
\hline & $\begin{array}{c}\text { Número de Particulas } \\
\text { média liquida }\end{array}$ & $\mathbf{P}$ & 15340 & 13796 & 8140 & 9000 & 4980 & 523 \\
\hline & Desvio - Poisson & $\#$ & 123,85 & 117,45 & 90,22 & 94,87 & 70,57 & 22,87 \\
\hline & $\begin{array}{l}\text { Desvio - Poisson - } \\
\text { Relativo } \\
\end{array}$ & $\%$ & 0,8 & 0,9 & 1,1 & 1,1 & 1,4 & 4,4 \\
\hline & $\begin{array}{c}\text { Desvio padrão } \\
\text { Concentração } \\
\end{array}$ & $\mathrm{P} / \mathrm{m}^{3}$ & $1,57 E+03$ & $1,95 \mathrm{E}+03$ & $1,16 \mathrm{E}+03$ & $7,95 E+02$ & $6,17 E+02$ & $1,44 \mathrm{E}+02$ \\
\hline & DP/Concentração média & $\%$ & 0,0031 & 0,0042 & 0,0043 & 0,0027 & 0,0037 & 0,0083 \\
\hline \multicolumn{2}{|c|}{ Erro total medições( $(\varepsilon)$} & $\mathrm{P} / \mathrm{m}^{3}$ & $4,13 E+05$ & $3,92 \mathrm{E}+05$ & $3,01 E+05$ & $3,16 \mathrm{E}+05$ & $2,35 \mathrm{E}+05$ & $7,62 \mathrm{E}+04$ \\
\hline
\end{tabular}


Tabela B-3. Resultados das medições de partículas no assento (Sistema DV. à $18^{\circ} \mathrm{C}$ - injeção pelo assento $3 \mathrm{~B}$ )

\begin{tabular}{|c|c|c|c|c|c|c|c|c|}
\hline & & Unidade & $1,0-2,0 \mu \mathrm{m}$ & $2,0-3,0 \mu \mathrm{m}$ & $3,0-5,0 \mu \mathrm{m}$ & $5,0-7,0 \mu \mathrm{m}$ & $7,0-10,0 \mu \mathrm{m}$ & $>10,0 \mu \mathrm{m}$ \\
\hline \multirow{8}{*}{ Assento 3E } & $\begin{array}{c}\text { Concentração média de } \\
\text { fundo }\end{array}$ & $\mathrm{P} / \mathrm{m}^{3}$ & $1,00 E+05$ & $4,33 E+04$ & $3,33 \mathrm{E}+03$ & $0,00 E+00$ & $0,00 \mathrm{E}+00$ & $0,00 E+00$ \\
\hline & $\begin{array}{c}\text { Número de particulas } \\
\text { de fundo }\end{array}$ & $\mathbf{P}$ & 30 & 13 & 1 & 0 & 0 & 0 \\
\hline & $\begin{array}{c}\text { Concentração média } \\
\text { liquida }\end{array}$ & $\mathrm{P} / \mathrm{m}^{3}$ & $4,67 E+08$ & $4,42 E+08$ & $1,07 E+08$ & $9,33 E+07$ & $2,50 \mathrm{E}+07$ & $1,71 \mathrm{E}+06$ \\
\hline & $\begin{array}{c}\text { Número de Particulas } \\
\text { média liquida }\end{array}$ & $\mathbf{P}$ & 140162 & 132609 & 32000 & 28000 & 7500 & 514 \\
\hline & Desvio - Poisson & $\#$ & 374,38 & 364,16 & 178,89 & 167,33 & 86,60 & 22,67 \\
\hline & $\begin{array}{c}\text { Desvio - Poisson - } \\
\text { Relativo } \\
\end{array}$ & $\%$ & 0,3 & 0,3 & 0,6 & 0,6 & 1,2 & 4,4 \\
\hline & $\begin{array}{l}\text { Desvio padrão } \\
\text { Concentração }\end{array}$ & $\mathrm{P} / \mathrm{m}^{3}$ & $2,03 E+04$ & $4,06 E+04$ & $2,27 \mathrm{E}+04$ & $2,11 \mathrm{E}+04$ & $1,44 E+03$ & $2,64 E+03$ \\
\hline & DP/Concentração média & $\%$ & 0,0043 & 0,0092 & 0,0213 & 0,0226 & 0,0057 & 0,1538 \\
\hline \multicolumn{2}{|c|}{ Erro total medições $(\varepsilon)$} & $\mathrm{P} / \mathrm{m}^{3}$ & $1,25 E+06$ & $1,21 \mathrm{E}+06$ & $5,97 \mathrm{E}+05$ & $5,58 \mathrm{E}+05$ & $2,89 E+05$ & $7,56 \mathrm{E}+04$ \\
\hline & & Unidade & $1,0-2,0 \mu \mathrm{m}$ & $2,0-3,0 \mu \mathrm{m}$ & $3,0-5,0 \mu \mathrm{m}$ & $5,0-7,0 \mu \mathrm{m}$ & $7,0-10,0 \mu \mathrm{m}$ & $>10,0 \mu \mathrm{m}$ \\
\hline \multirow{8}{*}{ Assento 2D } & \begin{tabular}{|c|}
$\begin{array}{c}\text { Concentração média de } \\
\text { fundo }\end{array}$ \\
\end{tabular} & $\mathrm{P} / \mathrm{m}^{3}$ & $1,77 \mathrm{E}+05$ & $6,67 E+04$ & $1,00 E+04$ & $3,33 E+03$ & $0,00 E+00$ & $0,00 E+00$ \\
\hline & $\begin{array}{c}\text { Número de particulas } \\
\text { de fundo }\end{array}$ & $\mathbf{P}$ & 53 & 20 & 3 & 1 & 0 & 0 \\
\hline & $\begin{array}{c}\text { Concentração média } \\
\text { liquida }\end{array}$ & $\mathrm{P} / \mathrm{m}^{3}$ & $1,21 E+08$ & $1,18 \mathrm{E}+08$ & $9,65 E+07$ & $5,48 E+07$ & $1,89 \mathrm{E}+07$ & $1,48 \mathrm{E}+06$ \\
\hline & $\begin{array}{c}\text { Número de Particulas } \\
\text { média liquida }\end{array}$ & $\mathbf{P}$ & 36356 & 35401 & 28960 & 16432 & 5670 & 444 \\
\hline & Desvio - Poisson & $\#$ & 190,67 & 188,15 & 170,18 & 128,19 & 75,30 & 21,07 \\
\hline & $\begin{array}{c}\text { Desvio - Poisson - } \\
\text { Relativo } \\
\end{array}$ & $\%$ & 0,5 & 0,5 & 0,6 & 0,8 & 1,3 & 4,7 \\
\hline & $\begin{array}{l}\text { Desvio padrão } \\
\text { Concentração }\end{array}$ & $\mathrm{P} / \mathrm{m}^{3}$ & $4,90 E+03$ & $4,72 \mathrm{E}+03$ & $7,71 E+02$ & $1,63 \mathrm{E}+03$ & $1,20 E+03$ & $4,92 \mathrm{E}+01$ \\
\hline & DP/Concentração média & $\%$ & 0,0040 & 0,0040 & 0,0008 & 0,0030 & 0,0063 & 0,0033 \\
\hline \multirow{2}{*}{\multicolumn{2}{|c|}{ Erro total medições(દ) }} & $\mathrm{P} / \mathrm{m}^{3}$ & $6,36 \mathrm{E}+05$ & $6,27 E+05$ & $5,67 \mathrm{E}+05$ & $4,27 E+05$ & $2,51 \mathrm{E}+05$ & $7,02 \mathrm{E}+04$ \\
\hline & & Unidade & $1,0-2,0 \mu \mathrm{m}$ & $2,0-3,0 \mu \mathrm{m}$ & $3,0-5,0 \mu \mathrm{m}$ & $5,0-7,0 \mu \mathrm{m}$ & $7,0-10,0 \mu \mathrm{m}$ & $>10,0 \mu \mathrm{m}$ \\
\hline \multirow{8}{*}{ Assento $2 \mathrm{E}$} & $\begin{array}{c}\text { Concentração média de } \\
\text { fundo } \\
\end{array}$ & $\mathrm{P} / \mathrm{m}^{3}$ & $8,00 E+04$ & $5,67 E+04$ & $6,67 E+03$ & $0,00 E+00$ & $0,00 E+00$ & $0,00 E+00$ \\
\hline & $\begin{array}{l}\text { Número de particulas } \\
\text { de fundo }\end{array}$ & $\mathbf{p}$ & 24 & 17 & 2 & 0 & 0 & 0 \\
\hline & $\begin{array}{c}\text { Concentração média } \\
\text { liquida }\end{array}$ & $\mathrm{P} / \mathrm{m}^{3}$ & $1,18 \mathrm{E}+08$ & $1,16 \mathrm{E}+08$ & $6,18 \mathrm{E}+07$ & $2,85 \mathrm{E}+07$ & $1,33 \mathrm{E}+07$ & $2,62 E+06$ \\
\hline & $\begin{array}{c}\text { Número de Particulas } \\
\text { média liquida }\end{array}$ & $\mathbf{p}$ & 35536 & 34704 & 18540 & 8560 & 4000 & 785 \\
\hline & Desvio - Poisson & $\#$ & 188,51 & 186,29 & 136,16 & 92,52 & 63,25 & 28,02 \\
\hline & $\begin{array}{c}\text { Desvio - Poisson - } \\
\text { Relativo } \\
\end{array}$ & $\%$ & 0,5 & 0,5 & 0,7 & 1,1 & 1,6 & 3,6 \\
\hline & \begin{tabular}{|l|}
$\begin{array}{l}\text { Desvio padrão } \\
\text { Concentração }\end{array}$ \\
\end{tabular} & $\mathrm{P} / \mathrm{m}^{3}$ & $1,01 \mathrm{E}+04$ & $9,80 E+03$ & $5,45 E+03$ & $1,74 \mathrm{E}+03$ & $1,19 \mathrm{E}+03$ & $1,29 \mathrm{E}+02$ \\
\hline & DP/Concentração média & $\%$ & 0,0085 & 0,0085 & 0,0088 & 0,0061 & 0,0089 & 0,0049 \\
\hline \multicolumn{2}{|c|}{ Erro total medições( $(\varepsilon)$} & $\mathrm{P} / \mathrm{m}^{3}$ & $6,28 \mathrm{E}+05$ & $6,21 E+05$ & $4,54 \mathrm{E}+05$ & $3,08 \mathrm{E}+05$ & $2,11 \mathrm{E}+05$ & $9,34 \mathrm{E}+04$ \\
\hline
\end{tabular}




\begin{tabular}{|c|c|c|c|c|c|c|c|c|}
\hline & & Unidade & $\mid 1,0-2,0 \mu \mathrm{m}$ & $2,0-3,0 \mu \mathrm{m}$ & $3,0-5,0 \mu \mathrm{m}$ & $5,0-7,0 \mu \mathrm{m}$ & $7,0-10,0 \mu \mathrm{m}$ & $>10,0 \mu \mathrm{m}$ \\
\hline \multirow{8}{*}{ Assento 1D } & $\begin{array}{c}\text { Concentração média de } \\
\text { fundo }\end{array}$ & $\mathrm{P} / \mathrm{m}^{3}$ & $1,43 E+05$ & $9,67 E+04$ & $6,67 E+03$ & $0,00 \mathrm{E}+00$ & $0,00 E+00$ & $0,00 E+00$ \\
\hline & $\begin{array}{c}\text { Número de particulas } \\
\text { de fundo }\end{array}$ & $\mathbf{P}$ & 43 & 29 & 2 & 0 & 0 & 0 \\
\hline & $\begin{array}{c}\text { Concentração média } \\
\text { liquida }\end{array}$ & $\mathrm{P} / \mathrm{m}^{3}$ & $1,37 E+08$ & $1,34 \mathrm{E}+08$ & $9,65 \mathrm{E}+07$ & $4,99 \mathrm{E}+07$ & $1,32 \mathrm{E}+07$ & $4,90 \mathrm{E}+05$ \\
\hline & $\begin{array}{c}\text { Número de Particulas } \\
\text { média liquida }\end{array}$ & $\mathbf{P}$ & 41037 & 40116 & 28952 & 14966 & 3962 & 147 \\
\hline & Desvio - Poisson & $\#$ & 202,58 & 200,29 & 170,15 & 122,34 & 62,94 & 12,12 \\
\hline & $\begin{array}{c}\text { Desvio - Poisson - } \\
\text { Relativo } \\
\end{array}$ & $\%$ & 0,5 & 0,5 & 0,6 & 0,8 & 1,6 & 8,2 \\
\hline & $\begin{array}{l}\text { Desvio padrão } \\
\text { Concentração }\end{array}$ & $\mathrm{P} / \mathrm{m}^{3}$ & $2,83 E+03$ & $2,78 \mathrm{E}+03$ & $2,10 E+03$ & $1,43 E+03$ & $4,45 E+02$ & $1,61 E+01$ \\
\hline & DP/Concentração média & $\%$ & 0,0021 & 0,0021 & 0,0022 & 0,0029 & 0,0034 & 0,0033 \\
\hline \multirow{2}{*}{\multicolumn{2}{|c|}{ Erro total medições $(\varepsilon)$}} & $\mathrm{P} / \mathrm{m}^{3}$ & $6,75 E+05$ & $6,68 \mathrm{E}+05$ & $5,67 E+05$ & $4,08 \mathrm{E}+05$ & $2,10 E+05$ & $4,04 E+04$ \\
\hline & & Unidade & $1,0-2,0 \mu \mathrm{m}$ & $2,0-3,0 \mu \mathrm{m}$ & $3,0-5,0 \mu \mathrm{m}$ & $5,0-7,0 \mu \mathrm{m}$ & $7,0-10,0 \mu \mathrm{m}$ & $>10,0 \mu \mathrm{m}$ \\
\hline \multirow{8}{*}{ Assento $1 \mathrm{E}$} & \begin{tabular}{|c|}
$\begin{array}{c}\text { Concentração média de } \\
\text { fundo }\end{array}$ \\
\end{tabular} & $\mathrm{P} / \mathrm{m}^{3}$ & $2,23 E+05$ & $8,67 E+04$ & $1,33 \mathrm{E}+04$ & $0,00 \mathrm{E}+00$ & $0,00 \mathrm{E}+00$ & $0,00 \mathrm{E}+00$ \\
\hline & $\begin{array}{c}\text { Número de particulas } \\
\text { de fundo }\end{array}$ & $\mathbf{P}$ & 67 & 26 & 4 & 0 & 0 & 0 \\
\hline & $\begin{array}{c}\text { Concentração média } \\
\text { liquida }\end{array}$ & $\mathrm{P} / \mathrm{m}^{3}$ & $9,39 E+07$ & $9,22 E+07$ & $7,01 \mathrm{E}+07$ & $5,33 \mathrm{E}+07$ & $2,00 E+07$ & 4,37E+05 \\
\hline & $\begin{array}{c}\text { Número de Particulas } \\
\text { média liquida }\end{array}$ & $\mathbf{P}$ & 28162 & 27660 & 21025 & 16000 & 5987 & 131 \\
\hline & Desvio - Poisson & $\#$ & 167,82 & 166,31 & 145,00 & 126,49 & 77,38 & 11,45 \\
\hline & $\begin{array}{c}\text { Desvio - Poisson - } \\
\text { Relativo } \\
\end{array}$ & $\%$ & 0,6 & 0,6 & 0,7 & 0,8 & 1,3 & 8,7 \\
\hline & $\begin{array}{l}\text { Desvio padrão } \\
\text { Concentração }\end{array}$ & $\mathrm{P} / \mathrm{m}^{3}$ & $5,49 E+03$ & $5,37 E+03$ & $3,66 \mathrm{E}+03$ & $3,14 E+03$ & $1,88 \mathrm{E}+03$ & $1,76 \mathrm{E}+01$ \\
\hline & DP/Concentração média & $\%$ & 0,0059 & 0,0058 & 0,0052 & 0,0059 & 0,0094 & 0,0040 \\
\hline \multirow{2}{*}{\multicolumn{2}{|c|}{ Erro total medições(દ) }} & $\mathrm{P} / \mathrm{m}^{3}$ & $5,59 E+05$ & $5,54 E+05$ & $4,83 E+05$ & $4,22 E+05$ & $2,58 \mathrm{E}+05$ & $3,82 E+04$ \\
\hline & & Unidade & $1,0-2,0 \mu \mathrm{m}$ & $2,0-3,0 \mu \mathrm{m}$ & $3,0-5,0 \mu \mathrm{m}$ & $5,0-7,0 \mu \mathrm{m}$ & $7,0-10,0 \mu \mathrm{m}$ & $>10,0 \mu \mathrm{m}$ \\
\hline \multirow{8}{*}{ Assento 1B } & \begin{tabular}{|c}
$\begin{array}{c}\text { Concentração média de } \\
\text { fundo }\end{array}$ \\
\end{tabular} & $\mathrm{P} / \mathrm{m}^{3}$ & $2,37 E+05$ & $1,10 \mathrm{E}+05$ & $1,00 \mathrm{E}+04$ & $0,00 \mathrm{E}+00$ & $0,00 E+00$ & $0,00 E+00$ \\
\hline & $\begin{array}{c}\text { Número de particulas } \\
\text { de fundo }\end{array}$ & $\mathbf{P}$ & 71 & 33 & 3 & 0 & 0 & 0 \\
\hline & $\begin{array}{c}\text { Concentração média } \\
\text { liquida }\end{array}$ & $\mathrm{P} / \mathrm{m}^{3}$ & $1,23 E+08$ & $9,71 E+07$ & $5,84 E+07$ & $3,51 E+07$ & $6,25 E+06$ & $4,10 E+05$ \\
\hline & $\begin{array}{c}\text { Número de Particulas } \\
\text { média liquida }\end{array}$ & $\mathbf{p}$ & 36903 & 29132 & 17520 & 10520 & 1874 & 123 \\
\hline & Desvio - Poisson & $\#$ & 192,10 & 170,68 & 132,36 & 102,57 & 43,29 & 11,09 \\
\hline & $\begin{array}{c}\text { Desvio - Poisson - } \\
\text { Relativo } \\
\end{array}$ & $\%$ & 0,5 & 0,6 & 0,8 & 1,0 & 2,3 & 9,0 \\
\hline & $\begin{array}{l}\text { Desvio padrão } \\
\text { Concentração } \\
\end{array}$ & $\mathrm{P} / \mathrm{m}^{3}$ & $1,65 E+04$ & $1,34 \mathrm{E}+04$ & $3,77 \mathrm{E}+03$ & $3,81 E+03$ & $3,83 E+02$ & $3,13 E+01$ \\
\hline & DP/Concentração média & $\%$ & 0,0134 & 0,0138 & 0,0065 & 0,0109 & 0,0061 & 0,0076 \\
\hline \multicolumn{2}{|c|}{ Erro total medições( $(\varepsilon)$} & $\mathrm{P} / \mathrm{m}^{3}$ & $6,41 E+05$ & $5,69 \mathrm{E}+05$ & $4,41 E+05$ & $3,42 E+05$ & $1,44 E+05$ & $3,70 E+04$ \\
\hline
\end{tabular}




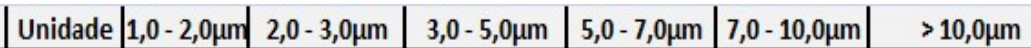

\begin{tabular}{|c|c|c|c|c|c|c|c|c|}
\hline \multirow{8}{*}{ Assento 1A } & \begin{tabular}{|c|}
$\begin{array}{c}\text { Concentração média de } \\
\text { fundo }\end{array}$ \\
\end{tabular} & $\mathrm{P} / \mathrm{m}^{3}$ & $2,07 E+05$ & $1,13 \mathrm{E}+05$ & $1,33 E+04$ & $0,00 \mathrm{E}+00$ & $0,00 E+00$ & $0,00 \mathrm{E}+00$ \\
\hline & $\begin{array}{c}\text { Número de particulas } \\
\text { de fundo }\end{array}$ & $\mathbf{P}$ & 62 & 34 & 4 & 0 & 0 & 0 \\
\hline & $\begin{array}{c}\text { Concentração média } \\
\text { liquida }\end{array}$ & $\mathrm{P} / \mathrm{m}^{3}$ & $9,91 E+07$ & $9,37 E+07$ & $2,67 E+07$ & $1,96 \mathrm{E}+07$ & $4,90 E+06$ & $3,50 \mathrm{E}+05$ \\
\hline & $\begin{array}{c}\text { Número de Particulas } \\
\text { média liquida }\end{array}$ & $\mathbf{P}$ & 29715 & 28121 & 8020 & 5876 & 1471 & 105 \\
\hline & Desvio - Poisson & $\#$ & 172,38 & 167,69 & 89,55 & 76,66 & 38,35 & 10,25 \\
\hline & $\begin{array}{l}\text { Desvio - Poisson - } \\
\text { Relativo }\end{array}$ & $\%$ & 0,6 & 0,6 & 1,1 & 1,3 & 2,6 & 9,8 \\
\hline & $\begin{array}{l}\text { Desvio padrão } \\
\text { Concentração } \\
\end{array}$ & $\mathrm{P} / \mathrm{m}^{3}$ & $3,93 \mathrm{E}+03$ & $3,28 \mathrm{E}+03$ & $8,43 \mathrm{E}+02$ & $1,77 E+03$ & $1,80 E+02$ & $4,22 \mathrm{E}+01$ \\
\hline & DP/Concentração média & $\%$ & 0,0040 & 0,0035 & 0,0032 & 0,0091 & 0,0037 & 0,0121 \\
\hline \multicolumn{2}{|c|}{ Erro total medições(દ) } & $\mathrm{P} / \mathrm{m}^{3}$ & $5,75 \mathrm{E}+05$ & $5,59 \mathrm{E}+05$ & $2,99 \mathrm{E}+05$ & $2,56 \mathrm{E}+05$ & $1,28 \mathrm{E}+05$ & $3,42 \mathrm{E}+04$ \\
\hline & & Unidade & $1,0-2,0 \mu \mathrm{m}$ & $2,0-3,0 \mu \mathrm{m}$ & $3,0-5,0 \mu \mathrm{m}$ & $5,0-7,0 \mu \mathrm{m}$ & $7,0-10,0 \mu \mathrm{m}$ & $>10,0 \mu \mathrm{m}$ \\
\hline \multirow{8}{*}{ Assento 2B } & $\begin{array}{c}\text { Concentração média de } \\
\text { fundo }\end{array}$ & $\mathrm{P} / \mathrm{m}^{3}$ & $1,87 E+05$ & $5,67 E+04$ & $6,67 E+03$ & $0,00 E+00$ & $0,00 \mathrm{E}+00$ & $0,00 \mathrm{E}+00$ \\
\hline & $\begin{array}{c}\text { Número de particulas } \\
\text { de fundo }\end{array}$ & $\mathbf{P}$ & 56 & 17 & 2 & 0 & 0 & 0 \\
\hline & $\begin{array}{l}\text { Concentração média } \\
\text { liquida }\end{array}$ & $\mathrm{P} / \mathrm{m}^{3}$ & $1,63 E+08$ & $1,59 \mathrm{E}+08$ & $4,52 \mathrm{E}+07$ & $2,63 \mathrm{E}+07$ & $1,03 \mathrm{E}+07$ & $5,67 E+05$ \\
\hline & $\begin{array}{c}\text { Número de Particulas } \\
\text { média liquida }\end{array}$ & $\mathbf{P}$ & 48805 & 47598 & 13560 & 7891 & 3082 & 170 \\
\hline & Desvio - Poisson & $\#$ & 220,92 & 218,17 & 116,45 & 88,83 & 55,52 & 13,04 \\
\hline & $\begin{array}{c}\text { Desvio - Poisson - } \\
\text { Relativo } \\
\end{array}$ & $\%$ & 0,5 & 0,5 & 0,9 & 1,1 & 1,8 & 7,7 \\
\hline & $\begin{array}{l}\text { Desvio padrão } \\
\text { Concentração } \\
\end{array}$ & $\mathrm{P} / \mathrm{m}^{3}$ & $1,45 E+04$ & $1,40 E+04$ & $4,73 \mathrm{E}+03$ & $1,12 E+03$ & $3,92 E+02$ & $3,32 \mathrm{E}+01$ \\
\hline & DP/Concentração média & $\%$ & 0,0089 & 0,0088 & 0,0105 & 0,0042 & 0,0038 & 0,0059 \\
\hline \multirow{2}{*}{\multicolumn{2}{|c|}{ Erro total medições( $(\varepsilon)$}} & $\mathrm{P} / \mathrm{m}^{3}$ & $7,37 E+05$ & $7,27 E+05$ & $3,88 \mathrm{E}+05$ & $2,96 \mathrm{E}+05$ & $1,85 \mathrm{E}+05$ & $4,35 \mathrm{E}+04$ \\
\hline & & Unidade & $1,0-2,0 \mu \mathrm{m}$ & $2,0-3,0 \mu \mathrm{m}$ & $3,0-5,0 \mu \mathrm{m}$ & $5,0-7,0 \mu \mathrm{m}$ & $7,0-10,0 \mu \mathrm{m}$ & $>10,0 \mu \mathrm{m}$ \\
\hline \multirow{8}{*}{ Assento 2A } & $\begin{array}{c}\text { Concentração média de } \\
\text { fundo } \\
\end{array}$ & $\mathrm{P} / \mathrm{m}^{3}$ & $1,80 E+05$ & $1,10 \mathrm{E}+05$ & $1,33 \mathrm{E}+04$ & $0,00 \mathrm{E}+00$ & $0,00 E+00$ & $0,00 \mathrm{E}+00$ \\
\hline & $\begin{array}{c}\text { Número de particulas } \\
\text { de fundo }\end{array}$ & $\mathbf{P}$ & 54 & 33 & 4 & 0 & 0 & 0 \\
\hline & $\begin{array}{c}\text { Concentração média } \\
\text { liquida }\end{array}$ & $\mathrm{P} / \mathrm{m}^{3}$ & $1,57 E+08$ & $9,71 E+07$ & $5,00 \mathrm{E}+07$ & $3,41 E+07$ & $9,68 \mathrm{E}+06$ & $6,03 \mathrm{E}+05$ \\
\hline & $\begin{array}{c}\text { Número de Particulas } \\
\text { média liquida }\end{array}$ & $\mathbf{P}$ & 47219 & 29137 & 15000 & 10220 & 2903 & 181 \\
\hline & Desvio - Poisson & $\#$ & 217,30 & 170,70 & 122,47 & 101,09 & 53,88 & 13,45 \\
\hline & $\begin{array}{c}\text { Desvio - Poisson - } \\
\text { Relativo } \\
\end{array}$ & $\%$ & 0,5 & 0,6 & 0,8 & 1,0 & 1,9 & 7,4 \\
\hline & $\begin{array}{l}\text { Desvio padrão } \\
\text { Concentração }\end{array}$ & $\mathrm{P} / \mathrm{m}^{3}$ & $2,61 \mathrm{E}+04$ & $1,21 E+05$ & $6,08 \mathrm{E}+03$ & $1,01 E+03$ & $7,57 E+02$ & $8,05 E+01$ \\
\hline & DP/Concentração média & $\%$ & 0,0166 & 0,1248 & 0,0122 & 0,0030 & 0,0078 & 0,0133 \\
\hline \multicolumn{2}{|c|}{ Erro total medições $(\varepsilon)$} & $\mathrm{P} / \mathrm{m}^{3}$ & $7,25 \mathrm{E}+05$ & $5,82 E+05$ & $4,08 \mathrm{E}+05$ & $3,37 E+05$ & $1,80 \mathrm{E}+05$ & $4,48 \mathrm{E}+04$ \\
\hline
\end{tabular}




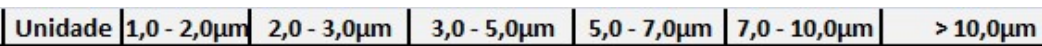

\begin{tabular}{|c|c|c|c|c|c|c|c|c|}
\hline \multirow{9}{*}{ Assento 3B } & & & & & & & & \\
\hline & $\begin{array}{c}\text { Concentração média de } \\
\text { fundo }\end{array}$ & $\mathrm{P} / \mathrm{m}^{3}$ & $1,30 \mathrm{E}+05$ & $7,67 E+04$ & $1,00 \mathrm{E}+04$ & $0,00 E+00$ & $0,00 E+00$ & $0,00 E+00$ \\
\hline & $\begin{array}{c}\text { Número de particulas } \\
\text { de fundo }\end{array}$ & $\mathbf{P}$ & 39 & 23 & 3 & 0 & 0 & 0 \\
\hline & $\begin{array}{c}\text { Concentração média } \\
\text { liquida }\end{array}$ & $\mathrm{P} / \mathrm{m}^{3}$ & $1,33 E+08$ & $1,21 E+08$ & $5,51 E+07$ & $3,51 \mathrm{E}+07$ & $1,83 \mathrm{E}+07$ & $8,13 E+05$ \\
\hline & $\begin{array}{l}\text { Número de Particulas } \\
\text { média liquida }\end{array}$ & $\mathbf{P}$ & 39829 & 36292 & 16520 & 10520 & 5492 & 244 \\
\hline & Desvio - Poisson & \# & 199,57 & 190,50 & 128,53 & 102,57 & 74,11 & 15,62 \\
\hline & $\begin{array}{l}\text { Desvio - Poisson - } \\
\text { Relativo }\end{array}$ & $\%$ & 0,5 & 0,5 & 0,8 & 1,0 & 1,3 & 6,4 \\
\hline & \begin{tabular}{|c|} 
Desvio padrão \\
Concentração \\
\end{tabular} & $\mathrm{P} / \mathrm{m}^{3}$ & $2,14 E+03$ & $1,26 \mathrm{E}+03$ & $1,81 E+04$ & $7,81 \mathrm{E}+03$ & $5,95 E+02$ & $4,47 E+01$ \\
\hline & DP/Concentração média & $\%$ & 0,0016 & 0,0010 & 0,0329 & 0,0223 & 0,0033 & 0,0055 \\
\hline \multirow{2}{*}{\multicolumn{2}{|c|}{ Erro total medições( $(\varepsilon)$}} & $\mathrm{P} / \mathrm{m}^{3}$ & $6,65 \mathrm{E}+05$ & $6,35 E+05$ & $4,29 E+05$ & $3,42 E+05$ & $2,47 E+05$ & $5,21 E+04$ \\
\hline & & Unidade & $1,0-2,0 \mu \mathrm{m}$ & $2,0-3,0 \mu \mathrm{m}$ & $3,0-5,0 \mu \mathrm{m}$ & $5,0-7,0 \mu \mathrm{m}$ & $7,0-10,0 \mu \mathrm{m}$ & $>10,0 \mu \mathrm{m}$ \\
\hline \multirow{8}{*}{ Assento 3A } & $\begin{array}{c}\begin{array}{c}\text { Concentração média de } \\
\text { fundo }\end{array} \\
\end{array}$ & $\mathrm{P} / \mathrm{m}^{3}$ & $7,67 E+04$ & $3,67 E+04$ & $2,33 E+04$ & $0,00 E+00$ & $0,00 E+00$ & $0,00 E+00$ \\
\hline & $\begin{array}{c}\text { Número de particulas } \\
\text { de fundo }\end{array}$ & $\mathbf{p}$ & 23 & 11 & 7 & 0 & 0 & 0 \\
\hline & $\begin{array}{c}\text { Concentração média } \\
\text { liquida }\end{array}$ & $\mathrm{P} / \mathrm{m}^{3}$ & $2,84 E+07$ & $2,05 E+07$ & $1,33 E+07$ & $3,15 E+07$ & $7,56 \mathrm{E}+06$ & $1,26 \mathrm{E}+06$ \\
\hline & $\begin{array}{l}\text { Número de Particulas } \\
\text { média liquida }\end{array}$ & $\mathbf{P}$ & 8534 & 6145 & 4000 & 9450 & 2268 & 377 \\
\hline & Desvio - Poisson & $\#$ & 92,38 & 78,39 & 63,25 & 97,21 & 47,62 & 19,42 \\
\hline & $\begin{array}{c}\text { Desvio - Poisson - } \\
\text { Relativo }\end{array}$ & $\%$ & 1,1 & 1,3 & 1,6 & 1,0 & 2,1 & 5,2 \\
\hline & \begin{tabular}{|c|}
$\begin{array}{l}\text { Desvio padrão } \\
\text { Concentração }\end{array}$ \\
\end{tabular} & $\mathrm{P} / \mathrm{m}^{3}$ & $2,83 E+04$ & $2,95 E+04$ & $7,92 E+02$ & $3,36 \mathrm{E}+03$ & $1,71 \mathrm{E}+03$ & $1,04 \mathrm{E}+02$ \\
\hline & DP/Concentração média & $\%$ & 0,0995 & 0,1441 & 0,0059 & 0,0107 & 0,0227 & 0,0083 \\
\hline \multicolumn{2}{|c|}{ Erro total medições( $(\varepsilon)$} & $\mathrm{P} / \mathrm{m}^{3}$ & $3,09 E+05$ & $2,63 E+05$ & $2,11 E+05$ & $3,24 E+05$ & $1,59 \mathrm{E}+05$ & $6,47 E+04$ \\
\hline
\end{tabular}


Tabela B-4. Resultados das medições de partículas no assento (Sistema $\mathrm{MV}$ à $22^{\circ} \mathrm{C}$ - injeção pelo assento $3 \mathrm{~B}$ )

\begin{tabular}{|c|c|c|c|c|c|c|c|c|}
\hline & & Unidade & $1,0-2,0 \mu \mathrm{m}$ & $2,0-3,0 \mu \mathrm{m}$ & $3,0-5,0 \mu \mathrm{m}$ & $5,0-7,0 \mu \mathrm{m}$ & $7,0-10,0 \mu \mathrm{m}$ & $>10,0 \mu \mathrm{m}$ \\
\hline \multirow{8}{*}{ Assento 3E } & \begin{tabular}{|c|}
$\begin{array}{c}\text { Concentração média de } \\
\text { fundo }\end{array}$ \\
\end{tabular} & $\mathrm{P} / \mathrm{m}^{3}$ & $1,67 E+05$ & $1,50 E+05$ & $1,00 E+04$ & $0,00 E+00$ & $0,00 E+00$ & $0,00 E+00$ \\
\hline & $\begin{array}{c}\text { Número de particulas } \\
\text { de fundo }\end{array}$ & $\mathbf{P}$ & 50 & 45 & 3 & 0 & 0 & 0 \\
\hline & $\begin{array}{l}\text { Concentração média } \\
\text { liquida }\end{array}$ & $\mathrm{P} / \mathrm{m}^{3}$ & $2,48 E+08$ & $2,39 E+08$ & $1,37 E+08$ & $1,03 E+08$ & $5,50 E+07$ & $1,20 E+06$ \\
\hline & $\begin{array}{c}\text { Número de Particulas } \\
\text { média liquida }\end{array}$ & $\mathbf{P}$ & 74332 & 71785,5 & 41000 & 31000 & 16500 & 361 \\
\hline & Desvio - Poisson & $\#$ & 272,64 & 267,93 & 202,48 & 176,07 & 128,45 & 19,00 \\
\hline & $\begin{array}{l}\text { Desvio - Poisson - } \\
\text { Relativo }\end{array}$ & $\%$ & 0,4 & 0,4 & 0,5 & 0,6 & 0,8 & 5,3 \\
\hline & $\begin{array}{l}\text { Desvio padrão } \\
\text { Concentração }\end{array}$ & $\mathrm{P} / \mathrm{m}^{3}$ & $2,79 E+04$ & $2,68 \mathrm{E}+04$ & $1,68 E+04$ & $1,04 E+04$ & $4,68 E+03$ & $8,36 E+01$ \\
\hline & DP/Concentração média & $\%$ & 0,0113 & 0,0112 & 0,0123 & 0,0100 & 0,0085 & 0,0069 \\
\hline \multirow{2}{*}{\multicolumn{2}{|c|}{ Erro total medições(દ) }} & $\mathrm{P} / \mathrm{m}^{3}$ & $9,09 E+05$ & $8,93 E+05$ & $6,75 \mathrm{E}+05$ & $5,87 E+05$ & $4,28 \mathrm{E}+05$ & $6,33 \mathrm{E}+04$ \\
\hline & & Unidade & $1,0-2,0 \mu \mathrm{m}$ & $2,0-3,0 \mu \mathrm{m}$ & $3,0-5,0 \mu \mathrm{m}$ & $5,0-7,0 \mu \mathrm{m}$ & $7,0-10,0 \mu \mathrm{m}$ & $>10,0 \mu \mathrm{m}$ \\
\hline \multirow{8}{*}{ Assento 2D } & $\begin{array}{c}\text { Concentração média de } \\
\text { fundo }\end{array}$ & $\mathrm{P} / \mathrm{m}^{3}$ & $6,67 E+04$ & $2,33 E+04$ & $3,33 E+03$ & $0,00 E+00$ & $0,00 E+00$ & $0,00 E+00$ \\
\hline & $\begin{array}{l}\text { Número de particulas } \\
\text { de fundo }\end{array}$ & $\mathbf{P}$ & 20 & 7 & 1 & 0 & 0 & 0 \\
\hline & $\begin{array}{c}\text { Concentração média } \\
\text { liquida }\end{array}$ & $\mathrm{P} / \mathrm{m}^{3}$ & $1,28 \mathrm{E}+08$ & $1,17 E+08$ & $1,05 E+08$ & $4,55 E+07$ & $8,17 E+06$ & $5,13 E+05$ \\
\hline & $\begin{array}{c}\text { Número de Particulas } \\
\text { média liquida }\end{array}$ & $\mathbf{P}$ & 38535 & 34964 & 31580 & 13650 & 2452 & 154 \\
\hline & Desvio - Poisson & $\#$ & 196,30 & 186,99 & 177,71 & 116,83 & 49,51 & 12,41 \\
\hline & $\begin{array}{c}\text { Desvio - Poisson - } \\
\text { Relativo } \\
\end{array}$ & $\%$ & 0,5 & 0,5 & 0,6 & 0,9 & 2,0 & 8,1 \\
\hline & $\begin{array}{c}\text { Desvio padrão } \\
\text { Concentração }\end{array}$ & $\mathrm{P} / \mathrm{m}^{3}$ & $9,57 E+03$ & $6,33 \mathrm{E}+03$ & $3,42 E+03$ & $9,58 \mathrm{E}+02$ & $1,04 \mathrm{E}+03$ & $1,04 \mathrm{E}+02$ \\
\hline & DP/Concentração média & $\%$ & 0,0075 & 0,0054 & 0,0032 & 0,0021 & 0,0127 & 0,0203 \\
\hline \multirow{2}{*}{\multicolumn{2}{|c|}{ Erro total medições( $\varepsilon)$}} & $\mathrm{P} / \mathrm{m}^{3}$ & $6,54 \mathrm{E}+05$ & $6,23 \mathrm{E}+05$ & $5,92 \mathrm{E}+05$ & $3,89 \mathrm{E}+05$ & $1,65 E+05$ & $4,14 \mathrm{E}+04$ \\
\hline & & Unidade & $1,0-2,0 \mu \mathrm{m}$ & $2,0-3,0 \mu \mathrm{m}$ & $3,0-5,0 \mu \mathrm{m}$ & $5,0-7,0 \mu \mathrm{m}$ & $7,0-10,0 \mu \mathrm{m}$ & $>10,0 \mu \mathrm{m}$ \\
\hline \multirow{8}{*}{ Assento 2E } & $\begin{array}{c}\text { Concentração média de } \\
\text { fundo }\end{array}$ & $\mathrm{P} / \mathrm{m}^{3}$ & $1,57 E+05$ & $7,00 E+04$ & $1,00 E+04$ & $0,00 E+00$ & $0,00 E+00$ & $0,00 E+00$ \\
\hline & $\begin{array}{c}\text { Número de particulas } \\
\text { de fundo }\end{array}$ & $\mathbf{P}$ & 47 & 21 & 3 & 0 & 0 & 0 \\
\hline & $\begin{array}{c}\text { Concentração média } \\
\text { liquida }\end{array}$ & $\mathrm{P} / \mathrm{m}^{3}$ & $1,43 E+08$ & $1,30 E+08$ & $1,03 E+08$ & $7,18 \mathrm{E}+07$ & $6,62 E+07$ & $8,33 E+05$ \\
\hline & $\begin{array}{c}\text { Número de Particulas } \\
\text { média liquida }\end{array}$ & $\mathbf{P}$ & 42884,14 & 38985,00 & 31000,00 & 21540,00 & 19871,00 & 250,00 \\
\hline & Desvio - Poisson & $\#$ & 207,08 & 197,45 & 176,07 & 146,77 & 140,96 & 15,81 \\
\hline & $\begin{array}{c}\text { Desvio - Poisson - } \\
\text { Relativo } \\
\end{array}$ & $\%$ & 0,5 & 0,5 & 0,6 & 0,7 & 0,7 & 6,3 \\
\hline & $\begin{array}{l}\text { Desvio padrão } \\
\text { Concentração }\end{array}$ & $\mathrm{P} / \mathrm{m}^{3}$ & $2,39 E+03$ & $7,24 E+03$ & $2,15 E+03$ & $1,89 \mathrm{E}+03$ & $1,79 E+03$ & $5,68 E+01$ \\
\hline & DP/Concentração média & $\%$ & 0,0017 & 0,0056 & 0,0021 & 0,0026 & 0,0027 & 0,0068 \\
\hline \multicolumn{2}{|c|}{ Erro total medições $(\varepsilon)$} & $\mathrm{P} / \mathrm{m}^{3}$ & $6,90 \mathrm{E}+05$ & $6,58 \mathrm{E}+05$ & $5,87 E+05$ & $4,89 \mathrm{E}+05$ & $4,70 \mathrm{E}+05$ & $5,27 E+04$ \\
\hline
\end{tabular}




\begin{tabular}{|c|c|c|c|c|c|c|c|c|}
\hline & & Unidade & $1,0-2,0 \mu \mathrm{m}$ & $2,0-3,0 \mu \mathrm{m}$ & $3,0-5,0 \mu \mathrm{m}$ & $5,0-7,0 \mu \mathrm{m}$ & $7,0-10,0 \mu \mathrm{m}$ & $>10,0 \mu \mathrm{m}$ \\
\hline \multirow{8}{*}{ Assento 1D } & $\begin{array}{c}\text { Concentração média de } \\
\text { fundo }\end{array}$ & $\mathrm{P} / \mathrm{m}^{3}$ & $1,77 \mathrm{E}+05$ & $7,00 E+04$ & $1,00 E+04$ & $0,00 \mathrm{E}+00$ & $0,00 E+00$ & $0,00 E+00$ \\
\hline & $\begin{array}{c}\text { Número de particulas } \\
\text { de fundo }\end{array}$ & $\mathbf{P}$ & 53 & 21 & 3 & 0 & 0 & 0 \\
\hline & $\begin{array}{c}\text { Concentração média } \\
\text { liquida }\end{array}$ & $\mathrm{P} / \mathrm{m}^{3}$ & $1,40 E+08$ & $1,05 E+08$ & $9,28 \mathrm{E}+07$ & $5,50 \mathrm{E}+07$ & $6,69 \mathrm{E}+06$ & $4,18 \mathrm{E}+05$ \\
\hline & $\begin{array}{l}\text { Número de Particulas } \\
\text { média liquida }\end{array}$ & $\mathbf{P}$ & 42141,833 & 31388 & 27850 & 16500 & 2006 & 125,5 \\
\hline & Desvio - Poisson & $\#$ & 205,28 & 177,17 & 166,88 & 128,45 & 44,79 & 11,20 \\
\hline & $\begin{array}{c}\text { Desvio - Poisson - } \\
\text { Relativo }\end{array}$ & $\%$ & 0,5 & 0,6 & 0,6 & 0,8 & 2,2 & 8,9 \\
\hline & $\begin{array}{l}\text { Desvio padrão } \\
\text { Concentração }\end{array}$ & $\mathrm{P} / \mathrm{m}^{3}$ & $7,58 \mathrm{E}+03$ & $7,53 E+03$ & $1,22 \mathrm{E}+03$ & $3,05 E+03$ & $5,77 \mathrm{E}+02$ & $2,23 E+01$ \\
\hline & DP/Concentração média & $\%$ & 0,0054 & 0,0072 & 0,0013 & 0,0055 & 0,0086 & 0,0053 \\
\hline \multirow{2}{*}{\multicolumn{2}{|c|}{ Erro total medições $(\varepsilon)$}} & $\mathrm{P} / \mathrm{m}^{3}$ & $6,84 E+05$ & $5,91 \mathrm{E}+05$ & $5,56 \mathrm{E}+05$ & $4,28 E+05$ & $1,49 \mathrm{E}+05$ & $3,73 \mathrm{E}+04$ \\
\hline & & Unidade & $1,0-2,0 \mu \mathrm{m}$ & $2,0-3,0 \mu \mathrm{m}$ & $3,0-5,0 \mu \mathrm{m}$ & $5,0-7,0 \mu \mathrm{m}$ & $7,0-10,0 \mu \mathrm{m}$ & $>10,0 \mu \mathrm{m}$ \\
\hline \multirow{8}{*}{ Assento 1E } & $\begin{array}{c}\text { Concentração média de } \\
\text { fundo }\end{array}$ & $\mathrm{P} / \mathrm{m}^{3}$ & $9,67 E+04$ & $4,67 E+04$ & $1,00 E+04$ & $3,33 E+03$ & $0,00 E+00$ & $0,00 E+00$ \\
\hline & $\begin{array}{c}\text { Número de particulas } \\
\text { de fundo }\end{array}$ & $\mathbf{P}$ & 29 & 14 & 3 & 1 & 0 & 0 \\
\hline & $\begin{array}{c}\text { Concentração média } \\
\text { liquida }\end{array}$ & $\mathrm{P} / \mathrm{m}^{3}$ & $1,27 E+08$ & $1,13 E+08$ & $9,33 E+07$ & $5,33 E+07$ & $4,69 E+06$ & $3,10 \mathrm{E}+05$ \\
\hline & $\begin{array}{l}\text { Número de Particulas } \\
\text { média liquida }\end{array}$ & $\mathbf{p}$ & 38109,375 & 33798,75 & 28000 & 16000 & 1407 & 93 \\
\hline & Desvio - Poisson & $\#$ & 195,22 & 183,84 & 167,33 & 126,49 & 37,51 & 9,64 \\
\hline & $\begin{array}{c}\text { Desvio - Poisson - } \\
\text { Relativo }\end{array}$ & $\%$ & 0,5 & 0,5 & 0,6 & 0,8 & 2,7 & 10,4 \\
\hline & \begin{tabular}{|l|}
$\begin{array}{l}\text { Desvio padrão } \\
\text { Concentração }\end{array}$ \\
\end{tabular} & $\mathrm{P} / \mathrm{m}^{3}$ & $2,40 E+03$ & $7,07 E+03$ & $2,83 \mathrm{E}+03$ & $3,33 \mathrm{E}+03$ & $2,50 E+02$ & $4,17 E+01$ \\
\hline & DP/Concentração média & $\%$ & 0,0019 & 0,0063 & 0,0030 & 0,0062 & 0,0053 & 0,0135 \\
\hline \multirow{2}{*}{\multicolumn{2}{|c|}{ Erro total medições $(\varepsilon)$}} & $\mathrm{P} / \mathrm{m}^{3}$ & $6,51 \mathrm{E}+05$ & $6,13 \mathrm{E}+05$ & $5,58 \mathrm{E}+05$ & $4,22 \mathrm{E}+05$ & $1,25 \mathrm{E}+05$ & $3,21 \mathrm{E}+04$ \\
\hline & & Unidade & $1,0-2,0 \mu \mathrm{m}$ & $2,0-3,0 \mu \mathrm{m}$ & $3,0-5,0 \mu \mathrm{m}$ & $5,0-7,0 \mu \mathrm{m}$ & $7,0-10,0 \mu \mathrm{m}$ & $>10,0 \mu \mathrm{m}$ \\
\hline \multirow{8}{*}{ Assento 1B } & $\begin{array}{c}\text { Concentração média de } \\
\text { fundo }\end{array}$ & $\mathrm{P} / \mathrm{m}^{3}$ & $1,10 \mathrm{E}+05$ & $6,33 E+04$ & $3,33 E+03$ & $0,00 E+00$ & $0,00 E+00$ & $0,00 E+00$ \\
\hline & $\begin{array}{c}\text { Número de particulas } \\
\text { de fundo }\end{array}$ & $\mathbf{P}$ & 33 & 19 & 1 & 0 & 0 & 0 \\
\hline & $\begin{array}{c}\text { Concentração média } \\
\text { liquida }\end{array}$ & $\mathrm{P} / \mathrm{m}^{3}$ & $1,18 \mathrm{E}+08$ & $9,86 \mathrm{E}+07$ & $7,52 \mathrm{E}+07$ & $4,67 E+07$ & $5,36 E+06$ & $3,73 E+05$ \\
\hline & $\begin{array}{c}\text { Número de Particulas } \\
\text { média liquida }\end{array}$ & $\mathbf{P}$ & 35365 & 29586 & 22560 & 14002 & 1608 & 112 \\
\hline & Desvio - Poisson & $\#$ & 188,05 & 172,01 & 150,20 & 118,33 & 40,10 & 10,58 \\
\hline & $\begin{array}{c}\text { Desvio - Poisson - } \\
\text { Relativo } \\
\end{array}$ & $\%$ & 0,5 & 0,6 & 0,7 & 0,8 & 2,5 & 9,4 \\
\hline & $\begin{array}{c}\text { Desvio padrão } \\
\text { Concentração } \\
\end{array}$ & $\mathrm{P} / \mathrm{m}^{3}$ & $1,40 \mathrm{E}+03$ & $2,26 E+03$ & $1,18 \mathrm{E}+03$ & $1,30 \mathrm{E}+03$ & $2,73 E+02$ & $4,52 E+01$ \\
\hline & DP/Concentração média & $\%$ & 0,0012 & 0,0023 & 0,0016 & 0,0028 & 0,0051 & 0,0121 \\
\hline \multicolumn{2}{|c|}{ Erro total medições( $(\varepsilon)$} & $\mathrm{P} / \mathrm{m}^{3}$ & $6,27 E+05$ & $5,73 E+05$ & $5,01 \mathrm{E}+05$ & $3,94 E+05$ & $1,34 \mathrm{E}+05$ & $3,53 \mathrm{E}+04$ \\
\hline
\end{tabular}




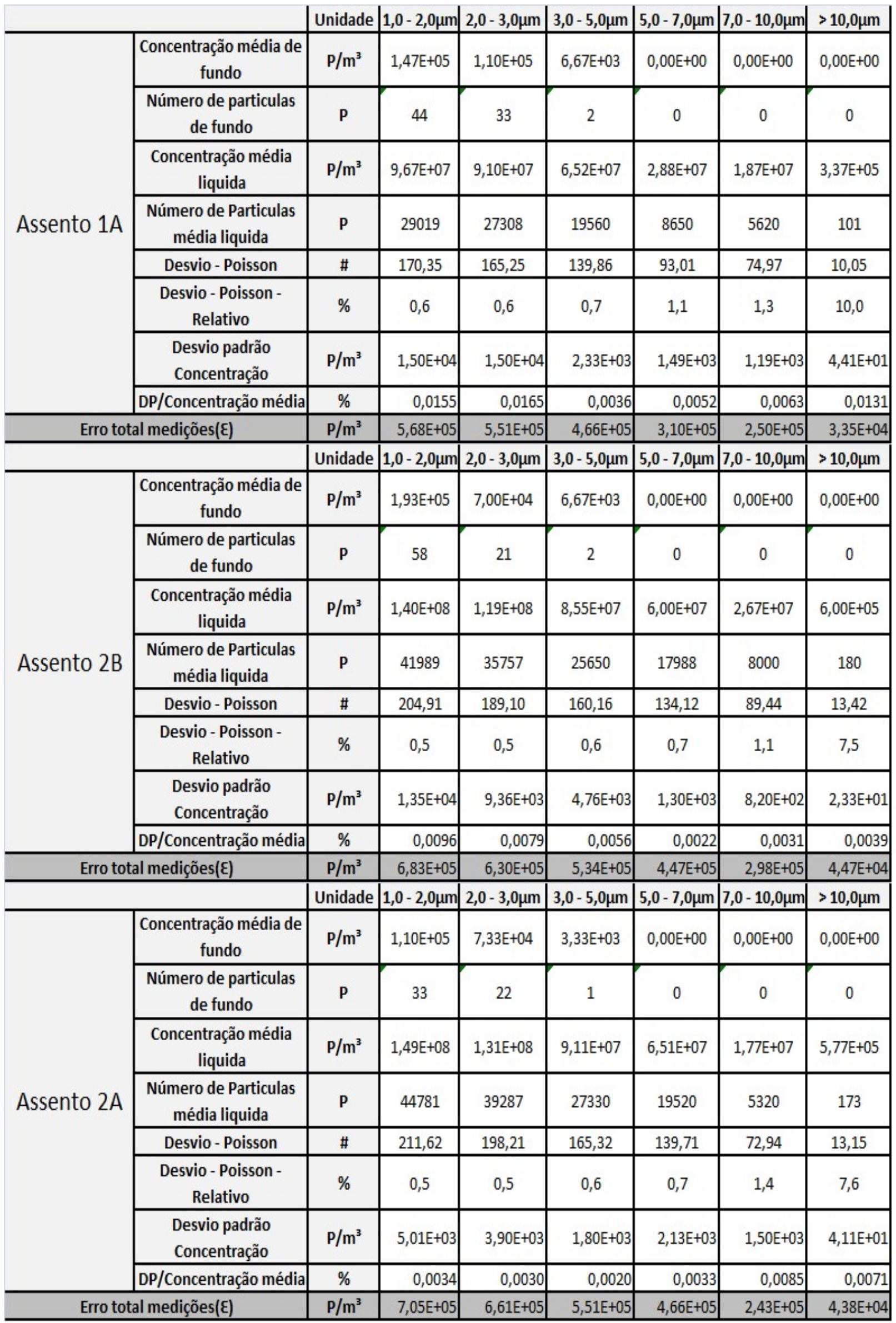


Unidade $1,0-2,0 \mu \mathrm{m}|2,0-3,0 \mu \mathrm{m}| 3,0-5,0 \mu \mathrm{m}|5,0-7,0 \mu \mathrm{m}| 7,0-10,0 \mu \mathrm{m} \mid>10,0 \mu \mathrm{m}$

\begin{tabular}{|c|c|c|c|c|c|c|c|c|}
\hline \multirow{8}{*}{ Assento 3B } & $\begin{array}{c}\text { Concentração média de } \\
\text { fundo }\end{array}$ & $\mathrm{P} / \mathrm{m}^{3}$ & $2,90 E+05$ & $2,20 E+05$ & $1,33 E+04$ & $1,67 E+03$ & $0,00 \mathrm{E}+00$ & $0,00 E+00$ \\
\hline & $\begin{array}{c}\text { Número de particulas } \\
\text { de fundo }\end{array}$ & $\mathbf{P}$ & 87 & 66 & 4 & 1 & 0 & 0 \\
\hline & $\begin{array}{c}\text { Concentração média } \\
\text { liquida }\end{array}$ & $\mathrm{P} / \mathrm{m}^{3}$ & $1,49 E+08$ & $1,39 \mathrm{E}+08$ & $1,20 E+08$ & $7,51 \mathrm{E}+07$ & $6,10 E+07$ & $4,07 E+06$ \\
\hline & $\begin{array}{l}\text { Número de Particulas } \\
\text { média liquida }\end{array}$ & $\mathbf{P}$ & 44795 & 41658 & 36000 & 22542 & 18287 & 1222 \\
\hline & Desvio - Poisson & $\#$ & 211,65 & 204,10 & 189,74 & 150,14 & 135,23 & 34,96 \\
\hline & $\begin{array}{c}\text { Desvio - Poisson - } \\
\text { Relativo }\end{array}$ & $\%$ & 0,5 & 0,5 & 0,5 & 0,7 & 0,7 & 2,9 \\
\hline & $\begin{array}{c}\text { Desvio padrão } \\
\text { Concentração }\end{array}$ & $\mathrm{P} / \mathrm{m}^{3}$ & $1,82 \mathrm{E}+03$ & $1,11 \mathrm{E}+03$ & $1,10 \mathrm{E}+03$ & $1,13 \mathrm{E}+03$ & $6,31 \mathrm{E}+02$ & $2,63 E+02$ \\
\hline & DP/Concentração média & $\%$ & 0,0012 & 0,0008 & 0,0009 & 0,0015 & 0,0010 & 0,0065 \\
\hline \multirow{2}{*}{\multicolumn{2}{|c|}{ Erro total medições( $\varepsilon)$}} & $\mathrm{P} / \mathrm{m}^{3}$ & $7,05 E+05$ & $6,80 \mathrm{E}+05$ & $6,32 \mathrm{E}+05$ & $5,00 E+05$ & $4,51 \mathrm{E}+05$ & $1,17 \mathrm{E}+05$ \\
\hline & & Unidade & $1,0-2,0 \mu \mathrm{m}$ & $2,0-3,0 \mu \mathrm{m}$ & $3,0-5,0 \mu \mathrm{m}$ & $5,0-7,0 \mu \mathrm{m}$ & $7,0-10,0 \mu \mathrm{m}$ & $>10,0 \mu \mathrm{m}$ \\
\hline \multirow{8}{*}{ Assento $3 \mathrm{~A}$} & $\begin{array}{c}\text { Concentração média de } \\
\text { fundo }\end{array}$ & $\mathrm{P} / \mathrm{m}^{3}$ & $3,67 E+04$ & $4,00 E+04$ & $8,33 E+03$ & $0,00 E+00$ & $0,00 E+00$ & $0,00 E+00$ \\
\hline & $\begin{array}{c}\text { Número de particulas } \\
\text { de fundo }\end{array}$ & $\mathbf{P}$ & 11 & 12 & 3 & 0 & 0 & 0 \\
\hline & $\begin{array}{c}\text { Concentração média } \\
\text { liquida }\end{array}$ & $\mathrm{P} / \mathrm{m}^{3}$ & $1,59 \mathrm{E}+08$ & $1,28 \mathrm{E}+08$ & $1,00 E+08$ & $5,92 E+07$ & $3,75 E+07$ & $1,41 E+06$ \\
\hline & $\begin{array}{c}\text { Número de Particulas } \\
\text { média liquida }\end{array}$ & $\mathbf{P}$ & 47570 & 38389 & 30000 & 17759 & 11264 & 423 \\
\hline & Desvio - Poisson & $\#$ & 218,11 & 195,93 & 173,21 & 133,26 & 106,13 & 20,57 \\
\hline & $\begin{array}{c}\text { Desvio - Poisson - } \\
\text { Relativo } \\
\end{array}$ & $\%$ & 0,5 & 0,5 & 0,6 & 0,8 & 0,9 & 4,9 \\
\hline & $\begin{array}{c}\text { Desvio padrão } \\
\text { Concentração }\end{array}$ & $\mathrm{P} / \mathrm{m}^{3}$ & $1,10 \mathrm{E}+04$ & $1,02 E+03$ & $1,66 \mathrm{E}+03$ & $7,75 E+02$ & $6,32 E+02$ & $5,22 \mathrm{E}+01$ \\
\hline & DP/Concentração média & $\%$ & 0,0069 & 0,0008 & 0,0017 & 0,0013 & 0,0017 & 0,0037 \\
\hline \multicolumn{2}{|c|}{ Erro total medições(દ) } & $\mathrm{P} / \mathrm{m}^{3}$ & $7,27 E+05$ & $6,53 E+05$ & $5,77 \mathrm{E}+05$ & $4,44 \mathrm{E}+05$ & $3,54 \mathrm{E}+05$ & $6,86 \mathrm{E}+04$ \\
\hline
\end{tabular}


Tabela B-5. Resultados das medições de partículas no assento (Sistema UFAD à $22^{\circ} \mathrm{C}$ - injeção pelo assento $3 \mathrm{~B}$ )

\begin{tabular}{|c|c|c|c|c|c|c|c|c|}
\hline & & Unidade & $1,0-2,0 \mu \mathrm{m}$ & $2,0-3,0 \mu \mathrm{m}$ & $3,0-5,0 \mu \mathrm{m}$ & $5,0-7,0 \mu \mathrm{m}$ & $7,0-10,0 \mu \mathrm{m}$ & $>10,0 \mu \mathrm{m}$ \\
\hline \multirow{8}{*}{ Assento 3E } & $\begin{array}{c}\text { Concentração média de } \\
\text { fundo }\end{array}$ & $\mathrm{P} / \mathrm{m}^{3}$ & $1,53 E+05$ & $1,17 E+05$ & $6,67 E+03$ & $0,00 \mathrm{E}+00$ & $0,00 \mathrm{E}+00$ & $0,00 \mathrm{E}+00$ \\
\hline & $\begin{array}{c}\text { Número de particulas de } \\
\text { fundo }\end{array}$ & $\mathbf{p}$ & 46 & 35 & 2 & 0 & 0 & 0 \\
\hline & $\begin{array}{c}\text { Concentração média } \\
\text { liquida }\end{array}$ & $\mathrm{P} / \mathrm{m}^{3}$ & $1,55 E+08$ & $1,40 \mathrm{E}+08$ & $9,52 \mathrm{E}+07$ & $9,63 \mathrm{E}+07$ & $3,28 \mathrm{E}+07$ & $2,02 E+06$ \\
\hline & $\begin{array}{l}\text { Número de Particulas } \\
\text { média liquida }\end{array}$ & $\mathbf{P}$ & 46458 & 42096 & 28560 & 28880 & 9850 & 607 \\
\hline & Desvio - Poisson & $\#$ & 215,54 & 205,17 & 169,00 & 169,94 & 99,25 & 24,64 \\
\hline & $\begin{array}{c}\text { Desvio - Poisson - } \\
\text { Relativo } \\
\end{array}$ & $\%$ & 0,5 & 0,5 & 0,6 & 0,6 & 1,0 & 4,1 \\
\hline & $\begin{array}{l}\text { Desvio padrão } \\
\text { Concentração }\end{array}$ & $\mathrm{P} / \mathrm{m}^{3}$ & $1,78 \mathrm{E}+04$ & $1,79 \mathrm{E}+04$ & $1,07 E+04$ & $1,09 E+04$ & $3,83 \mathrm{E}+03$ & $2,46 \mathrm{E}+02$ \\
\hline & DP/Concentração média & $\%$ & 0,0115 & 0,0127 & 0,0113 & 0,0113 & 0,0117 & 0,0122 \\
\hline \multirow{2}{*}{\multicolumn{2}{|c|}{ Erro total medições( $\varepsilon$ ) }} & $\mathrm{P} / \mathrm{m}^{3}$ & $7,19 \mathrm{E}+05$ & $6,84 \mathrm{E}+05$ & $5,63 E+05$ & $5,67 E+05$ & $3,31 E+05$ & $8,21 \mathrm{E}+04$ \\
\hline & & Unidade & $1,0-2,0 \mu \mathrm{m}$ & $2,0-3,0 \mu \mathrm{m}$ & $3,0-5,0 \mu \mathrm{m}$ & $5,0-7,0 \mu \mathrm{m}$ & $7,0-10,0 \mu \mathrm{m}$ & $>10,0 \mu \mathrm{m}$ \\
\hline \multirow{8}{*}{ Assento 2D } & $\begin{array}{c}\text { Concentração média de } \\
\text { fundo } \\
\end{array}$ & $\mathrm{P} / \mathrm{m}^{3}$ & $2,53 E+05$ & $7,33 E+04$ & $2,00 E+04$ & $0,00 E+00$ & $0,00 \mathrm{E}+00$ & $0,00 \mathrm{E}+00$ \\
\hline & $\begin{array}{c}\text { Número de particulas de } \\
\text { fundo }\end{array}$ & $\mathbf{P}$ & 76 & 22 & 6 & 0 & 0 & 0 \\
\hline & $\begin{array}{c}\text { Concentração média } \\
\text { liquida }\end{array}$ & $\mathrm{P} / \mathrm{m}^{3}$ & $1,35 \mathrm{E}+08$ & $1,24 \mathrm{E}+08$ & $7,85 \mathrm{E}+07$ & $5,19 \mathrm{E}+07$ & $1,44 \mathrm{E}+07$ & $1,71 E+06$ \\
\hline & $\begin{array}{l}\text { Número de Particulas } \\
\text { média liquida }\end{array}$ & $\mathbf{p}$ & 40536 & 37088 & 23560 & 15560 & 4309 & 514 \\
\hline & Desvio - Poisson & $\#$ & 201,34 & 192,58 & 153,49 & 124,74 & 65,64 & 22,67 \\
\hline & $\begin{array}{c}\text { Desvio - Poisson - } \\
\text { Relativo } \\
\end{array}$ & $\%$ & 0,5 & 0,5 & 0,7 & 0,8 & 1,5 & 4,4 \\
\hline & Desvio padrão & $\mathrm{P} / \mathrm{m}^{3}$ & $1,38 \mathrm{E}+04$ & $9,11 E+03$ & $6,43 E+03$ & $3,00 E+03$ & $8,30 E+02$ & $1,39 \mathrm{E}+02$ \\
\hline & DP/Concentração média & $\%$ & 0,0102 & 0,0074 & 0,0082 & 0,0058 & 0,0058 & 0,0081 \\
\hline \multirow{2}{*}{\multicolumn{2}{|c|}{ Erro total medições(દ) }} & $\mathrm{P} / \mathrm{m}^{3}$ & $6,71 E+05$ & $6,42 \mathrm{E}+05$ & $5,12 \mathrm{E}+05$ & $4,16 \mathrm{E}+05$ & $2,19 E+05$ & $7,56 \mathrm{E}+04$ \\
\hline & & Unidade & $1,0-2,0 \mu \mathrm{m}$ & $2,0-3,0 \mu \mathrm{m}$ & $3,0-5,0 \mu \mathrm{m}$ & $5,0-7,0 \mu \mathrm{m}$ & $7,0-10,0 \mu \mathrm{m}$ & $>10,0 \mu \mathrm{m}$ \\
\hline \multirow{8}{*}{ Assento 2E } & $\begin{array}{c}\text { Concentração média de } \\
\text { fundo }\end{array}$ & $\mathrm{P} / \mathrm{m}^{3}$ & $1,43 E+05$ & $5,00 \mathrm{E}+04$ & $3,33 E+03$ & $0,00 \mathrm{E}+00$ & $0,00 \mathrm{E}+00$ & $0,00 \mathrm{E}+00$ \\
\hline & $\begin{array}{c}\text { Número de particulas de } \\
\text { fundo }\end{array}$ & $\mathbf{p}$ & 43 & 15 & 1 & 0 & 0 & 0 \\
\hline & $\begin{array}{c}\text { Concentração média } \\
\text { liquida }\end{array}$ & $\mathrm{P} / \mathrm{m}^{3}$ & $1,26 E+08$ & $9,43 E+07$ & $6,31 E+07$ & $3,63 \mathrm{E}+07$ & $1,62 E+07$ & $2,76 \mathrm{E}+06$ \\
\hline & $\begin{array}{c}\text { Número de Particulas } \\
\text { média liquida }\end{array}$ & $\mathbf{P}$ & 37764 & 28281 & 18941 & 10897 & 4870 & 826,5 \\
\hline & Desvio - Poisson & $\#$ & 194,33 & 168,17 & 137,63 & 104,39 & 69,79 & 28,75 \\
\hline & $\begin{array}{c}\text { Desvio - Poisson - } \\
\text { Relativo } \\
\end{array}$ & $\%$ & 0,5 & 0,6 & 0,7 & 1,0 & 1,4 & 3,5 \\
\hline & Desvio padrão & $\mathrm{P} / \mathrm{m}^{3}$ & $9,40 E+03$ & $9,22 E+03$ & $1,56 \mathrm{E}+03$ & $1,66 \mathrm{E}+03$ & $8,69 \mathrm{E}+02$ & $1,19 \mathrm{E}+02$ \\
\hline & DP/Concentração média & $\%$ & 0,0075 & 0,0098 & 0,0025 & 0,0046 & 0,0054 & 0,0043 \\
\hline \multicolumn{2}{|c|}{ Erro total medições(દ) } & $\mathrm{P} / \mathrm{m}^{3}$ & $6,48 E+05$ & $5,61 E+05$ & $4,59 E+05$ & $3,48 \mathrm{E}+05$ & $2,33 E+05$ & $9,58 \mathrm{E}+04$ \\
\hline
\end{tabular}




\begin{tabular}{|c|c|c|c|c|c|c|c|c|}
\hline & & Unidade & $1,0-2,0 \mu \mathrm{m}$ & $2,0-3,0 \mu \mathrm{m}$ & $3,0-5,0 \mu \mathrm{m}$ & $5,0-7,0 \mu \mathrm{m}$ & $7,0-10,0 \mu \mathrm{m}$ & $>10,0 \mu \mathrm{m}$ \\
\hline \multirow{8}{*}{ Assento 1D } & $\begin{array}{c}\text { Concentração média de } \\
\text { fundo }\end{array}$ & $\mathrm{P} / \mathrm{m}^{3}$ & $7,00 \mathrm{E}+04$ & $1,47 E+05$ & $6,67 \mathrm{E}+03$ & $0,00 \mathrm{E}+00$ & $0,00 \mathrm{E}+00$ & $0,00 E+00$ \\
\hline & $\begin{array}{c}\text { Número de particulas de } \\
\text { fundo }\end{array}$ & $\mathbf{P}$ & 21 & 44 & 2 & 0 & 0 & 0 \\
\hline & $\begin{array}{c}\text { Concentração média } \\
\text { liquida }\end{array}$ & $\mathrm{P} / \mathrm{m}^{3}$ & $1,15 E+08$ & $1,08 \mathrm{E}+08$ & $7,00 \mathrm{E}+07$ & $5,96 \mathrm{E}+07$ & $1,00 \mathrm{E}+07$ & $1,46 \mathrm{E}+06$ \\
\hline & $\begin{array}{l}\text { Número de Particulas } \\
\text { média liquida }\end{array}$ & $\mathbf{p}$ & 34459 & 32423,5 & 21000 & 17890 & 3011,5 & 436,5 \\
\hline & Desvio - Poisson & $\#$ & 185,63 & 180,07 & 144,91 & 133,75 & 54,88 & 20,89 \\
\hline & $\begin{array}{c}\text { Desvio - Poisson - } \\
\text { Relativo } \\
\end{array}$ & $\%$ & 0,5 & 0,6 & 0,7 & 0,7 & 1,8 & 4,8 \\
\hline & $\begin{array}{l}\text { Desvio padrão } \\
\text { Concentração }\end{array}$ & $\mathrm{P} / \mathrm{m}^{3}$ & $4,56 \mathrm{E}+03$ & $6,16 \mathrm{E}+03$ & $1,40 \mathrm{E}+03$ & $1,92 \mathrm{E}+03$ & $8,80 E+02$ & $1,14 E+02$ \\
\hline & DP/Concentração média & $\%$ & 0,0040 & 0,0057 & 0,0020 & 0,0032 & 0,0088 & 0,0078 \\
\hline \multirow{2}{*}{\multicolumn{2}{|c|}{ Erro total medições(દ) }} & $\mathrm{P} / \mathrm{m}^{3}$ & $6,19 E+05$ & $6,00 \mathrm{E}+05$ & $4,83 E+05$ & $4,46 \mathrm{E}+05$ & $1,83 \mathrm{E}+05$ & $6,96 \mathrm{E}+04$ \\
\hline & & Unidade & $1,0-2,0 \mu \mathrm{m}$ & $2,0-3,0 \mu \mathrm{m}$ & $3,0-5,0 \mu \mathrm{m}$ & $5,0-7,0 \mu \mathrm{m}$ & $7,0-10,0 \mu \mathrm{m}$ & $>10,0 \mu \mathrm{m}$ \\
\hline \multirow{8}{*}{ Assento 1E } & $\begin{array}{c}\text { Concentração média de } \\
\text { fundo }\end{array}$ & $\mathrm{P} / \mathrm{m}^{3}$ & $8,00 E+04$ & $4,33 E+04$ & $1,33 E+04$ & $3,33 E+03$ & $0,00 \mathrm{E}+00$ & $0,00 E+00$ \\
\hline & $\begin{array}{c}\text { Número de particulas de } \\
\text { fundo }\end{array}$ & $\mathbf{P}$ & 24 & 13 & 4 & 1 & 0 & 0 \\
\hline & $\begin{array}{c}\text { Concentração média } \\
\text { liquida }\end{array}$ & $\mathrm{P} / \mathrm{m}^{3}$ & $1,16 \mathrm{E}+08$ & $1,10 \mathrm{E}+08$ & $6,33 \mathrm{E}+07$ & $7,00 E+07$ & $1,75 \mathrm{E}+07$ & $1,51 \mathrm{E}+06$ \\
\hline & $\begin{array}{c}\text { Número de Particulas } \\
\text { média liquida }\end{array}$ & $\mathbf{P}$ & 34821 & 32860 & 19004 & 21000 & 5247 & 453 \\
\hline & Desvio - Poisson & $\#$ & 186,60 & 181,27 & 137,85 & 144,91 & 72,44 & 21,28 \\
\hline & $\begin{array}{c}\text { Desvio - Poisson - } \\
\text { Relativo } \\
\end{array}$ & $\%$ & 0,5 & 0,6 & 0,7 & 0,7 & 1,4 & 4,7 \\
\hline & $\begin{array}{l}\text { Desvio padrão } \\
\text { Concentração }\end{array}$ & $\mathrm{P} / \mathrm{m}^{3}$ & $1,31 \mathrm{E}+04$ & $8,65 E+03$ & $1,62 \mathrm{E}+03$ & $6,51 \mathrm{E}+03$ & $1,81 \mathrm{E}+03$ & $1,87 E+02$ \\
\hline & DP/Concentração média & $\%$ & 0,0113 & 0,0079 & 0,0026 & 0,0093 & 0,0104 & 0,0124 \\
\hline \multirow{2}{*}{\multicolumn{2}{|c|}{ Erro total medições $(\varepsilon)$}} & $\mathrm{P} / \mathrm{m}^{3}$ & $6,22 E+05$ & $6,04 E+05$ & $4,60 E+05$ & $4,83 E+05$ & $2,41 E+05$ & $7,09 \mathrm{E}+04$ \\
\hline & & Unidade & $1,0-2,0 \mu \mathrm{m}$ & $2,0-3,0 \mu \mathrm{m}$ & $3,0-5,0 \mu \mathrm{m}$ & $5,0-7,0 \mu \mathrm{m}$ & $7,0-10,0 \mu \mathrm{m}$ & $>10,0 \mu \mathrm{m}$ \\
\hline \multirow{8}{*}{ Assento 1B } & $\begin{array}{c}\text { Concentração média de } \\
\text { fundo }\end{array}$ & $\mathrm{P} / \mathrm{m}^{3}$ & $1,23 E+05$ & $7,00 E+04$ & $5,00 E+03$ & $0,00 E+00$ & $0,00 E+00$ & $0,00 E+00$ \\
\hline & $\begin{array}{c}\text { Número de particulas de } \\
\text { fundo }\end{array}$ & $\mathbf{P}$ & 37 & 21 & 2 & 0 & 0 & 0 \\
\hline & $\begin{array}{c}\text { Concentração média } \\
\text { liquida }\end{array}$ & $\mathrm{P} / \mathrm{m}^{3}$ & $8,34 \mathrm{E}+07$ & $7,77 \mathrm{E}+07$ & $5,32 E+07$ & $5,28 \mathrm{E}+07$ & $2,18 \mathrm{E}+07$ & $1,27 E+06$ \\
\hline & $\begin{array}{l}\text { Número de Particulas } \\
\text { média liquida }\end{array}$ & $\mathbf{P}$ & 25015 & 23321 & 15960 & 15850 & 6550 & 380 \\
\hline & Desvio - Poisson & $\#$ & 158,16 & 152,71 & 126,33 & 125,90 & 80,93 & 19,49 \\
\hline & $\begin{array}{l}\text { Desvio - Poisson - } \\
\text { Relativo }\end{array}$ & $\%$ & 0,6 & 0,7 & 0,8 & 0,8 & 1,2 & 5,1 \\
\hline & $\begin{array}{l}\text { Desvio padrão } \\
\text { Concentração }\end{array}$ & $\mathrm{P} / \mathrm{m}^{3}$ & $5,54 \mathrm{E}+03$ & $5,42 E+03$ & $2,70 E+03$ & $2,69 E+03$ & $6,79 E+02$ & $1,12 \mathrm{E}+02$ \\
\hline & DP/Concentração média & $\%$ & 0,0066 & 0,0070 & 0,0051 & 0,0051 & 0,0031 & 0,0088 \\
\hline \multicolumn{2}{|c|}{ Erro total medições( $(\varepsilon)$} & $\mathrm{P} / \mathrm{m}^{3}$ & $5,27 E+05$ & $5,09 E+05$ & $4,21 E+05$ & $4,20 E+05$ & $2,70 E+05$ & $6,50 E+04$ \\
\hline
\end{tabular}




\begin{tabular}{|c|c|c|c|c|c|c|c|c|}
\hline & & Unidade & $1,0-2,0 \mu \mathrm{m}$ & $2,0-3,0 \mu \mathrm{m}$ & $3,0-5,0 \mu \mathrm{m}$ & $5,0-7,0 \mu \mathrm{m}$ & $7,0-10,0 \mu \mathrm{m}$ & $>10,0 \mu \mathrm{m}$ \\
\hline \multirow{8}{*}{ Assento 1A } & $\begin{array}{c}\text { Concentração média de } \\
\text { fundo }\end{array}$ & $\mathrm{P} / \mathrm{m}^{3}$ & $1,10 \mathrm{E}+05$ & $5,67 E+04$ & $6,67 \mathrm{E}+03$ & $0,00 \mathrm{E}+00$ & $0,00 \mathrm{E}+00$ & $0,00 E+00$ \\
\hline & $\begin{array}{c}\text { Número de particulas de } \\
\text { fundo }\end{array}$ & P & 33 & 17 & 2 & 0 & 0 & 0 \\
\hline & $\begin{array}{c}\text { Concentração média } \\
\text { liquida }\end{array}$ & $\mathrm{P} / \mathrm{m}^{3}$ & $8,22 \mathrm{E}+07$ & $6,96 \mathrm{E}+07$ & $4,57 E+07$ & $3,29 \mathrm{E}+07$ & $2,17 E+07$ & $1,50 E+06$ \\
\hline & $\begin{array}{l}\text { Número de Particulas } \\
\text { média liquida }\end{array}$ & $\mathbf{p}$ & 24663 & 20882 & 13697 & 9871 & 6520 & 450 \\
\hline & Desvio - Poisson & $\#$ & 157,04 & 144,51 & 117,03 & 99,35 & 80,75 & 21,21 \\
\hline & $\begin{array}{l}\text { Desvio - Poisson - } \\
\text { Relativo } \\
\end{array}$ & $\%$ & 0,6 & 0,7 & 0,9 & 1,0 & 1,2 & 4,7 \\
\hline & $\begin{array}{l}\text { Desvio padrão } \\
\text { Concentração }\end{array}$ & $\mathrm{P} / \mathrm{m}^{3}$ & $9,44 E+03$ & $5,05 E+03$ & $2,51 E+03$ & $1,76 E+03$ & $1,84 \mathrm{E}+03$ & $6,07 E+01$ \\
\hline & DP/Concentração média & $\%$ & 0,0115 & 0,0072 & 0,0055 & 0,0053 & 0,0085 & 0,0040 \\
\hline \multirow{2}{*}{\multicolumn{2}{|c|}{ Erro total medições(દ) }} & $\mathrm{P} / \mathrm{m}^{3}$ & $5,24 E+05$ & $4,82 E+05$ & $3,90 \mathrm{E}+05$ & $3,31 \mathrm{E}+05$ & $2,69 E+05$ & $7,07 \mathrm{E}+04$ \\
\hline & & Unidade & $1,0-2,0 \mu \mathrm{m}$ & $2,0-3,0 \mu \mathrm{m}$ & $3,0-5,0 \mu \mathrm{m}$ & $5,0-7,0 \mu \mathrm{m}$ & $7,0-10,0 \mu \mathrm{m}$ & $>10,0 \mu \mathrm{m}$ \\
\hline \multirow{8}{*}{ Assento 2B } & $\begin{array}{c}\text { Concentração média de } \\
\text { fundo } \\
\end{array}$ & $\mathrm{P} / \mathrm{m}^{3}$ & $5,33 E+04$ & $3,00 E+04$ & $6,67 E+03$ & $0,00 \mathrm{E}+00$ & $0,00 \mathrm{E}+00$ & $0,00 E+00$ \\
\hline & \begin{tabular}{|c|} 
Número de particulas de \\
fundo \\
\end{tabular} & P & 16 & 9 & 2 & 0 & 0 & 0 \\
\hline & $\begin{array}{c}\text { Concentração média } \\
\text { liquida }\end{array}$ & $\mathrm{P} / \mathrm{m}^{3}$ & $1,05 E+08$ & $9,18 \mathrm{E}+07$ & $6,67 \mathrm{E}+07$ & $4,33 \mathrm{E}+07$ & $2,67 \mathrm{E}+07$ & $1,07 E+06$ \\
\hline & $\begin{array}{c}\text { Número de Particulas } \\
\text { média liquida }\end{array}$ & p & 31635 & 27547 & 20000 & 13002 & 8000 & 320 \\
\hline & Desvio - Poisson & $\#$ & 177,86 & 165,97 & 141,42 & 114,03 & 89,44 & 17,89 \\
\hline & $\begin{array}{c}\text { Desvio - Poisson - } \\
\text { Relativo } \\
\end{array}$ & $\%$ & 0,6 & 0,6 & 0,7 & 0,9 & 1,1 & 5,6 \\
\hline & $\begin{array}{l}\text { Desvio padrão } \\
\text { Concentração }\end{array}$ & $\mathrm{P} / \mathrm{m}^{3}$ & $4,66 E+03$ & $1,12 \mathrm{E}+04$ & $2,78 \mathrm{E}+03$ & $2,14 \mathrm{E}+03$ & $1,70 E+03$ & $1,11 \mathrm{E}+02$ \\
\hline & DP/Concentração média & $\%$ & 0,0044 & 0,0121 & 0,0042 & 0,0049 & 0,0064 & 0,0104 \\
\hline \multirow{2}{*}{\multicolumn{2}{|c|}{ Erro total medições( $(\varepsilon)$}} & $\mathrm{P} / \mathrm{m}^{3}$ & $5,93 \mathrm{E}+05$ & $5,53 \mathrm{E}+05$ & $4,71 E+05$ & $3,80 E+05$ & $2,98 \mathrm{E}+05$ & $5,96 \mathrm{E}+04$ \\
\hline & & Unidade & $1,0-2,0 \mu \mathrm{m}$ & $2,0-3,0 \mu \mathrm{m}$ & $3,0-5,0 \mu \mathrm{m}$ & $5,0-7,0 \mu \mathrm{m}$ & $7,0-10,0 \mu \mathrm{m}$ & $>10,0 \mu \mathrm{m}$ \\
\hline \multirow{8}{*}{ Assento 2A } & $\begin{array}{c}\text { Concentração média de } \\
\text { fundo }\end{array}$ & $\mathrm{P} / \mathrm{m}^{3}$ & $1,00 \mathrm{E}+05$ & $4,33 E+04$ & $3,33 \mathrm{E}+03$ & $0,00 E+00$ & $0,00 \mathrm{E}+00$ & $0,00 E+00$ \\
\hline & \begin{tabular}{|c|}
$\begin{array}{c}\text { Número de particulas de } \\
\text { fundo }\end{array}$ \\
\end{tabular} & $\mathbf{p}$ & 30 & 13 & 1 & 0 & 0 & 0 \\
\hline & $\begin{array}{c}\text { Concentração média } \\
\text { liquida }\end{array}$ & $\mathrm{P} / \mathrm{m}^{3}$ & $6,42 E+07$ & $5,50 \mathrm{E}+07$ & $3,34 \mathrm{E}+07$ & $2,29 \mathrm{E}+07$ & $6,15 E+06$ & $1,08 \mathrm{E}+06$ \\
\hline & $\begin{array}{c}\text { Número de Particulas } \\
\text { média liquida }\end{array}$ & $\mathbf{P}$ & 19248 & 16513 & 10005 & 6866 & 1845 & 324 \\
\hline & Desvio - Poisson & $\#$ & 138,74 & 128,50 & 100,02 & 82,86 & 42,95 & 18,00 \\
\hline & $\begin{array}{c}\text { Desvio - Poisson - } \\
\text { Relativo } \\
\end{array}$ & $\%$ & 0,7 & 0,8 & 1,0 & 1,2 & 2,3 & 5,6 \\
\hline & $\begin{array}{l}\text { Desvio padrão } \\
\text { Concentração }\end{array}$ & $\mathrm{P} / \mathrm{m}^{3}$ & $4,54 E+03$ & $4,30 E+03$ & $7,63 \mathrm{E}+02$ & $6,90 E+02$ & $3,27 E+02$ & $1,20 \mathrm{E}+02$ \\
\hline & DP/Concentração média & $\%$ & 0,0071 & 0,0078 & 0,0023 & 0,0030 & 0,0053 & 0,0111 \\
\hline \multicolumn{2}{|c|}{ Erro total medições(દ) } & $\mathrm{P} / \mathrm{m}^{3}$ & $4,62 E+05$ & $4,28 \mathrm{E}+05$ & $3,33 E+05$ & $2,76 E+05$ & $1,43 E+05$ & $6,00 E+04$ \\
\hline
\end{tabular}




\begin{tabular}{|c|c|c|c|c|c|c|c|c|}
\hline & & Unidade & $1,0-2,0 \mu \mathrm{m}$ & $2,0-3,0 \mu \mathrm{m}$ & $3,0-5,0 \mu \mathrm{m}$ & $5,0-7,0 \mu \mathrm{m}$ & $7,0-10,0 \mu \mathrm{m}$ & $>10,0 \mu \mathrm{m}$ \\
\hline \multirow{8}{*}{ Assento 3B } & $\begin{array}{c}\text { Concentração média de } \\
\text { fundo }\end{array}$ & $\mathrm{P} / \mathrm{m}^{3}$ & $1,10 \mathrm{E}+05$ & $5,00 E+04$ & $1,00 E+04$ & $1,67 E+03$ & $0,00 E+00$ & $0,00 \mathrm{E}+00$ \\
\hline & $\begin{array}{c}\text { Número de particulas de } \\
\text { fundo }\end{array}$ & $\mathbf{P}$ & 33 & 15 & 3 & 1 & 0 & 0 \\
\hline & $\begin{array}{c}\text { Concentração média } \\
\text { liquida }\end{array}$ & $\mathrm{P} / \mathrm{m}^{3}$ & $1,06 \mathrm{E}+08$ & $9,14 \mathrm{E}+07$ & $7,53 \mathrm{E}+07$ & $5,21 \mathrm{E}+07$ & $1,39 E+07$ & $2,53 \mathrm{E}+06$ \\
\hline & $\begin{array}{l}\text { Número de Particulas } \\
\text { média liquida }\end{array}$ & $\mathbf{P}$ & 31778 & 27426 & 22580 & 15620 & 4163 & 760 \\
\hline & Desvio - Poisson & $\#$ & 178,26 & 165,61 & 150,27 & 124,98 & 64,52 & 27,57 \\
\hline & $\begin{array}{c}\text { Desvio - Poisson - } \\
\text { Relativo } \\
\end{array}$ & $\%$ & 0,6 & 0,6 & 0,7 & 0,8 & 1,5 & 3,6 \\
\hline & $\begin{array}{c}\text { Desvio padrão } \\
\text { Concentração }\end{array}$ & $\mathrm{P} / \mathrm{m}^{3}$ & $6,06 E+03$ & $8,52 E+03$ & $1,75 E+03$ & $1,03 E+03$ & $9,16 \mathrm{E}+02$ & $6,22 E+01$ \\
\hline & DP/Concentração média & $\%$ & 0,0057 & 0,0093 & 0,0023 & 0,0020 & 0,0066 & 0,0025 \\
\hline \multirow{2}{*}{\multicolumn{2}{|c|}{ Erro total medições( $(\varepsilon)$}} & $\mathrm{P} / \mathrm{m}^{3}$ & $5,94 E+05$ & $5,52 E+05$ & $5,01 E+05$ & $4,17 E+05$ & $2,15 E+05$ & $9,19 E+04$ \\
\hline & & Unidade & $1,0-2,0 \mu \mathrm{m}$ & $2,0-3,0 \mu \mathrm{m}$ & $3,0-5,0 \mu \mathrm{m}$ & $5,0-7,0 \mu \mathrm{m}$ & $7,0-10,0 \mu \mathrm{m}$ & $>10,0 \mu \mathrm{m}$ \\
\hline \multirow{8}{*}{ Assento $3 \mathrm{~A}$} & $\begin{array}{c}\text { Concentração média de } \\
\text { fundo }\end{array}$ & $\mathrm{P} / \mathrm{m}^{3}$ & $2,23 E+05$ & $1,20 E+05$ & $6,67 E+03$ & $0,00 E+00$ & $0,00 E+00$ & $0,00 E+00$ \\
\hline & \begin{tabular}{|c|}
$\begin{array}{c}\text { Número de particulas de } \\
\text { fundo }\end{array}$ \\
\end{tabular} & $\mathbf{P}$ & 67 & 36 & 2 & 0 & 0 & 0 \\
\hline & $\begin{array}{c}\text { Concentração média } \\
\text { liquida }\end{array}$ & $\mathrm{P} / \mathrm{m}^{3}$ & $6,39 \mathrm{E}+07$ & $6,31 E+07$ & $5,07 E+07$ & $2,88 \mathrm{E}+07$ & $6,83 E+06$ & $5,00 E+05$ \\
\hline & $\begin{array}{c}\text { Número de Particulas } \\
\text { média liquida }\end{array}$ & $\mathbf{P}$ & 19183 & 18926 & 15210 & 8652 & 2050 & 150 \\
\hline & Desvio-Poisson & $\#$ & 138,50 & 137,57 & 123,33 & 93,02 & 45,28 & 12,25 \\
\hline & $\begin{array}{c}\text { Desvio - Poisson - } \\
\text { Relativo } \\
\end{array}$ & $\%$ & 0,7 & 0,7 & 0,8 & 1,1 & 2,2 & 8,2 \\
\hline & \begin{tabular}{|c|}
$\begin{array}{c}\text { Desvio padrão } \\
\text { Concentração }\end{array}$ \\
\end{tabular} & $\mathrm{P} / \mathrm{m}^{3}$ & $4,48 \mathrm{E}+03$ & $4,43 E+03$ & $3,78 \mathrm{E}+03$ & $9,94 E+02$ & $9,41 E+01$ & $6,62 E+01$ \\
\hline & DP/Concentração média & $\%$ & 0,0070 & 0,0070 & 0,0075 & 0,0034 & 0,0014 & 0,0132 \\
\hline \multicolumn{2}{|c|}{ Erro total medições( $(\varepsilon)$} & $\mathrm{P} / \mathrm{m}^{3}$ & $4,62 E+05$ & $4,59 E+05$ & $4,11 E+05$ & $3,10 \mathrm{E}+05$ & $1,51 \mathrm{E}+05$ & $4,08 E+04$ \\
\hline
\end{tabular}


Tabela B-6. Resultados das medições de partículas no assento (Sistema DV mod. à $22^{\circ} \mathrm{C}$ - injeção pelo assento $3 \mathrm{~B}$ )

\begin{tabular}{|c|c|c|c|c|c|c|c|c|}
\hline & & Unidade & $1,0-2,0 \mu \mathrm{m}$ & $2,0-3,0 \mu \mathrm{m}$ & $3,0-5,0 \mu \mathrm{m}$ & $5,0-7,0 \mu \mathrm{m}$ & $7,0-10,0 \mu \mathrm{m}$ & $>10,0 \mu \mathrm{m}$ \\
\hline \multirow{8}{*}{ Assento 3E } & $\begin{array}{c}\text { Concentração média de } \\
\text { fundo }\end{array}$ & $\mathrm{P} / \mathrm{m}^{3}$ & $1,00 E+05$ & $4,50 E+04$ & $1,67 E+03$ & $0,00 E+00$ & $0,00 E+00$ & $0,00 E+00$ \\
\hline & $\begin{array}{l}\text { Número de particulas } \\
\text { de fundo }\end{array}$ & $\mathbf{P}$ & 30 & 13,5 & 0,5 & 0 & 0 & 0 \\
\hline & $\begin{array}{c}\text { Concentração média } \\
\text { liquida } \\
\end{array}$ & $\mathrm{P} / \mathrm{m}^{3}$ & $1,48 E+08$ & $1,37 E+08$ & $1,03 E+08$ & $1,33 E+08$ & $8,33 E+07$ & $1,97 E+07$ \\
\hline & $\begin{array}{c}\text { Número de Particulas } \\
\text { média liquida }\end{array}$ & $\mathbf{P}$ & 44330 & 40969 & 31000 & 39860 & 25000 & 5897 \\
\hline & Desvio - Poisson & $\#$ & 210,55 & 202,41 & 176,07 & 199,65 & 158,11 & 76,79 \\
\hline & $\begin{array}{c}\text { Desvio - Poisson - } \\
\text { Relativo } \\
\end{array}$ & $\%$ & 0,5 & 0,5 & 0,6 & 0,5 & 0,6 & 1,3 \\
\hline & $\begin{array}{l}\text { Desvio padrão } \\
\text { Concentração }\end{array}$ & $\mathrm{P} / \mathrm{m}^{3}$ & $1,29 E+03$ & $1,05 \mathrm{E}+03$ & $1,75 \mathrm{E}+03$ & $1,80 E+03$ & $2,02 E+03$ & $6,49 E+02$ \\
\hline & DP/Concentração média & $\%$ & 0,0009 & 0,0008 & 0,0017 & 0,0014 & 0,0024 & 0,0033 \\
\hline \multirow{2}{*}{\multicolumn{2}{|c|}{ Erro total medições(દ) }} & $\mathrm{P} / \mathrm{m}^{3}$ & $7,02 \mathrm{E}+05$ & $6,75 \mathrm{E}+05$ & $5,87 E+05$ & $6,66 \mathrm{E}+05$ & $5,27 E+05$ & $2,56 \mathrm{E}+05$ \\
\hline & & Unidade & $1,0-2,0 \mu \mathrm{m}$ & $2,0-3,0 \mu \mathrm{m}$ & $3,0-5,0 \mu \mathrm{m}$ & $5,0-7,0 \mu \mathrm{m}$ & $7,0-10,0 \mu \mathrm{m}$ & $>10,0 \mu \mathrm{m}$ \\
\hline \multirow{8}{*}{ Assento 2D } & $\begin{array}{l}\text { Concentração média de } \\
\text { fundo }\end{array}$ & $\mathrm{P} / \mathrm{m}^{3}$ & $1,75 E+05$ & $7,17 E+04$ & $1,00 E+04$ & $1,67 E+03$ & $0,00 E+00$ & $0,00 \mathrm{E}+00$ \\
\hline & $\begin{array}{c}\begin{array}{c}\text { Número de particulas } \\
\text { de fundo }\end{array} \\
\end{array}$ & $\mathbf{P}$ & 52,5 & 21,5 & 3 & 0,5 & 0 & 0 \\
\hline & $\begin{array}{c}\text { Concentração média } \\
\text { liquida }\end{array}$ & $\mathrm{P} / \mathrm{m}^{3}$ & $1,31 E+08$ & $1,28 \mathrm{E}+08$ & $1,12 \mathrm{E}+08$ & $7,00 E+07$ & $3,35 \mathrm{E}+07$ & $1,48 \mathrm{E}+06$ \\
\hline & $\begin{array}{l}\text { Número de Particulas } \\
\text { média liquida }\end{array}$ & $\mathbf{P}$ & 39275 & 38473 & 33560 & 21000 & 10050 & 444 \\
\hline & Desvio - Poisson & $\#$ & 198,18 & 196,15 & 183,19 & 144,91 & 100,25 & 21,07 \\
\hline & $\begin{array}{c}\text { Desvio - Poisson - } \\
\text { Relativo }\end{array}$ & $\%$ & 0,5 & 0,5 & 0,5 & 0,7 & 1,0 & 4,7 \\
\hline & \begin{tabular}{|l|} 
Desvio padrão \\
Concentração \\
\end{tabular} & $\mathrm{P} / \mathrm{m}^{3}$ & $1,14 \mathrm{E}+04$ & $1,11 E+04$ & $1,85 E+03$ & $1,14 \mathrm{E}+03$ & $9,59 E+02$ & $1,26 \mathrm{E}+02$ \\
\hline & DP/Concentração média & $\%$ & 0,0087 & 0,0087 & 0,0017 & 0,0016 & 0,0029 & 0,0085 \\
\hline \multirow{2}{*}{\multicolumn{2}{|c|}{ Erro total medições( $(\varepsilon)$}} & $\mathrm{P} / \mathrm{m}^{3}$ & $6,61 \mathrm{E}+05$ & $6,54 \mathrm{E}+05$ & $6,11 \mathrm{E}+05$ & $4,83 E+05$ & $3,34 \mathrm{E}+05$ & $7,02 E+04$ \\
\hline & & Unidade & $1,0-2,0 \mu \mathrm{m}$ & $2,0-3,0 \mu \mathrm{m}$ & $3,0-5,0 \mu \mathrm{m}$ & $5,0-7,0 \mu \mathrm{m}$ & $7,0-10,0 \mu \mathrm{m}$ & $>10,0 \mu \mathrm{m}$ \\
\hline \multirow{8}{*}{ Assento $2 \mathrm{E}$} & $\begin{array}{c}\text { Concentração média de } \\
\text { fundo } \\
\end{array}$ & $\mathrm{P} / \mathrm{m}^{3}$ & $1,73 E+05$ & $5,67 E+04$ & $6,67 E+03$ & $0,00 E+00$ & $0,00 E+00$ & $0,00 E+00$ \\
\hline & $\begin{array}{c}\text { Número de particulas } \\
\text { de fundo }\end{array}$ & $\mathbf{P}$ & 52 & 17 & 2 & 0 & 0 & 0 \\
\hline & $\begin{array}{c}\text { Concentração média } \\
\text { liquida }\end{array}$ & $\mathrm{P} / \mathrm{m}^{3}$ & $1,53 E+08$ & $1,50 \mathrm{E}+08$ & $8,47 E+07$ & $5,16 \mathrm{E}+07$ & $1,54 \mathrm{E}+07$ & $1,43 E+06$ \\
\hline & $\begin{array}{c}\text { Número de Particulas } \\
\text { média liquida }\end{array}$ & $\mathbf{P}$ & 45824 & 45003 & 25414 & 15480 & 4613 & 428 \\
\hline & Desvio - Poisson & $\#$ & 214,07 & 212,14 & 159,42 & 124,42 & 67,92 & 20,68 \\
\hline & $\begin{array}{l}\text { Desvio - Poisson - } \\
\text { Relativo }\end{array}$ & $\%$ & 0,5 & 0,5 & 0,6 & 0,8 & 1,5 & 4,8 \\
\hline & \begin{tabular}{|l|} 
Desvio padrão \\
Concentração \\
\end{tabular} & $\mathrm{P} / \mathrm{m}^{3}$ & $1,06 \mathrm{E}+04$ & $1,03 \mathrm{E}+04$ & $4,78 \mathrm{E}+03$ & $1,59 \mathrm{E}+03$ & $7,40 E+02$ & $1,01 \mathrm{E}+02$ \\
\hline & DP/Concentração média & $\%$ & 0,0070 & 0,0069 & 0,0056 & 0,0031 & 0,0048 & 0,0071 \\
\hline \multicolumn{2}{|c|}{ Erro total medições( $(\varepsilon)$} & $\mathrm{P} / \mathrm{m}^{3}$ & $7,14 E+05$ & $7,07 E+05$ & $5,31 E+05$ & $4,15 E+05$ & $2,26 E+05$ & $6,89 \mathrm{E}+04$ \\
\hline
\end{tabular}




\begin{tabular}{|c|c|c|c|c|c|c|c|c|}
\hline & & Unidade & $1,0-2,0 \mu \mathrm{m}$ & $2,0-3,0 \mu \mathrm{m}$ & $3,0-5,0 \mu \mathrm{m}$ & $5,0-7,0 \mu \mathrm{m}$ & $7,0-10,0 \mu \mathrm{m}$ & $>10,0 \mu \mathrm{m}$ \\
\hline \multirow{8}{*}{ Assento 1D } & $\begin{array}{c}\text { Concentração média de } \\
\text { fundo }\end{array}$ & $\mathrm{P} / \mathrm{m}^{3}$ & $2,20 E+05$ & $9,67 E+04$ & $1,50 E+04$ & $1,67 E+03$ & $0,00 E+00$ & $0,00 E+00$ \\
\hline & $\begin{array}{c}\text { Número de particulas } \\
\text { de fundo }\end{array}$ & $\mathbf{P}$ & 66 & 29 & 5 & 1 & 0 & 0 \\
\hline & $\begin{array}{c}\text { Concentração média } \\
\text { liquida } \\
\end{array}$ & $\mathrm{P} / \mathrm{m}^{3}$ & $1,24 E+08$ & $1,10 \mathrm{E}+08$ & $9,95 E+07$ & $6,33 E+07$ & $1,29 \mathrm{E}+07$ & $4,90 E+05$ \\
\hline & $\begin{array}{c}\text { Número de Particulas } \\
\text { média liquida }\end{array}$ & $\mathbf{p}$ & 37122 & 33086 & 29850 & 18985 & 3870 & 147 \\
\hline & Desvio - Poisson & $\#$ & 192,67 & 181,90 & 172,77 & 137,79 & 62,21 & 12,12 \\
\hline & $\begin{array}{c}\text { Desvio - Poisson - } \\
\text { Relativo } \\
\end{array}$ & $\%$ & 0,5 & 0,5 & 0,6 & 0,7 & 1,6 & 8,2 \\
\hline & $\begin{array}{l}\text { Desvio padrão } \\
\text { Concentração }\end{array}$ & $\mathrm{P} / \mathrm{m}^{3}$ & $9,95 E+03$ & $8,14 E+03$ & $1,29 \mathrm{E}+03$ & $1,59 \mathrm{E}+03$ & $8,29 E+02$ & $6,07 E+01$ \\
\hline & DP/Concentração média & $\%$ & 0,0080 & 0,0074 & 0,0013 & 0,0025 & 0,0064 & 0,0124 \\
\hline \multirow{2}{*}{\multicolumn{2}{|c|}{ Erro total medições( $\varepsilon)$}} & $\mathrm{P} / \mathrm{m}^{3}$ & $6,42 E+05$ & $6,06 \mathrm{E}+05$ & $5,76 \mathrm{E}+05$ & $4,59 \mathrm{E}+05$ & $2,07 E+05$ & $4,04 \mathrm{E}+04$ \\
\hline & & Unidade & $1,0-2,0 \mu \mathrm{m}$ & $2,0-3,0 \mu \mathrm{m}$ & $3,0-5,0 \mu \mathrm{m}$ & $5,0-7,0 \mu \mathrm{m}$ & $7,0-10,0 \mu \mathrm{m}$ & $>10,0 \mu \mathrm{m}$ \\
\hline \multirow{8}{*}{ Assento $1 \mathrm{E}$} & $\begin{array}{c}\text { Concentração média de } \\
\text { fundo }\end{array}$ & $\mathrm{P} / \mathrm{m}^{3}$ & $2,23 E+05$ & $8,67 E+04$ & $1,33 E+04$ & $0,00 E+00$ & $0,00 E+00$ & $0,00 E+00$ \\
\hline & $\begin{array}{c}\text { Número de particulas } \\
\text { de fundo }\end{array}$ & $\mathbf{P}$ & 67 & 26 & 4 & 0 & 0 & 0 \\
\hline & $\begin{array}{c}\text { Concentração média } \\
\text { liquida } \\
\end{array}$ & $\mathrm{P} / \mathrm{m}^{3}$ & $8,55 \mathrm{E}+07$ & $8,43 E+07$ & $7,01 \mathrm{E}+07$ & $3,76 \mathrm{E}+07$ & $6,96 \mathrm{E}+06$ & $4,37 E+05$ \\
\hline & $\begin{array}{l}\text { Número de Particulas } \\
\text { média liquida }\end{array}$ & $\mathbf{P}$ & 25640 & 25287 & 21025 & 11282 & 2089 & 131 \\
\hline & Desvio - Poisson & $\#$ & 160,12 & 159,02 & 145,00 & 106,22 & 45,71 & 11,45 \\
\hline & $\begin{array}{c}\text { Desvio - Poisson - } \\
\text { Relativo } \\
\end{array}$ & $\%$ & 0,6 & 0,6 & 0,7 & 0,9 & 2,2 & 8,7 \\
\hline & $\begin{array}{l}\text { Desvio padrão } \\
\text { Concentração } \\
\end{array}$ & $\mathrm{P} / \mathrm{m}^{3}$ & $2,53 \mathrm{E}+03$ & $2,48 \mathrm{E}+03$ & $1,71 \mathrm{E}+03$ & $1,07 E+03$ & $2,13 \mathrm{E}+02$ & $1,96 \mathrm{E}+01$ \\
\hline & DP/Concentração média & $\%$ & 0,0030 & 0,0029 & 0,0024 & 0,0028 & 0,0031 & 0,0045 \\
\hline \multirow{2}{*}{\multicolumn{2}{|c|}{ Erro total medições(દ) }} & $\mathrm{P} / \mathrm{m}^{3}$ & $5,34 E+05$ & $5,30 E+05$ & $4,83 \mathrm{E}+05$ & $3,54 \mathrm{E}+05$ & $1,52 \mathrm{E}+05$ & $3,82 \mathrm{E}+04$ \\
\hline & & Unidade & $1,0-2,0 \mu \mathrm{m}$ & $2,0-3,0 \mu \mathrm{m}$ & $3,0-5,0 \mu \mathrm{m}$ & $5,0-7,0 \mu \mathrm{m}$ & $7,0-10,0 \mu \mathrm{m}$ & $>10,0 \mu \mathrm{m}$ \\
\hline \multirow{8}{*}{ Assento 1B } & $\begin{array}{c}\text { Concentração média de } \\
\text { fundo }\end{array}$ & $\mathrm{P} / \mathrm{m}^{3}$ & $2,50 E+05$ & $1,22 \mathrm{E}+05$ & $1,17 \mathrm{E}+04$ & $0,00 \mathrm{E}+00$ & $0,00 E+00$ & $0,00 E+00$ \\
\hline & $\begin{array}{l}\text { Número de particulas } \\
\text { de fundo }\end{array}$ & $\mathbf{P}$ & 75 & 37 & 4 & 0 & 0 & 0 \\
\hline & $\begin{array}{c}\text { Concentração média } \\
\text { liquida }\end{array}$ & $\mathrm{P} / \mathrm{m}^{3}$ & $7,04 \mathrm{E}+07$ & $6,43 E+07$ & $3,80 \mathrm{E}+07$ & $2,16 \mathrm{E}+07$ & $6,25 E+06$ & $4,10 E+05$ \\
\hline & $\begin{array}{c}\text { Número de Particulas } \\
\text { média liquida }\end{array}$ & $\mathbf{P}$ & 21134 & 19282 & 11410 & 6467 & 1874 & 123 \\
\hline & Desvio - Poisson & $\#$ & 145,38 & 138,86 & 106,82 & 80,42 & 43,29 & 11,09 \\
\hline & $\begin{array}{c}\text { Desvio - Poisson - } \\
\text { Relativo } \\
\end{array}$ & $\%$ & 0,7 & 0,7 & 0,9 & 1,2 & 2,3 & 9,0 \\
\hline & $\begin{array}{c}\text { Desvio padrão } \\
\text { Concentração }\end{array}$ & $\mathrm{P} / \mathrm{m}^{3}$ & $2,37 E+03$ & $6,43 E+02$ & $2,13 E+03$ & $7,91 \mathrm{E}+02$ & $3,50 E+02$ & $2,40 E+01$ \\
\hline & DP/Concentração média & $\%$ & 0,0034 & 0,0010 & 0,0056 & 0,0037 & 0,0056 & 0,0059 \\
\hline \multicolumn{2}{|c|}{ Erro total medições(દ) } & $\mathrm{P} / \mathrm{m}^{3}$ & $4,85 E+05$ & $4,63 E+05$ & $3,56 E+05$ & $2,68 E+05$ & $1,44 E+05$ & $3,70 E+04$ \\
\hline
\end{tabular}




\begin{tabular}{|c|c|c|c|c|c|c|c|c|}
\hline & & Unidade & $1,0-2,0 \mu \mathrm{m}$ & $2,0-3,0 \mu \mathrm{m}$ & $3,0-5,0 \mu \mathrm{m}$ & $5,0-7,0 \mu \mathrm{m}$ & $7,0-10,0 \mu \mathrm{m}$ & $>10,0 \mu \mathrm{m}$ \\
\hline \multirow{8}{*}{ Assento 1A } & $\begin{array}{c}\text { Concentração média de } \\
\text { fundo }\end{array}$ & $\mathrm{P} / \mathrm{m}^{3}$ & $3,03 E+05$ & $1,30 E+05$ & $1,67 E+04$ & $0,00 E+00$ & $0,00 E+00$ & $0,00 E+00$ \\
\hline & $\begin{array}{c}\text { Número de particulas } \\
\text { de fundo }\end{array}$ & $\mathbf{P}$ & 91 & 39 & 5 & 0 & 0 & 0 \\
\hline & $\begin{array}{l}\text { Concentração média } \\
\text { liquida }\end{array}$ & $\mathrm{P} / \mathrm{m}^{3}$ & $5,30 \mathrm{E}+07$ & $5,25 E+07$ & $2,88 \mathrm{E}+07$ & $3,11 E+07$ & $4,90 \mathrm{E}+06$ & $2,57 E+05$ \\
\hline & $\begin{array}{c}\text { Número de Particulas } \\
\text { média liquida }\end{array}$ & $\mathbf{p}$ & 15894 & 15742 & 8650 & 9341 & 1471 & 77 \\
\hline & Desvio - Poisson & $\#$ & 126,07 & 125,47 & 93,01 & 96,65 & 38,35 & 8,77 \\
\hline & $\begin{array}{c}\text { Desvio - Poisson - } \\
\text { Relativo }\end{array}$ & $\%$ & 0,8 & 0,8 & 1,1 & 1,0 & 2,6 & 11,4 \\
\hline & $\begin{array}{l}\text { Desvio padrão } \\
\text { Concentração }\end{array}$ & $\mathrm{P} / \mathrm{m}^{3}$ & $1,13 E+03$ & $8,32 E+02$ & $7,78 \mathrm{E}+02$ & $1,41 E+03$ & $1,18 \mathrm{E}+02$ & $1,12 \mathrm{E}+01$ \\
\hline & DP/Concentração média & $\%$ & 0,0021 & 0,0016 & 0,0027 & 0,0045 & 0,0024 & 0,0044 \\
\hline \multirow{2}{*}{\multicolumn{2}{|c|}{ Erro total medições( $(\varepsilon)$}} & $\mathrm{P} / \mathrm{m}^{3}$ & $4,20 \mathrm{E}+05$ & $4,18 \mathrm{E}+05$ & $3,10 \mathrm{E}+05$ & $3,22 E+05$ & $1,28 \mathrm{E}+05$ & $2,92 E+04$ \\
\hline & & Unidade & $1,0-2,0 \mu \mathrm{m}$ & $2,0-3,0 \mu \mathrm{m}$ & $3,0-5,0 \mu \mathrm{m}$ & $5,0-7,0 \mu \mathrm{m}$ & $7,0-10,0 \mu \mathrm{m}$ & $>10,0 \mu \mathrm{m}$ \\
\hline \multirow{8}{*}{ Assento 2B } & $\begin{array}{c}\text { Concentração média de } \\
\text { fundo }\end{array}$ & $\mathrm{P} / \mathrm{m}^{3}$ & $3,37 E+05$ & $1,83 \mathrm{E}+05$ & $1,67 E+04$ & $0,00 E+00$ & $0,00 \mathrm{E}+00$ & $0,00 E+00$ \\
\hline & $\begin{array}{c}\text { Número de particulas } \\
\text { de fundo }\end{array}$ & $\mathbf{P}$ & 101 & 55 & 5 & 0 & 0 & 0 \\
\hline & $\begin{array}{l}\text { Concentração média } \\
\text { liquida }\end{array}$ & $\mathrm{P} / \mathrm{m}^{3}$ & $1,04 \mathrm{E}+08$ & $8,37 E+07$ & $5,53 \mathrm{E}+07$ & $3,75 E+07$ & $1,03 E+07$ & $5,67 E+05$ \\
\hline & $\begin{array}{c}\text { Número de Particulas } \\
\text { média liquida }\end{array}$ & $\mathbf{P}$ & 31117 & 25105 & 16589 & 11250 & 3082 & 170 \\
\hline & Desvio - Poisson & $\#$ & 176,40 & 158,44 & 128,80 & 106,07 & 55,52 & 13,04 \\
\hline & $\begin{array}{c}\text { Desvio - Poisson - } \\
\text { Relativo } \\
\end{array}$ & $\%$ & 0,6 & 0,6 & 0,8 & 0,9 & 1,8 & 7,7 \\
\hline & $\begin{array}{l}\text { Desvio padrão } \\
\text { Concentração }\end{array}$ & $\mathrm{P} / \mathrm{m}^{3}$ & $9,09 \mathrm{E}+03$ & $1,05 \mathrm{E}+03$ & $1,15 E+03$ & $3,86 \mathrm{E}+03$ & $5,68 \mathrm{E}+02$ & $6,62 E+01$ \\
\hline & DP/Concentração média & $\%$ & 0,0088 & 0,0013 & 0,0021 & 0,0103 & 0,0055 & 0,0117 \\
\hline \multirow{2}{*}{\multicolumn{2}{|c|}{ Erro total medições( $(\varepsilon)$}} & $\mathrm{P} / \mathrm{m}^{3}$ & $5,88 \mathrm{E}+05$ & $5,28 \mathrm{E}+05$ & $4,29 E+05$ & $3,54 \mathrm{E}+05$ & $1,85 \mathrm{E}+05$ & $4,35 E+04$ \\
\hline & & Unidade & $1,0-2,0 \mu \mathrm{m}$ & $2,0-3,0 \mu \mathrm{m}$ & $3,0-5,0 \mu \mathrm{m}$ & $5,0-7,0 \mu \mathrm{m}$ & $7,0-10,0 \mu \mathrm{m}$ & $>10,0 \mu \mathrm{m}$ \\
\hline \multirow{8}{*}{ Assento 2A } & $\begin{array}{c}\text { Concentração média de } \\
\text { fundo }\end{array}$ & $\mathrm{P} / \mathrm{m}^{3}$ & $3,23 E+05$ & $1,53 \mathrm{E}+05$ & $2,00 E+04$ & $0,00 E+00$ & $0,00 E+00$ & $0,00 E+00$ \\
\hline & $\begin{array}{c}\text { Número de particulas } \\
\text { de fundo }\end{array}$ & $\mathbf{P}$ & 97 & 46 & 6 & 0 & 0 & 0 \\
\hline & $\begin{array}{c}\text { Concentração média } \\
\text { liquida } \\
\end{array}$ & $\mathrm{P} / \mathrm{m}^{3}$ & $2,56 \mathrm{E}+07$ & $2,19 \mathrm{E}+07$ & $7,83 \mathrm{E}+06$ & $5,07 E+06$ & $1,87 E+06$ & $6,03 E+05$ \\
\hline & $\begin{array}{c}\text { Número de Particulas } \\
\text { média liquida }\end{array}$ & $\mathbf{P}$ & 7684 & 6564 & 2350 & 1520 & 560 & 181 \\
\hline & Desvio - Poisson & $\#$ & 87,66 & 81,02 & 48,48 & 38,99 & 23,66 & 13,45 \\
\hline & $\begin{array}{c}\text { Desvio - Poisson - } \\
\text { Relativo } \\
\end{array}$ & $\%$ & 1,1 & 1,2 & 2,1 & 2,6 & 4,2 & 7,4 \\
\hline & $\begin{array}{l}\text { Desvio padrão } \\
\text { Concentração }\end{array}$ & $\mathrm{P} / \mathrm{m}^{3}$ & $8,47 E+02$ & $2,65 \mathrm{E}+02$ & $3,49 \mathrm{E}+02$ & $9,53 \mathrm{E}+01$ & $1,11 \mathrm{E}+02$ & $3,11 \mathrm{E}+01$ \\
\hline & DP/Concentração média & $\%$ & 0,0033 & 0,0012 & 0,0045 & 0,0019 & 0,0060 & 0,0052 \\
\hline \multicolumn{2}{|c|}{ Erro total medições(દ) } & $\mathrm{P} / \mathrm{m}^{3}$ & $2,92 \mathrm{E}+05$ & $2,70 E+05$ & $1,62 \mathrm{E}+05$ & $1,30 \mathrm{E}+05$ & $7,89 \mathrm{E}+04$ & $4,48 E+04$ \\
\hline
\end{tabular}


Unidade $1,0-2,0 \mu \mathrm{m}|2,0-3,0 \mu \mathrm{m}| 3,0-5,0 \mu \mathrm{m}|5,0-7,0 \mu \mathrm{m}| 7,0-10,0 \mu \mathrm{m} \mid>10,0 \mu \mathrm{m}$

\begin{tabular}{|c|c|c|c|c|c|c|c|c|}
\hline \multirow{8}{*}{ Assento 3B } & $\begin{array}{c}\begin{array}{c}\text { Concentração média de } \\
\text { fundo }\end{array} \\
\end{array}$ & $\mathrm{P} / \mathrm{m}^{3}$ & $1,87 E+05$ & $9,33 E+04$ & $1,00 E+04$ & $0,00 E+00$ & $0,00 \mathrm{E}+00$ & $0,00 E+00$ \\
\hline & $\begin{array}{c}\text { Número de particulas } \\
\text { de fundo }\end{array}$ & $\mathbf{P}$ & 56 & 28 & 3 & 0 & 0 & 0 \\
\hline & $\begin{array}{l}\text { Concentração média } \\
\text { liquida }\end{array}$ & $\mathrm{P} / \mathrm{m}^{3}$ & $9,41 E+07$ & $6,86 \mathrm{E}+07$ & $5,20 \mathrm{E}+07$ & $3,42 E+07$ & $1,83 E+07$ & $8,13 E+05$ \\
\hline & $\begin{array}{l}\text { Número de Particulas } \\
\text { média liquida }\end{array}$ & $\mathbf{P}$ & 28235 & 20586 & 15600 & 10250 & 5492 & 244 \\
\hline & Desvio - Poisson & $\#$ & 168,03 & 143,48 & 124,90 & 101,24 & 74,11 & 15,62 \\
\hline & $\begin{array}{c}\text { Desvio - Poisson - } \\
\text { Relativo }\end{array}$ & $\%$ & 0,6 & 0,7 & 0,8 & 1,0 & 1,3 & 6,4 \\
\hline & $\begin{array}{l}\text { Desvio padrão } \\
\text { Concentração }\end{array}$ & $\mathrm{P} / \mathrm{m}^{3}$ & $8,00 E+03$ & $7,14 \mathrm{E}+02$ & $7,91 \mathrm{E}+02$ & $7,43 E+02$ & $4,75 E+02$ & $3,94 \mathrm{E}+01$ \\
\hline & DP/Concentração média & $\%$ & 0,0085 & 0,0010 & 0,0015 & 0,0022 & 0,0026 & 0,0048 \\
\hline \multirow{2}{*}{\multicolumn{2}{|c|}{ Erro total medições( $\varepsilon)$}} & $\mathrm{P} / \mathrm{m}^{3}$ & $5,60 E+05$ & $4,78 \mathrm{E}+05$ & $4,16 \mathrm{E}+05$ & $3,37 E+05$ & $2,47 E+05$ & $5,21 \mathrm{E}+04$ \\
\hline & & Unidade & $1,0-2,0 \mu \mathrm{m}$ & $2,0-3,0 \mu \mathrm{m}$ & $3,0-5,0 \mu \mathrm{m}$ & $5,0-7,0 \mu \mathrm{m}$ & $7,0-10,0 \mu \mathrm{m}$ & $>10,0 \mu \mathrm{m}$ \\
\hline \multirow{8}{*}{ Assento 3A } & $\begin{array}{c}\text { Concentração média de } \\
\text { fundo }\end{array}$ & $\mathrm{P} / \mathrm{m}^{3}$ & $1,83 E+05$ & $8,33 E+04$ & $1,00 E+04$ & $0,00 E+00$ & $0,00 \mathrm{E}+00$ & $0,00 E+00$ \\
\hline & $\begin{array}{c}\text { Número de particulas } \\
\text { de fundo }\end{array}$ & $\mathbf{P}$ & 55 & 25 & 3 & 0 & 0 & 0 \\
\hline & $\begin{array}{l}\text { Concentração média } \\
\text { liquida }\end{array}$ & $\mathrm{P} / \mathrm{m}^{3}$ & $4,06 E+07$ & $3,16 \mathrm{E}+07$ & $1,72 \mathrm{E}+07$ & $1,37 E+07$ & $7,56 \mathrm{E}+06$ & $1,26 E+06$ \\
\hline & $\begin{array}{l}\text { Número de Particulas } \\
\text { média liquida }\end{array}$ & $\mathbf{P}$ & 12169 & 9492 & 5157 & 4096 & 2268 & 377 \\
\hline & Desvio - Poisson & $\#$ & 110,31 & 97,43 & 71,81 & 64,00 & 47,62 & 19,42 \\
\hline & $\begin{array}{c}\text { Desvio - Poisson - } \\
\text { Relativo } \\
\end{array}$ & $\%$ & 0,9 & 1,0 & 1,4 & 1,6 & 2,1 & 5,2 \\
\hline & $\begin{array}{l}\text { Desvio padrão } \\
\text { Concentração }\end{array}$ & $\mathrm{P} / \mathrm{m}^{3}$ & $5,12 E+02$ & $5,38 \mathrm{E}+02$ & $5,46 \mathrm{E}+02$ & $3,43 \mathrm{E}+01$ & $1,04 \mathrm{E}+02$ & $1,67 E+02$ \\
\hline & DP/Concentração média & $\%$ & 0,0013 & 0,0017 & 0,0032 & 0,0003 & 0,0014 & 0,0133 \\
\hline \multicolumn{2}{|c|}{ Erro total medições( $(\varepsilon)$} & $\mathrm{P} / \mathrm{m}^{3}$ & $3,68 \mathrm{E}+05$ & $3,25 \mathrm{E}+05$ & $2,39 E+05$ & $2,13 \mathrm{E}+05$ & $1,59 \mathrm{E}+05$ & $6,47 E+04$ \\
\hline
\end{tabular}


Tabela B-7. Resultados das medições de partículas no assento (Sistema MV à $18^{\circ} \mathrm{C}$ - injeção pelo assento $3 \mathrm{~A}$ )

\begin{tabular}{|c|c|c|c|c|c|c|c|c|}
\hline & & Unidade & $1,0-2,0 \mu \mathrm{m}$ & $2,0-3,0 \mu \mathrm{m}$ & $3,0-5,0 \mu \mathrm{m}$ & $5,0-7,0 \mu \mathrm{m}$ & $7,0-10,0 \mu \mathrm{m}$ & $>10,0 \mu \mathrm{m}$ \\
\hline \multirow{8}{*}{ Assento 3D } & $\begin{array}{c}\text { Concentração média de } \\
\text { fundo }\end{array}$ & $\mathrm{P} / \mathrm{m}^{3}$ & $1,07 E+05$ & $4,83 E+04$ & $6,67 E+03$ & $0,00 \mathrm{E}+00$ & $0,00 \mathrm{E}+00$ & $0,00 \mathrm{E}+00$ \\
\hline & \begin{tabular}{|c|}
$\begin{array}{c}\text { Número de particulas de } \\
\text { fundo }\end{array}$ \\
\end{tabular} & $\mathbf{P}$ & 32 & 14,5 & 2 & 0 & 0 & 0 \\
\hline & $\begin{array}{c}\begin{array}{c}\text { Concentração média } \\
\text { liquida }\end{array} \\
\end{array}$ & $\mathrm{P} / \mathrm{m}^{3}$ & $9,25 E+00$ & $7,11 \mathrm{E}+00$ & $6,60 \mathrm{E}+00$ & $5,95 \mathrm{E}+07$ & $5,40 E+07$ & $1,93 \mathrm{E}+06$ \\
\hline & $\begin{array}{c}\text { Número de Particulas } \\
\text { média liquida }\end{array}$ & $\mathbf{p}$ & 41372,5 & 31797,5 & 29540 & 17849 & 16198 & 579,5 \\
\hline & Desvio - Poisson & $\#$ & 203,40 & 178,32 & 171,87 & 133,60 & 127,27 & 24,07 \\
\hline & $\begin{array}{c}\text { Desvio - Poisson - } \\
\text { Relativo } \\
\end{array}$ & $\%$ & 0,5 & 0,6 & 0,6 & 0,7 & 0,8 & 4,2 \\
\hline & $\begin{array}{l}\text { Desvio padrão } \\
\text { Concentração }\end{array}$ & $\mathrm{P} / \mathrm{m}^{3}$ & $1,58 \mathrm{E}+03$ & $9,79 E+02$ & $1,33 \mathrm{E}+03$ & $7,35 \mathrm{E}+02$ & $2,70 E+03$ & $1,28 \mathrm{E}+02$ \\
\hline & DP/Concentração média & $\%$ & 17105,5782 & 13783,2214 & 20088,5693 & 0,0012 & 0,0050 & 0,0066 \\
\hline \multirow{2}{*}{\multicolumn{2}{|c|}{ Erro total medições(દ) }} & $\mathrm{P} / \mathrm{m}^{3}$ & $6,78 \mathrm{E}+05$ & $5,94 \mathrm{E}+05$ & $5,73 E+05$ & $4,45 E+05$ & $4,24 E+05$ & $8,02 \mathrm{E}+04$ \\
\hline & & Unidade & $1,0-2,0 \mu \mathrm{m}$ & $2,0-3,0 \mu \mathrm{m}$ & $3,0-5,0 \mu \mathrm{m}$ & $5,0-7,0 \mu \mathrm{m}$ & $7,0-10,0 \mu \mathrm{m}$ & $>10,0 \mu \mathrm{m}$ \\
\hline \multirow{8}{*}{ Assento 2D } & $\begin{array}{c}\begin{array}{c}\text { Concentração média de } \\
\text { fundo }\end{array} \\
\end{array}$ & $\mathrm{P} / \mathrm{m}^{3}$ & $1,07 E+05$ & $4,83 E+04$ & $6,67 E+03$ & $0,00 E+00$ & $0,00 E+00$ & $0,00 \mathrm{E}+00$ \\
\hline & $\begin{array}{c}\text { Número de particulas de } \\
\text { fundo }\end{array}$ & $\mathbf{P}$ & 32 & 15 & 2 & 0 & 0 & 0 \\
\hline & \begin{tabular}{|c|}
$\begin{array}{c}\text { Concentração média } \\
\text { liquida }\end{array}$ \\
\end{tabular} & $\mathrm{P} / \mathrm{m}^{3}$ & $1,15 E+08$ & $1,05 E+08$ & $8,00 E+07$ & $6,07 E+07$ & $2,20 E+07$ & $1,60 \mathrm{E}+05$ \\
\hline & $\begin{array}{c}\text { Número de Particulas } \\
\text { média liquida }\end{array}$ & $\mathbf{P}$ & 34517,5 & 31571,5 & 24000 & 18220 & 6589 & 48 \\
\hline & Desvio - Poisson & $\#$ & 185,79 & 177,68 & 154,92 & 134,98 & 81,17 & 6,93 \\
\hline & $\begin{array}{l}\text { Desvio - Poisson - } \\
\text { Relativo }\end{array}$ & $\%$ & 0,5 & 0,6 & 0,6 & 0,7 & 1,2 & 14,4 \\
\hline & $\begin{array}{l}\text { Desvio padrão } \\
\text { Concentração } \\
\end{array}$ & $\mathrm{P} / \mathrm{m}^{3}$ & $1,12 \mathrm{E}+03$ & $4,99 \mathrm{E}+03$ & $1,04 E+03$ & $5,40 E+02$ & $9,26 E+02$ & $9,07 E+00$ \\
\hline & DP/Concentração média & $\%$ & 0,0010 & 0,0047 & 0,0013 & 0,0009 & 0,0042 & 0,0057 \\
\hline \multirow{2}{*}{\multicolumn{2}{|c|}{ Erro total medições(દ) }} & $\mathrm{P} / \mathrm{m}^{3}$ & $6,19 \mathrm{E}+05$ & $5,92 \mathrm{E}+05$ & $5,16 \mathrm{E}+05$ & $4,50 E+05$ & $2,71 \mathrm{E}+05$ & $2,31 \mathrm{E}+04$ \\
\hline & & Unidade & $1,0-2,0 \mu \mathrm{m}$ & $2,0-3,0 \mu \mathrm{m}$ & $3,0-5,0 \mu \mathrm{m}$ & $5,0-7,0 \mu \mathrm{m}$ & $7,0-10,0 \mu \mathrm{m}$ & $>10,0 \mu \mathrm{m}$ \\
\hline \multirow{8}{*}{ Assento $2 \mathrm{E}$} & $\begin{array}{c}\text { Concentração média de } \\
\text { fundo }\end{array}$ & $\mathrm{P} / \mathrm{m}^{3}$ & $1,10 \mathrm{E}+05$ & $5,33 E+04$ & $6,67 E+03$ & $3,33 E+03$ & $3,33 \mathrm{E}+03$ & $0,00 \mathrm{E}+00$ \\
\hline & $\begin{array}{c}\text { Número de particulas de } \\
\text { fundo }\end{array}$ & $\mathbf{P}$ & 33 & 16 & 2 & 1 & 1 & 0 \\
\hline & $\begin{array}{c}\text { Concentração média } \\
\text { liquida }\end{array}$ & $\mathrm{P} / \mathrm{m}^{3}$ & $9,78 E+07$ & $9,14 \mathrm{E}+07$ & $7,52 \mathrm{E}+07$ & $5,51 E+07$ & $2,98 \mathrm{E}+07$ & $8,33 E+04$ \\
\hline & $\begin{array}{c}\text { Número de Particulas } \\
\text { média liquida }\end{array}$ & $\mathbf{P}$ & 29336,5 & 27420 & 22546 & 16520 & 8954 & 25 \\
\hline & Desvio - Poisson & $\#$ & 171,28 & 165,59 & 150,15 & 128,53 & 94,63 & 5,00 \\
\hline & $\begin{array}{c}\text { Desvio - Poisson - } \\
\text { Relativo }\end{array}$ & $\%$ & 0,6 & 0,6 & 0,7 & 0,8 & 1,1 & 20,0 \\
\hline & $\begin{array}{l}\text { Desvio padrão } \\
\text { Concentração } \\
\end{array}$ & $\mathrm{P} / \mathrm{m}^{3}$ & $8,65 E+02$ & $1,83 \mathrm{E}+02$ & $5,86 \mathrm{E}+02$ & $6,78 \mathrm{E}+02$ & $7,76 \mathrm{E}+02$ & $1,01 \mathrm{E}+01$ \\
\hline & DP/Concentração média & $\%$ & 0,0009 & 0,0002 & 0,0008 & 0,0012 & 0,0026 & 0,0122 \\
\hline \multicolumn{2}{|c|}{ Erro total medições( $\varepsilon$ ) } & $\mathrm{P} / \mathrm{m}^{3}$ & $5,71 E+05$ & $5,52 E+05$ & $5,01 E+05$ & $4,28 E+05$ & $3,15 \mathrm{E}+05$ & $1,67 E+04$ \\
\hline
\end{tabular}




\begin{tabular}{|c|c|c|c|c|c|c|c|c|}
\hline & & Unidade & $1,0-2,0 \mu \mathrm{m}$ & $2,0-3,0 \mu \mathrm{m}$ & $3,0-5,0 \mu \mathrm{m}$ & $5,0-7,0 \mu \mathrm{m}$ & $7,0-10,0 \mu \mathrm{m}$ & $>10,0 \mu \mathrm{m}$ \\
\hline \multirow{8}{*}{ Assento 1D } & $\begin{array}{c}\text { Concentração média de } \\
\text { fundo }\end{array}$ & $\mathrm{P} / \mathrm{m}^{3}$ & $1,10 \mathrm{E}+05$ & $5,33 E+04$ & $6,67 E+03$ & $3,33 \mathrm{E}+03$ & $3,33 E+03$ & $0,00 E+00$ \\
\hline & \begin{tabular}{|c|} 
Número de particulas de \\
fundo
\end{tabular} & $\mathbf{P}$ & 33 & 16 & 2 & 1 & 1 & 0 \\
\hline & $\begin{array}{c}\text { Concentração média } \\
\text { liquida }\end{array}$ & $\mathrm{P} / \mathrm{m}^{3}$ & $8,20 \mathrm{E}+07$ & $7,45 \mathrm{E}+07$ & $6,68 \mathrm{E}+07$ & $5,08 E+07$ & $1,34 \mathrm{E}+07$ & $5,67 E+04$ \\
\hline & $\begin{array}{c}\text { Número de Particulas } \\
\text { média liquida }\end{array}$ & $\mathbf{P}$ & 24587 & 22350 & 20032 & 15230 & 4012 & 17 \\
\hline & Desvio - Poisson & $\#$ & 156,80 & 149,50 & 141,53 & 123,41 & 63,34 & 4,12 \\
\hline & $\begin{array}{c}\text { Desvio - Poisson - } \\
\text { Relativo } \\
\end{array}$ & $\%$ & 0,6 & 0,7 & 0,7 & 0,8 & 1,6 & 24,3 \\
\hline & $\begin{array}{l}\text { Desvio padrão } \\
\text { Concentração } \\
\end{array}$ & $\mathrm{P} / \mathrm{m}^{3}$ & $2,06 \mathrm{E}+03$ & $1,32 \mathrm{E}+03$ & $1,42 E+03$ & $1,82 \mathrm{E}+03$ & $4,19 E+02$ & $3,52 E+00$ \\
\hline & DP/Concentração média & $\%$ & 0,0025 & 0,0018 & 0,0021 & 0,0036 & 0,0031 & 0,0062 \\
\hline \multirow{2}{*}{\multicolumn{2}{|c|}{ Erro total medições(દ) }} & $\mathrm{P} / \mathrm{m}^{3}$ & $5,23 E+05$ & $4,98 \mathrm{E}+05$ & $4,72 E+05$ & $4,11 E+05$ & $2,11 E+05$ & $1,37 \mathrm{E}+04$ \\
\hline & & Unidade & $1,0-2,0 \mu \mathrm{m}$ & $2,0-3,0 \mu \mathrm{m}$ & $3,0-5,0 \mu \mathrm{m}$ & $5,0-7,0 \mu \mathrm{m}$ & $7,0-10,0 \mu \mathrm{m}$ & $>10,0 \mu \mathrm{m}$ \\
\hline \multirow{8}{*}{ Assento 1E } & $\begin{array}{c}\begin{array}{c}\text { Concentração média de } \\
\text { fundo }\end{array} \\
\end{array}$ & $\mathrm{P} / \mathrm{m}^{3}$ & $1,10 \mathrm{E}+05$ & $5,33 E+04$ & $6,67 E+03$ & $3,33 E+03$ & $3,33 E+03$ & $0,00 E+00$ \\
\hline & $\begin{array}{c}\text { Número de particulas de } \\
\text { fundo }\end{array}$ & $\mathbf{P}$ & 33 & 16 & 2 & 1 & 1 & 0 \\
\hline & $\begin{array}{c}\text { Concentração média } \\
\text { liquida }\end{array}$ & $\mathrm{P} / \mathrm{m}^{3}$ & $1,39 \mathrm{E}+08$ & $1,11 E+08$ & $6,35 \mathrm{E}+07$ & $3,42 E+07$ & $8,37 E+06$ & $6,33 E+04$ \\
\hline & $\begin{array}{c}\text { Número de Particulas } \\
\text { média liquida }\end{array}$ & $\mathbf{p}$ & 41599 & 33239 & 19054 & 10250 & 2510 & 19 \\
\hline & Desvio - Poisson & $\#$ & 203,96 & 182,31 & 138,04 & 101,24 & 50,10 & 4,36 \\
\hline & $\begin{array}{c}\text { Desvio - Poisson - } \\
\text { Relativo } \\
\end{array}$ & $\%$ & 0,5 & 0,5 & 0,7 & 1,0 & 2,0 & 22,9 \\
\hline & $\begin{array}{l}\text { Desvio padrão } \\
\text { Concentração }\end{array}$ & $\mathrm{P} / \mathrm{m}^{3}$ & $3,77 E+02$ & $1,45 E+04$ & $1,09 E+03$ & $7,34 \mathrm{E}+02$ & $1,19 \mathrm{E}+03$ & $4,36 E+00$ \\
\hline & DP/Concentração média & $\%$ & 0,0003 & 0,0131 & 0,0017 & 0,0021 & 0,0143 & 0,0069 \\
\hline \multirow{2}{*}{\multicolumn{2}{|c|}{ Erro total medições(દ) }} & $\mathrm{P} / \mathrm{m}^{3}$ & $6,80 \mathrm{E}+05$ & $6,08 \mathrm{E}+05$ & $4,60 E+05$ & $3,37 E+05$ & $1,67 E+05$ & $1,45 \mathrm{E}+04$ \\
\hline & & Unidade & $1,0-2,0 \mu \mathrm{m}$ & $2,0-3,0 \mu \mathrm{m}$ & $3,0-5,0 \mu \mathrm{m}$ & $5,0-7,0 \mu \mathrm{m}$ & $7,0-10,0 \mu \mathrm{m}$ & $>10,0 \mu \mathrm{m}$ \\
\hline \multirow{8}{*}{ Assento 1B } & $\begin{array}{c}\begin{array}{c}\text { Concentração média de } \\
\text { fundo }\end{array} \\
\end{array}$ & $\mathrm{P} / \mathrm{m}^{3}$ & $1,25 E+05$ & $4,17 E+04$ & $5,00 \mathrm{E}+03$ & $1,67 E+03$ & $0,00 E+00$ & $0,00 E+00$ \\
\hline & $\begin{array}{c}\text { Número de particulas de } \\
\text { fundo } \\
\end{array}$ & $\mathbf{P}$ & 38 & 13 & 2 & 1 & 0 & 0 \\
\hline & $\begin{array}{l}\text { Concentração média } \\
\text { liquida } \\
\end{array}$ & $\mathrm{P} / \mathrm{m}^{3}$ & $1,89 \mathrm{E}+07$ & $1,86 \mathrm{E}+07$ & $1,57 \mathrm{E}+07$ & $7,41 E+06$ & $1,25 E+06$ & $5,33 \mathrm{E}+04$ \\
\hline & $\begin{array}{c}\text { Número de Particulas } \\
\text { média liquida }\end{array}$ & $\mathbf{p}$ & 5660 & 5574 & 4725 & 2224 & 376 & 16 \\
\hline & Desvio - Poisson & $\#$ & 75,23 & 74,66 & 68,73 & 47,15 & 19,39 & 4,00 \\
\hline & $\begin{array}{c}\text { Desvio - Poisson - } \\
\text { Relativo } \\
\end{array}$ & $\%$ & 1,3 & 1,3 & 1,5 & 2,1 & 5,2 & 25,0 \\
\hline & $\begin{array}{l}\text { Desvio padrão } \\
\text { Concentração } \\
\end{array}$ & $\mathrm{P} / \mathrm{m}^{3}$ & $4,81 E+02$ & $4,81 E+02$ & $3,98 \mathrm{E}+02$ & $1,74 \mathrm{E}+02$ & $3,78 E+01$ & $5,49 \mathrm{E}+00$ \\
\hline & DP/Concentração média & $\%$ & 0,0026 & 0,0026 & 0,0025 & 0,0023 & 0,0030 & 0,0103 \\
\hline \multicolumn{2}{|c|}{ Erro total medições(દ) } & $\mathrm{P} / \mathrm{m}^{3}$ & $2,51 E+05$ & $2,49 E+05$ & $2,29 \mathrm{E}+05$ & $1,57 \mathrm{E}+05$ & $6,46 \mathrm{E}+04$ & $1,33 \mathrm{E}+04$ \\
\hline
\end{tabular}




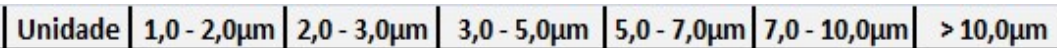

\begin{tabular}{|c|c|c|c|c|c|c|c|c|}
\hline \multirow{8}{*}{ Assento $1 \mathrm{~A}$} & $\begin{array}{c}\text { Concentração média de } \\
\text { fundo }\end{array}$ & $\mathrm{P} / \mathrm{m}^{3}$ & $1,60 \mathrm{E}+05$ & $5,67 E+04$ & $6,67 \mathrm{E}+03$ & $0,00 \mathrm{E}+00$ & $0,00 \mathrm{E}+00$ & $0,00 \mathrm{E}+00$ \\
\hline & $\begin{array}{c}\text { Número de particulas de } \\
\text { fundo }\end{array}$ & $\mathbf{P}$ & 48 & 17 & 2 & 0 & 0 & 0 \\
\hline & $\begin{array}{l}\text { Concentração média } \\
\text { liquida }\end{array}$ & $\mathrm{P} / \mathrm{m}^{3}$ & $5,78 \mathrm{E}+07$ & $5,08 \mathrm{E}+07$ & $3,85 E+07$ & $2,92 \mathrm{E}+07$ & $6,85 \mathrm{E}+06$ & $7,00 E+04$ \\
\hline & $\begin{array}{l}\text { Número de Particulas } \\
\text { média liquida }\end{array}$ & $\mathbf{p}$ & 17340 & 15241 & 11562 & 8756 & 2056 & 21 \\
\hline & Desvio - Poisson & $\#$ & 131,68 & 123,45 & 107,53 & 93,57 & 45,34 & 4,58 \\
\hline & $\begin{array}{l}\text { Desvio - Poisson - } \\
\text { Relativo }\end{array}$ & $\%$ & 0,8 & 0,8 & 0,9 & 1,1 & 2,2 & 21,8 \\
\hline & $\begin{array}{l}\text { Desvio padrão } \\
\text { Concentração }\end{array}$ & $\mathrm{P} / \mathrm{m}^{3}$ & $1,17 E+03$ & $1,35 E+02$ & $8,90 \mathrm{E}+02$ & $8,70 E+02$ & $7,98 \mathrm{E}+01$ & $1,38 \mathrm{E}+01$ \\
\hline & DP/Concentração média & $\%$ & 0,0020 & 0,0003 & 0,0023 & 0,0030 & 0,0012 & 0,0198 \\
\hline \multirow{2}{*}{\multicolumn{2}{|c|}{ Erro total medições(દ) }} & $\mathrm{P} / \mathrm{m}^{3}$ & $4,39 \mathrm{E}+05$ & $4,12 E+05$ & $3,58 \mathrm{E}+05$ & $3,12 \mathrm{E}+05$ & $1,51 E+05$ & $1,53 \mathrm{E}+04$ \\
\hline & & Unidade & $1,0-2,0 \mu \mathrm{m}$ & $2,0-3,0 \mu \mathrm{m}$ & $3,0-5,0 \mu \mathrm{m}$ & $5,0-7,0 \mu \mathrm{m}$ & $7,0-10,0 \mu \mathrm{m}$ & $>10,0 \mu \mathrm{m}$ \\
\hline \multirow{8}{*}{ Assento 2B } & $\begin{array}{c}\text { Concentração média de } \\
\text { fundo }\end{array}$ & $\mathrm{P} / \mathrm{m}^{3}$ & $1,93 \mathrm{E}+05$ & $7,67 \mathrm{E}+04$ & $1,00 \mathrm{E}+04$ & $0,00 \mathrm{E}+00$ & $0,00 \mathrm{E}+00$ & $0,00 \mathrm{E}+00$ \\
\hline & $\begin{array}{c}\text { Número de particulas de } \\
\text { fundo }\end{array}$ & $\mathbf{P}$ & 58 & 23 & 3 & 0 & 0 & 0 \\
\hline & $\begin{array}{l}\text { Concentração média } \\
\text { liquida }\end{array}$ & $\mathrm{P} / \mathrm{m}^{3}$ & $9,11 E+07$ & $8,40 \mathrm{E}+07$ & $7,53 \mathrm{E}+07$ & $5,15 E+07$ & $2,85 \mathrm{E}+07$ & $1,27 E+05$ \\
\hline & $\begin{array}{l}\text { Número de Particulas } \\
\text { média liquida }\end{array}$ & $\mathbf{P}$ & 27331 & 25213 & 22587 & 15444 & 8560 & 38 \\
\hline & Desvio - Poisson & $\#$ & 165,32 & 158,79 & 150,29 & 124,27 & 92,52 & 6,16 \\
\hline & $\begin{array}{c}\text { Desvio - Poisson - } \\
\text { Relativo } \\
\end{array}$ & $\%$ & 0,6 & 0,6 & 0,7 & 0,8 & 1,1 & 16,2 \\
\hline & $\begin{array}{l}\text { Desvio padrão } \\
\text { Concentração }\end{array}$ & $\mathrm{P} / \mathrm{m}^{3}$ & $5,92 \mathrm{E}+03$ & $1,02 E+03$ & $9,95 \mathrm{E}+02$ & $9,07 E+02$ & $7,57 \mathrm{E}+02$ & $4,07 E+01$ \\
\hline & DP/Concentração média & $\%$ & 0,0065 & 0,0012 & 0,0013 & 0,0018 & 0,0027 & 0,0321 \\
\hline \multirow{2}{*}{\multicolumn{2}{|c|}{ Erro total medições(દ) }} & $\mathrm{P} / \mathrm{m}^{3}$ & $5,51 E+05$ & $5,29 \mathrm{E}+05$ & $5,01 E+05$ & $4,14 E+05$ & $3,08 \mathrm{E}+05$ & $2,05 E+04$ \\
\hline & & Unidade & $1,0-2,0 \mu \mathrm{m}$ & $2,0-3,0 \mu \mathrm{m}$ & $3,0-5,0 \mu \mathrm{m}$ & $5,0-7,0 \mu \mathrm{m}$ & $7,0-10,0 \mu \mathrm{m}$ & $>10,0 \mu \mathrm{m}$ \\
\hline \multirow{8}{*}{ Assento 2A } & $\begin{array}{c}\text { Concentração média de } \\
\text { fundo }\end{array}$ & $\mathrm{P} / \mathrm{m}^{3}$ & $1,68 E+05$ & $7,50 \mathrm{E}+04$ & $5,00 E+03$ & $0,00 E+00$ & $0,00 \mathrm{E}+00$ & $0,00 \mathrm{E}+00$ \\
\hline & $\begin{array}{c}\text { Número de particulas de } \\
\text { fundo }\end{array}$ & $\mathbf{P}$ & 51 & 23 & 2 & 0 & 0 & 0 \\
\hline & $\begin{array}{c}\text { Concentração média } \\
\text { liquida } \\
\end{array}$ & $\mathrm{P} / \mathrm{m}^{3}$ & $7,45 \mathrm{E}+07$ & $6,86 \mathrm{E}+07$ & $6,08 \mathrm{E}+07$ & $2,85 E+07$ & $1,75 \mathrm{E}+07$ & $1,07 E+05$ \\
\hline & $\begin{array}{c}\text { Número de Particulas } \\
\text { média liquida }\end{array}$ & $\mathbf{P}$ & 22359 & 20573 & 18250 & 8547 & 5260 & 32 \\
\hline & Desvio - Poisson & $\#$ & 149,53 & 143,43 & 135,09 & 92,45 & 72,53 & 5,66 \\
\hline & $\begin{array}{l}\text { Desvio - Poisson - } \\
\text { Relativo }\end{array}$ & $\%$ & 0,7 & 0,7 & 0,7 & 1,1 & 1,4 & 17,7 \\
\hline & $\begin{array}{l}\text { Desvio padrão } \\
\text { Concentração } \\
\end{array}$ & $\mathrm{P} / \mathrm{m}^{3}$ & $5,79 E+03$ & $9,69 \mathrm{E}+02$ & $7,38 \mathrm{E}+02$ & $2,36 \mathrm{E}+03$ & $6,89 \mathrm{E}+01$ & $6,46 \mathrm{E}+00$ \\
\hline & DP/Concentração média & $\%$ & 0,0078 & 0,0014 & 0,0012 & 0,0083 & 0,0004 & 0,0061 \\
\hline \multicolumn{2}{|c|}{ Erro total medições(દ) } & $\mathrm{P} / \mathrm{m}^{3}$ & $4,98 \mathrm{E}+05$ & $4,78 E+05$ & $4,50 E+05$ & $3,08 \mathrm{E}+05$ & $2,42 E+05$ & $1,89 \mathrm{E}+04$ \\
\hline
\end{tabular}


\begin{tabular}{|l|l|l|l|l|l|l|} 
Unidade & $1,0-2,0 \mu \mathrm{m}$ & $2,0-3,0 \mu \mathrm{m}$ & $3,0-5,0 \mu \mathrm{m}$ & $5,0-7,0 \mu \mathrm{m}$ & $7,0-10,0 \mu \mathrm{m}$ & $>10,0 \mu \mathrm{m}$ \\
\hline
\end{tabular}

\begin{tabular}{|c|c|c|c|c|c|c|c|c|}
\hline \multirow{8}{*}{ Assento 3B } & $\begin{array}{c}\begin{array}{c}\text { Concentração média de } \\
\text { fundo }\end{array} \\
\end{array}$ & $\mathrm{P} / \mathrm{m}^{3}$ & $1,95 \mathrm{E}+05$ & $8,33 E+04$ & $6,67 E+03$ & $0,00 E+00$ & $0,00 E+00$ & $0,00 E+00$ \\
\hline & $\begin{array}{c}\text { Número de particulas de } \\
\text { fundo }\end{array}$ & $\mathbf{P}$ & 59 & 25 & 2 & 0 & 0 & 0 \\
\hline & $\begin{array}{c}\text { Concentração média } \\
\text { liquida }\end{array}$ & $\mathrm{P} / \mathrm{m}^{3}$ & $1,18 \mathrm{E}+08$ & $1,09 \mathrm{E}+08$ & $8,19 \mathrm{E}+07$ & $5,00 \mathrm{E}+07$ & $2,13 \mathrm{E}+07$ & $3,27 E+05$ \\
\hline & $\begin{array}{c}\text { Número de Particulas } \\
\text { média liquida }\end{array}$ & $\mathbf{P}$ & 35270 & 32558 & 24560 & 14999 & 6380 & 98 \\
\hline & Desvio - Poisson & $\#$ & 187,80 & 180,44 & 156,72 & 122,47 & 79,87 & 9,90 \\
\hline & $\begin{array}{c}\text { Desvio - Poisson - } \\
\text { Relativo } \\
\end{array}$ & $\%$ & 0,5 & 0,6 & 0,6 & 0,8 & 1,3 & 10,1 \\
\hline & $\begin{array}{l}\text { Desvio padrão } \\
\text { Concentração }\end{array}$ & $\mathrm{P} / \mathrm{m}^{3}$ & $6,97 E+03$ & $6,59 \mathrm{E}+03$ & $1,85 \mathrm{E}+03$ & $9,82 E+02$ & $1,83 \mathrm{E}+03$ & $1,15 \mathrm{E}+01$ \\
\hline & DP/Concentração média & $\%$ & 0,0059 & 0,0061 & 0,0023 & 0,0020 & 0,0086 & 0,0035 \\
\hline \multirow{2}{*}{\multicolumn{2}{|c|}{ Erro total medições( $\varepsilon)$}} & $\mathrm{P} / \mathrm{m}^{3}$ & $6,26 \mathrm{E}+05$ & $6,01 E+05$ & $5,22 \mathrm{E}+05$ & $4,08 E+05$ & $2,66 E+05$ & $3,30 E+04$ \\
\hline & & Unidade & $1,0-2,0 \mu \mathrm{m}$ & $2,0-3,0 \mu \mathrm{m}$ & $3,0-5,0 \mu \mathrm{m}$ & $5,0-7,0 \mu \mathrm{m}$ & $7,0-10,0 \mu \mathrm{m}$ & $>10,0 \mu \mathrm{m}$ \\
\hline \multirow{8}{*}{ Assento $3 \mathrm{~A}$} & $\begin{array}{c}\text { Concentração média de } \\
\text { fundo }\end{array}$ & $\mathrm{P} / \mathrm{m}^{3}$ & $1,93 \mathrm{E}+05$ & $6,67 E+04$ & $1,00 E+04$ & $3,33 E+03$ & $3,33 E+03$ & $0,00 E+00$ \\
\hline & $\begin{array}{c}\text { Número de particulas de } \\
\text { fundo }\end{array}$ & $\mathbf{p}$ & 58 & 20 & 3 & 1 & 1 & 0 \\
\hline & $\begin{array}{c}\text { Concentração média } \\
\text { liquida }\end{array}$ & $\mathrm{P} / \mathrm{m}^{3}$ & $7,78 \mathrm{E}+07$ & $7,12 \mathrm{E}+07$ & $6,52 E+07$ & $4,00 E+07$ & $1,74 \mathrm{E}+07$ & $3,10 \mathrm{E}+05$ \\
\hline & $\begin{array}{c}\text { Número de Particulas } \\
\text { média liquida }\end{array}$ & $\mathbf{P}$ & 23331 & 21361 & 19547 & 12003 & 5210 & 93 \\
\hline & Desvio - Poisson & $\#$ & 152,74 & 146,15 & 139,81 & 109,56 & 72,18 & 9,64 \\
\hline & $\begin{array}{c}\text { Desvio - Poisson - } \\
\text { Relativo } \\
\end{array}$ & $\%$ & 0,7 & 0,7 & 0,7 & 0,9 & 1,4 & 10,4 \\
\hline & $\begin{array}{l}\text { Desvio padrão } \\
\text { Concentração }\end{array}$ & $\mathrm{P} / \mathrm{m}^{3}$ & $2,84 \mathrm{E}+03$ & $1,08 \mathrm{E}+03$ & $1,28 \mathrm{E}+03$ & $2,01 E+03$ & $1,65 E+03$ & $3,34 \mathrm{E}+01$ \\
\hline & DP/Concentração média & $\%$ & 0,0036 & 0,0015 & 0,0020 & 0,0050 & 0,0095 & 0,0108 \\
\hline \multicolumn{2}{|c|}{ Erro total medicões $(\varepsilon)$} & $\mathrm{P} / \mathrm{m}^{3}$ & $5,09 \mathrm{E}+05$ & $4,87 E+05$ & $4,66 \mathrm{E}+05$ & $3,65 \mathrm{E}+05$ & $2,41 E+05$ & $3,21 \mathrm{E}+04$ \\
\hline
\end{tabular}


Tabela B-8. Resultados das medições de partículas no assento (Sistema UFAD à $18^{\circ} \mathrm{C}$ - injeção pelo assento $3 \mathrm{~A}$ )

\begin{tabular}{|c|c|c|c|c|c|c|c|c|}
\hline & & Unidade & $1,0-2,0 \mu \mathrm{m}$ & $2,0-3,0 \mu \mathrm{m}$ & $3,0-5,0 \mu \mathrm{m}$ & $5,0-7,0 \mu \mathrm{m}$ & $7,0-10,0 \mu \mathrm{m}$ & $>10,0 \mu \mathrm{m}$ \\
\hline \multirow{8}{*}{ Assento 3D } & $\begin{array}{l}\text { Concentração média de } \\
\text { fundo }\end{array}$ & $\mathrm{P} / \mathrm{m}^{3}$ & $1,93 E+05$ & $1,50 E+05$ & $1,00 E+04$ & $0,00 \mathrm{E}+00$ & $0,00 E+00$ & $0,00 \mathrm{E}+00$ \\
\hline & $\begin{array}{l}\text { Número de particulas de } \\
\text { fundo }\end{array}$ & $\mathbf{P}$ & 58 & 45 & 3 & 0 & 0 & 0 \\
\hline & Concentração média liquida & $\mathrm{P} / \mathrm{m}^{3}$ & $1,12 \mathrm{E}+08$ & $8,25 \mathrm{E}+07$ & $6,33 \mathrm{E}+07$ & $4,54 \mathrm{E}+07$ & $2,07 E+07$ & $2,02 E+06$ \\
\hline & \begin{tabular}{|c|} 
Número de Particulas média \\
liquida
\end{tabular} & $\mathbf{p}$ & 33583,5 & 24738,5 & 18997 & 13620 & 6206,5 & 606,5 \\
\hline & Desvio - Poisson & $\#$ & 183,26 & 157,28 & 137,83 & 116,70 & 78,78 & 24,63 \\
\hline & Desvio - Poisson - Relativo & $\%$ & 0,5 & 0,6 & 0,7 & 0,9 & 1,3 & 4,1 \\
\hline & Desvio padrão Concentração & $\mathrm{P} / \mathrm{m}^{3}$ & $2,06 \mathrm{E}+03$ & $1,30 E+03$ & $2,49 E+03$ & $2,34 \mathrm{E}+03$ & $7,40 E+02$ & $5,55 E+01$ \\
\hline & DP/Concentração média & $\%$ & 0,0018 & 0,0016 & 0,0039 & 0,0051 & 0,0036 & 0,0027 \\
\hline \multirow{2}{*}{\multicolumn{2}{|c|}{ Erro total medições(દ) }} & $\mathrm{P} / \mathrm{m}^{3}$ & $6,11 \mathrm{E}+05$ & $5,24 \mathrm{E}+05$ & $4,59 \mathrm{E}+05$ & $3,89 \mathrm{E}+05$ & $2,63 E+05$ & $8,21 E+04$ \\
\hline & & Unidade & $1,0-2,0 \mu \mathrm{m}$ & $2,0-3,0 \mu \mathrm{m}$ & $3,0-5,0 \mu \mathrm{m}$ & $5,0-7,0 \mu \mathrm{m}$ & $7,0-10,0 \mu \mathrm{m}$ & $>10,0 \mu \mathrm{m}$ \\
\hline \multirow{8}{*}{ Assento 2D } & $\begin{array}{c}\text { Concentração média de } \\
\text { fundo }\end{array}$ & $\mathrm{P} / \mathrm{m}^{3}$ & $1,10 E+05$ & $4,00 E+04$ & $3,33 E+03$ & $0,00 \mathrm{E}+00$ & $0,00 E+00$ & $0,00 \mathrm{E}+00$ \\
\hline & $\begin{array}{c}\text { Número de particulas de } \\
\text { fundo }\end{array}$ & $\mathbf{P}$ & 33 & 12 & 1 & 0 & 0 & 0 \\
\hline & Concentração média liquida & $\mathrm{P} / \mathrm{m}^{3}$ & $6,35 E+07$ & $6,29 \mathrm{E}+07$ & $5,51 E+07$ & $3,81 E+07$ & $9,82 E+06$ & $1,13 \mathrm{E}+06$ \\
\hline & $\begin{array}{c}\text { Número de Particulas média } \\
\text { liquida }\end{array}$ & $\mathbf{P}$ & 19047 & 18883,5 & 16522,5 & 11418,5 & 2945,5 & 339,5 \\
\hline & Desvio - Poisson & $\#$ & 138,01 & 137,42 & 128,54 & 106,86 & 54,27 & 18,43 \\
\hline & Desvio - Poisson - Relativo & $\%$ & 0,7 & 0,7 & 0,8 & 0,9 & 1,8 & 5,4 \\
\hline & Desvio padrão Concentração & $\mathrm{P} / \mathrm{m}^{3}$ & $3,39 E+03$ & $3,34 E+03$ & $2,70 E+03$ & $1,96 \mathrm{E}+03$ & $5,16 E+02$ & $6,05 E+01$ \\
\hline & DP/Concentração média & $\%$ & 0,0053 & 0,0053 & 0,0049 & 0,0052 & 0,0053 & 0,0053 \\
\hline \multirow{2}{*}{\multicolumn{2}{|c|}{ Erro total medições $(\varepsilon)$}} & $\mathrm{P} / \mathrm{m}^{3}$ & $4,60 E+05$ & $4,58 E+05$ & $4,28 \mathrm{E}+05$ & $3,56 \mathrm{E}+05$ & $1,81 E+05$ & $6,14 \mathrm{E}+04$ \\
\hline & & Unidade & $1,0-2,0 \mu \mathrm{m}$ & $2,0-3,0 \mu \mathrm{m}$ & $3,0-5,0 \mu \mathrm{m}$ & $5,0-7,0 \mu \mathrm{m}$ & $7,0-10,0 \mu \mathrm{m}$ & $>10,0 \mu \mathrm{m}$ \\
\hline \multirow{8}{*}{ Assento 2E } & $\begin{array}{l}\text { Concentração média de } \\
\text { fundo }\end{array}$ & $\mathrm{P} / \mathrm{m}^{3}$ & $7,00 E+04$ & $3,00 E+04$ & $3,33 E+03$ & $0,00 E+00$ & $0,00 E+00$ & $0,00 \mathrm{E}+00$ \\
\hline & $\begin{array}{c}\text { Número de particulas de } \\
\text { fundo }\end{array}$ & $\mathbf{P}$ & 21 & 9 & 1 & 0 & 0 & 0 \\
\hline & Concentração média liquida & $\mathrm{P} / \mathrm{m}^{3}$ & $7,24 \mathrm{E}+07$ & $7,38 \mathrm{E}+07$ & $6,23 E+07$ & $4,65 E+07$ & $1,96 \mathrm{E}+07$ & $3,08 \mathrm{E}+06$ \\
\hline & $\begin{array}{c}\text { Número de Particulas média } \\
\text { liquida }\end{array}$ & $\mathbf{p}$ & 21706 & 22135 & 18694 & 13945 & 5879 & 924 \\
\hline & Desvio - Poisson & $\#$ & 147,33 & 148,78 & 136,73 & 118,09 & 76,67 & 30,40 \\
\hline & Desvio - Poisson - Relativo & $\%$ & 0,7 & 0,7 & 0,7 & 0,8 & 1,3 & 3,3 \\
\hline & Desvio padrão Concentração & $\mathrm{P} / \mathrm{m}^{3}$ & $9,43 E+02$ & $3,24 \mathrm{E}+02$ & $2,71 \mathrm{E}+03$ & $8,08 \mathrm{E}+02$ & $8,35 E+02$ & $7,09 \mathrm{E}+01$ \\
\hline & DP/Concentração média & $\%$ & 0,0013 & 0,0004 & 0,0043 & 0,0017 & 0,0043 & 0,0023 \\
\hline \multicolumn{2}{|c|}{ Erro total medições $(\varepsilon)$} & $\mathrm{P} / \mathrm{m}^{3}$ & $4,91 E+05$ & $4,96 \mathrm{E}+05$ & $4,56 \mathrm{E}+05$ & $3,94 \mathrm{E}+05$ & $2,56 \mathrm{E}+05$ & $1,01 E+05$ \\
\hline
\end{tabular}




\begin{tabular}{|c|c|c|c|c|c|c|c|c|}
\hline & & Unidade & $1,0-2,0 \mu \mathrm{m}$ & $2,0-3,0 \mu \mathrm{m}$ & $3,0-5,0 \mu \mathrm{m}$ & $5,0-7,0 \mu \mathrm{m}$ & $7,0-10,0 \mu \mathrm{m}$ & $>10,0 \mu \mathrm{m}$ \\
\hline \multirow{8}{*}{ Assento 1D } & $\begin{array}{l}\text { Concentração média de } \\
\text { fundo }\end{array}$ & $\mathrm{P} / \mathrm{m}^{3}$ & $1,47 E+05$ & $1,20 E+05$ & $6,67 \mathrm{E}+03$ & $0,00 E+00$ & $0,00 E+00$ & $0,00 E+00$ \\
\hline & $\begin{array}{l}\text { Número de particulas de } \\
\text { fundo }\end{array}$ & $\mathbf{p}$ & 44 & 36 & 2 & 0 & 0 & 0 \\
\hline & Concentração média liquida & $\mathrm{P} / \mathrm{m}^{3}$ & $7,72 \mathrm{E}+07$ & $7,58 \mathrm{E}+07$ & $4,13 E+07$ & $3,19 E+07$ & $6,62 E+06$ & $1,78 \mathrm{E}+06$ \\
\hline & $\begin{array}{c}\text { Número de Particulas média } \\
\text { liquida }\end{array}$ & $\mathbf{p}$ & 23148 & 22746 & 12399 & 9578 & 1985 & 534 \\
\hline & Desvio - Poisson & $\#$ & 152,14 & 150,82 & 111,35 & 97,87 & 44,55 & 23,11 \\
\hline & Desvio - Poisson - Relativo & $\%$ & 0,7 & 0,7 & 0,9 & 1,0 & 2,2 & 4,3 \\
\hline & Desvio padrão Concentração & $\mathrm{P} / \mathrm{m}^{3}$ & $1,54 E+03$ & $2,41 E+03$ & $7,06 \mathrm{E}+02$ & $1,95 \mathrm{E}+03$ & $2,07 E+02$ & $9,77 E+01$ \\
\hline & DP/Concentração média & $\%$ & 0,0020 & 0,0032 & 0,0017 & 0,0061 & 0,0031 & 0,0055 \\
\hline \multirow{2}{*}{\multicolumn{2}{|c|}{ Erro total medições $(\varepsilon)$}} & $\mathrm{P} / \mathrm{m}^{3}$ & $5,07 \mathrm{E}+05$ & $5,03 E+05$ & $3,71 E+05$ & $3,26 \mathrm{E}+05$ & $1,49 E+05$ & $7,70 E+04$ \\
\hline & & Unidade & $1,0-2,0 \mu \mathrm{m}$ & $2,0-3,0 \mu \mathrm{m}$ & $3,0-5,0 \mu \mathrm{m}$ & $5,0-7,0 \mu \mathrm{m}$ & $7,0-10,0 \mu \mathrm{m}$ & $>10,0 \mu \mathrm{m}$ \\
\hline \multirow{8}{*}{ Assento $1 \mathrm{E}$} & $\begin{array}{c}\text { Concentração média de } \\
\text { fundo }\end{array}$ & $\mathrm{P} / \mathrm{m}^{3}$ & $1,87 E+05$ & $9,33 E+04$ & $0,00 E+00$ & $0,00 E+00$ & $0,00 E+00$ & $0,00 E+00$ \\
\hline & $\begin{array}{l}\text { Número de particulas de } \\
\text { fundo }\end{array}$ & $\mathbf{p}$ & 56 & 28 & 0 & 0 & 0 & 0 \\
\hline & Concentração média liquida & $\mathrm{P} / \mathrm{m}^{3}$ & $7,62 E+07$ & $7,69 \mathrm{E}+07$ & $3,75 E+07$ & $2,18 E+07$ & $4,18 E+06$ & $1,84 \mathrm{E}+06$ \\
\hline & $\begin{array}{c}\text { Número de Particulas média } \\
\text { liquida }\end{array}$ & $\mathbf{P}$ & 22846 & 23071 & 11250 & 6542 & 1254 & 551 \\
\hline & Desvio - Poisson & $\#$ & 151,15 & 151,89 & 106,07 & 80,88 & 35,41 & 23,46 \\
\hline & Desvio - Poisson - Relativo & $\%$ & 0,7 & 0,7 & 0,9 & 1,2 & 2,8 & 4,3 \\
\hline & Desvio padrão Concentração & $\mathrm{P} / \mathrm{m}^{3}$ & $2,10 E+03$ & $2,12 \mathrm{E}+03$ & $6,39 \mathrm{E}+02$ & $2,95 \mathrm{E}+02$ & $1,38 E+02$ & $4,06 \mathrm{E}+01$ \\
\hline & DP/Concentração média & $\%$ & 0,0028 & 0,0028 & 0,0017 & 0,0014 & 0,0033 & 0,0022 \\
\hline \multirow{2}{*}{\multicolumn{2}{|c|}{ Erro total medições(६) }} & $\mathrm{P} / \mathrm{m}^{3}$ & $5,04 E+05$ & $5,06 \mathrm{E}+05$ & $3,54 \mathrm{E}+05$ & $2,70 E+05$ & $1,18 \mathrm{E}+05$ & $7,82 \mathrm{E}+04$ \\
\hline & & Unidade & $1,0-2,0 \mu \mathrm{m}$ & $2,0-3,0 \mu \mathrm{m}$ & $3,0-5,0 \mu \mathrm{m}$ & $5,0-7,0 \mu \mathrm{m}$ & $7,0-10,0 \mu \mathrm{m}$ & $>10,0 \mu \mathrm{m}$ \\
\hline \multirow{8}{*}{ Assento 1B } & $\begin{array}{c}\text { Concentração média de } \\
\text { fundo }\end{array}$ & $\mathrm{P} / \mathrm{m}^{3}$ & $1,57 \mathrm{E}+05$ & $5,33 E+04$ & $1,00 E+04$ & $0,00 E+00$ & $0,00 E+00$ & $0,00 E+00$ \\
\hline & $\begin{array}{l}\text { Número de particulas de } \\
\text { fundo }\end{array}$ & $\mathbf{P}$ & 47 & 16 & 3 & 0 & 0 & 0 \\
\hline & Concentração média liquida & $\mathrm{P} / \mathrm{m}^{3}$ & $6,20 \mathrm{E}+07$ & $6,29 \mathrm{E}+07$ & $3,94 \mathrm{E}+07$ & $3,17 E+07$ & $6,05 E+06$ & $8,58 E+05$ \\
\hline & \begin{tabular}{|c|} 
Número de Particulas média \\
liquida
\end{tabular} & $\mathbf{P}$ & 18587 & 18860 & 11817 & 9520 & 1816 & 258 \\
\hline & Desvio-Poisson & $\#$ & 136,33 & 137,33 & 108,70 & 97,57 & 42,61 & 16,05 \\
\hline & Desvio - Poisson - Relativo & $\%$ & 0,7 & 0,7 & 0,9 & 1,0 & 2,3 & 6,2 \\
\hline & Desvio padrão Concentração & $\mathrm{P} / \mathrm{m}^{3}$ & $2,73 E+03$ & $2,06 \mathrm{E}+03$ & $1,02 E+03$ & $1,28 \mathrm{E}+03$ & $8,41 E+01$ & $3,11 \mathrm{E}+01$ \\
\hline & DP/Concentração média & $\%$ & 0,0044 & 0,0033 & 0,0026 & 0,0040 & 0,0014 & 0,0036 \\
\hline \multicolumn{2}{|c|}{ Erro total medições( $(\varepsilon)$} & $\mathrm{P} / \mathrm{m}^{3}$ & $4,54 \mathrm{E}+05$ & $4,58 E+05$ & $3,62 E+05$ & $3,25 E+05$ & $1,42 E+05$ & $5,35 E+04$ \\
\hline
\end{tabular}




\begin{tabular}{|c|c|c|c|c|c|c|c|c|}
\hline & & Unidade & $1,0-2,0 \mu \mathrm{m}$ & $2,0-3,0 \mu \mathrm{m}$ & $3,0-5,0 \mu \mathrm{m}$ & $5,0-7,0 \mu \mathrm{m}$ & $7,0-10,0 \mu \mathrm{m}$ & $>10,0 \mu \mathrm{m}$ \\
\hline \multirow{8}{*}{ Assento $1 \mathrm{~A}$} & $\begin{array}{l}\text { Concentração média de } \\
\text { fundo }\end{array}$ & $\mathrm{P} / \mathrm{m}^{3}$ & $2,23 \mathrm{E}+05$ & $8,00 \mathrm{E}+04$ & $6,67 E+03$ & $0,00 E+00$ & $0,00 \mathrm{E}+00$ & $0,00 \mathrm{E}+00$ \\
\hline & $\begin{array}{l}\text { Número de particulas de } \\
\text { fundo }\end{array}$ & P & 67 & 24 & 2 & 0 & 0 & 0 \\
\hline & Concentração média liquida & $\mathrm{P} / \mathrm{m}^{3}$ & $3,13 \mathrm{E}+07$ & $2,67 \mathrm{E}+07$ & $2,65 \mathrm{E}+07$ & $1,53 \mathrm{E}+07$ & $3,28 \mathrm{E}+06$ & $7,00 \mathrm{E}+05$ \\
\hline & \begin{tabular}{|c|} 
Número de Particulas média \\
liquida
\end{tabular} & $\mathbf{P}$ & 9377 & 8022 & 7954 & 4585 & 985 & 210 \\
\hline & Desvio - Poisson & $\#$ & 96,83 & 89,57 & 89,19 & 67,71 & 31,38 & 14,49 \\
\hline & Desvio - Poisson - Relativo & $\%$ & 1,0 & 1,1 & 1,1 & 1,5 & 3,2 & 6,9 \\
\hline & Desvio padrão Concentração & $\mathrm{P} / \mathrm{m}^{3}$ & $3,73 \mathrm{E}+03$ & $1,36 \mathrm{E}+03$ & $1,18 \mathrm{E}+03$ & $7,64 \mathrm{E}+02$ & $9,78 E+01$ & $8,63 E+01$ \\
\hline & DP/Concentração média & $\%$ & 0,0119 & 0,0051 & 0,0045 & 0,0050 & 0,0030 & 0,0123 \\
\hline \multirow{2}{*}{\multicolumn{2}{|c|}{ Erro total medições $(\varepsilon)$}} & $\mathrm{P} / \mathrm{m}^{3}$ & $3,23 \mathrm{E}+05$ & $2,99 \mathrm{E}+05$ & $2,97 E+05$ & $2,26 E+05$ & $1,05 E+05$ & $4,83 E+04$ \\
\hline & & Unidade & $1,0-2,0 \mu \mathrm{m}$ & $2,0-3,0 \mu \mathrm{m}$ & $3,0-5,0 \mu \mathrm{m}$ & $5,0-7,0 \mu \mathrm{m}$ & $7,0-10,0 \mu \mathrm{m}$ & $>10,0 \mu \mathrm{m}$ \\
\hline \multirow{8}{*}{ Assento 2B } & $\begin{array}{l}\text { Concentração média de } \\
\text { fundo }\end{array}$ & $\mathrm{P} / \mathrm{m}^{3}$ & $1,37 \mathrm{E}+05$ & $1,13 \mathrm{E}+05$ & $3,33 \mathrm{E}+03$ & $0,00 E+00$ & $0,00 E+00$ & $0,00 \mathrm{E}+00$ \\
\hline & $\begin{array}{l}\text { Número de particulas de } \\
\text { fundo }\end{array}$ & P & 41 & 34 & 1 & 0 & 0 & 0 \\
\hline & Concentração média liquida & $\mathrm{P} / \mathrm{m}^{3}$ & $6,29 \mathrm{E}+07$ & $6,68 \mathrm{E}+07$ & $5,97 E+07$ & $4,42 E+07$ & $2,15 \mathrm{E}+07$ & $1,06 \mathrm{E}+06$ \\
\hline & \begin{tabular}{|c|} 
Número de Particulas média \\
liquida
\end{tabular} & $\mathbf{P}$ & 18877 & 20033 & 17899 & 13258 & 6452 & 318 \\
\hline & Desvio - Poisson & $\#$ & 137,39 & 141,54 & 133,79 & 115,14 & 80,32 & 17,83 \\
\hline & Desvio - Poisson - Relativo & $\%$ & 0,7 & 0,7 & 0,7 & 0,9 & 1,2 & 5,6 \\
\hline & Desvio padrão Concentração & $\mathrm{P} / \mathrm{m}^{3}$ & $3,35 \mathrm{E}+03$ & $4,55 \mathrm{E}+03$ & $1,12 \mathrm{E}+03$ & $1,21 E+03$ & $9,12 E+02$ & $7,61 E+01$ \\
\hline & DP/Concentração média & $\%$ & 0,0053 & 0,0068 & 0,0019 & 0,0027 & 0,0042 & 0,0072 \\
\hline \multirow{2}{*}{\multicolumn{2}{|c|}{ Erro total medições(દ) }} & $\mathrm{P} / \mathrm{m}^{3}$ & $4,58 E+05$ & $4,72 E+05$ & $4,46 E+05$ & $3,84 E+05$ & $2,68 E+05$ & $5,94 E+04$ \\
\hline & & Unidade & $1,0-2,0 \mu \mathrm{m}$ & $2,0-3,0 \mu \mathrm{m}$ & $3,0-5,0 \mu \mathrm{m}$ & $5,0-7,0 \mu \mathrm{m}$ & $7,0-10,0 \mu \mathrm{m}$ & $>10,0 \mu \mathrm{m}$ \\
\hline \multirow{8}{*}{ Assento 2A } & $\begin{array}{l}\text { Concentração média de } \\
\text { fundo }\end{array}$ & $\mathrm{P} / \mathrm{m}^{3}$ & $4,33 E+04$ & $2,00 E+04$ & $0,00 E+00$ & $0,00 E+00$ & $0,00 E+00$ & $0,00 E+00$ \\
\hline & $\begin{array}{c}\text { Número de particulas de } \\
\text { fundo }\end{array}$ & $\mathbf{P}$ & 13 & 6 & 0 & 0 & 0 & 0 \\
\hline & Concentração média liquida & $\mathrm{P} / \mathrm{m}^{3}$ & $5,03 E+07$ & $4,35 E+07$ & $3,51 \mathrm{E}+07$ & $1,68 \mathrm{E}+07$ & $6,74 E+06$ & $1,34 \mathrm{E}+06$ \\
\hline & \begin{tabular}{|c|}
$\begin{array}{c}\text { Número de Particulas média } \\
\text { liquida }\end{array}$ \\
\end{tabular} & $\mathbf{P}$ & 15094 & 13038 & 10520 & 5040 & 2023 & 402 \\
\hline & Desvio - Poisson & $\#$ & 122,86 & 114,18 & 102,57 & 70,99 & 44,98 & 20,05 \\
\hline & Desvio - Poisson - Relativo & $\%$ & 0,8 & 0,9 & 1,0 & 1,4 & 2,2 & 5,0 \\
\hline & Desvio padrão Concentração & $\mathrm{P} / \mathrm{m}^{3}$ & $3,18 \mathrm{E}+03$ & $3,16 \mathrm{E}+03$ & $1,93 \mathrm{E}+03$ & $8,75 E+02$ & $4,96 \mathrm{E}+02$ & $1,45 \mathrm{E}+01$ \\
\hline & DP/Concentração média & $\%$ & 0,0063 & 0,0073 & 0,0055 & 0,0052 & 0,0073 & 0,0011 \\
\hline \multicolumn{2}{|c|}{ Erro total medições $(\varepsilon)$} & $\mathrm{P} / \mathrm{m}^{3}$ & $4,10 E+05$ & $3,81 \mathrm{E}+05$ & $3,42 E+05$ & $2,37 E+05$ & $1,50 E+05$ & $6,68 E+04$ \\
\hline
\end{tabular}




\begin{tabular}{|c|c|c|c|c|c|c|c|c|}
\hline & & Unidade & $1,0-2,0 \mu \mathrm{m}$ & $2,0-3,0 \mu \mathrm{m}$ & $3,0-5,0 \mu \mathrm{m}$ & $5,0-7,0 \mu \mathrm{m}$ & $7,0-10,0 \mu \mathrm{m}$ & $>10,0 \mu \mathrm{m}$ \\
\hline \multirow{8}{*}{ Assento 3B } & $\begin{array}{l}\text { Concentração média de } \\
\text { fundo }\end{array}$ & $\mathrm{P} / \mathrm{m}^{3}$ & $2,23 E+05$ & $1,13 E+05$ & $6,67 E+03$ & $0,00 \mathrm{E}+00$ & $0,00 \mathrm{E}+00$ & $0,00 \mathrm{E}+00$ \\
\hline & $\begin{array}{l}\text { Número de particulas de } \\
\text { fundo }\end{array}$ & $\mathbf{P}$ & 67 & 34 & 2 & 0 & 0 & 0 \\
\hline & Concentração média liquida & $\mathrm{P} / \mathrm{m}^{3}$ & $1,00 E+08$ & $9,90 \mathrm{E}+07$ & $3,92 E+07$ & $3,12 \mathrm{E}+07$ & $1,46 \mathrm{E}+07$ & $1,16 \mathrm{E}+06$ \\
\hline & \begin{tabular}{|c|}
$\begin{array}{c}\text { Número de Particulas média } \\
\text { liquida }\end{array}$ \\
\end{tabular} & $\mathbf{P}$ & 30125 & 29688 & 11765 & 9345 & 4372 & 348 \\
\hline & Desvio - Poisson & $\#$ & 173,56 & 172,30 & 108,46 & 96,67 & 66,12 & 18,65 \\
\hline & Desvio - Poisson - Relativo & $\%$ & 0,6 & 0,6 & 0,9 & 1,0 & 1,5 & 5,4 \\
\hline & Desvio padrão Concentração & $\mathrm{P} / \mathrm{m}^{3}$ & $1,95 \mathrm{E}+03$ & $1,90 E+03$ & $4,73 E+02$ & $9,11 E+02$ & $2,22 \mathrm{E}+02$ & $2,04 E+01$ \\
\hline & DP/Concentração média & $\%$ & 0,0019 & 0,0019 & 0,0012 & 0,0029 & 0,0015 & 0,0018 \\
\hline \multirow{2}{*}{\multicolumn{2}{|c|}{ Erro total medições $(\varepsilon)$}} & $\mathrm{P} / \mathrm{m}^{3}$ & $5,79 \mathrm{E}+05$ & $5,74 \mathrm{E}+05$ & $3,62 E+05$ & $3,22 E+05$ & $2,20 E+05$ & $6,22 \mathrm{E}+04$ \\
\hline & & Unidade & $1,0-2,0 \mu \mathrm{m}$ & $2,0-3,0 \mu \mathrm{m}$ & $3,0-5,0 \mu \mathrm{m}$ & $5,0-7,0 \mu \mathrm{m}$ & $7,0-10,0 \mu \mathrm{m}$ & $>10,0 \mu \mathrm{m}$ \\
\hline \multirow{8}{*}{ Assento $3 \mathrm{~A}$} & $\begin{array}{l}\text { Concentração média de } \\
\text { fundo }\end{array}$ & $\mathrm{P} / \mathrm{m}^{3}$ & $1,30 \mathrm{E}+05$ & $5,00 E+04$ & $3,33 E+03$ & $0,00 E+00$ & $0,00 E+00$ & $0,00 E+00$ \\
\hline & $\begin{array}{l}\text { Número de particulas de } \\
\text { fundo }\end{array}$ & $\mathbf{P}$ & 39 & 15 & 1 & 0 & 0 & 0 \\
\hline & Concentração média liquida & $\mathrm{P} / \mathrm{m}^{3}$ & $1,00 E+08$ & $9,90 E+07$ & $6,13 \mathrm{E}+07$ & $4,30 E+07$ & $2,01 E+07$ & $1,00 E+06$ \\
\hline & $\begin{array}{c}\text { Número de Particulas média } \\
\text { liquida }\end{array}$ & $\mathbf{P}$ & 30125 & 29688 & 18400 & 12890 & 6042 & 300 \\
\hline & Desvio - Poisson & $\#$ & 173,56 & 172,30 & 135,65 & 113,53 & 77,73 & 17,32 \\
\hline & Desvio - Poisson - Relativo & $\%$ & 0,6 & 0,6 & 0,7 & 0,9 & 1,3 & 5,8 \\
\hline & Desvio padrão Concentração & $\mathrm{P} / \mathrm{m}^{3}$ & $1,95 \mathrm{E}+03$ & $1,90 E+03$ & $1,46 \mathrm{E}+03$ & $7,36 \mathrm{E}+02$ & $1,36 \mathrm{E}+03$ & $1,54 E+01$ \\
\hline & DP/Concentração média & $\%$ & 0,0019 & 0,0019 & 0,0024 & 0,0017 & 0,0067 & 0,0015 \\
\hline \multicolumn{2}{|c|}{ Erro total medições $(\varepsilon)$} & $\mathrm{P} / \mathrm{m}^{3}$ & $5,79 E+05$ & $5,74 \mathrm{E}+05$ & $4,52 E+05$ & $3,78 \mathrm{E}+05$ & $2,59 E+05$ & $5,77 \mathrm{E}+04$ \\
\hline
\end{tabular}


Tabela B-9. Resultados das medições de partículas no assento (Sistema DV à $18^{\circ} \mathrm{C}$ - injeção pelo assento $3 \mathrm{~A}$ )

\begin{tabular}{|c|c|c|c|c|c|c|c|c|}
\hline & & Unidade & $1,0-2,0 \mu \mathrm{m}$ & $2,0-3,0 \mu \mathrm{m}$ & $3,0-5,0 \mu \mathrm{m}$ & $5,0-7,0 \mu \mathrm{m}$ & $7,0-10,0 \mu \mathrm{m}$ & $>10,0 \mu \mathrm{m}$ \\
\hline \multirow{8}{*}{ Assento 3D } & $\begin{array}{c}\text { Concentração média de } \\
\text { fundo }\end{array}$ & $\mathrm{P} / \mathrm{m}^{3}$ & $1,17 \mathrm{E}+05$ & $3,67 \mathrm{E}+04$ & $3,33 \mathrm{E}+03$ & $0,00 E+00$ & $0,00 E+00$ & $0,00 E+00$ \\
\hline & $\begin{array}{c}\text { Número de particulas de } \\
\text { fundo }\end{array}$ & $\mathbf{P}$ & 35 & 11 & 1 & 0 & 0 & 0 \\
\hline & $\begin{array}{l}\text { Concentração média } \\
\text { liquida } \\
\end{array}$ & $\mathrm{P} / \mathrm{m}^{3}$ & $1,20 E+08$ & $1,03 E+08$ & $8,00 E+07$ & $6,67 \mathrm{E}+07$ & $3,33 \mathrm{E}+07$ & $5,97 E+06$ \\
\hline & $\begin{array}{l}\text { Número de Particulas } \\
\text { média liquida }\end{array}$ & $\mathbf{P}$ & 36118 & 30815 & 24000 & 20000 & 10000 & 1791 \\
\hline & Desvio - Poisson & $\#$ & 190,05 & 175,54 & 154,92 & 141,42 & 100,00 & 42,32 \\
\hline & $\begin{array}{c}\text { Desvio - Poisson - } \\
\text { Relativo } \\
\end{array}$ & $\%$ & 0,5 & 0,6 & 0,6 & 0,7 & 1,0 & 2,4 \\
\hline & $\begin{array}{l}\text { Desvio padrão } \\
\text { Concentração }\end{array}$ & $\mathrm{P} / \mathrm{m}^{3}$ & $5,26 E+02$ & $9,35 E+02$ & $3,13 \mathrm{E}+03$ & $7,05 E+02$ & $7,68 \mathrm{E}+02$ & $2,98 E+02$ \\
\hline & DP/Concentração média & $\%$ & 0,0004 & 0,0009 & 0,0039 & 0,0011 & 0,0023 & 0,0050 \\
\hline \multirow{2}{*}{\multicolumn{2}{|c|}{ Erro total medições(દ) }} & $\mathrm{P} / \mathrm{m}^{3}$ & $6,33 \mathrm{E}+05$ & $5,85 E+05$ & $5,16 \mathrm{E}+05$ & $4,71 E+05$ & $3,33 \mathrm{E}+05$ & $1,41 \mathrm{E}+05$ \\
\hline & & Unidade & $1,0-2,0 \mu \mathrm{m}$ & $2,0-3,0 \mu \mathrm{m}$ & $3,0-5,0 \mu \mathrm{m}$ & $5,0-7,0 \mu \mathrm{m}$ & $7,0-10,0 \mu \mathrm{m}$ & $>10,0 \mu \mathrm{m}$ \\
\hline \multirow{8}{*}{ Assento 2D } & $\begin{array}{c}\text { Concentração média de } \\
\text { fundo }\end{array}$ & $\mathrm{P} / \mathrm{m}^{3}$ & $1,87 \mathrm{E}+05$ & $1,10 \mathrm{E}+05$ & $6,67 E+03$ & $3,33 \mathrm{E}+03$ & $0,00 E+00$ & $0,00 E+00$ \\
\hline & $\begin{array}{c}\text { Número de particulas de } \\
\text { fundo }\end{array}$ & $\mathbf{P}$ & 56 & 33 & 2 & 1 & 0 & 0 \\
\hline & $\begin{array}{c}\text { Concentração média } \\
\text { liquida }\end{array}$ & $\mathrm{P} / \mathrm{m}^{3}$ & $9,38 \mathrm{E}+07$ & $8,16 \mathrm{E}+07$ & $6,33 \mathrm{E}+07$ & $4,53 \mathrm{E}+07$ & $1,50 \mathrm{E}+07$ & $7,42 E+05$ \\
\hline & $\begin{array}{l}\text { Número de Particulas } \\
\text { média liquida }\end{array}$ & $\mathbf{P}$ & 28130 & 24483 & 19000 & 13580 & 4500 & 223 \\
\hline & Desvio - Poisson & $\#$ & 167,72 & 156,47 & 137,84 & 116,53 & 67,08 & 14,92 \\
\hline & $\begin{array}{l}\text { Desvio - Poisson - } \\
\text { Relativo }\end{array}$ & $\%$ & 0,6 & 0,6 & 0,7 & 0,9 & 1,5 & 6,7 \\
\hline & $\begin{array}{l}\text { Desvio padrão } \\
\text { Concentração }\end{array}$ & $\mathrm{P} / \mathrm{m}^{3}$ & $1,25 \mathrm{E}+03$ & $1,00 \mathrm{E}+03$ & $9,08 \mathrm{E}+02$ & $7,17 E+02$ & $5,78 E+02$ & $2,37 E+01$ \\
\hline & DP/Concentração média & $\%$ & 0,0013 & 0,0012 & 0,0014 & 0,0016 & 0,0039 & 0,0032 \\
\hline \multirow{2}{*}{\multicolumn{2}{|c|}{ Erro total medições( $(\varepsilon)$}} & $\mathrm{P} / \mathrm{m}^{3}$ & $5,59 \mathrm{E}+05$ & $5,22 \mathrm{E}+05$ & $4,59 \mathrm{E}+05$ & $3,88 \mathrm{E}+05$ & $2,24 \mathrm{E}+05$ & $4,97 E+04$ \\
\hline & & Unidade & $1,0-2,0 \mu \mathrm{m}$ & $2,0-3,0 \mu \mathrm{m}$ & $3,0-5,0 \mu \mathrm{m}$ & $5,0-7,0 \mu \mathrm{m}$ & $7,0-10,0 \mu \mathrm{m}$ & $>10,0 \mu \mathrm{m}$ \\
\hline \multirow{8}{*}{ Assento $2 \mathrm{E}$} & $\begin{array}{l}\text { Concentração média de } \\
\text { fundo }\end{array}$ & $\mathrm{P} / \mathrm{m}^{3}$ & $2,53 \mathrm{E}+05$ & $9,00 E+04$ & $3,33 \mathrm{E}+03$ & $0,00 E+00$ & $0,00 E+00$ & $0,00 E+00$ \\
\hline & $\begin{array}{c}\text { Número de particulas de } \\
\text { fundo }\end{array}$ & $\mathbf{P}$ & 76 & 27 & 1 & 0 & 0 & 0 \\
\hline & $\begin{array}{c}\text { Concentração média } \\
\text { liquida } \\
\end{array}$ & $\mathrm{P} / \mathrm{m}^{3}$ & $1,04 \mathrm{E}+08$ & $8,89 \mathrm{E}+07$ & $6,42 \mathrm{E}+07$ & $5,29 \mathrm{E}+07$ & $2,28 \mathrm{E}+07$ & $6,87 E+05$ \\
\hline & $\begin{array}{l}\text { Número de Particulas } \\
\text { média liquida }\end{array}$ & $\mathbf{P}$ & 31213 & 26684 & 19250 & 15870 & 6854 & 206 \\
\hline & Desvio - Poisson & $\#$ & 176,67 & 163,35 & 138,74 & 125,98 & 82,79 & 14,35 \\
\hline & $\begin{array}{c}\text { Desvio - Poisson - } \\
\text { Relativo } \\
\end{array}$ & $\%$ & 0,6 & 0,6 & 0,7 & 0,8 & 1,2 & 7,0 \\
\hline & $\begin{array}{l}\text { Desvio padrão } \\
\text { Concentração }\end{array}$ & $\mathrm{P} / \mathrm{m}^{3}$ & $4,06 \mathrm{E}+02$ & $2,37 E+03$ & $1,13 E+03$ & $9,11 E+02$ & $1,22 \mathrm{E}+03$ & $3,89 \mathrm{E}+01$ \\
\hline & DP/Concentração média & $\%$ & 0,0004 & 0,0027 & 0,0018 & 0,0017 & 0,0054 & 0,0057 \\
\hline \multicolumn{2}{|c|}{ Erro total medições(દ) } & $\mathrm{P} / \mathrm{m}^{3}$ & $5,89 \mathrm{E}+05$ & $5,45 \mathrm{E}+05$ & $4,62 \mathrm{E}+05$ & $4,20 E+05$ & $2,76 \mathrm{E}+05$ & $4,78 \mathrm{E}+04$ \\
\hline
\end{tabular}




\begin{tabular}{|c|c|c|c|c|c|c|c|c|}
\hline & & Unidade & $1,0-2,0 \mu \mathrm{m}$ & $2,0-3,0 \mu \mathrm{m}$ & $3,0-5,0 \mu \mathrm{m}$ & $5,0-7,0 \mu \mathrm{m}$ & $7,0-10,0 \mu \mathrm{m}$ & $>10,0 \mu \mathrm{m}$ \\
\hline \multirow{8}{*}{ Assento 1D } & $\begin{array}{c}\text { Concentração média de } \\
\text { fundo }\end{array}$ & $\mathrm{P} / \mathrm{m}^{3}$ & $7,67 E+04$ & $2,00 E+04$ & $3,33 E+03$ & $0,00 E+00$ & $0,00 E+00$ & $0,00 E+00$ \\
\hline & $\begin{array}{c}\text { Número de particulas de } \\
\text { fundo }\end{array}$ & $\mathbf{p}$ & 23 & 6 & 1 & 0 & 0 & 0 \\
\hline & $\begin{array}{c}\text { Concentração média } \\
\text { liquida }\end{array}$ & $\mathrm{P} / \mathrm{m}^{3}$ & $1,02 E+08$ & $7,38 \mathrm{E}+07$ & $5,85 E+07$ & $3,53 E+07$ & $1,00 E+07$ & $4,12 E+05$ \\
\hline & $\begin{array}{c}\text { Número de Particulas } \\
\text { média liquida }\end{array}$ & $\mathbf{P}$ & 30516 & 22128 & 17560 & 10584 & 2999 & 124 \\
\hline & Desvio - Poisson & $\#$ & 174,687885 & 148,756272 & 132,5141502 & 102,8785692 & 54,7631263 & 11,1130554 \\
\hline & $\begin{array}{c}\text { Desvio - Poisson - } \\
\text { Relativo }\end{array}$ & $\%$ & 0,6 & 0,7 & 0,8 & 1,0 & 1,8 & 9,0 \\
\hline & $\begin{array}{l}\text { Desvio padrão } \\
\text { Concentração }\end{array}$ & $\mathrm{P} / \mathrm{m}^{3}$ & $2,31 E+02$ & $1,72 \mathrm{E}+03$ & $9,73 E+02$ & $6,13 E+02$ & $5,15 E+02$ & $1,27 E+01$ \\
\hline & DP/Concentração média & $\%$ & 0,0002 & 0,0023 & 0,0017 & 0,0017 & 0,0052 & 0,0031 \\
\hline \multirow{2}{*}{\multicolumn{2}{|c|}{ Erro total medições(દ) }} & $\mathrm{P} / \mathrm{m}^{3}$ & $5,82 E+05$ & $4,96 \mathrm{E}+05$ & $4,42 E+05$ & $3,43 E+05$ & $1,83 \mathrm{E}+05$ & $3,70 E+04$ \\
\hline & & Unidade & $1,0-2,0 \mu \mathrm{m}$ & $2,0-3,0 \mu \mathrm{m}$ & $3,0-5,0 \mu \mathrm{m}$ & $5,0-7,0 \mu \mathrm{m}$ & $7,0-10,0 \mu \mathrm{m}$ & $>10,0 \mu \mathrm{m}$ \\
\hline \multirow{8}{*}{ Assento 1E } & $\begin{array}{c}\text { Concentração média de } \\
\text { fundo }\end{array}$ & $\mathrm{P} / \mathrm{m}^{3}$ & $9,67 E+04$ & $3,67 E+04$ & $3,33 \mathrm{E}+03$ & $0,00 E+00$ & $0,00 E+00$ & $0,00 E+00$ \\
\hline & $\begin{array}{c}\text { Número de particulas de } \\
\text { fundo }\end{array}$ & $\mathbf{p}$ & 29 & 11 & 1 & 0 & 0 & 0 \\
\hline & $\begin{array}{c}\text { Concentração média } \\
\text { liquida }\end{array}$ & $\mathrm{P} / \mathrm{m}^{3}$ & $1,09 \mathrm{E}+08$ & $1,07 E+08$ & $5,30 \mathrm{E}+07$ & $2,66 \mathrm{E}+07$ & 1,87E+06 & $3,40 E+05$ \\
\hline & $\begin{array}{l}\text { Número de Particulas } \\
\text { média liquida }\end{array}$ & $\mathbf{P}$ & 32744 & 32037 & 15890 & 7985 & 560 & 102 \\
\hline & Desvio - Poisson & $\#$ & 180,95 & 178,99 & 126,06 & 89,36 & 23,66 & 10,10 \\
\hline & $\begin{array}{c}\text { Desvio - Poisson - } \\
\text { Relativo } \\
\end{array}$ & $\%$ & 0,6 & 0,6 & 0,8 & 1,1 & 4,2 & 9,9 \\
\hline & $\begin{array}{l}\text { Desvio padrão } \\
\text { Concentração }\end{array}$ & $\mathrm{P} / \mathrm{m}^{3}$ & $1,51 \mathrm{E}+03$ & $1,46 \mathrm{E}+03$ & $1,25 \mathrm{E}+03$ & $1,17 E+03$ & $3,85 E+01$ & $1,06 \mathrm{E}+01$ \\
\hline & DP/Concentração média & $\%$ & 0,0014 & 0,0014 & 0,0024 & 0,0044 & 0,0021 & 0,0031 \\
\hline \multirow{2}{*}{\multicolumn{2}{|c|}{ Erro total medições( $(\varepsilon)$}} & $\mathrm{P} / \mathrm{m}^{3}$ & $6,03 E+05$ & $5,97 \mathrm{E}+05$ & $4,20 E+05$ & $2,98 \mathrm{E}+05$ & $7,89 \mathrm{E}+04$ & $3,37 \mathrm{E}+04$ \\
\hline & & Unidade & $1,0-2,0 \mu \mathrm{m}$ & $2,0-3,0 \mu \mathrm{m}$ & $3,0-5,0 \mu \mathrm{m}$ & $5,0-7,0 \mu \mathrm{m}$ & $7,0-10,0 \mu \mathrm{m}$ & $>10,0 \mu \mathrm{m}$ \\
\hline \multirow{8}{*}{ Assento $1 \mathrm{~B}$} & $\begin{array}{c}\text { Concentração média de } \\
\text { fundo }\end{array}$ & $\mathrm{P} / \mathrm{m}^{3}$ & $1,47 E+05$ & $5,00 E+04$ & $5,00 E+03$ & $0,00 E+00$ & $0,00 E+00$ & $0,00 E+00$ \\
\hline & $\begin{array}{c}\text { Número de particulas de } \\
\text { fundo }\end{array}$ & $\mathbf{p}$ & 44 & 15 & 2 & 0 & 0 & 0 \\
\hline & $\begin{array}{l}\text { Concentração média } \\
\text { liquida }\end{array}$ & $\mathrm{P} / \mathrm{m}^{3}$ & $9,51 E+07$ & $9,33 E+07$ & $6,98 \mathrm{E}+07$ & $3,31 \mathrm{E}+07$ & $5,33 E+06$ & $2,87 E+05$ \\
\hline & $\begin{array}{l}\text { Número de Particulas } \\
\text { média liquida }\end{array}$ & $\mathbf{p}$ & 28526 & 28001 & 20931 & 9931 & 1599 & 86 \\
\hline & Desvio - Poisson & $\#$ & 168,90 & 167,33 & 144,68 & 99,65 & 39,99 & 9,27 \\
\hline & $\begin{array}{c}\text { Desvio - Poisson - } \\
\text { Relativo }\end{array}$ & $\%$ & 0,6 & 0,6 & 0,7 & 1,0 & 2,5 & 10,8 \\
\hline & $\begin{array}{l}\text { Desvio padrão } \\
\text { Concentração }\end{array}$ & $\mathrm{P} / \mathrm{m}^{3}$ & $8,91 \mathrm{E}+02$ & $8,54 \mathrm{E}+02$ & $5,93 \mathrm{E}+02$ & $4,91 E+02$ & $9,41 E+01$ & $1,01 E+01$ \\
\hline & DP/Concentração média & $\%$ & 0,0009 & 0,0009 & 0,0008 & 0,0015 & 0,0018 & 0,0035 \\
\hline \multicolumn{2}{|c|}{ Erro total medições $(\varepsilon)$} & $\mathrm{P} / \mathrm{m}^{3}$ & $5,63 E+05$ & $5,58 \mathrm{E}+05$ & $4,82 E+05$ & $3,32 E+05$ & $1,33 E+05$ & $3,09 E+04$ \\
\hline
\end{tabular}




\begin{tabular}{|c|c|c|c|c|c|c|c|c|}
\hline & & Unidade & $1,0-2,0 \mu \mathrm{m}$ & $2,0-3,0 \mu \mathrm{m}$ & $3,0-5,0 \mu \mathrm{m}$ & $5,0-7,0 \mu \mathrm{m}$ & $7,0-10,0 \mu \mathrm{m}$ & $>10,0 \mu \mathrm{m}$ \\
\hline \multirow{8}{*}{ Assento $1 \mathrm{~A}$} & $\begin{array}{c}\text { Concentração média de } \\
\text { fundo }\end{array}$ & $\mathrm{P} / \mathrm{m}^{3}$ & $1,70 \mathrm{E}+05$ & $7,67 E+04$ & $8,33 E+03$ & $0,00 \mathrm{E}+00$ & $0,00 \mathrm{E}+00$ & $0,00 E+00$ \\
\hline & $\begin{array}{c}\text { Número de particulas de } \\
\text { fundo }\end{array}$ & $\mathbf{P}$ & 51 & 23 & 3 & 0 & 0 & 0 \\
\hline & $\begin{array}{l}\text { Concentração média } \\
\text { liquida }\end{array}$ & $\mathrm{P} / \mathrm{m}^{3}$ & $3,93 \mathrm{E}+07$ & $2,39 \mathrm{E}+07$ & $1,62 \mathrm{E}+07$ & $8,49 \mathrm{E}+06$ & $1,75 E+06$ & $3,45 E+05$ \\
\hline & $\begin{array}{c}\text { Número de Particulas } \\
\text { média liquida }\end{array}$ & $\mathbf{p}$ & 11801 & 7169 & 4852 & 2546 & 526 & 104 \\
\hline & Desvio - Poisson & $\#$ & 108,63 & 84,67 & 69,66 & 50,46 & 22,93 & 10,17 \\
\hline & $\begin{array}{c}\text { Desvio - Poisson - } \\
\text { Relativo }\end{array}$ & $\%$ & 0,9 & 1,2 & 1,4 & 2,0 & 4,4 & 9,8 \\
\hline & $\begin{array}{l}\text { Desvio padrão } \\
\text { Concentração } \\
\end{array}$ & $\mathrm{P} / \mathrm{m}^{3}$ & $4,28 \mathrm{E}+02$ & $5,52 E+02$ & $5,17 E+02$ & $6,92 \mathrm{E}+01$ & $8,98 \mathrm{E}+01$ & $3,75 \mathrm{E}+01$ \\
\hline & DP/Concentração média & $\%$ & 0,0011 & 0,0023 & 0,0032 & 0,0008 & 0,0051 & 0,0109 \\
\hline \multirow{2}{*}{\multicolumn{2}{|c|}{ Erro total medições(દ) }} & $\mathrm{P} / \mathrm{m}^{3}$ & $3,62 E+05$ & $2,82 \mathrm{E}+05$ & $2,32 \mathrm{E}+05$ & $1,68 \mathrm{E}+05$ & $7,64 \mathrm{E}+04$ & $3,39 \mathrm{E}+04$ \\
\hline & & Unidade & $1,0-2,0 \mu \mathrm{m}$ & $2,0-3,0 \mu \mathrm{m}$ & $3,0-5,0 \mu \mathrm{m}$ & $5,0-7,0 \mu \mathrm{m}$ & $7,0-10,0 \mu \mathrm{m}$ & $>10,0 \mu \mathrm{m}$ \\
\hline \multirow{8}{*}{ Assento 2B } & $\begin{array}{c}\text { Concentração média de } \\
\text { fundo }\end{array}$ & $\mathrm{P} / \mathrm{m}^{3}$ & $1,13 \mathrm{E}+05$ & $2,33 E+04$ & $8,33 \mathrm{E}+03$ & $0,00 E+00$ & $0,00 E+00$ & $0,00 E+00$ \\
\hline & $\begin{array}{c}\text { Número de particulas de } \\
\text { fundo }\end{array}$ & $\mathbf{P}$ & 34 & 7 & 3 & 0 & 0 & 0 \\
\hline & \begin{tabular}{|c|}
$\begin{array}{c}\text { Concentração média } \\
\text { liquida }\end{array}$ \\
\end{tabular} & $\mathrm{P} / \mathrm{m}^{3}$ & $6,78 \mathrm{E}+07$ & $4,79 E+07$ & $3,36 \mathrm{E}+07$ & $1,96 \mathrm{E}+07$ & $1,45 \mathrm{E}+07$ & $6,18 \mathrm{E}+05$ \\
\hline & $\begin{array}{l}\text { Número de Particulas } \\
\text { média liquida }\end{array}$ & $\mathbf{P}$ & 20354 & 14370 & 10078 & 5870 & 4350 & 186 \\
\hline & Desvio - Poisson & $\#$ & 142,67 & 119,87 & 100,39 & 76,62 & 65,95 & 13,62 \\
\hline & $\begin{array}{c}\text { Desvio - Poisson - } \\
\text { Relativo } \\
\end{array}$ & $\%$ & 0,7 & 0,8 & 1,0 & 1,3 & 1,5 & 7,3 \\
\hline & $\begin{array}{c}\text { Desvio padrão } \\
\text { Concentração } \\
\end{array}$ & $\mathrm{P} / \mathrm{m}^{3}$ & $8,67 \mathrm{E}+02$ & $8,43 E+02$ & $7,23 E+02$ & $5,75 E+02$ & $9,19 E+02$ & $3,02 E+01$ \\
\hline & DP/Concentração média & $\%$ & 0,0013 & 0,0018 & 0,0022 & 0,0029 & 0,0063 & 0,0049 \\
\hline \multirow{2}{*}{\multicolumn{2}{|c|}{ 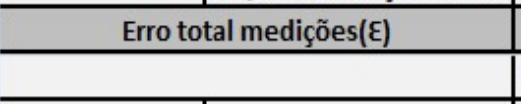 }} & $\mathrm{P} / \mathrm{m}^{3}$ & $4,76 E+05$ & $4,00 E+05$ & $3,35 \mathrm{E}+05$ & $2,55 E+05$ & $2,20 E+05$ & $4,54 \mathrm{E}+04$ \\
\hline & & Unidade & $1,0-2,0 \mu \mathrm{m}$ & $2,0-3,0 \mu \mathrm{m}$ & $3,0-5,0 \mu \mathrm{m}$ & $5,0-7,0 \mu \mathrm{m}$ & $7,0-10,0 \mu \mathrm{m}$ & $>10,0 \mu \mathrm{m}$ \\
\hline \multirow{8}{*}{ Assento $2 \mathrm{~A}$} & $\begin{array}{c}\text { Concentração média de } \\
\text { fundo }\end{array}$ & $\mathrm{P} / \mathrm{m}^{3}$ & $1,03 E+05$ & $5,67 E+04$ & $8,33 \mathrm{E}+03$ & $0,00 \mathrm{E}+00$ & $0,00 E+00$ & $0,00 E+00$ \\
\hline & $\begin{array}{c}\begin{array}{c}\text { Número de particulas de } \\
\text { fundo }\end{array} \\
\end{array}$ & $\mathbf{p}$ & 31 & 17 & 3 & 0 & 0 & 0 \\
\hline & $\begin{array}{c}\text { Concentração média } \\
\text { liquida }\end{array}$ & $\mathrm{P} / \mathrm{m}^{3}$ & $3,22 \mathrm{E}+07$ & $2,06 \mathrm{E}+07$ & $1,20 E+07$ & $8,49 E+06$ & $2,82 E+06$ & $6,15 E+05$ \\
\hline & $\begin{array}{c}\text { Número de Particulas } \\
\text { média liquida }\end{array}$ & $\mathbf{P}$ & 9670 & 6183 & 3589 & 2548 & 847 & 185 \\
\hline & Desvio - Poisson & $\#$ & 98,34 & 78,63 & 59,91 & 50,48 & 29,10 & 13,58 \\
\hline & $\begin{array}{c}\text { Desvio - Poisson - } \\
\text { Relativo } \\
\end{array}$ & $\%$ & 1,0 & 1,3 & 1,7 & 2,0 & 3,4 & 7,4 \\
\hline & \begin{tabular}{|l|} 
Desvio padrão \\
Concentração \\
\end{tabular} & $\mathrm{P} / \mathrm{m}^{3}$ & $8,12 \mathrm{E}+02$ & $5,62 E+02$ & $6,95 E+02$ & $2,66 \mathrm{E}+02$ & $1,07 \mathrm{E}+02$ & $3,91 \mathrm{E}+01$ \\
\hline & DP/Concentração média & $\%$ & 0,0025 & 0,0027 & 0,0058 & 0,0031 & 0,0038 & 0,0064 \\
\hline \multicolumn{2}{|c|}{ Erro total medições( $\varepsilon)$} & $\mathrm{P} / \mathrm{m}^{3}$ & $3,28 \mathrm{E}+05$ & $2,62 E+05$ & $2,00 E+05$ & $1,68 \mathrm{E}+05$ & $9,70 E+04$ & $4,53 E+04$ \\
\hline
\end{tabular}




\begin{tabular}{|c|c|c|c|c|c|c|c|c|}
\hline & & Unidade & $1,0-2,0 \mu \mathrm{m}$ & $2,0-3,0 \mu \mathrm{m}$ & $3,0-5,0 \mu \mathrm{m}$ & $5,0-7,0 \mu \mathrm{m}$ & $7,0-10,0 \mu \mathrm{m}$ & $>10,0 \mu \mathrm{m}$ \\
\hline \multirow{8}{*}{ Assento 3B } & $\begin{array}{c}\text { Concentração média de } \\
\text { fundo }\end{array}$ & $\mathrm{P} / \mathrm{m}^{3}$ & $2,27 E+05$ & $6,33 E+04$ & $3,33 E+03$ & $0,00 \mathrm{E}+00$ & $0,00 \mathrm{E}+00$ & $0,00 E+00$ \\
\hline & $\begin{array}{c}\text { Número de particulas de } \\
\text { fundo }\end{array}$ & $\mathbf{P}$ & 68 & 19 & 1 & 0 & 0 & 0 \\
\hline & $\begin{array}{l}\text { Concentração média } \\
\text { liquida }\end{array}$ & $\mathrm{P} / \mathrm{m}^{3}$ & $5,21 E+07$ & $4,24 \mathrm{E}+07$ & $3,41 E+07$ & $3,51 \mathrm{E}+07$ & $2,49 E+07$ & $9,93 E+05$ \\
\hline & $\begin{array}{c}\text { Número de Particulas } \\
\text { média liquida }\end{array}$ & $\mathbf{P}$ & 15619 & 12728 & 10230 & 10520 & 7464 & 298 \\
\hline & Desvio - Poisson & $\#$ & 124,98 & 112,82 & 101,14 & 102,57 & 86,39 & 17,26 \\
\hline & $\begin{array}{l}\text { Desvio - Poisson - } \\
\text { Relativo }\end{array}$ & $\%$ & 0,8 & 0,9 & 1,0 & 1,0 & 1,2 & 5,8 \\
\hline & $\begin{array}{l}\text { Desvio padrão } \\
\text { Concentração } \\
\end{array}$ & $\mathrm{P} / \mathrm{m}^{3}$ & $3,95 E+02$ & $1,53 \mathrm{E}+03$ & $1,10 \mathrm{E}+03$ & $1,89 \mathrm{E}+02$ & $4,51 E+02$ & $1,21 \mathrm{E}+02$ \\
\hline & DP/Concentração média & $\%$ & 0,0008 & 0,0036 & 0,0032 & 0,0005 & 0,0018 & 0,0122 \\
\hline \multirow{2}{*}{\multicolumn{2}{|c|}{ Erro total medições( $(\varepsilon)$}} & $\mathrm{P} / \mathrm{m}^{3}$ & $4,17 E+05$ & $3,76 \mathrm{E}+05$ & $3,37 \mathrm{E}+05$ & $3,42 E+05$ & $2,88 \mathrm{E}+05$ & $5,75 E+04$ \\
\hline & & Unidade & $1,0-2,0 \mu \mathrm{m}$ & $2,0-3,0 \mu \mathrm{m}$ & $3,0-5,0 \mu \mathrm{m}$ & $5,0-7,0 \mu \mathrm{m}$ & $7,0-10,0 \mu \mathrm{m}$ & $>10,0 \mu \mathrm{m}$ \\
\hline \multirow{8}{*}{ Assento $3 \mathrm{~A}$} & $\begin{array}{c}\text { Concentração média de } \\
\text { fundo }\end{array}$ & $\mathrm{P} / \mathrm{m}^{3}$ & $7,00 E+04$ & $3,33 E+04$ & $6,67 E+03$ & $0,00 E+00$ & $0,00 E+00$ & $0,00 \mathrm{E}+00$ \\
\hline & $\begin{array}{c}\text { Número de particulas de } \\
\text { fundo }\end{array}$ & $\mathbf{P}$ & 21 & 10 & 2 & 0 & 0 & 0 \\
\hline & $\begin{array}{c}\text { Concentração média } \\
\text { liquida }\end{array}$ & $\mathrm{P} / \mathrm{m}^{3}$ & $6,34 \mathrm{E}+07$ & $5,45 \mathrm{E}+07$ & $3,51 \mathrm{E}+07$ & $3,23 E+07$ & $2,33 E+07$ & $3,33 \mathrm{E}+05$ \\
\hline & $\begin{array}{c}\text { Número de Particulas } \\
\text { média liquida }\end{array}$ & $\mathbf{P}$ & 19008 & 16358 & 10524 & 9698 & 7000 & 100 \\
\hline & Desvio - Poisson & $\#$ & 137,87 & 127,90 & 102,59 & 98,48 & 83,67 & 10,00 \\
\hline & $\begin{array}{l}\text { Desvio - Poisson - } \\
\text { Relativo }\end{array}$ & $\%$ & 0,7 & 0,8 & 1,0 & 1,0 & 1,2 & 10,0 \\
\hline & $\begin{array}{c}\text { Desvio padrão } \\
\text { Concentração } \\
\end{array}$ & $\mathrm{P} / \mathrm{m}^{3}$ & $9,20 \mathrm{E}+02$ & $4,07 E+02$ & $2,25 E+03$ & $1,48 \mathrm{E}+03$ & $7,60 \mathrm{E}+02$ & $4,58 \mathrm{E}+01$ \\
\hline & DP/Concentração média & $\%$ & 0,0015 & 0,0007 & 0,0064 & 0,0046 & 0,0033 & 0,0137 \\
\hline \multicolumn{2}{|c|}{ Erro total medições(દ) } & $\mathrm{P} / \mathrm{m}^{3}$ & $4,60 E+05$ & $4,26 E+05$ & $3,42 \mathrm{E}+05$ & $3,28 E+05$ & $2,79 E+05$ & $3,33 \mathrm{E}+04$ \\
\hline
\end{tabular}


Tabela B-10. Resultados das medições de partículas no assento (Sistema MV à $22^{\circ} \mathrm{C}$ - injeção pelo assento $3 \mathrm{~A}$ )

\begin{tabular}{|c|c|c|c|c|c|c|c|c|}
\hline & & Unidade & $1,0-2,0 \mu \mathrm{m}$ & $2,0-3,0 \mu \mathrm{m}$ & $3,0-5,0 \mu \mathrm{m}$ & $5,0-7,0 \mu \mathrm{m}$ & $7,0-10,0 \mu \mathrm{m}$ & $>10,0 \mu \mathrm{m}$ \\
\hline \multirow{8}{*}{ Assento 3D } & $\begin{array}{l}\text { Concentração média de } \\
\text { fundo }\end{array}$ & $\mathrm{P} / \mathrm{m}^{3}$ & $1,50 \mathrm{E}+05$ & $4,00 E+04$ & $3,33 \mathrm{E}+03$ & $0,00 E+00$ & $0,00 E+00$ & $0,00 \mathrm{E}+00$ \\
\hline & $\begin{array}{c}\text { Número de particulas de } \\
\text { fundo }\end{array}$ & $\mathbf{P}$ & 45 & 12 & 1 & 0 & 0 & 0 \\
\hline & $\begin{array}{l}\text { Concentração média } \\
\text { liquida }\end{array}$ & $\mathrm{P} / \mathrm{m}^{3}$ & $8,87 E+00$ & $8,06 \mathrm{E}+00$ & $6,27 \mathrm{E}+00$ & $8,37 \mathrm{E}+07$ & $3,68 \mathrm{E}+07$ & $1,38 \mathrm{E}+06$ \\
\hline & $\begin{array}{l}\text { Número de Particulas } \\
\text { média liquida }\end{array}$ & $\mathbf{P}$ & 45244 & 41065 & 31985 & 25120 & 11052 & 414 \\
\hline & Desvio - Poisson & $\#$ & 212,71 & 202,65 & 178,84 & 158,49 & 105,13 & 20,35 \\
\hline & $\begin{array}{l}\text { Desvio - Poisson - } \\
\text { Relativo } \\
\end{array}$ & $\%$ & 0,5 & 0,5 & 0,6 & 0,6 & 1,0 & 4,9 \\
\hline & $\begin{array}{l}\text { Desvio padrão } \\
\text { Concentração }\end{array}$ & $\mathrm{P} / \mathrm{m}^{3}$ & $9,78 \mathrm{E}+03$ & $1,18 \mathrm{E}+03$ & $1,29 \mathrm{E}+03$ & $1,75 \mathrm{E}+03$ & $4,56 \mathrm{E}+03$ & $1,20 \mathrm{E}+02$ \\
\hline & DP/Concentração média & $\%$ & 110184,8687 & 14638,7377 & 20577,4685 & 0,0021 & 0,0124 & 0,0087 \\
\hline \multirow{2}{*}{\multicolumn{2}{|c|}{ Erro total medições(દ) }} & $\mathrm{P} / \mathrm{m}^{3}$ & $7,09 \mathrm{E}+05$ & $6,75 E+05$ & $5,96 \mathrm{E}+05$ & $5,28 E+05$ & $3,50 \mathrm{E}+05$ & $6,78 \mathrm{E}+04$ \\
\hline & & Unidade & $1,0-2,0 \mu \mathrm{m}$ & $2,0-3,0 \mu \mathrm{m}$ & $3,0-5,0 \mu \mathrm{m}$ & $5,0-7,0 \mu \mathrm{m}$ & $7,0-10,0 \mu \mathrm{m}$ & $>10,0 \mu \mathrm{m}$ \\
\hline \multirow{8}{*}{ Assento 2D } & $\begin{array}{l}\text { Concentração média de } \\
\text { fundo }\end{array}$ & $\mathrm{P} / \mathrm{m}^{3}$ & $1,10 \mathrm{E}+05$ & $3,33 E+04$ & $6,67 E+03$ & $0,00 E+00$ & $0,00 E+00$ & $0,00 E+00$ \\
\hline & $\begin{array}{c}\text { Número de particulas de } \\
\text { fundo }\end{array}$ & $\mathbf{P}$ & 33 & 10 & 2 & 0 & 0 & 0 \\
\hline & $\begin{array}{c}\text { Concentração média } \\
\text { liquida } \\
\end{array}$ & $\mathrm{P} / \mathrm{m}^{3}$ & $1,04 \mathrm{E}+08$ & $9,80 E+07$ & $8,30 \mathrm{E}+07$ & $4,80 \mathrm{E}+07$ & $1,85 \mathrm{E}+07$ & $1,17 \mathrm{E}+05$ \\
\hline & $\begin{array}{l}\text { Número de Particulas } \\
\text { média liquida }\end{array}$ & $\mathbf{p}$ & 31244 & 29412 & 24899 & 14396 & 5541 & 35 \\
\hline & Desvio - Poisson & $\#$ & 176,76 & 171,50 & 157,79 & 119,98 & 74,44 & 5,92 \\
\hline & $\begin{array}{l}\text { Desvio - Poisson - } \\
\text { Relativo }\end{array}$ & $\%$ & 0,6 & 0,6 & 0,6 & 0,8 & 1,3 & 16,9 \\
\hline & $\begin{array}{l}\text { Desvio padrão } \\
\text { Concentração }\end{array}$ & $\mathrm{P} / \mathrm{m}^{3}$ & $4,77 E+03$ & $6,58 \mathrm{E}+03$ & $2,49 \mathrm{E}+03$ & $1,08 \mathrm{E}+03$ & $2,04 E+03$ & $6,99 \mathrm{E}+00$ \\
\hline & DP/Concentração média & $\%$ & 0,0046 & 0,0067 & 0,0030 & 0,0023 & 0,0110 & 0,0060 \\
\hline \multirow{2}{*}{\multicolumn{2}{|c|}{ Erro total medições(દ) }} & $\mathrm{P} / \mathrm{m}^{3}$ & $5,89 \mathrm{E}+05$ & $5,72 E+05$ & $5,26 \mathrm{E}+05$ & $4,00 E+05$ & $2,48 \mathrm{E}+05$ & $1,97 \mathrm{E}+04$ \\
\hline & & Unidade & $1,0-2,0 \mu \mathrm{m}$ & $2,0-3,0 \mu \mathrm{m}$ & $3,0-5,0 \mu \mathrm{m}$ & $5,0-7,0 \mu \mathrm{m}$ & $7,0-10,0 \mu \mathrm{m}$ & $>10,0 \mu \mathrm{m}$ \\
\hline \multirow{8}{*}{ Assento $2 \mathrm{E}$} & $\begin{array}{l}\text { Concentração média de } \\
\text { fundo }\end{array}$ & $\mathrm{P} / \mathrm{m}^{3}$ & $1,87 E+05$ & $1,13 E+05$ & $6,67 \mathrm{E}+03$ & $0,00 E+00$ & $0,00 \mathrm{E}+00$ & $0,00 \mathrm{E}+00$ \\
\hline & $\begin{array}{c}\text { Número de particulas de } \\
\text { fundo }\end{array}$ & $\mathbf{P}$ & 56 & 34 & 2 & 0 & 0 & 0 \\
\hline & $\begin{array}{c}\text { Concentração média } \\
\text { liquida }\end{array}$ & $\mathrm{P} / \mathrm{m}^{3}$ & $1,09 \mathrm{E}+08$ & $1,03 E+08$ & $8,80 \mathrm{E}+07$ & $7,19 \mathrm{E}+07$ & $3,75 \mathrm{E}+07$ & $3,73 E+05$ \\
\hline & $\begin{array}{c}\text { Número de Particulas } \\
\text { média liquida }\end{array}$ & $\mathbf{P}$ & 32587 & 30759 & 26410 & 21558 & 11250 & 112 \\
\hline & Desvio - Poisson & $\#$ & 180,52 & 175,38 & 162,51 & 146,83 & 106,07 & 10,58 \\
\hline & $\begin{array}{l}\text { Desvio - Poisson - } \\
\text { Relativo }\end{array}$ & $\%$ & 0,6 & 0,6 & 0,6 & 0,7 & 0,9 & 9,4 \\
\hline & $\begin{array}{l}\text { Desvio padrão } \\
\text { Concentração }\end{array}$ & $\mathrm{P} / \mathrm{m}^{3}$ & $6,70 \mathrm{E}+03$ & $1,05 E+04$ & $1,93 E+03$ & $3,15 E+03$ & $1,96 \mathrm{E}+03$ & $4,18 \mathrm{E}+01$ \\
\hline & DP/Concentração média & $\%$ & 0,0062 & 0,0103 & 0,0022 & 0,0044 & 0,0052 & 0,0112 \\
\hline \multicolumn{2}{|c|}{ Erro total medições(દ) } & $\mathrm{P} / \mathrm{m}^{3}$ & $6,02 E+05$ & $5,85 E+05$ & $5,42 E+05$ & $4,89 E+05$ & $3,54 E+05$ & $3,53 E+04$ \\
\hline
\end{tabular}


| Unidade $1,0-2,0 \mu \mathrm{m}|2,0-3,0 \mu \mathrm{m}| 3,0-5,0 \mu \mathrm{m}|5,0-7,0 \mu \mathrm{m}| 7,0-10,0 \mu \mathrm{m} \mid>10,0 \mu \mathrm{m}$

\begin{tabular}{|c|c|c|c|c|c|c|c|c|}
\hline \multirow{8}{*}{ Assento 1D } & $\begin{array}{c}\text { Concentração média de } \\
\text { fundo }\end{array}$ & $\mathrm{P} / \mathrm{m}^{3}$ & $2,23 E+05$ & $1,07 E+05$ & $3,33 E+03$ & $0,00 \mathrm{E}+00$ & $0,00 E+00$ & $0,00 E+00$ \\
\hline & $\begin{array}{c}\text { Número de particulas de } \\
\text { fundo }\end{array}$ & $\mathbf{P}$ & 67 & 32 & 1 & 0 & 0 & 0 \\
\hline & $\begin{array}{l}\text { Concentração média } \\
\text { liquida }\end{array}$ & $\mathrm{P} / \mathrm{m}^{3}$ & $9,83 E+07$ & $8,85 \mathrm{E}+07$ & $7,85 \mathrm{E}+07$ & $3,84 \mathrm{E}+07$ & $2,34 \mathrm{E}+07$ & $6,00 E+04$ \\
\hline & $\begin{array}{l}\text { Número de Particulas } \\
\text { média liquida }\end{array}$ & $\mathbf{p}$ & 29491 & 26552 & 23560 & 11520 & 7012 & 18 \\
\hline & Desvio - Poisson & \# & 171,73 & 162,95 & 153,49 & 107,33 & 83,74 & 4,24 \\
\hline & $\begin{array}{l}\text { Desvio - Poisson - } \\
\text { Relativo }\end{array}$ & $\%$ & 0,6 & 0,6 & 0,7 & 0,9 & 1,2 & 23,6 \\
\hline & $\begin{array}{l}\text { Desvio padrão } \\
\text { Concentração }\end{array}$ & $\mathrm{P} / \mathrm{m}^{3}$ & $8,86 \mathrm{E}+03$ & $1,53 \mathrm{E}+03$ & $2,28 \mathrm{E}+03$ & $8,99 \mathrm{E}+02$ & $7,53 \mathrm{E}+02$ & $3,10 \mathrm{E}+00$ \\
\hline & DP/Concentração média & $\%$ & 0,0090 & 0,0017 & 0,0029 & 0,0023 & 0,0032 & 0,0052 \\
\hline \multirow{2}{*}{\multicolumn{2}{|c|}{ Erro total medições( $\varepsilon)$}} & $\mathrm{P} / \mathrm{m}^{3}$ & $5,73 E+05$ & $5,43 E+05$ & $5,12 \mathrm{E}+05$ & $3,58 \mathrm{E}+05$ & $2,79 \mathrm{E}+05$ & $1,41 \mathrm{E}+04$ \\
\hline & & Unidade & $1,0-2,0 \mu \mathrm{m}$ & $2,0-3,0 \mu \mathrm{m}$ & $3,0-5,0 \mu \mathrm{m}$ & $5,0-7,0 \mu \mathrm{m}$ & $7,0-10,0 \mu \mathrm{m}$ & $>10,0 \mu \mathrm{m}$ \\
\hline \multirow{8}{*}{ Assento $1 \mathrm{E}$} & $\begin{array}{c}\text { Concentração média de } \\
\text { fundo }\end{array}$ & $\mathrm{P} / \mathrm{m}^{3}$ & $1,37 E+05$ & $7,33 E+04$ & $6,67 E+03$ & $0,00 E+00$ & $0,00 E+00$ & $0,00 E+00$ \\
\hline & $\begin{array}{c}\text { Número de particulas de } \\
\text { fundo }\end{array}$ & $\mathbf{P}$ & 41 & 22 & 2 & 0 & 0 & 0 \\
\hline & $\begin{array}{c}\text { Concentração média } \\
\text { liquida }\end{array}$ & $\mathrm{P} / \mathrm{m}^{3}$ & $9,52 E+07$ & $8,69 \mathrm{E}+07$ & $7,52 \mathrm{E}+07$ & $5,51 E+07$ & $1,81 E+07$ & $5,33 E+04$ \\
\hline & $\begin{array}{c}\text { Número de Particulas } \\
\text { média liquida }\end{array}$ & $\mathbf{P}$ & 28554 & 26078 & 22560 & 16542 & 5420 & 16 \\
\hline & Desvio - Poisson & $\#$ & 168,98 & 161,49 & 150,20 & 128,62 & 73,62 & 4,00 \\
\hline & $\begin{array}{c}\text { Desvio - Poisson - } \\
\text { Relativo } \\
\end{array}$ & $\%$ & 0,6 & 0,6 & 0,7 & 0,8 & 1,4 & 25,0 \\
\hline & $\begin{array}{l}\text { Desvio padrão } \\
\text { Concentração }\end{array}$ & $\mathrm{P} / \mathrm{m}^{3}$ & $1,03 E+03$ & $1,16 \mathrm{E}+03$ & $6,75 E+03$ & $2,30 E+03$ & $1,94 \mathrm{E}+03$ & $4,24 \mathrm{E}+00$ \\
\hline & DP/Concentração média & $\%$ & 0,0011 & 0,0013 & 0,0090 & 0,0042 & 0,0107 & 0,0080 \\
\hline \multirow{2}{*}{\multicolumn{2}{|c|}{ Erro total medições( $\varepsilon)$}} & $\mathrm{P} / \mathrm{m}^{3}$ & $5,63 E+05$ & $5,38 \mathrm{E}+05$ & $5,01 E+05$ & $4,29 E+05$ & $2,45 E+05$ & $1,33 \mathrm{E}+04$ \\
\hline & & Unidade & $1,0-2,0 \mu \mathrm{m}$ & $2,0-3,0 \mu \mathrm{m}$ & $3,0-5,0 \mu \mathrm{m}$ & $5,0-7,0 \mu \mathrm{m}$ & $7,0-10,0 \mu \mathrm{m}$ & $>10,0 \mu \mathrm{m}$ \\
\hline \multirow{8}{*}{ Assento 1B } & $\begin{array}{c}\text { Concentração média de } \\
\text { fundo }\end{array}$ & $\mathrm{P} / \mathrm{m}^{3}$ & $1,87 E+05$ & $1,20 \mathrm{E}+05$ & $6,67 E+03$ & $0,00 E+00$ & $0,00 E+00$ & $0,00 \mathrm{E}+00$ \\
\hline & $\begin{array}{c}\text { Número de particulas de } \\
\text { fundo }\end{array}$ & $\mathbf{P}$ & 56 & 36 & 2 & 0 & 0 & 0 \\
\hline & $\begin{array}{c}\text { Concentração média } \\
\text { liquida }\end{array}$ & $\mathrm{P} / \mathrm{m}^{3}$ & $7,16 \mathrm{E}+07$ & $6,47 E+07$ & $5,52 E+07$ & $2,35 E+07$ & $7,85 E+06$ & $4,33 E+04$ \\
\hline & $\begin{array}{l}\text { Número de Particulas } \\
\text { média liquida }\end{array}$ & $\mathbf{P}$ & 21489 & 19395 & 16547 & 7052 & 2356 & 13 \\
\hline & Desvio - Poisson & $\#$ & 146,59 & 139,27 & 128,64 & 83,98 & 48,54 & 3,61 \\
\hline & $\begin{array}{c}\text { Desvio - Poisson - } \\
\text { Relativo } \\
\end{array}$ & $\%$ & 0,7 & 0,7 & 0,8 & 1,2 & 2,1 & 27,7 \\
\hline & $\begin{array}{l}\text { Desvio padrão } \\
\text { Concentração }\end{array}$ & $\mathrm{P} / \mathrm{m}^{3}$ & $2,45 E+02$ & $4,52 E+02$ & $1,82 \mathrm{E}+03$ & $9,83 E+02$ & $3,58 \mathrm{E}+02$ & $4,14 \mathrm{E}+00$ \\
\hline & DP/Concentração média & $\%$ & 0,0003 & 0,0007 & 0,0033 & 0,0042 & 0,0046 & 0,0095 \\
\hline \multicolumn{2}{|c|}{ Erro total medições( $(\varepsilon)$} & $\mathrm{P} / \mathrm{m}^{3}$ & $4,89 E+05$ & $4,64 \mathrm{E}+05$ & $4,29 E+05$ & $2,80 E+05$ & $1,62 E+05$ & $1,20 E+04$ \\
\hline
\end{tabular}




\begin{tabular}{|c|c|c|c|c|c|c|c|c|}
\hline & & Unidade & $1,0-2,0 \mu \mathrm{m}$ & $2,0-3,0 \mu \mathrm{m}$ & $3,0-5,0 \mu \mathrm{m}$ & $5,0-7,0 \mu \mathrm{m}$ & $7,0-10,0 \mu \mathrm{m}$ & $>10,0 \mu \mathrm{m}$ \\
\hline \multirow{8}{*}{ Assento $1 \mathrm{~A}$} & \begin{tabular}{|c|}
$\begin{array}{c}\text { Concentração média de } \\
\text { fundo }\end{array}$ \\
\end{tabular} & $\mathrm{P} / \mathrm{m}^{3}$ & $1,60 \mathrm{E}+05$ & $5,67 E+04$ & $6,67 E+03$ & $0,00 \mathrm{E}+00$ & $0,00 E+00$ & $0,00 E+00$ \\
\hline & $\begin{array}{c}\text { Número de particulas de } \\
\text { fundo }\end{array}$ & $\mathbf{P}$ & 48 & 17 & 2 & 0 & 0 & 0 \\
\hline & $\begin{array}{c}\text { Concentração média } \\
\text { liquida }\end{array}$ & $\mathrm{P} / \mathrm{m}^{3}$ & $6,57 \mathrm{E}+07$ & $5,81 E+07$ & $4,83 E+07$ & $3,17 \mathrm{E}+07$ & $8,45 E+06$ & $6,83 \mathrm{E}+05$ \\
\hline & $\begin{array}{c}\text { Número de Particulas } \\
\text { média liquida }\end{array}$ & $\mathbf{P}$ & 19700 & 17436 & 14503 & 9513 & 2536 & 205 \\
\hline & Desvio - Poisson & $\#$ & 140,36 & 132,05 & 120,43 & 97,53 & 50,36 & 14,32 \\
\hline & $\begin{array}{c}\text { Desvio - Poisson - } \\
\text { Relativo } \\
\end{array}$ & $\%$ & 0,7 & 0,8 & 0,8 & 1,0 & 2,0 & 7,0 \\
\hline & $\begin{array}{l}\text { Desvio padrão } \\
\text { Concentração }\end{array}$ & $\mathrm{P} / \mathrm{m}^{3}$ & $2,17 E+03$ & $1,50 E+03$ & $9,91 E+02$ & $7,94 \mathrm{E}+02$ & $5,81 E+02$ & $4,10 E+01$ \\
\hline & DP/Concentração média & $\%$ & 0,0033 & 0,0026 & 0,0021 & 0,0025 & 0,0069 & 0,0060 \\
\hline \multirow{2}{*}{\multicolumn{2}{|c|}{ Erro total medições(દ) }} & $\mathrm{P} / \mathrm{m}^{3}$ & $4,68 \mathrm{E}+05$ & $4,40 E+05$ & $4,01 \mathrm{E}+05$ & $3,25 \mathrm{E}+05$ & $1,68 \mathrm{E}+05$ & 4,77E+04 \\
\hline & & Unidade & $1,0-2,0 \mu \mathrm{m}$ & $2,0-3,0 \mu \mathrm{m}$ & $3,0-5,0 \mu \mathrm{m}$ & $5,0-7,0 \mu \mathrm{m}$ & $7,0-10,0 \mu \mathrm{m}$ & $>10,0 \mu \mathrm{m}$ \\
\hline \multirow{8}{*}{ Assento 2B } & $\begin{array}{c}\text { Concentração média de } \\
\text { fundo }\end{array}$ & $\mathrm{P} / \mathrm{m}^{3}$ & $7,00 E+04$ & $4,00 E+04$ & $6,67 E+03$ & $0,00 E+00$ & $0,00 E+00$ & $0,00 E+00$ \\
\hline & $\begin{array}{c}\text { Número de particulas de } \\
\text { fundo } \\
\end{array}$ & $\mathbf{P}$ & 21 & 12 & 2 & 0 & 0 & 0 \\
\hline & $\begin{array}{c}\text { Concentração média } \\
\text { liquida }\end{array}$ & $\mathrm{P} / \mathrm{m}^{3}$ & $1,13 E+08$ & $9,57 E+07$ & $8,84 \mathrm{E}+07$ & $6,52 E+07$ & $2,98 \mathrm{E}+07$ & $1,27 E+05$ \\
\hline & $\begin{array}{c}\text { Número de Particulas } \\
\text { média liquida }\end{array}$ & $\mathbf{P}$ & 33880 & 28713 & 26530 & 19560 & 8952 & 38 \\
\hline & Desvio - Poisson & $\#$ & 184,07 & 169,45 & 162,88 & 139,86 & 94,62 & 6,16 \\
\hline & $\begin{array}{l}\text { Desvio - Poisson - } \\
\text { Relativo } \\
\end{array}$ & $\%$ & 0,5 & 0,6 & 0,6 & 0,7 & 1,1 & 16,2 \\
\hline & $\begin{array}{l}\text { Desvio padrão } \\
\text { Concentração } \\
\end{array}$ & $\mathrm{P} / \mathrm{m}^{3}$ & $2,19 \mathrm{E}+03$ & $8,17 E+03$ & $8,78 \mathrm{E}+02$ & $1,98 \mathrm{E}+03$ & $8,09 E+02$ & $8,76 \mathrm{E}+00$ \\
\hline & DP/Concentração média & $\%$ & 0,0019 & 0,0085 & 0,0010 & 0,0030 & 0,0027 & 0,0069 \\
\hline \multirow{2}{*}{\multicolumn{2}{|c|}{ Erro total medições(દ) }} & $\mathrm{P} / \mathrm{m}^{3}$ & $6,14 \mathrm{E}+05$ & $5,65 \mathrm{E}+05$ & $5,43 E+05$ & $4,66 \mathrm{E}+05$ & $3,15 \mathrm{E}+05$ & $2,05 \mathrm{E}+04$ \\
\hline & & Unidade & $1,0-2,0 \mu \mathrm{m}$ & $2,0-3,0 \mu \mathrm{m}$ & $3,0-5,0 \mu \mathrm{m}$ & $5,0-7,0 \mu \mathrm{m}$ & $7,0-10,0 \mu \mathrm{m}$ & $>10,0 \mu \mathrm{m}$ \\
\hline \multirow{8}{*}{ Assento 2A } & $\begin{array}{c}\text { Concentração média de } \\
\text { fundo }\end{array}$ & $\mathrm{P} / \mathrm{m}^{3}$ & $1,70 \mathrm{E}+05$ & $7,50 E+04$ & $3,33 E+03$ & $0,00 E+00$ & $0,00 \mathrm{E}+00$ & $0,00 E+00$ \\
\hline & $\begin{array}{c}\text { Número de particulas de } \\
\text { fundo }\end{array}$ & $\mathbf{P}$ & 51 & 23 & 1 & 0 & 0 & 0 \\
\hline & $\begin{array}{c}\text { Concentração média } \\
\text { liquida }\end{array}$ & $\mathrm{P} / \mathrm{m}^{3}$ & $8,20 E+07$ & $7,84 \mathrm{E}+07$ & $6,19 \mathrm{E}+07$ & $4,17 E+07$ & $1,20 \mathrm{E}+07$ & $4,60 E+05$ \\
\hline & $\begin{array}{c}\text { Número de Particulas } \\
\text { média liquida }\end{array}$ & $\mathbf{P}$ & 24615 & 23522 & 18560 & 12520 & 3589 & 138 \\
\hline & Desvio - Poisson & $\#$ & 156,89 & 153,37 & 136,24 & 111,89 & 59,91 & 11,75 \\
\hline & $\begin{array}{l}\text { Desvio - Poisson - } \\
\text { Relativo } \\
\end{array}$ & $\%$ & 0,6 & 0,7 & 0,7 & 0,9 & 1,7 & 8,5 \\
\hline & $\begin{array}{c}\text { Desvio padrão } \\
\text { Concentração }\end{array}$ & $\mathrm{P} / \mathrm{m}^{3}$ & $1,02 E+04$ & $2,98 \mathrm{E}+03$ & $3,20 E+03$ & $9,81 E+02$ & $3,55 E+02$ & $3,69 \mathrm{E}+01$ \\
\hline & DP/Concentração média & $\%$ & 0,0124 & 0,0038 & 0,0052 & 0,0024 & 0,0030 & 0,0080 \\
\hline \multicolumn{2}{|c|}{ Erro total medições $(\varepsilon)$} & $\mathrm{P} / \mathrm{m}^{3}$ & $5,23 E+05$ & $5,11 \mathrm{E}+05$ & $4,54 \mathrm{E}+05$ & $3,73 \mathrm{E}+05$ & $2,00 E+05$ & $3,92 \mathrm{E}+04$ \\
\hline
\end{tabular}




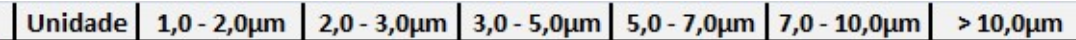

\begin{tabular}{|c|c|c|c|c|c|c|c|c|}
\hline \multirow{8}{*}{ Assento 3B } & $\begin{array}{c}\text { Concentração média de } \\
\text { fundo }\end{array}$ & $\mathrm{P} / \mathrm{m}^{3}$ & $9,33 E+04$ & $4,00 E+04$ & $3,33 \mathrm{E}+03$ & $0,00 E+00$ & $0,00 E+00$ & $0,00 E+00$ \\
\hline & \begin{tabular}{|c|}
$\begin{array}{c}\text { Número de particulas de } \\
\text { fundo }\end{array}$ \\
\end{tabular} & $\mathbf{P}$ & 28 & 12 & 1 & 0 & 0 & 0 \\
\hline & $\begin{array}{l}\text { Concentração média } \\
\text { liquida }\end{array}$ & $\mathrm{P} / \mathrm{m}^{3}$ & $9,78 E+07$ & $9,22 \mathrm{E}+07$ & $8,84 \mathrm{E}+07$ & $6,02 E+07$ & $2,82 E+07$ & $6,40 \mathrm{E}+05$ \\
\hline & $\begin{array}{c}\text { Número de Particulas } \\
\text { média liquida }\end{array}$ & $\mathbf{P}$ & 29339 & 27653 & 26530 & 18052 & 8452 & 192 \\
\hline & Desvio - Poisson & \# & 171,29 & 166,29 & 162,88 & 134,36 & 91,93 & 13,86 \\
\hline & $\begin{array}{l}\text { Desvio - Poisson - } \\
\text { Relativo }\end{array}$ & $\%$ & 0,6 & 0,6 & 0,6 & 0,7 & 1,1 & 7,2 \\
\hline & $\begin{array}{l}\text { Desvio padrão } \\
\text { Concentração }\end{array}$ & $\mathrm{P} / \mathrm{m}^{3}$ & $5,71 E+03$ & $3,50 E+03$ & $3,68 \mathrm{E}+03$ & $2,02 E+03$ & $2,03 E+03$ & $8,35 E+01$ \\
\hline & DP/Concentração média & $\%$ & 0,0058 & 0,0038 & 0,0042 & 0,0033 & 0,0072 & 0,0130 \\
\hline \multirow{2}{*}{\multicolumn{2}{|c|}{ Erro total medições( $\varepsilon)$}} & $\mathrm{P} / \mathrm{m}^{3}$ & $5,71 E+05$ & $5,54 \mathrm{E}+05$ & $5,43 E+05$ & $4,48 E+05$ & $3,06 E+05$ & $4,62 E+04$ \\
\hline & & Unidade & $1,0-2,0 \mu \mathrm{m}$ & $2,0-3,0 \mu \mathrm{m}$ & $3,0-5,0 \mu \mathrm{m}$ & $5,0-7,0 \mu \mathrm{m}$ & $7,0-10,0 \mu \mathrm{m}$ & $>10,0 \mu \mathrm{m}$ \\
\hline \multirow{8}{*}{ Assento 3A } & \begin{tabular}{|c|}
$\begin{array}{c}\text { Concentração média de } \\
\text { fundo }\end{array}$ \\
\end{tabular} & $\mathrm{P} / \mathrm{m}^{3}$ & $1,30 \mathrm{E}+05$ & $8,00 E+04$ & $3,33 E+03$ & $0,00 E+00$ & $0,00 E+00$ & $0,00 \mathrm{E}+00$ \\
\hline & $\begin{array}{c}\begin{array}{c}\text { Número de particulas de } \\
\text { fundo }\end{array} \\
\end{array}$ & $\mathbf{P}$ & 39 & 24 & 1 & 0 & 0 & 0 \\
\hline & $\begin{array}{c}\text { Concentração média } \\
\text { liquida }\end{array}$ & $\mathrm{P} / \mathrm{m}^{3}$ & $9,43 E+07$ & $8,74 \mathrm{E}+07$ & $6,85 E+07$ & $4,51 E+07$ & $2,65 \mathrm{E}+07$ & $4,50 E+05$ \\
\hline & $\begin{array}{l}\text { Número de Particulas } \\
\text { média liquida }\end{array}$ & $\mathbf{P}$ & 28297 & 26234 & 20560 & 13520 & 7952 & 135 \\
\hline & Desvio - Poisson & $\#$ & 168,22 & 161,97 & 143,39 & 116,28 & 89,17 & 11,62 \\
\hline & $\begin{array}{l}\text { Desvio - Poisson - } \\
\text { Relativo }\end{array}$ & $\%$ & 0,6 & 0,6 & 0,7 & 0,9 & 1,1 & 8,6 \\
\hline & $\begin{array}{l}\begin{array}{l}\text { Desvio padrão } \\
\text { Concentração }\end{array} \\
\end{array}$ & $\mathrm{P} / \mathrm{m}^{3}$ & $6,92 E+03$ & $1,92 E+03$ & $3,37 E+03$ & $2,74 \mathrm{E}+03$ & $2,51 E+03$ & $2,13 E+01$ \\
\hline & DP/Concentração média & $\%$ & 0,0073 & 0,0022 & 0,0049 & 0,0061 & 0,0095 & 0,0047 \\
\hline \multicolumn{2}{|c|}{ Erro total medições( $\varepsilon)$} & $\mathrm{P} / \mathrm{m}^{3}$ & $5,61 E+05$ & $5,40 E+05$ & $4,78 E+05$ & $3,88 \mathrm{E}+05$ & $2,97 \mathrm{E}+05$ & $3,87 E+04$ \\
\hline
\end{tabular}


Tabela B-11. Resultados das medições de partículas no assento (Sistema UFAD à $22^{\circ} \mathrm{C}$ - injeção pelo assento $3 \mathrm{~A}$ )

\begin{tabular}{|c|c|c|c|c|c|c|c|c|}
\hline & & Unidade & $1,0-2,0 \mu \mathrm{m}$ & $2,0-3,0 \mu \mathrm{m}$ & $3,0-5,0 \mu \mathrm{m}$ & $5,0-7,0 \mu \mathrm{m}$ & $7,0-10,0 \mu \mathrm{m}$ & $>10,0 \mu \mathrm{m}$ \\
\hline \multirow{8}{*}{ Assento 3D } & $\begin{array}{c}\text { Concentração média de } \\
\text { fundo }\end{array}$ & $\mathrm{P} / \mathrm{m}^{3}$ & $7,67 E+04$ & $3,67 E+04$ & $6,67 E+03$ & $0,00 E+00$ & $0,00 E+00$ & $0,00 E+00$ \\
\hline & $\begin{array}{c}\begin{array}{c}\text { Número de particulas de } \\
\text { fundo }\end{array} \\
\end{array}$ & $\mathbf{P}$ & 23 & 11 & 2 & 0 & 0 & 0 \\
\hline & $\begin{array}{c}\text { Concentração média } \\
\text { liquida }\end{array}$ & $\mathrm{P} / \mathrm{m}^{3}$ & $9,20 E+07$ & $9,47 E+07$ & $7,68 \mathrm{E}+07$ & $5,44 E+07$ & $1,51 E+07$ & $1,65 E+06$ \\
\hline & $\begin{array}{c}\text { Número de Particulas } \\
\text { média liquida }\end{array}$ & $\mathbf{P}$ & 27611 & 28423 & 23048 & 16309 & 4524 & 495 \\
\hline & Desvio - Poisson & $\#$ & 166,16 & 168,59 & 151,81 & 127,71 & 67,26 & 22,25 \\
\hline & $\begin{array}{c}\text { Desvio - Poisson - } \\
\text { Relativo }\end{array}$ & $\%$ & 0,6 & 0,6 & 0,7 & 0,8 & 1,5 & 4,5 \\
\hline & $\begin{array}{l}\text { Desvio padrão } \\
\text { Concentração }\end{array}$ & $\mathrm{P} / \mathrm{m}^{3}$ & $3,77 E+03$ & $3,09 \mathrm{E}+03$ & $1,27 E+03$ & $2,59 E+03$ & $7,59 E+02$ & $6,11 E+01$ \\
\hline & DP/Concentração média & $\%$ & 0,0041 & 0,0033 & 0,0017 & 0,0048 & 0,0050 & 0,0037 \\
\hline \multirow{2}{*}{\multicolumn{2}{|c|}{ Erro total medições( $\varepsilon)$}} & $\mathrm{P} / \mathrm{m}^{3}$ & $5,54 \mathrm{E}+05$ & $5,62 E+05$ & $5,06 \mathrm{E}+05$ & $4,26 E+05$ & $2,24 E+05$ & $7,42 \mathrm{E}+04$ \\
\hline & & Unidade & $1,0-2,0 \mu \mathrm{m}$ & $2,0-3,0 \mu \mathrm{m}$ & $3,0-5,0 \mu \mathrm{m}$ & $5,0-7,0 \mu \mathrm{m}$ & $7,0-10,0 \mu \mathrm{m}$ & $>10,0 \mu \mathrm{m}$ \\
\hline \multirow{8}{*}{ Assento 2D } & $\begin{array}{c}\text { Concentração média de } \\
\text { fundo }\end{array}$ & $\mathrm{P} / \mathrm{m}^{3}$ & $1,87 E+05$ & $1,10 \mathrm{E}+05$ & $3,33 \mathrm{E}+03$ & $0,00 E+00$ & $0,00 E+00$ & $0,00 E+00$ \\
\hline & \begin{tabular}{|c|} 
Número de particulas de \\
fundo \\
\end{tabular} & $\mathbf{P}$ & 56 & 33 & 1 & 0 & 0 & 0 \\
\hline & $\begin{array}{c}\text { Concentração média } \\
\text { liquida }\end{array}$ & $\mathrm{P} / \mathrm{m}^{3}$ & $9,20 E+07$ & $9,08 E+07$ & $6,26 E+07$ & $5,46 \mathrm{E}+07$ & $2,18 \mathrm{E}+07$ & $1,68 \mathrm{E}+06$ \\
\hline & $\begin{array}{l}\text { Número de Particulas } \\
\text { média liquida }\end{array}$ & $\mathbf{P}$ & 27607 & 27235 & 18785 & 16394 & 6542 & 504 \\
\hline & Desvio - Poisson & $\#$ & 166,15 & 165,03 & 137,06 & 128,04 & 80,88 & 22,45 \\
\hline & $\begin{array}{l}\text { Desvio - Poisson - } \\
\text { Relativo }\end{array}$ & $\%$ & 0,6 & 0,6 & 0,7 & 0,8 & 1,2 & 4,5 \\
\hline & $\begin{array}{c}\text { Desvio padrão } \\
\text { Concentração }\end{array}$ & $\mathrm{P} / \mathrm{m}^{3}$ & $6,44 E+03$ & $6,31 E+03$ & $4,03 E+03$ & $2,58 \mathrm{E}+03$ & $9,24 E+02$ & $1,20 E+02$ \\
\hline & DP/Concentração média & $\%$ & 0,0070 & 0,0070 & 0,0064 & 0,0047 & 0,0042 & 0,0072 \\
\hline \multirow{2}{*}{\multicolumn{2}{|c|}{ Erro total medições(દ) }} & $\mathrm{P} / \mathrm{m}^{3}$ & $5,54 \mathrm{E}+05$ & $5,50 \mathrm{E}+05$ & $4,57 E+05$ & $4,27 E+05$ & $2,70 E+05$ & $7,48 \mathrm{E}+04$ \\
\hline & & Unidade & $1,0-2,0 \mu \mathrm{m}$ & $2,0-3,0 \mu \mathrm{m}$ & $3,0-5,0 \mu \mathrm{m}$ & $5,0-7,0 \mu \mathrm{m}$ & $7,0-10,0 \mu \mathrm{m}$ & $>10,0 \mu \mathrm{m}$ \\
\hline \multirow{8}{*}{ Assento $2 \mathrm{E}$} & $\begin{array}{c}\text { Concentração média de } \\
\text { fundo }\end{array}$ & $\mathrm{P} / \mathrm{m}^{3}$ & $7,33 E+04$ & $3,33 E+04$ & $3,33 \mathrm{E}+03$ & $0,00 E+00$ & $0,00 \mathrm{E}+00$ & $0,00 E+00$ \\
\hline & $\begin{array}{c}\text { Número de particulas de } \\
\text { fundo }\end{array}$ & $\mathbf{P}$ & 22 & 10 & 1 & 0 & 0 & 0 \\
\hline & $\begin{array}{l}\text { Concentração média } \\
\text { liquida }\end{array}$ & $\mathrm{P} / \mathrm{m}^{3}$ & $9,05 E+07$ & $7,97 E+07$ & $7,47 E+07$ & $5,11 E+07$ & $1,97 E+07$ & $1,67 E+06$ \\
\hline & $\begin{array}{c}\text { Número de Particulas } \\
\text { média liquida }\end{array}$ & $\mathbf{P}$ & 27163 & 23920 & 22411 & 15316 & 5908 & 500 \\
\hline & Desvio - Poisson & $\#$ & 164,81 & 154,66 & 149,70 & 123,76 & 76,86 & 22,36 \\
\hline & $\begin{array}{c}\text { Desvio - Poisson - } \\
\text { Relativo } \\
\end{array}$ & $\%$ & 0,6 & 0,6 & 0,7 & 0,8 & 1,3 & 4,5 \\
\hline & $\begin{array}{l}\text { Desvio padrão } \\
\text { Concentração }\end{array}$ & $\mathrm{P} / \mathrm{m}^{3}$ & $4,28 E+03$ & $3,10 E+03$ & $2,35 E+03$ & $8,71 E+02$ & $9,53 E+02$ & $1,04 \mathrm{E}+02$ \\
\hline & DP/Concentração média & $\%$ & 0,0047 & 0,0039 & 0,0031 & 0,0017 & 0,0048 & 0,0062 \\
\hline \multicolumn{2}{|c|}{ Erro total medições( $(\varepsilon)$} & $\mathrm{P} / \mathrm{m}^{3}$ & $5,49 \mathrm{E}+05$ & $5,16 \mathrm{E}+05$ & $4,99 \mathrm{E}+05$ & $4,13 E+05$ & $2,56 \mathrm{E}+05$ & $7,45 \mathrm{E}+04$ \\
\hline
\end{tabular}




\begin{tabular}{|c|c|c|c|c|c|c|c|c|}
\hline & & Unidade & $1,0-2,0 \mu \mathrm{m}$ & $2,0-3,0 \mu \mathrm{m}$ & $3,0-5,0 \mu \mathrm{m}$ & $5,0-7,0 \mu \mathrm{m}$ & $7,0-10,0 \mu \mathrm{m}$ & $>10,0 \mu \mathrm{m}$ \\
\hline \multirow{8}{*}{ Assento 1D } & $\begin{array}{c}\text { Concentração média de } \\
\text { fundo }\end{array}$ & $\mathrm{P} / \mathrm{m}^{3}$ & $2,53 E+05$ & $1,87 E+05$ & $1,00 E+04$ & $0,00 E+00$ & $0,00 E+00$ & $0,00 \mathrm{E}+00$ \\
\hline & $\begin{array}{c}\text { Número de particulas de } \\
\text { fundo }\end{array}$ & $\mathbf{P}$ & 76 & 56 & 3 & 0 & 0 & 0 \\
\hline & $\begin{array}{l}\text { Concentração média } \\
\text { liquida }\end{array}$ & $\mathrm{P} / \mathrm{m}^{3}$ & $9,68 E+07$ & $9,54 \mathrm{E}+07$ & $5,47 E+07$ & $4,00 E+07$ & $1,63 E+07$ & $1,71 \mathrm{E}+06$ \\
\hline & $\begin{array}{c}\text { Número de Particulas } \\
\text { média liquida }\end{array}$ & $\mathbf{P}$ & 29030 & 28626 & 16410 & 11987 & 4882 & 513 \\
\hline & Desvio - Poisson & $\#$ & 170,38 & 169,19 & 128,10 & 109,49 & 69,87 & 22,64 \\
\hline & $\begin{array}{c}\text { Desvio - Poisson - } \\
\text { Relativo } \\
\end{array}$ & $\%$ & 0,6 & 0,6 & 0,8 & 0,9 & 1,4 & 4,4 \\
\hline & $\begin{array}{l}\text { Desvio padrão } \\
\text { Concentração } \\
\end{array}$ & $\mathrm{P} / \mathrm{m}^{3}$ & $5,17 E+03$ & $5,06 E+03$ & $2,84 \mathrm{E}+03$ & $1,53 \mathrm{E}+03$ & $8,92 E+02$ & $1,31 \mathrm{E}+02$ \\
\hline & DP/Concentração média & $\%$ & 0,0053 & 0,0053 & 0,0052 & 0,0038 & 0,0055 & 0,0077 \\
\hline \multirow{2}{*}{\multicolumn{2}{|c|}{ Erro total medições(દ) }} & $\mathrm{P} / \mathrm{m}^{3}$ & $5,68 \mathrm{E}+05$ & $5,64 \mathrm{E}+05$ & $4,27 E+05$ & $3,65 E+05$ & $2,33 \mathrm{E}+05$ & $7,55 \mathrm{E}+04$ \\
\hline & & Unidade & $1,0-2,0 \mu \mathrm{m}$ & $2,0-3,0 \mu \mathrm{m}$ & $3,0-5,0 \mu \mathrm{m}$ & $5,0-7,0 \mu \mathrm{m}$ & $7,0-10,0 \mu \mathrm{m}$ & $>10,0 \mu \mathrm{m}$ \\
\hline \multirow{8}{*}{ Assento 1E } & $\begin{array}{c}\text { Concentração média de } \\
\text { fundo } \\
\end{array}$ & $\mathrm{P} / \mathrm{m}^{3}$ & $1,87 E+05$ & $7,67 \mathrm{E}+04$ & $3,33 \mathrm{E}+03$ & $0,00 E+00$ & $1,67 E+03$ & $0,00 \mathrm{E}+00$ \\
\hline & $\begin{array}{c}\text { Número de particulas de } \\
\text { fundo } \\
\end{array}$ & $\mathbf{P}$ & 56 & 23 & 1 & 0 & 1 & 0 \\
\hline & $\begin{array}{c}\text { Concentração média } \\
\text { liquida }\end{array}$ & $\mathrm{P} / \mathrm{m}^{3}$ & $1,02 E+08$ & $9,08 E+07$ & $6,07 \mathrm{E}+07$ & $4,19 \mathrm{E}+07$ & $2,85 E+07$ & $2,40 E+06$ \\
\hline & $\begin{array}{c}\text { Número de Particulas } \\
\text { média liquida }\end{array}$ & $\mathbf{P}$ & 30567 & 27233 & 18205 & 12558 & 8537 & 721 \\
\hline & Desvio - Poisson & $\#$ & 174,83 & 165,02 & 134,93 & 112,06 & 92,39 & 26,84 \\
\hline & $\begin{array}{c}\text { Desvio - Poisson - } \\
\text { Relativo } \\
\end{array}$ & $\%$ & 0,6 & 0,6 & 0,7 & 0,9 & 1,1 & 3,7 \\
\hline & $\begin{array}{l}\text { Desvio padrão } \\
\text { Concentração } \\
\end{array}$ & $\mathrm{P} / \mathrm{m}^{3}$ & $5,22 E+03$ & $5,71 E+03$ & $8,87 E+02$ & $9,35 E+02$ & $1,34 E+03$ & $1,03 \mathrm{E}+02$ \\
\hline & DP/Concentração média & $\%$ & 0,0051 & 0,0063 & 0,0015 & 0,0022 & 0,0047 & 0,0043 \\
\hline \multirow{2}{*}{\multicolumn{2}{|c|}{ Erro total medições $(\varepsilon)$}} & $\mathrm{P} / \mathrm{m}^{3}$ & $5,83 E+05$ & $5,50 E+05$ & $4,50 E+05$ & $3,74 \mathrm{E}+05$ & $3,08 \mathrm{E}+05$ & $8,95 \mathrm{E}+04$ \\
\hline & & Unidade & $1,0-2,0 \mu \mathrm{m}$ & $2,0-3,0 \mu \mathrm{m}$ & $3,0-5,0 \mu \mathrm{m}$ & $5,0-7,0 \mu \mathrm{m}$ & $7,0-10,0 \mu \mathrm{m}$ & $>10,0 \mu \mathrm{m}$ \\
\hline \multirow{8}{*}{ Assento 1B } & $\begin{array}{c}\text { Concentração média de } \\
\text { fundo }\end{array}$ & $\mathrm{P} / \mathrm{m}^{3}$ & $2,23 E+05$ & $1,10 E+05$ & $3,33 E+03$ & $0,00 E+00$ & $0,00 E+00$ & $0,00 \mathrm{E}+00$ \\
\hline & $\begin{array}{c}\text { Número de particulas de } \\
\text { fundo } \\
\end{array}$ & $\mathbf{P}$ & 67 & 33 & 1 & 0 & 0 & 0 \\
\hline & $\begin{array}{l}\text { Concentração média } \\
\text { liquida }\end{array}$ & $\mathrm{P} / \mathrm{m}^{3}$ & $7,10 E+07$ & $6,99 \mathrm{E}+07$ & $5,01 E+07$ & $3,52 E+07$ & $8,03 E+06$ & $1,69 \mathrm{E}+06$ \\
\hline & $\begin{array}{c}\text { Número de Particulas } \\
\text { média liquida }\end{array}$ & $\mathbf{P}$ & 21295 & 20983 & 15031 & 10547 & 2409 & 507 \\
\hline & Desvio - Poisson & \# & 145,93 & 144,86 & 122,60 & 102,70 & 49,08 & 22,52 \\
\hline & $\begin{array}{c}\text { Desvio - Poisson - } \\
\text { Relativo } \\
\end{array}$ & $\%$ & 0,7 & 0,7 & 0,8 & 1,0 & 2,0 & 4,4 \\
\hline & $\begin{array}{l}\text { Desvio padrão } \\
\text { Concentração } \\
\end{array}$ & $\mathrm{P} / \mathrm{m}^{3}$ & $5,32 E+03$ & $5,24 E+03$ & $4,08 \mathrm{E}+03$ & $2,72 E+03$ & $7,30 E+02$ & $1,23 \mathrm{E}+02$ \\
\hline & DP/Concentração média & $\%$ & 0,0075 & 0,0075 & 0,0081 & 0,0077 & 0,0091 & 0,0073 \\
\hline \multicolumn{2}{|c|}{ Erro total medições( $\varepsilon)$} & $\mathrm{P} / \mathrm{m}^{3}$ & $4,86 E+05$ & $4,83 E+05$ & $4,09 E+05$ & $3,42 E+05$ & $1,64 \mathrm{E}+05$ & $7,51 \mathrm{E}+04$ \\
\hline
\end{tabular}




\begin{tabular}{|c|c|c|c|c|c|c|c|c|}
\hline & & Unidade & $1,0-2,0 \mu \mathrm{m}$ & $2,0-3,0 \mu \mathrm{m}$ & $3,0-5,0 \mu \mathrm{m}$ & $5,0-7,0 \mu \mathrm{m}$ & $7,0-10,0 \mu \mathrm{m}$ & $>10,0 \mu \mathrm{m}$ \\
\hline \multirow{8}{*}{ Assento $1 \mathrm{~A}$} & $\begin{array}{c}\text { Concentração média de } \\
\text { fundo }\end{array}$ & $\mathrm{P} / \mathrm{m}^{3}$ & $1,70 E+05$ & $5,67 E+04$ & $6,67 E+03$ & $0,00 E+00$ & $0,00 E+00$ & $0,00 E+00$ \\
\hline & $\begin{array}{c}\text { Número de particulas de } \\
\text { fundo }\end{array}$ & $\mathbf{P}$ & 51 & 17 & 2 & 0 & 0 & 0 \\
\hline & $\begin{array}{l}\text { Concentração média } \\
\text { liquida }\end{array}$ & $\mathrm{P} / \mathrm{m}^{3}$ & $7,11 E+07$ & $7,01 \mathrm{E}+07$ & $3,81 \mathrm{E}+07$ & $2,85 E+07$ & $1,17 E+07$ & $1,26 E+06$ \\
\hline & $\begin{array}{c}\text { Número de Particulas } \\
\text { média liquida }\end{array}$ & $\mathbf{p}$ & 21340 & 21042 & 11420 & 8563 & 3510 & 378 \\
\hline & Desvio - Poisson & $\#$ & 146,08 & 145,06 & 106,86 & 92,54 & 59,25 & 19,44 \\
\hline & $\begin{array}{c}\text { Desvio - Poisson - } \\
\text { Relativo }\end{array}$ & $\%$ & 0,7 & 0,7 & 0,9 & 1,1 & 1,7 & 5,1 \\
\hline & $\begin{array}{l}\text { Desvio padrão } \\
\text { Concentração } \\
\end{array}$ & $\mathrm{P} / \mathrm{m}^{3}$ & $4,56 \mathrm{E}+03$ & $4,47 E+03$ & $1,78 \mathrm{E}+03$ & $1,23 \mathrm{E}+03$ & $5,72 E+02$ & $1,12 \mathrm{E}+02$ \\
\hline & DP/Concentração média & $\%$ & 0,0064 & 0,0064 & 0,0047 & 0,0043 & 0,0049 & 0,0089 \\
\hline \multirow{2}{*}{\multicolumn{2}{|c|}{ Erro total medições(દ) }} & $\mathrm{P} / \mathrm{m}^{3}$ & $4,87 E+05$ & $4,84 E+05$ & $3,56 \mathrm{E}+05$ & $3,08 \mathrm{E}+05$ & $1,97 \mathrm{E}+05$ & $6,48 \mathrm{E}+04$ \\
\hline & & Unidade & $1,0-2,0 \mu \mathrm{m}$ & $2,0-3,0 \mu \mathrm{m}$ & $3,0-5,0 \mu \mathrm{m}$ & $5,0-7,0 \mu \mathrm{m}$ & $7,0-10,0 \mu \mathrm{m}$ & $>10,0 \mu \mathrm{m}$ \\
\hline \multirow{8}{*}{ Assento $2 \mathrm{~B}$} & $\begin{array}{c}\text { Concentração média de } \\
\text { fundo } \\
\end{array}$ & $\mathrm{P} / \mathrm{m}^{3}$ & $2,03 E+05$ & $7,00 E+04$ & $6,67 \mathrm{E}+03$ & $0,00 E+00$ & $0,00 \mathrm{E}+00$ & $0,00 E+00$ \\
\hline & $\begin{array}{c}\text { Número de particulas de } \\
\text { fundo } \\
\end{array}$ & $\mathbf{P}$ & 61 & 21 & 2 & 0 & 0 & 0 \\
\hline & $\begin{array}{c}\text { Concentração média } \\
\text { liquida }\end{array}$ & $\mathrm{P} / \mathrm{m}^{3}$ & $7,11 \mathrm{E}+07$ & $6,18 \mathrm{E}+07$ & $6,32 \mathrm{E}+07$ & $5,51 E+07$ & $1,19 \mathrm{E}+07$ & $1,19 \mathrm{E}+06$ \\
\hline & $\begin{array}{c}\text { Número de Particulas } \\
\text { média liquida }\end{array}$ & $\mathbf{P}$ & 21340 & 18542 & 18960 & 16520 & 3562 & 356 \\
\hline & Desvio - Poisson & $\#$ & 146,08 & 136,17 & 137,70 & 128,53 & 59,68 & 18,87 \\
\hline & $\begin{array}{c}\text { Desvio - Poisson - } \\
\text { Relativo } \\
\end{array}$ & $\%$ & 0,7 & 0,7 & 0,7 & 0,8 & 1,7 & 5,3 \\
\hline & $\begin{array}{l}\text { Desvio padrão } \\
\text { Concentração } \\
\end{array}$ & $\mathrm{P} / \mathrm{m}^{3}$ & $4,56 \mathrm{E}+03$ & $4,57 E+03$ & $3,63 E+03$ & $9,41 E+02$ & $7,09 E+02$ & $8,37 E+01$ \\
\hline & DP/Concentração média & $\%$ & 0,0064 & 0,0074 & 0,0057 & 0,0017 & 0,0060 & 0,0071 \\
\hline \multirow{2}{*}{\multicolumn{2}{|c|}{ Erro total medições $(\varepsilon)$}} & $\mathrm{P} / \mathrm{m}^{3}$ & $4,87 E+05$ & $4,54 E+05$ & $4,59 E+05$ & $4,28 E+05$ & $1,99 \mathrm{E}+05$ & $6,29 \mathrm{E}+04$ \\
\hline & & Unidade & $1,0-2,0 \mu \mathrm{m}$ & $2,0-3,0 \mu \mathrm{m}$ & $3,0-5,0 \mu \mathrm{m}$ & $5,0-7,0 \mu \mathrm{m}$ & $7,0-10,0 \mu \mathrm{m}$ & $>10,0 \mu \mathrm{m}$ \\
\hline \multirow{8}{*}{ Assento 2A } & $\begin{array}{c}\text { Concentração média de } \\
\text { fundo } \\
\end{array}$ & $\mathrm{P} / \mathrm{m}^{3}$ & $1,13 E+05$ & $3,67 E+04$ & $1,00 E+04$ & $0,00 \mathrm{E}+00$ & $0,00 \mathrm{E}+00$ & $0,00 \mathrm{E}+00$ \\
\hline & $\begin{array}{c}\text { Número de particulas de } \\
\text { fundo } \\
\end{array}$ & $\mathbf{p}$ & 34 & 11 & 3 & 0 & 0 & 0 \\
\hline & $\begin{array}{l}\text { Concentração média } \\
\text { liquida }\end{array}$ & $\mathrm{P} / \mathrm{m}^{3}$ & $7,11 \mathrm{E}+07$ & $5,48 E+07$ & $4,18 \mathrm{E}+07$ & $2,63 E+07$ & $1,01 E+07$ & $1,34 \mathrm{E}+06$ \\
\hline & $\begin{array}{c}\text { Número de Particulas } \\
\text { média liquida }\end{array}$ & $\mathbf{p}$ & 21340 & 16439 & 12528 & 7895 & 3039 & 402 \\
\hline & Desvio - Poisson & $\#$ & 146,08 & 128,21 & 111,93 & 88,85 & 55,13 & 20,04 \\
\hline & $\begin{array}{c}\text { Desvio - Poisson - } \\
\text { Relativo } \\
\end{array}$ & $\%$ & 0,7 & 0,8 & 0,9 & 1,1 & 1,8 & 5,0 \\
\hline & $\begin{array}{l}\text { Desvio padrão } \\
\text { Concentração }\end{array}$ & $\mathrm{P} / \mathrm{m}^{3}$ & $4,56 \mathrm{E}+03$ & $1,68 \mathrm{E}+03$ & $7,17 \mathrm{E}+02$ & $1,15 \mathrm{E}+03$ & $8,26 \mathrm{E}+02$ & $1,16 E+02$ \\
\hline & DP/Concentração média & $\%$ & 0,0064 & 0,0031 & 0,0017 & 0,0044 & 0,0082 & 0,0087 \\
\hline \multicolumn{2}{|c|}{ Erro total medições( $(\varepsilon)$} & $\mathrm{P} / \mathrm{m}^{3}$ & $4,87 E+05$ & $4,27 E+05$ & $3,73 \mathrm{E}+05$ & $2,96 \mathrm{E}+05$ & $1,84 \mathrm{E}+05$ & $6,68 \mathrm{E}+04$ \\
\hline
\end{tabular}




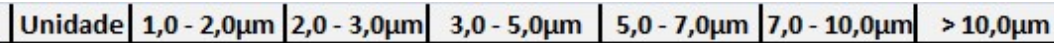

\begin{tabular}{|c|c|c|c|c|c|c|c|c|}
\hline \multirow{8}{*}{ Assento 3B } & $\begin{array}{c}\text { Concentração média de } \\
\text { fundo }\end{array}$ & $\mathrm{P} / \mathrm{m}^{3}$ & $2,23 \mathrm{E}+05$ & $6,50 \mathrm{E}+04$ & $6,67 E+03$ & $0,00 E+00$ & $0,00 \mathrm{E}+00$ & $0,00 E+00$ \\
\hline & $\begin{array}{c}\begin{array}{c}\text { Número de particulas de } \\
\text { fundo }\end{array} \\
\end{array}$ & $\mathbf{P}$ & 67 & 20 & 2 & 0 & 0 & 0 \\
\hline & $\begin{array}{c}\text { Concentração média } \\
\text { liquida }\end{array}$ & $\mathrm{P} / \mathrm{m}^{3}$ & $8,81 E+07$ & $8,67 E+07$ & $5,95 \mathrm{E}+07$ & $4,51 E+07$ & $1,19 E+07$ & $1,29 E+06$ \\
\hline & $\begin{array}{c}\text { Número de Particulas } \\
\text { média liquida }\end{array}$ & $\mathbf{P}$ & 26425 & 26016 & 17842 & 13520 & 3563 & 387 \\
\hline & Desvio - Poisson & \# & 162,56 & 161,29 & 133,57 & 116,28 & 59,69 & 19,67 \\
\hline & $\begin{array}{c}\text { Desvio - Poisson - } \\
\text { Relativo } \\
\end{array}$ & $\%$ & 0,6 & 0,6 & 0,7 & 0,9 & 1,7 & 5,1 \\
\hline & $\begin{array}{l}\text { Desvio padrão } \\
\text { Concentração }\end{array}$ & $\mathrm{P} / \mathrm{m}^{3}$ & $4,34 \mathrm{E}+03$ & $4,24 \mathrm{E}+03$ & $7,68 \mathrm{E}+02$ & $1,36 \mathrm{E}+03$ & $8,87 E+02$ & $4,64 E+01$ \\
\hline & DP/Concentração média & $\%$ & 0,0049 & 0,0049 & 0,0013 & 0,0030 & 0,0075 & 0,0036 \\
\hline \multirow{2}{*}{\multicolumn{2}{|c|}{ Erro total medições(દ) }} & $\mathrm{P} / \mathrm{m}^{3}$ & $5,42 \mathrm{E}+05$ & $5,38 \mathrm{E}+05$ & $4,45 E+05$ & $3,88 \mathrm{E}+05$ & $1,99 \mathrm{E}+05$ & $6,56 \mathrm{E}+04$ \\
\hline & & Unidade & $1,0-2,0 \mu \mathrm{m}$ & $2,0-3,0 \mu \mathrm{m}$ & $3,0-5,0 \mu \mathrm{m}$ & $5,0-7,0 \mu \mathrm{m}$ & $7,0-10,0 \mu \mathrm{m}$ & $>10,0 \mu \mathrm{m}$ \\
\hline \multirow{8}{*}{ Assento $3 \mathrm{~A}$} & $\begin{array}{c}\text { Concentração média de } \\
\text { fundo }\end{array}$ & $\mathrm{P} / \mathrm{m}^{3}$ & $1,37 E+05$ & $7,00 E+04$ & $3,33 \mathrm{E}+03$ & $0,00 \mathrm{E}+00$ & $0,00 \mathrm{E}+00$ & $0,00 E+00$ \\
\hline & $\begin{array}{c}\begin{array}{c}\text { Número de particulas de } \\
\text { fundo }\end{array} \\
\end{array}$ & $\mathbf{P}$ & 41 & 21 & 1 & 0 & 0 & 0 \\
\hline & $\begin{array}{c}\text { Concentração média } \\
\text { liquida }\end{array}$ & $\mathrm{P} / \mathrm{m}^{3}$ & $6,30 \mathrm{E}+07$ & $5,45 E+07$ & $5,12 E+07$ & $2,62 E+07$ & $1,17 \mathrm{E}+07$ & $2,10 E+06$ \\
\hline & $\begin{array}{c}\text { Número de Particulas } \\
\text { média liquida }\end{array}$ & $\mathbf{P}$ & 18886 & 16360 & 15350 & 7852 & 3520 & 630 \\
\hline & Desvio - Poisson & $\#$ & 137,43 & 127,91 & 123,90 & 88,61 & 59,33 & 25,10 \\
\hline & $\begin{array}{c}\text { Desvio - Poisson - } \\
\text { Relativo } \\
\end{array}$ & $\%$ & 0,7 & 0,8 & 0,8 & 1,1 & 1,7 & 4,0 \\
\hline & $\begin{array}{l}\text { Desvio padrão } \\
\text { Concentração }\end{array}$ & $\mathrm{P} / \mathrm{m}^{3}$ & $9,17 E+02$ & $2,93 E+02$ & $4,90 \mathrm{E}+02$ & $8,17 E+02$ & $1,83 E+02$ & $1,24 E+02$ \\
\hline & DP/Concentração média & $\%$ & 0,0015 & 0,0005 & 0,0010 & 0,0031 & 0,0016 & 0,0059 \\
\hline \multicolumn{2}{|c|}{ Erro total medições(દ) } & $\mathrm{P} / \mathrm{m}^{3}$ & $4,58 E+05$ & $4,26 \mathrm{E}+05$ & $4,13 E+05$ & $2,95 \mathrm{E}+05$ & $1,98 \mathrm{E}+05$ & $8,37 E+04$ \\
\hline
\end{tabular}


Tabela B-12. Resultados das medições de partículas no assento (Sistema DV à $22^{\circ} \mathrm{C}$ - injeção pelo assento $3 \mathrm{~A}$ )

\begin{tabular}{|c|c|c|c|c|c|c|c|c|}
\hline & & Unidade & $1,0-2,0 \mu \mathrm{m}$ & $2,0-3,0 \mu \mathrm{m}$ & $3,0-5,0 \mu \mathrm{m}$ & $5,0-7,0 \mu \mathrm{m}$ & $7,0-10,0 \mu \mathrm{m}$ & $>10,0 \mu \mathrm{m}$ \\
\hline \multirow{8}{*}{ Assento 3D } & $\begin{array}{l}\text { Concentração média de } \\
\text { fundo }\end{array}$ & $\mathrm{P} / \mathrm{m}^{3}$ & $1,40 \mathrm{E}+05$ & $1,07 E+05$ & $6,67 E+03$ & $0,00 E+00$ & $0,00 E+00$ & $0,00 E+00$ \\
\hline & $\begin{array}{c}\text { Número de particulas de } \\
\text { fundo }\end{array}$ & $\mathbf{P}$ & 42 & 32 & 2 & 0 & 0 & 0 \\
\hline & $\begin{array}{c}\text { Concentração média } \\
\text { liquida } \\
\end{array}$ & $\mathrm{P} / \mathrm{m}^{3}$ & $1,18 \mathrm{E}+08$ & $1,05 E+08$ & $8,85 E+07$ & $6,51 E+07$ & $3,35 E+07$ & $5,00 E+05$ \\
\hline & $\begin{array}{l}\text { Número de Particulas } \\
\text { média liquida }\end{array}$ & $\mathbf{P}$ & 35333 & 31441 & 26542 & 19520 & 10057 & 150 \\
\hline & Desvio - Poisson & $\#$ & 187,97 & 177,31 & 162,92 & 139,71 & 100,28 & 12,25 \\
\hline & $\begin{array}{c}\text { Desvio - Poisson - } \\
\text { Relativo } \\
\end{array}$ & $\%$ & 0,5 & 0,6 & 0,6 & 0,7 & 1,0 & 8,2 \\
\hline & $\begin{array}{l}\text { Desvio padrão } \\
\text { Concentração }\end{array}$ & $\mathrm{P} / \mathrm{m}^{3}$ & $1,51 E+03$ & $8,24 E+02$ & $1,47 E+03$ & $2,43 E+03$ & $1,73 \mathrm{E}+03$ & $3,18 \mathrm{E}+01$ \\
\hline & DP/Concentração média & $\%$ & 0,0013 & 0,0008 & 0,0017 & 0,0037 & 0,0052 & 0,0064 \\
\hline \multirow{2}{*}{\multicolumn{2}{|c|}{ Erro total medições $(\varepsilon)$}} & $\mathrm{P} / \mathrm{m}^{3}$ & $6,27 E+05$ & $5,91 \mathrm{E}+05$ & $5,43 E+05$ & $4,66 E+05$ & $3,34 \mathrm{E}+05$ & $4,08 E+04$ \\
\hline & & Unidade & $1,0-2,0 \mu \mathrm{m}$ & $2,0-3,0 \mu \mathrm{m}$ & $3,0-5,0 \mu \mathrm{m}$ & $5,0-7,0 \mu \mathrm{m}$ & $7,0-10,0 \mu \mathrm{m}$ & $>10,0 \mu \mathrm{m}$ \\
\hline \multirow{8}{*}{ Assento 2D } & $\begin{array}{l}\text { Concentração média de } \\
\text { fundo }\end{array}$ & $\mathrm{P} / \mathrm{m}^{3}$ & $1,90 \mathrm{E}+05$ & $6,67 E+04$ & $3,33 \mathrm{E}+03$ & $0,00 E+00$ & $0,00 E+00$ & $0,00 \mathrm{E}+00$ \\
\hline & $\begin{array}{c}\text { Número de particulas de } \\
\text { fundo }\end{array}$ & $\mathbf{P}$ & 57 & 20 & 1 & 0 & 0 & 0 \\
\hline & $\begin{array}{c}\text { Concentração média } \\
\text { liquida }\end{array}$ & $\mathrm{P} / \mathrm{m}^{3}$ & $1,14 \mathrm{E}+08$ & $8,10 \mathrm{E}+07$ & $7,22 \mathrm{E}+07$ & $4,18 E+07$ & $1,91 E+07$ & $9,63 E+05$ \\
\hline & $\begin{array}{l}\text { Número de Particulas } \\
\text { média liquida }\end{array}$ & $\mathbf{P}$ & 34250 & 24295 & 21648 & 12530 & 5722 & 289 \\
\hline & Desvio - Poisson & $\#$ & 185,07 & 155,87 & 147,13 & 111,94 & 75,64 & 17,00 \\
\hline & $\begin{array}{c}\text { Desvio - Poisson - } \\
\text { Relativo } \\
\end{array}$ & $\%$ & 0,5 & 0,6 & 0,7 & 0,9 & 1,3 & 5,9 \\
\hline & $\begin{array}{l}\text { Desvio padrão } \\
\text { Concentração }\end{array}$ & $\mathrm{P} / \mathrm{m}^{3}$ & $1,20 E+06$ & $2,82 \mathrm{E}+02$ & $7,43 E+02$ & $1,02 \mathrm{E}+03$ & $6,80 E+02$ & $2,62 \mathrm{E}+01$ \\
\hline & DP/Concentração média & $\%$ & 1,0510 & 0,0003 & 0,0010 & 0,0024 & 0,0036 & 0,0027 \\
\hline \multirow{2}{*}{\multicolumn{2}{|c|}{ Erro total medições $(\varepsilon)$}} & $\mathrm{P} / \mathrm{m}^{3}$ & $1,35 \mathrm{E}+06$ & $5,20 \mathrm{E}+05$ & $4,90 E+05$ & $3,73 E+05$ & $2,52 E+05$ & $5,67 \mathrm{E}+04$ \\
\hline & & Unidade & $1,0-2,0 \mu \mathrm{m}$ & $2,0-3,0 \mu \mathrm{m}$ & $3,0-5,0 \mu \mathrm{m}$ & $5,0-7,0 \mu \mathrm{m}$ & $7,0-10,0 \mu \mathrm{m}$ & $>10,0 \mu \mathrm{m}$ \\
\hline \multirow{8}{*}{ Assento 2E } & $\begin{array}{c}\text { Concentração média de } \\
\text { fundo }\end{array}$ & $\mathrm{P} / \mathrm{m}^{3}$ & $1,07 E+05$ & $5,67 E+04$ & $3,33 \mathrm{E}+03$ & $0,00 E+00$ & $0,00 \mathrm{E}+00$ & $0,00 \mathrm{E}+00$ \\
\hline & $\begin{array}{c}\text { Número de particulas de } \\
\text { fundo } \\
\end{array}$ & $\mathbf{P}$ & 32 & 17 & 1 & 0 & 0 & 0 \\
\hline & $\begin{array}{c}\text { Concentração média } \\
\text { liquida }\end{array}$ & $\mathrm{P} / \mathrm{m}^{3}$ & $1,35 E+08$ & $1,19 E+08$ & $9,86 \mathrm{E}+07$ & $6,63 E+07$ & $2,51 E+07$ & $9,67 E+05$ \\
\hline & $\begin{array}{c}\text { Número de Particulas } \\
\text { média liquida }\end{array}$ & $\mathbf{P}$ & 40454 & 35551 & 29574 & 19875 & 7540 & 290 \\
\hline & Desvio - Poisson & $\#$ & 201,13 & 188,55 & 171,97 & 140,98 & 86,83 & 17,03 \\
\hline & $\begin{array}{c}\text { Desvio - Poisson - } \\
\text { Relativo } \\
\end{array}$ & $\%$ & 0,5 & 0,5 & 0,6 & 0,7 & 1,2 & 5,9 \\
\hline & $\begin{array}{l}\text { Desvio padrão } \\
\text { Concentração } \\
\end{array}$ & $\mathrm{P} / \mathrm{m}^{3}$ & $8,61 E+03$ & $8,58 \mathrm{E}+03$ & $5,28 \mathrm{E}+02$ & $3,79 \mathrm{E}+03$ & $7,96 \mathrm{E}+02$ & $1,84 \mathrm{E}+01$ \\
\hline & DP/Concentração média & $\%$ & 0,0064 & 0,0072 & 0,0005 & 0,0057 & 0,0032 & 0,0019 \\
\hline \multicolumn{2}{|c|}{ Erro total medições $(\varepsilon)$} & $\mathrm{P} / \mathrm{m}^{3}$ & $6,70 \mathrm{E}+05$ & $6,29 E+05$ & $5,73 \mathrm{E}+05$ & $4,70 \mathrm{E}+05$ & $2,89 \mathrm{E}+05$ & $5,68 \mathrm{E}+04$ \\
\hline
\end{tabular}




\begin{tabular}{|c|c|c|c|c|c|c|c|c|}
\hline & & Unidade & $1,0-2,0 \mu \mathrm{m}$ & $2,0-3,0 \mu \mathrm{m}$ & $3,0-5,0 \mu \mathrm{m}$ & $5,0-7,0 \mu \mathrm{m}$ & $7,0-10,0 \mu \mathrm{m}$ & $>10,0 \mu \mathrm{m}$ \\
\hline \multirow{8}{*}{ Assento 1D } & $\begin{array}{l}\text { Concentração média de } \\
\text { fundo }\end{array}$ & $\mathrm{P} / \mathrm{m}^{3}$ & $2,23 E+05$ & $1,13 \mathrm{E}+05$ & $6,67 \mathrm{E}+03$ & $0,00 E+00$ & $0,00 \mathrm{E}+00$ & $0,00 E+00$ \\
\hline & $\begin{array}{l}\text { Número de particulas de } \\
\text { fundo }\end{array}$ & $\mathbf{p}$ & 67 & 34 & 2 & 0 & 0 & 0 \\
\hline & $\begin{array}{c}\text { Concentração média } \\
\text { liquida }\end{array}$ & $\mathrm{P} / \mathrm{m}^{3}$ & $1,07 \mathrm{E}+08$ & $1,05 E+08$ & $5,97 E+07$ & $5,08 \mathrm{E}+07$ & $9,42 E+06$ & $5,90 \mathrm{E}+05$ \\
\hline & $\begin{array}{l}\text { Número de Particulas } \\
\text { média liquida }\end{array}$ & $\mathbf{P}$ & 32158 & 31601 & 17899 & 15235 & 2826 & 177 \\
\hline & Desvio - Poisson & $\#$ & 179,33 & 177,77 & 133,79 & 123,43 & 53,16 & 13,30 \\
\hline & $\begin{array}{l}\text { Desvio - Poisson - } \\
\text { Relativo }\end{array}$ & $\%$ & 0,6 & 0,6 & 0,7 & 0,8 & 1,9 & 7,5 \\
\hline & $\begin{array}{l}\text { Desvio padrão } \\
\text { Concentração }\end{array}$ & $\mathrm{P} / \mathrm{m}^{3}$ & $2,72 E+03$ & $2,67 E+03$ & $1,09 \mathrm{E}+03$ & $1,41 E+03$ & $2,56 \mathrm{E}+02$ & $1,31 \mathrm{E}+01$ \\
\hline & DP/Concentração média & $\%$ & 0,0025 & 0,0025 & 0,0018 & 0,0028 & 0,0027 & 0,0022 \\
\hline \multirow{2}{*}{\multicolumn{2}{|c|}{ Erro total medições( $(\varepsilon)$}} & $\mathrm{P} / \mathrm{m}^{3}$ & $5,98 E+05$ & $5,93 E+05$ & $4,46 E+05$ & $4,11 E+05$ & $1,77 \mathrm{E}+05$ & $4,43 E+04$ \\
\hline & & Unidade & $1,0-2,0 \mu \mathrm{m}$ & $2,0-3,0 \mu \mathrm{m}$ & $3,0-5,0 \mu \mathrm{m}$ & $5,0-7,0 \mu \mathrm{m}$ & $7,0-10,0 \mu \mathrm{m}$ & $>10,0 \mu \mathrm{m}$ \\
\hline \multirow{8}{*}{ Assento $1 \mathrm{E}$} & $\begin{array}{l}\text { Concentração média de } \\
\text { fundo }\end{array}$ & $\mathrm{P} / \mathrm{m}^{3}$ & $1,47 E+05$ & $1,13 \mathrm{E}+05$ & $1,00 E+04$ & $0,00 E+00$ & $0,00 E+00$ & $0,00 E+00$ \\
\hline & $\begin{array}{l}\text { Número de particulas de } \\
\text { fundo }\end{array}$ & $\mathbf{p}$ & 44 & 34 & 3 & 0 & 0 & 0 \\
\hline & $\begin{array}{c}\text { Concentração média } \\
\text { liquida }\end{array}$ & $\mathrm{P} / \mathrm{m}^{3}$ & $9,66 \mathrm{E}+07$ & $9,51 E+07$ & $7,51 \mathrm{E}+07$ & $4,40 E+07$ & $8,58 \mathrm{E}+06$ & $5,70 E+05$ \\
\hline & $\begin{array}{c}\text { Número de Particulas } \\
\text { média liquida }\end{array}$ & $\mathbf{p}$ & 28983 & 28545 & 22538 & 13187 & 2575 & 171 \\
\hline & Desvio - Poisson & $\#$ & 170,24 & 168,95 & 150,12 & 114,83 & 50,74 & 13,08 \\
\hline & $\begin{array}{c}\text { Desvio - Poisson - } \\
\text { Relativo } \\
\end{array}$ & $\%$ & 0,6 & 0,6 & 0,7 & 0,9 & 2,0 & 7,6 \\
\hline & $\begin{array}{l}\text { Desvio padrão } \\
\text { Concentração }\end{array}$ & $\mathrm{P} / \mathrm{m}^{3}$ & $3,20 E+03$ & $3,11 \mathrm{E}+03$ & $1,40 E+03$ & $1,11 E+03$ & $2,02 E+02$ & $1,19 \mathrm{E}+01$ \\
\hline & DP/Concentração média & $\%$ & 0,0033 & 0,0033 & 0,0019 & 0,0025 & 0,0024 & 0,0021 \\
\hline \multirow{2}{*}{\multicolumn{2}{|c|}{ Erro total medições $(\varepsilon)$}} & $\mathrm{P} / \mathrm{m}^{3}$ & $5,67 E+05$ & $5,63 E+05$ & $5,00 E+05$ & $3,83 \mathrm{E}+05$ & $1,69 \mathrm{E}+05$ & $4,36 \mathrm{E}+04$ \\
\hline & & Unidade & $1,0-2,0 \mu \mathrm{m}$ & $2,0-3,0 \mu \mathrm{m}$ & $3,0-5,0 \mu \mathrm{m}$ & $5,0-7,0 \mu \mathrm{m}$ & $7,0-10,0 \mu \mathrm{m}$ & $>10,0 \mu \mathrm{m}$ \\
\hline \multirow{8}{*}{ Assento $1 \mathrm{~B}$} & $\begin{array}{c}\text { Concentração média de } \\
\text { fundo }\end{array}$ & $\mathrm{P} / \mathrm{m}^{3}$ & $7,00 \mathrm{E}+04$ & $3,33 E+04$ & $3,33 \mathrm{E}+03$ & $0,00 E+00$ & $0,00 E+00$ & $0,00 E+00$ \\
\hline & $\begin{array}{l}\text { Número de particulas de } \\
\text { fundo }\end{array}$ & $\mathbf{p}$ & 21 & 10 & 1 & 0 & 0 & 0 \\
\hline & $\begin{array}{c}\text { Concentração média } \\
\text { liquida }\end{array}$ & $\mathrm{P} / \mathrm{m}^{3}$ & $6,58 \mathrm{E}+07$ & $6,51 E+07$ & $5,26 E+07$ & $2,89 \mathrm{E}+07$ & $5,34 \mathrm{E}+06$ & $3,53 E+05$ \\
\hline & $\begin{array}{l}\text { Número de Particulas } \\
\text { média liquida }\end{array}$ & $\mathbf{p}$ & 19745 & 19530 & 15790 & 8677 & 1602 & 106 \\
\hline & Desvio - Poisson & $\#$ & 140,5169029 & 139,7497764 & 125,6582667 & 93,15 & 40,02 & 10,30 \\
\hline & $\begin{array}{l}\text { Desvio - Poisson - } \\
\text { Relativo }\end{array}$ & $\%$ & 0,7 & 0,7 & 0,8 & 1,1 & 2,5 & 9,7 \\
\hline & $\begin{array}{l}\text { Desvio padrão } \\
\text { Concentração }\end{array}$ & $\mathrm{P} / \mathrm{m}^{3}$ & $2,56 \mathrm{E}+03$ & $2,50 E+03$ & $1,74 \mathrm{E}+03$ & $1,15 E+03$ & $2,65 E+02$ & $2,35 \mathrm{E}+01$ \\
\hline & DP/Concentração média & $\%$ & 0,0039 & 0,0038 & 0,0033 & 0,0040 & 0,0050 & 0,0066 \\
\hline \multicolumn{2}{|c|}{ Erro total medições(દ) } & $\mathrm{P} / \mathrm{m}^{3}$ & $4,68 \mathrm{E}+05$ & $4,66 \mathrm{E}+05$ & $4,19 \mathrm{E}+05$ & $3,11 E+05$ & $1,33 \mathrm{E}+05$ & $3,43 \mathrm{E}+04$ \\
\hline
\end{tabular}




\begin{tabular}{|c|c|c|c|c|c|c|c|c|}
\hline & & Unidade & $1,0-2,0 \mu \mathrm{m}$ & $2,0-3,0 \mu \mathrm{m}$ & $3,0-5,0 \mu \mathrm{m}$ & $5,0-7,0 \mu \mathrm{m}$ & $7,0-10,0 \mu \mathrm{m}$ & $>10,0 \mu \mathrm{m}$ \\
\hline \multirow{8}{*}{ Assento 1A } & $\begin{array}{l}\text { Concentração média de } \\
\text { fundo }\end{array}$ & $\mathrm{P} / \mathrm{m}^{3}$ & $1,50 E+05$ & $5,00 E+04$ & $3,33 E+03$ & $0,00 E+00$ & $0,00 E+00$ & $0,00 E+00$ \\
\hline & $\begin{array}{c}\text { Número de particulas de } \\
\text { fundo }\end{array}$ & $\mathbf{P}$ & 45 & 15 & 1 & 0 & 0 & 0 \\
\hline & $\begin{array}{c}\text { Concentração média } \\
\text { liquida } \\
\end{array}$ & $\mathrm{P} / \mathrm{m}^{3}$ & $6,20 E+07$ & $6,15 \mathrm{E}+07$ & $1,40 \mathrm{E}+07$ & $7,83 \mathrm{E}+06$ & $1,95 \mathrm{E}+06$ & $3,10 \mathrm{E}+05$ \\
\hline & $\begin{array}{c}\text { Número de Particulas } \\
\text { média liquida }\end{array}$ & $\mathbf{p}$ & 18603 & 18461 & 4200 & 2350 & 586 & 93 \\
\hline & Desvio - Poisson & $\#$ & 136,39 & 135,87 & 64,81 & 48,48 & 24,21 & 9,64 \\
\hline & $\begin{array}{c}\text { Desvio - Poisson - } \\
\text { Relativo } \\
\end{array}$ & $\%$ & 0,7 & 0,7 & 1,5 & 2,1 & 4,1 & 10,4 \\
\hline & $\begin{array}{l}\text { Desvio padrão } \\
\text { Concentração }\end{array}$ & $\mathrm{P} / \mathrm{m}^{3}$ & $1,17 \mathrm{E}+03$ & $1,36 \mathrm{E}+03$ & $5,08 E+02$ & $8,57 \mathrm{E}+01$ & $1,23 \mathrm{E}+02$ & $8,54 \mathrm{E}+00$ \\
\hline & DP/Concentração média & $\%$ & 0,0019 & 0,0022 & 0,0036 & 0,0011 & 0,0063 & 0,0028 \\
\hline \multirow{2}{*}{\multicolumn{2}{|c|}{ Erro total medições(£) }} & $\mathrm{P} / \mathrm{m}^{3}$ & $4,55 E+05$ & $4,53 E+05$ & $2,16 E+05$ & $1,62 E+05$ & $8,07 E+04$ & $3,21 \mathrm{E}+04$ \\
\hline & & Unidade & $1,0-2,0 \mu \mathrm{m}$ & $2,0-3,0 \mu \mathrm{m}$ & $3,0-5,0 \mu \mathrm{m}$ & $5,0-7,0 \mu \mathrm{m}$ & $7,0-10,0 \mu \mathrm{m}$ & $>10,0 \mu \mathrm{m}$ \\
\hline \multirow{8}{*}{ Assento 2B } & $\begin{array}{c}\text { Concentração média de } \\
\text { fundo }\end{array}$ & $\mathrm{P} / \mathrm{m}^{3}$ & $1,77 E+05$ & $8,17 E+04$ & $1,33 \mathrm{E}+04$ & $0,00 E+00$ & $0,00 E+00$ & $0,00 E+00$ \\
\hline & $\begin{array}{c}\text { Número de particulas de } \\
\text { fundo } \\
\end{array}$ & $\mathbf{p}$ & 53 & 25 & 4 & 0 & 0 & 0 \\
\hline & $\begin{array}{c}\text { Concentração média } \\
\text { liquida }\end{array}$ & $\mathrm{P} / \mathrm{m}^{3}$ & $6,18 \mathrm{E}+07$ & $6,07 E+07$ & $5,21 E+07$ & $3,36 E+07$ & $9,82 E+06$ & $1,50 \mathrm{E}+06$ \\
\hline & $\begin{array}{c}\text { Número de Particulas } \\
\text { média liquida }\end{array}$ & $\mathbf{p}$ & 18554 & 18205 & 15644 & 10067 & 2945 & 450 \\
\hline & Desvio - Poisson & $\#$ & 136,21 & 134,93 & 125,08 & 100,33 & 54,27 & 21,21 \\
\hline & $\begin{array}{c}\text { Desvio - Poisson - } \\
\text { Relativo } \\
\end{array}$ & $\%$ & 0,7 & 0,7 & 0,8 & 1,0 & 1,8 & 4,7 \\
\hline & $\begin{array}{l}\text { Desvio padrão } \\
\text { Concentração } \\
\end{array}$ & $\mathrm{P} / \mathrm{m}^{3}$ & $1,12 \mathrm{E}+04$ & $1,10 E+04$ & $7,00 E+03$ & $3,22 \mathrm{E}+03$ & $5,69 \mathrm{E}+02$ & $1,30 \mathrm{E}+02$ \\
\hline & DP/Concentração média & $\%$ & 0,0181 & 0,0181 & 0,0134 & 0,0096 & 0,0058 & 0,0086 \\
\hline \multirow{2}{*}{\multicolumn{2}{|c|}{ Erro total medições(દ) }} & $\mathrm{P} / \mathrm{m}^{3}$ & $4,54 \mathrm{E}+05$ & $4,50 E+05$ & $4,17 E+05$ & $3,34 E+05$ & $1,81 E+05$ & $7,07 E+04$ \\
\hline & & Unidade & $1,0-2,0 \mu \mathrm{m}$ & $2,0-3,0 \mu \mathrm{m}$ & $3,0-5,0 \mu \mathrm{m}$ & $5,0-7,0 \mu \mathrm{m}$ & $7,0-10,0 \mu \mathrm{m}$ & $>10,0 \mu \mathrm{m}$ \\
\hline \multirow{8}{*}{ Assento $2 \mathrm{~A}$} & $\begin{array}{c}\text { Concentração média de } \\
\text { fundo }\end{array}$ & $\mathrm{P} / \mathrm{m}^{3}$ & $9,00 E+04$ & $1,03 E+05$ & $6,67 E+03$ & $0,00 E+00$ & $0,00 E+00$ & $0,00 E+00$ \\
\hline & $\begin{array}{c}\text { Número de particulas de } \\
\text { fundo }\end{array}$ & $\mathbf{P}$ & 27 & 31 & 2 & 0 & 0 & 0 \\
\hline & $\begin{array}{c}\text { Concentração média } \\
\text { liquida }\end{array}$ & $\mathrm{P} / \mathrm{m}^{3}$ & $4,05 E+07$ & $2,77 E+07$ & $2,19 \mathrm{E}+07$ & $1,51 \mathrm{E}+07$ & $4,10 E+06$ & $8,93 E+05$ \\
\hline & $\begin{array}{c}\text { Número de Particulas } \\
\text { média liquida }\end{array}$ & $\mathbf{P}$ & 12141 & 8313 & 6582 & 4520 & 1230 & 268 \\
\hline & Desvio - Poisson & $\#$ & 110,19 & 91,18 & 81,13 & 67,23 & 35,07 & 16,37 \\
\hline & $\begin{array}{c}\text { Desvio - Poisson - } \\
\text { Relativo } \\
\end{array}$ & $\%$ & 0,9 & 1,1 & 1,2 & 1,5 & 2,9 & 6,1 \\
\hline & $\begin{array}{l}\text { Desvio padrão } \\
\text { Concentração } \\
\end{array}$ & $\mathrm{P} / \mathrm{m}^{3}$ & $1,05 \mathrm{E}+03$ & $7,43 E+02$ & $7,72 E+01$ & $8,78 \mathrm{E}+01$ & $1,03 E+02$ & $1,13 E+02$ \\
\hline & DP/Concentração média & $\%$ & 0,0026 & 0,0027 & 0,0004 & 0,0006 & 0,0025 & 0,0126 \\
\hline \multicolumn{2}{|c|}{ Erro total medições(દ) } & $\mathrm{P} / \mathrm{m}^{3}$ & $3,67 E+05$ & $3,04 E+05$ & $2,70 E+05$ & $2,24 E+05$ & $1,17 E+05$ & $5,46 \mathrm{E}+04$ \\
\hline
\end{tabular}




\begin{tabular}{|c|c|c|c|c|c|c|c|c|}
\hline & & Unidade & $1,0-2,0 \mu \mathrm{m}$ & $2,0-3,0 \mu \mathrm{m}$ & $3,0-5,0 \mu \mathrm{m}$ & $5,0-7,0 \mu \mathrm{m}$ & $7,0-10,0 \mu \mathrm{m}$ & $>10,0 \mu \mathrm{m}$ \\
\hline \multirow{8}{*}{ Assento 3B } & $\begin{array}{c}\text { Concentração média de } \\
\text { fundo }\end{array}$ & $\mathrm{P} / \mathrm{m}^{3}$ & $2,97 \mathrm{E}+05$ & $1,87 E+05$ & $3,33 \mathrm{E}+03$ & $0,00 \mathrm{E}+00$ & $0,00 E+00$ & $0,00 \mathrm{E}+00$ \\
\hline & $\begin{array}{l}\text { Número de particulas de } \\
\text { fundo }\end{array}$ & $\mathbf{P}$ & 89 & 56 & 1 & 0 & 0 & 0 \\
\hline & $\begin{array}{c}\text { Concentração média } \\
\text { liquida }\end{array}$ & $\mathrm{P} / \mathrm{m}^{3}$ & $8,89 \mathrm{E}+07$ & $8,15 E+07$ & $5,23 E+07$ & $1,81 E+07$ & $7,96 \mathrm{E}+06$ & $1,16 \mathrm{E}+06$ \\
\hline & $\begin{array}{c}\text { Número de Particulas } \\
\text { média liquida }\end{array}$ & $\mathbf{P}$ & 26671 & 24437 & 15682 & 5423 & 2389 & 348 \\
\hline & Desvio - Poisson & $\#$ & 163,31 & 156,32 & 125,23 & 73,64 & 48,88 & 18,65 \\
\hline & $\begin{array}{l}\text { Desvio - Poisson - } \\
\text { Relativo }\end{array}$ & $\%$ & 0,6 & 0,6 & 0,8 & 1,4 & 2,0 & 5,4 \\
\hline & $\begin{array}{l}\text { Desvio padrão } \\
\text { Concentração } \\
\end{array}$ & $\mathrm{P} / \mathrm{m}^{3}$ & $1,43 E+03$ & $2,08 \mathrm{E}+04$ & $8,80 E+02$ & $3,94 E+01$ & $2,02 E+02$ & $1,79 E+01$ \\
\hline & DP/Concentração média & $\%$ & 0,0016 & 0,0256 & 0,0017 & 0,0002 & 0,0025 & 0,0015 \\
\hline \multirow{2}{*}{\multicolumn{2}{|c|}{ Erro total medições(દ) }} & $\mathrm{P} / \mathrm{m}^{3}$ & $5,44 E+05$ & $5,21 \mathrm{E}+05$ & $4,17 E+05$ & $2,45 E+05$ & $1,63 E+05$ & $6,22 \mathrm{E}+04$ \\
\hline & & Unidade & $1,0-2,0 \mu \mathrm{m}$ & $2,0-3,0 \mu \mathrm{m}$ & $3,0-5,0 \mu \mathrm{m}$ & $5,0-7,0 \mu \mathrm{m}$ & $7,0-10,0 \mu \mathrm{m}$ & $>10,0 \mu \mathrm{m}$ \\
\hline \multirow{8}{*}{ Assento $3 \mathrm{~A}$} & $\begin{array}{l}\text { Concentração média de } \\
\text { fundo }\end{array}$ & $\mathrm{P} / \mathrm{m}^{3}$ & $1,23 E+05$ & $5,33 E+04$ & $6,67 E+03$ & $0,00 \mathrm{E}+00$ & $0,00 E+00$ & $0,00 E+00$ \\
\hline & $\begin{array}{c}\text { Número de particulas de } \\
\text { fundo }\end{array}$ & $\mathbf{p}$ & 37 & 16 & 2 & 0 & 0 & 0 \\
\hline & $\begin{array}{c}\text { Concentração média } \\
\text { liquida }\end{array}$ & $\mathrm{P} / \mathrm{m}^{3}$ & $1,05 E+08$ & $8,42 E+07$ & $3,29 \mathrm{E}+07$ & $1,52 E+07$ & $5,08 \mathrm{E}+06$ & $5,07 E+05$ \\
\hline & $\begin{array}{c}\text { Número de Particulas } \\
\text { média liquida }\end{array}$ & $\mathbf{P}$ & 31617 & 25249 & 9875 & 4560 & 1524 & 152 \\
\hline & Desvio - Poisson & $\#$ & 177,81 & 158,90 & 99,37 & 67,53 & 39,04 & 12,33 \\
\hline & $\begin{array}{c}\text { Desvio - Poisson - } \\
\text { Relativo } \\
\end{array}$ & $\%$ & 0,6 & 0,6 & 1,0 & 1,5 & 2,6 & 8,1 \\
\hline & $\begin{array}{l}\text { Desvio padrão } \\
\text { Concentração }\end{array}$ & $\mathrm{P} / \mathrm{m}^{3}$ & $1,81 E+04$ & $4,74 E+02$ & $2,97 E+00$ & $1,07 E+00$ & $2,36 \mathrm{E}+00$ & $2,13 \mathrm{E}+00$ \\
\hline & DP/Concentração média & $\%$ & 0,0172 & 0,0006 & 0,0000 & 0,0000 & 0,0000 & 0,0004 \\
\hline \multicolumn{2}{|c|}{ Erro total medições(E) } & $\mathrm{P} / \mathrm{m}^{3}$ & $5,93 E+05$ & $5,30 E+05$ & $3,31 E+05$ & $2,25 \mathrm{E}+05$ & $1,30 \mathrm{E}+05$ & $4,11 \mathrm{E}+04$ \\
\hline
\end{tabular}




\section{ANEXO A}

Os manequins aquecidos foram construídos em fibra de vidro e tubos e conexões de PVC (Moura, 2009), com forma semelhante a um corpo humano sentado, conforme mostrado na Figura A-1.

$\mathrm{Na}$ parte interna existe uma resistência elétrica, que dissipa calor, e um ventilador que propicia uma distribuição uniforme da temperatura do ar ao longo de toda a superfície do manequim. Os manequins são acoplados a uma unidade de potência por meio de cabos tripolares. A potência de dissipação de calor é ajustável por meio de software. A faixa de operação dos manequins aquecidos é de 30 a 120 $\mathrm{W} / \mathrm{m}^{2}$.
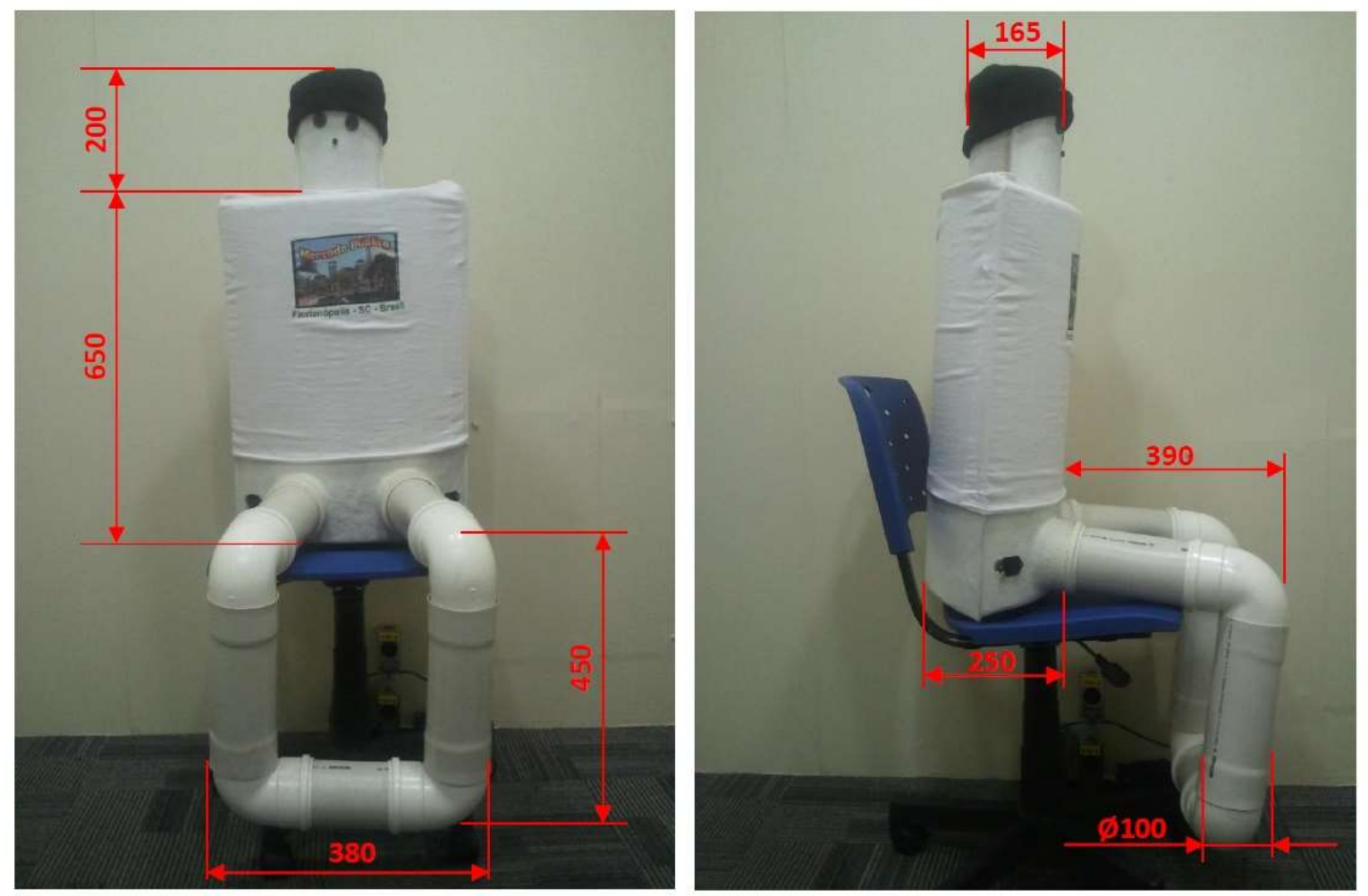

Figura A-1 - Os manequins aquecidos e suas respectivas dimensões. 
ANEXO B

\section{Memorial de cálculo do manômetro diferencial}

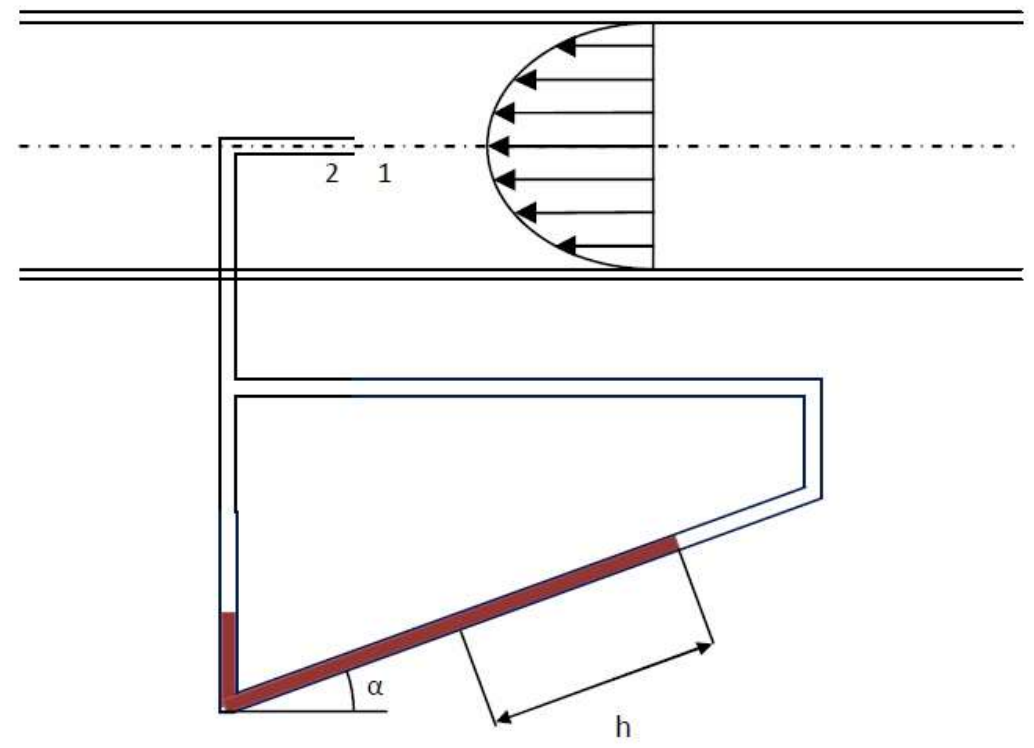

Cálculo:

Utilizando a equação de conservação de energia

$$
\begin{aligned}
H_{1} & =H_{2} \\
\frac{v_{1}^{2}}{2 g}+\frac{P_{1}}{\gamma}+z_{1} & =\frac{v_{2}^{2}}{2 g}+\frac{P_{2}}{\gamma}+z_{2}
\end{aligned}
$$

Adotando-se o ponto 1 muito próximo do ponto 2 tem-se:

$$
v_{1}=\sqrt[2]{2 g\left(\frac{P_{2}-P_{1}}{\gamma_{a r}}\right)}
$$

Pois,

$v_{2}=0$ (ponto de estagnação)

$$
z_{1}=z_{2}=0
$$

Aplicando-se a equação manométrica entre os pontos 1 e 2 tem-se:

$$
P_{2}+\gamma_{a r} \cdot h-\gamma_{f} \cdot h=P_{1}
$$

Portanto, tem-se:

$$
\frac{P_{2}-P_{1}}{\gamma_{a r}}=h\left(\frac{\gamma_{f}}{\gamma_{a r}}-1\right)
$$

Substituindo (2) em (1) tem-se: 


$$
v_{1}=\sqrt[2]{2 g\left[h\left(\frac{\gamma_{f}}{\gamma_{a r}}-1\right)\right]}
$$

Em que:

$$
v_{1}=v_{\text {máx }}
$$

Se o escoamento for turbulento, $\operatorname{Re}>2400$

$$
v_{\text {méd }}=\frac{49}{60} v_{\text {máx }}
$$

Se o escoamento for laminar, $\operatorname{Re}<2400$

$$
v_{\text {méd }}=0,5 \cdot v_{\text {máx }}
$$

A vazão média é dada por:

$$
Q_{\text {méd }}=A \cdot v_{\text {méd }}
$$

Em que:

$$
A=\frac{\pi \cdot d^{2}}{4}
$$

Dados para o cálculo do manômetro

$$
\begin{gathered}
g_{\text {local }}=9,7856 \frac{\mathrm{m}}{\mathrm{s}} \\
\rho_{\text {ar } @ 20^{\circ} \mathrm{C}}=1,204 \frac{\mathrm{kg}}{\mathrm{m}^{3}} \\
\rho_{\text {fluido }}=0,8260 @ 20{ }^{\circ} \mathrm{C} \\
\rho_{\mathrm{H}_{2} \mathrm{O} @ 20^{\circ} \mathrm{C}}=998,2071 \frac{\mathrm{kg}}{\mathrm{m}^{3}} \\
\mu_{\text {ar }}=1,74 \times 10^{-5} \mathrm{~Pa} \cdot \mathrm{s} \\
d_{\text {duto }}=100 \mathrm{~mm}
\end{gathered}
$$

Substituindo os valores, tem-se:
$v_{1}=115,685 \sqrt[2]{h}$
( $h$ é dado em metros)
ou
$v_{1}=3,658 \sqrt[2]{h}$
( $h$ é dado em milímetros) 